Editora Poisson

\title{
Gestão da Produção em Foco Volume 34
}

\author{
1a Edição
}

Belo Horizonte

Poisson

2019 
Editor Chefe: Dr. Darly Fernando Andrade

\section{Conselho Editorial}

Dr. Antônio Artur de Souza - Universidade Federal de Minas Gerais

Ms. Davilson Eduardo Andrade

Dr. José Eduardo Ferreira Lopes - Universidade Federal de Uberlândia

Dr. Otaviano Francisco Neves - Pontifícia Universidade Católica de Minas Gerais

Dr. Luiz Cláudio de Lima - Universidade FUMEC

Dr. Nelson Ferreira Filho - Faculdades Kennedy

Ms. Valdiney Alves de Oliveira - Universidade Federal de Uberlândia

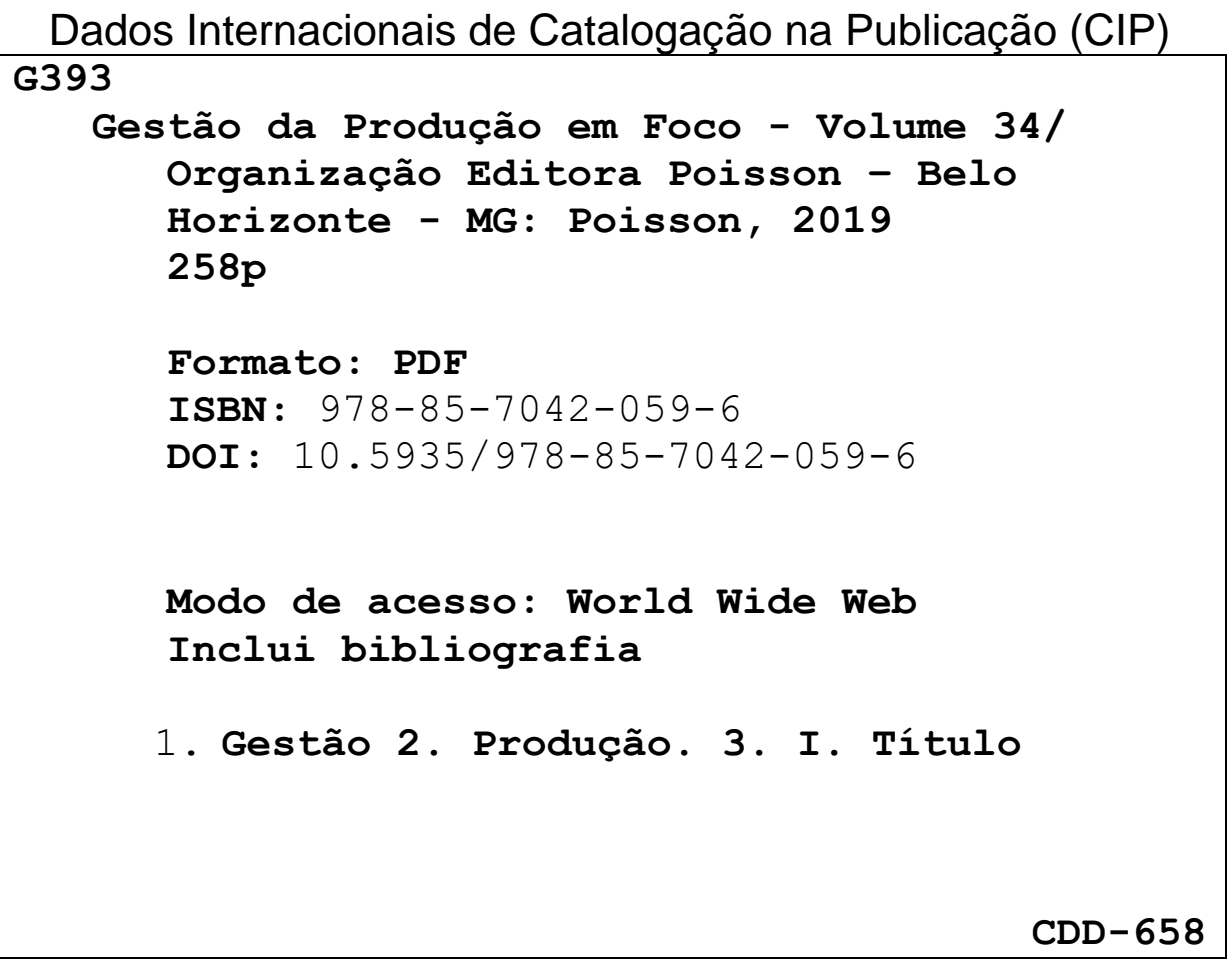

O conteúdo dos artigos e seus dados em sua forma, correção e confiabilidade são de responsabilidade exclusiva dos seus respectivos autores.

Baixe outros títulos gratuitamente em www.poisson.com.br

contato@poisson.com.br 


\section{SUMÁRIO}

Capítulo 1: A busca de alternativas energéticas em uma indústria do setor metal metalúrgico para minimizar a dependência da rede pública de energia 7 Mario Fernando de Mello, Jean Veiga, Camila Uggeri, Leilane Rech

Capítulo 2: Um estudo bibliométrico da produção acadêmica brasileira sobre produção mais limpa publicada em periódicos indexados pela Scopus e Web of Science 18

Thales Botelho de Sousa, Francisco Raphael Cabral Furtado, Jean Mimar Santa Cruz Yabarrena, Sherfis Gibran Ruwer, Carlos Eduardo Pinto

Capítulo 3: Implantação de ferramenta de inteligência de negócio para otimização da gestão na Eletrobras Distribuição Piauí 31

Edward Lennon da Fontoura Daniel, Josué Fernandes Alves Silva, Andrea Cristina dos Santos Silva, Valdenrique Soares Torres

Capítulo 4: Avaliação da qualidade dos serviços prestados pela empresa "Beta" utilizando a Escala Servqual 40

Luciane Kemmerich Lied, Renata Coradini Bianchi, Vanessa Almeida da Silva

Capítulo 5: Integração das metodologias Sipoc e Fault Tree Analys (FTA) no processo de análise das falhas existentes na linha de produção de uma empresa

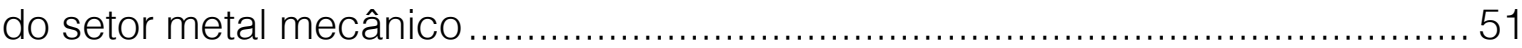
Juan Pablo Silva Moreira, Saulo Fonseca Soares, Célio Adriano Lopes, Janaína Aparecida Pereira

Capítulo 6: Aplicação do mapeamento do fluxo de valor em uma célula de usinagem de bielas

Davenilcio Luiz de Souza, Pablo Fogaça, Rossano Noronha, Leandra da Silva

Capítulo 7: Padronização descritiva como melhoria de processo na área de materiais

Luana Weiand Fazolo, Tatiane Pereira Librelato

Capítulo 8: Utilização do ciclo PDCA para desenvolvimento de uma estufa agrícola automatizada

Vitor Abel Monteiro Alves, Gustavo Schuster, Uilson Diego Gomes Prestes, Alejandro Martins Rodriguez 


\section{SUMÁRIO}

Capítulo 9: Problemas com a infraestrutura do transporte de cargas especiais em Santos 98

Adriano Alfinito Raimundo, Alexandre Ricardo Machado, Matheus Palmieri Gobbetti, Rodolfo Pinheiro, Viktor Doll Schwenck

Capítulo 10: Operadores logísticos terceirizados: Uma inovação estratégica na distribuição de medicamentos 109

Adriana Formigone

Capítulo 11: Análise do desempenho logístico como estratégia para fidelização de clientes no e-commerce 117

Marcelo Vinicius da Silva Santos, André Di Girolamo, Rafael Franco Mendes de Oliveira, Eder de Jesus Carvalho

Capítulo 12: Plano Mestre de Produção como suporte à distribuição: Um estudo de caso em uma panificadora.

Yasmim Luana Mafra de Lira, Tarcizio da Silva Barbosa, Clelma Feliz Santos, Avylon Silva Santos, Denilson Ricardo de Lucena Nunes

Capítulo 13: Práticas da logística reversa a luz da política nacional de resíduos sólidos: Um estudo bibliométrico 138

Graciela Maria Miranda Borges, André Geraldo da Costa Coelho, Danilo Henrique Divardin, Christiane Oliveira Valente

Capítulo 14: Inovação na cadeia de fornecedores de empresas brasileiras com atuação internacional: Um estudo multicaso da Marcopolo e da Gerdau.. 150 Maria Laura Romão Degaspari, Helder Sacks, Leandro José Morilhas, Marcos Alberto Castelhano Bruno

Capítulo15: Estudo para a determinação do ponto de ressuprimento do setor de almoxarifado da SEFAZ-MA

Alisson Castro Barreto, Bárbara Elis Pereira Silva

Capítulo 16: Método de inteligência computacional aplicado na otimização da produção por meio da detecção do sistema de coordenadas do centro de massa de uma estrutura

Guilherme Damasceno Silva, Denis Carlos Lima Costa, Heictor Alves de Oliveira Costa 


\section{SUMÁRIO}

Capítulo 17: Comparativo da lucratividade de linhas de produção de pequena indústria de confecções

Beatriz Silvestri Ghisi, Rodney Wernke, Ivanir Rufatto, Ivone Junges

Capítulo 18: Modelos de padrões de qualidade de fios de algodão baseado em Redes Neurais Artificiais que relacionam a matéria-prima ao processo de produção e ao produto final 192

Gilberto Clóvis Antonelli , Patrícia Lopes da Silva de Araújo, Rosa Maria de Castro Fernandes Vasconcelos

Capítulo 19: Elaboração de rede PERT/CPM no processo de confecção de camisas: Um estudo de caso 204

Andressa Raquel Weber, Andressa Strey, Ivete Linn Ruppenthal

Capítulo 20: Estimativa de produtividade no setor de usinagem utilizando o método da Teoria das Filas.

Carlos Henrique Haefliger, Geniel de Mello Dias, Ivete Linn Ruppenthal

Capítulo 21: Gestão da Inovação na cadeia de suprimentos de Micro e Pequenas Empresas

Ismael Cristofer Baierle, Jones Luis Schaefer, João Victor Kothe, Elpidio Oscar Benitez Nara, Cristiano Roos

Capítulo 22: Métodos gráficos para análise e solução de problemas na manutenção de instalações universitárias 232 Lenon Pinheiro da Silva, Cátia Fröhlich 


\title{
Capítulo 1
}

\section{A BUSCA DE ALTERNATIVAS ENERGÉTICAS EM UMA INDÚSTRIA DO SETOR METAL METALÚRGICO PARA MINIMIZAR A DEPENDENCIA DA REDE PÚBLICA DE ENERGIA}

\author{
Mario Fernando de Mello \\ Jean Veiga \\ Camila Uggeri \\ Leilane Rech
}

Resumo: A energia elétrica tornou-se indispensável para praticamente qualquer função que o homem venha realizar. Desde o cotidiano até o funcionamento de uma indústria a energia elétrica estará presente. Entre outras coisas, cada vez mais as maquinas tem realizado funções que antes eram desenvolvidas manualmente, o que justifica maior consumo de eletricidade. O presente estudo foi realizado numa empresa do setor metalúrgico que atua basicamente três segmentos de mercado: terceirização de serviços de metalurgia, fornecimento de peças para implementos agrícolas e fabricação de produtos voltados à linha rodoviária. A maioria das peças é fabricada pelo processo de fundição. Esse processo é o maior responsável pelo consumo de energia elétrica, tendo em vista que há um forno de indução, o qual se utiliza de energia elétrica para aquecimento e fusão de metais usados no processo. Como tentativa de esclarecer alguns pontos que podem auxiliar a geração de alternativas para contornar esta situação, este estudo tem como finalidade analisar e verificar qual a melhor forma de diminuir a dependência de uma indústria da rede de abastecimento pública em horários de pico, com a finalidade de garantir o uso pleno da capacidade de um setor de fundição, sem o aumento nos custos com energia elétrica. Como desenvolvimento do estudo foi feita uma análise comparativa entre alternativas para diminuir a dependência da energia elétrica pública através de uma análise de custos que envolve a compra de geradores. Ficou evidenciado no estudo que a substituição parcial da fonte energética necessária para a empresa, é viável. Após a realização do comparativo concluiu-se que é viável a substituição parcial da energia comprada por energia proveniente dos geradores, ou seja, utilizar os geradores somente no horário de ponta onde a tarifa cobrada pela concessionária é mais de três vezes o valor da tarifa normal.

Palavras-Chave: Energia elétrica; Substituição fonte energética; Custos 


\section{INTRODUÇÃO}

Ao analisar o cenário energético mundial é possível perceber a diversidade, nos métodos de obtenção de energia, dentro de suas possibilidades, cada nação procura suprir suas demandas energéticas com os recursos disponíveis, ou ainda optam pela importação para garantir o abastecimento.

Ao olhar para o cenário energético brasileiro, ficam claras algumas limitações, apesar do grande número de oportunidades de melhoria e criação nas formas de obtenção, distribuição e minimização de impactos. Surgindo aí uma oportunidade e ao mesmo tempo um desafio ao público acadêmico para a valorização da inovação, aos órgãos governamentais, para uma análise das políticas vigentes e à iniciativa privada para atentar à vulnerabilidade da matriz energética brasileira.

O homem tornou-se dependente da energia elétrica, tornando-a indispensável para praticamente qualquer função que este venha a realizar, desde um momento de lazer, até o funcionamento de uma indústria. Atualmente cada vez mais as maquinas tem realizado funções que antes eram desenvolvidas manualmente, o que justifica maior consumo de eletricidade.

Como tentativa de esclarecer alguns pontos que podem auxiliar a geração de alternativas para contornar esta situação, este estudo tem como finalidade analisar e verificar qual a melhor forma de diminuir a dependência de uma indústria da rede de abastecimento pública em horários de pico, com a finalidade de garantir o uso pleno da capacidade de um setor de fundição, sem o aumento nos custos com energia elétrica.

\section{REFERENCIAL TEÓRICO}

\subsection{RECURSOS ENERGÉTICOS UTILIZADOS}

Usinas hidroelétricas, de acordo com Goldemberg e Luz (2003), não produzem poluentes associados como o que ocorre com a queima de combustíveis fósseis, exceto metano, mas influem no meio ambiente pela construção de grandes represas, formação de lagos e alterações sobre o fluxo dos rios. Segundo Moura (2004) "Trata-se, realmente de uma "energia limpa" em todos os estágios, desde a produção até uso final".

Apesar deste método de transformação ter seus pontos positivos em relação à emissão de poluentes, possui o grande problema da sua instalação, pois o alagamento causado pelas represas tem consequências ambientais drásticas com perda da fauna e flora do ecossistema local. Por isso uma obra desse porte necessita de estudos de impactos ambientais e ações de mitigação, destacando aqui o EIA (Estudo de Impacto Ambiental) e RIMA (Relatório de Impactos Ambientais).

Entre as energias renováveis, a hidroeletricidade continua sendo a maior fonte para o setor elétrico e é uma das mais eficientes, em termos de conversão, entre todas as fontes de energia. Essa tecnologia precisa de um investimento inicial relativamente alto, porém tem um longo tempo de vida útil (de 50 a 100 anos), aliado a baixos custos de operação e manutenção. Aqui, estamos tratando de um recurso local, a água do rio, que não é dependente das variantes do mercado, como é o caso dos combustíveis fósseis, o que termina gerando uma consequência positiva ao assegurar uma estabilidade financeira. (PINTO, 2013).

Por usinas termoelétricas são conhecidas as usinas que utilizam a queima de combustíveis para gerar energia elétrica. Seu funcionamento é caracterizado pela utilização de um combustível que serve para aquecer uma caldeira, a água sofrerá o processo de vaporização e este vapor será o responsável por movimentar uma turbina acoplada a um gerador.

A energia nuclear é considerada uma forma "limpa" de energia pois durante sua produção não há geração de gases lançados à atmosfera, principalmente $\mathrm{CO} 2$, maior causador do efeito estufa (MOURA, 2004). Diferentemente das instalações que se utilizam de queima de combustíveis para realizar o aquecimento da turbina, as usinas nucleares utilizam a energia atômica.

A energia cinética contida nos ventos, ou seja, massas de ar em movimento é denominada energia eólica. O aproveitamento desta energia pode ser realizado através do uso de turbinas eólicas ou aero geradores. A energia eólica é vista hoje como uma das fontes de transformação de energia com maiores perspectivas de geração de energia sem os impactos ambientais provocados por grande parte das fontes convencionais (REIS, 2011)

De acordo com Reis, Cunha (2006), os níveis de radiação solar em um plano horizontal na superfície da terra variam com as flutuações climáticas, especialmente com as estações 
do ano, e variam também de acordo com a região, em razão principalmente das diferenças de latitude, das condições meteorológicas e altitudes. Considerando essa variabilidade nos níveis de radiação, torna-se indispensável o conhecimento do nível de radiação nos locais onde ser pretende instalar os dispositivos, para o correto dimensionamento e melhor rendimento do sistema.

A energia proveniente da irradiação solar pode ser aproveitada de duas formas, sobre a forma de calor ou sobre a forma fotovoltaica.

\subsection{COMBUSTIVEIS}

Utilizar combustíveis para geração de energia pode causar problemas não só para o meio ambiente como também para a saúde da população, um exemplo disso é a poluição do ar em grandes cidades, muitas vezes causada por veículos e pelas indústrias. Os combustíveis mais pesados causam os maiores problemas, como o óleo combustível pesado, que faz parte do grupo dos "ultras viscosos ou do fundo do barril", que contém enxofre e metais pesados de modo próximo ao carvão, depois vêm os demais como o óleo diesel, gasolina e, finalmente o gás natural, considerado um combustível limpo (MOURA, 2004).

O biodiesel é um combustível menos poluente que os de origem fóssil (petróleo e derivados), produzido a partir de fontes renováveis, como óleos vegetais e gorduras animais, sua definição química é a de um éster metílico ou etílico destes óleos e gorduras. De acordo com a APROBIO (2014), a reação é catalisada com hidróxido de sódio, ou soda cáustica, como é mais conhecido o catalisador, o mais empregado na fabricação do combustível.

O etanol ou álcool é um combustível gerado a partir matéria orgânica, podendo ser obtido de várias fontes vegetais, sendo que a canade-açúcar é a que oferece maior vantagem energética e econômica. Sua utilização teve um grande aumento nas décadas de 80 e 90 causando inclusive a incapacidade atendimento da elevada demanda da época.

O gás natural é um combustível extraído da natureza, através da perfuração de rochas porosas presentes no subsolo, sendo que pode ou não vir acompanhado de petróleo. Segundo Reis (2011), o gás natural (GN) é uma mistura de hidrocarbonetos leves, que à temperatura ambiente e à pressão atmosférica, permanece no estado gasoso, o principal componente do gás natural é o metano $(\mathrm{CH} 4)$.

\subsection{A MATRIZ ENERGÉTICA BRASILEIRA}

A matriz energética brasileira é conhecida pela sua diversidade e versatilidade, isso só é possível graças às condições geográficas, à biodiversidade e à grande monta de recursos naturais para conversão em energia.

Entretanto fatores como o desequilíbrio ambiental têm causado anormalidades climáticas graves sendo que uma delas afeta de forma direta o funcionamento das usinas hidrelétricas, o aumento dos períodos e da intensidade das secas. Considerando que as usinas hidrelétricas necessitam de volumes e vazão constantes para o correto funcionamento de suas turbinas, fica claro que períodos de seca impactam de forma direta na quantidade de energia lançada na rede.

Como forma de suprir essas emergências é comum o uso de usinas termoelétricas, pois essas dependem do abastecimento de combustível e, portanto, tem independência maior em relação a condições pluviais desfavoráveis.

Com o objetivo de reverter esse quadro para alcançar um sistema energético mais estável, têm se buscado novas formas de obtenção de energia, como a energia solar e a eólica.

O Brasil ainda conta com uma modesta participação de usinas nucleares na obtenção de energia elétrica, contribuição essa feita pelas usinas Almirante Álvaro Alberto unidades 1 e 2 , usinas essas que eram até tempo atrás conhecidas como Angra 1 e Angra 2, ambas situadas na cidade de Angra dos Reis no estado do Rio de Janeiro. Essas usinas utilizam como combustível o elemento Urânio e tem sua energia destinada ao estado de São Paulo. (EPE, 2014)

De acordo com estudos realizados pela Empresa de Pesquisa Energética, vinculada ao Ministério de Minas e Energia -EPE - tendo como base os anos de 2008, 2009, 2010, 2011, 2012 e 2013, foi gerado o Quadro 1, que ilustra as evoluções e retrações nas quantidades de energia gerada. 
Quadro 1 - Balanço Energético Nacional

\begin{tabular}{|c|c|c|c|c|c|c|c|}
\hline & 2009 & 2010 & 2011 & 2012 & 2013 & $\begin{array}{l}\text { Variação } \\
\text { 2013/2012 }\end{array}$ & Part. \%2013 \\
\hline Total & 466158 & 515799 & 531758 & 522498 & 570025 & 3,2 & 100 \\
\hline Gás Natural & 13332 & 36476 & 25095 & 46760 & 69003 & 47,6 & 12,1 \\
\hline Hidráulica (i) & 39098 & 403290 & 428333 & 415342 & 390992 & $-5,9$ & 68,6 \\
\hline $\begin{array}{c}\text { Derivados do } \\
\text { Petróleo (ii) }\end{array}$ & 12724 & 14216 & 12239 & 16214 & 22090 & 36,2 & 3,9 \\
\hline Carvão & 5429 & 6992 & 6485 & 8422 & 14801 & 75,7 & 2,6 \\
\hline Nuclear & 12957 & 14523 & 16569 & 16038 & 14640 & $-8,7$ & 2,6 \\
\hline Biomassa (iii) & 21851 & 31209 & 31633 & 34662 & 39679 & 14,5 & 7 \\
\hline Eólica & 1238 & 2177 & 2705 & 5050 & 6576 & 30,2 & 1,2 \\
\hline Outras (iv) & 7640 & 6916 & 9609 & 10010 & 12244 & 22,3 & 2,1 \\
\hline
\end{tabular}

Fonte: Empresa de Pesquisa Energética -adaptado pelos autores, 2014

Sobre a quadro 3 é importante ressaltar alguns pontos. Na geração hidráulica na qual há a anotação (i) estão inclusos os casos de autoprodução de energia como, por exemplo, o caso de algumas indústrias. Já na parte de Derivados de Petróleo, no qual há a nota (ii) é importante ressaltar que são considerados o óleo diesel e o óleo combustível. No item biomassa (iii) é considerada a geração através da queima de lenha, bagaço de cana e lixívia. E finalmente no item outras (iv) onde estão referidas as recuperações, o gás de coqueria e outros secundários.

Apesar da redução significativa da participação das hidrelétricas na matriz energética, a mesma ainda é a principal fonte correspondendo a $68,6 \%$ do total de energia gerada no país.

Em contrapartida a energia eólica vem aumentando sua participação na matriz, o que é positivo do ponto de vista ambiental e econômico. Já que as emissões são mínimas e o aumento da energia proveniente dos ventos é mais barata do que as termoelétricas que são utilizadas para complementar a deficiência das hidrelétricas.

Conhecer os sistemas elétricos de potência e seu funcionamento em linhas gerais é imprescindível para planejar formas de interligação. Os sistemas elétricos de potência têm a função precípua de fornecer energia elétrica aos usuários, grandes ou pequenos, com a qualidade adequada no instante em que for solicitada. (KAGAN, OLIVEIRA e ROBBA, 2010).

\section{METODOLOGIA}

A empresa escolhida para desenvolvimento do estudo de caso trabalha em basicamente três segmentos de mercado: terceirização de serviços de metalurgia, fornecimento de peças para implementos agrícolas no mercado paralelo e fabricação de produtos próprios voltados à linha rodoviária.

A mesma tem a necessidade de fornecimento rápido de peças variadas e em quantidades reduzidas, onde a maioria das peças é fabricada pelo processo de fundição. Esse processo é o maior responsável pelo consumo de energia elétrica, tendo em vista que há um forno de indução, o qual se utiliza de energia elétrica para aquecimento e fusão de metais usados no processo.

Viu-se aí uma oportunidade para estudo de alternativas e viabilidade, de forma a diminuir os custos e aumentar o resultado da organização, buscando minimizar impactos ambientais.

A coleta de dados foi feita através de pesquisa documental, tendo em vista que foram usados recursos como relatórios da empresa, documentos da mesma e dados disponibilizados pela empresa concessionária de energia. Após a coleta destas informações foram feitas planilhas com o uso da 
ferramenta Microsoft Excel@, com o intuito de tabelar, agrupar e segmentar os dados obtidos de forma que esses possam gerar conhecimento e auxiliar nas propostas de tomada de decisão.

\section{RESULTADOS}

\subsection{DADOS HISTÓRICOS}

Ao analisar os dados de consumo da empresa no período de um pouco mais de 2 anos é possível acompanhar a variação entre a proporção de consumo e o valor pago em cada período.
O horário de pico, ou horário de ponta é o período de maior consumo energético no sistema, na região ele se estende entre 18 e 21 horas. Como a carga é maior em todo sistema nesse horário, em função dos altos níveis de consumo, a tarifa praticada para consumidores não residenciais também sofre acréscimo. Desta forma toda e qualquer atividade industrial que requeira grandes volumes de energia elétrica, como é o caso da fundição, deve ser evitada em função do alto custo tarifário.

A partir de dados consultados junto à concessionária local, Centrais Elétricas de Carazinho (2015) de energia elétrica foi elaborado $\quad 0 \quad$ gráfico 1.

Gráfico 1: Variação de consumo energético

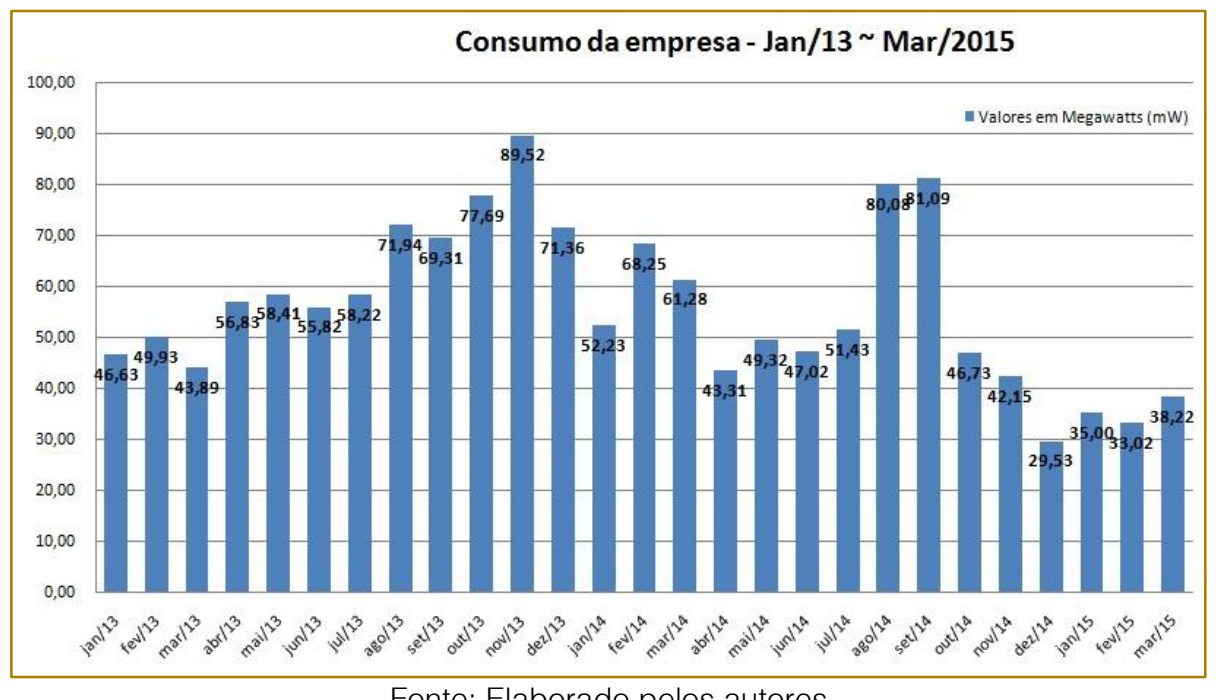

Fonte: Elaborado pelos autores

A partir da análise do consumo energético foram levantadas também informações do custo dessa energia consumida. Estes dados deram origem ao gráfico 2, que expressa o custo de cada período. 
Gráfico 2: Custos com energia elétrica

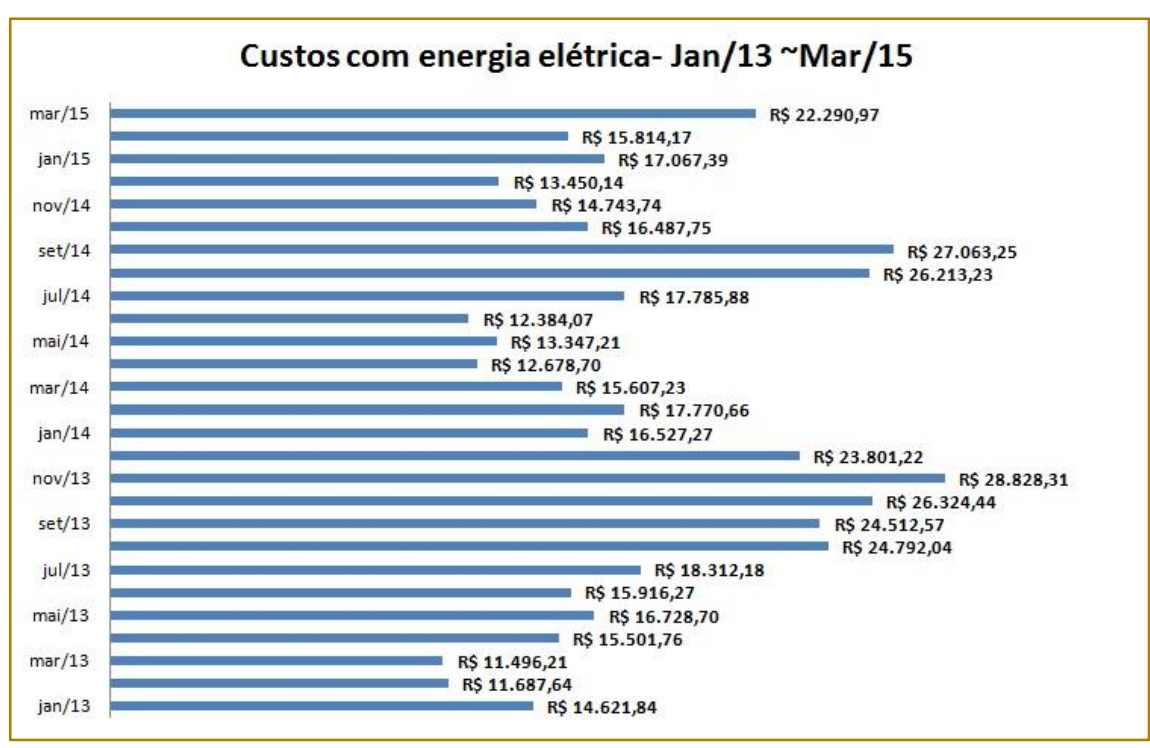

Fonte: Elaborado pelos autores

Tendo em vista os altos valores, foram verificadas as possibilidades de redução de custos na área de energia elétrica. Então, foi utilizado o Gráfico de Pareto como forma de determinar os recursos produtivos nos quais as ações terão maior impacto.

Foram selecionados os 4 setores com maior representatividade na fábrica, bem como avaliada sua demanda energética e sua importância estratégica para o andamento de outros processos. Os setores selecionados foram o setor de conformação, corte laser, fundição e usinagem.

Foram definidas pontuações de em escala de 0 a 10 pontos em três critérios, importância estratégica para o resultado da empresa, impacto em outros processos e consumo energético. De acordo com análises realizadas pelo Coordenador de PCP da empresa foi elaborado o quadro 2.

Quadro 2 - Critérios de importância estratégica

\begin{tabular}{|c|c|c|c|c|c|}
\hline \multicolumn{2}{|c|}{ Setor } & $\begin{array}{c}\text { Importância } \\
\text { estratégica }\end{array}$ & $\begin{array}{c}\text { Consumo } \\
\text { energético }\end{array}$ & $\begin{array}{c}\text { Impacto em outros } \\
\text { processos }\end{array}$ & Total \\
\hline Fundição & 9 & 9 & 8 & 26 & 29,21 \\
\hline Usinagem & 9 & 5 & 9 & 23 & 25,84 \\
\hline Corte Laser & 9 & 6 & 7 & 22 & 24,72 \\
\hline Conformação & 7 & 3 & 8 & 89 & 100 \\
\hline \multicolumn{2}{|c|}{ Soma } \\
\hline
\end{tabular}

Fonte: Elaborado pelos autores

Para a realização da análise de Pareto foi elaborado o gráfico 3 , a partir dos dados contidos no quadro 4. O gráfico apontou como setor a ser priorizado o setor de fundição. 
Gráfico 3-Análise de Pareto

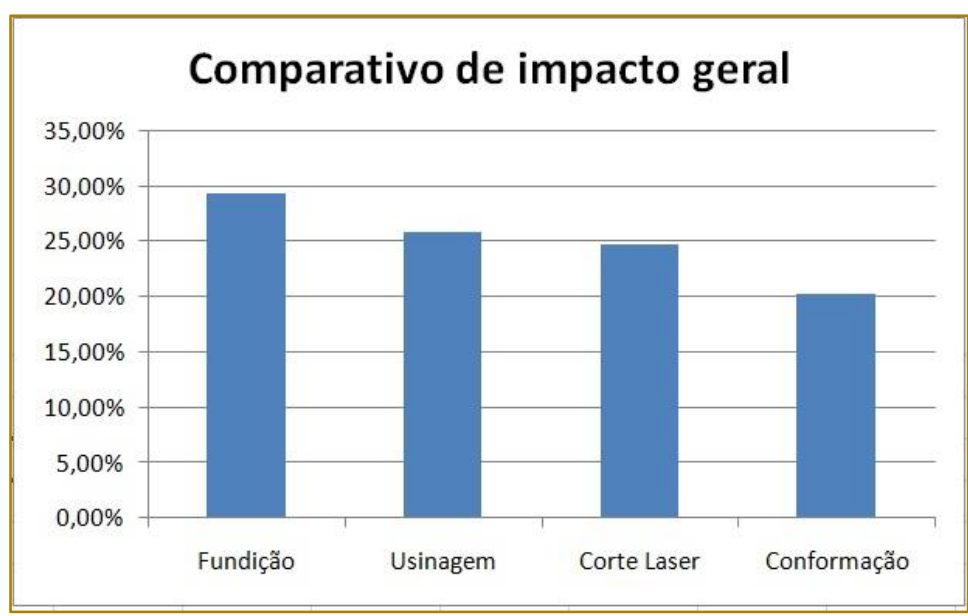

Fonte: Elaborado pelos autores

\subsection{O CONSUMO DE ENERGIA ELÉTRICA}

Após as análises de processo tanto no setor de fundição como em toda a fábrica ficou evidente que o forno elétrico é o item com maior consumo energético e por isso é em relação a ele que serão tomadas as devidas ações.

$\mathrm{Na}$ empresa em algumas ocasiões, em função da alta demanda por itens fundidos, o horário de operação da fundição se estende por dois e até três turnos de trabalho, desta forma o consumo é tarifado com acréscimos. No período estudado os meses onde esse aumento foi maior foram os meses de agosto, setembro, outubro, novembro e dezembro de 2013 onde o custo do consumo de ponta foi $32,51 \%$; 33,73\%; 32,40\%; 31,63\% e 30,65\%, respectivamente. Sendo que nos demais períodos estudados essa despesa varia de 15 a $20 \%$ do total da conta paga.

\subsection{PESQUISA NO MERCADO DE SOLUÇÕES ALTERNATIVAS}

Foram contatados dois fabricantes e ou distribuidores de soluções em geração para análise de custos, consumo e capacidade de atendimento da demanda.

Os dois equipamentos analisados são movidos a óleo diesel e possuem algumas características que os diferem entre si.

O gerador estacionário do Fabricante $\mathrm{A}$, possui motor movido a diesel de 04 cilindros em linha, com sistema de regulação de velocidade eletrônico e aspiração e pós arrefecimento turbinado. Seu consumo com 100\% de carga é de 24 litros por hora. Desta forma a autonomia do tanque é de aproximadamente 8 horas e 20 minutos de funcionamento. Sua capacidade de geração a $100 \%$ de carga é de $85 \mathrm{~kW}$. Já a $75 \%$ da carga seu consumo cai para 18 litros por hora e sua capacidade de geração é de 63,75 kW, e custa cerca de $\mathrm{R} \$ 70.000,00$.

O gerador estacionário do Fabricante $\mathrm{B}$ possui motor movido a diesel de 06 cilindros em linha com sistema regulador de velocidade eletrônico e aspiração turbinada. Seu consumo a $100 \%$ de carga é de 23,2 litros por hora. Sua capacidade de geração a $100 \%$ é de $76,8 \mathrm{~kW}$. Já com $75 \%$ de carga seu consumo passa a ser de 17,4 litros por hora, a capacidade de geração cai para $57,6 \mathrm{~kW}$, e custa cerca de $\mathrm{R} \$ 62.800,00$.

\subsection{CÁLCULOS COMPARATIVOS}

De posse dos dados sobre os geradores, suas capacidades e particularidades, foi utilizado o software Microsoft Excell $\circledast$ para os devidos cálculos.

\subsubsection{CÁLCULO DE DEMANDA ENERGÉTICA}

Considerando que o forno tem é um modelo de $75 \mathrm{kVa}$, e assumindo o fator de potência 0,8 seu consumo é calculado em $60 \mathrm{~kW} / \mathrm{h}$. Partindo deste resultado foi calculada a demanda para 1 turno de 9 horas e 45 minutos, já que o equipamento permanece em funcionamento durante o horário de almoço. Também se calculou a demanda para 2 turnos, ou seja, 19 horas e 30 minutos, conforme quadro 3. 
Quadro 3 - Cálculo de consumo de energia do forno

\begin{tabular}{|c|c|c|c|c|}
\hline \multicolumn{5}{|c|}{ Calculo de consumo forno Powertrack $75-30$} \\
\hline $\mathrm{kVA}$ & Fator de potência & $\mathrm{kW} / \mathrm{h}$ & 1 turno $(9: 45)$ & 2 turnos $(19: 30)$ \\
\hline 75 & 0,8 & 60 & $585 \mathrm{~kW}$ & $1170 \mathrm{~kW}$ \\
\hline Consum & o em 20 dias de op & eraçã̃o & $11700 \mathrm{~kW}$ & $23400 \mathrm{~kW}$ \\
\hline
\end{tabular}

Fonte: Elaborado pelos autores

\subsubsection{COMPARATIVO ENTRE OS DOIS MODELOS DE GERADORES}

Primeiramente foi realizado o cálculo dos valores de investimento inicial para aquisição dos equipamentos, sendo que a expectativa é que seus valores sejam diluídos em 5 anos, com a economia gerada conforme quadro 4 .

Quadro 4- Comparativo de investimentos iniciais

\begin{tabular}{|l|cc|r|rr|}
\hline \multicolumn{5}{|c|}{ Payback/ Amotização do investimento } \\
\hline & \multicolumn{2}{|c|}{ Invest. Inicial } & $N^{\circ}$ meses & \multicolumn{2}{|c|}{ Valor/ Mês } \\
\hline Gerador A & $\mathrm{R} \$$ & $70.000,00$ & 60 & $\mathrm{R} \$$ & $1.166,67$ \\
\hline Gerador B & $\mathrm{R} \$$ & $62.800,00$ & 60 & $\mathrm{R} \$$ & $1.046,67$ \\
\hline
\end{tabular}

Fonte: Elaborado pelos autores

O gerador " $A$ " requer um investimento mais alto, por se tratar de uma máquina mais potente que o gerador "B". A etapa realizada após o comparativo de investimento inicial foi o cálculo do consumo dos dois modelos com base nos dados fornecidos nos respectivos catálogos técnicos. Uma observação importante torna-se evidente nesta etapa, em função da diferença de capacidades dos dois modelos, o mais potente não necessita necessariamente operar com o máximo de sua capacidade de trabalho, mas sim com $75 \%$, enquanto que o modelo de menor capacidade não tem essa opção, optando por manter a capacidade máxima nos cálculos.

Os dados de consumo calculados foram expressos no quadro 5.

Quadro 5 - Comparativo entre consumo de combustível

\begin{tabular}{|c|c|c|c|c|c|c|c|}
\hline \multirow[b]{2}{*}{ Gerador A } & \multirow{2}{*}{$\begin{array}{l}\text { Consumo } \\
18 \mathrm{lh}\end{array}$} & \multirow{2}{*}{\multicolumn{2}{|c|}{\begin{tabular}{|r|r|} 
Capacidade & Potência gerada \\
$75 \%$ & $79,5 \mathrm{kva}-63,75 \mathrm{~kW}$ \\
\end{tabular}}} & \multicolumn{2}{|c|}{ Custo da hora } & \multicolumn{2}{|c|}{ Valor do $\mathrm{kW}$} \\
\hline & & & & $\mathrm{R} \$$ & 50,40 & $\mathrm{R} \$$ & 1,26 \\
\hline Gerador B & $19,26 \mathrm{lh}$ & $83 \%$ & $79,7 \mathrm{kva}-63,75 \mathrm{~kW}$ & $\mathrm{R} \$$ & 53,93 & $\mathrm{R} \$$ & 1,42 \\
\hline & Valor diesel & R\$ 2,80 & & & & & \\
\hline
\end{tabular}

Como demonstrado no quadro 8 o gerador "A" operando com $75 \%$ de sua capacidade entrega potência de $79,5 \mathrm{kVa}-63,75 \mathrm{~kW}$, isso consumindo 18 litros por hora de operação. Enquanto que o gerador $\mathrm{B}$ operando com $83 \%$ de sua capacidade entrega potência de 79,7 kVA- 63,75kW, consumindo 19,26 litros por hora.

Também é possível observar que os valores por hora e do kW diferem entre os dois modelos, enquanto o modelo " $A$ " tem um custo de combustível por hora de $R \$ 50,40$, e custo por kW de $\mathrm{R} \$ 1,26$, o modelo "B" tem custo por hora de $\mathrm{R} \$ 53,93$ e $\mathrm{R} \$ 1,42$ por $\mathrm{kW}$.

\subsubsection{TARIFAS DA CONCESSIONÁRIA}

Através de análise da conta de energia elétrica da empresa foram observados os seguintes valores de tarifas: $R \$ 0,32501 / \mathrm{kWh}$ para consumo fora do horário de ponta e $\mathrm{R} \$ 1,19974 / \mathrm{kWh}$ para consumo em horário de 
ponta. Sendo esses valores originais, no entanto são acrescidos: bandeira vermelha, ICMS, PIS e COFINS (3,5\% sobre valor com
ICMS). Para esse cálculo foi gerado o quadro 6.

Quadro 6 - Cálculo de tarifas

\begin{tabular}{|c|c|c|c|c|c|c|c|c|c|c|}
\hline \multicolumn{11}{|c|}{ Composiçăo das tarifas } \\
\hline \multirow[b]{2}{*}{ Ponta } & \multicolumn{2}{|c|}{ Valor referência } & \multicolumn{2}{|c|}{$\begin{array}{c}\text { Bandeira Vermelha } \\
\text { (R\$ 0,05495) }\end{array}$} & \multicolumn{2}{|c|}{ ICMS $(17 \%)$} & \multirow{2}{*}{$\begin{array}{l}\text { PIS }(0,8 \%) \\
R \$ 0,01174\end{array}$} & $\begin{array}{l}\text { COFINS } \\
(3,5 \%)\end{array}$ & \multicolumn{2}{|c|}{$\begin{array}{c}\text { Tarifa } \\
\text { considerada }\end{array}$} \\
\hline & $\mathrm{R} \$$ & 1,19974 & $\mathrm{R} \$$ & 1,25469 & $\mathrm{R} \$$ & 0,21330 & & $R \$ 0,05138$ & RS & 1,53 \\
\hline
\end{tabular}

Fonte: Elaborado pelos autores

\begin{abstract}
4.4.4 ANÁLISE 1 (VIABILIDADE DE SUBSTITUIÇÃO TOTAL DA FONTE ENERGÉTICA)

Tendo os dados de tarifa por kWh da concessionária, seus respectivos valores de custo para os geradores "A" e "B", e o consumo estimado do forno, foi calculada a viabilidade de substituição total da energia da concessionária pela energia proveniente dos geradores.
\end{abstract}

O quadro 7 expressa esses valores multiplicados pela demanda calculada no quadro 3 , onde foram encontrados os valores de $585 \mathrm{~kW}$ de demanda para um turno de funcionamento, o que em 20 dias somava $11700 \mathrm{~kW}$ e para dois turnos nos quais eram necessários $1170 \mathrm{~kW}$, sendo que em 20 dias de operação somavam $23400 \mathrm{~kW}$.

Quadro 7 - Análise de viabilidade para substituição total

\begin{tabular}{|c|c|c|c|c|c|c|c|c|}
\hline & Valo & do $\mathrm{k}^{\mathrm{T}}$ & & $585 \mathrm{~kW}$ & $11700 \mathrm{~kW}$ & & $1170 \mathrm{~kW}$ & $23400 \mathrm{~kW}$ \\
\hline Gera & $\mathrm{R} \$$ & 1,26 & $\mathrm{R} s$ & 739,96 & $\mathrm{R} \$ 14.799,11$ & $\mathrm{R} \$$ & $1.479,91$ & $\mathrm{R} \$ 29.598,21$ \\
\hline Gerador B & $\mathrm{R} \$$ & 1,42 & $\mathrm{R}$ & 833,11 & $\mathrm{R} \$ 16.662,22$ & $\mathrm{R} \$$ & $1.666,22$ & $\mathrm{R} \$ 33.324,43$ \\
\hline Concessionária & $\mathrm{R} \$$ & 0,46 & $\mathrm{R} 9$ & 269,10 & $\mathrm{R} \$ 5.382,00$ & $\mathrm{R} \$$ & 538,20 & $\mathrm{R} \$ 10.764,00$ \\
\hline
\end{tabular}

Fonte: Elaborado pelos autores

Analisando o quadro 7, conclui-se que não é viável a substituição total da energia comprada da concessionária pois a tarifa calculada é inferior aos custos de geração dos dois geradores.

\subsubsection{ANÁLISE 2 (VIABILIDADE DE SUBSTITUIÇÃO PARCIAL DA FONTE ENERGÉTICA)}

Considerando que a substituição total traria prejuízos para a empresa, foi realizado o cálculo de substituição parcial, ou seja, utilizar - gerador somente nas 3 horas de ponta, onde a tarifa é mais elevada. Desta forma o valor de demanda energética diária passa a ser $180 \mathrm{~kW}(60 \mathrm{~kW}$ por hora multiplicado pelas 3 horas do período de pico) e $3600 \mathrm{~kW}$ que seria a demanda para 20 dias de operação ou um mês, cujo cálculos estão no quadro 8.

Quadro 8 - Análise de viabilidade para substituição parcial

\begin{tabular}{|l|ll|ll|ll|}
\hline & \multicolumn{3}{|c|}{ Valor do $\mathrm{kW}$} & $180 \mathrm{~kW}$ & $3600 \mathrm{~kW}$ \\
\hline Gerador $\mathrm{A}$ & $\mathrm{R} \$$ & 1,26 & $\mathrm{R} \$$ & 226,80 & $\mathrm{R} \$$ & $4.536,00$ \\
\hline Gerador B & $\mathrm{R} \$$ & 1,42 & $\mathrm{R} \$$ & 255,60 & $\mathrm{R} \$$ & $5.112,00$ \\
\hline Concessionária & $\mathrm{R} \$$ & 1,53 & $\mathrm{R} \$$ & 275,40 & $\mathrm{R} \$$ & $5.508,00$ \\
\hline \multicolumn{5}{|c}{ Fonte: Elaborado pelos autores }
\end{tabular}


Considerando a substituição parcial percebese que os dois geradores têm custo inferior em relação à energia adquirida da concessionária. Partindo deste princípio foi calculado o retorno do investimento em ambos os geradores.

Quadro 9 - Retorno sobre investimento

\begin{tabular}{|l|l|l|l|l|}
\hline & $\begin{array}{l}\text { Custo mensal } \\
(3600 \mathrm{~kW})\end{array}$ & $\begin{array}{l}\text { Re dução de } \\
\text { custo mensal }\end{array}$ & $\begin{array}{l}\text { Valor do } \\
\text { investimento }\end{array}$ & $\begin{array}{l}\text { Numero de } \\
\text { meses p/ } \\
\text { retorno }\end{array}$ \\
\hline Gerador A & $\mathrm{R} \$ 4.536,00$ & $\mathrm{R} \$ 972,00$ & $\mathrm{R} \$ 70.000,00$ & 73 \\
\hline Gerador B & $\mathrm{R} \$ 5.112,00$ & $\mathrm{R} \$ 396,00$ & $\mathrm{R} \$ 62.800,00$ & 159 \\
\hline Concessionária & $\mathrm{R} \$ 5.508,00$ & \multicolumn{3}{|l}{} \\
\cline { 1 - 5 }
\end{tabular}

Fonte: Elaborado pelos autores

Analisando o quadro 9, percebe-se que apesar do gerador "A" requerer um investimento maior, em função do consumo menor ele tem um retorno de investimento em menos da metade do período do gerador "B" o que o torna a melhor opção de substituição. O gerador "B" por consumir mais combustível, gera um custo por kWh apenas $\mathrm{R} \$ 0,11$ menor que a tarifa da concessionária, desta forma a redução de custos mensal chega a $R \$ 396,00$, quase $7,2 \%$ de redução em relação à energia adquirida da concessionária. Essa redução absorveria o custo do gerador em 159 meses ou ainda 13 anos e 3 meses sendo ainda neste cenário uma opção ainda melhor do que comprar a energia da concessionária, apesar de ter um payback mais longo.

\section{CONCLUSÃO}

Tendo em vista os dados analisados, desde o contexto da organização, passando pela análise do processo e suas particularidades conclui-se que o equipamento que demanda maior quantidade de energia na fábrica em questão é o forno da fundição.

A partir desse pressuposto foram realizadas análises dos dados de consumo e de custos com energia elétrica partiu-se para uma análise da possibilidade de substituição da fonte energética.

A partir dessa premissa foram consultados fabricantes e revendedores de grupos

\section{REFERÊNCIAS}

[1] ASSOCIAÇÃO DOS PRODUTORES DE BIODIESEL DO BRASIL (APROBIO). Informações. geradores para avaliar a viabilidade técnica e financeira da utilização destes equipamentos. De quatro fabricantes contatados, somente 2 forneceram todas as informações solicitadas, permitindo a realização de estudos comparativos entre os produtos. Através dos manuais técnicos pôde-se avaliar qual o equipamento com menor consumo de combustível.

Após a realização do comparativo concluiu-se que é viável a substituição parcial da energia comprada por energia proveniente dos geradores, ou seja, utilizar os geradores somente no horário de ponta onde a tarifa cobrada pela concessionária é mais de 3 vezes o valor da tarifa normal. Dos dois equipamentos comparados nenhum deles gera economia que absorva o investimento em 5 anos. Um equipamento se pagará em 6 anos e 1 mês, e o outro somente em 13 anos e 3 meses.

Conclui-se que a substituição deve ser buscada se a demanda exigir o funcionamento do setor em horário de pico, já que é o mercado quem determina esse regime de funcionamento. Sem contar que a aquisição de um gerador traz como benefício uma fonte alternativa e/ou emergencial para contornar blackouts, diminuindo o impacto negativo destes acontecimentos sobre a produção.

Disponível em: www.aprobio.com.br/informacoes. Acesso em: 15 out. 2014. 
[2] BANCO MUNDIAL (WORLD BANK). Brasil, visão panorâmica do país. Disponível em www.worldbank.org/pt/country/brazil. . Acesso em: 31 ago. 2014.

[3] CENTRAIS ELÉTRICAS DE CARAZINHO. Geração de Energia, Usinas. Disponível em: www.eletrocar.com.br/index.php?menu=usinas. Acesso 10/03/2015

[4] EMPRESA DE PESQUISA ENERGÉTICA (EPE). Anuário Estatístico de Energia Elétrica. Disponível em: www.epe.gov.br/AnuarioEstatisticodeEnergiaEletric a/Forms/Anurio.aspx. Acesso em 28 out. 2014.

[5] EMPRESA DE PESQUISA ENERGÉTICA. Balanço Energético Nacional 2014. Disponível em: www.epe.gov.br/pt/publicacoes-dadosabertos/publicacoes/Balanco-Energetico-Nacional2014. Acesso em 25 jun 2016.

[6] GOLDEMBERG, José; LUZ DonderoVillanueva. Energia, Meio Ambiente e Desenvolvimento. Tradução André Koch. 2. ed. rev. São Paulo:Editora da Universidade de São Paulo,2003.

[7] KAGAN, Nelson; OLIVEIRA, Carlos C. B. e ROBBA, João E.Introdução aos Sistemas de
Distribuição de Energia Elétrica- 2ed. -São Paulo Blucher, 2010.

[8] MOURA,Luiz Antônio Abdalla de. Qualidade e Gestão Ambiental. 4ed. São Paulo: Editora Juarez de Oliveira, 2004.

[9] PINTO, Milton de Oliveira. Energia Elétrica Geração, Transmissão e Sistemas Interligados.LTC, 2013. VitalBook file.

[10] REIS, Lineu Belico dos. Geração de energia elétrica. 2. Ed. rev. e atual. - Barueri: Manole, 2011.

[11] REIS, Lineu Belico dos. Matrizes energéticas: conceitos e usos em gestão de planejamento. Barueri, SP: Manole, 2011.

[12] REIS, Lineu Belicodos; CUNHA, Eldis Camargo Neves da.Energia elétrica e Sustentabilidade: aspectos tecnológicos, socioambientais e Legais. Barueri, SP: Manole, 2006.

[13] SLACK, Nigel; CHAMBERS Stuart, JOHNSTON Robert.Administração da Produção; tradução Maria Teresa Corrêa de Oliveira. 3.ed.São Paulo: 2009. 


\section{Bapítulo 2}

\section{UM ESTUDO BIBLIOMÉTRICO DA PRODUCÃO ACADÊMICA BRASILEIRA SOBRE PRODUCÃO MAIS LIMPA PUBLICADA EM PERIODICOS INDEXADOS PELA SCOPUS E WEB OF SCIENCE}

\section{Thales Botelho de Sousa \\ Francisco Raphael Cabral Furtado \\ Jean Mimar Santa Cruz Yabarrena \\ Sherfis Gibran Ruwer \\ Carlos Eduardo Pinto}

Resumo: A Produção mais Limpa $(P+L)$ está sendo cada vez mais utilizada (independente do setor industrial) nas áreas de operação, projeto, planejamento e gestão e, quando incorporada ao desenvolvimento de produtos, possibilita ganhos sociais e ambientais, além de melhoria da qualidade e preço. O objetivo deste estudo foi avaliar o conjunto de artigos sobre $\mathrm{P}+\mathrm{L}$ publicado por pesquisadores brasileiros em periódicos indexados nas bases de dados SCOPUS e/ou Web of Science. A metodologia adotada foi uma análise bibliométrica, visando apresentar os periódicos que constituem o principal fórum de discussão da pesquisa brasileira, abordagens e procedimentos técnicos do campo de gestão de operações mais utilizados, instituições mais produtivas e artigos com maior fator de impacto. Os resultados mostram que os principais periódicos acadêmicos que publicaram artigos brasileiros sobre o tema são o Journal of Cleaner Production e Espacios, a abordagem qualitativa tem predominância no desenvolvimento das pesquisas, os procedimentos técnicos mais utilizados são o estudo de caso e a revisão de literatura, a USP, UNESP, UNIP, UNINOVE e UFRGS são as instituições mais produtivas em relação ao número de artigos publicados. Embora o primeiro artigo brasileiro relacionado a esse tema tenha sido publicado em 2000, o número de publicações brasileiras sobre o assunto só começou a aumentar substancialmente em 2012, apesar das flutuações. O fato de muitos estudos serem de abordagem qualitativa indica que a pesquisa brasileira sobre o tema ainda se encontra em fase exploratória, necessitando de mais validação empírica.

Palavras-chave: Produção mais Limpa, Estudo Bibliométrico, Produção Acadêmica Brasileira, SCOPUS, Web of Science. 


\section{INTRODUÇÃO}

Segundo Ramos et al. (2018), a Produção mais Limpa $(P+L)$ está entre as práticas de sustentabilidade mais significativas que têm sido integradas em cadeias de valor. $\mathrm{P}+\mathrm{L}$ representa a aplicação contínua de uma estratégia preventiva integrada que visa: desenvolver produtos e serviços; fazer uso eficiente de matérias-primas, energia e água; reduzir emissões e resíduos; e reduzir riscos para o ser humano e o meio ambiente (ROBÈRT et al., 2002). P+L é um importante método que tem promovido o desenvolvimento sustentável da sociedade desde sua criação. A P+L analisa aspectos relacionados à operação de um negócio e identifica oportunidades para melhoria em termos de desempenho econômico e ambiental (KHAN, 2008).

A $P+L$ não se baseia apenas na tecnologia, mas também na forma de gestão da empresa, e o comprometimento da alta gestão para o sucesso do programa é fundamental, pois os gestores influenciam diretamente no nível de aprendizado das práticas ambientais de sua equipe (SILVA; MORAES; MACHADO, 2015). Segundo Ramos et al. (2018), no que diz respeito aos produtos, a $\mathrm{P}+\mathrm{L}$ se concentra em seu ciclo de vida e busca reduzir o impacto ambiental desde a extração de matériasprimas até sua disposição final. $A P+L$ atua diretamente na fonte, buscando avaliar: (1) processos de extração e qualidade de matérias-primas; (2) geração, distribuição e consumo de energia; (3) tipo de transporte utilizado para abastecer o processo (incluindo a distribuição dos produtos); (4) características e volume das embalagens adotadas (verificando seu destino após o uso e a possibilidade de reciclagem); e (5) uso e destino final do produto após o término de sua vida útil (como reciclagem e implicações de descarte).

A $\mathrm{P}+\mathrm{L}$ foi proposta pelo United Nations Environment Program (UNEP) juntamente com a United Nations Industrial Development Organization (UNIDO) e representa um programa de prevenção da poluição baseado na gestão de resíduos e uso devido de energia e materiais (MASSOTI; SANTI, 2013). Segundo Oliveira Neto, Shibao e Godinho Filho (2016), a $P+L$ foi introduzida no Brasil em 1995 por meio da criação do Centro Nacional de Tecnologias Limpas (CNTL).

Embora Oliveira Neto, Shibao e Godinho Filho (2016) afirmem que a aplicação das práticas de $\mathrm{P}+\mathrm{L}$ em empresas não seja comum no Brasil, a produção acadêmica brasileira sobre $\mathrm{P}+\mathrm{L}$ tem crescido substancialmente $\mathrm{e}$ despertado interesse em muitos pesquisadores. Em relação à produção científica mundial sobre o tema, na Scopus o Brasil é o terceiro país com mais trabalhos publicados em periódicos indexados, enquanto que na Web of Science é o quarto. Uma pesquisa bibliográfica realizada na Scopus e Web of Science apresenta que Oliveira Neto e Shibao (2014) e Oliveira Neto, Shibao e Godinho Filho (2016) desenvolveram estudos bibliométricos sobre pesquisas acadêmicas brasileiras sobre $\mathrm{P}+\mathrm{L}$ publicadas em um congresso promovido pelo Journal of Cleaner Production.

Como inexiste qualquer artigo que analise 0 estado da pesquisa brasileira sobre $\mathrm{P}+\mathrm{L}$ publicada em periódicos indexados nas duas principais bases bibliográficas mundiais, 0 objetivo deste artigo foi identificar através da bibliometria uma visão geral de trabalhos publicados na Scopus e Web of Science. Seu foco está nos seguintes construtos: (I) periódicos que constituem o principal fórum de discussão da pesquisa brasileira, (II) abordagens e procedimentos técnicos do campo de gestão de operações mais utilizados, (III) instituições mais produtivas, e (IV) fator de impacto dos artigos mais relevantes. Os resultados permitem discutir o estado atual de tais pesquisas no Brasil e sugerir os trabalhos mais relevantes desenvolvidos, as melhores fontes de publicação e os procedimentos técnicos que podem ajudar a desenvolver o tema.

\section{METODOLOGIA}

A metodologia utilizada visa obter resultados capazes de abordar o progresso da produção acadêmica brasileira sobre P+L. Apenas artigos publicados em periódicos indexados nas bases de dados Scopus e Web of Science foram analisados. Os critérios de seleção para esses bancos de dados foram a qualidade e a quantidade de publicações; logo, a Web of Science foi selecionada porque pode atingir todos os periódicos indexados com um fator de impacto calculado no Journal Citation Report (JCR) e a Scopus foi selecionada porque é o maior banco de dados de literatura revisada por pares (HOMRICH et al., 2018). A Scopus indexa 22.794 periódicos revisados por pares, enquanto que a Web of Science indexa 
14.498

(MACHIN-MASTROMATTEO; TARANGO; MEDINA-YLLESCAS, 2017).

A busca bibliográfica foi finalizada em fevereiro de 2018, e apenas estudos publicados em periódicos foram selecionados, pois são considerados como estudos de mais alto nível científico (CARNEVALLI; MIGUEL, 2008; NGAI et al., 2008).

A Tabela 1 apresenta as etapas utilizadas para a obtenção dos trabalhos analisados neste estudo.

Tabela 1 - Etapas do levantamento bibliográfico dos artigos

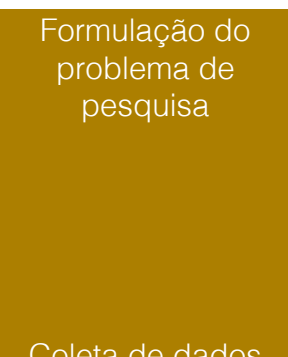

Coleta de dados dados
A questão que levou ao desenvolvimento desta pesquisa foi: Qual o estado das publicações acadêmicas brasileiras sobre $P+L$ nas bases de dados Scopus e Web of Science?

Para alcançar as publicações de interesse, foram utilizados os seguintes termos:

- Scopus:

TITLE-ABS-KEY ("Cleaner Production" AND LIMIT-TO (LANGUAGE: "English") OR LIMITTO (LANGUAGE: "Portuguese") OR LIMIT-TO (LANGUAGE: "Spanish") AND LIMIT-TO (DOCTYPE: "ar") AND LIMIT-TO (AFFILCOUNTRY: Brazil).

- Web of Science:

TOPIC ("Cleaner Production" AND LIMIT-TO (LANGUAGE: "English") OR LIMIT-TO (LANGUAGE: "Portuguese") OR LIMIT-TO (LANGUAGE: "Spanish") AND LIMIT-TO (DOCTYPE: "ar") AND LIMIT-TO (AFFILCOUNTRY: Brazil).

Nesta etapa, o resumo e a introdução dos artigos foram analisados para verificar se eles realmente estavam relacionados à $\mathrm{P}+\mathrm{L}$ ou apenas mencionavam o termo no título e/ou palavras-chave e/ou resumo. Como resultado, pode-se concluir que 151 artigos publicados em periódicos indexados no Scopus e/ou Web of Science apresentaram efetivamente estudos sobre o assunto e eram de autores filiados a instituições brasileiras. Artigos publicados até 28/02/2018 foram considerados.
A abordagem bibliométrica tem sido usada para o desenvolvimento deste artigo porque ela é econômica, acessível, fácil de implementar e é usada em uma variedade de áreas científicas, como desenvolvimento sustentável, mudanças climáticas, energia solar e mercado de carbono (GENG et al., 2017).

\section{RESULTADOS}

Nesta seção, os resultados e a análise do estudo serão apresentados em tabelas e figuras, de acordo com os critérios previamente definidos.

\subsection{PUBLICAÇÕES POR PERIÓDICO}

A Tabela 2 apresenta que o primeiro artigo brasileiro sobre $\mathrm{P}+\mathrm{L}$ foi publicado em 2000. Não houve nenhuma publicação em 2001, 2002 e 2005. Embora existam algumas flutuações, o número de publicações brasileiras sobre o assunto começou a aumentar substancialmente em 2012. 
Tabela 2. Distribuição anual dos artigos sobre $P+L$ publicados em periódicos indexados na Scopus elou Web of Science

\begin{tabular}{|c|c|c|c|c|c|c|c|c|c|c|c|c|c|c|c|c|c|c|}
\hline Periódico & $\begin{array}{l}\text { Fator de } \\
\text { impacto } \\
\text { (JCR) }\end{array}$ & & & 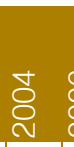 & & 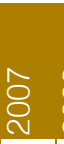 & 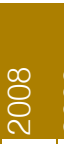 & סे & $\begin{array}{l}\text { Ar } \\
\stackrel{\circ}{\circ} \\
\stackrel{N}{N}\end{array}$ & no & $\frac{N}{i}$ & $\stackrel{m}{5}$ & $\frac{5}{2}$ & $\sum_{\substack{n\\
}}^{10}$ & $\frac{0}{2}$ & $\frac{1}{2}$ & $\frac{\infty}{2}$ & $\stackrel{\bar{\sigma}}{\stackrel{\sigma}{\circ}}$ \\
\hline $\begin{array}{l}\text { Journal of Cleaner } \\
\text { Production }\end{array}$ & 5,715 & 2 & & & & & 3 & 1 & 1 & 1 & 4 & 7 & 3 & 8 & 7 & $\begin{array}{l}1 \\
0\end{array}$ & $\begin{array}{l}1 \\
1\end{array}$ & 58 \\
\hline $\begin{array}{l}\text { Journal of Materials } \\
\text { Processing Technology }\end{array}$ & 3,147 & & & & & & & & & & 1 & & & & & & & 1 \\
\hline $\begin{array}{l}\text { Resources, Conservation } \\
\text { and Recycling }\end{array}$ & 3,313 & & & & & & & & & 1 & & 1 & & 1 & & & & 3 \\
\hline Ecological Modelling & 2,363 & & & & & & & 1 & & & & & & & & & & 1 \\
\hline $\begin{array}{l}\text { Journal of Environmental } \\
\text { Management }\end{array}$ & 4,010 & & & & & & & & & & & & & & 1 & 1 & & 2 \\
\hline $\begin{array}{l}\text { Environmental Impact } \\
\text { Assessment Review }\end{array}$ & 3,094 & & & & & & & & & & & & & 2 & & & & 2 \\
\hline $\begin{array}{l}\text { Construction and Building } \\
\text { Materials }\end{array}$ & 3,169 & & & & & & & & & & & & & & 1 & & & 1 \\
\hline Waste Management & 4,030 & & & & & & & & & & 1 & & & & & & & 1 \\
\hline Gestão \& Produção & - & & & & 2 & & & 1 & 1 & & & 1 & 1 & 2 & & 1 & & 9 \\
\hline Revista Escola de Minas & $\begin{array}{l}0,103 \\
(2013)\end{array}$ & & & & & & & & & & 2 & & & & & & & 2 \\
\hline $\begin{array}{l}\text { International Journal of Oil } \\
\text { Gas and Coal Technology }\end{array}$ & 0,582 & & & & & & & & & & & & 1 & & & & & 1 \\
\hline $\begin{array}{l}\text { International Journal of Life } \\
\text { Cycle Assessment }\end{array}$ & 3,173 & & & & & & & & & & & & & & & 1 & & 1 \\
\hline $\begin{array}{l}\text { Environmental Science and } \\
\text { Pollution Research }\end{array}$ & 2,741 & & & & & & & & & & & 1 & & & & & & 1 \\
\hline $\begin{array}{l}\text { Clean Technologies and } \\
\text { Environmental Policy }\end{array}$ & 3,331 & & & & & & & & & & & & & 1 & 1 & 1 & & 3 \\
\hline $\begin{array}{l}\text { Bioprocess and Biosystems } \\
\text { Engineering }\end{array}$ & 1,870 & & & & & & & & & & & & & & & 1 & & 1 \\
\hline $\begin{array}{l}\text { Water Science and } \\
\text { Technology }\end{array}$ & 1,197 & & & 1 & & & & & & & & & & & 1 & & & 2 \\
\hline Production & - & & & & & 2 & & & & & 1 & 1 & & 1 & 2 & & & 7 \\
\hline $\begin{array}{l}\text { Journal of Environmental } \\
\text { Accounting and } \\
\text { Management }\end{array}$ & - & & & & & & & & & & & & 1 & & 1 & & & 2 \\
\hline Custos e @gronegócio & 0,162 & & & & & & & & & & & & & 1 & & & & 1 \\
\hline $\begin{array}{l}\text { Environmental Science \& } \\
\text { Policy }\end{array}$ & 3,751 & & & & 1 & & & & & & & & & & & & & 1 \\
\hline $\begin{array}{l}\text { Engenharia Sanitária e } \\
\text { Ambiental }\end{array}$ & 0,222 & & & & & & & & & & & & & 1 & 2 & & & 3 \\
\hline Cerâmica & - & & & & & & & & & & & & & & & 1 & & 1 \\
\hline
\end{tabular}


Tabela 2. Distribuição anual dos artigos sobre $P+L$ publicados em periódicos indexados na Scopus e/ou Web of Science

(continuação...)

\begin{tabular}{|c|c|c|c|c|c|c|c|c|c|c|c|c|c|c|c|c|c|c|}
\hline Periódico & $\begin{array}{l}\text { Fator de } \\
\text { impacto } \\
\text { (JCR) }\end{array}$ & $\stackrel{8}{\stackrel{8}{2}}$ & 赵 & 离 & $\begin{array}{l}\mathscr{8} \\
\stackrel{8}{N}\end{array}$ & ¿े & $\begin{array}{l}\infty \\
\stackrel{\infty}{o} \\
\stackrel{\sim}{N}\end{array}$ & \& & $\begin{array}{l}\text { An } \\
\text { 은 } \\
\text { i }\end{array}$ & ì & 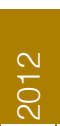 & $\stackrel{m}{\stackrel{m}{N}}$ & $\stackrel{+}{\stackrel{\sim}{\sim}}$ & 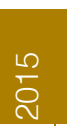 & $\stackrel{0}{\circ}$ & ì & $\stackrel{\infty}{\frac{\infty}{2}}$ & $\frac{\bar{\sigma}}{\circ}$ \\
\hline Matéria & 0,062 & & & & & & & & & & & & & 1 & & & & 1 \\
\hline Materials Research & 0,634 & & & & & & & & & & & & & & & 1 & & 1 \\
\hline $\begin{array}{l}\text { Revista em Agronegócios e } \\
\text { Meio Ambiente }\end{array}$ & - & & & & & & 1 & & & & & & & & & & & 1 \\
\hline Interciencia & 0,221 & & & & & & & & & & & & & 1 & & & & 1 \\
\hline $\begin{array}{l}\text { Chemical Engineering } \\
\text { Transactions }\end{array}$ & - & & & & & & & & & & & & 1 & & & & & 1 \\
\hline $\begin{array}{l}\text { Revista de Administração } \\
\text { de Empresas }\end{array}$ & 0,408 & & & & & & & & & & & & & & 1 & & & 1 \\
\hline Espacios & - & & & & & & & & & & 2 & 1 & 2 & 1 & 2 & 2 & & 10 \\
\hline $\begin{array}{l}\text { Journal of Technology } \\
\text { Management \& Innovation }\end{array}$ & - & & & & & & & & & & & 2 & & & & & & 2 \\
\hline $\begin{array}{l}\text { International Journal of } \\
\text { Environmental Studies }\end{array}$ & - & & & & & & & & & & & 1 & & & & & & 1 \\
\hline Industry and Environment & - & & 1 & & & & & & & & & & & & & & & 1 \\
\hline $\begin{array}{l}\text { Acta Scientiarum. } \\
\text { Technology }\end{array}$ & 0,259 & & & & & & & & & & & & & & & 1 & & 1 \\
\hline $\begin{array}{l}\text { Revista Brasileira de Gestão } \\
\text { de Negócios }\end{array}$ & 0,153 & & & & & & & & & & & & & 1 & & & & 1 \\
\hline Revista Ambiente \& Água & - & & & & & & & & & & & & & & & 1 & & 1 \\
\hline $\begin{array}{l}\text { Environmental Quality } \\
\text { Management }\end{array}$ & - & & & & & & & & & & & & & 1 & 1 & & & 2 \\
\hline Sustainability & 1,789 & & & & & & & & & & & & & & & 1 & & 1 \\
\hline $\begin{array}{l}\text { Electronic Journal of } \\
\text { Geotechnical Engineering }\end{array}$ & - & & & & & & & & & & & & 1 & & & & & 1 \\
\hline $\begin{array}{l}\text { International Journal of } \\
\text { Security and Networks }\end{array}$ & - & & & & & 1 & & & & & & & & & & & & 1 \\
\hline $\begin{array}{l}\text { International Journal of } \\
\text { Product Lifecycle } \\
\text { Management }\end{array}$ & - & & & & & & & & & & & & & & 1 & & & 1 \\
\hline Environmental Politics & 1,922 & & & & & & 1 & & & & & & & & & & & 1 \\
\hline Engenharia Agrícola & 0,353 & & & & & & & & & & & & 1 & & & & & 1 \\
\hline $\begin{array}{l}\text { Revista de Gestão } \\
\text { Ambiental e } \\
\text { Sustentabilidade }\end{array}$ & - & & & & & & & & & & & & & 1 & 1 & & & 2 \\
\hline $\begin{array}{l}\text { Mine Water and the } \\
\text { Environment }\end{array}$ & 1,278 & & & & & & & & & & & & & & & 1 & & 1 \\
\hline $\begin{array}{l}\text { Boletim do Instituto de } \\
\text { Pesca }\end{array}$ & 0,295 & & & & & & 1 & & & & & & & & & & & 1 \\
\hline $\begin{array}{l}\text { International Journal of } \\
\text { Human Resource } \\
\text { Management }\end{array}$ & 1,650 & & & & & & 1 & & 1 & & & & & & & & & 2 \\
\hline $\begin{array}{l}\text { Management of } \\
\text { Environmental Quality: An } \\
\text { International Journal }\end{array}$ & - & & & & & & & & & & & & & & & 1 & & 1 \\
\hline $\begin{array}{l}\text { Revista Eletrônica em } \\
\text { Gestão, Educação e } \\
\text { Tecnologia Ambiental }\end{array}$ & - & & & & & & & & & & & & & 1 & 2 & & & 3 \\
\hline Boletim de Indústria Animal & - & & & & & & & & & & & & & & & 1 & & 1 \\
\hline $\begin{array}{l}\text { RISUS - Journal on } \\
\text { Innovation and } \\
\text { Sustainability }\end{array}$ & - & & & & & & & & & & & & & & & 1 & & 1 \\
\hline $\begin{array}{l}\text { Revista Metropolitana de } \\
\text { Sustentabilidade }\end{array}$ & - & & & & & & & & & & & & & 2 & & 1 & & 3 \\
\hline
\end{tabular}


Na Tabela 2 também é apresentado o fator de impacto (relativo a 2016, exceto em alguns casos) dos periódicos onde os artigos foram publicados. Para Hsieh e Chang (2009) o valor das publicações é comumente avaliado pela classificação dos periódicos no Journal Citation Report (JCR). O fator de impacto ajuda a avaliar a importância relativa de um periódico, especialmente quando comparado com outros do mesmo campo. Dos 151 artigos analisados, 99 foram publicados em periódicos que possuem JCR. Em relação ao número de trabalhos publicados, os periódicos mais produtivos são Journal of Cleaner Production (58), Espacios (10), Gestão \& Produção (9) e Production (7). A Figura 1 apresenta a quantidade anual de artigos publicados em periódicos com e sem JCR. Pode-se argumentar que a predominância de publicação dos artigos em periódicos de alto impacto é uma tendência crescente, o que indica que a pesquisa acadêmica brasileira sobre o tema tem qualidade e é bastante atrativa para a ciência mundial.

Figura 1 - Quantidade anual de artigos publicada em periódicos com e sem JCR.

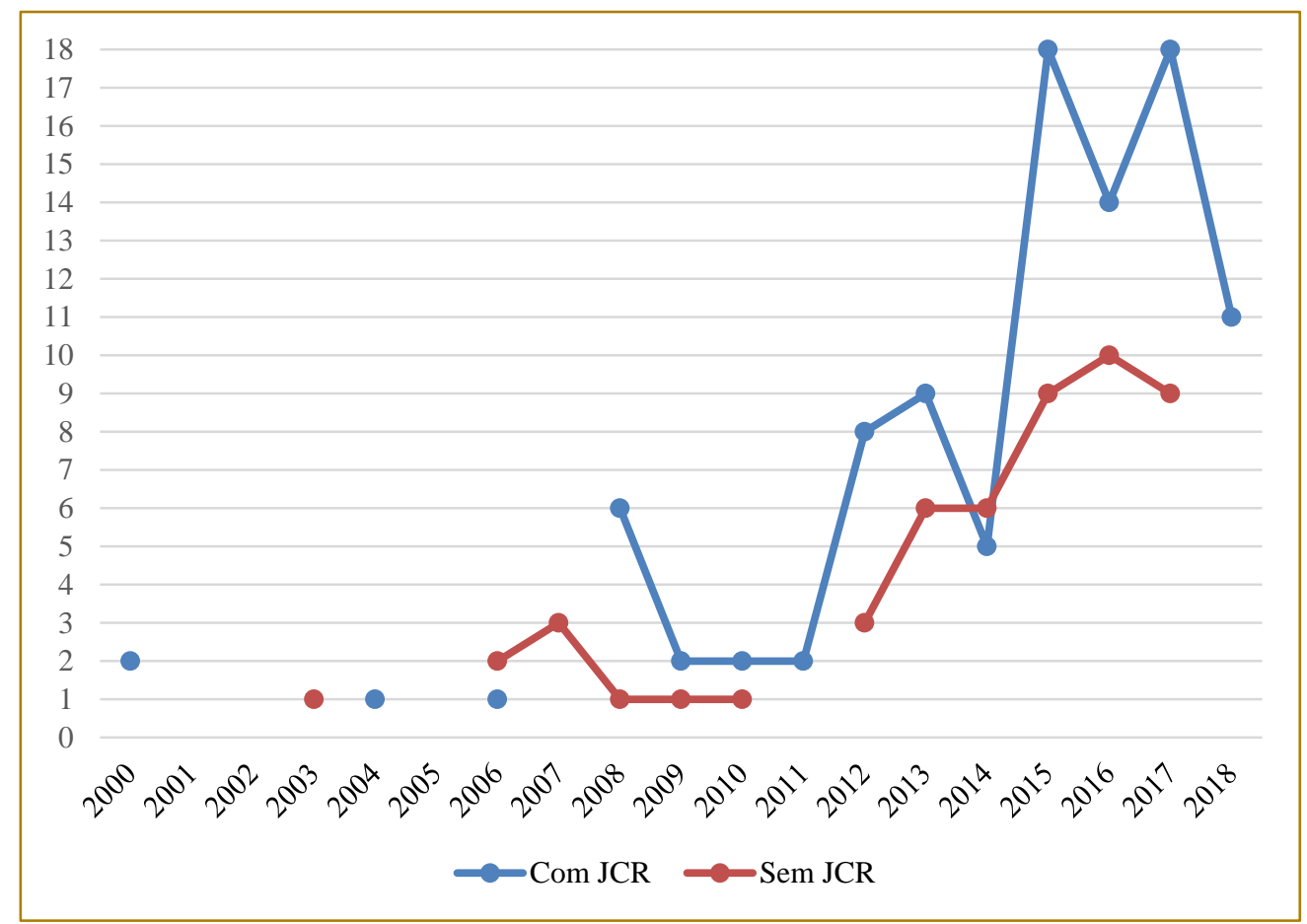

\subsection{ABORDAGENS E PROCEDIMENTOS TÉCNICOS}

A Figura 2 apresenta a classificação dos artigos em relação às abordagens utilizadas para o seu desenvolvimento. Segundo Martins (2012), a pesquisa quantitativa requer o uso de recursos e técnicas estatísticas e entre as suas principais preocupações estão a mensurabilidade, causalidade, generalização e replicação; enquanto a pesquisa qualitativa enfatiza a perspectiva do indivíduo em estudo, tendo um caráter subjetivo, fazendo pouco ou nenhum uso de métodos quantitativos. 
Figura 2 - Classificação e distribuição anual dos artigos de acordo com a abordagem

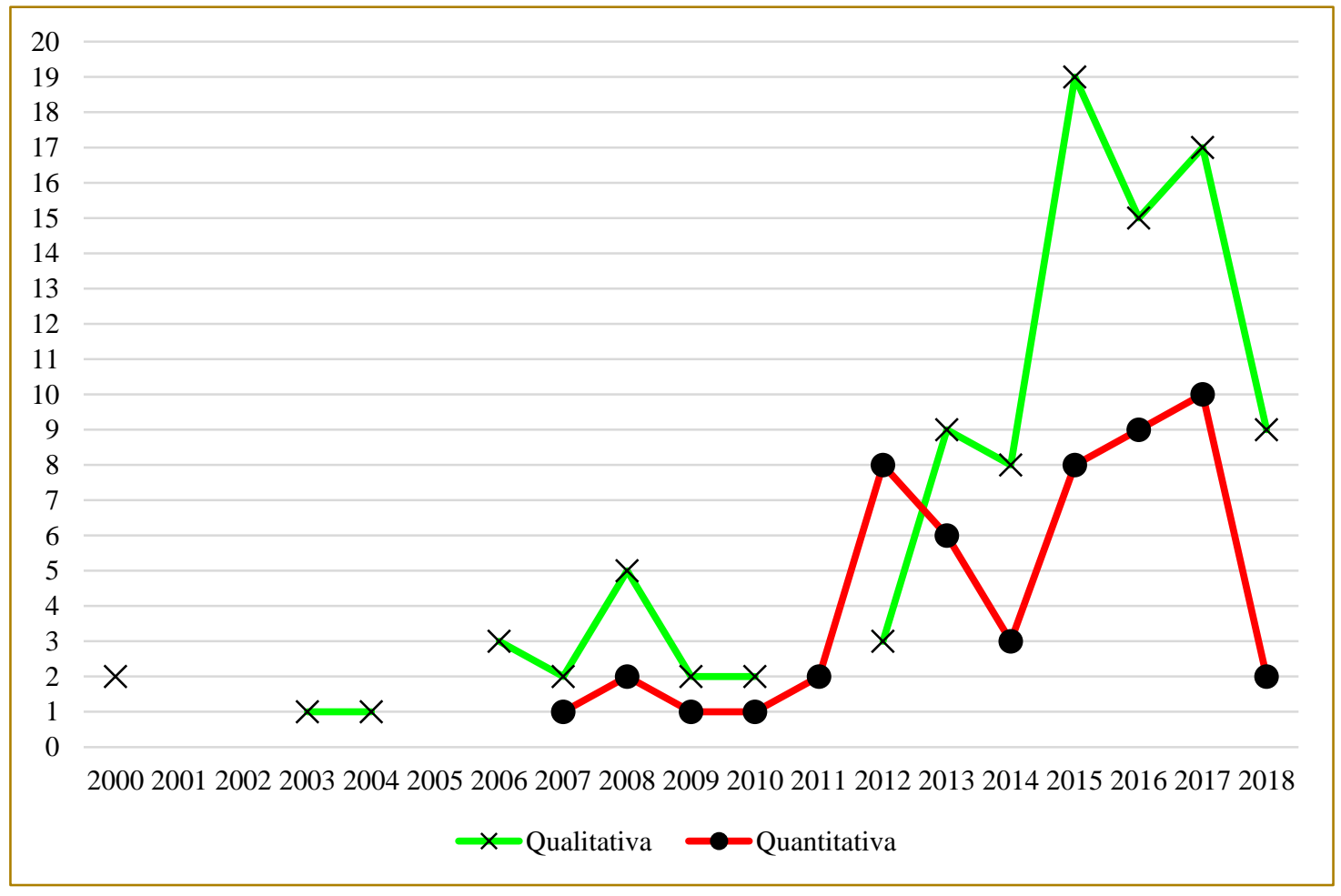

A maior ocorrência de pesquisas qualitativas evidencia que o tema ainda está em expansão no país. Oliveira Neto, Shibao e Godinho Filho (2016) afirmam que a P+L ainda é uma tendência na realidade brasileira e sugerem a melhoria dos canais de comunicação entre governo, empresas, universidades e sociedade, a fim de trocar experiências.

A Figura 3 apresenta a distribuição anual dos artigos em relação ao procedimento técnico utilizado para seu desenvolvimento, com base na classificação de Nakano (2012) para a área de gestão de operações. A revisão da literatura baseia-se em discussões conceituais sobre os principais estudos publicados. A modelagem usa técnicas matemáticas para ilustrar como um sistema de produção opera total ou parcialmente; enquanto a simulação usa técnicas de computação para simular as operações. O estudo de caso realiza uma análise detalhada de um ou mais objetos de estudo sem a participação ativa do pesquisador nos resultados coletados. O survey emprega o uso de instrumento de coleta de dados, fazendo uso de técnicas de amostragem e análise e inferência estatística. A pesquisaação envolve a produção de práticas orientadas ao conhecimento, com a modificação de uma dada realidade que faz parte do processo de pesquisa. Pesquisas experimentais estudam a associação causal entre duas variáveis de um sistema sob condições controladas pelo pesquisador. 
Figura 3 - Classificação e distribuição anual dos artigos de acordo com o procedimento técnico

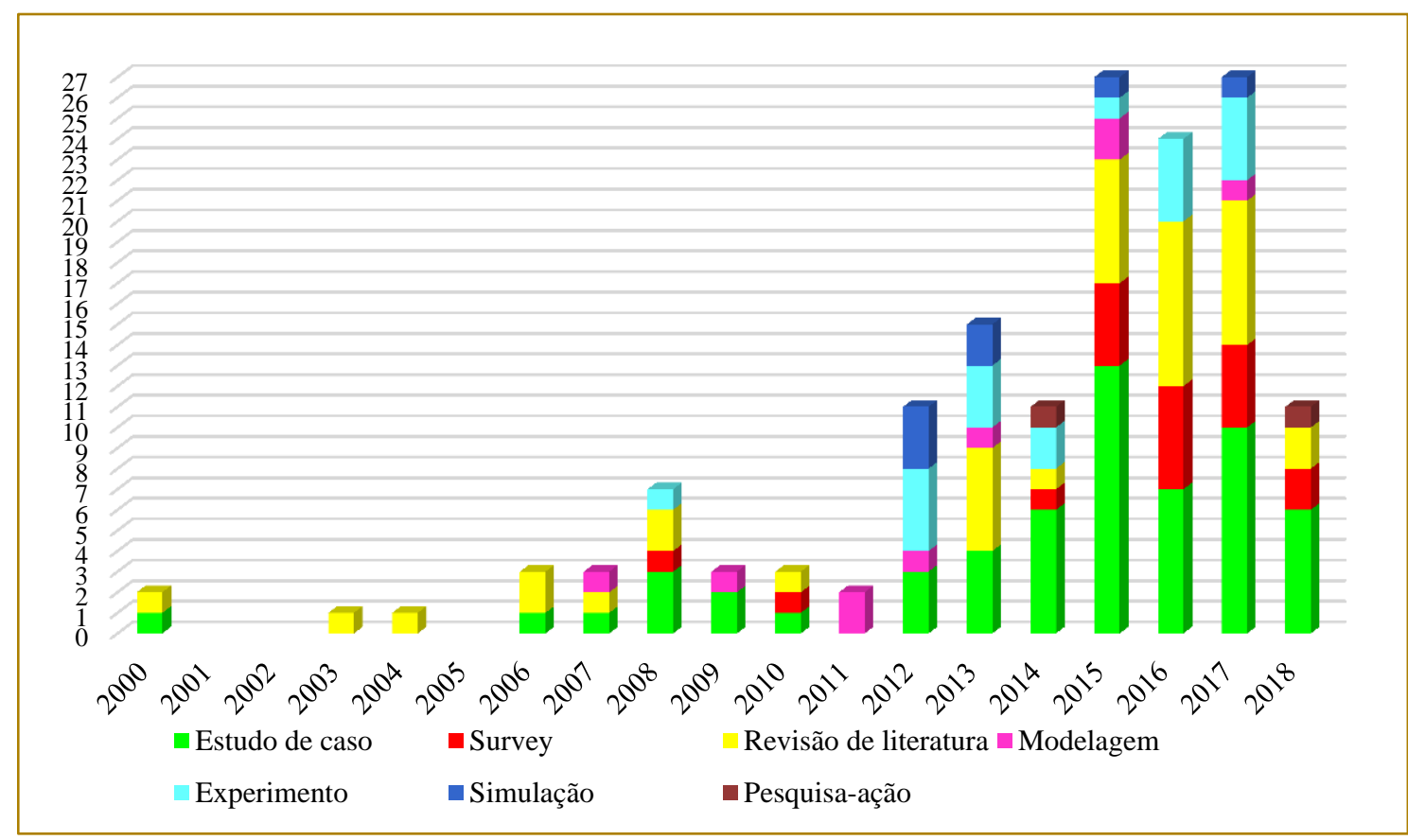

Observando a Figura 3, pode-se observar que o estudo de caso apresentou a maior incidência $(38,4 \%)$, seguido pela revisão de literatura $(25,2 \%)$, experimento $(12,6 \%)$, survey $(11,9 \%)$, modelagem $(6 \%)$, simulação $(4,6 \%)$ e pesquisa-ação (1,3\%). Embora a revisão de literatura seja essencial para o desenvolvimento de qualquer trabalho acadêmico, neste estudo apenas os artigos que adotaram somente a abordagem conceitual em seu desenvolvimento foram classificados como artigos teóricos. A pesquisa-ação precisa ser mais explorada, pois de acordo com Oliveira Neto, Shibao e Godinho Filho (2016), seu uso na realidade operacional pode gerar inovações, possibilitando um ciclo contínuo de aprendizagem social. Para promover o uso desse tipo de pesquisa, é necessário desenvolver parcerias entre universidades e empresas, o que raramente é encontrado no Brasil.

\subsection{INSTITUIÇÕES MAIS PRODUTIVAS}

A Figura 4 apresenta uma nuvem de palavras que contém as instituições que participaram do desenvolvimento dos trabalhos. Com 28 artigos desenvolvidos por pesquisadores vinculados a ela, a USP é a instituição mais produtiva em relação ao número de artigos publicados. Em seguida vem a UNESP (18), UNIP (12), UNINOVE (11), UFRGS (10), UFSCAR (8), UFSC (6) e UCS (6).

Pela Figura 4, pode-se notar que a presença de empresas industriais é bastante escassa, o que reforça os argumentos de Oliveira Neto, Shibao e Godinho Filho (2016). Das 139 instituições que participaram do desenvolvimento das pesquisas brasileiras sobre $\mathrm{P}+\mathrm{L}$, apenas 5 são empresas industriais. 
Figura 4 - Nuvem de palavras das instituições mais produtivas em relação ao número de artigos publicados

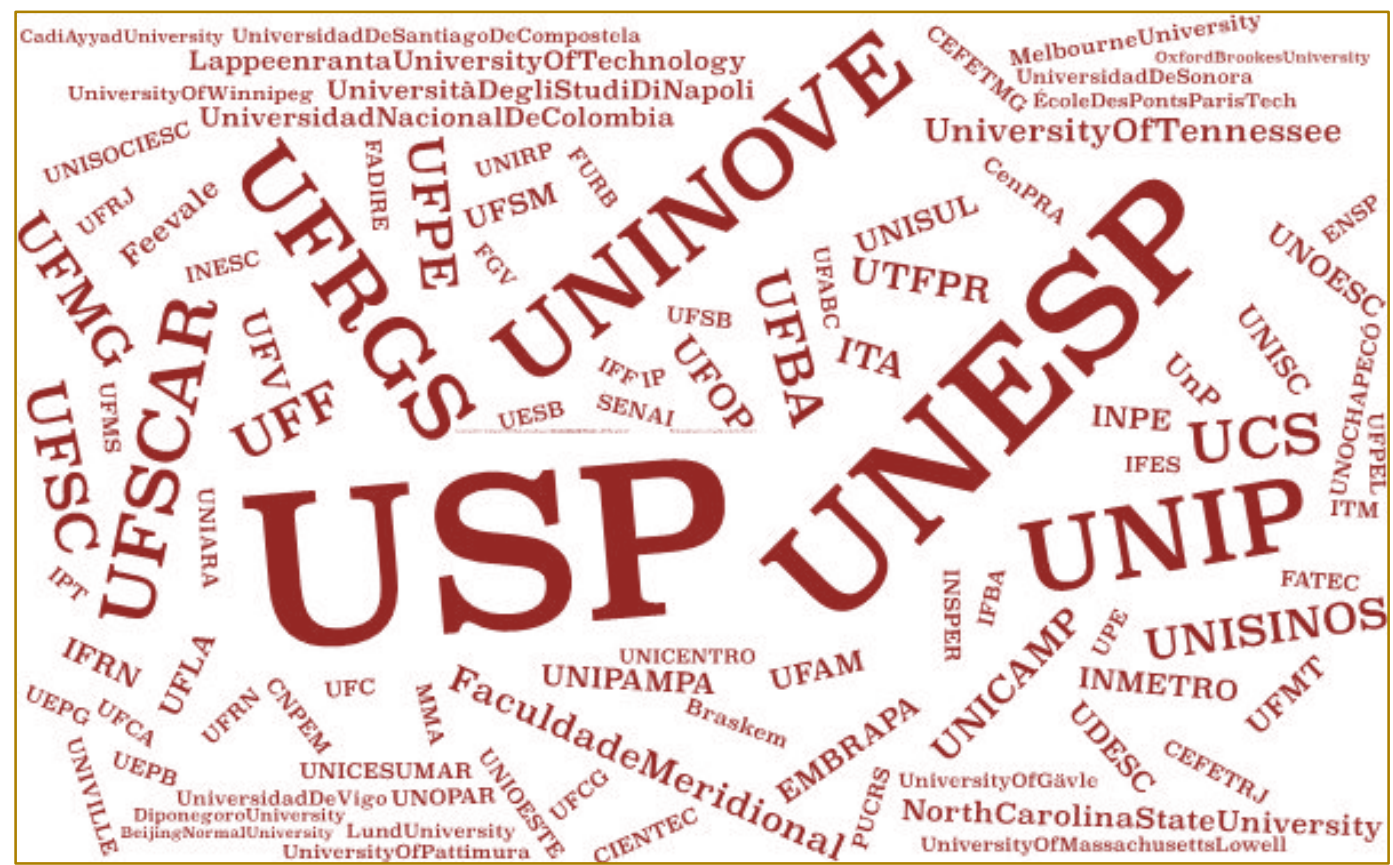

\subsection{FATOR DE IMPACTO DOS ARTIGOS}

A análise do impacto de um artigo para a ciência é um índice de difícil mensuração. Se o número de citações for tido como base, pode-se criar um certo viés temporal, já que os trabalhos mais antigos têm uma grande vantagem fornecida pelo tempo. Homrich et al. (2018) afirmam que a avaliação do impacto de um artigo para áreas científicas deve considerar tanto a média de citações anuais quanto o fator de impacto do periódico onde o artigo foi publicado, já que o fator de impacto pode mudar a posição de um artigo no ranking de citações e a consideração da média anual de citações é menos sensível às variações anuais das citações. O cálculo do fator de impacto do artigo é apresentado na Equação 1, desenvolvida por Carvalho, Fleury e Lopes (2013).

Fator de impacto do artigo = média anual de citações $\times(1+J C R)$

As Tabelas 3 e 4 apresentam os artigos de pesquisadores brasileiros sobre $\mathrm{P}+\mathrm{L}$ com maior impacto para a ciência, considerando o número de citações recebidas nas bases de dados Scopus e Web of Science, respectivamente. 
Tabela 3 - Artigos com maior fator de impacto na Scopus

\begin{tabular}{|c|c|c|c|c|c|}
\hline Ano & Título do artigo & Periódico & JCR & $\begin{array}{l}\text { Média } \\
\text { anual de } \\
\text { citações }\end{array}$ & $\begin{array}{l}\text { Fator de } \\
\text { impacto do } \\
\text { artigo }\end{array}$ \\
\hline 2015 & $\begin{array}{l}\text { Cleaner production, environmental sustainability } \\
\text { and organizational performance: an empirical } \\
\text { study in the Brazilian Metal-Mechanic industry }\end{array}$ & $\begin{array}{l}\text { Journal of } \\
\text { Cleaner } \\
\text { Production }\end{array}$ & 5,715 & 9,333 & 62,67 \\
\hline 2010 & $\begin{array}{l}\text { The roles of cleaner production in the sustainable } \\
\text { development of modern societies: an introduction } \\
\text { to this special issue }\end{array}$ & $\begin{array}{l}\text { Journal of } \\
\text { Cleaner } \\
\text { Production }\end{array}$ & 5,715 & 8,875 & 59,60 \\
\hline 2013 & Cleaner production: levulinic acid from rice husks & $\begin{array}{l}\text { Journal of } \\
\text { Cleaner } \\
\text { Production }\end{array}$ & 5,715 & 7,6 & 51,03 \\
\hline 2013 & $\begin{array}{l}\text { Quality tools applied to Cleaner Production } \\
\text { programs: a first approach toward a new } \\
\text { methodology }\end{array}$ & $\begin{array}{l}\text { Journal of } \\
\text { Cleaner } \\
\text { Production }\end{array}$ & 5,715 & 6 & 40,29 \\
\hline 2015 & $\begin{array}{l}\text { Integrating cleaner production into sustainability } \\
\text { strategies: an introduction to this special volume }\end{array}$ & $\begin{array}{l}\text { Journal of } \\
\text { Cleaner } \\
\text { Production }\end{array}$ & 5,715 & 6 & 40,29 \\
\hline 2015 & $\begin{array}{l}\text { Utilization of water treatment plant sludge in } \\
\text { structural ceramics }\end{array}$ & $\begin{array}{l}\text { Journal of } \\
\text { Cleaner } \\
\text { Production }\end{array}$ & 5,715 & 5,667 & 38,05 \\
\hline 2013 & $\begin{array}{l}\text { Identification and conception of cleaner } \\
\text { production opportunities with the Theory of } \\
\text { Inventive Problem Solving }\end{array}$ & $\begin{array}{l}\text { Journal of } \\
\text { Cleaner } \\
\text { Production }\end{array}$ & 5,715 & 5,4 & 36,26 \\
\hline 2015 & $\begin{array}{l}\text { How the Brazilian government can use public } \\
\text { policies to induce recycling and still save money? }\end{array}$ & $\begin{array}{l}\text { Journal of } \\
\text { Cleaner } \\
\text { Production }\end{array}$ & 5,715 & 5,333 & 35,81 \\
\hline 2016 & $\begin{array}{l}\text { Advancing sustainable solutions: an } \\
\text { interdisciplinary and collaborative research } \\
\text { agenda }\end{array}$ & $\begin{array}{l}\text { Journal of } \\
\text { Cleaner } \\
\text { Production }\end{array}$ & 5,715 & 5 & 33,58 \\
\hline 2017 & $\begin{array}{l}\text { Cleaner production and environmental } \\
\text { management as sustainable product innovation } \\
\text { antecedents: A survey in Brazilian industries }\end{array}$ & $\begin{array}{l}\text { Journal of } \\
\text { Cleaner } \\
\text { Production }\end{array}$ & 5,715 & 5 & 33,58 \\
\hline 2017 & $\begin{array}{l}\text { Cleaner Production towards a sustainable } \\
\text { transition }\end{array}$ & $\begin{array}{l}\text { Journal of } \\
\text { Cleaner } \\
\text { Production }\end{array}$ & 5,715 & 5 & 33,58 \\
\hline 2017 & $\begin{array}{l}\text { Framework to overcome barriers in the } \\
\text { implementation of cleaner production in small and } \\
\text { medium-sized enterprises: multiple case studies } \\
\text { in Brazil }\end{array}$ & $\begin{array}{l}\text { Journal of } \\
\text { Cleaner } \\
\text { Production }\end{array}$ & 5,715 & 5 & 33,58 \\
\hline
\end{tabular}


Tabela 4 - Artigos com maior fator de impacto na Web of Science

\begin{tabular}{|c|c|c|c|c|c|}
\hline Ano & Título do artigo & Periódico & $\mathrm{JCR}$ & $\begin{array}{l}\text { Média } \\
\text { anual de } \\
\text { citações }\end{array}$ & $\begin{array}{l}\text { Fator de } \\
\text { impacto do } \\
\text { artigo }\end{array}$ \\
\hline 2014 & A Lean \& Green Model for a production cell & $\begin{array}{l}\text { Journal of } \\
\text { Cleaner } \\
\text { Production }\end{array}$ & 5,715 & 19,667 & 132,06 \\
\hline 2013 & Cleaner production: levulinic acid from rice husks & $\begin{array}{l}\text { Journal of } \\
\text { Cleaner } \\
\text { Production }\end{array}$ & 5,715 & 8,5 & 57,08 \\
\hline 2015 & $\begin{array}{l}\text { Cleaner production, environmental sustainability } \\
\text { and organizational performance: an empirical } \\
\text { study in the Brazilian Metal-Mechanic industry }\end{array}$ & $\begin{array}{l}\text { Journal of } \\
\text { Cleaner } \\
\text { Production }\end{array}$ & 5,715 & 8,333 & 55,96 \\
\hline 2013 & $\begin{array}{l}\text { Cleaner Production initiatives and challenges for } \\
\text { a sustainable world: an introduction to this special } \\
\text { volume }\end{array}$ & $\begin{array}{l}\text { Journal of } \\
\text { Cleaner } \\
\text { Production }\end{array}$ & 5,715 & 7,75 & 52,04 \\
\hline 2010 & $\begin{array}{l}\text { The roles of cleaner production in the sustainable } \\
\text { development of modern societies: an introduction } \\
\text { to this special issue }\end{array}$ & $\begin{array}{l}\text { Journal of } \\
\text { Cleaner } \\
\text { Production }\end{array}$ & 5,715 & 7,375 & 49,52 \\
\hline 2013 & $\begin{array}{l}\text { Quality tools applied to Cleaner Production } \\
\text { programs: a first approach toward a new } \\
\text { methodology }\end{array}$ & $\begin{array}{l}\text { Journal of } \\
\text { Cleaner } \\
\text { Production }\end{array}$ & 5,715 & 6,75 & 45,33 \\
\hline 2016 & $\begin{array}{l}\text { Green training and green supply chain } \\
\text { management: evidence from Brazilian firms }\end{array}$ & $\begin{array}{l}\text { Journal of } \\
\text { Cleaner } \\
\text { Production }\end{array}$ & 5,715 & 6 & 40,29 \\
\hline 2016 & $\begin{array}{l}\text { Evolution of integrated management systems } \\
\text { research on the Journal of Cleaner Production: } \\
\text { Identification of contributions and gaps in the } \\
\text { literature }\end{array}$ & $\begin{array}{l}\text { Journal of } \\
\text { Cleaner } \\
\text { Production }\end{array}$ & 5,715 & 6 & 40,29 \\
\hline 2015 & $\begin{array}{l}\text { Integrating cleaner production into sustainability } \\
\text { strategies: an introduction to this special volume }\end{array}$ & $\begin{array}{l}\text { Journal of } \\
\text { Cleaner } \\
\text { Production }\end{array}$ & 5,715 & 5,667 & 38,02 \\
\hline
\end{tabular}

Entre os artigos com maior fator de impacto, os temas mais discutidos foram: desempenho organizacional de empresas industriais, revisão bibliográfica de artigos sobre $\mathrm{P}+\mathrm{L}$ publicados em congressos, melhoria da sustentabilidade de processos operacionais, aplicação de ferramentas de qualidade em programas de $\mathrm{P}+\mathrm{L}$, crescimento econômico, inovação sustentável de produtos, implementação de $P+L$ em pequenas e médias empresas e programas de treinamento ambiental.

\section{CONSIDERAÇÕES FINAIS}

Este trabalho serviu para tecer um panorama geral da produção acadêmica brasileira sobre $\mathrm{P}+\mathrm{L}$ publicada em periódicos indexados na Scopus e/ou Web of Science. A apresentação dos periódicos mais produtivos em relação às publicações sobre o tema direciona as principais fontes para a divulgação de trabalhos futuros. $\mathrm{O}$ estudo bibliométrico revelou que o Journal of Cleaner Production é o periódico mais prolífico em relação à pesquisa brasileira sobre $\mathrm{P}+\mathrm{L}$. Tal atratividade e importância não são surpreendentes, uma vez que este é o primeiro periódico inteiramente dedicado à pesquisa sobre $\mathrm{P}+\mathrm{L}$ e, além disso, promove e auxilia diversos workshops ao redor do mundo para desenvolver o tema (OLIVEIRA NETO; SHIBAO; GODINHO FILHO, 2016). Além de ser a principal fonte de divulgação dos estudos brasileiros sobre $\mathrm{P}+\mathrm{L}$, o Journal of Cleaner Production têm as publicações com maior impacto para a ciência.

A predominância do estudo de caso como procedimento técnico mais utilizado para o desenvolvimento das pesquisas reforça os resultados de Berto e Nakano (2000) e Walter e Tubino (2013), que afirmam que este é o 
procedimento técnico mais utilizado nas pesquisas da área de gestão de operações.

Apesar do crescente número de artigos publicados em periódicos indexados na Scopus e/ou Web of Science, observou-se que a pesquisa brasileira ainda se encontra em fase exploratória, pois cerca de $65 \%$ dos estudos foram desenvolvidos com a abordagem qualitativa, utilizando principalmente estudos de caso e revisões de literatura. Tomando como base a definição de Carvalho, Fleury e Lopes (2013), pode-se afirmar que a maior incidência da abordagem qualitativa nas pesquisas demonstra que o tema ainda está em consolidação no país e reforça a necessidade de desenvolvimento de pesquisas com abordagem quantitativa $e$ validação empírica.

Como em qualquer estudo bibliométrico, é importante enfatizar que o método utilizado para 0 desenvolvimento deste artigo apresenta algumas limitações. A amostra de artigos analisada foi extraída de apenas duas bases de dados, o que pode ter

\section{REFERÊNCIAS}

[1] BERTO, R. M. V. S.; NAKANO, D. N. A produção científica nos anais do Encontro Nacional de Engenharia de Produção: um levantamento de métodos e tipos de pesquisa. Production, v. 9, n. 2, p. 65-76, 2000.

[2] CARneVAlLI, J. A.; Miguel, P. A. C. Review, analysis and classification of the literature on QFD - types of research, difficulties and benefits. International Journal of Production Economics, v. 114, n. 2, p. 737-754, 2008.

[3] CARVALHO, M. M.; FLEURY, A. L.; LOPES, A. P. An overview of the literature on technology roadmapping (TRM): contributions and trends. Technological Forecasting \& Social Change, v. 80, n. 7, p. 1418-1437, 2013.

[4] GENG, S. et al. Building life cycle assessment research: a review by bibliometric analysis. Renewable and Sustainable Energy Reviews, v. 76, p. 176-184, 2017.

[5] $\mathrm{HOMRICH}, \mathrm{A}$. S. et al. The circular economy umbrella: trends and gaps on integrating pathways. Journal of Cleaner Production, v. 175, p. 525-543, 2018

[6] HSIEH, P-N.; CHANG, P-L. An assessment of world-wide research productivity in production and operations management. International Journal of Production Economics, v. 120, n. 2, p. 540-551, 2009 . desconsiderado estudos relevantes publicados em outras fontes. Além disso, o fato de apenas artigos publicados em periódicos (devido à sua maior relevância e qualidade) não significa que artigos publicados em anais de congressos não possam ter contribuições importantes para o desenvolvimento do tema. E, finalmente, o estudo bibliométrico desenvolvido baseou-se nas percepções dos autores, o que pode desconsiderar aspectos tidos como importantes a partir de outros pontos de vista.

No entanto, apesar das limitações, este estudo ajuda a iluminar a literatura brasileira sobre $\mathrm{P}+\mathrm{L}$, uma vez que apresenta a caracterização da produção científica, mostrando os temas de maior atratividade para a ciência, bem como os métodos a serem adotados e que podem ajudar a desenvolver o tema no país. Outros estudos bibliométricos podem ir além dos tópicos discutidos aqui, para que uma visão geral da produção científica seja mais ampla e mais detalhada em relação aos temas analisados.

[7] KHAN, Z. Cleaner production: An economical option for ISO certification in developing countries. Journal of Cleaner Production, v. 16, n. 1, p. 22-27, 2008.

[8] MACHIN-MASTROMATTEO, J. D.; TARANGO, J.; MEDINA-YLLESCAS, E. Latin American triple-A journals I: a quality roadmap from the quality indicators and journals' presence in Web of Science and Scopus. Information Development, v. 33, n. 4, p. 436-441, 2017.

[9] MARTINS, R. A. Abordagens quantitativa e qualitativa. In: MIGUEL, P. A. C. (Org.). Metodologia de pesquisa em engenharia de produção e gestão de operações. $2^{\underline{a}}$ ed. Rio de Janeiro: Elsevier: ABEPRO, 2012.

[10] MASSOTI, C. H. R.; SANTI, A. M. M. Implementation of a cleaner production program in a Brazilian wooden furniture factory. Journal of Cleaner Production, v. 46, p. 89-97, 2013.

[11] NAKANO, D. N. Métodos de pesquisa adotados na engenharia de produção e gestão de operações. In: MIGUEL, P. A. C. (Org.). Metodologia de pesquisa em engenharia de produção e gestão de operações. $2^{\underline{a}}$ ed. Rio de Janeiro: Elsevier: ABEPRO, 2012.

[12] NGAI, E. W.T. et al. RFID research: an academic literature review (1995-2005) and future research directions. International Journal of 
Production Economics, v. 112, n. 1, p. 510-520, 2008.

[13] OlIVEIRA NETO, G. C.; SHIBAO, F. Y. Bibliometric Analysis of the International Workshop on Advances in Cleaner Production in Brazil. Journal of Environmental Accounting and Management, v. 2, n. 3, p. 281-291, 2014.

[14] OLIVEIRA NETO, G. C.; SHIBAO, F. Y.; GODINHO FILHO, M. The state of research on Cleaner Production in Brazil. Revista de Administração de Empresas, v. 56, n. 5, p. 547577,2016

[15] RAMOS, A. R. et al. A lean and cleaner production benchmarking method for sustainability assessment: a study of manufacturing companies in Brazil. Journal of Cleaner Production, v. 177, p. 218-231, 2018.

[16] ROBÈRT, K-H. et al. Strategic sustainable development - selection, design and synergies of applied tools. Journal of Cleaner Production, v. 10, n. 3, p. 197-214, 2002.

[17] SILVA, A. L. E.; MORAES, J. A. R.; MACHADO, E. L. Proposta de produção mais limpa voltada às práticas de ecodesign e logística reversa. Engenharia Sanitária e Ambiental, v. 20, n. 1, p. 29-37, 2015.

[18] WALTER, O. M. F. C.; TUBINO, D. F. Métodos de avaliação da implantação da manufatura enxuta: uma revisão da literatura e classificação. Gestão \& Produção, v. 20, n. 1, p. 23-45, 2013. 


\section{Bapítulo 3}

\section{IMPLANTAÇÃO DE FERRAMENTA DE INTELIGÊNCIA DE NEGÓCIO ELETROBRAS DISTRIBUIÇÃO PIAUÍ}

\section{Edward Lennon da Fontoura Daniel}

\section{Josué Fernandes Alves Silva}

Andrea Cristina dos Santos Silva

Valdenrique Soares Torres

Resumo: Visando a busca de soluções inovadores a fim de garantir a sobrevivência do negócio e estabelecer projetos e ações voltados ao aprimoramento empresarial. Em um ambiente composto por usuários que ainda organizam informações e relatórios de alta relevância em planilhas, torna-se crítico o incremento e avanço nas habilidades em se trabalhar informações. Com isso, tendo em vista a melhoria operacional e financeira da Eletrobras Distribuição Piauí, o Departamento de Tecnologia da Informação e Telecomunicações investiu na implantação de solução de inteligência de negócios. Portanto, este artigo apresenta os fatores críticos para o sucesso do projeto e os respectivos resultados obtidos. Primeiramente, é apresentado o cenário e a metodologia utilizada na implementação. Posteriormente, são demonstrados os resultados obtidos com a ferramenta e as considerações finais.

Palavras-chave: Inteligência de Negócio, Gestão Estratégica e Otimização de Resultados. 


\section{INTRODUÇÃO}

O aumento da competição global entre as organizações torna imperativa a necessidade de novos meios na busca da eficiência e efetividade nas estratégias empresariais. O avanço tecnológico é um dos fatores que contribui significativamente com as mudanças na forma de agir das organizações. Para isso, é de extrema importância que a empresa entenda que a busca de soluções inovadores garante a sobrevivência do negócio e estabeleça projetos e ações voltados ao aprimoramento empresarial. Em um ambiente composto por usuários que ainda organizam informações e relatórios de alta relevância em planilhas, torna-se crítico $o$ incremento $e$ avanço nas habilidades em se trabalhar informações.

Neste sentido, a Eletrobras Distribuição Piauí elaborou seu Plano Estratégico de Tecnologia da Informação e Telecomunicações - PETIC, em 2016. Ele contém as macro iniciativas que, alinhadas as orientações estratégicas da organização, conduzem o Departamento de Tecnologia da Informação e Telecomunicações - DGT no apoio as áreas de negócio da empresa. Entre os direcionadores estratégicos do plano estão: aproximar e adequar a Tecnologia da Informação - Tl ao negócio, adequar os níveis de serviços de $\mathrm{Tl}$ e melhorar a segurança da informação (ELETROBRAS, 2016).

O alinhamento estratégico do PETIC ao negócio permite o alcance de benefícios, tais como: a melhoria da confiança das áreas de negócio e dos clientes em relação à $\mathrm{TI}$ e ampliação da capacidade de produção e análise de informação gerencial. Está última foco do trabalho aqui apresentado.

Assim, visando o aumento da eficácia e eficiência operacionais, melhoria da qualidade dos serviços e redução das perdas de energia e da inadimplência. Além de influenciar na modernização da estrutura organizacional e do sistema de gestão, melhoria e integração dos processos administrativos, e capacitação e profissionalização do quadro gerencial e técnico-administrativo da empresa, o DGT investiu na implementação de ferramenta de inteligência de negócio (Business Intelligence $-B$ ).

A implantação da ferramenta de $\mathrm{BI}$ nasceu de um projeto empresarial, liderado pelo DGT, com o objetivo de catalisar as extrações de informações dos principais sistemas críticos ao negócio da empresa a fim de se melhorar a assertividade na tomada de decisões, minimizando riscos por meio de avaliações mais precisas, utilizando fatos ao invés de subjetividade.

$\mathrm{Na}$ sequência, o projeto foi submetido ao Comitê de Tecnologia da Informação, Automação e Telecomunicações - CETIAT. Este é composto por representantes de todas as diretorias da empresa e definiu que os sistemas selecionados seriam: Comercial, Gestão Empresarial, Recursos Humanos e Gestão Técnica da Distribuição. Os principais benefícios esperados para o projeto são: maior agilidade e confiabilidade na disponibilização de informações e maior precisão na tomada de decisões baseadas em fatos.

Portanto, com as diretrizes básicas definidas, o DGT analisou as ferramentas disponíveis no mercado e buscou a contratação da mais adequada ao contexto da empresa a fim de obter sucesso na implementação. Com isso, optou-se pela contratação da solução fornecida pela Qlik, o Qlik Sense. Este é de fácil usabilidade e possui arquitetura capaz de disponibilizar as informações de forma dinâmica e robusta. $O$ presente trabalho explanará sobre a forma de implantação e uso da ferramenta. Além disso, os fatores críticos de sucesso e os resultados obtidos serão comentados.

\section{CENÁRIO: IMPLANTAÇÃO DA FERRAMENTA (BUSINESS INTELLIGENCE - $B$ )}

Uma ferramenta de $\mathrm{Bl}$ é capaz de coletar e analisar dados não estruturados, em grandes quantidades e em diversas bases de dados. Existem diversas plataformas de softwares disponíveis no mercado, inclusive livres (opensource). Portanto, não há grandes dificuldades na implantação e operação.

Entretanto, a implementação bem sucedida somente pode ser obtida com o alinhamento perfeito entre os especialistas de negócio e os analistas de sistemas (TAPADINHAS, 2016). Considerando a restrição de não dispor de analistas de sistemas exclusivos para o projeto e a tentativa falha de implantação de ferramenta livre no passado sem a devida expertise no tema, a organização optou por contratar solução composta de software e consultoria especializada. Com isso, as expectativas do negócio tenderiam a ser 
atendidas. Esse foi o foco do projeto na Eletrobras Distribuição Piauí.

A Diretoria da empresa estabeleceu como premissa que os especialistas de cada área de negócio demandada seriam disponibilizados por suas gerências ao DGT para apoio na customização da ferramenta, quando solicitados. Além disso, as diretorias envolvidas deveriam incentivar o uso da solução. Soma-se a isso o fato de o DGT dispor de analista de negócio com formação em análise de sistemas capaz de fazer a interlocução entre o negócio e a tecnologia.

O projeto foi desenhado de forma a minimizar os riscos gerados por falhas nas integrações entre as partes interessadas e a falta de governança nos processos. Portanto, a atuação orquestrada entre o fornecedor da solução, analistas de sistemas do DGT e especialistas do negócio das diversas áreas da empresa maximiza a chance de sucesso (DUNCAN, 2015).

\section{Quadro 01: Partes Envolvidas}

\begin{tabular}{|c|c|c|}
\hline \multicolumn{2}{|c}{ Fornecedor } & \multicolumn{2}{c|}{ Analistas de Sistemas } & Especialistas de Negócio \\
\hline $\begin{array}{c}\text { Expertise na solução e apoio } \\
\text { técnico na implementação da } \\
\text { ferramenta. }\end{array}$ & $\begin{array}{c}\text { Conhecimento prévio dos bancos de } \\
\text { dados e interlocução com as áreas de } \\
\text { negócio. Configuração do acesso as } \\
\text { fontes de dados. }\end{array}$ & $\begin{array}{c}\text { Demanda de informações e } \\
\text { indicadores a serem extraídos } \\
\text { pela ferramenta. }\end{array}$ \\
\hline
\end{tabular}

O cronograma do projeto foi desenhado de forma a se aproveitar o paralelismo nas ações e reduzir o tempo de conclusão. Os prazos previstos no quadro 02 já incluem os tempos necessários às homologações das Diretorias responsáveis por cada sistema. A atuação da
TI na transformação digital de forma BIMODAL, ou seja, tratando as rotinas diárias da forma tradicional e as inovações de forma Ágil. Isto é mais uma diretriz do projeto que permitirá a exploração da nova tecnologia a ser adotada de forma a transformar o negócio.

Quadro 02: Cronograma

\begin{tabular}{|c|c|c|c|c|c|c|}
\hline \multirow{2}{*}{ Atividades } & \multirow{2}{*}{ Início } & \multirow{2}{*}{ Término } & \multicolumn{4}{|c|}{ Previsões por Trimestre (acumulado) } \\
\hline & & & 10 & $2^{\circ}$ & $3^{\circ}$ & $4^{\circ}$ \\
\hline $\begin{array}{c}\text { Preparação dos Servidores e } \\
\text { Criação de Ambiente }\end{array}$ & Jan/17 & Fev/17 & $100 \%$ & $100 \%$ & $100 \%$ & $100 \%$ \\
\hline Implantação no Comercial & Fev/17 & Mar/17 & $100 \%$ & $100 \%$ & $100 \%$ & $100 \%$ \\
\hline Implantação no RH & Mar/17 & Abr/17 & $50 \%$ & $100 \%$ & $100 \%$ & $100 \%$ \\
\hline Implantação no ERP & Abr/17 & Mai/17 & & $100 \%$ & $100 \%$ & $100 \%$ \\
\hline Implantação na Técnica & Abr/17 & Mai/17 & & $100 \%$ & $100 \%$ & $100 \%$ \\
\hline Emissão de Informações & Abr/17 & Dez/17 & & $30 \%$ & $60 \%$ & $100 \%$ \\
\hline TOTAL & & & $42 \%$ & $88 \%$ & $93 \%$ & $100 \%$ \\
\hline
\end{tabular}

A preparação dos servidores e criação do ambiente para instalação da solução é significativamente importante, uma vez que a extração de dados de forma ágil e precisa contribui para a boa receptibilidade da ferramenta pelos usuários. O Qlik Sense conta com mecanismos de armazenamento dos dados em memória e as análises associativas permitem que os clientes sejam capazes de dispor de soluções robustas e interativas. Isso substitui os aplicativos de consultas de informações baseadas em SQL e os relatórios internos gerados em cada sistema específico.
O fornecedor do produto adotado está posicionado no quadrante mágico de líderes do Gartner, ou seja, é referência no mercado global (TAPADINHAS ET AL, 2017). Além disso, a facilidade no uso e a interatividade dos painéis na visualização das informações torna bastante atrativa a solução adotada.

Já os sistemas selecionados para o projeto foram os que geram maior impacto ao negócio da empresa, conforme explicitado na sequência: 
Sistema Comercial: Responsável por cadastramento e leitura de unidades consumidores, faturamento de Baixa e Alta Tensão, Cobrança e Mercado de Energia, Medição e Combate as Perdas de Energia Elétrica, Atendimento e Serviços Comerciais.

Sistema de Gestão Empresarial: Responsável pelo Acompanhamento de Ordens em Curso, Mão-de-Obra e Transporte, Acompanhamento de Projetos, Contabilidade, Financeiro, Gestão Fiscal, Imobilizado, Orçamentos, Gestão de Ativos e Vendas.

- Sistema de Recursos Humanos: Responsável pela Folha de Pagamento, Gestão de Pessoas e Medicina e Segurança do Trabalho.

Sistema de Gestão Técnica da Distribuição: Responsável pela Operação e Despacho de Ordens de Serviços, Cadastro, Projetos e Gestão da Rede de Distribuição de Energia Elétrica da companhia.

Com isso, as informações gerencias a serem disponibilizadas as partes interessadas da empresa irão ampliar a capacidade e a velocidade nas decisões, uma vez que as bases de dados utilizadas nas extrações serão atualizadas conforme as demandas do negócio, ou seja, a ferramenta não utiliza diretamente as informações contidas nos bancos de dados dos sistemas por critérios de segurança e até mesmo desempenho das aplicações durante os usos rotineiros. Então, tais extrações são cargas de dados aplicadas as bases de dados formadas no próprio ambiente do $\mathrm{Bl}$.

Outra decisão importante para o sucesso do projeto foi optar por não disponibilizar aos usuários finais, inicialmente, a possibilidade alterações estruturais nos painéis dinâmicos que disponibilizam as informações. Isso poderia desfocar a objetividade da ferramenta, uma vez que deve haver o amadurecimento natural da cultura organizacional com as novas tecnologias.

Portanto, estabeleceu-se também que todas as construções iniciais e alterações posteriores necessárias seriam executadas pela equipe multifuncional, conforme composição explicitada no quadro 01.

Reforça-se ainda que dentre os principais benefícios esperados pelo projeto está a maior facilidade na identificação de riscos e problemas relacionados com a análise de cenários e tendências futuras, uma vez que todo o histórico de dados analisado possibilitará a realização dos estudos relacionados aos temas relevantes para a empresa.

3 METODOLOGIA: IMPLANTAÇÃO DA FERRAMENTA (BUSINESS INTELLIGENCE $B)$

A metodologia descrita abaixo foi utilizada para todos os sistemas em questão (QLIK, 2017). Todas as fases de construção de um Data Mart estão descritas:

a) Mapeamento do Modelo de Dados: São levantadas todas as informações e as respectivas localizações nos Bancos de Dados de cada sistema, ou seja, definição de Tabelas e relacionamentos a serem utilizados e acessados como fontes de dados. É realizada análise dos dicionários de dados por meio dos scripts de DDL (Data Definition Language) e identificadas as Tabelas que serão consideradas os Cabeçalhos dos Documentos, as Tabelas que serão consideradas itens dos documentos e as consideradas componentes principais dos Itens dos Documentos (e.g. TB_NOTA_FISCAL; TB_ITEM_NF_VENDA; TB_PRODUTO). Essas Tabelas e seus relacionamentos compõem a "Espinha Dorsal" do Modelo de Dados. Após o levantamento inicial, são identificadas todas as Chaves Estrangeiras existentes nas Tabelas da "Espinha Dorsal" que passarão a representar as dimensões do Data Mart, pois a ligam com as tabelas que contém informações descritivas (e.g. TB_CLIENTE; TB_VENDEDOR; $\quad$ TB_FILIAL; TB_TIPO_VENDA). Já os campos numéricos (e.g. quantidades, valores, saldos, percentuais) encontrados nas tabelas que fazem parte da "Espinha Dorsal" do Data Mart são as medidas.

b) Criação da Conexão com o Banco de Dados: São criadas as conexões para os bancos de dados de desenvolvimento e produção a fim de serem usados na homologação.

c) Desenvolvimento dos Scripts de ETL (Extract, Transform and Load) para as Dimensões padronizadas;

d) Desenvolvimento dos Scripts de ETL (Extract, Transform and Load) para o Fato que representa o Data Mart;

e) Desenvolvimento dos Scripts de Integração do Data Mart no Barramento dos demais Data 
Marts (e.g. através da estratégia de Link Table) conforme a Arquitetura de Barramento (Bus Architecture);

f) Desenvolvimento dos Painéis de Análise Padrão Genéricos de Business Discovery. Por Data Mart são desenvolvidos 2 painéis Genéricos que respondem a qualquer pergunta. O primeiro é um Painel de Indicadores no estilo Dashboard e o Segundo um Painel de Análise com a possibilidade da troca do Eixo X e Y dos Gráficos pelo usuário de negócio para ver as informações agrupadas por todas as Dimensões e Medidas disponíveis. Nesse painel haverá pelo menos 3 tipos de gráfico: Gráfico de Barras para mostrar Comparações; Gráfico de Linhas para mostrar Evolução Temporal; Gráfico de Dispersão para mostrar a Relação entre duas ou três Medidas. Quando estiverem disponíveis dados geográficos, cada Data Mart também contará com Gráfico de Mapas;

g) Desenvolvimento das Dimensões e Medidas desse Data Mart para o Painel de Combinação Geral que mostrará a possibilidade de se gerar uma planilha com qualquer combinação de todas as Dimensões e todas as Medidas de todos os Data Marts;

h) Desenvolvimento do Agendamento das Cargas Periódicas e da Carga Inicial Histórica;

i) Execução da Carga Inicial Histórica dos Dados;

j) Homologação dos dados pela equipe de usuários de negócio; k) Desenvolvimento da Configuração de Segurança de Acesso onde são criados e/ou expostos os mecanismos por meio do qual os administradores do ambiente por parte do cliente podem configurar todas as regras de segurança de acesso onde informarão quais usuários ou grupos de usuários podem acessar;

I) Desenvolvimento de outros Painéis livres e outras Customizações conforme a demanda do usuários, com base nas estruturas de dados carregadas;

\section{RESULTADOS ALCANÇADOS}

A implantação do projeto ocorreu conforme planejado e explicitado acima. Não houve atraso no projeto e a maior dificuldade encontrada foi a localização das informações nas tabelas dos bancos de dados, ou seja, mapear adequadamente onde estavam as informações a serem extraídas. Salienta-se ainda que o sucesso da implantação se deve, fundamentalmente, ao perfeito engajamento das partes interessadas envolvidas, conforme quadro 01. Os usuários finais já dispõem da ferramenta em produção para uso em suas atividades laborais. $\mathrm{Na}$ sequência, serão ilustrados alguns dos painéis da ferramenta.

A figura 01 ilustra a tela inicial desenvolvida para o Sistema Comercial. Entretanto, cada um dos demais sistemas explorados possui a sua. Funciona como um índice explicativo onde já podem ser executados filtros básicos, no caso, ano e mês. A referida tela possui botões direcionadores para painéis específicos segmentados por temas.

Figura 01

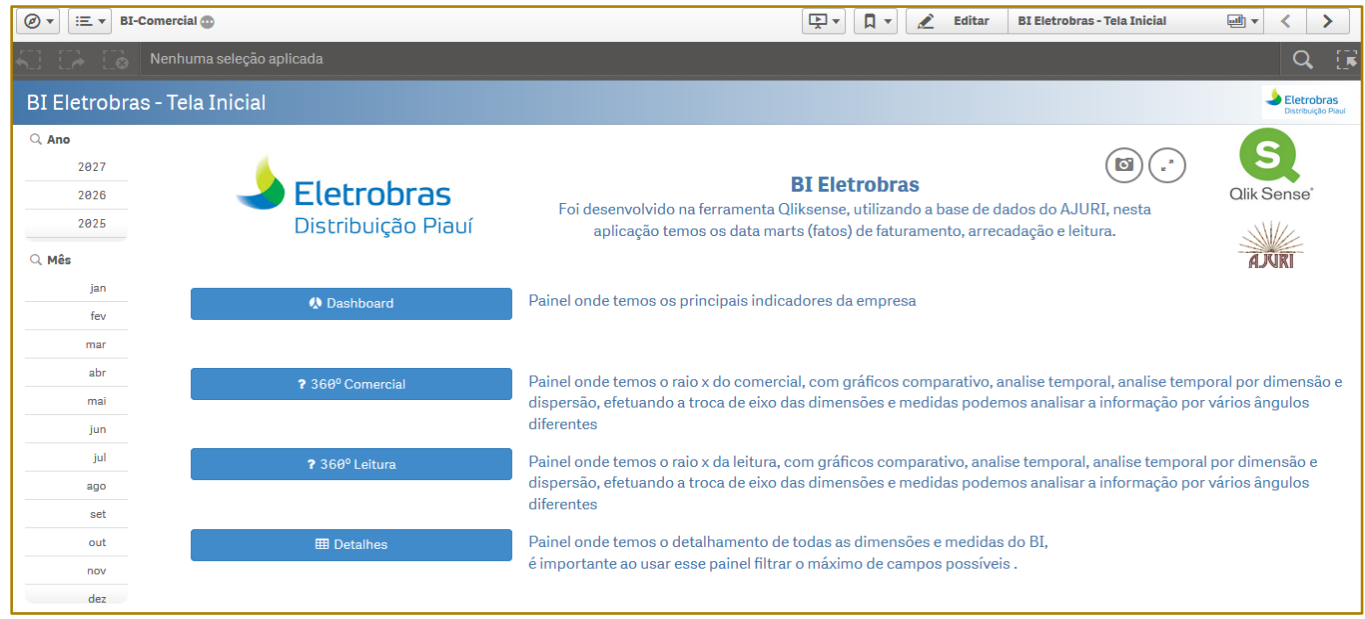


A figura 02 ilustra o painel relacionado a visão global do faturamento. Informações detalhadas e categorizadas podem ser obtidas de forma dinâmica. Inclusive com mapas térmicos apontando as regiões mais críticas.

Figura 02

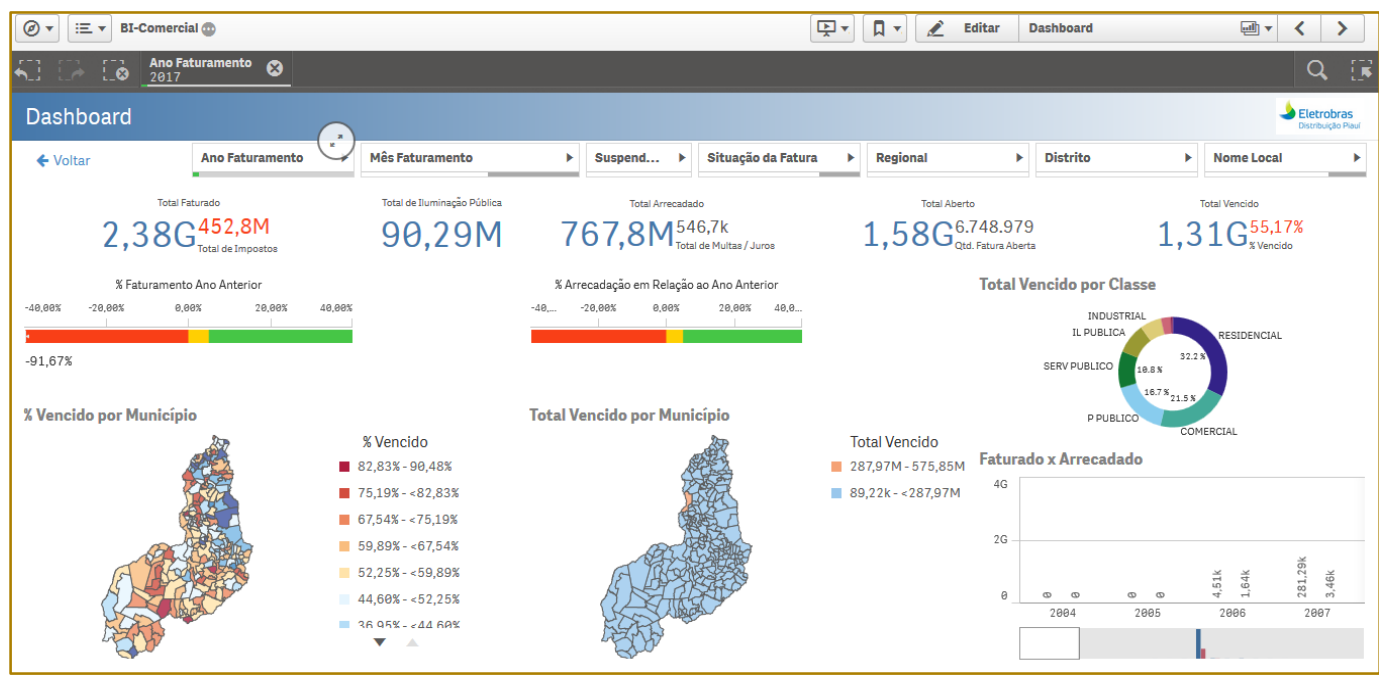

Já na figura 03, outro painel relacionado ao faturamento é ilustrado. Entretanto, a dimensão tempo é explorada com maior ênfase para a coleta de informações históricas.

Figura 03

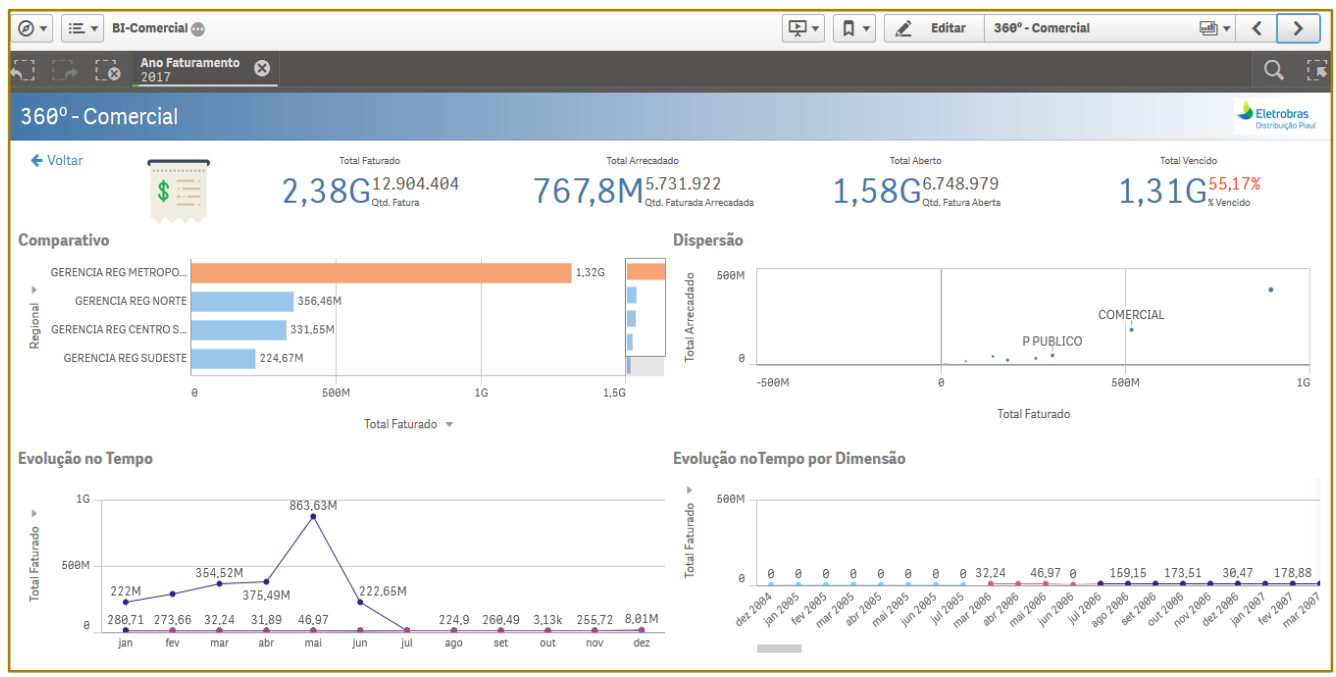

A figura 04 apresenta um painel exploratório, ou seja, nele o usuário da área de negócio pode montar dinamicamente o relatório desejado. Vale lembrar que qualquer filtro ou definição de variável em um painel reflete imediatamente na visão dos demais, o que agrega bastante valor as análises realizadas. 
Figura 04

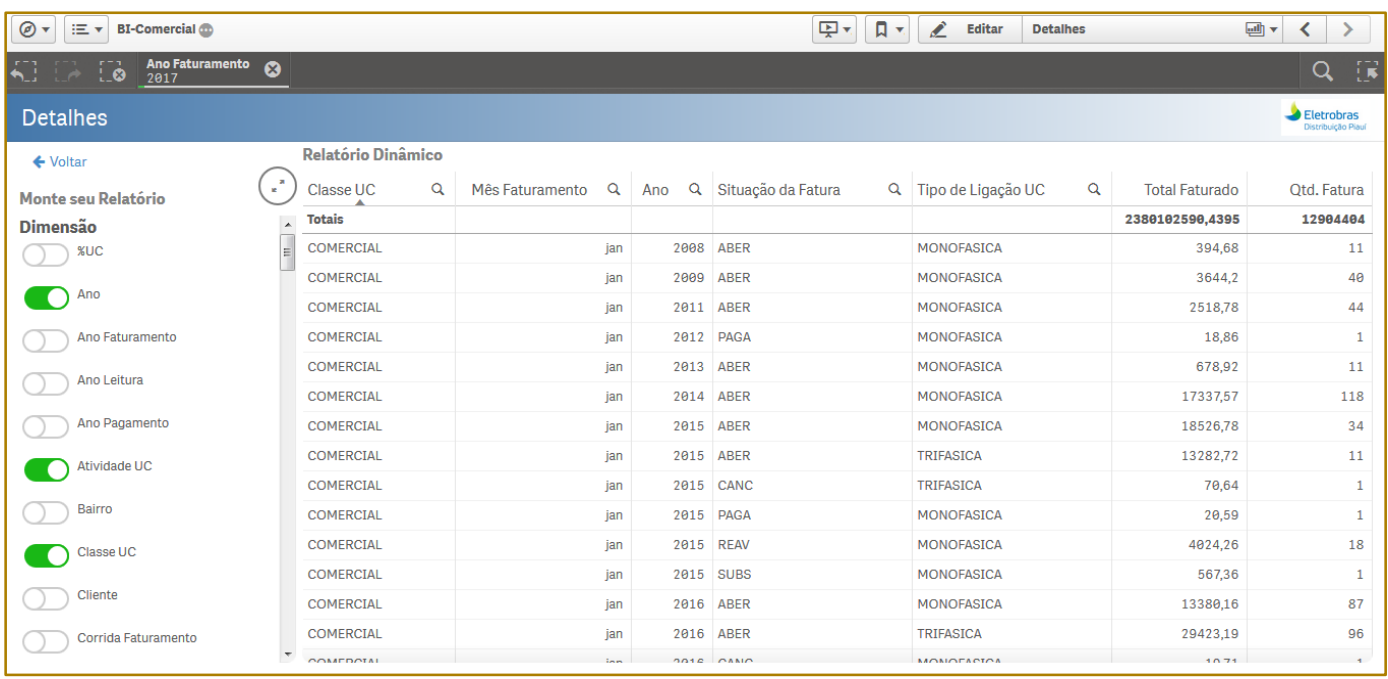

A figura 05 apresenta um dos painéis relacionados ao Sistema de Gestão Empresarial. Nele, o Departamento de Logística e Suprimentos - DGS pode explorar de forma simples e prática o controle de materiais em almoxarifado.

Observa-se que os pontos de ressuprimento por itens, consumo médio por tipo de estoque, consumo médio por local e demais informações necessárias à rotina de controle estoque são facilmente visualizadas. Inclusive, o próprio gerente do DGS relatou à Diretoria os ganhos expressivos de tempo com a implementação do BI. Colaboradores puderam ser alocados para outras atividades.

Figura 05

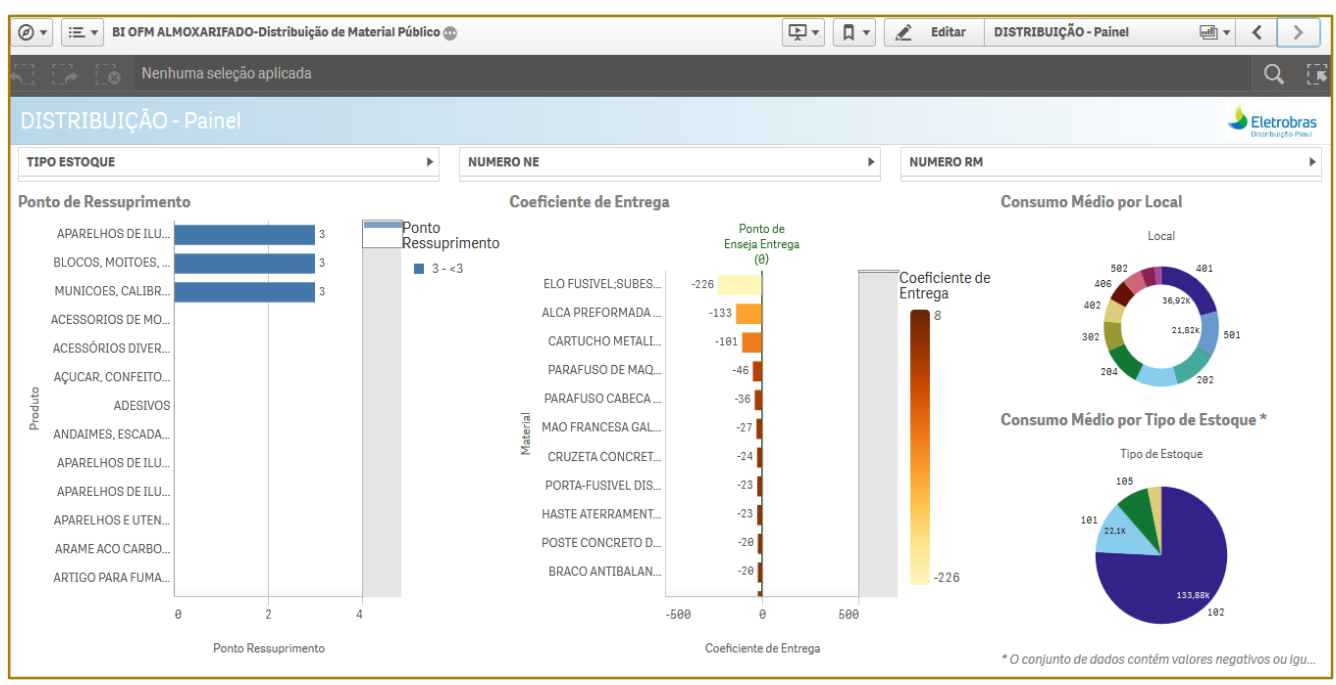

A figura 06 ilustra 0 painel do ERP responsável pelo acompanhamento da execução do orçamento. Já na figura 07, encontra-se um painel do Sistema de Recursos Humanos. 
Figura 06

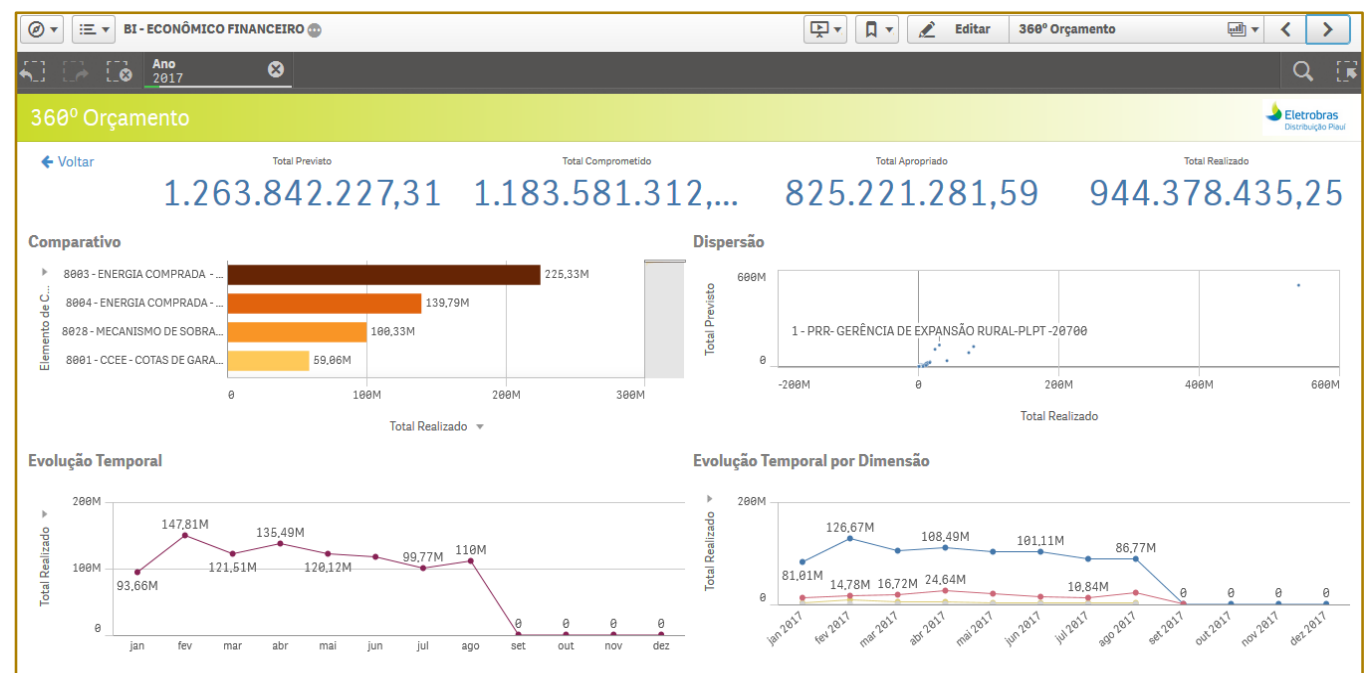

Figura 07

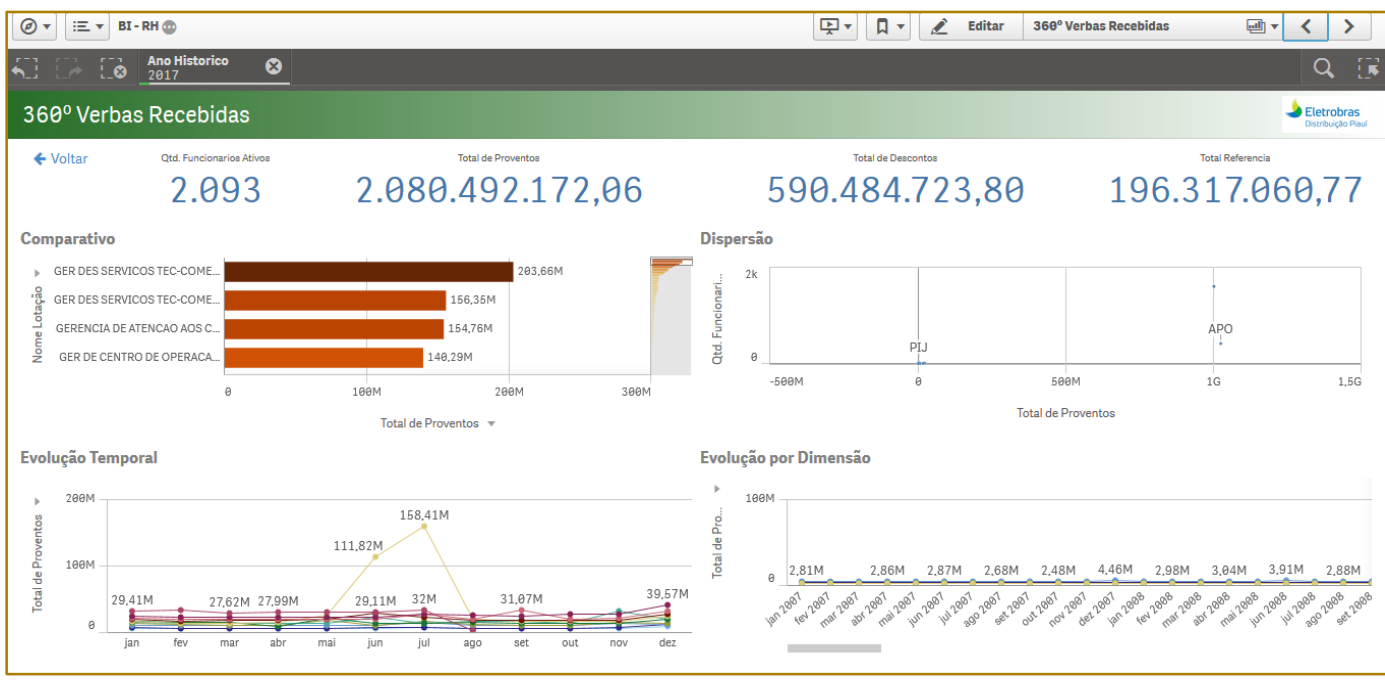

Finalizando, na figura 08, tem-se um painel relacionado ao Sistema de Gestão Técnica da Distribuição. Nele, a equipe do Centro de Operações Integradas - COI pode acompanhar as ocorrências em todo o estado do Piauí e atuar de forma mais assertiva. Além disso, a elaboração de cenários para planejamentos futuros tornou-se mais efetiva com o uso do Bl. 
Figura 08

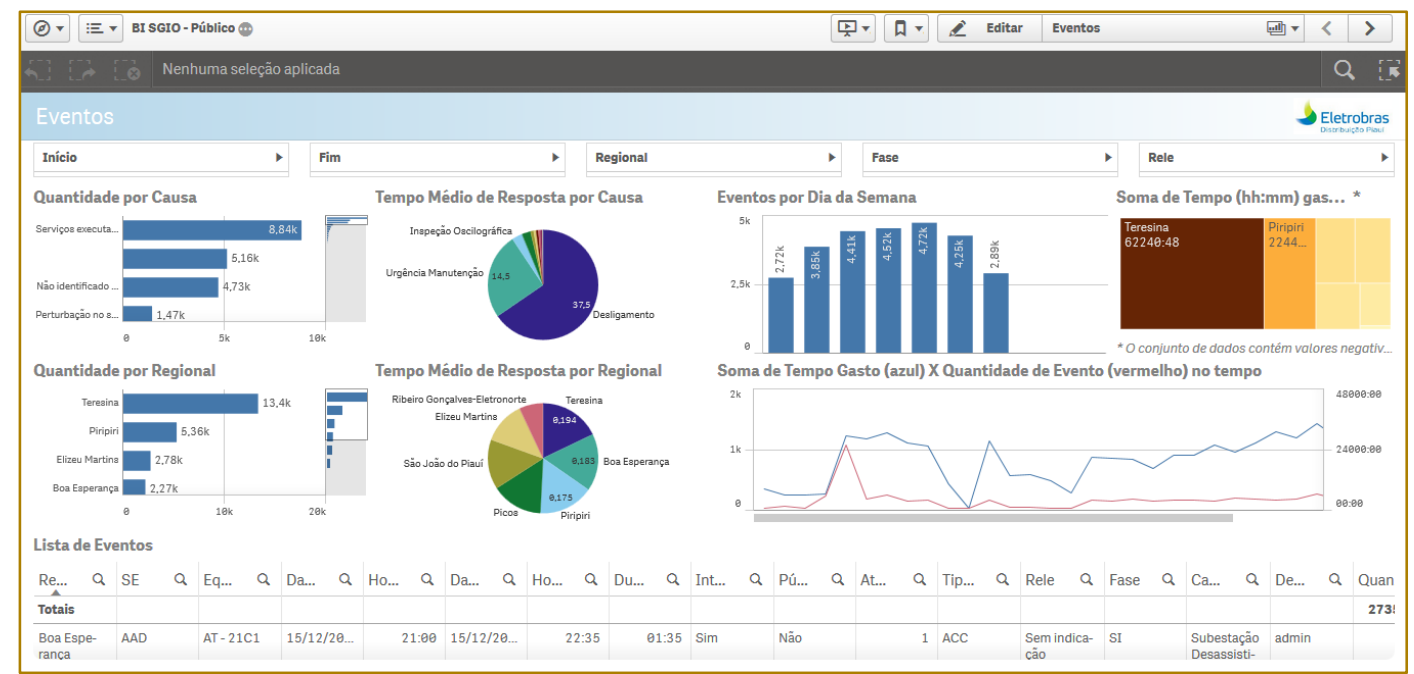

\section{CONCLUSÕES}

Dentre os resultados alcançados estão a maior independência das áreas de negócio no que tange a busca por informações, assim como uma maior confiança na área de $\mathrm{TI}$ da empresa. Áreas não envolvidas, inicialmente, passaram a solicitar implementações.

Alguns usuários já começaram a desenvolver seus próprios painéis, uma vez que a ferramenta adotada possui interface amigável. A visualização de informações de forma interativa é outro diferencial, ou seja, análises podem ser aprofundadas em tempo real. Vale

\section{REFERÊNCIAS}

[1] DUNCAN, A. D. Business Intelligence Teams Need to Change With the Times, February 2015, GARTNER, G00270899.

[2] TAPADINHAS, J. How to Implement a Modern Business Intelligence and Analytics Platform, April 2016, GARTNER, G00291781.

[3] ELETROBRAS DISTRIBUIÇÃO PIAUÍ. Plano Estratégico de Tecnologia da Informação e Comunicações, Teresina, 2016. salientar, que foi criado portal de informações com os principais sistemas críticos da empresa, o que torna a obtenção de informações pela diretoria ágil e precisa.

Portanto, considerando-se que a implementação ocorreu dentro dos prazos planejados e que o projeto começou a disponibilizar informações gerenciais em menos de 90 dias, pode-se considerar de extrema valia a implantação da ferramenta de BI na Eletrobras Distribuição Piauí.

[4] TAPADINHAS, J., RICHARDSON, J. L., OESTREICH, T. W., IDOINE, C. J., HOWSON, C., SALLAM, R. L. Magic Quadrant for Business Intelligence and Analytics Platforms, February, 2017, GARTNER, G00301340.

[5] QLIK. Disponível em: http://help.qlik.com/pt-

BR/sense/1.1/Content/Home.htm. Qlik Sense, Acesso em: 23/08/2017 Agosto 2017. 


\section{Eapítulo 4}

\section{AVALIAÇÃO DA QUALIDADE DOS SERVIÇOS PRESTADOS PELA EMPRESA "BETA" UTILIZANDO A ESCALA SERVQUAL}

\section{Luciane Kemmerich Lied}

\section{Renata Coradini Bianchi}

Vanessa Almeida da Silva

Resumo: Visando analisar a qualidade dos serviços prestados por uma empresa do ramo de serviços, a fim de auxiliar na elaboração de estratégias de marketing e ações de relacionamento com o cliente. Diante da pesquisa de estudo de caso feito na empresa com uma amostra dos clientes com o objetivo de avaliar a qualidade dos serviços prestados utilizando o instrumento de mensuração da qualidade em serviços, a escala SERVQUAL, para verificar e compreender a percepção do cliente em relação aos serviços prestados, a fim de auxiliar na elaboração de estratégias de marketing e ações de relacionamento com o cliente.

Palavras-chave: serviços; clientes; qualidade. 


\section{INTRODUÇÃO}

Os empreendimentos, nos dias atuais, necessitam de um amplo suporte e conhecimento sobre administração, pois se torna possível conhecer ferramentas responsáveis por alavancar a empresa em frente, rumo ao sucesso. Dentre essas ferramentas essenciais que podem ser usadas se destaca o marketing e suas estratégias.

A sobrevivência de uma empresa é sempre o resultado das estratégias estabelecidas e para que as mesmas consigam sucesso, torna-se imprescindível o conhecimento dos dados que integram o mercado e ainda, dos que se pode empregar para alcançar a diferenciação. (CHURCHILL JR; PETER, 2003).

A estratégia de marketing primeiramente se determina em como a empresa irá atender os desejos e as necessidades de seus clientes. A relevância da estratégia em marketing se dará em função da diferenciação, deste modo, a empresa concentra seus esforços para alcançar desempenho superior em uma respeitável área de beneficio para o consumidor, apreciada por grande parte do mercado. Podendo se esforçar para ser líder em serviços, em qualidade, atendimento, em tecnologia, em estilo, ou seja, no que se faz para diferenciar-se dos concorrentes, mas não sendo possível liderar em todos campos (FERRELL; HARTLINE, 2005).

Ter o domínio da percepção dos consumidores a respeito dos serviços proporcionados na empresa é o que pode distingui-la no mercado. Os administradores, proprietários e funcionários podem, dessa forma, ter uma informação autêntica da qualidade e da satisfação que estão proporcionando aos seus clientes e desse modo efetuar melhorias se necessário, adequando-se as novas demandas dos clientes e agindo dessa forma estará superando os concorrentes e se destacando no mercado (KOTLER, 2008).

O objetivo deste estudo é avaliar a qualidade dos serviços prestados, a fim de auxiliar na elaboração de estratégias de marketing e ações de relacionamento com o cliente.

Este estudo justifica-se a partir de um aprofundamento teórico-prático de uma prestadora de serviços. Os serviços são intangíveis, resultando no objetivo principal de uma transação. Quando se aborda o setor de serviços, existem estratégias peculiares para atingir o desempenho e os benefícios esperados dentro de um mercado, que acontece com a missão fundamental de garantir a satisfação ao consumidor (COURTIS, 1991). Constituir uma proximidade saudável com o cliente é a melhor forma de garantir um longo do período dele em sua empresa.

\section{MARKETING DE SERVIÇOS}

Kotler e Keller (2012) afirmam que serviço é qualquer ato ou desempenho essencialmente intangível, e seu desempenho pode ou não estar ligado a um bem concreto. Asseguram, ainda, que os serviços possuem quatro características distintas dos demais produtos que influenciam fortemente a preparação dos programas de marketing: são elas intangibilidade, inseparabilidade, perecebilidade e variabilidade. As características dos serviços são especificadas no Quadro 1.

Quadro 1: programas de marketing

\begin{tabular}{|c|l|}
\hline \multicolumn{2}{|c|}{ Características } \\
Intangibilidade & $\begin{array}{l}\text { Os serviços não podem ser provados e vistos antes de serem adquiridos, ao } \\
\text { inverso dos bens tangíveis. }\end{array}$ \\
\hline Inseparabilidade & $\begin{array}{l}\text { os serviços não podem ser fabricados, distribuídos e estocados posteriormente } \\
\text { como os bens tangíveis. Em regra são produzidos e consumidos respetivamente, } \\
\text { como os serviços da área de saúde. }\end{array}$ \\
\hline Perecibilidade & $\begin{array}{l}\text { como os serviços não podem ser estocados, a variação da demanda pode } \\
\text { acarretar um problema. }\end{array}$ \\
\hline Variabilidade & $\begin{array}{l}\text { os serviços são altamente variáveis, pois dependem de quem, quando e onde } \\
\text { são realizados. Onde esta variabilidade é julgada pelos clientes, por isso, muitos } \\
\text { habituam pedir recomendações antes de contratar os serviços de determinada } \\
\text { empresa ou profissional. }\end{array}$ \\
\hline
\end{tabular}


Fonte: Adaptado de Kotler e Keller (2012)

O quadro 1 mostra as quatro características apresentadas pelos serviços, sendo estas influenciam diretamente no desenvolvimento dos programas de marketing. Todos os serviços possuem em si uma dessas características, listadas de forma mais acentuada cabendo aos gestores identificalas e buscar melhores resultados para a empresa.

O campo de serviços é o que mais demanda mão de obra e o que igualmente mais vem se ampliando na economia mundial. Perante este progresso no setor, as estratégias de marketing de serviços vêm se concretizando como ações fundamentais para as organizações se estabelecerem e consequentemente conquistar seus clientes (MINADEO, 2008).

\subsection{COMPOSTO DO MARKETING DE SERVIÇOS - 8 P'S}

Para Lovelock e Wrigth (2001), os serviços possuem 8 elementos básicos para uma boa administração, denominado composto do marketing de serviços, mix de serviços ou 8 P's. O mix de serviços é combinado de instrumentos, recursos e técnicas controláveis e podem ser aproveitadas para formar estratégias. Como mostra-se no quadro 2 abaixo.

\section{Quadro 2: 8 P's do marketing de serviços}

\begin{tabular}{|c|c|}
\hline P's & Descrição \\
\hline $\begin{array}{l}\text { Produto - (Product } \\
\text { elements) }\end{array}$ & $\begin{array}{l}\text { Está relacionado à elaboração e identificação das particularidades dos serviços com } \\
\text { destaque nas vantagens e benefícios relevantes ao atendimento das necessidades do } \\
\text { mercado, acrescentando valor aos clientes. }\end{array}$ \\
\hline $\begin{array}{l}\text { Lugar e Tempo - } \\
\text { (Place and time) }\end{array}$ & $\begin{array}{l}\text { São decisões gerenciais sobre onde, quando e como entregar serviços aos clientes. A } \\
\text { entrega do produto/serviços para os clientes abrange decisões sobre o lugar e o } \\
\text { tempo da entrega e também pode envolver canais de distribuição física ou eletrônica, } \\
\text { ou ambas, dependendo da natureza em que o serviço esta sendo prestado. }\end{array}$ \\
\hline Processo & $\begin{array}{l}\text { Representa todos os fluxos, metodologias e procedimentos de trabalho empregados } \\
\text { na prestação de um serviço. É um elemento importante de certificar a assertividade e } \\
\text { exatidão do resultado final. }\end{array}$ \\
\hline $\begin{array}{l}\text { Produtividade e } \\
\text { qualidade }\end{array}$ & $\begin{array}{l}\text { são essenciais para organizações de quaisquer ramos de atividade. Contudo, para o } \\
\text { segmento de serviços, são fatores fundamentais do sucesso ou fracasso de uma } \\
\text { empresa. A produtividade refere-se à obtenção mais sensata na prática e na } \\
\text { execução dos serviços para reduzir as despesas, aumentar os recursos, otimizar o } \\
\text { tempo das equipes. A qualidade é a garantia da entrega nas condições acertadas e, } \\
\text { de preferência, ultrapassar às expectativas, para alcançar a satisfação dos clientes. }\end{array}$ \\
\hline Pessoas/Profissionais & $\begin{array}{l}\text { são todos que estão envolvidos indiretamente ou direta na prestação do serviço. A } \\
\text { força de trabalho é a matéria-prima, deste modo, a preocupação com as pessoas é } \\
\text { primordial. Onde a capacitação, o treinamento, orientação, a motivação ao cliente } \\
\text { necessitam ser continuas, pois ocasiona impacto diretamente na qualidade do serviço } \\
\text { prestado. }\end{array}$ \\
\hline $\begin{array}{l}\text { Promoção e } \\
\text { educação }\end{array}$ & $\begin{array}{l}\text { Está diretamente relacionada às estratégias de divulgação e comunicação dos } \\
\text { serviços, como a finalidade de apresentar ao seu público-alvo os diferenciais e } \\
\text { benefícios dos serviços. Mostrando a confiabilidade da empresa e sua capacidade } \\
\text { técnica é uma das melhores modos de promover um serviço, obtendo vantagem } \\
\text { competitiva. }\end{array}$ \\
\hline $\begin{array}{l}\text { Evidência física - } \\
\text { (Physical evidence) }\end{array}$ & $\begin{array}{l}\text { É a percepção do ambiente onde o serviço é prestado, associa-se a múltiplos fatores, } \\
\text { que vai desde a apresentação pessoal, placas, cartões de visita até a organização } \\
\text { das instalações e equipamentos. Ė o modo como a empresa interage com o cliente e o } \\
\text { lugar onde isso acontece. }\end{array}$ \\
\hline $\begin{array}{l}\text { Preço e outros } \\
\text { custos do serviço }\end{array}$ & $\begin{array}{l}\text { Envolve a mensuração do empenho da equipe, igualmente como o tempo necessário } \\
\text { para o desempenho do serviço, a complexidade de cada projeto e o perfil de cada } \\
\text { cliente. Sendo muito importante avaliar todas as despesas e custos gerados na } \\
\text { prestação do serviço. }\end{array}$ \\
\hline
\end{tabular}


Conforme o quadro 2, a empresa necessita analisar as características dos serviços ao elaborar seus programas de marketing. A administração integrada de serviços possui oito variáveis que ajudam no processo de decisão, essas variáveis necessitam encontrar-se em harmonia para poderem alcançar a eficácia. A conexão entre estas oito variáveis se faz necessária para alcançar o sucesso de qualquer empresa de serviços competitiva.

\subsection{AVALIAÇÃO DA QUALIDADE DOS SERVIÇOS - ESCALA SERVQUAL}

Qualidade é uma maneira que a organização elege para viabilizar a ampliação dos processos em serviços ou produtos, tornando importante compreender que cliente busca e quais são seus critérios de avaliação de um serviço que se mensura por meio dos critérios da qualidade em serviços (PALADINI, 2011).

Com a finalidade de mensurar de forma evidente Fitzsimmons e Fitzsimmons (2010), definem qualidade nos serviços como sendo a comparação da percepção do serviço prestado com as perspectivas do serviço desejado, dessa forma, pode-se assegurar que o cliente é quem vai mensurar o nível de qualidade de uma empresa. Por meio da avaliação do serviço identificam-se os critérios estabelecidos pelos clientes através do processo de execução, amparando a empresa a detectar prováveis problemas de desenvolvimento das atividades conseguindo determinar os principais pontos a serem avaliados para buscar melhorias.

Um dos primeiros indicadores desenvolvidos especificamente com intuito de mensurar e analisar quantitativamente e qualitativamente o grau de satisfação do cliente e a qualidade de um serviço foi à pesquisa SERVQUAL (ZEITHAML ET AL, 2011).

O modelo SERVQUAL fornece uma estrutura básica através de seu formato de expectativas e percepções que proporciona sentenças para cada uma das cinco dimensões da qualidade de serviço. Esse modelo apresenta cinco dimensões da qualidade do serviço, conforme representado no Quadro 3.

Quadro 3- Dimensões da qualidade em serviços

\begin{tabular}{|c|l|}
\hline \multicolumn{2}{|c|}{ Dimensões } \\
\hline Tangibilidade & Se relaciona aos aspectos físicos \\
\hline Empatia & Disposição em demonstrar interesse e atenção aos clientes \\
\hline Confiabilidade & Habilidade de prestar o serviço prometido com perfeição \\
\hline Capacidade de resposta & Disposição para auxiliar os clientes com responsabilidade \\
\hline Segurança & Cortesia, capacidade de transmitir confidencialidade e conhecimento \\
\hline
\end{tabular}

Segundo o autor Dettmer et. al. (2002) a escala SERVQUAL é um procedimento de mensuração da qualidade, que apresenta o nível de satisfação do cliente em uma percepção do desempenho de um serviço prestado, com a intenção de buscar melhorias em seus processos.

\subsection{ESTRATÉGIAS E AÇÕES DE RELACIONAMENTO COM O CLIENTE}

Para Kotler e Keller (2006), o marketing de relacionamento tem como meta edificar relacionamentos de longo prazo reciprocamente satisfatórios com partes chave; clientes, distribuidores, fornecedores e outros parceiros de marketing; a fim de difundir-se ou sustentar negócios com elas. 0 marketing que precisa executar não somente gestão do relacionamento com o cliente, como igualmente a gestão do relacionamento com os parceiros, se constitui de quatro elementos principais: clientes, parceiros de marketing (canais, fornecedores, distribuidores, revendedores, agências), funcionários, e membros da comunidade financeira (acionistas, investidores, analistas).

Para Poser (2005) a ferramenta mais respeitável no marketing de relacionamento é a comunicação, para isso, a empresa necessita instituir um verdadeiro relacionamento com seus clientes, usuários e 
consumidores, afirmando que o conjunto de sua postura, linguagem e gestos fazem parte do seu principal o cartão de visita.

O objetivo do marketing de relacionamento é a edificação e a manutenção de um alicerce de clientes compromissados e que são lucrativos para a organização, de acordo com a representação na Figura 1.

Figura 1: Objetivos do marketing de relacionamento

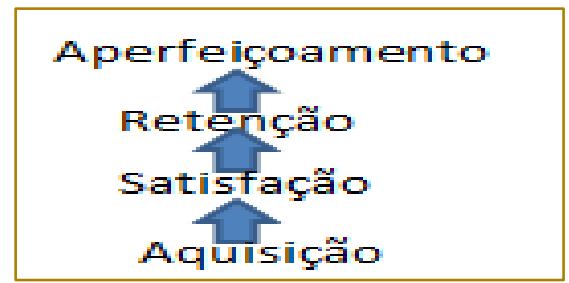

Fonte: Adaptado Zeithaml (2011)

Como mostra a figura 1 , o objetivo do marketing de relacionamento é de construir relações com os clientes como sugere Zeithaml et al (2011) as seguintes etapas: 1) começa na aquisição de clientes; 2) após a satisfação dos clientes; 3) a retenção dos clientes; 4) aperfeiçoamento do relacionamento com os clientes.

Tendo como sua meta fazer com que os clientes se desloquem ao longo do relacionamento, desde o ponto em que ele é um estranho que necessita ser fascinado à aquela em que o cliente é altamente valorizado pela organização, sendo um relacionamento de longo prazo e cujo foi aprimorado pela empresa. Para tanto, a solução de problemas do cliente, e a edificação da confiança, da satisfação e do compromisso estando relacionada com a disposição do cliente. $\mathrm{Na}$ perspectiva da alocação dos recursos de uma empresa, a viabilização de valor diferenciado ou customizado tem correlação positiva com a capacidade ou desejo de motivar um relacionamento de familiarização de amizade ou parceria, passando a um relacionamento de compromisso (ZEITHAML ET AL, 2011).

Conforme Kotler e Armstrong (2004) o marketing de relacionamento denota criar, aprimorar e manter relacionamento forte com os clientes. Assim como preparar estratégias para aproximar novos clientes e criar ligações entre eles, as empresas forçam-se em deter os clientes existentes e construir relacionamentos lucrativos e duradouros.

\section{MÉTODO}

Quanto aos procedimentos metodológicos, o estudo apresenta-se como qualitativo/quantitativo no momento que se aborda a natureza. No que compete aos procedimentos técnicos, o estudo é considerado como um estudo de caso, trazendo como objetivos uma pesquisa de caráter descritivo.

Inicialmente, realizou-se uma análise documental da organização e de sua cartela clientes, uma entrevista informal com os gestores da empresa, a fim de levantar informações com 0 propósito de poder identificar as principais necessidades de estudo e com intuito de gerar soluções para a empresa. Além disto, realizou-se uma análise bibliográfica sobre o tema escolhido.

$\mathrm{Na}$ coleta de dados buscaram-se informações através da consulta em dados fornecidos pela empresa, com a intenção de auxiliar em estratégias de serviços e a relação entre empresa/cliente. Foi utilizado o instrumento de mensuração da qualidade em serviços, a escala SERVQUAL, de modo adaptado, para verificar e compreender a percepção do cliente em relação aos serviços prestados.

O instrumento de pesquisa em forma de questionário, que foi adaptado e elaborado com base no modelo de avaliação da qualidade proposto por Parasuraman, Zeithaml e Berry, denominado SERVQUAL (ZEITHAML, 2011). Foram utilizadas 22 frases afirmativas positivas para verificar a percepção sobre os serviços, que os respondentes deveriam assinalar, em uma escala Likert com 7 pontos, o seu nível de concordância com as afirmativas, variando de 
(1) "discordo totalmente" a (7) "concordo totalmente". A amostra da pesquisa foi por conveniência, onde a aplicação do questionário se deu pessoalmente pela pesquisadora. A análise dos questionários se deu por meio da estatística descritiva, através da apresentação de frequência de cada uma das respostas, a média estatística e o desvio padrão. Em relação aos dados qualitativos, a analise dos dados/resultados foi feita de modo comparativo aliando a teoria a pratica.

\section{ANÁLISE PRATICA DO MARKETING DE SERVIÇOS E A AVALIAÇÃO DOS SERVIÇOS}

\subsection{MARKETING DE SERVIÇOS}

Neste tópico foi analisado o composto de marketing de serviços, a fim de apresentar como a empresa atua.

Quadro 4: 8 P's de serviços

\begin{tabular}{|c|c|}
\hline 8 P's & Descrição \\
\hline Serviços & $\begin{array}{l}\text { - oferece os serviços contábeis, imobiliários e correspondente Banrisul. } \\
\text { - os serviços prestados pela mesma não se diferem das empresas concorrentes que } \\
\text { cada setor oferece }\end{array}$ \\
\hline Preços & $\begin{array}{l}\text { - os preços cobrados pela imobiliária seguem as normas, regras do CRECI-RS } \\
\text { (Conselho Regional de Corretores de Imóveis) e a Lei número } 6530 \text { e o decreto } \\
\text { número } 81.871 / 78 \text {. } \\
\text { - contabilidade é a média de } 10 \% \text { do salário mínimo, geralmente as aberturas são as } \\
\text { tarifas de despesas mais uma porcentagem de ganho pelo trabalho feito. } \\
\text { - correspondente Banrisul não é cobrado pelos serviços prestados, pois estes são } \\
\text { pagamento de boletos e contas em geral. }\end{array}$ \\
\hline Promoção & $\begin{array}{l}\text { - promoções quem as realiza e as cria é a sócia proprietária. } \\
\text { - faz sorteios de cestas em datas comemorativas como dias dos pais, dia do } \\
\text { gaúcho, dia da criança, natal entre outras. }\end{array}$ \\
\hline Praça & $\begin{array}{l}\text { - empresa é mais retirada em relação aos seus concorrentes, sendo a única neste } \\
\text { ponto de localização que presta serviços. } \\
\text { - todas as atividades são praticadas no espaço físico, sendo amplo e possui boa } \\
\text { estrutura para atender os clientes. }\end{array}$ \\
\hline Pessoas/Profissionais & $\begin{array}{l}\text { - os colaboradores são tratados como amigos parceiros. } \\
\text { - a colaboradora do departamento contábil participa de cursos, palestras, etc... } \\
\text { - o ambiente de trabalho é agradável os colaboradores tem liberdade para dar } \\
\text { sugestões e opiniões. }\end{array}$ \\
\hline Processos & $\begin{array}{l}\text { - as tarefas e os serviços são padronizadas e executados seguindo um padrão nos } \\
\text { serviços realizados para não ocorrer lacuna na realização dos mesmos e } \\
\text { consequentemente não deixar o cliente insatisfeito }\end{array}$ \\
\hline Physical evidence & $\begin{array}{l}\text { - ambiente interno da empresa há uma confusão de cores no interior da mesma, o } \\
\text { que deixa o ambiente pesado e despadronizado sem harmonização entre as } \\
\text { mesmas e os departamentos, os móveis também são de diversas cores e formas o } \\
\text { que deixa o ambiente desarmônico. }\end{array}$ \\
\hline $\begin{array}{l}\text { Produtividade e } \\
\text { qualidade }\end{array}$ & $\begin{array}{l}\text { - a empresa busca atender da melhor maneira seus clientes, enquanto os mesmos } \\
\text { aguardam o atendimento possui cadeiras e sofás para aguardar o atendimento e } \\
\text { balas, pirulitos para os mesmos. }\end{array}$ \\
\hline
\end{tabular}

Fonte: elaborado pela autora 


\subsection{ANÁLISE QUALIDADE DOS SERVIÇOS PRESTADOS}

Com o intuito de aprofundar a analise da área de serviços da empresa estudada foi realizada a aplicação de um questionário com 65 clientes dos três setores da organização, com intuito de identificar e analisar a percepção da importância da qualidade prestada e o relacionamento com os mesmos das cinco dimensões confiabilidade, presteza, garantia, empatia e aspectos tangíveis.

Após tabular os dados da pesquisa, é apresentado a seguir os resultados da percepção dos respondentes.

\subsubsection{PERFIL DOS RESPONDENTES}

Quanto à pesquisa realizada na empresa foi constatado que os clientes que predominam são do gênero masculino com um percentual de $53,9 \%$ e o gênero feminino com percentual de 46,2\%. Quanto ao estado civil, predominam pessoas casadas, com renda mensal familiar entre $\mathrm{R} \$ 4.754,00$ e $\mathrm{R} \$$ 8.295,00 ambas somados auferem o percentual de $40 \%$ dos respondentes, em relação à idade, as informações foram bastante heterogêneas, entre menores de 24 anos até maiores de 60 anos.

\subsubsection{PERCEPÇÃO SOBRE OS SERVIÇOS}

Para Pereira (2003) as organizações necessitam fazer avaliações constantes de suas operações e processos, se disponibilizando sempre nas possíveis melhorias que possam agregar valor ao serviço e gerando oportunidades de solucionar as ameaças, abrangendo os passivos e percebendo seu fluxo de relacionamento seja externo como interno, após isso consegue se desejar as perspectivas e objetivos podendo quantificar e avaliar probabilidade dos pontos fortes e fracos na prestação dos serviços realizados. Nesse contexto, avaliar a percepção dos clientes é um processo importante para contribuir com as organizações.

O nível de concordância foi numerado de 1 a 7: 1 - Discordo totalmente; 2 - Discordo em grande parte; 3 - Discordo em parte; 4 Indiferente (neutro); 5 - Concordo em parte; 6 - Concordo em grande parte e 7 - Concordo totalmente.

$\mathrm{Na}$ tabela 01 será demonstrado os dados referente à tangibilidade que faz alusão aos meios, como as ferramentas e equipamentos utilizados para prestação de serviços, referese a instalações que a empresa dispõe para seus clientes, bem como a aparência dos colaboradores.

Tabela 01: Dimensões da Tangibilidade

\begin{tabular}{|c|c|c|c|c|c|c|c|c|}
\hline & 1 & 2 & 3 & 4 & 5 & 6 & 7 & Total \\
$\%$
\end{tabular}

Fonte: elaborado pela autora

Quanto à percepção dos respondentes, averiguou-se que equipamentos para diagnósticos e ferramentas modernas são consideradas relevantes para grande parte da amostra $(24,6 \%$ concordam em parte $+21,5 \%$ concordam plenamente). Quanto à fachada e pintura da empresa $46,2 \%$ dos respondentes concordam totalmente que esta faz a diferença quando é bonita, bem estruturada, tornando-se convidativa e chamando a atenção dos clientes, com o propósito de retenção da atenção das pessoas. 
Referente à aparência dos funcionários para atender o cliente 30,8\% concordam totalmente sendo importante uma boa aparência, passando uma forma de padronização, identificação da marca, inspira confiança, comprometimento e até higiene do ambiente e do segmento de mercado, pode acarretar na imagem que empresa quer repassar para seu cliente mediante seus funcionários. Quanto ao ambiente 43,1\% concordam totalmente que este deve ser agradável ao proporcionando ao cliente a espera menos enfadonha.

Em relação aos prazos determinados pela empresa $38,5 \%$ concordam totalmente que esta deve cumpri-los no tempo programado, e que a mesma deve passar confiabilidade sobre o serviço que está sendo executado pela mesma, demonstrando preocupação em relação as suas tarefas realizadas.

Las Casas (1999) enfatiza que as empresas necessitam estar voltadas a atender os clientes da melhor maneira presumível, adequando sua estrutura física para evidenciar a confiabilidade de seu serviço prestado, o que motiva que a mesma possua preocupação neste quisito, visto que o cliente da valor para as instalações físicas.

$\mathrm{Na}$ tabela 02 são demostrados os dados referentes à presteza que são considerados as solicitações, a disposição a fornecer ajuda com o andamento sobre o serviço que esta sendo prestado.

Tabela 02: Dimensão da presteza

\begin{tabular}{|l|c|c|c|c|c|c|c|c|}
\hline & 1 & 2 & 3 & 4 & 5 & 6 & 7 & \multicolumn{1}{c|}{ Total } \\
\hline $\begin{array}{l}\text { Quando um cliente tem um problema, } \\
\text { a empresa mostra um interesse } \\
\text { sincero em solucioná-lo. }\end{array}$ & 0,0 & 0,0 & 3,1 & 3,1 & 24,6 & 35,4 & 33,9 & 100 \\
\hline $\begin{array}{l}\text { A empresa realiza bem o serviço à } \\
\text { primeira vez, passando confiança a } \\
\text { você. }\end{array}$ & 0,0 & 0,0 & 0,0 & 7,7 & 26,2 & 32,3 & 33,9 & 100 \\
\hline $\begin{array}{l}\text { Os funcionários devem atender } \\
\text { prontamente aos seus pedidos. }\end{array}$ & 0,0 & 0,0 & 0,0 & 9,2 & 23,1 & 38,5 & 29,2 & 100 \\
\hline $\begin{array}{l}\text { A empresa deve dar condições para } \\
\text { os funcionários realizarem suas } \\
\text { tarefas corretamente (treinamento, } \\
\text { tempo e equipamentos). }\end{array}$ & 0,0 & 0,0 & 4,6 & 3,1 & 21,5 & 26,2 & 44,6 & 100 \\
\hline
\end{tabular}

Fonte: elaborado pela autora

Através dos dados contabilizados percebe-se que $44,6 \%$ dos clientes dão muita importância às boas condições de trabalho e fornece treinamento a colaboradores da empresa para o melhor andamento dos processos. Neste atributo de presteza, percebe-se uma média de concordância das respostas com a dimensão serem altas. Pode-se concluir que é pelo fato da empresa estudada ser prestadora de serviços fazendo-se importante que a mesma ocorra.

Em continuidade na tabela 03 são apresentados os dados referentes à garantia. Nesta dimensão são analisados se a empresa passa segurança a seus clientes na execução de suas tarefas, se o colaborador tem habilidades e transmite rapidez na solução de problemas.

Conforme demonstra a tabela 03 há uma grande parcela $46,2 \%$ que concordam totalmente que a empresa deve possuir funcionários educados e que os mesmos devam transmitir confiança nas tarefas que estão realizando. Quanto a esta dimensão os clientes em sua maioria concordam totalmente que o serviço seja executado de modo imediato por parte do funcionário, auxiliando sempre o cliente da melhor maneira possível e ressalta-se que os mesmos igualmente dão valor se a empresa ampara seus funcionários na execução de suas tarefas. 
Tabela 03: Dimensão da garantia

\begin{tabular}{|l|c|c|c|c|c|c|c|c|c|}
\hline & \multicolumn{2}{c}{1} & 2 & 3 & 4 & 5 & 6 & 7 & \multicolumn{1}{c|}{ Total } \\
\hline $\begin{array}{l}\text { Os funcionários da empresa devem } \\
\text { atender o cliente imediatamente após } \\
\text { sua chegada }\end{array}$ & 0,0 & 0,0 & 3,1 & 13,9 & 29,2 & 29,2 & 24,6 & 100 \\
\hline $\begin{array}{l}\text { O comportamento dos funcionários da } \\
\text { empresa transmitem confiança aos } \\
\text { clientes }\end{array}$ & 0,0 & 0,0 & 0,0 & 4,6 & 15,4 & 46,2 & 33,9 & 100 \\
\hline $\begin{array}{l}\text { Ao negociar com os funcionários da } \\
\text { empresa você deve poder sentir-se } \\
\text { seguro (Sentir que não está sendo } \\
\text { enganado) }\end{array}$ & 1,5 & 0,0 & 1,5 & 6,2 & 13,9 & 35,4 & 41,5 & 100 \\
\hline $\begin{array}{l}\text { A empresa deve ter funcionários } \\
\text { educados }\end{array}$ & 0,0 & 1,5 & 1,5 & 3,1 & 24,6 & 23,1 & 46,2 & 100 \\
\hline
\end{tabular}

Fonte: elaborado pela autora

Percebe-se que $46,2 \%$ dos respondentes acredita que a empresa deve ter colaboradores que passe confiança e sejam educados na hora do atendimento, dessa forma almeja-se que a empresa tenha colaboradores que passem confiabilidade mediante as informações que prestam, tenham agilidade garantindo um bom serviço.
$\mathrm{Na}$ tabela 04 , estão os dados referentes à dimensão empatia que abrange a forma como o colaborador demonstra sua sensibilidade e esforços a fim de ajudar nas necessidades dos

Tabela 04: Dimensão da empatia

\begin{tabular}{|c|c|c|c|c|c|c|c|c|}
\hline \multirow{2}{*}{\multicolumn{2}{|c|}{$\begin{array}{l}1 \\
\%\end{array}$}} & 2 & 3 & 4 & 5 & 6 & 7 & Total \\
\hline & & $\%$ & $\%$ & $\%$ & $\%$ & $\%$ & $\%$ & $\%$ \\
\hline $\begin{array}{l}\text { A empresa deve oferecer atenção } \\
\text { individualizada aos clientes }\end{array}$ & 0,0 & 3,1 & 1,5 & 9,2 & 26,2 & 27,7 & 32,3 & 100 \\
\hline $\begin{array}{l}\text { Os funcionários devem dar atenção pessoal } \\
\text { aos clientes }\end{array}$ & 1,5 & 1,5 & 4,6 & 10,8 & 27,7 & 29,2 & 24,6 & 100 \\
\hline $\begin{array}{l}\text { A empresa deve ter como objetivo a } \\
\text { satisfação dos clientes }\end{array}$ & 0,0 & 0,0 & 0,0 & 4,6 & 21,5 & 29,2 & 44,6 & 100 \\
\hline $\begin{array}{l}\text { A empresa deve ter horário de } \\
\text { funcionamento conveniente aos seus } \\
\text { clientes }\end{array}$ & 0,0 & 4,6 & 10,8 & 6,2 & 20,0 & 29,2 & 29,2 & 100 \\
\hline
\end{tabular}

Fonte: elaborado pela autora

Quando a atenção personalizada aos clientes, os mesmos em uma proporção total de 38,5\% sendo que $27,7 \%$ concordam em parte e $10,8 \%$ indiferente ou neutro com esta afirmação, pois nem sempre a empresa consegue dar atenção que gostaria aos mesmos. Um ponto que chama a atenção na tabela acima é que 4,6\%, 10,8\% e 6,2\% mostraram-se neutros ou discordam que a empresa deve atender em horários flexíveis.
O que explana o fato das médias serem as altas e baixas porque se trata de questões de cortesias e atendimento o que na percepção dos clientes é difusão que interfere no nível satisfação do mesmo.

$\mathrm{Na}$ tabela 05 demonstram-se as dimensões relacionadas à confiabilidade, a qual relaciona-se aos processos claros e transparentes, comprometimento com a negociação acordada com cliente, assim 
como as informações precisas e consistentes. A confiabilidade, na Tabela abaixo, é um fator muito relevante analisado pelo cliente no momento de avaliar e dar sua opinião sobre o serviço que está sendo prestado. Em relação a este fator os clientes dão grande importância ao que a empresa promete e cumpre, devendo a mesma possuir registros de clientes sempre atualizados sendo que somado aufere $64,6 \%$ (dos que concordam em grande parte e concordam totalmente).

Tabela 05: Dimensão da confiabilidade

\begin{tabular}{|c|c|c|c|c|c|c|c|c|}
\hline & $\begin{array}{l}1 \\
\%\end{array}$ & $\begin{array}{l}2 \\
\%\end{array}$ & $\begin{array}{l}3 \\
\%\end{array}$ & $\begin{array}{l}4 \\
\%\end{array}$ & $\begin{array}{l}5 \\
\%\end{array}$ & $\begin{array}{l}6 \\
\%\end{array}$ & $\begin{array}{l}7 \\
\%\end{array}$ & $\begin{array}{c}\text { Total } \\
\%\end{array}$ \\
\hline $\begin{array}{l}\text { A empresa conclui os seus serviços no } \\
\text { tempo que tinha prometido }\end{array}$ & 0,0 & 0,0 & 1,5 & 10,8 & 23,1 & 26,2 & 38,5 & 100 \\
\hline $\begin{array}{c}\text { A empresa deve manter registro de clientes e } \\
\text { serviços realizados }\end{array}$ & 1,5 & 0,0 & 0,0 & 13,9 & 20,0 & 32,3 & 32,3 & 100 \\
\hline $\begin{array}{c}\text { A empresa deve informar data e horário de } \\
\text { entrega do serviço }\end{array}$ & 0,0 & 0,0 & 6,2 & 7,7 & 26,2 & 36,9 & 23,1 & 100 \\
\hline $\begin{array}{l}\text { Os funcionários da empresa estão sempre } \\
\text { dispostos a ajudar os clientes }\end{array}$ & 0,0 & 0,0 & 0,0 & 6,2 & 35,4 & 26,2 & 32,3 & 100 \\
\hline $\begin{array}{l}\text { O comportamento dos funcionários da } \\
\text { empresa transmitem confiança aos clientes }\end{array}$ & 0,0 & 0,0 & 0,0 & 4,6 & 15,4 & 46,2 & 33,9 & 100 \\
\hline
\end{tabular}

Fonte: elaborado pela autora

Diante da pesquisa concretizada com os clientes da empresa sobre a atuação dos serviços mediante suas percepções, percebeu-se uma maior representatividade dos fatores como se a empresa deve ter uma fachada bem pintada e convidativa a seus clientes; condições para os funcionários realizarem suas tarefas corretamente (treinamento, tempo e equipamentos); comportamento dos funcionários da empresa transmitem confiança aos clientes e se a mesma conclui os seus serviços no tempo que tinha prometido. Com os resultados podese verificar que os clientes dão muita importância ao ambiente da empresa, sugerese a empresa que a mesma reveja este aspecto e procure atender as necessidades de seu público. Em relação ao comportamento dos funcionários a empresa pode investir em cursos de atendimento ao cliente. Os mesmos igualmente acham importante que a empresa possua seus cadastros atualizados, sendo assim a mesma deve investir neste aspecto.

\section{CONCLUSÃO}

A pesquisa realizada teve como objetivo principal avaliar a qualidade dos serviços prestados por uma empresa de serviços, a fim de auxiliar na elaboração de estratégias de marketing e ações de relacionamento com o cliente.

A prestação de um serviço deve ser caracterizada para que a empresa possa se manter no mercado alcançando desempenhar suas ações, mediante as expectativas dos clientes, pois uma metodologia não qualificada acaba gerando o retrabalho, falhas na prestação de seus serviços e, por conseguinte ocorre a perda de clientes. Como o setor de serviços esta entre as posições de evidência na economia brasileira e mundial, e gera novas oportunidades de empregos.

Com o crescimento deste setor, se faz de suma importância que a organização satisfaça as necessidades e desejos dos mesmos, para tanto a empresa necessita investir cada vez mais em qualidade. Por isso a importância em medir a percepção do cliente em relação ao seu serviço prestado, para assim conhecer as reais necessidades dos mesmos e suas expectativas, para melhor atende-los.

Foi levantado os 8p's de serviços na empresa, sendo analisada cada uma das variáveis, e sugerido melhorias em cada uma delas. $\mathrm{Na}$ evidência física pode-se observar que a empresa necessita de algumas mudanças, com isso proporcionando um melhor ambiente interno para seus clientes. 
Por meio da pesquisa pode-se averiguar informações relevantes para que a gestora da empresa possa aplicar e agregar valor na mesma, pois através desta foi possível constatar a importância da prestação de serviços e o quão essencial se faz a avaliação dos clientes para obter-se resultados satisfatórios e positivos para a organização. Diante isso a procura por dados e informações que possam gerar melhorias é um fator importante para a mesma se manter no mercado e estar atenta as mudanças.

Percebe-se que a empresa oferece serviço diferenciado em relação aos concorrentes, pois a mesma possui três departamentos em

\section{REFERÊNCIAS}

[1] CHURCHILL JR., G. A.; PETER, J. P. Marketing criando valor para o cliente. 2. ed. São Paulo: Saraiva, 2003.

[2] FITZSIMMONS, J. A.; FITZSIMMONS, M. J. Administração de Serviços - Operação, estratégia e tecnologia da informação. 6 ed. São Paulo: Bookmann, 2010.

[3] FUTRELL, C. M. Vendas: fundamentos e novas práticas de gestão. São Paulo: Saraiva, 2003

[4] KOTLER, P., \& KELLER, K. L. Administração de Marketing 14. ed. São Paulo: Pearson Education do Brasil, 2012.

[5] KOTLER, Philip; RACKHAM, Neil. Conceitos e práticas executivas: marketing e vendas. Argentina: HSM, 2008.

[6] KOTLER, P, KELLER, K. L. Administração de marketing: a bíblia do marketing. São Paulo: Prentice Hall, 2006.

[7] KOTLER, P; ARMStRONG, G. Princípios de marketing. 9. ed. São Paulo: Pearson, 2004.

[8] LAS CASAS, A., L. Marketing de Serviços. 4 ed. São Paulo: Atlas, 2006. um mesmo espaço físico. A mesma conta com profissionais capacitados e sempre dispostos a resolver problemas com paciência e simpatia, sendo considerado hoje um dos fatores para a fidelização do cliente, a organização sempre está atenta as necessidades dos clientes.

Para estudos futuros, por ser uma empresa que possui três departamentos e está em constantes mudanças seria interessante analisar os aspectos positivos da criação de uma marca para se estabelecer no mercado e analisar os efeitos de marketing e o retorno que a criação de uma marca proporciona.

[9] LOVELOCK, C.; WRIGHT, L. Serviços: Marketing e Gestão. 1a Edição. São Paulo: Saraiva, 2003.

[10] Serviços: marketing e gestão. São Paulo, SP: Saraiva, 2001.

[11] MINADEO, R.; Gestão de Marketing, São Paulo: Atlas, 2008.

[12] PALADINI, E. P. Gestão de qualidade: teoria e pratica. São Paulo: Atlas, 2011.

[13] PEREIRA, M. L. C. Qualidade de vida na terceirização; um estudo de caso no setor de manutenção de telecomunicações Florianópolis, SC. 2003. 152f. Dissertação (Mestrado em Engenharia de Produção) - Universidade Federal de Santa Catarina, Florianópolis, 2003.

[14] POSER, D. V. Marketing de relacionamento: maior lucratividade para empresas vencedoras. São Paulo: Manole, 2005.

[15] ZEITHAML, V. A.; BITNER, Mary Jo; GREMLER, D. D. Marketing de serviços: a empresa como foco no cliente.5. ed. Porto Alegre: Bookmamn, 2011. 


\section{Bapítulo 5}

\section{INTEGRACÃO DAS METODOLOGIAS SIPOC E FAULT TREE ANALYS (FTA) NO PROCESSO DE ANÁLISE DAS FALHAS EXISTENTES NA LINHA DE PRODUÇÃO DE UMA EMPRESA DO SETOR METAL MECANNICO}

\section{Juan Pablo Silva Moreira \\ Saulo Fonseca Soares \\ Célio Adriano Lopes}

Janaína Aparecida Pereira

Resumo: Com o crescente aumento do cenário competitivo e do dinamismo das organizações, torna-se essencialmente importante que as obtenham de vantagens competitivas e de valor agregado para os seus serviços. O objetivo deste artigo é, portanto, é apresentar com o auxílio da ferramenta SIPOC - Suppliers (fornecedores), Inputs (insumos), Process (processo), Outputs (produtos obtidos na saída) e Customers (consumidores) - e da metodologia Fault Tree Analys (FTA) - ou traduzida para o português como a Análise da Árvore de Falhas (AAF) - uma forma de classificar e listar os riscos existentes no processo de vendas e emissão de compras dos sidecars comercializados pela Empresa Zeta. Por isso, a fim de tornar a concretização visível aos colaboradores da empresa, nessa análise foi utilizado formulários de maneira descritiva e qualitativa, pois essas formas pesquisa permitem maior interação com o cotidiano da linha de produção organizacional. Desta forma, foi possível evidenciar, através deste estudo, que a solução deste problema garantiu uma melhora significa nos processo de vendas e expedição dos sidecars fabricados pela Empresa Zeta, além disso, pode-se perceber que este instrumento será um grande aliado para garantir a melhoria contínua no empreendimento, já que possibilita uma visualização significativa dos riscos existentes na linha de produção, bem como as restrições quanto às áreas ou setores em que esta metodologia pode ser aplicada.

Palavras-chaves: Análise de Falhas, melhoria contínua, SIPOC, FTA, indústria. 


\section{INTRODUÇÃO}

Com o crescente aumento do cenário competitivo e do dinamismo das organizações, torna-se essencialmente importante que as obtenham de vantagens competitivas e de valor agregado para os seus serviços. Segundo Gonçalves (2000) "o futuro vai pertencer às empresas que conseguirem explorar o potencial da centralização das prioridades, as ações e os recursos nos seus processos".

Desta maneira, as mudanças impostas pela globalização têm se tornado preponderantes para a determinação de um novo vínculo entre as condições trabalho, o gerenciamento, a aprendizagem e a capacidade dos funcionários, o que garante o crescimento das organizações (CONTE e DURSKI, 2002). Nesta nova visualização do mercado, têm-se tornado muito importante que as empresas adotem uma visão mais abrangente para garantir a inclusão de aprimoramentos que ocorrem na linha de produção, elevando, desta maneira, o controle de qualidade que é exigido pelo cliente e que é fornecido pelos seus concorrentes.

Os modelos de sidecars (dispositivo inseridos lateralmente às motocicletas), utilizados anteriormente para efetuar o deslocamento de militares durante as disputas territoriais ocorridas na Segunda Guerra Mundial, passaram a transportar diversos produtos, possibilitando uma maior comodidade ao cotidiano da sociedade. Para Miranda (2012) apud Moreira (2015) os primeiros modelos de sidecar foram criados "pelo exército alemão no período da Segunda Guerra Mundial com a finalidade de possibilitar que os veículos da época pudessem transportar uma quantidade maior de soldados do Eixo para combater nas linhas de frente contra o exército Aliado".

O objetivo deste artigo é, portanto, é apresentar com o auxílio da ferramenta SIPOC - Suppliers (fornecedores), Inputs (insumos), Process (processo), Outputs (produtos obtidos na saída) e Customers (consumidores) - e da metodologia Fault Tree Analys (FTA) - ou traduzida para o português como a Análise da Árvore de Falhas (AAF) uma forma de classificar e listar os riscos existentes no processo de vendas e emissão de compras dos sidecars comercializados pela Empresa Zeta.

Para Simon (2001) a aplicação da metodologia de SIPOC, de maneira particular se mostra útil quando o gargalo não é observado de forma clara, propondo contribuições, para atender as exigências dos verdadeiros clientes do processo, bem como as exigências do consumidor final. Fernandes (2006) reforça que a metodologia SIPOC é um dos instrumentos mais indicados para definir, de forma adequada, o gargalo, além de identificar as fronteiras deste problema, ou seja, "quais os fornecedores e clientes do processo em estudo, e também quais as principais 'entradas' a serem processadas e a relação das características mais críticas aos clientes quanto às 'saídas' geradas".

Desta forma, com a finalidade de demonstrar o tema com maior poder de exatidão, elaborou-se um trabalho mediante os conhecimentos sistematizados disponíveis em métodos, técnicas e procedimentos de caráter técnico e cientifico. Por esse motivo, esta pesquisa foi caracterizada como descritiva e de caráter qualitativo, pois para Gil (2008), este tipo de pesquisa tem a finalidade de proporcionar aos autores maior grau de familiaridade com o problema, tornando possível a evidência de uma problemática de forma clara e objetiva. Rampazzo (2005) informa também que a pesquisa de caráter descritivo "observa, registra, analisa e correlaciona os fatos e fenômenos, sem manipula-los", permitindo assim, uma análise sem que o pesquisador visualize os fatos sem interferir nos resultados da pesquisa.

E por fim, o autor Godoy (1995) evidencia ainda que este tipo de pesquisa permite que pesquisadores vão "a campo buscando "captar" o fenômeno a partir da perspectiva das pessoas nele envolvidas, considerando todos os pontos de vista relevantes" para atingir o problema em sua essência.

\section{GESTÃO DA QUALIDADE}

A Gestão da Qualidade pode ser visualizada como um agrupamento de ações de caráter operacional e gerencial que visa garantir os produtos/processos estejam sendo realizados em conformidade com as diretrizes esperadas pelos consumidores e pelos órgãos de caráter nacional e internacional (MONTGOMERY, 1996). Carvalho e Paladini (2005) apud MOREIRA (2017) salienta ainda que "a Gestão da Qualidade tem o objetivo de propor técnicas que melhorem o resultado das organizações e que auxiliem desta maneira, na minimização dos defeitos existentes na linha de produção". 
Hraqdesky (1997) salienta que a finalidade da Gestão da Qualidade é a de tornar todos os processos produtivos mais eficientes e com uma garantia de são realizados com base na melhoria contínua pré-estabelecida pelos gestores da organização. "A melhoria continua pode ser visualizada com uma filosofia que tem como princípio a produção com qualidade, reduzindo o tempo e padronizando os processos necessários para se agregar valor a um produto" (MOURA, 1994 apud MOREIRA, 2017).

A Gestão da Qualidade permite demonstrar indicadores que confiabilidade e satisfação para os empreendimentos e para os seus clientes (MOREIRA et al., 2015). A figura abaixo correlaciona as atividades relacionadas com o Gerenciamento da Qualidade ao cenário atual:

Figura 1 - Atividades relacionadas com a Gestão da Qualidade

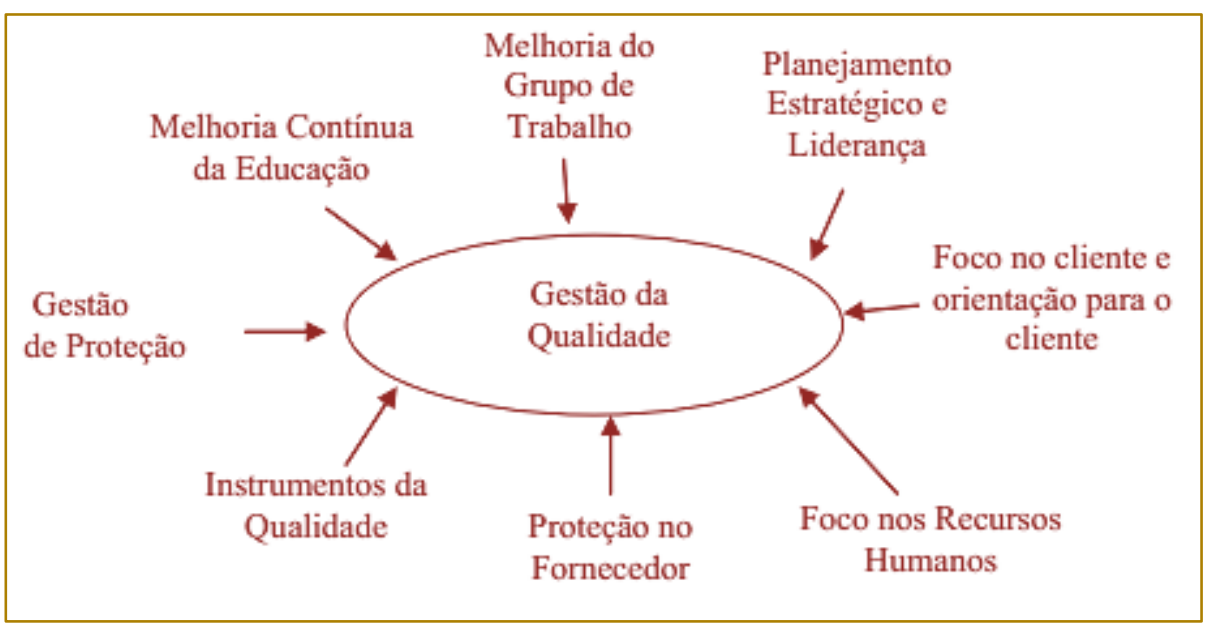

Fonte: Adaptado de Mahdiraji et al. (2012)

A Gestão da Qualidade tende a concentrar suas premissas no princípio da melhoria contínua, e para alcançar tal realização, tornase necessário a incidência de integração que viabilize as ações intermediárias que possuem interligação entre 0 capital intelectual (Recursos Humanos), os Fornecedores, o Trabalho em Equipe com o Planejamento Estratégico que visa uma Liderança fornecida aos demais colaboradores (Empowerment), pois através desta forma de gerenciamento, torna-se possível realizar que será visível tanto para os consumidores quanto para os membros envolvidos no processo produtivo do empreendimento (MOREIRA et al., 2015).

\subsection{GERENCIAMENTO DE FALHAS}

Usar métodos científicos para evidenciar o índice de falhas na linha de produção, é visto pelos autores Fernandes e Santos (2008), como um fator essencial para garantir a melhoria contínua dos produtos, já que para cada falha não visualizada há um consumidor insatisfeito e consumidores insatisfeitos não costumam comunicar os problemas ocorridos aos gestores, pois eles simplesmente deixam de consumir o produto.

Por esse motivo, tem se tornado de suma importância que as empresas analisem periodicamente o seu processo produtivo para garantir uma redução das despesas com gargalos existentes na linha de produção. De acordo com Campos (2004) "o custo não é só visto como custo final do produto ou serviço, mas inclui também os custos intermediários", já que eles refletem diretamente na qualidade e no valor agregado que o produto final irá receber.

Geralmente estes custos podem ser definidos ou caracterizados como custos de falhas internas ou custos de falhas externas. As falhas internas ocorrem quando existe a possibilidade de um erro ocorrer antes do produto ou serviço chegar ao seu consumidor final, neste caso, é possível realizar modificações sem que o cliente tenha conhecimento, "já as falhas externas são caracterizadas por defeitos percebidos pelos clientes" (MOREIRA, 2017).

Quando se refere às peças defeituosas, são definidas algumas diretrizes para estimar o 
valor deste defeito, como por exemplo, custo com retrabalhos e o custo de se produzir uma nova peça. Além disso, quando ocorre uma falha externa, neste caso, o consumidor já visualizou o erro e procura o empreendimento para trocar a mercadoria, "para estes eventos devem-se levar em consideração os custos administrativos perdidos e custos de expedição e transporte" (ROBLES, 2003 apud MOREIRA, 2017).

Com o mercado cada vez mais competitivo a incidência destes custos deve ser reduzida e analisada com maior frequência, pois uma deficiência não analisada pode significar a falência de uma empresa. Atualmente os empreendimentos do ramo automotivo tem sempre buscado atender aos conceitos de "zero defeito", assim, para alcançar este objetivo faz-se necessário a minimização dos riscos através de pesquisas em técnicas que permitem demonstrar as falhas não visualizadas pelos colaboradores (CARVALHO \& PALADINI, 2005).

"A utilização desta metodologia torna possível a realização de uma análise sistemática em busca da causa raiz do problema, permitindo identificar e diagnosticar as falhas existentes no processo produtivo da organização" (PASSAMANI, 2010 apud MOREIRA, 2017).

\subsection{FTA (FAULT TREE ANALYS)}

Para Alter (1999) a Fault Tree Analys (FTA) ou traduzida para o português como a Análise da Árvore de Falhas (AAF) é um modelo gráfico que permite demostrar, de maneira sistemática, o desdobramento de diferentes eventos que podem estar correlacionados com um gargalo. Ele parte se inicia de um modo de falha, conhecido como "evento de topo" ou "modelo top-down", que tem a finalidade de analisar as possíveis causas da incidência de determinado evento, ou seja, é um procedimento que se inicia através de uma possível falha e termina com a identificação das causas dessa falha vir a ocorrer no processo produtivo da organização.

Scapin (1999) salienta que a FTA é uma técnica analítica que auxilia na garantia da confiabilidade e da segurança, fatores considerados essenciais para garantir uma relação de harmonia no processo como um todo. O mesmo autor evidencia ainda que a sua utilização se deve à identificação de pontos falhos em que são possíveis introduzir melhorias ou de modificações para garantir que o projeto de execução do produto seja mais rigoroso, utilizando de uma abordagem sistêmica, traçando a rota entre os sintomas percebidos pelos clientes e as causas das anomalias dentro da arquitetura do produto.

Shalev e Tiran (2007), por sua vez, afirmam que a FTA é uma ferramenta utilizada para analisar, de forma aplicável e útil, as situações que causam algum risco e, a partir disso desenvolver um método de sistemas com engenharia simples que contemple todos os estágios de realização do projeto. A figura 2 demonstra um exemplo da aplicação da FTA em uma situação hipotética.

Figura 2 - Exemplo da Aplicação da FTA

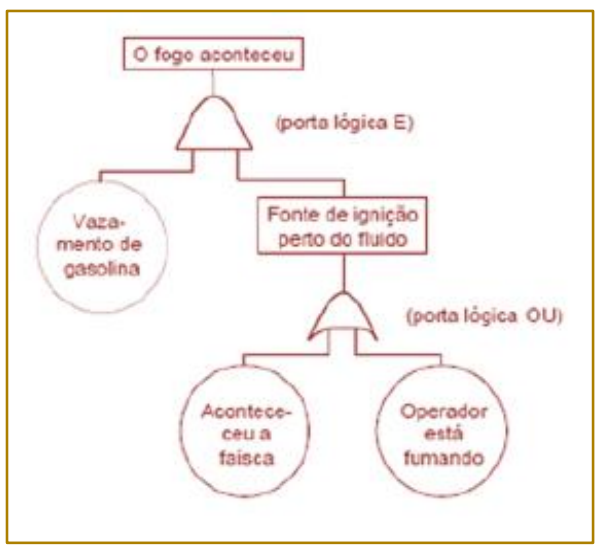

Fonte: Scapin (1999)

De acordo com a Figura 2 é possível perceber que existe um evento básico que causa a falha e, a partir disso, tem-se o possivel caminho representando a "árvore" ou os "pés 
da árvore" (SHALEV e TIRAN, 2007). Na sequência, é realizada a determinação de cada um dos eventos básicos que compõem - gargalo e são identificadas as taxa de falhas, que são, geralmente, dados estatísticos provenientes de variadas fontes. "O evento de saída conectado pela porta lógica "E" ocorre somente se todos os eventos de entrada ocorrer simultaneamente, em sentido oposto, o evento de saída conectado pela porta lógica "OU" somente ocorre se qualquer um dos eventos de entrada ocorrer" (LEAL et al., 2008).

Almeida et al. (2006) propõe a utilização de dados de gerenciamento, como documentos, descrições, fotos, para associá-las aos "nós" e conexões da "árvore", possibilitando desta forma que as organizações reconheçam a esquematização das falhas existente no processo produtivo do empreendimento. "A gestão deste conhecimento associada à construção das arvores de falhas se aplica a treinamentos e a tomada de decisões, focando evitar a reincidência destas falhas" (ANDRADE, 2012).

\section{SIPOC}

A sigla SIPOC tem origem nos termos em inglês: Suppliers (fornecedores), Inputs (insumos), Process (processo), Outputs (produtos obtidos na saída) e Customers (consumidores) (RASIS et al., 2002).

Esta técnica tem como objetivo melhorar a visualização da sequência de processos por todos os membros da empresa diretamente ligados a estes. Para isso será necessário levantar os seguintes dados (Figura 3) de cada processo: as entradas, as saídas, as especificações de cada etapa e o fluxo de cada um. Com uma visão mais clara do fluxo dos processos é possível realizar melhorias destes de modo que por futuras ações seja obtido um nível de qualidade ainda maior de acordo com as informações obtidas tais como:

- Fronteira do projeto, onde inicia e onde termina o campo de atuação;

- Lista de entradas e saídas do processo e seus respectivos fornecedores e cliente. Esta informação é fundamental na definição da equipe de trabalho;

- Especificações atuais para as entradas e saídas do processo. Neste ponto normalmente são detectadas falhas ou falta de especificações.

Figura 3 - Exemplo de um modelo SIPOC

\begin{tabular}{|c|c|c|c|c|c|c|}
\hline $\begin{array}{c}\text { Fornecedores } \\
\text { Suppliers }\end{array}$ & $\begin{array}{c}\text { Entradas } \\
\text { Inputs }\end{array}$ & \multicolumn{2}{|c|}{$\begin{array}{c}\text { Processo } \\
\text { Process }\end{array}$} & $\begin{array}{l}\text { Saídas } \\
\text { Outputs }\end{array}$ & \multicolumn{2}{|c|}{$\begin{array}{l}\text { Clientes } \\
\text { Customers }\end{array}$} \\
\hline & & $\begin{array}{c}\text { Requerimentos } \\
\text { Requirements }\end{array}$ & & & $\begin{array}{l}\text { Requerimentos } \\
\text { Requirements }\end{array}$ & \\
\hline $\begin{array}{l}\mathrm{S}_{1} \text { Fornecedores } \\
\text { de matéria-prima }\end{array}$ & $\begin{array}{l}\text { It Matéria } \\
\text { prima }\end{array}$ & $\begin{array}{l}R_{1} \quad \text { Parâmetros de } \\
\text { qualidade definidos } \\
\text { nocontrato }\end{array}$ & $P_{1}$ & $\begin{array}{l}\mathrm{O}_{1} \\
\text { Produtos }\end{array}$ & $\begin{array}{l}\mathrm{R}_{\mathrm{s}} \text { De acordo com o } \\
\text { pedido de comprae } \\
\text { as normas de } \\
\text { qualidade do setor }\end{array}$ & $\mathrm{C}^{\mathrm{C}}$ Cliente \\
\hline $\mathrm{S}_{2}$ Empresa de RH & $\begin{array}{l}12 \text { Recursos } \\
\text { humanos }\end{array}$ & $\begin{array}{l}\mathrm{R}_{2} \quad \text { Habilidades } \\
\text { curriculares pré- } \\
\text { definidas }\end{array}$ & $\begin{array}{l}\text { Empresa } \\
\text { analisada }\end{array}$ & $\begin{array}{l}\mathrm{O}_{2} \\
\text { Residuos }\end{array}$ & $\begin{array}{c}\mathrm{R}_{2} \text { De acordo com as } \\
\text { exigências do } \\
\text { controle ambiental } \\
\text { municipal }\end{array}$ & $\begin{array}{l}\mathrm{C}_{2} \\
\text { Departamento } \\
\text { Municipalde } \\
\text { Meio Ambiento }\end{array}$ \\
\hline $\begin{array}{c}\text { Sistribuidora } \\
\text { de energia }\end{array}$ & Is Energia & $\begin{array}{c}\text { R3 Distribuição sem } \\
\text { interrupçāo e sem } \\
\text { oscilaçōes }\end{array}$ & & $\mathrm{O}_{3}$ Lucro & $\begin{array}{l}\text { R3 } \quad \text { Dentro da } \\
\text { rentabilidade } \\
\text { mínima esperada }\end{array}$ & $\mathrm{C}_{3}$ Acionistas \\
\hline Cliente & $\begin{array}{l}\text { I4 Pedidos } \\
\text { de } \\
\text { compra }\end{array}$ & $\begin{array}{c}\text { Re Pedidos compativeis } \\
\text { em tipo, quantidade } \\
\text { e prazo }\end{array}$ & & $\mathrm{O}_{4}$ Benfeitorias & $\begin{array}{c}\text { R4 Qualidade e } \\
\text { quantidades } \\
\text { definidas em acordo } \\
\text { coma prefeitura }\end{array}$ & $\mathrm{C}_{4}$ Município \\
\hline
\end{tabular}

Fonte: Andrade et al. (2012) 
Através deste diagrama torna-se possível a identificação dos processos do empreendimento, além de garantir a qualidade dos produtos ao cliente final, que são requerimentos para um bom relacionamento com os fornecedores, o que garante a eficiência das entradas, das etapas de processamento e das saídas, bem como o atendimento das perspectivas do cliente (GEORGE, 2004)

\section{METODOLOGIA}

Para iniciar o processo de implantação da metodologia SIPOC - Suppliers, Inputs, Process, Outputs, Customers e Requirements, foi realizado um estudo teórico quanto à utilização deste instrumento juntamente com metodologia FTA (Fault Tree Analysis) como instrumentos impulsionadores para o processo de vendas dos sidecars fabricados pela Empresa Beta. Em seguida, possibilitar maior compreensão e eficiência dos dados analisados quanto aos resultados pesquisa desenvolveram-se formulários, compostos por questões abertas e fechadas, aplicados a todos os doze (12) colaboradores da organização. Os dados posteriores desta pesquisa foram obtidos através da análise em sites, artigos de caráter técnico-científicos, livros, monografias, teses e dissertações.

As questões contidas nos formulários tratam sobre a organização estratégica do empreendimento, sobre a produção dos equipamentos, a missão, a visão e os objetivos da empresa. Além disso, os formulários serviram também para identificar os possíveis fatores que influenciam no gargalo do processo produtivo, bem como, avaliar a opinião dos envolvidos no processo de melhoria e monitorar os resultados obtidos em todo o processo de fabricação dos sidecars fabricados pelo empreendimento evidenciado.

\section{ANÁLISE DOS RESULTADOS}

Com base nas informações coletadas, foi desenvolvida uma proposta para a implantação da metodologia SIPOC no processo produtivo da Empresa Zeta. A primeira atividade evidenciada nesta proposta foi à realização de uma reunião para que tanto gestores quanto colaboradores pudessem esclarecer seus pontos de vistas e, com isso fornecer informações sobre o funcionamento dos sidecars e como é realizado o processo de fabricação dos equipamentos da organização, que vai desde a ordem de pedido até a entrega ao consumidor final. A execução de uma melhoria que envolva todos os setores do empreendimento, só se torna bem-sucedida quando todos os colaboradores entendem os motivos de se realizar uma melhoria no processo produtivo e quando há a contribuição de todos para a manipulação de informações dos setores operacionais e administrativos (VASCONCELOS, 2009).

Com base nas informações adquiridas, foi possível definir que o setor de compras de matérias primas e o setor de expedição detinham alguns problemas que prejudicavam o tempo entrega dos sidecars aos consumidores finais, então foram definidos os objetivos estratégicos necessários para a elaboração de uma análise eficiente que beneficiasse tanto colaboradores quanto os consumidores finais que adquirem os produtos da organização em evidência. Moreira (2015) afirma que a aplicação de uma melhoria só se torna eficiente para a organização, quando nela são considerados todos os fatores que podem ser prejudiciais tanto para os gestores quanto para o cliente final.

Por isso, para desenvolver tal estudo levando todos os fatores que podem ocorrer em todos os setores da Empresa Zeta foi elaborado um mapeamento (anexo A), tendo como base as premissas propostas pela metodologia SIPOC em que nele são considerados fatores como: os fornecedores, os insumos, o processo produtivo, os produtos obtidos na saída da linha de produção e os consumidores finais.

Com base nas informações reunidas pela metodologia SIPOC, foi proposta uma nova reunião para delimitar e elaborar o fluxograma do setor de vendas, comercial e emissão das notas fiscais (contas a receber) da organização (anexo B), além de debater sobre os eventuais problemas que ocorrem no setor vendas e expedição.

Após a delimitação de todas as etapas que ocorrem nesses setores da organização, foi possível identificar através de conversas informais com os fornecedores e com os colaboradores do empreendimento que não há um controle efetivo do momento em que se deve realizar os pedidos de compra. Então para este problema foi realizado um controle, com base em um software já adquirido pela Empresa Zeta, para auxiliar no ponto de 
pedido e ressuprimento da matéria-prima. $\mathrm{O}$ software, até então não utilizado, foi "alimentado" para garantir que os colaboradores pudessem ter um controle com maior frequência das peças que entram e que saem do estoque.
Já quanto ao problema com o setor de vendas e de emissão de notas fiscais, foram definidos alguns eventos, com base na metodologia FTA para minimizar os atrasos na obtidos na Ordem de Produção (figura 4).

Figura 4 - FTA do processo de emissão do pedido de compra

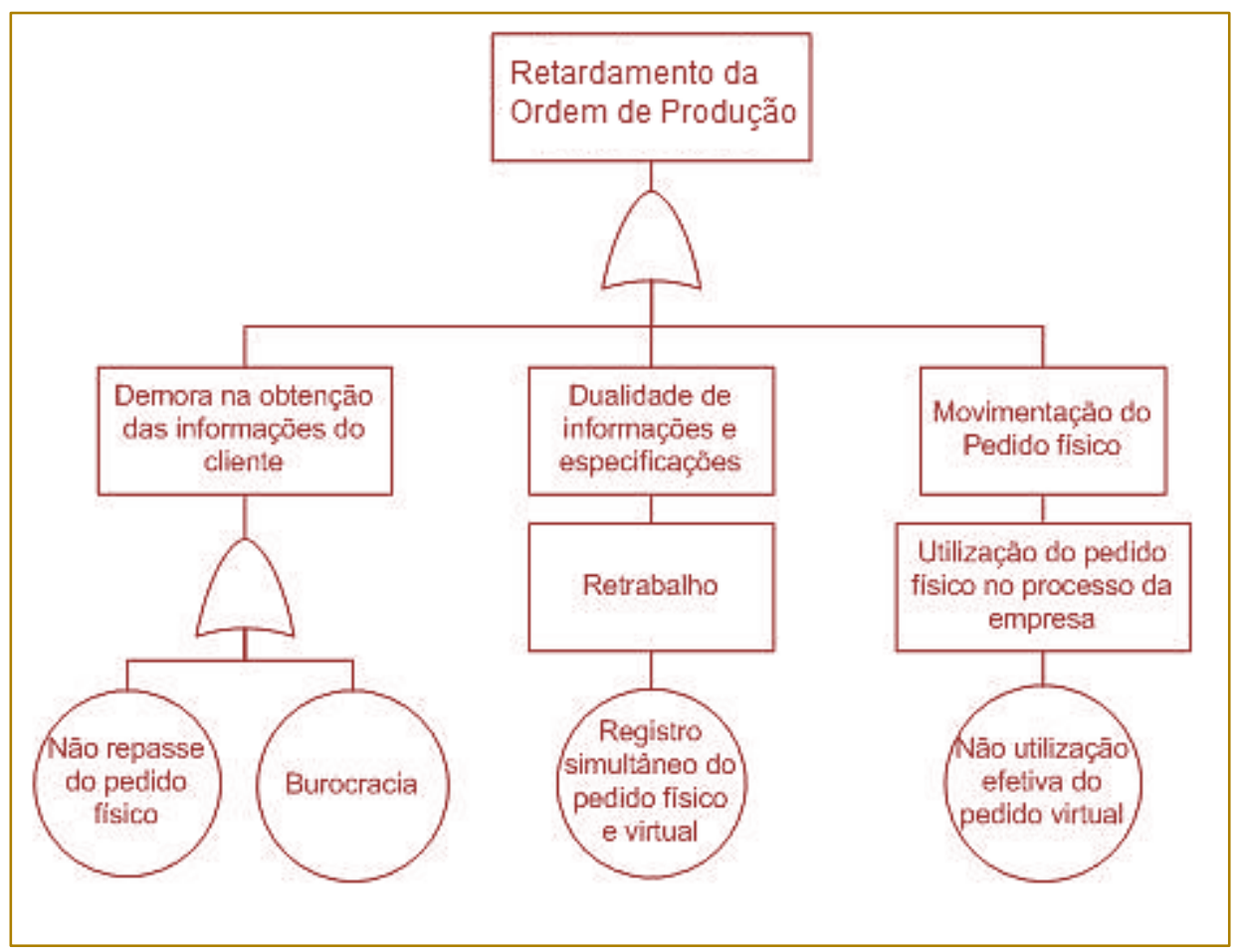

Fonte: adaptado de Andrade (2012)

A partir da aplicação conjunta das duas metodologias foi possível identificar com maior poder de eficiência a falha que afeta os processos relacionados à área de vendas e expedição do empreendimento em análise: o delongamento ou demora no processo de emissão da Ordem de Produção e da emissão da nota fiscal do sidecar vendido. O Anexo C demonstra, de maneira sistemática, as melhorias realizadas nas etapas de Process (processo) e Customers (consumidores) nos setores evidenciados pela Empresa Zeta.

Após a conclusão de todos os procedimentos referentes ao processo de implantação das metodologias, passando-se algumas semanas do novo processo produtivo em andamento, foi realizada uma comparação entre o antes e o depois da implantação destes conceitos, em que foi possível evidenciar a incidência de uma redução significativa das falhas nos processos de fabricação dos sidecars, as informações obtidas foram evidenciadas no gráfico, representadas como figura 5. A média de 10 falhas semanais (representado de azul) foi substituída por uma média inferior a 5 falhas (representado de laranja), ou seja, houve uma diminuição de aproximadamente $50 \%$ das falhas existentes no setor, acarretando um ampliação na produtividade e uma melhoria significativa nos sidecars entregues aos clientes finais. 
Figura 5 - Gráfico Comparativo das Falhas

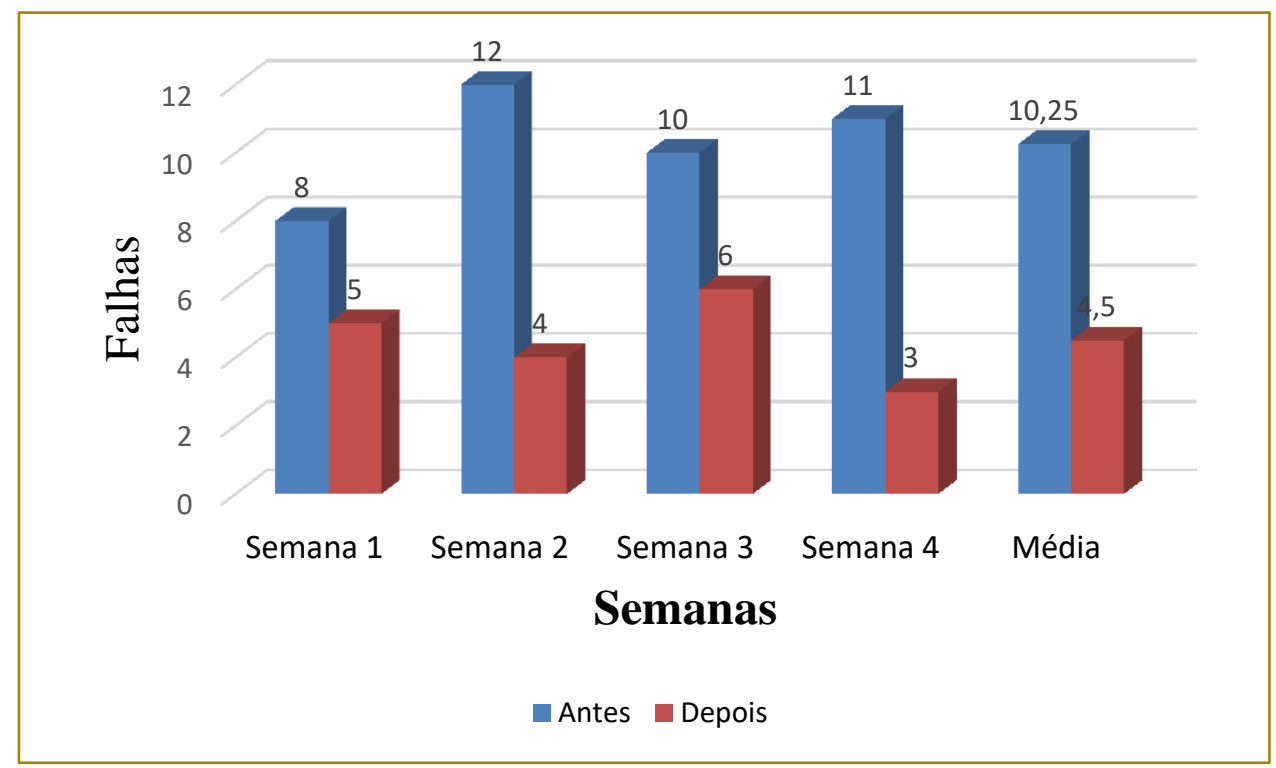

Deste modo, foi possível perceber que após a implantação desta melhoria os colaboradores tem maior respaldo sobre que devem ser tomadas em caso da incidência deste problema ou de outro similar. O auxílio dos colaboradores na solução deste problema fez com que fosse a motivação dos funcionários, já que por terem seus pontos de vistas considerados no processo de decisão, eles se sentem parte da equipe e "vestem a camisa" da organização e auxiliam efetivamente no aumento da qualidade dos sidecars comercializados pela organização.

\section{CONSIDERAÇÕES FINAIS}

Tendo em vista a busca constante dos empreendimentos por soluções eficientes e definitivas para suas dificuldades encontradas no cotidiano do ambiente industrial, a união das metodologias SIPOC e FTA se mostraram ferramentas de grande utilidade para o mercado, uma vez que permitem a visualização de solução que auxiliam na extinção de gargalos, ao mesmo passo que evita a expansão de problemas que se originam da sua não prevenção (TOLEDO, 2007). Com a finalidade de demonstrar a eficiência desta metodologia realizou-se um estudo de caso, em que foi explanado os conceitos da metodologia SIPOC em contribuição a ferramenta FTA, aplicadas no processo de expedição dos sidecars desenvolvidos pela organização em análise. Durante sua aplicação foi possível evidenciar os fatores que levam a incidência deste gargalo, tornando possível a sua resolução definitiva.

Desta forma, foi possível evidenciar, através deste estudo, que a solução deste problema garantiu uma melhora significa nos processo de vendas e expedição dos sidecars fabricados pela Empresa Zeta, além disso, pode-se perceber que este instrumento será um grande aliado para garantir a melhoria contínua no empreendimento, já que possibilita uma visualização significativa dos riscos existentes na linha de produção, bem como as restrições quanto às áreas ou setores em que esta metodologia pode ser aplicada.

Por ser uma metodologia relativamente nova para aplicação de melhorias no processo produtivo dos empreendimentos manufatureiros, como sugestão para futuros trabalhos, recomenda-se a aplicação de estudos desse âmbito em outros segmentos, para que se possa verificar a eficiência desta metodologia na análise de riscos existentes no ambiente operacional das organizações. 


\section{REFERÊNCIAS}

[1] ALMEIDA, D.A. de; LEAL, F.; PINHO, A.F. de; FAGUNDES, L.D. Gestão do Conhecimento na análise de falhas: mapeamento de falhas através de sistema de informação. Revista Produção, v.16, n. 1, p.171-186, 2006.

[2] ANDRADE, G. E. V; et al. Análise da aplicação conjunta das técnicas SIPOC, Fluxograma e FTA em uma empresa de médio porte. In: XXXII Encontro Nacional de Engenharia De Produção. Bento Gonçalves, 2012.

[3] CAMPOS, Vicente Falconi. Gerenciamento da rotina de trabalho do dia-a-dia. 8 ed. Nova Lima: INDG Tecnologia e Serviços Ltda., 2004.

[4] CARVALHO, M. M.; PALADINI, E. P.(Coord.). Gestão da Qualidade: teoria e casos. Rio de Janeiro: Elsevier, 2005.

[5] CONTE, Antônio Lázaro; DURSKI, Gislene Regina. Qualidade. In: MENDES, Judas Tadeu Grassi. Gestão empresarial. Curitiba: Editora Gazeta do Povo, 2002.

[6] FERNADES, M.M. Análise do processo de seleção de projetos seis sigma em empresas de manufatura no Brasil. Dissertação Mestrado em Engenharia de Produção, Programa de PósGraduação em Engenharia de Produção, Itajubá, MG, UNIFEI, 2006

[7] FERNANDES, D.; SANTOS, C.. As consequências comportamentais da insatisfação dos clientes. Curitiba, 2008. Disponível em: <www.spell.org.br/documentos/download/8252>. Acesso em: 15 jan. 2017

[8] GEORGE, M. L. Lean Seis Sigma para serviços: como utilizar velocidade Lean e qualidade Seis Sigma para melhorar serviços e transações. Tradução de Carlos Henrique Trieschmiann. Rio de Janeiro: Qualitymark, 2004.

[9] GIL, Antonio Carlos. Como elaborar projetos de pesquisa. 4. Ed. São Paulo: Atlas, 2008.

[10] GODOY, A. S. Pesquisa qualitativa tipos fundamentais. Revista de Administração de Empresas. São Paulo, v.35, n.3, p. 20-29, mai./jun. 1995.

[11] GONÇALVES, José Ernesto Lima. As empresas são grandes coleções de processos. RAE - Revista de Administração de empresas. São Paulo, v.40, n.1, p. 6-19, jan/mar, 2000.

[12] HRAQDESKY. J. Aperfeiçoamento da qualidade e produtividade. São Paulo: Makron Books, 1997.

[13] KARA-ZAITRI, C. An improved minimal cut set algorithm. International Journal of Quality \&
Reliability Management, v.13, n.2, p. 114-132, 1996.

[14] LEAL, F.; ALMEIDA, D.A.de; MONTEVECHI, J.A.B. Uma Proposta de Técnica de Modelagem Conceitual para a Simulação através de elementos do IDEF. In: Anais do XL Simpósio Brasileiro de Pesquisa Operacional, João Pessoa, PB, 2008.

[15] MAHDIRAJI, H.A., et al. Supply chain quality management. Growing Science Ltd., p. 2463-2472, 2012.

[16] MONTEGOMERY, D.C. Introduction to statistical quality control. $3^{\mathrm{a}}$ ed. Nova York: Wiley, 1996.

[17] MOREIRA, J. P. S. Análise de falhas com base na metodologia Troubleshooting: um estudo de caso em uma empresa do setor industrial. In: Anais do XXXVII Encontro Nacional de Engenharia de Produção, Joinville/SC. 2017.

[18] MOREIRA, J. P. S. et al. Implantação das Metodologias MASP e 5S no almoxarifado de uma indústria de sidecar. In: Anais do XXXV Encontro Nacional de Engenharia de Produção, Fortaleza/CE. 2015

[19] RAMPAZZO, L. Metodologia científica. São Paulo: ed. Loyola, 2005.

[20] RASIS, Dana; GITLOW, Howard S.; POOVICH, Edward. Paper organizars international: a fictitious Six Sigma Green Belt case study. I. Quality Engineering. v. 15, n. 1, p. 127-145, 2002.

[21] ROBLES, A. Jr. Custos da Qualidade: Aspectos Econômicos da Gestão da Qualidade e da Gestão Ambiental, 2003, 2 ed. 68p.

[22] SCAPIN, C.A. Análise Sistêmica de Falhas. Belo Horizonte: Editora de Desenvolvimento Gerencial, 1999.

[23] SHALEV, D.M.; TIRAN, J. Condition-based fault tree analysis (CBFTA): A new method for improved fault tree analysis (FTA), reliability and safety calculations. Reliability Engineering \& System Safety, v. 92, p. 1231-1241, 2007.

[24] SIMON, K. SIPOC Diagram, 2001. Disponível em: <www.isixsigma.com/library /content/c010429a.asp >. Acesso em 20 abr. 2017.

[25] TOLEDO, José C. Qualidade industrial: conceitos, sistemas e estratégias. São Paulo: Atlas, 2007

[26] VASCONCELOS, D. S. C. A utilização das ferramentas da qualidade como suporte a melhoria do processo de produção - Estudo de caso na indústria têxtil. In: Encontro Nacional de Engenharia de Produção, 29. Salvador/BA, 2009. 
ANEXOS

Anexo A: Mapeamento do SIPOC realizado no setor de vendas/comercial na Empresa Zeta, adaptado de Andrade (2012).

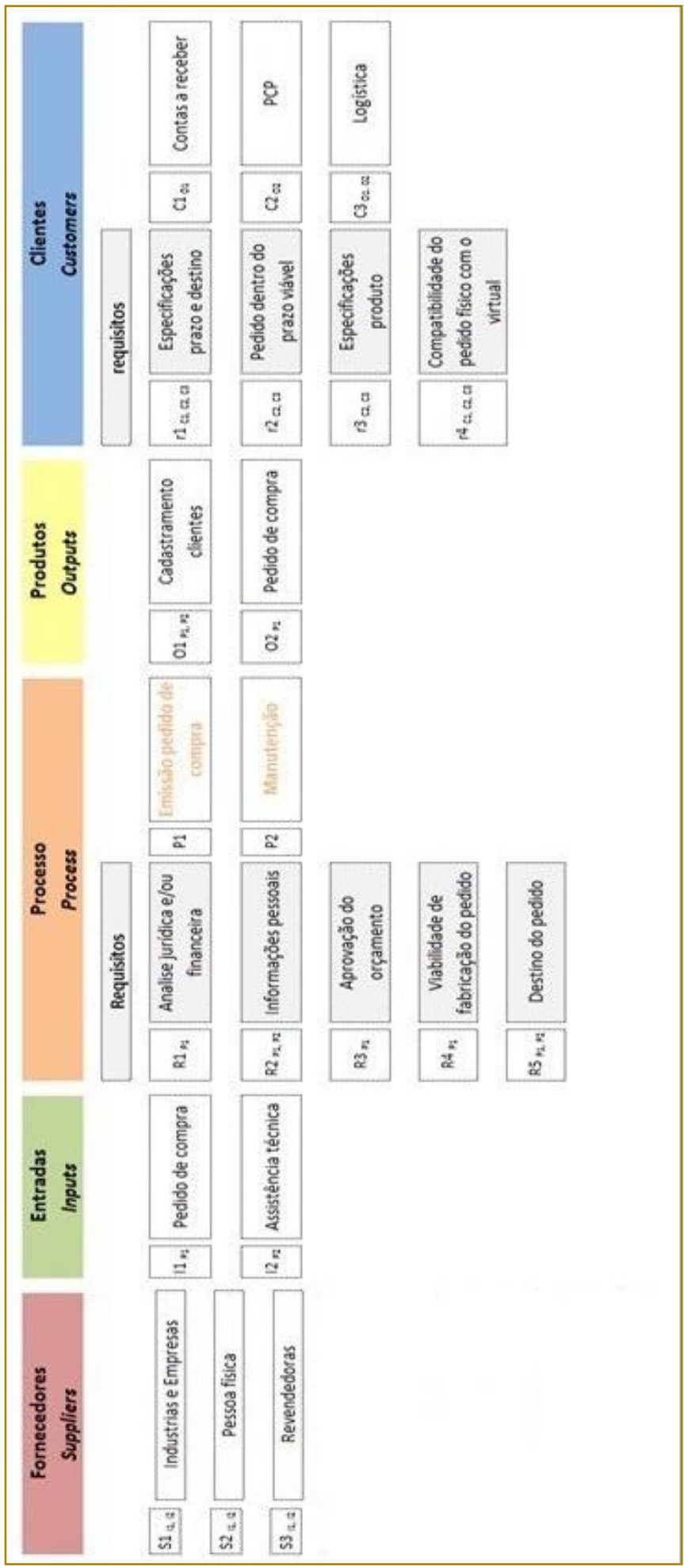


Anexo B: Fluxograma do processo de emissão pedido de compra de produto na Empresa Zeta, adaptado de Andrade (2012).

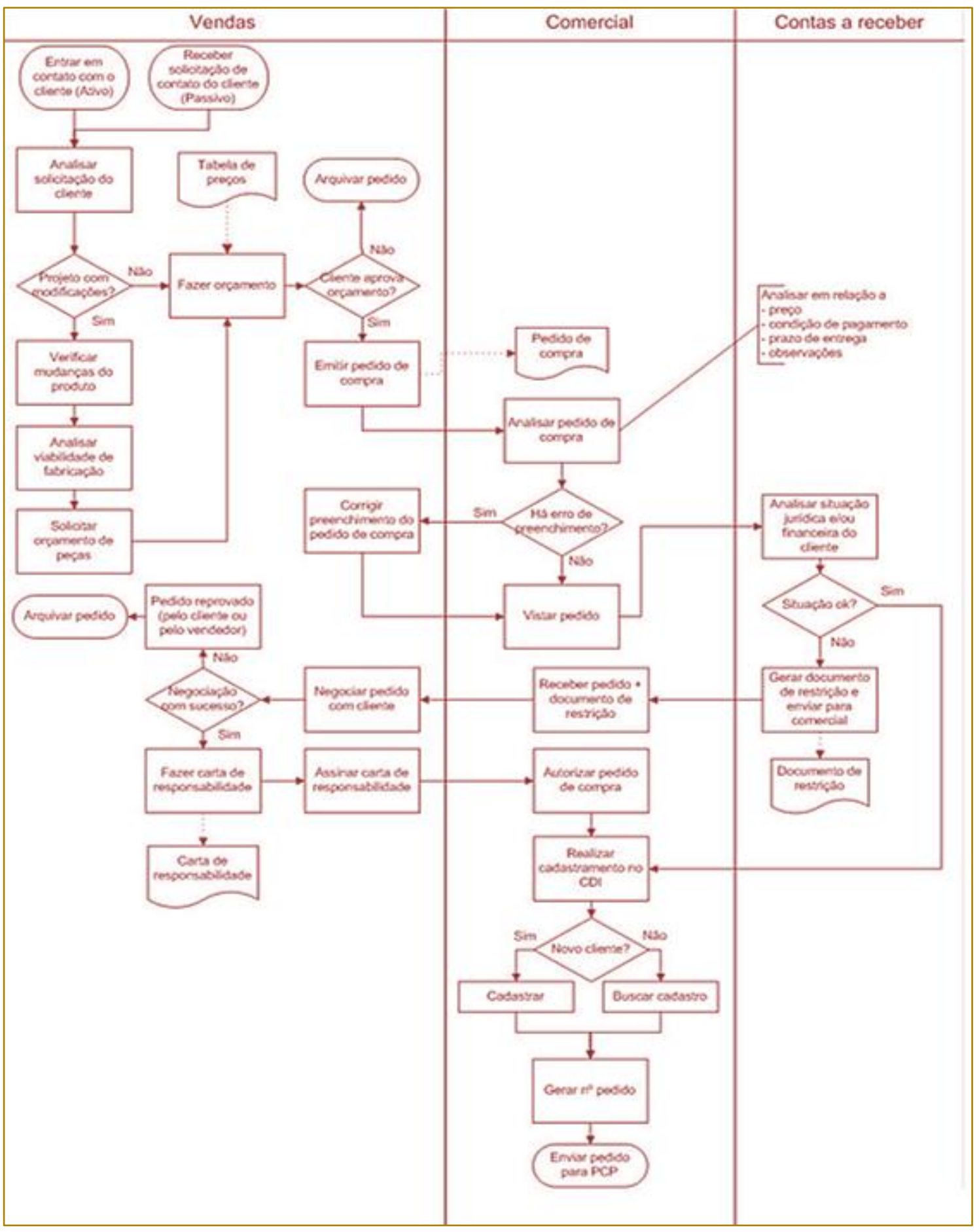


Anexo C: aplicação das metodologias SIPOC e FTA na Empresa Zeta, adaptado de Andrade (2012).

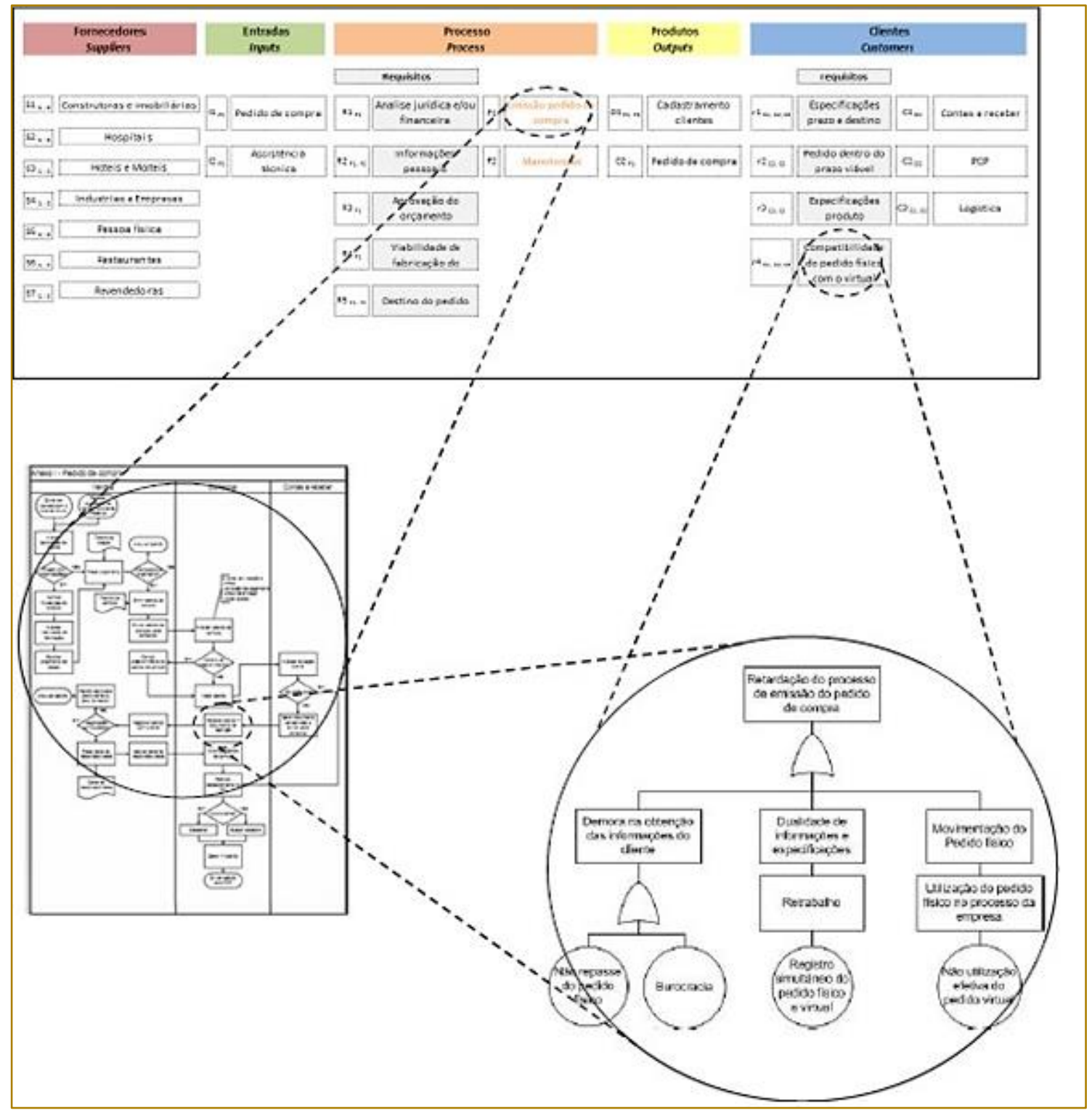




\section{Capítulo 6}

\section{APLICACÃO DO MAPEAMENTO DO FLUXO DE VALOR EM UMA CÉLULA DE USINAGEM DE BIELAS}

\section{Davenilcio Luiz de Souza}

\section{Pablo Fogaça}

\section{Rossano Noronha}

\section{Leandra da Silva}

Resumo: O presente estudo objetiva apresentar o uso do Mapeamento do Fluxo de Valor (MFV), em uma célula de usinagem de bielas de um fabricante de motores diesel. Adicionalmente ao MFV, elencar e discorrer sobre os resultados obtidos no desenvolvimento do projeto. O estudo traz a identificação do problema, o levantamento e tratamento de dados e a formatação de soluções, tendo como sustentação a atividade multidisciplinar. Os resultados são expressivos com a redução de $50 \%$ do Lead Time, redução de 50\% no WIP e a utilização de contentores de produtos como Kanban entre o estoque e a área cliente. $\mathrm{O}$ disciplinamento da célula através de nivelamento de operações para atender o tempo Takt e o treinamento intensivo do grupo de trabalho proporcionou a estabilidade necessária ao processo.

Palavras-chave: Fluxo de valor; Multidisciplinaridade; Lead Time; Tempo Takt 


\section{INTRODUÇÃO}

Mapear o fluxo de valor permite a visão dos desperdícios, o que proporciona melhorias no fluxo dos processos de produção. Segundo Rother e Shook (2003) as organizações precisam pensar no fluxo, ao invés de implementar sistemas de produção discretos ou processos isolados de melhorias.

Para Antunes (2008; 2013) o MFV destaca o entendimento do fluxo horizontal e vertical para a estabilidade de processos numa fábrica, a função processo e a função operação. Estas funções facilitam a implementação dos princípios enxutos no chão-de-fábrica (SANTOS; GOHR; SANTOS, 2011).

A identificação e a mitigação de fatores de desperdício no desenvolvimento de produtos como (tempo, atividades desnecessárias, retrabalho, etc.) podem reduzir o lead time do processo proporcionando uma vantagem competitiva para a organização, (SALGADO et al.,2009). O MFV é uma ferramenta que pode operacionalizar a identificação, pelo reconhecimento das atividades que agregam e que não agregam valor ao processo (SALGADO et al., 2009).

Para demonstrar a eficácia desta ferramenta, este artigo apresenta um caso de aplicação do MFV em uma empresa multinacional. Neste ambiente encontra-se a necessidade da quebra de barreiras funcionais, em hábitos arraigados pela aplicação empírica de conceitos como, desenvolver atividade numa célula de produção em regime de mutirão diário. O objetivo da pesquisa visa demonstrar que a aplicação de uma metodologia e seus conceitos, proporciona resultados de melhorias no tempo adequado à evolução do grupo de trabalho.

Alguns estudos verificaram as dificuldades de implementação, proposição de desperdícios e uma sistemática para a implementação da filosofia lean no processo de desenvolvimento do produto. (SOHAL; EGGLESTONE, 1994; MACHADO, 2006). Mencionam o uso do MFV como meio para identificação dos desperdícios do processo de desenvolvimento do produto, porém, limitamse a abordá-lo teoricamente, não descrevendo uma aplicação empírica, que é a contribuição da presente pesquisa.

Este artigo encontra-se organizado em seis seções, incluindo a presente introdução. $\mathrm{Na}$ seção 2 são apresentados os conceitos do
MFV. Na seção 3 é apresentado o método utilizado para a realização da pesquisa. $\mathrm{Na}$ seção 4, é apresentado o desenvolvimento da pesquisa com a descrição do MFV atual e com as melhorias implementadas. Na seção 5 são apresentados os resultados obtidos e por fim na seção 6 as principais conclusões do trabalho.

\section{CONCEITOS DO MAPEAMENTO DO FLUXO DE VALOR (MFV)}

O MFV ajuda a entender o fluxo de material e o da informação na medida em que o produto segue o fluxo de valor. É muito útil para enxergar o fluxo dos sistemas produtivos como um todo (MARTINS; CLETO,2016). A metodologia desta técnica, mapeia o fluxo de valor representado pelo fluxo dos materiais, fluxo de informações, o Takt time, o Lead time e a produção de cada máquina em uma folha de papel no formato A3. A ideia de melhoria e o desenvolvimento na implementação de sistemas enxutos de processos apoiam-se na análise de dois estados, o MFV "atual" e o MFV "futuro".

Rother \& Shook (2003) desenvolveram o MFV em quatro etapas:

Definição do grupo de produtos: escolhendo um grupo e não a totalidade de produtos torna-se mais fácil a aplicação do MFV.

Projeto do estado atual: é o desenho da situação atual do fluxo de material e de informação, parte-se do cliente até o início do processo do grupo de produtos escolhido.

Projeto do estado futuro: é o desenho ideal do fluxo de material e informação para aquele grupo de produtos escolhido. Trata-se de atender o cliente da forma mais rápida conforme suas solicitações, o cliente puxa o valor.

Conquistar a meta do estado futuro: trabalhar nas melhorias necessárias para a conquista do fluxo de valor enxuto especificado no mapa futuro.

No MFV percebe-se as funções processo e operação. Os processos de fabricação consistem em processamento, inspeção, transporte e as esperas. As operações são constituídas pela preparação ou setup, operações principais (essenciais e auxiliares) e as folgas (SHINGO, 1996). Com o propósito de ajustar as funções processo e operação, o subsistema Kanban é considerado o responsável por sincronizar e melhorar 
continuamente os processos de uma indústria.

Spearman et al. (1990) estudaram o Kanban e verificaram que a chave do sucesso do método é o mínimo de estoque em processo. Dessa maneira exploraram o (Work-in-process - WIP) para redução dos tempos de ciclo de produção, limitando os lançamentos no sistema. Isto evita flutuações no processo por uma baixa taxa média do WIP.

Com o objetivo de melhorar o método Kanban em razão de uma ampla variedade de produção, propõe-se a alternativa (CONstant Work In Process - CONWIP) (SERENO et al., 2011). O CONWIP busca interligar de forma constante o trabalho em processo. O sistema limita e libera o WIP máximo conforme o desempenho da produção. Diferente do Kanban, o CONWIP utiliza cartões por peça e não por lote de peças, de acordo com a determinação da lista backlog, que informa a demanda dos itens a produzir (PERGHER et al. 2013).

A produção é beneficiada tanto com o CONWIP quanto com o kanban, visto que atuam diretamente na diminuição dos estoques em processo, reduzem o lead time e melhoram o controle do fluxo produtivo (HOPP; SPEARMAN, 2000).

\section{METODOLOGIA}

De acordo com Miguel (2012), o método é o de estudo de caso com aplicação dos conceitos do Sistema Toyota de Produção (STP) da Manufatura Enxuta e suas ferramentas para desenvolvimento de um projeto no setor de Usinagem de Bielas para motor de média velocidade em uma empresa fabricante de motores diesel da Grande Porto Alegre. O objetivo principal do projeto é desenvolver fluxo puxado entre o setor de Usinagem da Biela e a Montagem do Motor, mapeando o Fluxo de Valor (MFV).

Como objetivos gerais tem-se, identificar quais dos sete desperdícios, segundo Ohno (1997) ocorrem no setor. Ohno (1997) identificou sete desperdícios que impactam um sistema produtivo no sentido de afastá-lo de um processo enxuto. São eles: Superprodução, Espera, Transporte excessivo, Processos inadequados, Inventário desnecessário, movimentação desnecessária e produtos defeituosos.
Realizou-se a cronometragem da usinagem para nivelar as operações em função do tempo Takt para o atendimento da demanda. Medição do estoque em processo (WIP), medição do Lead Time global entre abastecimento de componentes brutos até a disposição de peça pronta para montagem do motor. Na sequência a análise da situação atual do estoque disponível para a montagem. O trabalho em equipe e a multidisciplinaridade são a base para o desenvolvimento de atividades em projetos de melhoria contínua. A concentração de esforços permite encurtar o tempo de execução das ações para atender os objetivos propostos.

O projeto teve duração de uma semana. Participaram representantes de vários setores da empresa, como: Planejamento da Produção, Engenharia de Processos da Usinagem e Montagem, Operadores dos setores da Usinagem e da Montagem, Área de Abastecimento, Logística, Manutenção, $\mathrm{RH}$, Sistemas de Manufatura e Sistemas da Qualidade. Esta cooperação proporcionou a autonomia e a multidisciplinaridade necessária para as decisões pertinentes aos resultados almejados.

\section{DESENVOLVIMENTO DA PESQUISA}

Esta seção apresenta como ocorreu o desdobramento da pesquisa. Apresenta-se o MFV atual e o MFV com as melhorias implementadas.

\subsection{MAPEAMENTO DO FLUXO DE VALOR ATUAL \\ O projeto contou com a presença dos participantes do evento realizando o nivelamento de conceitos sobre Kaizen, cronometragem e a exposição de informações relevantes sobre a área objeto de estudo.}

O Layout da Usinagem de Bielas MS é composto por vinte (21) operações cativas. O arranjo da célula tem baixa flexibilidade em razão de duas máquinas Brochadeiras gêmeas, Op. 50 e 60 (brochamento das estrias) fundadas no subsolo (poço) para permitir passagem da ferramenta "brocha" verticalmente.

São produzidas Bielas similares de dois modelos do motor MS: NA - Normal Aspirada e TU - Turbo. A biela turbo difere apenas nos chanfros laterais executados na operação 
150. As quantidades de produção devem ser múltiplas de 4, trata-se de um motor com 4 cilindros e consequentemente recebe 4 Bielas. O lay-out da célula de usinagem da
Biela MS é visto na Figura 1, as setas indicam o fluxo do início, Op. 010, à última operação, Op.

Figura 01 - Layout - Usinagem de Bielas MS

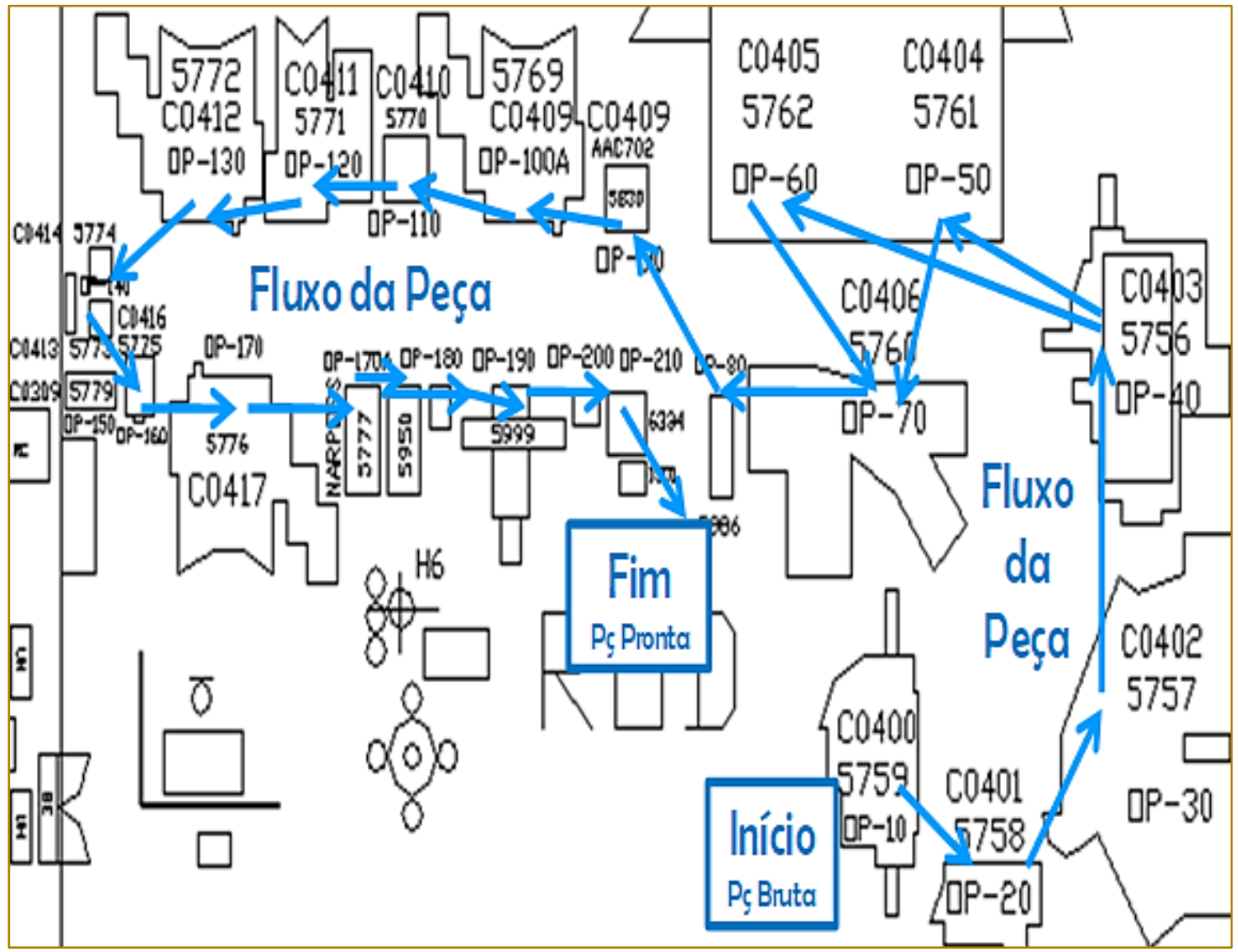

Fonte: Elaborado pelos autores

No MFV e na cronometragem das operações, identificou-se que o processo se dá em duas etapas no turno de trabalho. No início do turno, o grupo de 10 operadores abastece as operações da célula com quantidade de peças sem critério pré-estabelecido até o intervalo para a refeição, há concentração do maior estoque em processo entre as operações (OP-010 e OP-100) com quantidades de peças parcialmente usinadas que variam no dia a dia.
A ausência de cadência e de balanceamento entre as operações, promove baixa taxa de saída de peças prontas da célula. Após a refeição os operadores efetuam operações finais para a produção do volume de peças do programa diário. A Figura 2 ilustra o fluxo, a descrição das operações e o levantamento do Estoque atual em Processo "WIP", durante o turno de trabalho. 
Figura 02 - Fluxograma das operações - Mapa atual - Quantidade de Bielas em WIP

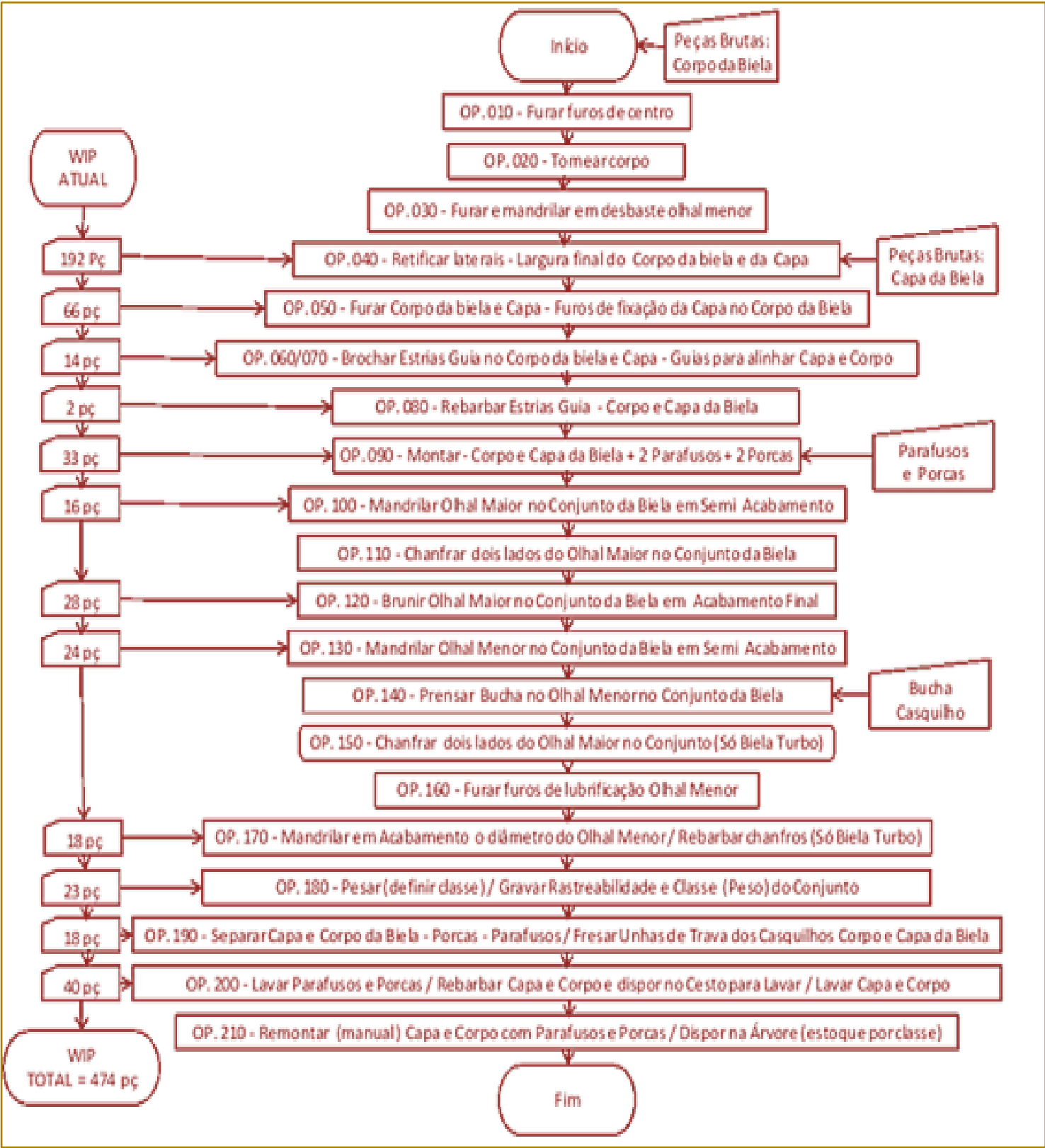

Fonte: elaborado pelos autores

A cronometragem revela oscilações significativas nos tempos individuais. A situação encontrada durante o levantamento de dados apresenta um arranjo praticado com 10 operadores. Neste arranjo os operadores trabalham nas primeiras operações no início do turno e migram para as operações finais no final do turno, para o cumprimento do plano de produção diário com eventual alocação de um $11^{\circ}$ operador. 
Figura 03 - 10 postos de trabalho e 10 operadores

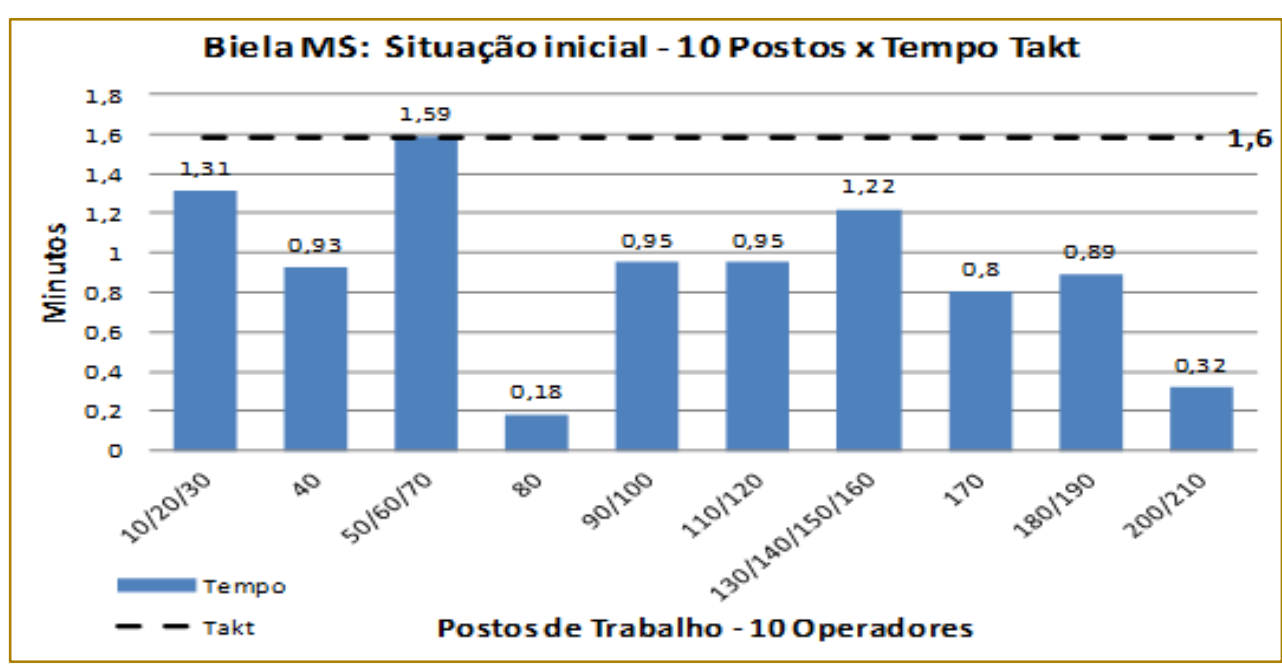

Fonte: Elaborado pelos autores

A disposição vista na Figura 3 em 10 postos de trabalho com 10 operadores, há falta de precisão na forma de alocação das pessoas, há ausência de ritmo e de balanceamento no arranjo encontrado. A seguir vê-se o MFV do estado atual ilustrado na Figura 4.

Figura 04 - Mapa do Fluxo de Valor Atual

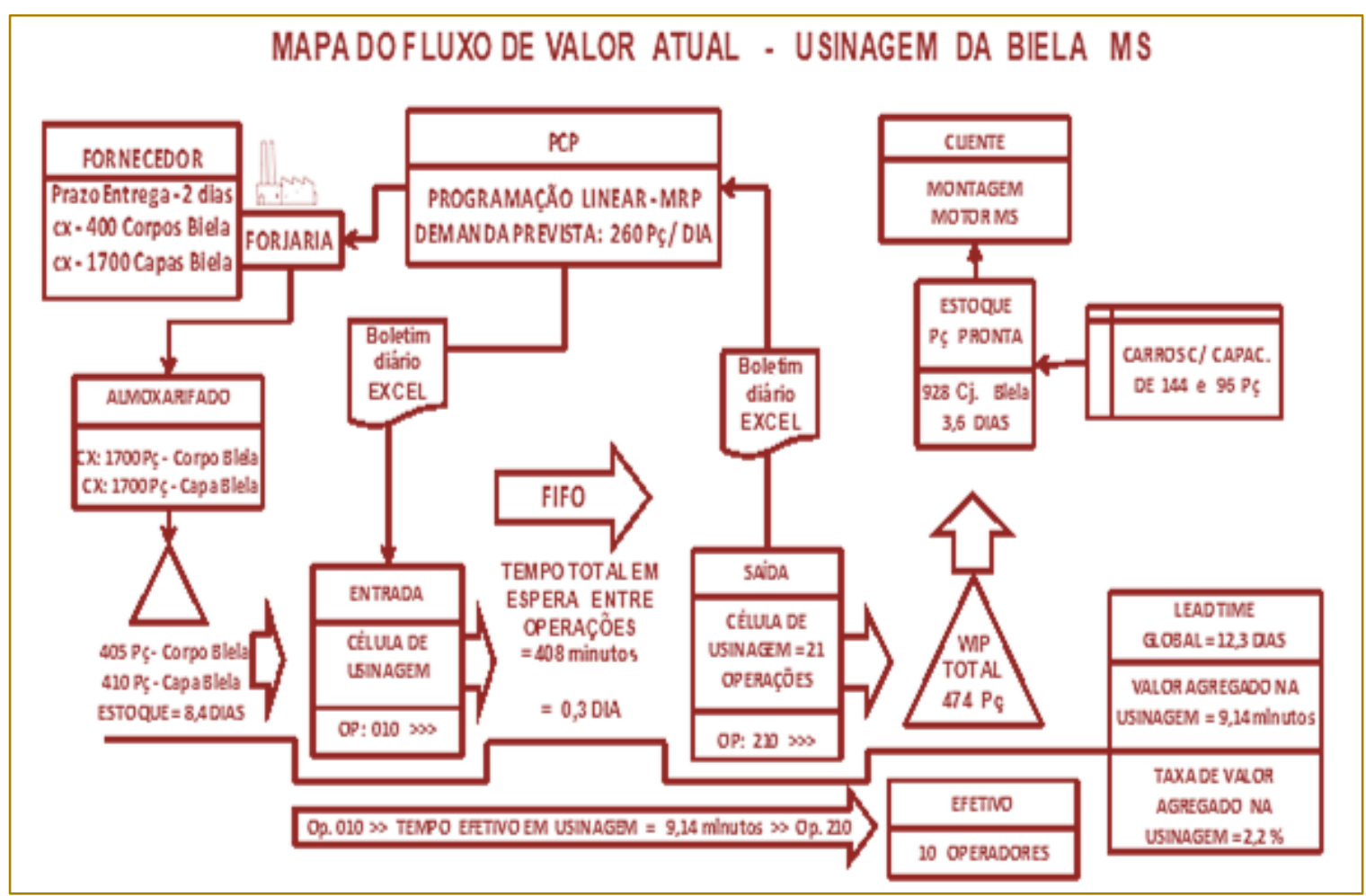

Fonte: Elaborado pelos autores

Depreende-se no Mapa do Fluxo de Valor do estado atual, a análise:

- Demanda prevista de 260 Bielas por dia. Corresponde a fabricação de 65 motores.
- WIP $=474$ peças, representando 1,9 dias de demanda prevista.

- Tempo total de espera entre as operações igual a 408 minutos, corresponde a 0,3 dias da demanda prevista. 
- Taxa de valor agregado nas operações igual a 9,14 minutos.

- Percentual da Taxa de valor agregado igual a $2,2 \%$.

- Tempo total de atravessamento (Lead Time) Global de 12,3 dias.

- Operações e postos de trabalho desbalanceados.

Das sete perdas segundo Ohno (1997), o Grupo Kaizen identificou.

Superprodução - 474 bielas em estoque no processo. No estado da arte, o ideal é uma peça em cada operação;

Excesso de Movimentação - Existe demasiada movimentação pelo excesso de peças em espera em algumas operações, falta em outras, desequilibrando o processo. Ausência de cadência e de taxa de retirada de peças em intervalos regulares $e$ operadores migrando entre postos de trabalho no início e no final de turno;

- Espera - tempo relacionado às 474 peças aguardando operação;

Estoque em excesso - Peças brutas, em processo e prontas disponíveis para a montagem;

- Processo inadequado -
Desbalanceamento da atividade nos postos de trabalho;

- Produção empurrada - Visa manter o estoque cheio na usinagem. A armazenagem é feita em carros no formato de árvore (carroárvore) que comportam 144 e 96 peças. São no total 12 carros-árvore, 5 com capacidade de 96 peças e 7 com capacidade de 144 peças.

Os carros-árvore com capacidade de 144 peças são de difícil transporte pelo excesso de peso, são conduzidos por empilhadeira até o setor de montagem de motores numa distância de 300m. O transporte por máquina gera risco de segurança e de danos às peças pelo desequilíbrio do carro-árvore na lança da empilhadeira. Os carros-árvore com capacidade de 96 peças oferecem a facilidade da condução manual empurrados por um operador até a montagem de motores.

Realizou-se o inventário do total de componentes da Biela em estoque nos locais dentro da fábrica, os custos relativos ao estoque dos componentes do conjunto da biela bem como o custo das operações da célula de usinagem. Conjuntamente com o Mapa atual do processo pode-se calcular o que representa em número de peças circulando na fábrica, na célula de usinagem, o custo dos componentes e o custo total da operação de usinagem coletados junto ao sistema de controle fiscal e de custos estabelecidos pela contabilidade de custos.

$\mathrm{Na}$ Tabela 1 verifica-se 474 conjuntos entre as operações, 928 conjuntos prontos à disposição para a montagem mais as quantidades dos componentes: parafusos, porcas e buchas no dentro do processo de usinagem. Dentre os custos, contabilizou-se o montante de $\mathrm{R} \$ 116.436,17$ em peças e o custo de $\mathrm{R} \$ 25.176,64$ relativo ao processo de produção dos 928 conjuntos prontos, totalizando $\mathrm{R} \$ 141.612,81$ de custo de inventário na fábrica.

Tabela 01 - Inventário e custo de produção relacionados - Situação Atual

\begin{tabular}{|c|c|c|c|c|c|c|c|c|c|c|c|}
\hline \multicolumn{12}{|c|}{ Inventário e Custos - Situação Atual } \\
\hline \multicolumn{8}{|c|}{ Quantidade de Componentes / Locais } & \multicolumn{4}{|c|}{ Custos } \\
\hline & & $\begin{array}{l}\text { Pecas por } \\
\text { Conjunto }\end{array}$ & \begin{tabular}{|c|} 
Almo- \\
xarifiado \\
\end{tabular} & \begin{tabular}{|c|} 
Entrada \\
Usinaggem
\end{tabular} & \begin{tabular}{|c|} 
Entre \\
Operaçōes \\
\end{tabular} & \begin{tabular}{|c|} 
Conjuntos \\
Prontos \\
\end{tabular} & \begin{tabular}{|l} 
N2 Total \\
Pegas
\end{tabular} & Unitário & \begin{tabular}{|l|} 
Total por \\
Conjunto \\
\end{tabular} & $\begin{array}{l}\text { Totalem } \\
\text { Estogue }\end{array}$ & Total Geral \\
\hline & Corpo Biela & 1 & 1.700 & 405 & 474 & 928 & 3.507 & $R S 21,55$ & $R \$ S 21,55$ & RS 75.575,85 & \multirow{5}{*}{ RS $116.436,17$} \\
\hline & Capa Biela & 1 & 1.700 & 410 & 474 & 928 & 3.512 & RS 8,86 & $R S 8,85$ & RS 31.116,32 & \\
\hline \multirow[t]{3}{*}{ a } & Parafuso & 2 & & & & 928 & 1.856 & RS 2,60 & RS 5,20 & RS 4.825,60 & \\
\hline & Porca & 2 & & & & 928 & 1.856 & $\operatorname{RS} 1,15$ & $\operatorname{RS} 2,30$ & RS $2.134,40$ & \\
\hline & Bucha & 1 & & & & 928 & 928 & $R S 3,00$ & $R S 3,00$ & RS $2.784,00$ & \\
\hline \multirow[t]{4}{*}{ b } & \begin{tabular}{|l|} 
Custo das \\
Operaç̧eses
\end{tabular} & 1 & & & & 928 & 928 & $R \$ 27,13$ & R\$ 27,13 & $R \$ 25.176,64$ & RS 25.176,64 \\
\hline & & & $a$ & Custodos C & componentes & sdoconjunt & Bo Biela & & $R S 40,91$ & & \\
\hline & & & $\mathrm{b}$ & Custodas C & peraçōes de & esinagem & & & $R S 27,13$ & & \\
\hline & & & $a+b$ & Custo total & por conjunto & & & & $\operatorname{RSS} 68,04$ & & \\
\hline
\end{tabular}

Fonte: Elaborado pelos autores 
O Grupo Kaizen desenvolveu suas atividades de levantamento de dados e mapeou o processo com o objetivo de identificar oportunidades de melhoria. O grupo de Operadores foi treinado durante e após o período do Kaizen para entendimento da nova forma de atuação nas operações. De forma produtiva implementaram melhorias na célula e nas operações.

Das oportunidades de melhoria listadas, cabe destacar:

- Redução do lote dos componentes brutos no Fornecedor, Corpo e Capa da Biela brutos de forjaria;

- Dimensionamento de todos carros-árvore para a quantidade de 96 peças (reforma de 7 carros com capacidade de 144 Peças). Padronização de lotes no estoque para facilitar o transporte manual, eliminando a empilhadeira do processo;

- Carro-árvore = Kanban. Definir os carrosárvore como mecanismo de disparo de produção. Critério: O carro vazio devolvido pela montagem sinaliza a necessidade de produção de conjuntos da biela na usinagem;

- Estabelecer o WIP padronizado entre as operações de usinagem;

- Balancear as operações para adequar ao Tempo Takt;

- Dimensionar o estoque conforme a projeção de demanda de produção.;
- Adotar controle hora/hora na produção para tornar visível o desempenho da área no atendimento à produção diária;

-Redução do inventário na fábrica em razão das ações anteriores.

\subsection{MAPEAMENTO DO FLUXO DE VALOR - MELHORIAS IMPLEMENTADAS}

Dentre as atividades junto a equipe de produção, objetivou-se adotar um padrão no dimensionamento do WIP. Na Figura 5 vê-se o fluxograma das operações individuais do estado futuro, onde temos a visão da quantidade de peças em WIP.

No primeiro estado futuro não é possível uma redução drástica de peças entre as operações pela dificuldade de adaptação dos operadores a um fluxo de 1 peça. A proposta visa principalmente manter todas operações com peças em fluxo após o dia de trabalho, visando assegurar iniciar o novo dia com retirada de peças prontas no início do novo turno. Os números de peças destacados no fluxograma são máximos com vistas a redução desse número durante a produção até um mínimo de 2 peças em cada operação.

Balanceamento das operações. Da mesma forma proposta para o novo WIP, tratou-se de um novo arranjo das operações, adequando os tempos por postos com o Tempo Takt. 
Figura 05 - Fluxograma das operações - Mapa futuro - Quantidade de Bielas em WIP

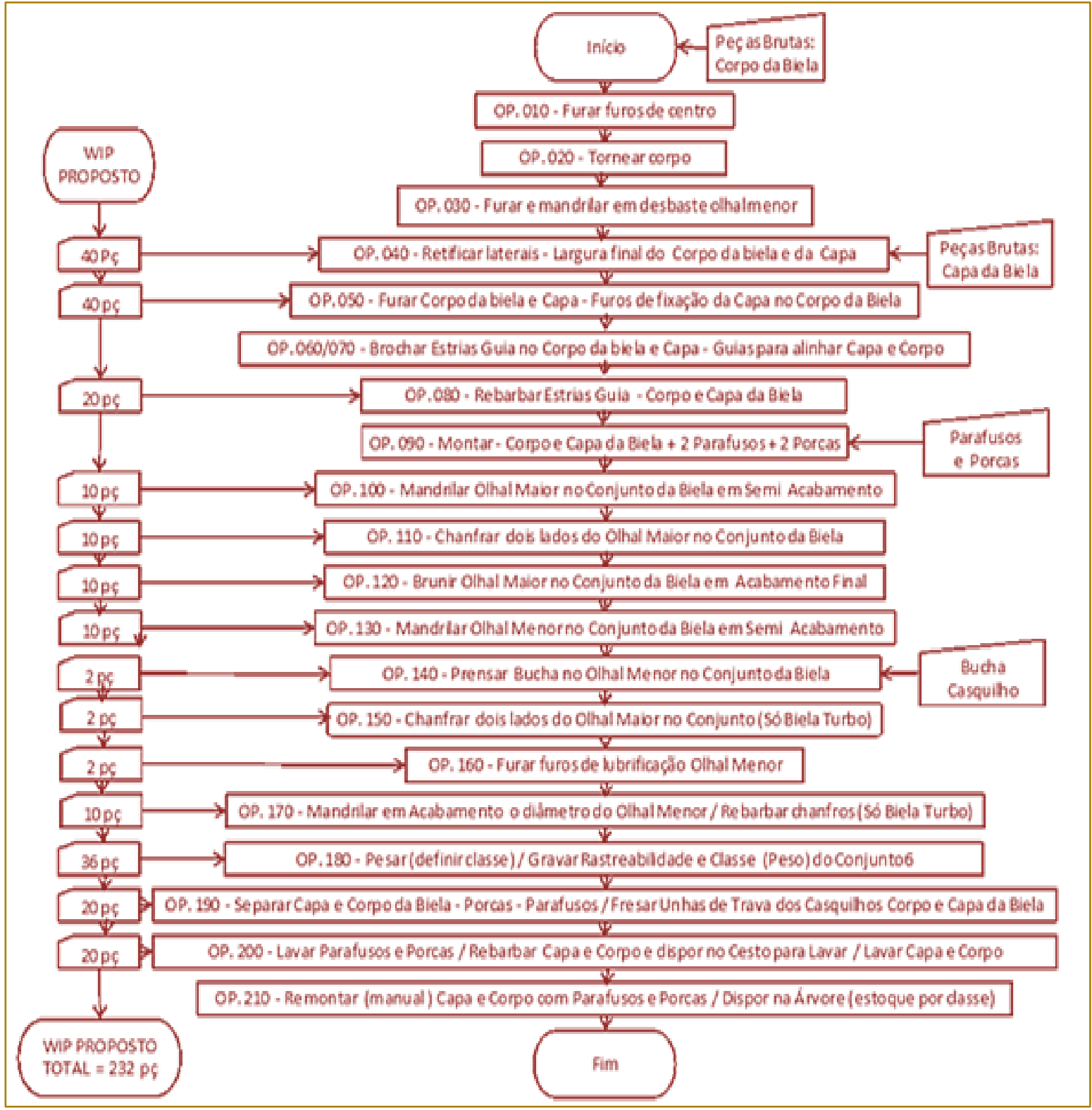

Fonte: Elaborado pelos autores

Como se vê na Figura 6, a melhor configuração para o balanceamento da célula ocupa 8 operadores com adequada proporção de tempos para o fluxo futuro. 
Figura 06 - Balanceamento das operações - 8 Postos de trabalho e 8 operadores

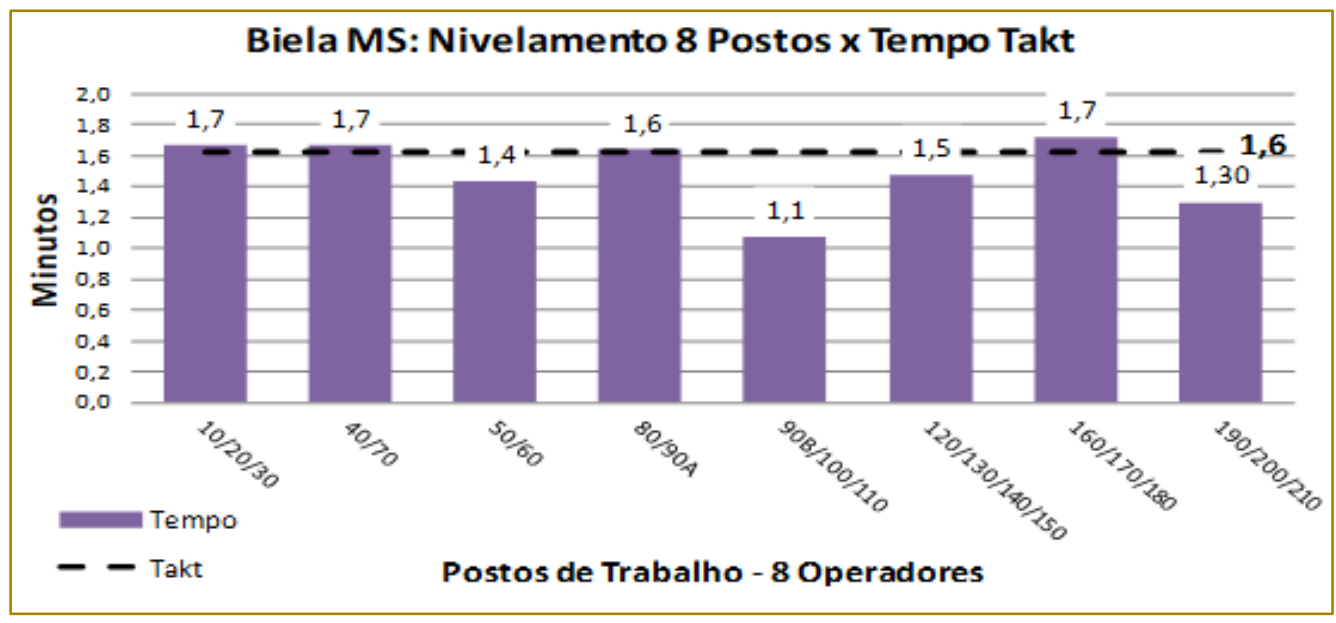

Fonte: Elaborado pelos autores

Esta configuração torna obrigatório o ritmo de retirada de peças da célula em cadência contínua de produção. Nos postos onde se verifica o tempo de 1,7 minutos, acima do tempo takt, há respaldo nos fatores de produtividade nos postos de menor tempo, cobrindo a capacidade produtiva necessária.

Figura 07 - Mapa do Fluxo de Valor Futuro

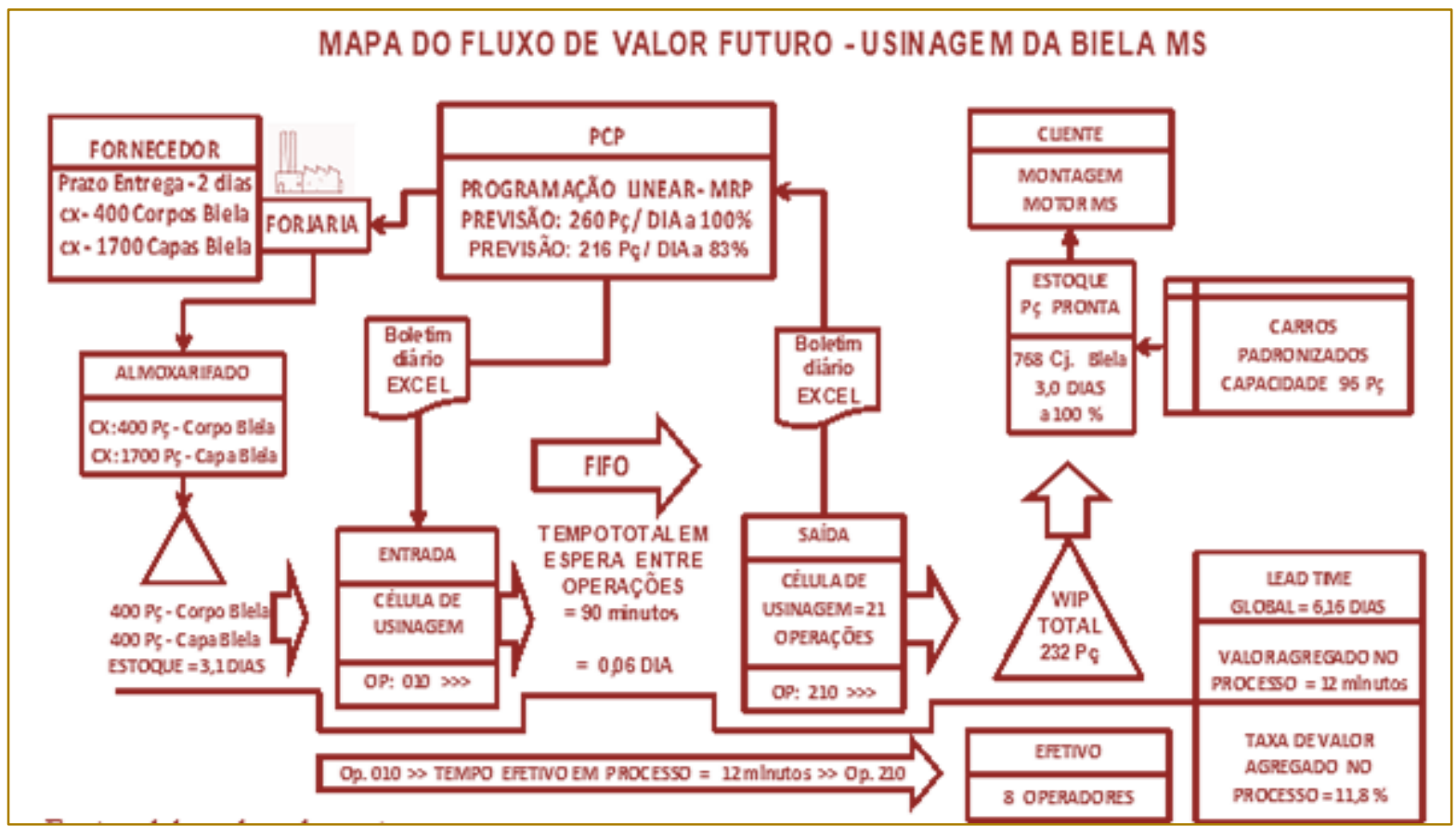

Fonte: Elaborado pelos autores

O Mapa do estado futuro visto na Figura 7 , está baseado na previsão anual de produção e o consequente desdobramento para a produção diária, sincronizado com a demanda e o redimensionamento dos estoques nos Carros-Árvore.
Na sequência tratou-se do dimensionamento da produção frente a demanda. Na Tabela 2, vê-se os dados gerais dos fatores que influenciam no desempenho da produção. 
Tabela 2 - Dimensionamento - capacidade, eficiência e taxa de saída de peças

\begin{tabular}{|c|c|c|}
\hline & Biela NA & Biela TURBO \\
\hline Capacidade Carros -Árvore & $96 \mathrm{pc}$ & $96 \mathrm{pc}$ \\
\hline Tempo de processamento & $12 \mathrm{~min}$ & \\
\hline Takt & $1,6 \mathrm{~min}$ & \\
\hline Takt com ineficiência & $1,96 \mathrm{~min}$ & \\
\hline Tempo disponivel por dia & $424 \mathrm{~min}$ & \\
\hline Duração da embalagem (carro) & $0,6 \mathrm{dia}$ & 1,5 dia \\
\hline Demanda (Montagem + Reposição) & $216 \mathrm{pç} / \mathrm{dia}$ & \\
\hline Percentual de Biela Turbo & & $15 \%$ \\
\hline Percentual de Biela Aspirada & $85 \%$ & \\
\hline Tempo disponivel & \multicolumn{2}{|c|}{$7,07 \mathrm{~h} / \mathrm{dia}-424 \mathrm{~min} / \mathrm{dia}$} \\
\hline Eficiência & \multicolumn{2}{|l|}{$0,83 \%$} \\
\hline Produção projetada a $100 \%$ & $260 \mathrm{pc}$ & Tx saida $=37 \mathrm{pcc/h}$ \\
\hline Produção demandada a $83 \%$ & $216 \mathrm{pc}$ & Tx saida $=31 \mathrm{pc} / \mathrm{h}$ \\
\hline
\end{tabular}

Fonte: Elaborado pelos autores

Tudo se inicia a partir da previsão anual de produção, onde se toma os números para cálculo da produção prevista atualizada mensalmente e a consequente produção diária.

Em razão das melhorias implementadas, todos carros-árvore foram dimensionados para 96 peças e a partir do dimensionamento da produção, estabeleceu-se critério de cores no estoque. A padronização do estoque e critério de cores estabelece o momento de produzir a partir da demanda sinalizada pela devolução de carros-árvore vazios da montagem, conforme Figura 08.

Figura 08 - Critério de cores - Estoque - Carros-árvore 96 peças (Kanban)

\begin{tabular}{|c|c|c|c|c|c|c|}
\hline $\begin{array}{l}\text { PADRÃO de CORES } \\
\text { ESTOQUE }\end{array}$ & $\underset{\text { Aspirada }}{\mathrm{NA}}$ & $\begin{array}{c}\text { № } \\
\text { Carros }\end{array}$ & $\underline{\text { Turbinada }}$ & $\begin{array}{c}\text { № } \\
\text { Carros }\end{array}$ & $\begin{array}{l}\text { Máximo no } \\
\text { ESTOQUE } \\
\text { NA + TURBO }\end{array}$ & $\begin{array}{c}\text { Critério das Cores: } \\
\text { FATORES }\end{array}$ \\
\hline Verde & 192 & 2 & 96 & 1 & 288 & $\begin{array}{c}\text { Atendimento da } \\
\text { demanda de consumo }\end{array}$ \\
\hline Amarela & 192 & 2 & 96 & 1 & 288 & \begin{tabular}{|c|} 
Conhecidos: \\
manutençăo, produtividade, \\
set-up, motor especial
\end{tabular} \\
\hline Vermelha & 192 & 2 & 0 & 0 & 192 & $\begin{array}{l}\text { Não conhecidos (outros): } \\
1 \text { Dia de Consumo }\end{array}$ \\
\hline Totais & 576 & 6 & 192 & 2 & 768 & ESTOQUE TOTAL \\
\hline
\end{tabular}

Fonte: Elaborado pelos autores

O critério de produção está claro, o carroárvore devolvido vazio é o Kanban da Usinagem, autorizando assim a produção até o preenchimento do estoque que terá no máximo 768 peças. Uma vez que o estoque esteja preenchido, a produção de bielas deve parar, não há sentido produzir sem consumo que sinaliza a ordem de produção. De outra forma, uma vez chegando à cor vermelha, entende-se que o estoque atende um dia de consumo na montagem. 
Uma vez iniciado o processo, a evolução é inevitável. O processo de MFV dá a nítida noção da aplicação das quatro etapas, da escolha do objeto de estudo bAaté a consolidação do estado futuro (ROTHER E SHOOK, 2003; WOMACK E JONES, 2004).

Os relatos e respectivos ganhos deste trabalho são:

- Redução de 51\% no WIP. Representada por uma diminuição de 474 para 232 peças dentro do processo. Além da redução da quantidade de peças, verifica-se a diminuição da possibilidade de erro e de confusão no processo;

- Balanceamento das operações de acordo com o Tempo Takt. Agora de forma científica o estabelecimento dos 8 postos de trabalho nivelados com os tempos, tarefas distribuídas com disciplina e a cadência das operações, visa a ótima utilização do tempo disponível para produção;

- Redução de 10 operadores para 8, possibilitando utilizá-los em novas atividades valorizando o corpo operacional;

- Redução do Lead Time em 50\%. Redução de 12,3 dias para 6,16 dias tornou o espaço entre a produção de bielas e a montagem do motor mais clara pela redução de inventário;

- Redução do tamanho do lote de peças brutas fornecidas. Não viabilizado pela dificuldade em adotar tamanho de embalagem menor que a atual pelo fornecedor;

- Redução do tempo de espera dentro do processo de 408 minutos para 90 minutos;
- A redução da movimentação foi promovida pelo balanceamento e a sincronização entre as operações, pela disposição adequada no fluxo produtivo. Eliminação da dispersão por ociosidade dos operadores no turno de trabalho (atividades que não agregam valor) com a consequente redução de problemas de qualidade;

- A implementação do estado futuro possibilitou o processo puxado pelo cliente Montagem, dimensionado pela demanda, combinado com a adoção da gestão visual no abastecimento e na retirada de peças do estoque. A definição de quantidade padrão de 96 peças e o disparo de produção dado pelo Carro-Árvore como Kanban, associados ao uso de cores, disciplinou e organizou o ambiente no estoque de peças prontas na usinagem;

- A adoção da gestão visual pelo controle hora/hora, disciplinou o controle da taxa de saída de peças prontas e o registro dos eventos que afetam a produção, além de manter a informação disponível para tomada de ações corretivas;

- A eliminação do transporte por empilhadeira pela redução da quantidade de peças nos carros-árvore reduziu a probabilidade de acidentes com danos materiais, além de proporcionar maior segurança no trabalho pela facilidade de transporte manual das peças;

- Redução do inventário com a consequente redução do custo relacionado.

Tabela 03 - Inventário e custo de produção relacionados - Situação Futura

\begin{tabular}{|c|c|c|c|c|c|c|c|c|c|c|c|}
\hline \multicolumn{12}{|c|}{ Inventário e Custos - Situação Futura } \\
\hline \multicolumn{8}{|c|}{ Quantidade de Componentes / Locais } & \multicolumn{4}{|c|}{ Custos } \\
\hline & & \begin{tabular}{|l|} 
Peças por \\
Conjunto
\end{tabular} & \begin{tabular}{|c|} 
Almo- \\
xarifado
\end{tabular} & \begin{tabular}{|c|} 
Entrada \\
Usinagem
\end{tabular} & \begin{tabular}{|c|} 
Entre \\
Operaçōes
\end{tabular} & \begin{tabular}{|c|} 
Conjuntos \\
Prontos
\end{tabular} & \begin{tabular}{|c|} 
No Total \\
Peccas
\end{tabular} & Unitário & $\begin{array}{l}\text { Total por } \\
\text { Conjunto }\end{array}$ & $\begin{array}{l}\text { Totalem } \\
\text { Estoque }\end{array}$ & Total Geral \\
\hline \multirow{5}{*}{ a } & Corpo Biela & 1 & 400 & 400 & 232 & 768 & 1.800 & $R \$ 21,55$ & $R \$ 21,55$ & RȘ $38.790,00$ & \multirow{5}{*}{$\mathrm{R} \$ \mathbf{7} 7.320,00$} \\
\hline & Capa Biela & 1 & 1.700 & 400 & 232 & 768 & 3.100 & $\operatorname{RS} 8,86$ & 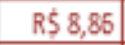 & RS $27.466,00$ & \\
\hline & Parafuso & 2 & & & & 768 & 1.536 & $R \$ 2,60$ & $R \$ 5,20$ & RȘ 3.993,60 & \\
\hline & Porca & 2 & & & & 768 & 1.536 & $\operatorname{R} \$ 1,15$ & $R \$ 2,30$ & $\operatorname{R} \$ 1.766,40$ & \\
\hline & Bucha & 1 & & & & 768 & 768 & $R S 3,00$ & $R \$ 3,00$ & RS 2.304,00 & \\
\hline $\mathrm{b}$ & $\begin{array}{l}\text { Custo das } \\
\text { Operaçōes }\end{array}$ & 1 & & & & 768 & 768 & RS 27,13 & $R \$ 27,13$ & RS\$ 20.835,84 & $R \$ 20,835,84$ \\
\hline
\end{tabular}

Fonte: Elaborado pelos autores 
Os resultados da redução no inventário, promovidos pela implementação de melhorias são verificados pela comparação da Tabela 1 com a Tabela 3. Houve redução de estoque de corpos da biela no almoxarifado de 1700 para 400 peças, o estoque em processo passou de 474 Capas e Corpos da Biela para 232 de cada e de 928 conjuntos prontos à disposição para a montagem passou-se a ter 768. Em relação aos custos, verificou-se a redução de $R \$ 116.436,17$ para $R \$ 74.320,00$ em peças e o custo de $R \$ 25.176,64$ relativo ao processo de produção dos conjuntos foi reduzido para $R \$ 20.835,84$. De um total geral de $R \$ 141.612,81$ de custo de inventário na fábrica passou para $R \$$ 95.155,84, proporcionando uma redução no custo da operação significativa de $\mathrm{R} \$ \quad 46.456,97$ equivalente a $32,8 \%$.

O processo de melhoria não cessa nesta etapa, há inúmeras oportunidades a explorar. O WIP praticado carece de revisão, a forma de estocar as peças merece estudo para facilitar o abastecimento na montagem, de preferência com quantidade menor. O Layout das operações na célula de usinagem merece um estudo aprofundado para identificar oportunidades de melhoria para tornar o ritmo de produção aprimorado. A manutenção do padrão atual estará assegurada pela incorporação da nova cultura e pela proatividade da equipe de trabalho. Portanto, o processo de evolução está assegurado e apto a novas abordagens.

\section{CONCLUSÃO}

Quanto aos objetivos propostos, há a nítida percepção que houve evolução no ambiente objeto do estudo de caso. A aplicação das ferramentas de melhoria aliadas a participação dos agentes do processo destaca o sucesso do projeto.
Resultados significativos foram obtidos a exemplo de tornar o processo puxado pelo processo cliente. Redução de 50\% no Lead Time, redução do WIP em 51\%, balanceamento das operações. Salienta-se a grande evolução na taxa de valor agregado de $2,2 \%$ para $11,8 \%$, demonstrando a importância da adoção de novas práticas de forma responsável, uma vez que este indicador gira em torno de $2 \%$ a $5 \%$ em processos produtivos de referência. A célula alcançou estabilidade necessária para empreender em um processo de melhoria contínua.

Obviamente o processo de mudança não para, há muito que realizar em amplos aspectos, haja visto que tanto em conhecimento quanto culturalmente a equipe mudou. Houve quebra de barreiras, de hábitos e de práticas arraigadas por longo tempo. Com parcimônia, fatos e dados e com a clareza das informações conseguiu-se atingir um patamar elevado de participação do grupo, tanto no aspecto operacional como no de apoio à produção.

Diversas são as ferramentas oferecidas e as metodologias desenvolvidas nos sistemas modelares como é o STP. A cultura organizacional é exclusiva, haja visto o presente ambiente de estudo. Não há como repudiar práticas nesses espaços, cabe respeito e avaliação dos verdadeiros motivadores para existência de determinada prática. Isto posto, torna o objeto da pesquisa mais atraente, cabe ao pesquisador envidar esforços na identificação desses motivadores e uma vez conhecedor da realidade, terá instrumental valioso para desenvolvimento de novas teses. Ele estará apto a influenciar a cultura organizacional na adoção de um modelo próprio de desenvolvimento.

\section{REFERÊNCIAS}

[1] ANTUNES, Jr. et al. Sistemas de produção: conceitos e práticas para projeto e gestão da produção enxuta. Porto Alegre: Bookman, 2008.

[2] ANTUNES, Jr. Et al. Uma revolução na produtividade: a gestão lucrativa dos postos de trabalho. Porto Alegre: Bookman, 2013.

[3] HOPP, W.J.; SPEARMAN, M.L. Factory Physics: foundations of manufcturing management. 2. ed. Boston: McGraw-Hill, 213 - 227, 2000. 
[4] MACHADO, M. C. Princípios enxutos no processo de desenvolvimento de produtos: proposta de uma metodologia para implementação. São Paulo, Tese (Doutorado) Escola Politécnica da Universidade de São Paulo, Departamento de Engenharia de Produção, Universidade de São Paulo.2006.

[5] MARTINS, G.H.; CLETO, M.G. Mapeamento do fluxo de valor e a análise do valor agregado: um estudo de caso no setor de embalagens de papel no brasil. Conhecimento Interativo, v.10, n.1, p.59-83, jan./jun. 2016.

[6] MIGUEL, P.A. C.; FLEURY, A.C.C. Metodologia de pesquisa em engenharia de produção e gestão de operações. 2. ed. Rio de Janeiro: Elsevier, 2012.

[7] OHNO, T. Sistema Toyota de Produção: além da produção em larga escala. Porto alegre: Bookman Companhia, 1997.

[8] PERGHER, I.; VACCARO, G.L.R. Impacto da preempção de ordens na lógica CONWIP: um estudo baseado em simulação e análise de cenários. XVI Simpósio de Pesquisa Operacional e Logística da Marinha, Anais SPOLM 2013. Rio de Janeiro (RJ): 2013.

[9] ROTHER, M.; SHOOK, J. Aprendendo a enxergar: mapeando o fluxo de valor para agregar valor e eliminar o desperdício. São Paulo: Lean Institute Brasil, 2003.
[10] SALGADO, E. G.et al. Análise da aplicação do mapeamento do fluxo de valor na identificação de desperdícios do processo de desenvolvimento de produtos. Gestão e Produção, v.16, n.3, p.344-356, 2009.

[11] SANTOS, L.C.; GOHR, C.F.; SANTOS, E.J. Aplicação do mapeamento do fluxo de valor para a implantação da produção enxuta na fabricação de fios de cobre. Revista Gestão Industrial.v.07, n.04: p.118-139, 2011.

[12] SERENO, B. et al. Método híbrido CONWIP/KANBAN: um estudo de caso. Gestão e Produção, v.18, n.3, p.651-672, 2011.

[13] SHINGO, S. Sistemas de produção com estoque zero: o sistema Shingo para melhorias contínuas. Porto Alegre: Bookman, 1996.

[14] SOHAL, A. S.; EGGLESTONE, A. Lean production: experience among australian organizations. International Journal of Operations \& Production Management, v. 14, n. 11, p. 35-51, 1994.

[15] SPEARMAN, M.L., WOODRUFF, D.L.; HOPP, W.J. CONWIP: a pull alternative to kanban. The International Journal of Production Research, 28(5), 879-894.1990.

[16] WOMACK, J. P.; JONES, D. T. A mentalidade enxuta nas empresas: elimine o desperdício e crie riqueza. Rio de Janeiro: Elsevier, 2004. 


\section{Capítulo 7}

\section{PADRONIZAÇÃO PROCESSO NA ÁREA DE MATERIAIS}

\section{Luana Weiand Fazolo}

\section{Tatiane Pereira Librelato}

Resumo: A finalidade deste artigo é identificar os impactos da padronização descritiva de materiais na gestão de estoque, identificando seus ganhos qualitativos, exemplificando o processo de padronização descritiva de materiais e analisando seus resultados. Esta pesquisa é de natureza aplicada e tem como objetivo de estudo descritivo, com escopo de estudo de caso, a qual expõe os resultados obtidos a partir da investigação realizada apresentando a aplicação da metodologia de padronização descritiva de materiais nos itens de almoxarifado das empresas analisadas e a comparação da descrição antes e depois da padronização descritiva, expondo os dados coletados na pesquisa. Este estudo foi realizado com múltiplas unidades de análise, através do cadastro de itens de almoxarifado de seis empresas de três ramos distintos, duas empresas de mineração, duas empresas de logística e duas empresas fabricantes de embalagens Com a padronização foi identificado melhorias no processo de compras, redução de duplicidades de descrições e consequentemente redução de itens duplos fisicamente, acuracidade de estoque, enriquecimento das descrições com maior número de informação técnicas identificando o item com maior assertividade. Com a metodologia de padronização descritiva de materiais a gestão dos itens de almoxarifado reduz custo e gera ganhos de qualidade nos processos

Palavras Chave: PDM, Padronização descritiva, Catalogação, Codificação. 


\section{INTRODUÇÃO}

As organizações têm a necessidade de comprar certo, pelo melhor preço e da forma mais rápida. Desta forma, é necessário que a descrição do material esteja correta, porém por muito tempo, esta atividade foi tratada como supérflua. A gestão adequada do estoque pode trazer benefícios econômicos para a organização, através de economia de investimentos em estoque. Salienta Wanke (2012, p.1) "As perguntas-chave que a gestão de estoque se propõe a responder, normalmente sujeitas a uma variedade de circunstâncias, são: quando pedir, quanto pedir e quanto manter em estoques de segurança". Portanto, devem ser estocados apenas os materiais necessários, nas quantidades corretas, para que não haja mobilização de ativo da empresa em estoques desnecessários.

A metodologia de padronização descritiva de materiais faz com que todo material cadastrado tenha características obrigatórias que atendam suas necessidades fiscais. Estas características diferenciarão um item do outro, evitando duplicidades. Assim, sendo é possível "comprar" o item certo para o lugar certo, otimizando as compras do almoxarifado e gerando uma administração de materiais de qualidade. O PDM identifica, classifica e enriquece o cadastro da empresa de forma organizada a fim de que se elimine as multiplicidades dos materiais, que se possibilite conferir com maior rapidez e qualidade na proporção que a otimização da administração de materiais (SANTOS, 2012, p.8).

A administração de materiais que é o tema central deste artigo, se bem administrada, tanto em termos negociação e estratégias de compra quanto de dimensionamento de estoque e sistema de distribuição, poderá trazer significativos ganhos para a organização (GONÇALVES, 2013), mas para que se possa comprar bem, é necessário que se tenha a descrição correta do item.

O objetivo da classificação de materiais é promover um processo de identificação, codificação, cadastramento e catalogação dos materiais de uma organização. A primeira fase da classificação é a identificação que analise os dados do material caracterizando sua individualidade. A partir da especificação estruturada será possível identificar cada item da empresa (GONÇALVES, 2013). Portanto, a catalogação irá estruturar de forma sistemática os materiais garantindo a qualidade da informação e uniformização dos dados.

Este trabalho tem por objetivo analisar o impacto das descrições padronizadas de materiais nos processos internos da gestão de estoques e para isso estrutura-se em quatro seções: Na seção 2 é feita uma revisão sobre trabalhos relacionados à padronização descritiva de materiais, na seção 3 a metodologia utilizada para esta pesquisa seção 4 finaliza o artigo com a apresentação dos resultados obtidos na pesquisa.

\section{REFERENCIAL TEORICO}

\subsection{ADMINISTRAÇÃO DE MATERIAIS}

A administração de materiais é responsável por todos os materiais existentes na empresa, matéria prima, produtos específicos, material de escritório, de limpeza, entre outros e deve buscar sempre melhor preço para estes itens. Segundo o entender de Gonçalves (2013, p. 4), "Uma administração de materiais bem estruturada permite a obtenção de vantagens competitivas [...]", estas vantagens se darão através de redução de custos, da redução dos investimentos em estoques, nas melhorias nas condições de compras mediante negociações com os fornecedores e da satisfação dos clientes e consumidores em relação aos produtos oferecidos pela empresa, podemos atribuir à administração de materiais o objetivo de maximização de retorno sobre capital investido e minimização sobre a necessidade de investimento de capital no estoque (GONÇALVES, 2013). Então a administração de materiais terá oportunidades de melhoria de preços, diminuindo a necessidade de investimento em estoque, aumentando assim o lucro da organização.

Afirma Silva et al (2014) "A gestão de materiais é uma atividade que mantém as evoluções da organização empresarial através da administração dos estoques, a qual dá suporte para as áreas que necessitam destes materiais, prevendo danos e prejuízos devido ao armazenamento, custos e outros fatores". Para estabelecer o que contempla a administração de materiais é necessário conhecer suas funções. Dentro da administração de materiais podemos montar uma cadeia de atividade que trará o pleno funcionamento da organização: cadastramento, gestão, compras, 
recebimento e inventário físico (JUNIOR, 2010). Em concordância Silva e Kons estabelecem que a administração de materiais tenha total abrangência dos fluxos de entrada e saídas de materiais da empresa e desta forma está ligado diretamente ao bom funcionamento da organização.

\subsection{PADRONIZAÇÃO DESCRITIVA DE MATERIAIS}

Para que se estabeleça a padronização descritiva de materiais é necessário estabelecer as regras de catalogação e nomenclaturas que serão utilizadas. Segundo Dias (2012, p. 170), "A normalização ocupase da maneira pela qual devem ser utilizados os materiais em suas diversas finalidades e da padronização e identificação do material e que tanto o usuário como o almoxarifado possam requisitar e atender aos itens, utilizando a mesma terminologia [...]". Para uma padronização descritiva efetiva são necessários alguns passos: (i) padronização dos nomes básicos; (ii) padronização dos dados técnicos; (iii) estruturação de PDMs; (iv) elaboração das regras de catalogação. Na medida em que estes passos são dados à estruturação da padronização vai sendo executada, é necessário estabelecer os termos que serão utilizados na composição dos padrões descritivos e na composição dos itens $e$ as regras básicas para a padronização.

As regras para a catalogação precisam ser claras e seguidas, para que a padronização ocorra de forma efetiva. Segundo Deus (2013, p. 42) "[...] a especificação (descrição) é a identificação dos aspectos mais relevantes de um produto, que ajuda a classificá-lo de acordo com algum critério de interesse circunstancial. Para que a descrição seja feita de maneira adequada, é preciso considerar alguns critérios ou regras, que ajudam a tornar o processo preciso e eficiente [...]". Desta forma algumas regras serão estabelecidas para esta metodologia, é importante que todas as regras sejam estabelecidas antes do cadastro dos itens, para que não corram retrabalhos posteriores. Conforme demonstra Figura 1.

Figura 1: Regras de catalogação

\begin{tabular}{|c|l|}
\hline$N^{\circ}$ & \multicolumn{1}{|c|}{ Regra } \\
\hline 2 & Sempre que houver dados numéricos utilizaremos duas casas após a vírgula; \\
\hline 3 & Os dados técnicos e nomes válidoss devem ser utilizados no singular; \\
\hline 4 & Os dados técnicos e nomes válidos devem ter abreviaturas; \\
\hline 5 & Não deve-se utilizar caracteres especiais na descrição; \\
\hline 6 & Não serão utilizados acentos; \\
\hline 7 & Não utilizar termos genéricos; \\
\hline 8 & Não utilizar marcas registradas como valores; \\
\hline 9 & Não utilizar preposições; \\
\hline 10 & Os termos com, sem e para, devem ser utilizados com barra (c/, s/, p/); \\
\hline 11 & Evitar termos estrangeiros. \\
\hline 12 & Será utilizado sempre caixa alta, jamais deve ser utilizadas letras minúscula. \\
\hline
\end{tabular}

A padronização descritiva fortalece o catálogo de materiais do almoxarifado de forma a evitar compras erradas, cadastros duplos e investimento em itens desnecessários. O PDM identifica, classifica e enriquece o cadastro da empresa de forma organizada a fim de que se elimine as multiplicidades dos materiais, que se possibilite conferir com maior rapidez e qualidade na proporção que a otimização da administração de materiais (SANTOS, 2012, p.8). Portanto, o ganho gerado para administração de materiais será alto, gerando lucratividade nas aquisições e saneando o estoque já existente, para que este ciclo seja continuo é necessário que o cadastro mantenha esta sistematização 
O PDM irá definir quais os dados técnicos irão compor a descrição e em qual ordem estará disposta na descrição. Desta forma o padrão descritivo de materiais deverá ser composto pelos dados que diferenciem um item do outro dentro de mesmo padrão e que sejam relevantes para identificação, compra e classificação fiscal. O padrão descritivo é definido pelo nome válido, o qual irá agrupar itens semelhantes, mantendo uma uniformização das descrições, a diferenciação entre os itens será obtida pelas características de seus atributos e materiais que tiverem atributos idênticos, serão identificados como duplicidades.

\subsubsection{ESTRUTURAÇÃO PDM}

Os PDMs devem ser previamente estruturados para que os itens possam ser catalogados de acordo com a demanda do almoxarifado, é importante que todo o cadastro seja inserido dentro desta metodologia. Para se classificar o universo de materiais com que lida uma ou diversas empresas, se faz necessário montar uma "árvore de PDM" (SANTOS, 2011, p. 10). Esta árvore será composta pelos dados utilizados na composição das descrições dos itens. O padrão é quem irá definir quais os dados são necessários para o cadastro e isso se tornará uma regra, todo dado do padrão será mandatário para seu cadastro. Qualquer material poderá ser descrito em um padrão descritivo, como por exemplo: rolamento, válvula, motor, lâmpada, anel. Para estes nomes válidos podem-se definir dados técnicos conforme exemplo da Figura 2.

Figura 2: Padrão descritivo de rolamento

\begin{tabular}{|c|c|}
\hline \multicolumn{2}{|c|}{ NOME VÁLIDO } \\
\hline TIPO ROLAMENTO & ESFERA \\
\hline CARGA & RADIAL \\
\hline CARREIRA & UMA CARREIRA \\
\hline MATERIAL GAIOLA & ACO LIGA \\
\hline FURO & CILINDRICO \\
\hline DIAMETRO INTERNO & $17,00 \mathrm{MM}$ \\
\hline DIAMETRO EXTERNO & $35,00 \mathrm{MM}$ \\
\hline LARGURA & 10,00MM \\
\hline PROTECAO & DUAS PLACAS PROTECAO \\
\hline FOLGA & NORMAL \\
\hline REFERENCIA & $60032 Z$ \\
\hline FABRICANTE & SKF \\
\hline
\end{tabular}

\section{METODOLOGIA}

O delineamento básico da pesquisa identifica como o estudo se estrutura e qual o seu objetivo, a classificação da pesquisa está dividida em: natureza, método cientifico, objetivo do estudo e abordagem, a pesquisa caracterizou-se conforme Figura 3. 
Figura 3: Delineamento Básico da Pesquisa

\begin{tabular}{|c|c|c|}
\hline Critério & Classificação & Característica \\
\hline Natureza & Aplicada & $\begin{array}{l}\text { Procura produzir conhecimentos para aplicação prática } \\
\text { dirigidos à solução de problemas específicos. }\end{array}$ \\
\hline Método cientifico & Indutivo & $\begin{array}{l}\text { O argumento passa do particular para o geral, uma vez que as } \\
\text { generalizações derivam de observações de casos da realidade } \\
\text { concreta }\end{array}$ \\
\hline Abordagem & Qualitativa & $\begin{array}{l}\text { O ambiente natural é fonte direta para coleta de dados, } \\
\text { interpretação de fenômenos e atribuição de significados. }\end{array}$ \\
\hline $\begin{array}{l}\text { Objetivo do } \\
\text { estudo }\end{array}$ & Descritiva & $\begin{array}{l}\text { Expõe as características de uma determinada população ou } \\
\text { fenômeno, demandando técnicas padronizadas de coleta de } \\
\text { dado. }\end{array}$ \\
\hline \multirow[b]{2}{*}{$\begin{array}{l}\text { Procedimento } \\
\text { Técnico }\end{array}$} & $\begin{array}{l}\text { Pesquisa } \\
\text { Bibliográfica }\end{array}$ & Concebida a partir de materiais já publicados \\
\hline & Estudo de Caso & $\begin{array}{l}\text { Representa a estratégia preferida quando colocamos questões } \\
\text { do tipo "como" e "por que", quando o pesquisador tem pouco } \\
\text { controle sobre os eventos e quando o foco se encontra em } \\
\text { fenômenos contemporâneos inseridos em algum contexto da } \\
\text { vida real. }\end{array}$ \\
\hline
\end{tabular}

Fonte: Adaptado de Prodanov (2013)

Logo esta pesquisa pode ser definida como de natureza aplicada, pois seu objetivo é o desenvolvimento de uma metodologia de padronização descritiva implementada aos itens de almoxarifado.

Apresenta método de pesquisa indutivo, pois suas conclusões derivam da aplicação do método na base de dados de seis empresas. A partir da análise dos dados de tais empresas, busca-se evidenciar a importância da padronização descritiva de materiais.

A abordagem da pesquisa foi qualitativa valendo-se do referencial teórico analisado e entrevistas efetuadas, a partir dos dados gerados pelo saneamento serão qualificados os materiais do almoxarifado, serão analisadas comparativas por amostragem de cadastros aplicados as seis empresas.

O objetivo de estudo da pesquisa caracterizase como descritivo foi avaliado os dados coletados, informações do saneamento dos itens de almoxarifado de seis empresas de três ramos distintos. Os procedimentos técnicos da pesquisa definem-se como pesquisa bibliográfica e estudo de caso.

Pesquisa bibliográfica, o referencial teórico baseia-se em material já publicado para validação das informações, utilizando-se de artigos científicos, livros e material disponível na internet, foi inserido na revisão da literatura estudos sobre gestão de estoques e materiais, métodos de padronização descritiva e logística, apresentados os principais métodos de catalogação, simplificação, especificação, normalização, padronização e codificação.

Estudo de caso é com múltiplas fontes de evidências (dados) e cruzamento dos dados recolhidos (triangulação de dados). Onde é analisada a base de dados de seis empresas de três ramos diferentes: logística, mineração e embalagens, as empresas analisadas atendem o critério de utilização da metodologia de padronização de descritivo para saneamento dos itens de almoxarifado, pode assim ser analisado o banco de dados antes da padronização e após a padronização.

Para preservar a identidade das empresas as mesmas foram denominadas como Empresa A, Empresa B, Empresa C, Empresa D, Empresa E e Empresa F. As empresas A e B atuam no ramo logístico, as empresas $C$ e $D$ atuam no ramo de mineração e as empresas E e F são fabricantes de embalagens.

\subsection{MÉTODO DE COLETA DE DADOS}

Os procedimentos adotados para realização da pesquisa estão estruturados de forma linear, porém interativas, formando o método de trabalho adotado. Esta estrutura divide-se em quatro etapas: preparação, coleta, 
análise, compartilhamento. Cada fase está estruturada com uma sequência de passos para obtenção da pesquisa. Conforme Figura 4.

Figura 4: Método de Trabalho

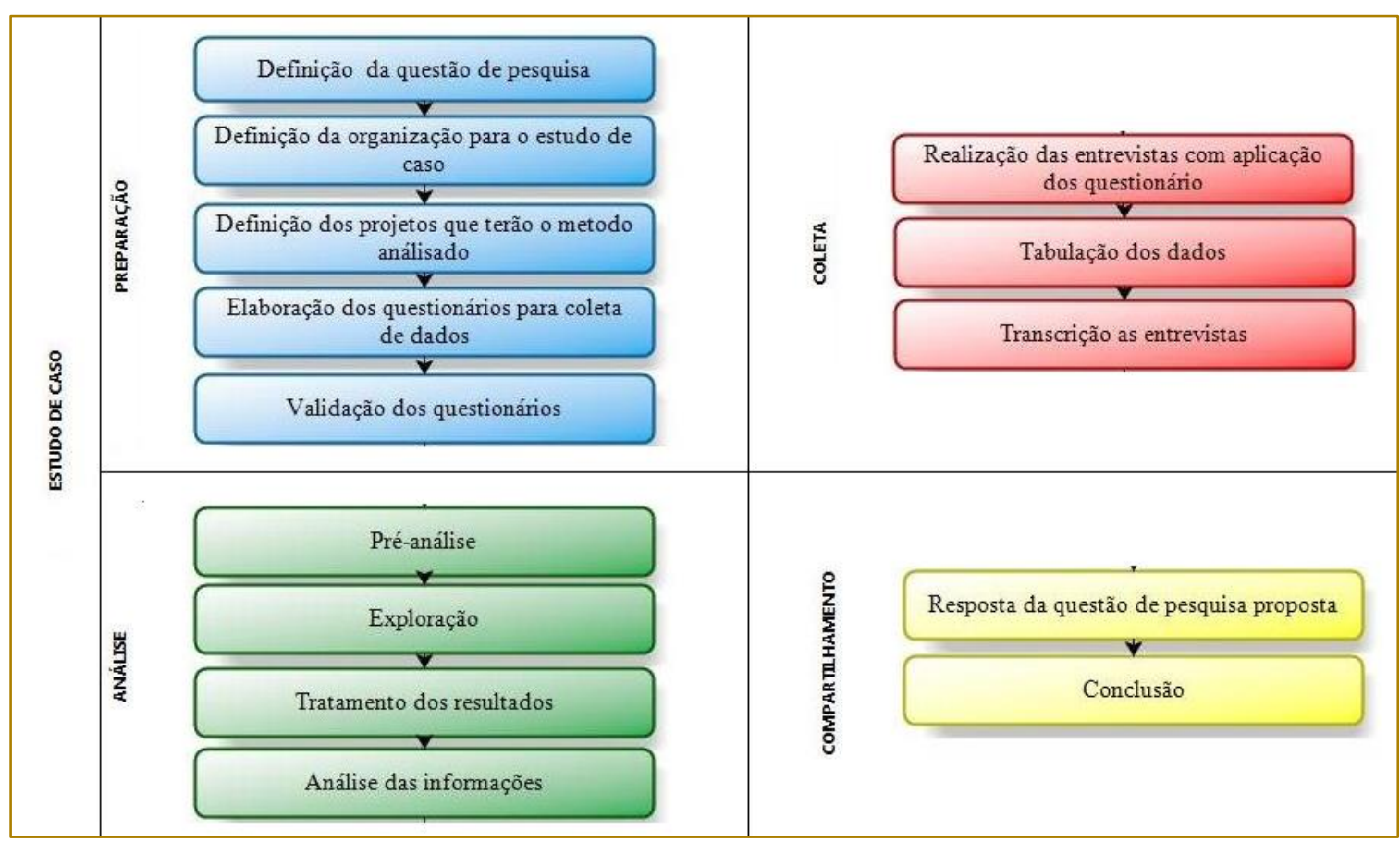

\subsubsection{PREPARAÇÃO}

Revisão da literatura para formulação do problema e escolha da empresa que será aplicada o estudo de caso e consequentemente os projetos que terão o método aplicado. Sendo dividida esta fase em cinco etapas: (i) definição da questão de pesquisa; (ii) definição dos projetos para estudo de caso; (iii) definição dos entrevistados; (iv) elaboração dos questionários para coleta de dados; (v) validação dos questionários

\subsubsection{DEFINIÇÃO DA QUESTÃO DA PESQUISA}

Definição do problema de pesquisa em questão: Como a padronização descritiva de materiais pode contribuir para a gestão de materiais de almoxarifado em uma empresa industrial?

Definiu-se o objetivo geral e três objetivos específicos: a) Explicar o que envolve a padronização descritiva; b) Identificar possíveis ganhos qualitativos da padronização descritiva nos processos internos da gestão de estoques; c) Analisar a efetividade e desempenho do modelo de padronização descritiva aplicado na gestão de materiais nos processos internos. A partir destas definições deu-se início a pesquisa do referencial teórico.

\subsubsection{DEFINIÇÃO DOS PROJETOS PARA O ESTUDO DE CASO}

Após a definição da pesquisa, fixou-se a utilização do banco de dados da Integra Consultoria S/S Ltda. para aplicação do projeto. A escolha da Integra deu-se pela empresa ter mais de trinta projetos com a metodologia de padronização descritiva implantada.

Este estudo de caso é com múltiplas unidades de análise, são seis bancos de dados para serem trabalhados, serão analisados o banco de dados de duas empresas de logísticas, duas empresas mineradoras e duas empresas que fabricam embalagens. Os bancos de dados dessas empresas são de tamanhos diferentes conforme demonstra Figura 5. 
Figura 5 Tamanho Almoxarifado

\begin{tabular}{|c|c|c|}
\hline \multirow{2}{*}{$\begin{array}{c}\text { Empresa } \\
\text { A }\end{array}$} & \multirow{2}{*}{ Ramo } & $\begin{array}{c}\text { Tamanho } \\
\text { Almoxarifado }\end{array}$ \\
\cline { 1 - 1 } B & Logística & +-112 mil itens \\
& \multirow{2}{*}{ Mineração } & +-12 mil itens \\
\cline { 1 - 1 } C & & +-30 mil itens \\
\hline D & \multirow{2}{*}{ Embalagem } & +-31 mil itens \\
\cline { 3 - 3 } E & & +-22 mil itens \\
\hline
\end{tabular}

\subsubsection{DEFINIÇÃO DOS ENTREVISTADOS}

Os entrevistados foram definidos através de dois critérios: sua utilização efetiva da descrição do material, que utilizam a descrição no dia a dia (compras, almoxarifado) e pessoas que participaram do projeto, são os gestores que contrataram a
Integra para fazer a catalogação. Em cada projeto foram definidos os entrevistados de acordo com sua participação no projeto de saneamento e atuação, conforme demonstrado na Figura 6.

Figura 6: Seleção de Entrevistas

\begin{tabular}{|c|c|}
\hline Projeto & $N^{\circ}$ entrevistados \\
\hline A & 8 \\
\hline B & 6 \\
\hline C & 14 \\
\hline D & 10 \\
\hline E & 6 \\
\hline F & 6 \\
\hline & 50 \\
\hline
\end{tabular}

\subsubsection{ELABORAÇÃO DOS QUESTIONÁRIOS PARA COLETA DE DADOS}

O questionário utilizado nesta pesquisa é composto por doze perguntas sendo quatro perguntas abertas que permitem que 0 informante responda livremente, três perguntas dicotômicas que são limitadas, que apresentam alternativas fixas e cinco perguntas de múltipla escolha (perguntas fechadas), que apresentam uma série de respostas possíveis. A distribuição das questões é demonstrada na Figura 7.

Figura 7: Classificação do questionário

\begin{tabular}{|c|c|}
\hline \multicolumn{1}{|c|}{ Questão } & $\begin{array}{c}\text { Classificação da } \\
\text { pergunta }\end{array}$ \\
\hline $1,3,4$ e 12 & Aberta \\
\hline $2,7,8,10$, e 11 & Múltipla Escolha \\
\hline 5,6 e 9 & Dicotômicas \\
\hline
\end{tabular}

Os questionários foram enviados aos entrevistados pré-definidos, via formulário eletrônico do Google Forms. Em um primeiro momento houve contato via telefone com o 
Gestor do projeto para explicar sobre a pesquisa e solicitar autorização para a realização da mesma. Após o questionário foi enviado via e-mail com apresentação e explicação do mesmo, sendo concedido um prazo de 14 dias para resposta dos entrevistados.

No questionário, as doze questões foram divididas em perfil do entrevistado e conhecimento da padronização descritiva. O questionário está disponível no APÊNDICE AQUESTIONÁRIO.

\subsubsection{VALIDAÇÃO DOS QUESTIONÁRIOS}

A validação dos questionários foi realizada através de apresentação a um especialista da área de catalogação que atuam em projetos da Integra e ao professor orientador do projeto. Foram feitos ajustes nas descrições de perguntas, melhorando o entendimento. As perguntas passaram a ser mais diretas, buscando a informação exata que se quer saber.

Após melhoramento das questões o questionário foi novamente analisado pelo professor orientador, sendo aprovada a versão final. A versão final foi aplicada como teste, o entendimento das questões foi satisfatório.

\subsubsection{COLETA DE DADOS}

Aplicação dos questionários aos 50 entrevistados, nas seis empresas selecionados previamente. Esta fase foi dividida em duas etapas, sendo elas a aplicação dos questionários e a tabulação dos dados coletados.

Após a aplicação dos questionários e o recebimento dos 50 questionários enviados preenchidos, foi feita a tabulação das respostas. Os questionários foram tabulados, sintetizados e ordenados de forma lógica para que seus gráficos e tabelas sejam criados baseados em seus dados coletados.

\subsubsection{ANÁLISE DE DADOS}

Para as perguntas de um a onze foi utilizada a ferramenta Excel® para geração dos gráficos e tabelas e para a pergunta doze foi utilizado à ferramenta Wordle ${ }^{\circledR}$. Todos os gráficos e tabelas foram criados pelo autor com auxílio das ferramentas mencionadas.
A pré análise estabelece o primeiro contato com os questionários já respondidos. Dividindo as respectivas respostas em quadros, divididos por ramo da empresa, setor de atuação e perfil dos entrevistados. Esta fase é analítica e descritiva, analisa os dados que foram tabulados na fase anterior.

Através da proposta de metodologia de padronização descritiva de materiais fundamentada pelo referencial teórico, questionários aplicados, exposição dos relatórios de saneamento e das percepções do pesquisador, feita a análise deste material responde-se o problema de pesquisa.

\section{RESULTADOS}

Para o estudo de caso foram consideradas múltiplas unidades de análise. Os bancos de dados de seis empresas de três ramos de atividades distintos foram utilizados, sendo que as empresas analisadas tiveram 0 método de padronização descritiva de materiais implementado pela empresa Integra Consultoria S/S Ltda., que atua a mais de 15 anos nesta atividade. Por questões legais a Integra não divulga informações particulares de seus clientes e esse quesito foi respeitado.

Constatou-se que $98 \%$ dos respondentes estão na empresa a mais de um ano e que $10 \%$ estão na empresa a mais de 10 anos. 0 questionário foi submetido a 50 respondentes

As respostas relacionadas ao ramo de atuação da empresa ficaram divididas em $48 \%$ trabalham na empresa de mineração, $28 \%$ trabalham na empresa de logística e $24 \%$ trabalham na empresa fabricante de embalagens.

Os 50 respondentes estão divididos em 13 cargos distintos, onde podemos identificar que os ocupantes dos cargos: Técnico em segurança do trabalho, Gerente de produção, Gerente de suprimentos, Gerente de operações e administrativo fazem parte dos 14\% não utilizam a descrição padronizada no seu dia a dia. Os demais cargos utilizam a descrição padronizada.

O cargo Gerente de Projetos são os responsáveis pela implementação da metodologia da padronização descritiva e representaram $22 \%$ dos entrevistados desta pesquisa. O cargo Almoxarife são os usuários que mais utilizam as descrições submetidas à metodologia de padronização descritiva de 
materiais representaram 24\% dos entrevistados desta pesquisa.

Foi identificado que $98 \%$ afirmaram que trabalham na empresa a mais de um ano, e contatou-se que $96 \%$ estão na função atual a mais de um ano, porém apenas $2 \%$ estão nesta função a mais de 10 anos.

Os 14\% de entrevistados que não utilizam as descrições dos itens de almoxarifado no seu dia, e $86 \%$ utilizam as descrições dos itens de almoxarifado no seu cotidiano.

Identificou-se que $86 \%$ afirmaram utilizar as descrições padronizadas no seu dia a dia, 94\% dos entrevistados conheceram a descrição antes dela ser submetida à padronização descritiva de materiais, sendo assim, 85\% dos usuários das descrições padronizadas e podem fazer um comparativo entre o antes e depois da padronização.

Para $54 \%$ é plenamente satisfatória a padronização descritiva para a compra de materiais e para $36 \%$ é razoavelmente satisfatória a padronização descritiva para a compra de materiais, estas duas respostas representam 90\% das respostas obtidas, porém $8 \%$ se demonstraram indiferentes e $2 \%$ razoavelmente insatisfeitos.

Esta questão busca saber se as descrições padronizadas estão atendendo as expectativas do setor de compras, demonstraram-se indiferentes os ocupantes o cargo de Almoxarife e o demonstraram-se razoavelmente insatisfeito os ocupantes do cargo de Assistente administrativo. Os entrevistados que ocupam o cargo de Comprador se demonstraram plenamente satisfeitos com as descrições de materiais padronizadas.

Para 58\% a acuracidade do estoque é plenamente satisfatório e para 32\% acuracidade do estoque é razoavelmente satisfatória. Os 10\% que indicaram sua posição quanto a esta questão ser indiferente são de áreas da empresa que não está ligada ao almoxarifado, desta forma não utilizam os materiais no seu dia a dia e não acompanham os inventários físicos.

É importante ressaltar que a acuracidade do estoque não será obtida apenas através da padronização descritiva, diversos fatores podem influenciar nesta questão e a padronização descritiva será apenas um fator que poderá contribuir para a acuracidade do estoque.
Para 98\% houve redução das duplicidades do cadastro e este aspecto demonstra-se plenamente satisfatório para $82 \%$ e razoavelmente satisfatório para $16 \%$, apenas um entrevistado demonstrou-se razoavelmente insatisfeito com a redução das duplicidades, representando $2 \%$ das respostas obtidas.

O respondente que afirma que a padronização descritiva de materiais não reduziu a duplicidade do cadastro tem cargo de assistente administrativo, está na organização há três anos e não utiliza as descrições padronizadas no seu dia a dia. $\mathrm{Na}$ questão 12, onde a resposta foi aberta, o respondente pode expressar suas dificuldades quanto à metodologia e utilização da mesma, foi relatada que a utilização de termos técnicos em sua opinião é a maior dificuldade do método, dificultando seu entendimento do item.

Os entrevistados que se demonstraram plenamente ou razoavelmente satisfeitos mencionaram na questão 12 a redução de duplicidades, qualidade das descrições, acuracidade de estoque, melhoria no processo de compra, abertura da descrição possibilitando a compra de mais de um fornecedor ou escolha do fornecedor pelo preço, codificação dos materiais de forma lógica facilitando a utilização, entre outras respostas.

As respostas objetivas identificaram que 58\% estão plenamente satisfeitos com as descrições dos itens, 32\% estão razoavelmente satisfeitos e 10\% demonstramse indiferentes a utilização das descrições e também estão identificados nas questões três e cinco, não utilizam a descrição padronizada no seu dia a dia, este fato está ligado a seu cargo.

Os respondentes que se demonstraram plenamente satisfeitos e razoavelmente satisfeitos representaram 90\% dos entrevistados, na questão 12 deixam claro seu grau de satisfação através de suas respostas, enfatizando redução de duplicidades, controle de estoque, descrição completa e facilidade de compra pela descrição.

Os respondentes identificaram os pontos de melhorias do processo: redução das duplicidades e unificação dos códigos duplos, melhoria no processo de compras com descrições técnicas completas onde consta referência e fabricante, processo continuo e uniforme na entrada de dados, 
codificação dos itens, enriquecimento das descrições dos materiais, classificação fiscal correta a partir da descrição padronizada.

Os questionamentos feitos no decorrer da pesquisa, os fatores mais mencionados foram redução de duplicidade, enriquecimento da descrição e qualidade no processo de compra. Todos estes fatos estão diretamente ligados à padronização descritiva dos materiais.

Os benefícios e propriedades da catalogação de materiais, a metodologia de padronização descritiva de materiais traz ganhos econômicos para a organização uma vez que possibilita a abertura da descrição para o mercado, podendo cobrar o item de qualquer fornecedor que atenda suas especificações, podendo assim barganhar preço combinado com qualidade. Através da unificação dos códigos duplos a empresa passa a comprar através de um único código um material que antes estavam sendo comprado através de vários códigos, este benefício da catalogação gere economia para organização.
A padronização descritiva de materiais com a unificação dos códigos consequentemente gera inventário destas peças localizadas com descrição igual, as unindo fisicamente dentro do estoque, para que sua utilização seja otimizada e suas compras sejam feitas mediante necessidade de estoque. Antes da unificação dos códigos era gerado um pedido de compra para cada código.

Com os itens descritos tecnicamente e enquadrados em um PDM é possível localizar a classificação NCM correta para o item, identificando o código NCM e sua taxa de IPI através do seu nome válido e dos seus dados técnicos. A classificação fiscal é complemento fundamental do cadastro de material.

Os benefícios da padronização descritiva de materiais estão sintetizados na Figura 8, identificando as melhorias ocorridas após a implementação do projeto de PDM.

Figura 8: Síntese dos benefícios da padronização descritiva de materiais

\begin{tabular}{|c|c|}
\hline $\begin{array}{l}\text { Área da Administração de } \\
\text { Materiais }\end{array}$ & Beneficio \\
\hline Compras & $\begin{array}{l}\text { Descrição completa, com todas as características do item, inclusive } \\
\text { referência e fabricante, possibilidade de buscar mais de um fornecedor ou } \\
\text { fabricante para o material podendo assim barganhar preço, certeza de } \\
\text { compra correta pela descrição. }\end{array}$ \\
\hline Recebimento & $\begin{array}{l}\text { Com as descrições padronizadas e completas é possível ter certeza do } \\
\text { material que está sendo recebido do fornecedor }\end{array}$ \\
\hline Inspeção & $\begin{array}{l}\text { O numero de itens rejeitados pela inspeção será diminuído sensivelmente, } \\
\text { pois com uma descrição completa o fornecedor terá condição de entregar } \\
\text { o item correto. }\end{array}$ \\
\hline Conferencia e pagamento & $\begin{array}{l}\text { Se os fornecedores estão entregando o produto correto, não haverá } \\
\text { problemas de devolução, desta forma não haverá problemas para fazer os } \\
\text { pagamentos dos materiais. }\end{array}$ \\
\hline Inventário & $\begin{array}{l}\text { Com a redução das duplicidades pelo saneamento dos itens e } \\
\text { padronização das descrições, os códigos duplos serão unificados, assim } \\
\text { o inventário físico será otimizado. }\end{array}$ \\
\hline Cadastro de material & $\begin{array}{l}\text { A partir da implementação da metodologia de padronização descritiva de } \\
\text { materiais todo item novo deverá ser enquadrado em um PDM de acordo } \\
\text { com seu nome válido, seguindo os dados técnicos necessários para } \\
\text { criação de seu cadastro, assim todo cadastro de material estará } \\
\text { padronizado. }\end{array}$ \\
\hline Classificação Fiscal & $\begin{array}{l}\text { A partir de uma descrição completa é possível identificar o código NCM e } \\
\text { taxa de IPI correto do material }\end{array}$ \\
\hline
\end{tabular}


Foram identificadas melhorias no processo de compras, redução de duplicidades de descrições e consequentemente redução de itens duplos fisicamente, acuracidade de estoque, enriquecimento das descrições com maior número de informação técnicas

\section{REFERÊNCIAS}

[1] DEUS ,Tamar Teles. A Importância de se Estabelecer Procedimentos de Controle de Estoque na Tree Computação. 2013. 50 f. Trabalho de Conclusão de Curso - Administração de Empresa. Fundação Pedro Leopoldo. Minas Gerais. 2013. Disponível em: <http://www.fpl.edu.br/2018/media/pdfs/graduacao /tcc/2013/tcc_tamar_teles_de_deus_2013.pdf>. Acessado em: 13 set .2018 .

[2] DIAS, Marco Aurélio P. Administração de Materiais: princípios, conceitos e gestão. 6 $6^{\underline{a}}$ ed. São Paulo: Atlas, 2012.

[3] GONÇALVES, Paulo Sérgio. Administração de Materiais. 4르 ed. Rio Janeiro: Elsevier, 2013.

[4] JUNIOR, Carlos Alberto Assis Montenegro. O impacto da utilização de um sistema de localização de materiais nas atividades do almoxarifado central do IFPB. Administração de materiais. 2010. 71 f.Trabalho de Conclusão de Curso - Especialista em Gestão de Logística Empresaria. Escola Superior Aberta do Brasil ESAB. Espirito Santo. 2010. Disponível em: < https://www.esab.edu.br/wp-

content/uploads/monografias/carlos-alberto-assismontenegro-junior.pdf>. Acessado em: 13 set 2018.

[5] PRODANOV, Cleber Cristiano; FREITAS, Ernani Cesar. Metodologia do Trabalho Científico: Métodos e Técnicas da Pesquisa e do Trabalho Acadêmico. $2^{\circ}$ edição. Rio Grande do Sul. FEEVALE. 2013.

[6] SANTOS, Charles Henrique Gonçalves. Uma proposta de modelagem ontológica para a identificando o item com maior assertividade. Com a metodologia de padronização descritiva de materiais a gestão dos itens de almoxarifado reduz custo e gera ganhos de qualidade nos processos.

NCM. 2011. 120 f. Dissertação - Mestrado Sistemas Mecatrônicos. Universidade de Brasília. Brasília. 2011.Disponivel em: <http://repositorio.unb.br/bitstream/10482/9812/1/2 011_CharlesHenriqueGoncalvesSantos.pdf>. Acessado em: 13 set .2018.

[7] SANTOS, Ciléa Natalia. A Padronização Descritiva de Materiais (PDM) e sua Importância como Ferramenta de Maximização de Processos e Atividades Empresariais. 2012. 44 f. Trabalho de Conclusão de Curso (Monografia) - Engenharia de Produção. Universidade Candido Mendes. Rio Janeiro. $2012 . \quad$ Disponível em: <http://www.avm.edu.br/docpdf/monografias_publi cadas/K220513.pdf > . Acessado em: 13 set .2018.

[8] SILVA, Ricardo Bernardo da; LEITE, Cesar Eduardo; PASCOALINO Hélio. Avaliação Da Gestão De Estoques Em Função De Nova Padronização De Materiais Nas Empresas De Serviços Públicos De Eletricidade Do Brasil: Estudo De Caso Na Ceb Distribuição S/A. 5. 2014. Congresso Nacional De Excelência Em Gestão. Rio de Janeiro. Anais...Rio de Janeiro: INOVARSE, 2014, p. 1-16. Disponível em: http://www.inovarse.org/sites/default/files/T14_0119 _0.pdf Acessado em: 29 set .2018.

[9] WANKE, Peter. Quadro conceitual para gestão de estoques: enfoque nos itens. Gestão Produção. São Carlos, v. 19, n. 4, p. 677-687, 2012. Rio de Janeiro. Disponível em: <http://www.scielo.br/pdf/gp/v19n4/a02v19n4>. Acessado em: 13 set .2018. 


\section{ANEXO}

\section{APÊNDICE A- QUESTIONÁRIO}

Este questionário visa à realização do Trabalho de Conclusão do Curso de Administração na Faculdade CNEC Gravataí , a pesquisa científica realizada tem por como objetivo de estudo a padronização descritiva como melhoria de processo na área de materiais

Para que este objetivo possa concretizar-se venho-lhe apresentar este questionário, contando com sua fundamental colaboração

\section{Questionário:}

1) Há quanto tempo você trabalha na empresa?

2) Qual ramo de atividade da sua empresa?
a)Logística
b)Mineração
c)Fabricante de embalagens

3) Qual o seu cargo?

4) Há quanto tempo você exerce este cargo?

5) Você utiliza no seu dia a dia as descrições dos itens de almoxarifado?
a) $\operatorname{Sim}$
b) Não

6) Você conheceu a descrição dos materiais de almoxarifado antes de serem padronizadas?
a) $\operatorname{Sim}$
b) Não

7) A padronização descritiva de materiais como fator de qualificação para a aquisição de materiais demonstrase
a) Plenamente satisfatório
b) Razoavelmente satisfatório
c) Indiferente
d) Razoavelmente insatisfeito
e) Plenamente insatisfeito
8) A acuracidade dos itens de almoxarifado com a aplicação da metodologia de padronização descritiva de materiais demonstra-se:
a) Plenamente satisfatório
e) Plenamente insatisfeito
b) Razoavelmente satisfatório
c) Indiferente
d) Razoavelmente insatisfeito
9) Com a aplicação da metodologia de padronização descritiva de materiais houve redução de duplicidades do cadastro?
a) $\operatorname{Sim}$
b) Não
10) Este fato demonstra-se
a) Plenamente satisfatório
b) Razoavelmente satisfatório
c) Indiferente
d) Razoavelmente insatisfeito e) Plenamente insatisfeito

11) As descrições padronizações facilitam a utilização do usuário
a) Plenamente satisfatório
b) Razoavelmente satisfatório
c) Indiferente
d) Razoavelmente insatisfeito
e) Plenamente insatisfeito
12) Em sua opinião houve melhorias com este processo? Se, sim, quais são? 


\section{Capítulo 8}

\section{UTILIZAČÃO DO CICLO \\ DESENVOLVIMENTO \\ DE UMA \\ PDCA \\ PARA AUTOMATIZADA}

Vitor Abel Monteiro Alves

\section{Gustavo Schuster}

Uilson Diego Gomes Prestes

Alejandro Martins Rodriguez.

Resumo: Estufas agrícolas são um modelo para se ganhar eficiência nos resultados no campo, pois possibilitam um controle parcial de umidade e temperatura, além de as estufas criarem um ambiente climático favorável para as plantas e protegemnas de más condições climáticas. Entretanto, muitas das vezes as estufas não nos proporcionam um controle completo dos parâmetros necessários para o desenvolvimento das plantações nelas inseridas. Desta forma, o presente estudo tem como o objetivo desenvolver uma estufa agrícola automatizada com o suporte do ciclo PDCA. Desta forma o presente estudo elaborou uma estufa agrícola comandada por um arduino.

Palavras Chave: Estufa, PDCA, automatização, ciclo, arduino, agrícola. 


\section{INTRODUÇÃO}

De acordo com Madalosso (2014) apesar do processo de modernização da agricultura, muitos agricultores continuam fazendo a irrigação de maneira manual, especialmente agricultores de pequeno e médio porte. Nestes casos, os agricultores têm a necessidade de prestarem atenção contínua às plantações para o caso de existir necessidade de irrigá-las. Além disso, alguns tipos de válvulas e outros dispositivos que permitem o fluxo de água devem ser acionados manualmente.

Dos Santos (1998) aborda que o crescimento do número de estufas dá-se devido ao melhoramento dos fatores produtivos que as mesmas proporcionam. Fatores como: intensificação da produção, aumento da qualidade dos produtos, uma redução de custos, uma atenuação de perdas por causas climáticas entre outros.

Segundo Marangoni (2014), as estufas criam um ambiente climático perfeito para as plantas e as protegem de más condições climáticas. Neste sentido, com o avanço da tecnologia nos setores da informática, eletrônica e agricultura, foram surgindo várias ferramentas que podem ser utilizadas para integrar essas três áreas.

\subsection{CICLO PDCA}

O PDCA (Plan, Do, Check e Act) é um método de gerenciamento de processos ou de sistemas. Ele é utilizado como um caminho para que se atinjam as metas atribuídas aos produtos dos sistemas empresariais (CAMPOS, 1991). Sendo assim, tem-se como premissa a determinação de uma meta para a utilização dessa metodologia. Segundo Andrade (2003), o ciclo PDCA é projetado para ser usado como um modelo dinâmico em que a conclusão de um ciclo irá fluir no começo do próximo ciclo, e assim sucessivamente. Além disso, o mesmo afirma que, o processo sempre pode ter uma nova análise, o que implica em novo processo de mudança.

O ciclo PDCA tem como objetivos principais o auxílio no diagnóstico, análise e prognóstico de problemas organizacionais, sendo de grande utilidade para a solução de problemas. São poucas as ferramentas que demonstram ser tão efetivas para a busca do melhoramento quanto este método de melhoria contínua (QUINQUIOLO, 2002).

Esta ferramenta possui quatro etapas bem definidas, e que segundo Andrade (2003), podem ser descritas da seguinte forma:

a) Plan (Planejar): nesta fase são definidos os objetivos e os processos necessários para proporcionar resultados de acordo com as condições do contratante e políticas da organização. Esta fase abrange: a localização do problema, a instituição de uma meta, a análise do fenômeno usando diagramas estatísticos, a análise do processo usando diagrama de causa e efeito e a elaboração do plano de ação;

b) Do (Fazer): são implantados os processos, execução das ações previstas junto ao plano de ação definidas na fase anterior, sendo desenvolvidas no cronograma determinado, tendo todas as ações registradas e supervisionas;

c) Check (Checar): nesta fase é preciso efetuar a acompanhamento da eficiência das ações definidas na fase anterior. Utilizando para a mesma a comparação dos resultados (planejados e executados), listagem das consequências secundárias, acompanhamento do seguimento ou não do problema (eficácia das ações tomadas);

d) Act (Agir): está fase é responsável pela uniformização dos métodos implantados na fase "Do", ou seja, sendo o resultado satisfatório se devem equalizar essas ações, transformando-as em métodos padrão. Para realizar essa uniformização é feita a elaboração ou substituição do padrão, comunicação, treinamento e acompanhamento da utilização do padrão. A efetivação do programa também ocorre nessa fase, sendo que serão capazes de ser estipuladas outras metas futuras para que o processo de aperfeiçoamento contínuo possa assim ser provocado.

Para um melhor entendimento, pode-se visualizar o ciclo PDCA de acordo com a imagem a seguir - Figura 1: 
Figura 1 - Ciclo PDCA

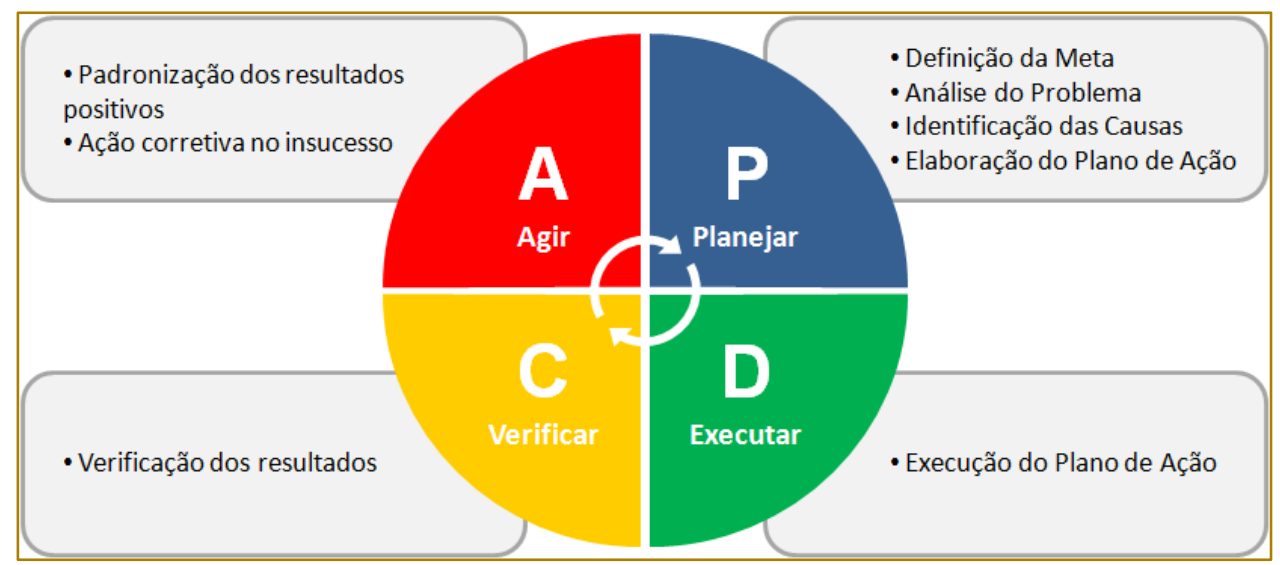

Fonte: (MACEDO; COELHO, 2015)

\subsection{PROBLEMA}

A empresa estudada neste artigo desenvolve suas atividades no ramo do desenvolvimento de plantas ornamentais em estufas agrícolas. A empresa utiliza as estufas para ter um controle maior do crescimento e desenvolvimento das plantas e assim poder gerenciar de uma maneira mais eficaz sua produção.

Para termos de sigilo, a empresa estudada neste artigo terá seu nome ocultado, e será chamada de empresa Beta. Tendo suas principais instalações na cidade de Pelotas, a empresa Beta sofre com alguns problemas para o desenvolvimento de suas atividades, problemas de caráter estrutural. A estufa não conta com um sistema de ventilação e refrigeração adequados, o que acarreta em diminuição dos resultados em função da falta de controle da temperatura. Também é necessário um sistema automatizado para a alimentação contínua das plantas, para que as mesmas acelerem seu processo de crescimento. Com a falta de controle em relação a irrigação das plantas, há perdas significativas, visto que em dias mais quentes, há uma necessidade maior de irrigação do que em dias mais amenos, entretanto, a empresa não conta com profissionais $24 \mathrm{~h}$ disponíveis para regular a frequência e duração das irrigações, o que causa estragos e perdas.

$\mathrm{Na}$ Figura 2 são apresentadas algumas imagens da estufa tomada como modelo para a implantação da automação nas estufas da empresa Beta.

Figura 2 - Foto estufa lateral 1 (a) e lateral 2 (b).

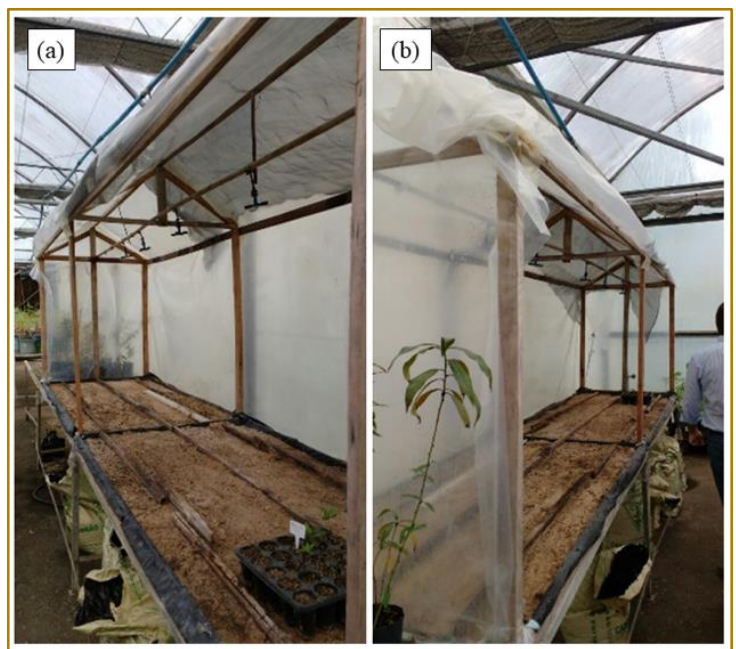

Fonte: Autores 
As imagens acima apresentam a estufa que será utilizada como modelo na automação da Beta, a mesma se localiza na cidade de Pelotas.

\subsection{A IDEIA}

Com o intuito de solucionar o problema, a empresa Beta resolveu realizar o desenvolvimento de uma Estufa Agrícola Automatizada. Sendo assim, será possível programar e ter maior controle e melhores resultados. Segundo Marangoni (2014), as estufas criam um ambiente climático perfeito para as plantas e protegem-nas de más condições climáticas. Sendo assim, neste estudo serão integradas ferramentas agrícolas no caso estudas, com ferramentas eletrônicas que será a parte do circuito comandado por arduino.

\section{DESENVOLVIMENTO}

\subsection{ETAPA DO PLANEJAMENTO (PLAN)}

A partir do que foi conversado através de reuniões e Brainstormings juntamente com responsáveis pela empresa, foi possível identificar a meta para o desenvolvimento do produto da empresa. A empresa necessitava de uma estufa agrícola, automatizada que possa controlar remotamente, tanto a umidade da estufa quanto sua temperatura, por meio de softwares remotamente. Esta necessidade está fortemente vinculada com as perdas que a empresa sofre por não ter um controle remoto dessas variáveis da estufa, sendo que em finais de semana por exemplo ou quando variações bruscas de temperatura ocorrem, funcionários devem se deslocar às pressas para alterar os parâmetros de temperatura e umidade para que não haja perdas.
Sendo assim, o desenvolvimento da estufa se daria por duas etapas; a) desenvolvimento de software e b) utilizar a plataforma arduino e periféricos para controle e automação do projeto. Este artigo não abordará o desenvolvimento de software realizado pela empresa, limitando-se apenas ao desenvolvimento do sistema de controle e automação para mesma.

A partir desse momento, a empresa possuía conhecimento dos objetivos que desejava alcançar, era necessário apenas avaliar a viabilidade técnica para tal. Por este motivo, foi realizado um estudo de Benchmarks, pois segundo Vieira, Durães e Madeira (2005) o objetivo da utilização dos benchmarks é proporcionar confiabilidade além de formas padronizadas de avaliação tanto da confiabilidade como do desempenho de sistemas e componentes informáticos.

Tendo o resultado dos Benchmarks foi possível especificar quais seriam os componentes necessários e quanto os mesmos custariam para a empresa, a fim de validar econômica e tecnicamente a execução do projeto. Foi definido também, que o sistema de irrigação seria o de aspersão, segundo Mendonça et al. (1999) a uniformidade de distribuição do sistema de irrigação influencia diretamente a qualidade da fertirrigação. Em sistemas convencionais de irrigação por aspersão, distribuição uniforme de água e fertilizantes é definida pelo perfil de distribuição dos aspersores utilizados além da disposição do equipamento no campo.

Diante das necessidades observadas para a implantação das estufas automatizadas, foram quantificados os componentes necessários, apresentados na Figura 3. Os mesmos foram adquiridos pela empresa e, posteriormente, foram realizadas as etapas de instalação e configuração, propiciando o início dos testes. 
Figura 3 - Componentes necessários

\begin{tabular}{|lclc|}
\hline \multicolumn{1}{c}{ Componente } & Quantidade & \multicolumn{1}{c}{ Componente } & Quantidade \\
\hline Ardúno & 1 & Fonte 12V & 1 \\
Sensor higrômetro & 4 & Caixa abrigo & 1 \\
Sensor DHT 11 & 2 & Cabo de rede & 1 \\
Módulo Rele & 1 & Chip & 1 \\
Módulo RTC & 1 & ESP 8266_V1 & 1 \\
Display LCD & 1 & Shield GSM & 1 \\
Jumper & 1 & Protoboard & 1 \\
\hline
\end{tabular}

Fonte: Autores

\subsection{ETAPA DA EXECUÇÃO (DO)}

Com as definições adquiridas na etapa anterior, nesta fase do projeto, iniciou-se a montagem da automatização da estufa. A estufa em que foi realizada a automatização é apresenta a partir de desenhos realizados no software Sketchup na imagem a seguir (Figura 4).

Figura 4 - Estufa Modelo

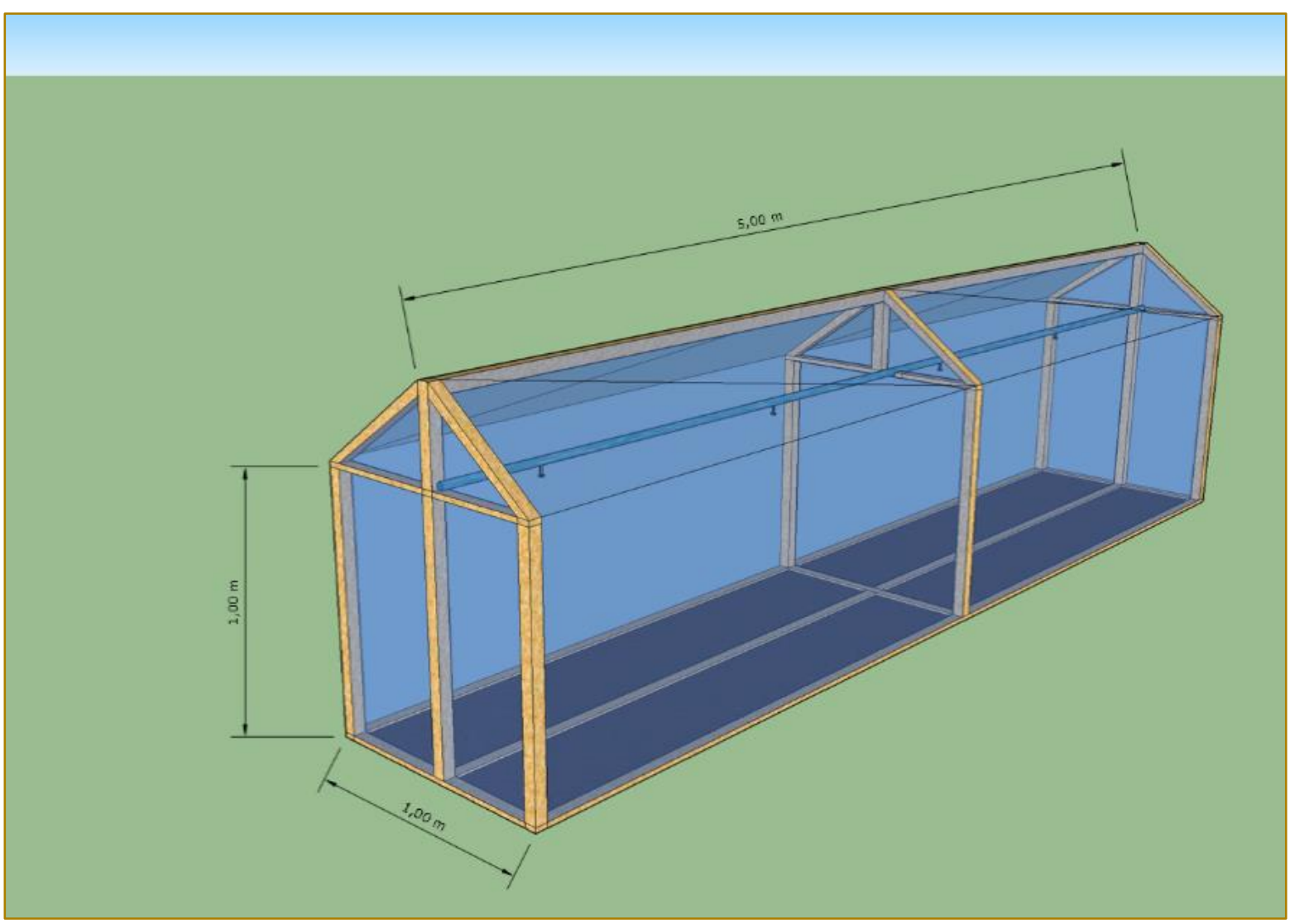

Fonte: Autores

Com as dimensões definidas, $(5 \mathrm{~m}$ de comprimento, 1 de altura até a aspersão e 1 de largura) e o sistema de irrigação também, no caso aspersão, foi desenhado um esquema de instalação dos sensores, para que em projetos futuros, já se possua uma padronização, o que é característico do ciclo PDCA. A ordem de montagem padrão definido pelo estudo foi: 
Fixação da placa arduino em um suporte ou dentro da própria caixa de PVC onde ficou abrigada e conectada a fonte de 12V/1A. Toda a montagem dos sensores e módulos foi feita sem a placa estar energizada para evitar possíveis danos ao equipamento;

Módulo RTC DS1302 Relógio: com auxílio dos jumpers conectou-se a alimentação do módulo com vermelho para positivo no borne de $5 \mathrm{~V}$ e preto para negativo no borne GND, tomar a alimentação na placa arduino; em seguida foi ligado o o borne SCL do modulo ao borne SCL da placa arduino e ao borne SCL do modulo I2C; para finalizar foi ligado o borne SDA do modulo ao borne SDA da placa arduino e ao borne SDA do modulo I2C.

Módulo I2C: ligações feitas junto com o modulo RTC DS1302; devemos somente conectar a alimentação do módulo com vermelho para positivo no borne de $5 \mathrm{~V}$ e preto para negativo no borne GND, tomar a alimentação na placa arduino; para finalizar conectou-se display LCD16x2 ao modulo I2C.

Modulo sensor umidade de solo: foi conectada a alimentação do módulo com vermelho para positivo no borne de $5 \mathrm{~V}$ e preto para negativo no borne GND, tomar a alimentação na placa arduino; conectar o borne $\mathrm{AO}$ do modulo ao borne $\mathrm{AO}$ da placa arduino; conectar o sensor de umidade ao modulo

DHT11 sensor de umidade e temperatura do ambiente: conectar a alimentação do módulo com vermelho para positivo no borne de $5 \mathrm{~V}$ e preto para negativo no borne GND, tomar a alimentação na placa arduino (positivo no borne 1 e negativo no borne 4); conectar o borne 2 do DHT11 ao borne A1 da placa arduino.

Modulo Relé (aciona o sistema de irrigação, exautores e ventiladores): conectar a alimentação do módulo com vermelho para positivo no borne de $5 \mathrm{~V}$ e preto para negativo no borne GND, tomar a alimentação na placa arduino; conectar o borne IN2 ao borne 7 da placa arduino; utilizar os bornes de K1 e K2 para fazer o acionamento do sistema de irrigação, exautores e ventiladores.

Após serem realizados os 6 passos de insta lação, o sistema montado é apresentado na Figura 5.

Figura 5 - Sistema Montado

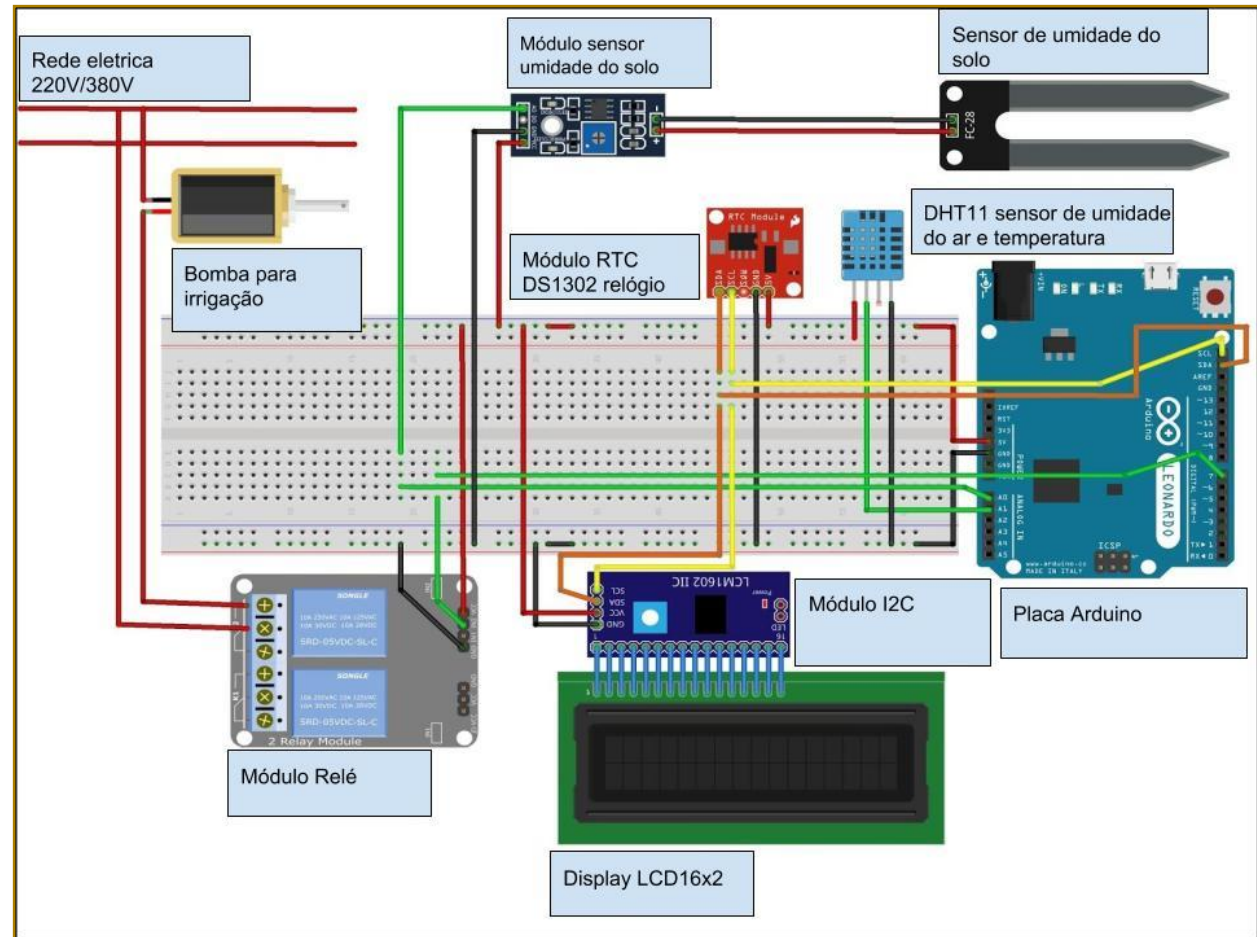

Fonte: (FREITAS, 2017) 


\subsection{ETAPA DE CHECAGEM (CHECK)}

$\mathrm{Na}$ etapa Check (Checagem) é verificada a eficácia das ações executadas. Esta análise usualmente é realizada com a comparação, mas como o objetivo deste artigo é de apenas construir um modelo de estufa automatizada e padroniza-la, não contemplando sua implementação, o que pôde ser checado foi a padronização e a capacidade de replicação.

Sendo assim, foi verificado que o projeto pode ser replicado para qualquer outra estufa da empresa, devendo respeitar apenas duas restrições que foram encontradas durante as execuções das atividades, sendo elas; i) utilização de um sensor higrômetro a cada $1,25 \mathrm{~m}^{2}$ e ii) utilização de 1 sensor DHT 11 a cada $2,5 \mathrm{~m}^{2}$.

\subsection{ETAPA DE AÇÃO (ACT)}

Por último, a etapa Act tem como base a padronização, entretanto, o desenvolvimento da estufa não se trata de um processo contínuo e repetitivo, sendo assim esta fase poderia ser realizada pela difusão das práticas desenvolvidas entre os membros da empresa, para que haja sugestões de melhoria. Assim, buscando sempre a utilização da tecnologia desenvolvida pela empresa e adaptando de acordo com a necessidade de cada projeto, pois como já falado anteriormente, existem restrições que

\section{REFERÊNCIAS:}

[1] MADALOSSO, Emanoeli. SISTEMA AUTOMATIZADO PARA IRRIGAÇÃO DE ESTUFAS. 2014. 76 f. TCC (Graduação) - Curso de Engenharia de Computação, Universidade TecnolÓgica Federal do ParanÁ, Pato Branco, 2014

[2] FORNARI JUNIOR, Celso Carlino Maria. Aplicação da Ferramenta da Qualidade (Diagrama de Ishikawa) e do PDCA no Desenvolvimento de Pesquisa para a reutilização dos Resíduos Sólidos de Coco Verde. Ingepro - Inovação, Gestão e Produção, São Paulo, v. 09, n. 02, p.1-7, set. 2010.

[3] VIEIRA, Marco; DURÃES, João; MADEIRA, Henrique. Especificação e Validação de Benchmarks de Confiabilidade para Sistemas Transaccionais. leee Latin America Transactions, Lisboa, v. 1, n. 3, p.72-80, mar. 2005. foram encontradas no projeto inicial, como a capacidade dos sensores.

\section{CONSIDERAÇÕES}

A utilização do ciclo PDCA se configurou como uma alternativa para otimizar as pesquisas referentes ao desenvolvimento de estufas agrícolas automatizadas, pois sua metodologia didática ofereceu um traçado linear a ser percorrido e demonstrava em cada etapa o que seria necessário para obter o resultado requerido.

No presente artigo, a utilização da metodologia presente no PDCA, foi bastante eficiente, pelo fato de que direcionou as decisões que deveriam ser tomadas pelos integrantes do projeto, assim como, definiu claramente os objetivos que seriam alcançados. É relevante ressaltar que, o método deve ser utilizado continuamente para que se otimize ainda mais o processo e se possua um fluxo totalmente padronizado e que atenda às necessidades da empresa.

Além disso, seguindo os métodos de aperfeiçoamento continuo relativo ao ciclo PDCA, no final do projeto ficou em aberto um novo objetivo, que tem potencial para desencadear um novo ciclo, que é a propagação da tecnologia desenvolvida pela empresa. Além disso, de proposição dentro do desenvolvimento de se identificar as melhores condições, sendo essas de materiais ou métodos que favoreçam um aperfeiçoamento de novas estufas.

[4] MENDONÇA, Fernando Campos et al. ADUBAÇÃO NITROGENADA DO MILHO EM UM SISTEMA DE IRRIGAÇÃO POR ASPERSÃO EM LINHA. Scientia Agricola, São Paulo, v. 56, n. 4, p.1035-1044, dez. 1999.

[5] DA FONSECA, Augusto VM; MIYAKE, Dario Ikuo. Uma análise sobre o Ciclo PDCA como um método para solução de problemas da qualidade. XXVI Encontro Nacional de Engenharia de Produção, pages 1-9, Fortaleza, CE, 2006.

[6] MACEDO, Kerlen de Sousa; COELHO, Georgea Paiva. DICAS DO TÉCNICO. 2015. Disponível em: $<$ http://www.ccprmg.com.br/pagina/3105/ciclopdca--me-233-todo-de-geste-227-o-aplicado-emfazendas-leiteiras---kerlen-de-sousamacedo.aspx>. Acesso em: 20 set. 2018. 
[7] FREITAS, Marcelo. Automatize a sua Horta ou Estufa Agrícola! 2017. Disponível em: <http://webestufa.blogspot.com/2017/01/automatiz e-sua-horta-ou-estufa-agricola.html>. Acesso em: 20 set. 2018

[8] ANDRADE, Fábio Felippe de. O método de melhorias PDCA. 2003. Tese de Doutorado. Universidade de São Paulo.

[9] CAMPOS, Vicente Falconi. TQC: controle da qualidade total. Belo Horizonte: Fundação Christiano Ottoni, v. 11, 1992.
[10] DOS SANTOS, Raul Manuel Pereira Morais. Estação Multisensorial para Estufas Agrícolas.

[11] QUINQUIOLO, José Manoel. Avaliação da eficácia de um sistema de gerenciamento para melhorias implantado na área de carroceria de uma linha de produção automotiva. Taubaté/ SP: Universidade de Taubaté, 2002. 


\section{Capítulo 9}

\section{PROBLEMAS COM A INFRAESTRUTURA TRANSPORTE DE CARGAS ESPECIAIS EM SANTOS}

\section{Adriano Alfinito Raimundo}

Alexandre Ricardo Machado

Matheus Palmieri Gobbetti

Rodolfo Pinheiro

Viktor Doll Schwenck

Resumo: O transporte de cargas especiais no porto de Santos é tido como um mercado de nicho, onde apenas alguns terminais são especializados nas técnicas de exportação deste tipo de material, porém a maioria dos terminais ainda assim recebem este tipo de cargas para execução dos trabalhos de exportação, mas como dito anteriormente fica claro a especialização de alguns dos terminais da área para realização destas tarefas. Os tipos de cargas especiais têm grandes dificuldades tanto na questão de transporte e tanto quanto na questão de segurança, os seus meios de locomoção exigem atenção de grandes órgãos como a CODESP entre outras entidades que regulam e auxiliam o processo logístico.As regulamentações que são executadas ano a ano são justamente pela dificuldade de transporte das cargas que normalmente são mais pesadas e maior dimensionadas o que leva a necessitar de todo um apoio logístico para a execução do transporte como um todo. Levando então esta consideração fica claro que os métodos de transporte sofrem alterações e regulamentações específicas cada ano, os responsáveis por estas atualizações são justamente os grandes órgãos reguladores do PORTO, tais como Agência Nacional de Transporte Aquaviário e a CODESP. O transporte e logística são sempre direcionados para o meio de transporte e ressalva de informações sobre os modais utilizados o presente trabalho tem uma premissa uma abordagem em relação a qualidade da infraestrutura e o planejamento da mesma que está diretamente ligado a seus problemas logísticos e resultados na questão de timinge qualidade do serviço prestado.

Palavras-chave: Transporte. Acesso ao porto. Cargas especiais. 


\section{INTRODUÇÃO}

A existência de cargas especiais que passam pelo porto de Santos não é nenhuma novidade, porém muitas vezes não fica claro como o processo é realizado e muito menos o preparo que um terminal precisa ter para conseguir executar o serviço de embarque, a utilização de serviços de apoio tais como ECOVIAS (2016), empresas de escolta e até mesmo empresas de apoio logístico são muitas vezes desconhecidos pelos moradores da cidade.

O porto de Santos tem uma movimentação de carga geral razoável que será abordada mais à frente no tópico sobre estatísticas e é muito importante ressaltar que por mais incrível que pareça anualmente o transporte de cargas representa uma grande fatia das movimentações dentro do porto de Santos e isto é visto através de gráfico abaixo retirado diretamente do mensário estatístico da CODESP (2016).

Por isto é interessante abordar não só a condição das vias de transporte tais como as estruturas presentes e métodos de transporte.

Segundo os relatórios publicados pela CODESP (2016) os terminais especializados (privados) são responsáveis por grande parte das movimentações destinadas destes $36,1 \%$, porém é possível dizer que grandes terminais tais como Libra Terminais e Brasil Terminais Portuários recebem ainda assim alguns pedidos de cargas de origem especial e indivisível.

Com estes dados então é possível dizer que qualquer melhora que seja executada e afete diretamente a movimentação, estrutura e a operação pode ser um ganho razoável e aumentar o índice com maior quantidade e melhor execução, sem esquecer que as questões de infraestrutura têm que ser atualizadas e constantemente revisadas para adequação para transportes de cargas maiores, aumento da movimentação por hora e prevenção de acidentes e incidentes.

\section{DEFINIÇÃO DO QUE SÃO CARGAS ESPECIAIS}

Por definição segundo o CONTRAN (2016) são cargas que não conseguem se encaixar dentro das resoluções 12/98 e 68/98, direcionando-se diretamente aos casos de excessos de peso e tamanho, considerando então que existem regulamentações direcionadas para todos os tipos de transporte o CONTRAN através de suas publicações criou certas regras para serem seguidas pelos meios de transporte de origem especial.

Ainda segmentando a resolução 12/98, CONTRAN (2016) diz:

Veículos que tenham como dimensões máximas, até 20,00 metros de comprimento; até 2,86 metros de largura, e até 4,40 metros de altura, será concedida Autorização Específica Definitiva, fornecida pela autoridade com circunscrição sobre a via, devidamente visada pelo proprietário do veículo ou seu representante credenciado, podendo circular durante as vinte e quatro horas do dia, com validade até o seu sucateamento. (CONTRAN, 2016)

Referenciando justamente que os veículos normais podem circular contanto que obtenham a Autorização Específica Definitiva, porém a regulamentação fica um pouco diferente quando o assunto são cargas especiais ou caminhões super dimensionados.

Ainda uma parte do texto retirado da resolução 12/98, CONTRAN (2016):

Para os veículos, cujas dimensões excedam os limites previstos no inciso I, será concedida Autorização Específica, fornecida pela autoridade com circunscrição sobre a via e considerando os limites dessa via, com validade de um ano, renovada até o sucateamento do veículo. (CONTRAN, 2016)

O interessante desta autorização específica é que esta é fornecida justamente para os caminhões que irão fazer os transportes das cargas diferenciadas e os parâmetros da obtenção da mesma são bem distintos:

a) Volume de tráfego;

b) Traçado da Via;

c) Projeto do conjunto veicular, indicando dimensão de largura, comprimento e altura, número de eixos, distância entre eles e pesos.

Levando estes dados relacionados com a metodologia criada pelo CONTRAN (2016) a resolução 68/98 adiciona os processos para veículos com longo comprimento e define as regras de visualização e controle que serão utilizadas pelos mesmos como visto na figura 1 abaixo. 
Figura 1 - Procedimento de identificação de veículos longos

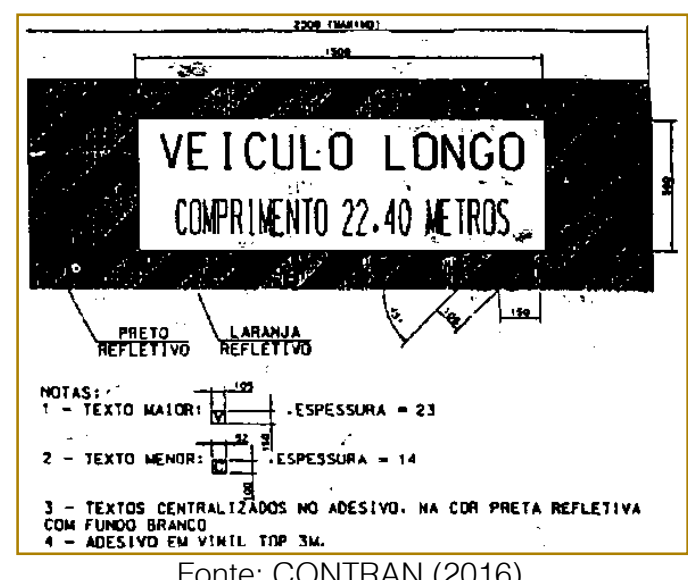

Fonte: CONTRAN (2016)

Isto entre outras formas de fiscalização tornam todo o processo de controle e regulamentação bem mais amarrado pois cada caminhão que for registrado de forma a ser identificado como meio de transporte de cargas especiais têm seu registro de forma acessível para facilitar o processo de fiscalização e metodologia de transporte, lembrando que segundo os relatórios da CODESP (2016) é possível visualizar que ainda com toda a burocracia envolvida no processo de estruturação logístico o transporte de cargas especiais para o Porto de Santos continua se mantendo e trazendo lucros para os terminais da região.

Como dito acima é muito importante o controle destes tipos de cargas já que as mesmas tem grande possibilidade que ao serem manuseadas de forma incorreta ou transportadas de forma irresponsável acarretar danos não só ao ambiente como a infraestrutura presente na pista, a figura 2 abaixo demonstra como deve ser o layout das autorizações.

Figura 2 - Layout das Autorizações Específicas

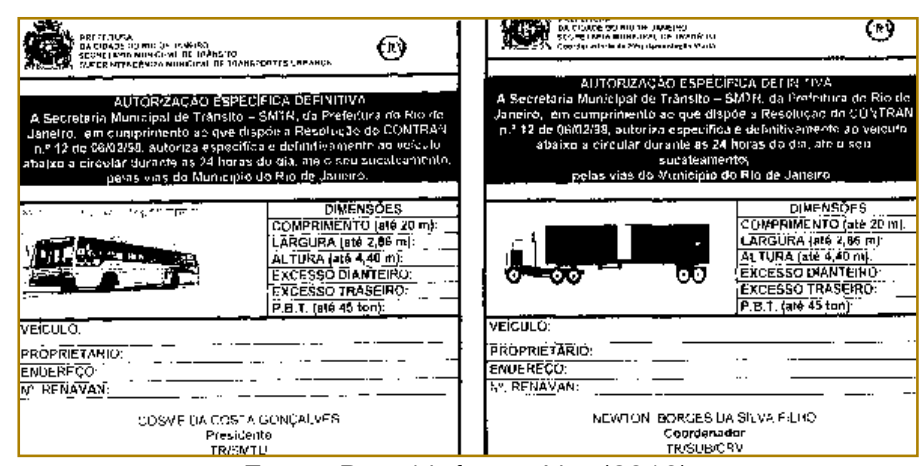

Fonte: Portal Informa Net (2016)

Segundo JOSÉ, GRI e FRANÇA (2015) "OS principais desafios desse transporte estavam à necessidade de estabelecer 0 trajeto baseado no peso e nas pontes disponíveis no caminho do transporte" e realmente o autor visualiza um dos problemas encontrados na região de Santos, já que a mesma conta com vias de acesso ao porto um pouco limitadas quanto a quantidade de peso suportada e a dimensão máxima que as cargas podem passar, estes problemas são recorrentes na região e já existem estudos sendo desenvolvidos por órgãos competentes para melhorá-los.

\subsection{CARGAS ESPECIAIS E O PORTO DE SANTOS}

O transporte de carga especial indivisível tem grande influência dentro dos portos do Brasil, sendo assim grande parte das grandes cargas de projeto são mais especificas e tem 
destinações para dentro e fora do país, sendo assim alguns terminais se especializaram dentro deste nicho de mercado, pois as maiorias das cargas que fazem parte deste tipo de transporte exigem muito mais do que uma logística especifica e um transporte diferenciado.
O Brasil consegue se manter como um dos grandes exportadores do mundo devido a sua grande capacidade de produção de commodities tais como podem ser observadas na figura 3 abaixo.

Figura 3 - Estatística retirada do site da ANTAQ (2015)

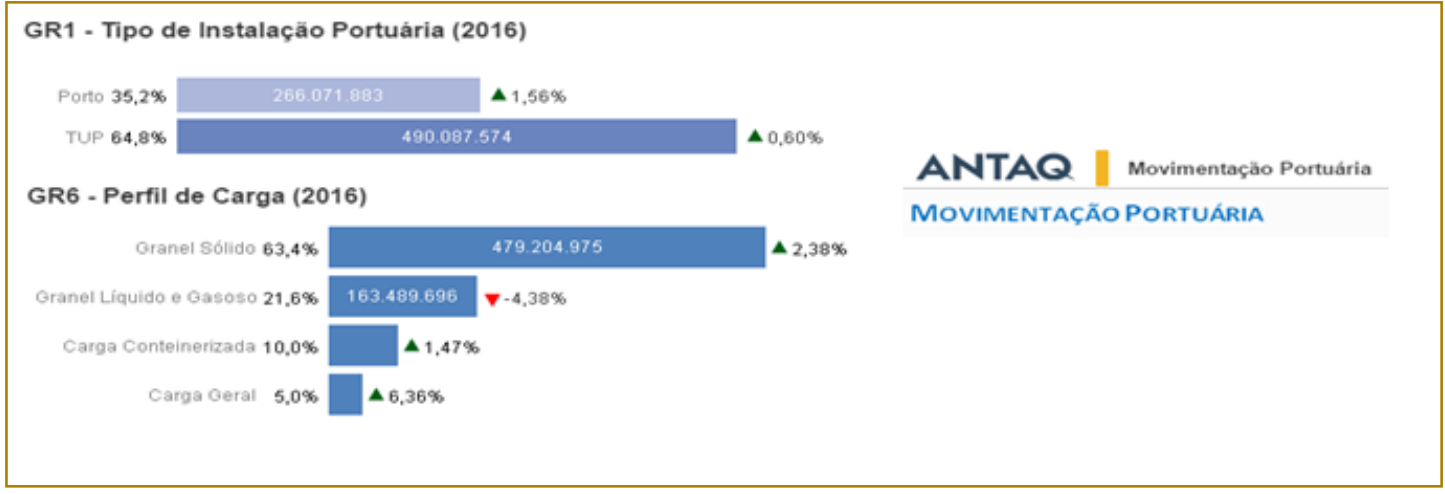

Fonte: ANTAQ (2015)

Segundo a ANTAQ (2015) como é visto no quadro acima o Brasil hoje é tratado como grande transportador e exportador de commodities tais como a soja, milho e até mesmo o café, porém recentemente outros tipos de carga como as pás eólicas e grandes transformadores são entregues nestes terminais para poderem seguir rumo para outros países. Através do Gráfico 1 abaixo é possível ter uma análise mais específica.

\section{Gráfico 1 - Gráfico de Comparações de Carga Geral}

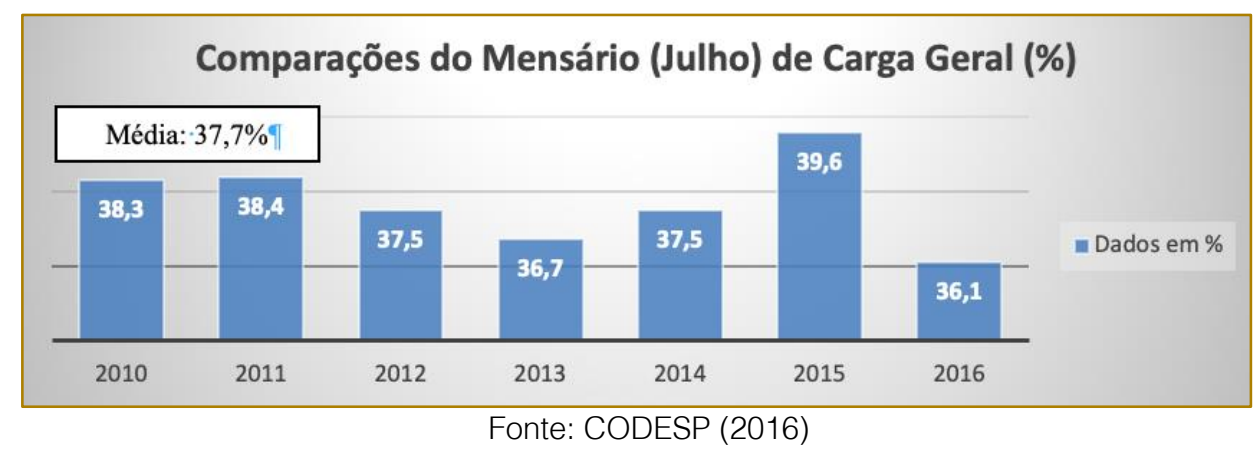

Como visto através do gráfico fica bem claro que com a crise de 2016 a movimentação de carga geral acabou recuando 3,5\%, o que é considerado uma margem bem razoável para qualquer tipo de mercado, mas mesmo assim é notável que o mercado ainda sim se manteve perto da média que é de 37,7\%, levando em consideração estes dados observe a Tabela 1 abaixo. 
Tabela 1- Movimentação do Porto de Santos - 07/2016

\begin{tabular}{|c|c|c|c|c|c|c|c|c|c|c|c|c|c|}
\hline \multicolumn{2}{|c|}{$\begin{array}{c}\text { EM } \\
\text { TONELADAS }\end{array}$} & \multicolumn{10}{|c|}{ MOVIMENTO NO PORTODE SANTOS } & \multicolumn{2}{|c|}{$\begin{array}{c}\text { CODESP - FL. } 04 \\
\text { ESTATISTICA - JUL / } 16\end{array}$} \\
\hline \multirow{2}{*}{\multicolumn{2}{|c|}{ ESPECIFICAÇÃO }} & \multicolumn{4}{|c|}{ IMPORTACCÅO } & \multicolumn{4}{|c|}{ EXPORTAÇÃO } & \multicolumn{4}{|c|}{ TOTAL } \\
\hline & & $\begin{array}{l}\text { Carga } \\
\text { Geral }\end{array}$ & $\begin{array}{c}\text { Sollidos } \\
\text { a Granel }\end{array}$ & $\begin{array}{l}\text { Liquidos } \\
\text { a Granel }\end{array}$ & Soma & $\begin{array}{l}\text { Carga } \\
\text { Geral }\end{array}$ & $\begin{array}{c}\text { Solidos } \\
\text { a Granel }\end{array}$ & $\begin{array}{l}\text { Liquidos } \\
\text { a Granel }\end{array}$ & Soma & $\begin{array}{l}\text { Carga } \\
\text { Geral }\end{array}$ & $\begin{array}{c}\text { Solidos } \\
\text { a Granel }\end{array}$ & $\begin{array}{l}\text { Liquidos } \\
\text { a Granel }\end{array}$ & Soma \\
\hline \multicolumn{14}{|c|}{ NO MES } \\
\hline \multirow{2}{*}{$\begin{array}{l}\text { LONGO } \\
\text { CURSO }\end{array}$} & Cais Público & 10.725 & 362.939 & 461.537 & 835.201 & 269.083 & 2.379 .316 & 374.257 & 3.022 .656 & 279.808 & 2.742 .255 & 835.794 & 3.857 .857 \\
\hline & 1.Privado & 964.982 & 184.810 & - & 1.149 .792 & 1.458 .626 & 1.407.397 & - & 2.866 .023 & 2.423 .608 & 1.592.207 & - & 4.015 .815 \\
\hline \multirow{4}{*}{$\begin{array}{l}\text { CABO- } \\
\text { TAGEM }\end{array}$} & Cais Público & 821 & 62.913 & 95.939 & 159.673 & 906 & - & 429.338 & 430.244 & 1.727 & 62.913 & 525.277 & 589.917 \\
\hline & T. Privado & 247.999 & 5.397 & - & 253.396 & 296.015 & - & - & 296.015 & 544.014 & 5.397 & - & 549.411 \\
\hline & T. Uso Privativo & 36.335 & $\cdot$ & 42.840 & 79.175 & 41.720 & - & 14.308 & 56.028 & 78.055 & - & 57.148 & 135.203 \\
\hline & SOMA & 285.155 & 68.310 & 138.779 & 492.244 & 338.641 & - & 443.646 & 782.287 & 623.796 & 68.310 & 582.425 & 1.274 .531 \\
\hline \multirow{3}{*}{ TOTAL } & Cais Público & 11.546 & 425.852 & 557.476 & 994.874 & 269.989 & 2.379 .316 & 803.595 & 3.452 .900 & 281.535 & 2.805 .168 & 1.361 .071 & 4.447.774 \\
\hline & T. Privado & 1.212 .981 & 190.207 & - & 1.403 .188 & 1.754 .641 & 1.407.397 & - & 3.162 .038 & 2.967 .622 & 1.597 .604 & - & 4.565.226 \\
\hline & T. Uso Privativo & 288.743 & 208.391 & 109.654 & 606.788 & 293.429 & 194.874 & 74.287 & 562.590 & 582.172 & 403.265 & 183.941 & 1.169 .378 \\
\hline
\end{tabular}

Fonte: CODESP (2016)

É possível visualizar através das estatísticas que realmente os terminais de origem privada dominam a questão de exportação e despacho de cargas gerais, neste contexto a carga especial e indivisível é anexada junto a este índice pois não existe um índice separado publicado somente com as cargas que são superdimensionadas e indivisíveis.

Dentro da especificação de transporte de cargas especiais é notável o grande knowledge logístico que é utilizado para executar todo o processo de operação portuário, segundo SCHOELER (2000, p. 244) "efetivou-se a modernização dos métodos, a busca de aumentona eficiência e a implantação de novos serviços de apoio, na administração das áreasrelativas à administração da CODESP" e isto é verdade, já que inúmeros projetos de modernização e controle foram adicionados ao leque de opções administrativas da CODESP, assim fazendo com que a gestão do Porto tivesse mais efeitos positivios, mas ainda assim é notável alguns problemas principalmente nos quesitos de infraestrutura de vias e processos logísticos quando o assunto se trata de cargas especiais.

As cargas especiais e de projeto apesar de representar uma margem pequena dentro do relatório da CODESP (2016) como visto na tabela 2 abaixo, influem em grandes clientes interessados a gerar lucro e evidentemente conseguir novas tecnologias para poder cada vez mais aprimorar o processo de carregamento. Através da Tabela 2 abaixo analise a seguinte situação de resultados finais.

Tabela 2 - Relatório do mês de Agosto de 2016

\begin{tabular}{|c|c|c|c|c|c|c|c|c|c|c|c|c|c|}
\hline \multicolumn{3}{|c|}{$\begin{array}{c}\text { EM } \\
\text { TONELADAS }\end{array}$} & \multicolumn{9}{|c|}{$\begin{array}{l}\text { MOVIMENTO ACUMULADO } \\
\text { PORTO DE SANTOS }\end{array}$} & \multicolumn{2}{|c|}{$\begin{array}{c}\text { CODESP }- \text { FL.03 } \\
\text { ESTATISIICA - AGO / } 16\end{array}$} \\
\hline \multirow{2}{*}{\multicolumn{2}{|c|}{$\begin{array}{l}\text { ESPECIF- } \\
\text { CAÇÄO }\end{array}$}} & \multicolumn{4}{|c|}{ IMPORTAÇÃO } & \multicolumn{4}{|c|}{ EXPORTAÇÃO } & \multicolumn{4}{|c|}{ TOTAL } \\
\hline & & $\begin{array}{l}\text { Carga } \\
\text { Geral }\end{array}$ & $\begin{array}{l}\text { Sollidos } \\
\text { a Granel }\end{array}$ & $\begin{array}{l}\text { Liquidos } \\
\text { a Granel }\end{array}$ & Soma & $\begin{array}{l}\text { Carga } \\
\text { Geral }\end{array}$ & $\begin{array}{l}\text { Solidos } \\
\text { a Granel }\end{array}$ & $\begin{array}{l}\text { Liquidos } \\
\text { a Granel }\end{array}$ & Soma & $\begin{array}{l}\text { Carga } \\
\text { Geral }\end{array}$ & $\begin{array}{l}\text { Sollidos } \\
\text { a Granel }\end{array}$ & $\begin{array}{l}\text { Liquidos } \\
\text { a Granel }\end{array}$ & Soma \\
\hline & 2007 & 7.447 .215 & 7.964 .064 & 2.391 .496 & 17.802.77 & 38.578 & 14.672 .418 & & 9.077 & 21.285 .793 & 22.636 .482 & 10.239 .577 & 54.161 .852 \\
\hline & 2008 & 8.709 .6 & 7.062 .285 & 2.477 .553 & 18.249 .481 & 12.966 .915 & 15.119 .659 & 6.362 .465 & 49.039 & 21.676 .558 & 22.181 .944 & 8.840 .018 & 52.698 .520 \\
\hline $\mathrm{T}$ & 2009 & 6.322 .144 & 5.066 .723 & 2.538 .708 & 13.927 .575 & 12.007 .158 & 20.343 .497 & 7.274 .568 & 39.625 .223 & 18.329 .302 & 25.410 .220 & 9.813 .276 & 53.552 .798 \\
\hline o & 2010 & 9.289 .127 & 7.640 .731 & 3.530 .763 & 20.460 .621 & 12.885 .442 & 22.783 .916 & 6.753 .210 & 42.422 .568 & 22.174 .569 & 30.424 .647 & 10.283 .973 & 62.883 .189 \\
\hline $\mathrm{T}$ & 2011 & 10.133 .809 & 8.897 .874 & 3.385 .754 & 22.417 .437 & 13.076 .966 & 21.785 .318 & 7.025 .909 & 41.888 .193 & 23.210 .775 & 30.683 .192 & 10.411 .663 & 64.305 .630 \\
\hline A & 2012 & 10.499 .289 & 7.888 .935 & 3.047 .734 & 21.435 .958 & 13.985 .717 & 24.654 .588 & 7.060 .843 & 45.701 .148 & 24.485 .006 & \begin{tabular}{|l|l|l}
32.543 .523 \\
\end{tabular} & 10.108 .577 & 67.137 .106 \\
\hline \multirow[t]{4}{*}{ L } & 2013 & 11.349 .325 & 8.343 .044 & 2.689 .035 & 22.381 .404 & 14.982 .363 & 30.366 .782 & 7.874 .578 & 53.223 .723 & 26.331 .688 & 38.709 .826 & 10.563 .613 & 75.605 .127 \\
\hline & 2014 & 11.968 .360 & 7.758 .157 & 2.962 .965 & 22.689 .482 & 15.841 .883 & 28.307 .346 & 6.870 .742 & 51.019 .971 & 27.810 .243 & \begin{tabular}{|l|}
36.065 .503 \\
\end{tabular} & 9.833 .707 & 73.709 .453 \\
\hline & 2015 & 12.717 .444 & 6.110 .970 & $\begin{array}{ll}.302 .300 \\
.187 .838\end{array}$ & 22. & 17.620 .374 & 30.599 .293 & 7.410 .203 & 55.629 .870 & 30.337 .818 & \begin{tabular}{|l|}
36.710 .263 \\
36.263
\end{tabular} & $\begin{array}{r}9.0598 .091 \\
0.598 .09\end{array}$ & 77.646 .172 \\
\hline & 2016 & 11.065 .084 & 5.318 .594 & 4.061 .420 & 20.445 .098 & 17.510 .546 & 34.320 .836 & 6.345 .232 & 58.176 .614 & 28.575 .630 & 39.639 .430 & 10.406 .652 & 78.621 .712 \\
\hline
\end{tabular}

Fonte:CODESP (2016)

É possível dizer que através desses resultados a movimentação de carga geral ainda tem um destaque em relação a movimentação total de granel, mesmo sendo um índice menor o resultado é razoável, ou seja, ainda produz lucratividade e se investido corretamente ainda pode gerar grandes resultados para a área portuária. 


\subsection{IMPACTOS NO PORTO E EM SEUS EQUIPAMENTOS}

O processo de carregamento de carga especial dentro do porto de Santos conta com alguns terminais especializados que utilizam equipamentos tais como equipamentos de bordo, MHC - mobile harbor cranes utilizados para embarque das cargas de projeto, que segundoMagalhães (2011)são os equipamentos com maior importância, portêiner dependendo da carga, por exemplo as pás eólicas que podem ser apenas utilizadas com as de pequeno porte, terminal tractor em conjunto com o rolltrailerque são equipamentos produzidos por grandes empresas onde a maior produtora é a MAFI, empilhadeiras de grande porte, caminhão munck (caminhões que conseguem erguer uma boa quantidade de peso) com plataforma elevadiça e por fim guindastes patolados.

Ainda seguimentando a idéia de Magalhães (2011 p.117) "Por serem de custo mais baixo que os portêineres e terem menor prazo de entrega, os MHC vêm conquistando operadores que procuram alternativas de baixo risco, com maior flexibilidade" com isto fica claro que os MHC são um dos equipamentos que mais estão em alta e estes são importantes para a movimentação das cargas especiais.

\section{CARGAS ESPECIAIS E O SEU ACESSO AO PORTO DE SANTOS}

O acesso ao porto de Santos é definitivamente um dos grandes tópicos do artigo, já que grande parte das vias de acesso portuário tem algumas deficiências. Segundo a CODESP (2016) uma das vias que faz a ligação principal para a via de acesso ao porto tem uma curva muito estreita fazendo com que alguns tipos de cargas tenham possibilidade de apresentar algumas dificuldades no fator de acesso.

Ainda segundo a CODESP (2016) "Fica claro que cada vez mais precisamos de maiores incentivos por parte de layouts logísticos e planejamento por parte de entidades superiores", ou seja, é definitivamente notável que existe a necessidade de órgãos para poder melhorar as questões de planejamento de área.

Levando em consideração estes fatos as cargas que normalmente sofrem este tipo de situação são as cargas que são superdimensionadas, tanto que uma das vias que compreendem a passagem faz com que o acesso seja dificultoso onde o caminhão ou o comboio que estiver passando tenha que até interferir no tráfego da via paralela como visto na figura 4 abaixo.

Figura 4 - Viaduto de Acesso a perimetral de Santos

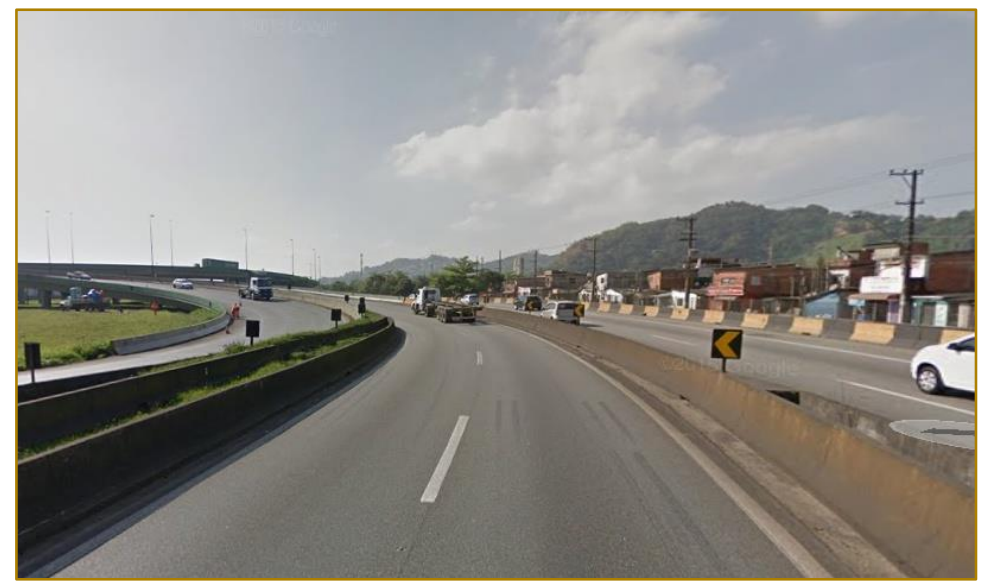

Fonte: Google Maps (2016)

Um caminhão superdimensionado com cargas especiais tem muitas dificuldades para conseguir passar por algumas regiões tais como os viadutos citados na figura acima.

Segundo ainda informações cedidas pela CODESP (2016) o porto de Santos tem grande movimentação de cargas gerais e especiais, porém por incrível que pareça grande parte dos problemas são direcionados para a aplicação de transporte como um todo, sendo assim é possível afirmar que mesmo com o grande potencial de movimentação ainda existem problemas relacionados a infraestrutura das vias da região, dificultando 
o acesso e assim fazendo com que cargas que deveriam ter um delay de entrega menor acabem travando no meio do caminho e gerando cada vez mais atrasos dentro da programação portuária.

Na próxima figura é possível notar um dos principais gargalos que existem dentro das vias de acesso ao porto de Santos, que segundo a CODESP (2016) já existem planos para uma tentativa de ajuste destas vias, porém este processo é complicado pois as vias já estão construídas e quaisquer ajustes além de demorar poderiam influir em alguns resultados negativos para os moradores perto do local sem contar os congestionamentos que quaisquer modificações da via poderiam acarretar assim atrasando ainda mais o escoamento de produção ou mesmo até a entrega de cargas especiais superdimensionadas.

\subsection{CARGAS ESPECIAIS NAS RODOVIAS E ENTRADAS DE SANTOS}

Segundo a CODESP (2016) quaisquer mudanças ou modificações destas vias precisam ser bem analisadas para não serem feitas em vão e de forma irresponsável, tanto que são projetadas como segue a figura 5 abaixo.

Figura 5 - Algumas vias de acesso ao porto.

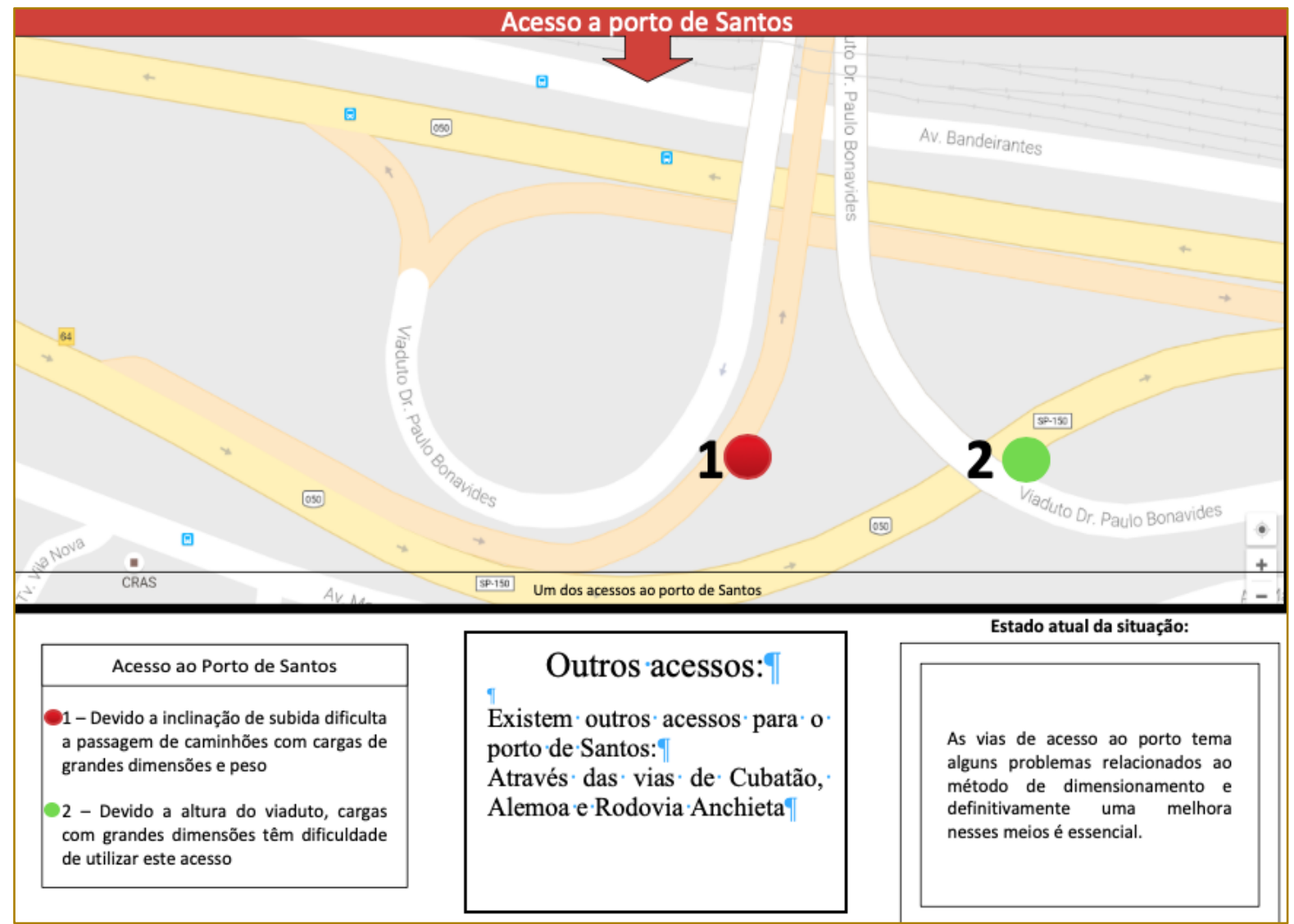

Fonte: Autores (2016)

Analisando a situação acima não é novidade que as cargas especiais tenham em consideração metodologias diferenciadas para execução do seu transporte, pois qualquer erro dentro deste processo de operação pode influir negativamente em todo o resultado do porto de Santos no sentido de travar alguma via principal de acesso ou mesmo até danificar a estrada parando todo o trânsito, lembrando diretamente o setor de transporte de commodities que movimenta inúmeros caminhões para a área diariamente.

Como dito acima as vias de acesso ao porto contam com uma infraestrutura deteriorada para o recebimento de cargas de tamanhos diferenciados o que já foi constatado e projetos para melhorar estes gargalos já estão em cogitação, segundo Porto de Santos 
(2016) "A Companhia Docas do Estado de São Paulo (Codesp) iniciará na segunda quinzena de outubro a segunda etapa das obras de melhoria da infraestrutura viária da margem direita do Porto de Santos, na região do Saboó" o que nada mais é que o começo para outras obras de melhorias para o recebimento de carga na área.

A figura 6 abaixo mostra o procedimento de curva que é pensado para a estruturação de infraestrutura rodoviária.

Figura 6 - Processo de curva de Caminhões

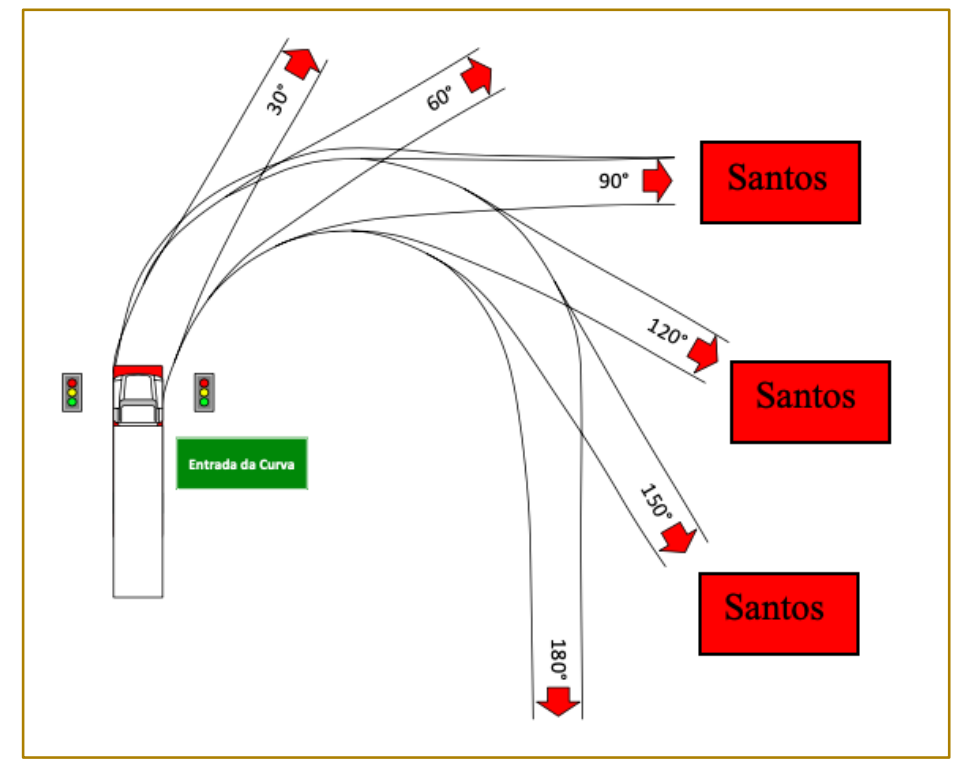

Fonte: Autores (2016)

Perto do viaduto Paulo Bonavides em Santos a curva presente em sua elaboração não permite que cargas muito longas consigam subir de forma adequada, tendo por referência dois docentes da Universidade Politécnica da Universidade de São Paulo, KABBACH JUNIOR e BOTTURA (2007) é possível visualizar através dos materiais disponibilizados (PTR 2378) onde é dito que "Combinações de veículos de carga geralmente são bastante longosrequerem grandes larguras para executar o giro" ou seja para que os caminhões de cargas especiais conseguissem passar pelo viaduto haveria a necessidade de aumentar a largura do viaduto para que a curva fosse possível, através então dos conteúdos passados em suas aulas fica notável que os viadutos em Santos não comportam o transporte para cargas muito dimensionadas.

Levando em consideração os materiais publicados por KABBACH JUNIOR e BOTTURA (2007) é possível ter uma grande ideia de que os procedimentos de criação de infraestrutura e construção das mesmas levam diversos fatores para serem concebidos e que definitivamente um viaduto ou uma curva que irá receber caminhões com grandes dimensões precisa ter uma largura muito maior para que a Carga consiga executar a curva e não danificar a via e muito menos a carga em si.

O raio de giro mínimo calculado é um estudo que consegue fazer com que o caminhão ao executar a curva tenha o espaço suficiente para fazer todas as manobras pensadas para a estrutura, e é justamente calculado para todos os caminhões que irão passar ou transitar pelas vias.

Como é possível visualizar na figura 7 abaixo já existem programas que simulam o cálculo de giro mínimo e podem ter a possibilidade de verificar essa margem para que nenhum caminhão tenha problema ao transitar nas vias projetadas. 
Figura 7 - Cálculo de Simulações de Manobras de Giro

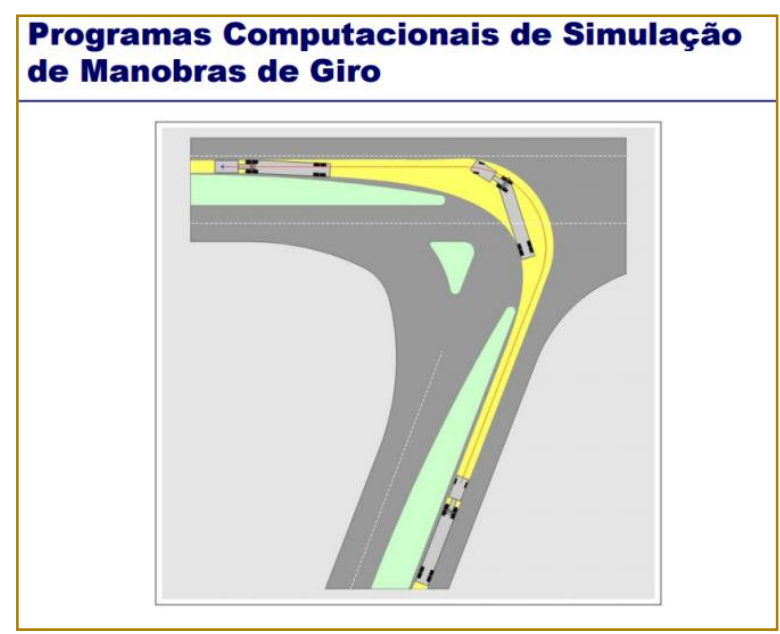

Fonte: Material - KABBACH JUNIOR e BOTTURA (2007)

Como foi dito anteriormente as vias de Santos poderiam nestas próximas atualizações e manutenções começar a ser modificadas para que 0 recebimento de cargas superdimensionadas e especiais fosse considerado, pois mesmo com a crise existe um crescimento para o mercado anualmente.

\subsection{IMPACTOS NA ÁREA PORTUÁRIA DA REGIÃO DE SANTOS}

Depois de todas essas informações é possível perceber que o processo de transporte de cargas especiais fazem com que o deslocamento normal das linhas de chegada ao porto seja modificado e este então este sofre algumas situações que podem sim fazer com que seu funcionamento normal possa ser prejudicado, no caso por exemplo, um transporte específico de grandes transformadores fazem com que a via perimetral e as vias de ligação com a cidade sejam fechadas, então tomando este raciocínio, mesmo que esta situação ocorra no período da madrugada e obviamente este processo só ocorre justamente neste período e com a autorizações dos órgãos competentes dado o devido os transtorno e perigo que esse tipo de transporte retorna, fica claro que esta situação irá gerar um reflexo diretamente no resultado de operações que trabalham durante o horário da operação em questão, pois o porto trabalha vinte e quatro horas por dia.

Então levando em consideração todos os tópicos de estudo em relação a adaptação a infraestrutura do acesso ao porto as Cargas Especiais ainda tem possibilidade de fechar as vias em formatos de comboios com velocidade controlada atrasando outras cargas que estão em espera nas vias, já que segundo a CODESP (2016) ainda que de madrugada o recebimento de carga não para, dito isto é possível perceber que o recebimento de cargas especiais através das vias de acesso é algo mais sério e que precisa ser trabalhado de forma responsável e precavida para que os resultados obtidos não sejam catastróficos ou negativos para o país como um todo.

\subsection{SITUAÇÕES ESTATÍSTICAS ENVOLVENDO OS TRANSPORTES E RELATÓRIOS}

É notável a quantidade de carros que se encontra uma fila de trânsito pesado devido ao tamanho e a velocidade de locomoção do caminhão com a carga especial, tendo em vista que em uma situação normal seria possível dizer que outros caminhões normais como caminhões de containers ou caminhões de granel sólido estariam "presos" neste mesmo congestionamento, seguindo esta lógica seria possível dizer que este tipos de processo de transporte podem sim, causar algum impacto em relação a chegada de caminhões no porto, grande parte das cargas que vem para o porto de Santos são destinadas à exportação e sendo assim trabalhando no caso de uma relação de mais de $70 \%$, abaixo no gráfico é possível ter uma ideia da movimentação do porto. 
Gráfico 2 - Estatística do Relatório da CODESP - Jan/Jul

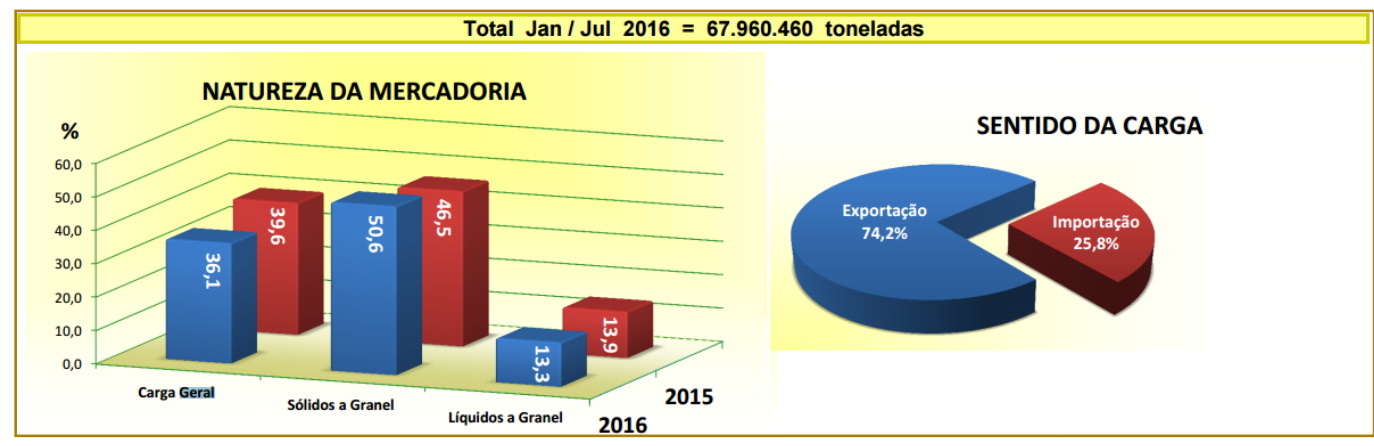

Fonte: CODESP (2016)

Ou seja, as cargas gerais representam $36,1 \%$ das movimentações de janeiro a julho de 2016 então quaisquer problemas que acontecerem relacionando o transporte rodoviário destes tipos de cargas podem influir diretamente no recebimento dos outros tipos de cargas que representam mais de $60 \%$ do recebimento de todo o porto.

Levando em consideração esses dados, fica bem nítido que mesmo sendo uma carga de menor movimentação, ainda assim exerce números surpreendentes considerando que existam terminais que não têm movimentações de cargas especiais, também é notável dizer que existe um processo muito maior de importação de cargas gerais do a própria exportação. Como visto durante o trabalho a figura 8 exemplifica o problema.

Figura 8 - Transporte de Transformadores (Acesso Santos)

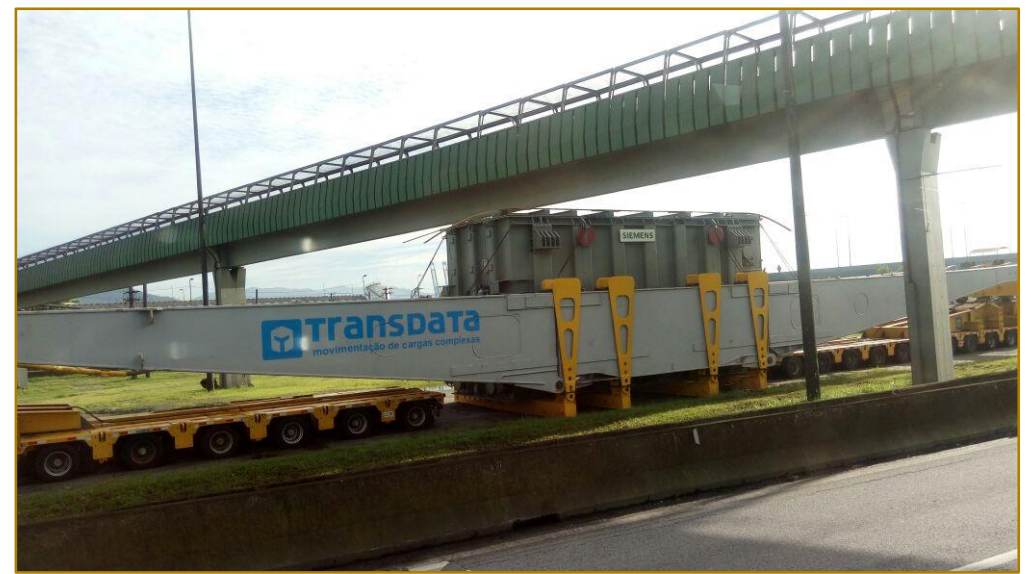

Fonte: Autores (2016)

\section{CONSIDERAÇÕES FINAIS}

Através de todos os tópicos abordados no artigo é possível analisar que Santos realmente tem um índice razoável de recebimento de cargas especiais levando em consideração a infraestrutura não muito bem construído, e que através de algumas mudanças e investimentos públicos nos setores corretos de mobilidade urbana e engenharia seria possível diminuir o tempo de viagem e a dificuldade que as cargas especiais encontram para chegar aos terminais responsáveis pela sua exportação.

Também é visto que o Santos tem alguns problemas no acesso primário ao porto e que alguns tipos de cargas que são superdimensionadas e não conseguiriam passar de forma adequada, assim sendo necessário obras de ampliação e infraestrutura por parte do Estado e com o auxílio da CODESP para que seja possível prever os futuros cenários da área. 
Fica definido então a real necessidade de maiores estudos para que quaisquer alterações que forem executadas na área não

\section{REFERÊNCIAS}

[1] ANTAQ. Agência Nacional de Transportes Aquaviários. ANTAQ, 2015. Disponivel em: <http://www.antaq.gov.br/Portal/>. Acesso em: 26 out. 2015.

[2] CODESP. Porto de Santos. Relatório Mensal, 2016. Disponivel em: $<$ http://www.portodesantos.com.br/>. Acesso em: 01 ago. 2016.

[3] CONTRAN. Contran, 2016. Disponivel em: <http://www. denatran.gov.br/index.php/contran>. Acesso em: 10 Setembro 2016.

[4] JOSÉ, L. L. D. O.; GRI, M. P. D. S.; FRANÇA, T. F. B. D. PLANEJAMENTO LOGÍSTICO DOS TRANSFORMADORES DE CORRENTE CONTÍNUA EM ALTA TENSÃO (HVDC), Santos, 28 Outubro 2015. 10. afetem a população e o resultado portuário negativamente.

[5] KABBACH JUNIOR, F. I.; BOTTURA, E. J. PTR 2378 - Projeto de infra-estrutura de vias de Transportes Terrestres. São Paulo: São Paulo, 2007. Desenvolvido na Politécnica da USP.

[6] MAGALHÃES, P. S. B. Transporte Marítimo: Cargas, Navios, Portos e Terminais. São Paulo: Aduaneiras, 2011. 242 páginas.

[7] Porto de Santos .Novas Obras de Acesso ao Porto. Disponivel em: <http://www.portodesantos.com.br/pressRelease.p hp?idRelease $=1046>$. Acesso em: 3 out. 2016.

[8] SCHOELER, S. L. A MOVIMENTAÇÃO DE CARGAS PESADAS EM PORTOS BRASILEIROS:, Florianópolis, p. 118, 2000. 


\section{Gapítulo 10}

\section{OPERADORES LOGISTICOS \\ TERCEIRIZADOS: \\ $U M A$ INOVAÇÃO ESTRATEGICA MEDICAMENTOS}

\section{Adriana Formigone}

Resumo: Na gestão de distribuição de medicamentos, as empresas precisam manter a qualidade e inovação do nível do serviço prestado e assim garantir lucro com a redução de custos.

Através desta informação, a terceirização da logística de distribuição deve ser considerada como uma oportunidade competitiva. Sendo assim, o objetivo deste estudo será a analise da contribuição do uso de operadores logísticos terceirizados, como estratégia de negócio na inovação da distribuição de medicamentos pelas empresas atacadistas e varejistas.

Para atingir este objetivo, uma análise bibliográfica com uma abordagem qualitativa descritiva foi desenvolvida sobre os cenários logísticos de distribuição do medicamento, sobre as vantagens e desvantagens, influências, complexidade das operações e inovações observadas com a terceirização da gestão por operadores logísticos.

Os resultados mais relevantes foram detectados como: as soluções de armazenagem e automação, excelência no nível dos serviços armazenagem, transporte, comunicação, sistema de informação eficaz, otimização do uso do espaço da planta para produção, oportunidades de inovação na distribuição de medicamentos, avanço da tecnologia na rastreabilidade dos produtos e maior globalização na distribuição de produtos.

O estudo concluiu que a influência dos operadores logísticos terceirizados, exerce positivamente melhorias na gestão da distribuição de medicamentos, tornando-se uma estratégia de negócio inovadora para as empresas do segmento de medicamentos.

Palavras-Chave: Medicamentos; Logística; Distribuição; Terceirização. 


\section{INTRODUÇÃO}

A logística está sempre inovando e desenvolvendo organizações que desenvolvam serviços para suprir a necessidade do mercado. A cadeia de suprimentos do setor industrial farmacêutico é um segmento de grande importância para o cenário econômico e na politica de saúde pública nacional, devido a isto, a busca por uma excelência logística de medicamentos, faz com que as empresas invistam em infraestrutura, para que o gerenciamento desta cadeia de suprimento seja peça fundamental na estratégia de negócio das empresas públicas e privadas tornando-se mais competitivas.

O aumento da busca por inovações na gestão da complexidade dos processos e infraestrutura, tem levado as indústrias farmacêuticas a optar pela terceirização de suas atividades, surgindo assim, a busca pelos serviços operacionais logísticos terceirizados.

Operadores Logísticos, são empresas capacitadas em analisar, planejar, operar de forma integral e inovar as múltiplas atividades ligadas a logística, como armazenagem, estoque e transporte.

Devido o assunto ser de amplo desdobramento, o objetivo proposto para este estudo será uma análise bibliográfica e descritiva sobre uma análise a respeito do uso de operadores logísticos terceirizados como uma estratégica inovadora na distribuição de medicamentos pelas empresas atacadistas e varejistas

Os itens que se seguem, descrevem a primeira parte da abordagem bibliográfica descritiva, sobre cadeia de valor do medicamento, a logística como estratégia de negócio e os centros de distribuição com suas redes de instalações. Durante o desenvolvimento deste estudo, foi realizada uma análise teórica apresentando as possibilidades para a implantação da atividade dos operadores de serviço logísticos associada a redução dos custos e assim, implementar estratégias de aperfeiçoamento dos processos para aumento da flexibilidade e escoamento do estoque, agregando valor a cadeia de medicamento.

\subsection{MEDICAMENTO: CADEIA DE VALOR}

As empresas públicas e privadas, envolvidas na fabricação dos medicamentos, requerem critérios de integridade, qualidade e segurança na fabricação.

Os medicamentos são constituídos, nos termos da Lei no 5.991/1973, como um produto farmacêutico com a intenção de promoção de resultados específicos como a cura da enfermidade, redução ou eliminação de sintomas, controle do progresso de doenças ou como medida de prevenção a enfermidades.

Como descrito por Graciani e Ferreira (2014, p.11), os medicamentos produzidos em larga escala consolidaram-se como elemento acessível a todos os extratos sociais e passíveis de utilização por indivíduos de toda e qualquer faixa etária.

\subsection{LOGÍSTICA: ESTRATÉGIA DE NEGÓCIO}

Devido a dinâmica e evolução da economia global, o sistema logístico se tornou uma estratégia fundamental na competitividade das empresas. Estes benefícios estratégicos da logística, começam com uma boa gestão de todas as áreas de trabalho, as convergências destes elos levam a obtenção do resultado esperado. Segundo Bowersox et al. (2014, p.37), o entrosamento e integração desta rede começa nas cinco áreas de trabalho logístico, são elas: Armazenamento/manuseio de materiais e embalagens, Estoque, Processamento de pedidos, Redes de instalações e Distribuição.

A logística é definida como processo de planejamento, implantação e controle do fluxo eficiente e eficaz de mercadorias, serviços e de manter as informações desde o ponto de origem até o destino final, com o propósito de atender as necessidades dos clientes. (Costa; Vilhena, 2016, p.3)

A cadeia de suprimentos envolve as atividades de compra, armazenamento, transformação, embalagem, transporte, movimentação interna, distribuição e todo o suporte necessário para que tudo possa acontecer integradora para administrar o fluxo total de um canal de distribuição do fornecedor até o usuário final. (MAZZALI; MAKIYA; CESAR, 2016, p. 2 e 11)

Em algumas situações e de acordo com a demanda, os produtos devem ser colocados em disponibilidade próximos dos mercados 
consumidores. Entretanto, nem sempre as fábricas que os produzem estão próximas dos mercados que os consomem.

De acordo com Gobbo (1999, p.23), como o consumo desses produtos ocorre continuamente, deve haver um fluxo contínuo de produtos escoados pelos canais de distribuição, para que os consumidores encontrem produtos nos pontos de vendas, o canal de distribuição precisa estar preenchido para atendimento ao consumidor final.

Sendo assim, o canal de distribuição deverá ser agregado com outros modais, como: depósitos, entrepostos, meios de transporte, distribuidores regionais e locais.

\subsection{CENTRO DE DISTRIBUIÇÃO: CADEIA DE MEDICAMENTO}

Os centros de distribuição são projetados para colocar produtos em movimento e não apenas para armazená-los. (SANTOS, 2006, p.35)

Diversas vantagens são identificadas na literatura quanto à adoção do centro de distribuição (CD) no sistema logístico. Essas vantagens obtidas pela centralização de estoque podem beneficiar todos os elos da cadeia: fornecedor, empresa e consumidor.

A principal finalidade dos CDs consiste em oferecer melhores níveis de serviço ao cliente, através da redução do lead time (tempo de ressuprimento) pela disponibilidade dos produtos o mais próximo do ponto de venda, agilizando $\mathrm{O}$ atendimento dos pedidos. (SANTOS, 2006, p.35)

Já no segmento varejista, segundo Setem (2015), os hospitais e planos de saúde mostram um movimento de introdução do conceito de logística nas suas operações, potencializando oportunidades de mercado para os operadores de serviços logísticos.

\subsection{CENTROS DE DISTRIBUIÇÃO: REDES DE INSTALAÇÃO}

A infraestrutura implantada é bem clara e especifica quanto ao controle do armazenamento e distribuição de medicamentos. Relacionada a redução de custos na distribuição, as indústrias estão investindo em centros de distribuição (CD) próprios ou terceirizados.
Conforme as legislações estabelecidas pela Agência de Vigilância Sanitária - ANVISA (2013, p.1-2), através da Resolução RDC n³9/2013, o qual atesta com a emissão do Certificado de Boas Práticas de Distribuição e/ou Armazenagem (CBPDA), os estabelecimentos de distribuição que praticam de suas exigências. Esta questão foi reforçada por Leonardi (2017), onde afirma que o almoxarifado deve ser projetado de acordo com as necessidades dos produtos e matérias-primas. O controle térmico e seu monitoramento são imprescindíveis durante todo o período de estocagem do produto, aumentando a segurança do processo.

Como descrito por Rodrigues e Pizzolato (2003, p.7), os centros de distribuição contribuem para um maior controle das operações logísticas e permitem uma melhoria nos serviços aos clientes.

Todo este rearranjo de uma rede de instalação, compreende algumas decisões, como: localização das instalações de produção e/ou armazenagem, capacidade de cada instalação e conexões entre instalações. Como reforçado por Fialho e Martins (2016, p. 822), onde declaram que as redes de instalação dependem do envolvimento através do número de armazéns e plantas, do tamanho dessas instalações, da sua localização geográfica, dos fluxos físicos, dos fluxos de informações necessárias e dos padrões de fornecimento.

\section{METODOLOGIA}

O tema relacionado sobre logística de armazenamento e distribuição, são de amplo desdobramento, portanto, para a construção deste estudo foi adotada a pesquisa bibliográfica a partir do levantamento de referências como livros, artigos científicos, páginas de web sites, com o objetivo traçado sobre a abordagem qualitativa descritiva referente aos cenários logísticos de distribuição do medicamento, apresentando suas vantagens, desvantagens, influências, complexidade das operações e inovações observadas com a terceirização da gestão por operadores logísticos.

Através destes temas e das palavras chaves, foi possível fazer o levantamento nas bases de dados nos sites de pesquisa de periódicos, como Capes, Google Acdemic, PubMed, Science academic e revistas institucionais do segmento farmacêutico. 
Foi adotado os critérios de impacto das informações a respeito do assuntos pesquisados, no período de 2000 a 2018, porém as relevâncias mais consistentes sobre o assunto, foi obtido no período de 2013 a 2018.

\section{MATERIAL E MÉTODOS}

\subsection{CENTROS DE DISTRIBUIÇÃO PRÓPRIOS (EMPRESA): VANTAGENS DA TERCEIRIZAÇÃO}

Os centros de distribuição podem ser de caráter próprio ou terceirizado e tem a função de controlar as operações logísticas, desenvolvendo a agilidade e flexibilidade dos pedidos solicitado pelo cliente.

A indústria farmacêutica possui lacunas operacionais quanto à automação e as soluções de armazenagem, além de restrições específicas no que diz respeito à movimentação e ao transporte de medicamentos. Tais buscas por melhorias e desenvolvimento abrem um grande potencial para terceirização. (SETEM, 2015)

A decisão de terceirizar parte do estoque permite que a indústria farmacêutica otimize o uso do espaço da planta para produção. Essa prática vem ampliando a importância dos operadores de serviço logístico, que de forma resumida possui a função de receber os medicamentos, estocá-los e de acordo com os pedidos de faturamento, expedi-los.

Para reduzir os custos de distribuição de seus produtos, uma das principais estratégias adotadas pela indústria é a utilização dos centros de distribuição terceirizados. (RODRIGUES e PIZZOLATO, 2003, p.7)

De acordo com Setem (2015), além da possibilidade de redução de custos, os principais motivadores para a terceirização na indústria farmacêutica estão ligados ao conhecimento (Know-how) para otimização das operações; Dificuldades em equilibrar as exigências específicas: carga delicada, rastreabilidade, rapidez e controle de temperatura; Visibilidade no inventário (localização, movimentação e controle); Ambiente regulatório complexo.

Sendo assim a demanda gerada, criará inovações tecnologias, de gerenciamento, software e sistemas de comunicação, permitindo uma melhor coordenação das atividades dispersas. (QUINN, 2000)
3.2 OPERADORES LOGÍSTICOS: TERCEIRIZAÇÃO - INFLUENCIAS NA CONTRATAÇÃO

Para Fleury (1999), a competência logística pode gerar significativa vantagem competitiva em três dimensões de desempenho: eficiência, eficácia e flexibilidade. É possível obter valor estratégico à atividade desempenhada por meio da logística e tal valor não se limita somente a tradicional visão de redução de custos. Sendo assim, segue abaixo, os 5 principais fatores que tem pressionado a logística no sentido de atingir uma maior complexidade estratégica.

\subsubsection{PROLIFERAÇÃO DE PRODUTOS}

Está associado ao desenvolvimento tecnológico e a difusão do conceito de diferenciação, fazendo com que as empresas farmacêuticas lancem novos produtos. (FLEURY, 1999).

Para Akkari et al. (2016, p.368), o estimulo dos pesquisadores as inovações farmacêuticas seria a a redução de impostos sobre os lucros a partir da criação de novas patentes, porém o que se cumpri é um padrão arbitrário de relação custo-eficácia.

\subsubsection{GLOBALIZAÇÃO E A REGULAMENTAÇÃO DE MEDICAMENTOS}

De acordo com Sanches (2018), estudos indicam que os gastos globais com medicamentos atingirão US\$1,3 trilhão.

A descentralização da produção de medicamentos e sua comercialização nas redes varejistas, se deparam com os produtos importados, porém a morosidade legislativa nacional impede o avanço destes produtos no mercado nacional e assim a perda de competitividade.

Com relação a mobilização global na internacionalização de mercados, quanto maior for a uniformidade entre os diferentes ordenamentos jurídicos, maior será a velocidade da circulação dos bens, pessoas e informações. (AITH et al, 2014, p.24.)

\subsubsection{MAIOR EXIGÊNCIA DOS SERVIÇOS}

A principal finalidade dos centros de distribuição (CD's) consiste em oferecer melhores níveis de serviço ao cliente, através da redução do lead time (tempo de 
ressuprimento) pela disponibilidade dos produtos o mais próximo do ponto de venda, agilizando 0 atendimento dos pedidos. (SANTOS, 2006, p.35)

O sistema de distribuição na cadeia produtiva, transporta o produto final da fábrica para um depósito ou centro de distribuição, e entrega as quantidades adequadas ao estabelecimento de varejo no momento em que for solicitado. (RODRIGUES, 2013, p.5)

\subsubsection{MENORES CICLO DE VIDA DOS PRODUTOS.}

Se relacionam as politica de lançamento de novos produtos mais eficazes e declínio de sua participação no mercado, criando uma logística de controle dos ciclos de produção, níveis de estoque e distribuição. (FLEURY, 1999)

Segundo relatório da IQVIA (Institute for Human Data Science), estima-se que o crescimento anual médio desses medicamentos de prescrição médica, será de $6,3 \%$ até 2020. Já os projetos de pesquisa e desenvolvimento de fármacos (P\&D) devem ser responsáveis por $50 \%$ do aumento das vendas em 2022. (PANORAMA FARMACÊUTICO, 2018)

\subsubsection{A SEGMENTAÇÃO DE MERCADOS}

De acordo com FLEURY (1999), a logística do processo necessita de estruturas flexíveis, que atendam as diversas exigências, sem aumentar os custos e de uma politica de utilização dos canais de distribuição, com padrões de serviço para o mesmo ou diferentes segmentos.

Como descrito por Fialho (2016, p. 822), os valores, crenças e significados compartilhados em uma cadeia de suprimentos podem explicar o desempenho da empresa em termos de custo, qualidade, entrega e flexibilidade.

\subsection{OPERADORES LOGÍSTICOS: DESVANTAGEM NA CONTRATAÇÃO}

Dentre as principais desvantagens da terceirização na cadeia de suprimentos estão o controle tecnológico e a maior dependência dos parceiros estratégicos. Logo o objetivo principal está na busca para as parcerias que tragam os benefícios associados à integração vertical sem, no entanto, incidir na perda de flexibilidade associado à uma estrutura, fato comum em organizações verticalmente integradas. (JARDIM; GUIMARÃES, 2004, p.3).

A redução dos custos, é a primeira opção de estratégia em qualquer empresa. Para isto os setores mais observados para esta redução estão os investimentos em infraestrutura, como, armazenagem, frota, tecnologia de informação e controle do estoque, porém a escolha da terceirização, deve ser avaliada com cautela pois pode apresentar algumas desvantagens como descritas a seguir.

\subsubsection{DIRECIONAMENTO ESTRATÉGICO}

Ribeiro e Prieto (2013, p. 671), afirmam que a terceirização torna o direcionamento estratégico mais lento e engessado.

\subsubsection{PREVISÃO DAS METAS ESTABELECIDAS}

A previsões de metas para Fleury (1999) é um fator a ser avaliado, os operadores logísticos podem dimensioná-las, não cumprindo com o estabelecido. Gerando um desapontamento entre as partes.

\subsubsection{DIMINUIÇÃO DE CONTROLE NOS PROCESSOS DECISÓRIOS.}

Como declarado por Ribeiro e Prieto (2013, p. 671), os processos com mais envolvidos e menor poder de cada um, aumenta a dificuldade de estabelecer objetivos comuns.

\subsubsection{ENFRAQUECIMENTO DA IDENTIDADE ORGANIZACIONAL}

Para Ribeiro e Prieto (2013, p. 671), a construção da identidade está baseada no consistente controle sobre o desempenho da empresa. A a partir do momento em que há outro envolvido a identidade de ambos tende a se fundir, prevalecendo o mais forte.

\subsubsection{PERDA DA COMPETÊNCIA INTERNA E CONHECIMENTO INTELECTUAL}

A dependência excessiva da empresa contratante ao operador logístico, declarado por Ribeiro e Prieto (2013, p. 671), o compartilhamento de formas de atuação pode 
gerar a transfer6encia de um conhecimento para outra empresa e acarretar desvantagens futuras.

\subsection{DESAFIOS DOS OPERADORES LOGÍ́STICOS}

Os principais fatores que influenciam o crescimento da demanda por produtos farmacêuticos no Brasil, são o envelhecimento da população, maior uso dos medicamentos genérico, subsídios concedidos, pelo governo federal, a consumidores de baixa renda, como o Programa Farmácia Popular. (FIGUEIREDO, 2017)

O Programa Farmácia Popular promulgado em 2004 preconiza a ampliação de ações voltadas à universalização do acesso da população aos medicamentos. Em 2016, o programa foi ampliado para que o setor varejista privado agregasse a distribuição a população.

Como declarado por Figueiredo (2017), as farmácias da rede privada, uma vez credenciadas ao programa, passaram a vender medicamentos a um custo menor, graças ao subsídio do governo federal.

Após dez anos, o Programa Farmácia Popular está disponível em 34,6 mil farmácias, presentes em 4.469 municípios, ou seja, está acessível a uma população de 192 milhões de habitantes, correspondendo a 94\% da população do País.

Em vista da demanda sobre este cenário nacional de distribuição de medicamentos, a terceirização criará novos mercados especializados para garantir a inovação neste segmento.

Entretanto os desafios na gestão das boas práticas são iminentes. De acordo com a resolução № 17/2007, todas as atividades de logística de produtos farmacêuticos devem ser realizadas de acordo com os princípios de boas praticas de fabricação (BPF), boas práticas de armazenagem (BPA), boas praticas de distribuição (BPD) e boas praticas de transporte (BPD). (MAZZALI; MAKIYA; CESAR, 2016, p. 2 e 11)

\subsubsection{TRANSPORTE}

Dentre os transportadores e operadores logísticos registrados no Brasil, estima-se que somente $30 \%$ possuam licenças e certificados perante a Anvisa para o transporte de medicamentos. (FLEURY, 1999)

Ainda segundo o estudo, a malha rodoviária nacional pavimentada, compreende $12,4 \%$, muito inferior à média latino-americana que é de $26 \%$ e a mundial de $57 \%$. Considerando que aproximadamente $57,3 \%$ desta malha viária pavimentada está qualificada como "regular", "ruim" ou "péssima".

Conforme descrito na REVISTA CARGONEWS (2016), o estudo apontou ainda dificuldades na contratação de mão de obra ( $86 \%$ dos entrevistados), principalmente devido à carência de qualificação, como também por causa dos elevados encargos sociais e da escassez de cursos específicos.

\section{RESULTADOS E DISCUSSÃO}

Os resultados observados, através dos levantamentos bibliográficos, mostram que a utilização da terceirização na distribuição de medicamentos por operadores logísticos, oferecem vantagens competitivas que atendam as necessidades das indústrias farmacêuticas, principalmente nas questões de infraestrutura na armazenagem, automação dos processos, tecnologia da informação e gestão de frota.

As vantagens observadas com relação a gestão da terceirização em substituição aos centros de distribuição próprios das empresas, foram nos serviços prestados e nas operações de armazenamento e distribuição de medicamentos garantindo um bom retorno operacional. Outra vantagem analisada, foram os treinamentos das equipes operacionais, devidamente qualificadas para execução das atividades especificas, dispondo de infraestrutura adequada e suporte tecnológico aos processos.

Considerando as desvantagens analisadas, é fundamental que a empresa contratante faça a gestão do alinhamento dos objetivos comuns, juntamente com a empresa contratada (terceirizada). Outros fatores como, controle tecnológico e a maior dependência dos parceiros interferem no direcionamento e previsão das metas estabelecidas, podendo agravar o direcionamento estratégico da empresa.

Com relação ao transporte de carga rodoviário nacional, a infraestrutura de pavimentação deste principal modal é de apenas $12,4 \%$ sendo que a metade está 
qualificada em "regular", "ruim" ou "péssima". Outro fator negativo com relação ao modal rodoviário é a carência de motoristas qualificados e a falta de licenças e certificados específicos para transporte de medicamentos, se somando aos problemas enfrentados na dinâmica logística de distribuição de medicamentos no Brasil.

Em discussão, estão as boas práticas estabelecidas no gerenciamento logístico das indústrias farmacêuticas, com a responsabilidade de oferecer serviço de qualidade flexibilidade e rapidez ao atendimento do setor varejista de medicamento. Em se tratando de uma cadeia onde o fluxo deverá ser constituído por uma distribuição fluida e dinâmica dos medicamentos, o fator competitivo depende da terceirização.

\section{CONCLUSÃO}

A logística apresenta vantagens competitivas no cenário estratégico das indústrias farmacêuticas, nas atividades de armazenamento e distribuição de medicamentos, tendo caráter efetivo no desempenho sobre a eficiência, eficácia e flexibilidade operacionais dos processos.

A análise deste estudo comprova que a terceirização pelos operadores logísticos na distribuição de medicamentos, se torna uma estratégia de negócio que vem evoluindo e inovando o crescimento das indústrias farmacêuticas.

\section{REFERÊNCIAS}

[1] ANVISA-Agência Nacional de Vigilância Sanitária- 2013. Dispõe sobre os procedimentos administrativo para concessão

[2] da Certificação de Boas Práticas de Fabricação e da Certificação de Boas Práticas de Distribuição e/ou Armazenagem. Disponível em: $<$ http://portal.anvisa.gov.br/documents/10181/2871 537/RDC_39_2013_COMP.pdf/f5c15b07-0bd6 4148bc01-8e96a7938d05> Acesso: 5 de junho de 2018.

[3] AITH, F.; DALLARI, S. G. Regulação de medicamentos no mundo globalizado. São Paulo: CEPEDISA, São Paulo, SP, Brasil, p. 24, 2014.

[4] AKKARI, A. C. S. et al. Inovação tecnológica na indústria farmacêutica: diferenças entre a Europa, os EUA e os países farmaemergentes. Gestão \& Produção, São Carlos, S.P, Brasil, v. 23, n. 2, p. 368, 14 jun. 2016.
Apesar do futuro promissor da terceirização dos centros de distribuição das indústrias farmacêuticas, existem desafios a serem explorados, como, a escassez de motoristas qualificados e habilitados para exercer os critérios mínimos necessários ao transporte de medicamentos, a dimensão da distribuição de medicamentos em todo o território nacional e a falta de estrutura na pavimentação nos modais rodoviários.

Mesmo com estes desafios apontados, o estudo oferece subsídios da contribuição pelos operadores logísticos terceirizados (outsourcing) na gestão da distribuição de medicamentos, interferindo positivamente como escolha estratégica no âmbito institucional (público e privado), como uma dinâmica inovadora neste setor da indústria.

Considerando que a logística de distribuição de medicamentos, seja baseada na infraestrutura operacional e tecnológica como princípios fundamentais para a escolha da terceirização pelos operadores logísticos, sugere-se como estudo futuro, uma abordagem no desafio desta distribuição a população brasileira, porém como uma análise mercadológica em um nível globalizado.

\section{AGRADECIMENTOS}

Agradeço ao meu orientador que com seus conhecimentos e orientações contribuíram para a elaboração deste artigo.

[5] BOWERSOX, D. J. Gestão Logística da Cadeia de Suprimentos. Edição: 4a ed. [s.I.] Mc Graw Hill, p.37, 2013.

[6] COSTA, H. S.; VILHENA, J. P. Logística de distribuição de medicamentos na rede pública de saúde do estado do Amapá. VIII Simpósio de Engenharia de Produção de Sergipe. São Cristovão, SE, Brasil, p.3, 2016.

[7] FIALHO, R. C. N.; MARTINS, R. S. Elementos institucionais e desempenho da logística de uma rede pública de assistência farmacêutica. Revista de Administração Pública, Rio de Janeiro, RJ, Brasil, v. 50, n. 5, p. 822, out. 2016.

[8] FIGUEIREDO, M, E. Mercado Farmacêutico: Visão Geral. 2017. Disponível em: $<$ http://www.pgifarma.com.br/mercado-

farmaceutico-visao-geral> Acesso em 30 mai. 2018. 
[9] FLEURY, P. Vantagens competitivas e estratégias no uso de operadores Logísticos. ILOS - Especialista em Logística e Supply Chain. Disponível em:

http://www.ilos.com.br/web/vantagens-

competitivas-e-estrategicas-no-uso-de-operadoreslogisticos> Acesso em 25 mai. 2018.

[10] Gobbo, J. A. J. Gestão da cadeia de suprimentos: Um estudo das transformações em uma relação montadora - fornecedor. Universidade Metodista de Piracicaba, Santa Barbara d'Oeste, SP, Brasil, p. 23, 1999.

[11] GRACIANI, F. S.; FERREIRA, G. L. B. V. Descarte de medicamentos: Panorama da logística reversa no Brasil. Revista ESPACIOS I Vol. 35 (No 5) Año 2014, p.11. 2014. Disponível em: <http://www.revistaespacios.com/a14v35n05/14350 411.html> Acesso em 31 mai. 2018.

[12] Jardim, E. G. M.; Guimarães, L. A. Operadores logísticos: uma síntese dos benefícios e riscos. XI SIMPEP Bauru, SP, Brasil, p.3, 2004

[13] Leonardi, E. Mapeamento térmico na armazenagem de medicamentos. 2017. Disponível em: $\quad<$ http://www.ictq.com.br/industriafarmaceutica/613-mapeamento-termico-naarmazenagem-de-medicamentos> Acesso em 1 jun. 2018.

[14] Mazzali, M. G.; Makiya, I.K.; Cesar, F. I. G. Cadeia logística de fármaco: Uma análise do perfil técnico gestor. XXXVI Encontro Nacional de Engenharia de Produção. João Pessoa, PB, Brasil. p. 2 e 11. 2016. Disponível em: <http://www.abepro.org.br/biblioteca/TN_STO_226_ 319_29679.pdf>. Acesso em: 02 jun. 2018

[15] Panorama Farmacêutico. Indústria farmacêutica: um mercado em ascensão. 2018. Disponível

[16] em: https://panoramafarmaceutico.com.br/2018/04/10/i ndustria-farmaceutica-um-mercado-em ascensão > Acesso em 28 mai. 2018.

[17] QUINN, J. B. Outsourcing Innovation: The New Engine of Growth. Sloan Management Review, ummer. Vol. 41, n. 4, p. 13-28, 2000.
[18] REVISTA CARGONEWS. Estudo da FGV destaca a importância e os desafios do setor de transporte de medicamentos no Brasil. 2016. Disponível em: $<$ http://www.cargonews.com.br/estudo-da-fgvdestaca-importancia-e-os-desafios-do-setor-detransporte-de-medicamentos-no-brasil> Acesso em 15 mai. 2018.

[19] Ribeiro B. B.; Prieto, V. C.. Franquia varejista como vantagem competitiva: múltiplos estudos de caso no segmento de farmácias e drogarias. Gestão \& Regionalidade, Vol. 25, № 75, p.671, $2009 . \quad$ Disponível em:<http://redalyc.org/pdf/1334/133412668008.pdf $>$ Acesso em 28 mai. 2018.

[20] RODRIGUES, G. G.; PIZZOLATO, N. D. Centros de Distribuição: armazenagem estratégica. ENEGEP. p. 7, 2003. Disponível em:< http://www. abepro. org. br/biblioteca/enegep2003_tr0112_0473. pdf> Acesso em: 18 mai. 2018.

[21] Rodrigues, E. F. et al. Processo de distribuição e terceirização: um estudo de caso sobre o impacto na qualidade na implantação do processo de terceirização no sistema de distribuição de uma fábrica de pães em São Paulo. Gestão e Tecnologia para a Competitividade. Resende, R.J. Brasil, p.5, 2013

[22] SANCHEZ, F. A logística como diferencial competitivo do setor farmacêutico I Revista Mundo Logística. Disponível em: <http://www.revistamundologistica.com.br/artigos/a -logistica-como-diferencial-competitivo-do-setorfarmaceutico>. Acesso em: 18 mai. 2018.

[23] Santos, A. Centros de distribuição como vantagem competitiva. Revista Ciências GeraisVol. 10 - № 12, p.35. 2006. Disponível em: <http://pgsskroton.com.br/seer/index.php/rcger/arti cle/view/2710/0> Acesso em 28 mai. 2018.

[24] SETEM, J. LOGÍSTICA NA INDÚSTRIA FARMACÊUTICA: DESAFIOS E OPORTUNIDADES NA TERCEIRIZAÇÃO. ILOS - Especialistas em Logística e Supply Chain, 10 jan. 2015. Disponível em: <http://www.ilos.com.br/web/logistica-naindustria-farmaceutica-desafios-e-oportunidadesna-terceirizacao/>. Acesso em: 28 mai. 2018 


\section{Capítulo 11}

\section{ANÁLISE DO DESEMPENHO LOGÍSTICO COMO ESTRATEGIA PARA FIDELIZAÇÃO DE CLIENTES NO E-COMMERCE}

\section{Marcelo Vinicius da Silva Santos \\ André Di Girolamo \\ Rafael Franco Mendes de Oliveira \\ Eder de Jesus Carvalho}

Resumo: O e-commerce é visto como um meio de transação eletrônica para a compra de produtos e serviços on-line. As empresas do segmento e-commerce enfrentam atualmente diversos desafios para a retenção dos seus clientes com o passar do tempo, os mesmos passaram a receber os produtos com atraso, defeituosos e com alto custo de frete, gerando assim uma insatisfação e a falta de fidelização dos clientes neste segmento. Mediante a isso e a forte concorrência no mercado, algumas empresas passaram a adotar uma estratégia diferenciada para um melhor desempenho logístico e a retenção dos seus clientes. O objetivo principal deste artigo é analisar a estratégia entre o desempenho logístico e a fidelização de clientes no segmento e-commerce. O método considerado para a realização desta pesquisa foi uma survey exploratória com a aplicação de um questionário aos clientes por meio de uma rede social, os resultados foram analisados quantitativamente e qualitativamente e apontam os fatores de desempenho logísticos relevantes para a escolha da melhor estratégia na fidelização de clientes no segmento e-commerce.

Palavras-chave: Estratégia na fidelização clientes; Desempenho logístico; Comércio eletrônico; 


\section{INTRODUÇÃO}

O e-commerce teve sua origem no início da década de 90, quando surgiram os primeiros sites na internet com o objetivo de realizar transações comerciais. Devido a ser um novo conceito, suas transações ainda eram bem reduzidas, porém com a mudança do mercado mundial este conceito de compra e venda se tornou cada vez maior e uma das mais volumosas formas de comercializar serviços ou produtos.

Diante deste aumento de consumidores e vendas nos últimos tempos, o e-commerce passou a ter importante representatividade dentro da economia brasileira, pois de acordo com uma a Empresa Especializada em Informações de Comércio Eletrônico (E-bit), há uma expectativa de alta de 10\% a 15\% para o ano de 2017. Diante deste crescimento, as empresas estão enfrentando atualmente diversos desafios visto que com o passar do tempo, os clientes que compravam através da internet passaram a receber os produtos com atraso, defeituosos e com alto custo de frete, gerando assim uma insatisfação e a falta de fidelização no segmento do e-commerce. Mediante a isso e a forte concorrência no mercado, passou então a ser adotada uma estratégia diferenciada entre o desempenho logístico e a fidelização de clientes. Segundo Kwak (2001) argumenta-se que com o avanço da internet, muitas organizações buscam desenvolver estratégias para fidelizar e manter clientes.

Observando que o desempenho logístico tinha um impacto direto na fidelização e satisfação do consumidor, o uso da logística passou a ser um dos principais pontos de desenvolvimento do e-commerce. Segundo Karpinski (1999) estudos enfatizam sobre a importância de fatores operacionais para determinar a relação entre desempenho logístico, satisfação do cliente e desempenho da empresa. O desempenho logístico foi estudado como um fator único ou como parte de um conjunto de fatores operacionais. A partir das considerações iniciais, o objetivo geral deste trabalho é analisar a estratégia entre o desempenho logístico e a fidelização de clientes no segmento e-commerce.

\section{REFERENCIAL TEÓRICO}

\subsection{DEFINIÇÃO DO E-COMMERCE}

Segundo Fernandes et al. (2011), a definição do e-commerce está relacionada com a utilização entre o computador e a internet, porém, décadas atrás já era válido 0 ecommerce, uma vez que era realizada uma transação comercial com a utilização de um equipamento eletrônico. Para Turban et al. (2005), e-commerce também é entendido pela transferência ou troca de produtos e serviços por rede de computador.

Albertin (2000) desta que este mercado é apresentado pela realização de toda a cadeia de valor dos processos de negócio dentro de um ambiente eletrônico, por meio da utilização das tecnologias de informação e comunicação e como objetivo atender as necessidades do negócio.

O comércio eletrônico é visto como um meio de transação e seu crescimento pode ser justificado pelo amadurecimento do mercado. Desta maneira, as empresas seguem três condutas nos seus direcionamentos estratégicos, como: trazer o máximo de segurança e privacidade ao consumidor e a loja virtual; maior interação e relacionamento com o cliente e alinhamento entre a criação deste mercado para empresa com as demais estratégias, visando maior eficiência entre as transações (ALBERTIN, 2000).

Dentro do e-commerce, existe um contato direto entre as empresas e o cliente. As empresas e os clientes se aproximam muito mais fazendo um contato direto. A agilidade dos serviços e identificação exata das necessidades também se apresentam como vantagem competitiva (LEITE e FERREIRA, 2009).

\subsection{LOGÍSTICA NO E-COMMERCE}

A logística é uma plataforma onde seus serviços são construídos para facilitar o fluxo eficiente de informações, bens e dinheiro. Nos últimos anos, vem interagindo de forma significativa com e-commerce, o assunto está sendo abordado em meios acadêmicos, empresariais e no setor público, considerada a logística como o fator diferencial na competitividade empresarial.

Pontini (2011) apresenta um estudo de caso do funcionamento dos processos de logística reversa utilizadas no e-commerce de uma rede varejista na qual foram identificados e descritos os processos de logística reversa de pós-venda da empresa. Esta empresa tem suas atividades de e-commerce compartilhadas com o uso de suas lojas físicas. A empresa foca as atividades reversas 
como alternativa de competitividade, oferecendo um serviço capaz de satisfazer seu cliente. Percebe-se que o gerenciamento da logística reversa é imprescindível, que seria importante haver um mapeamento e formalização de processos que são efetuados apenas na prática e um amadurecimento nas relações entre a empresa e as transportadoras.

Segundo Fleury \& Monteiro (2000), os grandes gargalos no processo logístico dentro do mercado eletrônico, situam-se nas etapas desde a preparação de seu pedido e seu envio para o consumidor, até o processo de transferência para quem transportar a carga.

\subsection{DESEMPENHO LOGÍSTICO PARA FIDELIZAÇÃO DE CLIENTES}

A capacidade de uma organização para atrair e reter clientes é vital para o seu sucesso. A fidelidade do cliente requer um forte desejo, do cliente, para um produto, o qual vários fornecedores estão disponíveis (DICK e BASU, 1994).

A fidelização do cliente tem ganhado cada vez mais atenção no contexto do ecommerce na literatura recente (ARAÚJO et al, 2014). Vários estudos salientaram a importância de vários fatores operacionais na determinação de retenção de clientes e lealdade e, finalmente, $O$ sucesso das empresas por exemplo (RAMANATHAN, 2010).

A Logística desempenha um papel muito importante no sentido de garantir a fidelidade do cliente. Os fatores relacionados à logística são vivenciados pelos clientes depois de fazer os pagamentos e são frequentemente agrupados como um dos fatores pós-compra. Os clientes geralmente consideram a entrega física como um fator muito importante para a fidelização da loja. (ESPER et al, 2003; AGATZ et al, 2008). É muito importante que a mercadoria chegue ao cliente sem nenhum tipo de dano. As empresas que usaram transportadoras confiáveis para a entrega, tinham um número maior de clientes fidelizados. (ESPER et al, 2003; HEIM e CAMPO, 2007).

Malaquias (2010) afirma que o cliente precisa ser conquistado, e quando a empresa constrói esse relacionamento visando também - lado emocional, a fidelidade torna-se efetiva. Faz-se importante ressaltar que o cliente precisa ser conquistado no dia-a-dia.

\section{METODOLOGIA DA PESQUISA}

O método considerado para a realização desta pesquisa foi uma survey exploratória, que segundo Forza (2002), envolve a coleta de informações por meio de indivíduos sobre eles mesmos ou sobre as organizações às quais eles pertencem. No que diz respeito aos objetivos, esta pesquisa se caracteriza como exploratória, pois segundo Gil, (2007) a pesquisa tem como objetivo proporcionar maior familiaridade com problema, com vistas a torná-lo mais explicito. Quanto a técnica de coleta de dados, foi aplicado um questionário aos clientes do e- commerce por meio de uma rede social. O tamanho da amostra foi estimado com um erro máximo de 0,05 e confiabilidade de $80 \%$, sendo necessário minimamente 164 respondidos. Para a análise dos dados, foi utilizada análise estatística descritiva, bem como inferencial (correlação). Assim sendo, para a realização desta pesquisa, foi avaliada uma amostra do fenômeno investigado a fim de extrair conclusões, com vistas a torná-lo mais explícito. Os fatores considerados para o estudo da relação entre o desempenho logístico e a fidelização dos clientes do ecommerce estão listados no Quadro 1. 
QUADRO 1 - Fatores de avaliação de comércio eletrônico e fidelização de clientes.

\begin{tabular}{|c|c|c|}
\hline \multicolumn{2}{|c|}{$\begin{array}{c}\text { Categoria/Fator } \\
\text { de Fidelização }\end{array}$} & Descrição \\
\hline \multirow{4}{*}{ 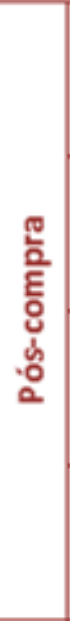 } & $\begin{array}{l}\text { Entrega } \\
\text { no prazo }\end{array}$ & $\begin{array}{c}\text { Esta categoria permite avaliar as práticas de cumprimento aos prazos pelos } \\
\text { sites de compra. Os produtos entregues no prazo e não danificados garantem } \\
\text { a fidelização dos clientes para novas compras? }\end{array}$ \\
\hline & $\begin{array}{l}\text { Reclamações } \\
\text { não atendidas }\end{array}$ & $\begin{array}{l}\text { Esta categoria permite avaliar o impacto do histórico de reclamações na } \\
\text { realização de novas compras pelos clientes. O histórico de reclamações não } \\
\text { atendidas influenciam os clientes a não realizarem novas compras? }\end{array}$ \\
\hline & $\begin{array}{l}\text { Suporte } \\
\text { ao cliente }\end{array}$ & $\begin{array}{l}\text { Esta categoria permite avaliar o suporte pós-compra ao cliente. Um bom } \\
\text { serviço de atendimento ao consumidor (SAC) garante a fidelização dos } \\
\text { clientes aos sites de compras? }\end{array}$ \\
\hline & $\begin{array}{c}\text { Facilidade } \\
\text { para devolução }\end{array}$ & $\begin{array}{l}\text { Esta categoria permite avaliar a facilidade de devolução como fator de } \\
\text { desempenho logístico. A facilidade para a devolução/troca de produtos } \\
\text { influencia os clientes em compras futuras? }\end{array}$ \\
\hline \multirow{4}{*}{ 起 } & $\begin{array}{c}\text { Disponibilidade } \\
\text { dos produtos }\end{array}$ & $\begin{array}{l}\text { Esta categoria permite avaliar se os produtos oferecidos pelos sites de } \\
\text { compras estão disponiveis ou esgotados no momento da compra. } \\
\text { A disponibilidade dos produtos influencia os clientes em compras futuras? }\end{array}$ \\
\hline & $\begin{array}{c}\text { Processo } \\
\text { de pagamento }\end{array}$ & $\begin{array}{l}\text { Esta categoria permite avaliar se a diversidade de opções de pagamento é } \\
\text { fator determinante para escolha do site de compras. A diversidade de } \\
\text { opções de pagamento fidelizam os clientes para uma nova compra? }\end{array}$ \\
\hline & $\begin{array}{c}\text { Preço } \\
\text { do frete }\end{array}$ & $\begin{array}{l}\text { Esta categoria permite avaliar o impacto do preço do frete na escolha do site } \\
\text { para compra de um produto e/ou serviço pelo cliente. O preço do frete para } \\
\text { a entrega dos produtos/serviços influencia os clientes do e-commerce para } \\
\text { novas compras? }\end{array}$ \\
\hline & $\begin{array}{l}\text { Segurança } \\
\text { e Privacidade }\end{array}$ & $\begin{array}{l}\text { Esta categoria permite avaliar se a segurança oferecidade pelos sites é } \\
\text { fundamental para a realização de novas compras pelos clientes. As compras } \\
\text { são concluídas quando os clientes não se sentem seguros em informar seus } \\
\text { dados pessoais e dados de cobrança para o site de compras? }\end{array}$ \\
\hline
\end{tabular}

\section{ANÁLISE DOS RESULTADOS}

Para a verificação do objetivo proposto, os dados foram coletados a partir da aplicação de um questionário composto de 24 questões elaboradas pelos autores e disponibilizada aos clientes do e-commerce em uma rede social. As questões foram divididas em 8 clusters e as alternativas de respostas foram disponibilizadas conforme escala Likert, sendo: (1) discordo totalmente, (2) discordo mais do que concordo, (3) não concordo nem discordo, (4) concordo mais do que discordo e (5) concordo totalmente. Além das questões propostas para verificação do problema proposto, foram aplicadas inicialmente quatro questões relacionadas a caracterização dos clientes de e-commerce: sexo, idade, frequência de realização de compras no e-commerce e a preferência pela categoria de compras. Foram obtidas 185 respostas para a realização deste trabalho e os resultados estão apresentados a seguir.

Na primeira questão, foi questionado o sexo dos usuários e considerando a proximidade das respostas, não foi possível apontar se o sexo masculino ou feminino é responsável pelo maior número de compras no segmento e-commerce (Figura 1). 
FIGURA 1 - Sexo.

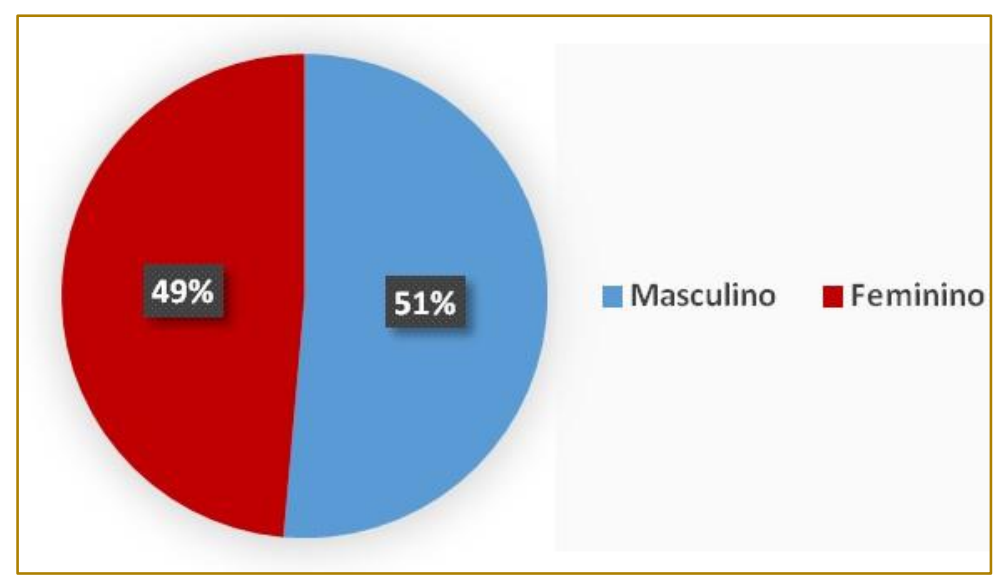

$\mathrm{Na}$ segunda questão, foi analisada a idade dos clientes e-commerce que responderam a pesquisa sendo: $2 \%$ com idade inferior a 18 anos, $48 \%$ com idade entre 18 e 25 anos, $25 \%$ com idade entre 25 e 30 anos, $8 \%$ com idade entre 30 e 35 anos e 17\% dos pesquisados com idade superior a 35 anos conforme ilustrado na figura 2. O perfil predominante dos clientes pesquisados é de jovens com idade entre 18 e 25 anos.

FIGURA 2 - Idade.

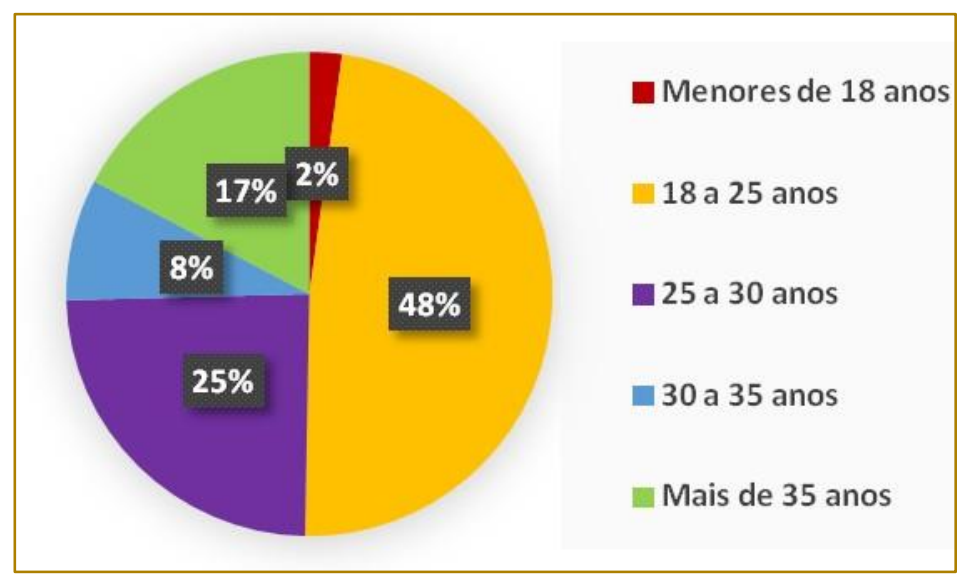

Na terceira questão, ilustrada na Figura 3, foi identificada a frequência com que os clientes pesquisados realizam suas compras via ecommerce. Dos clientes do e-commerce pesquisados, foram apuradas as seguintes respostas: $1 \%$ responderam que nunca fizeram compras via e-commerce, $28 \%$ fazem compras raramente, $48 \%$ responderam fazer as compras em período razoável e $23 \%$ dos clientes responderam sempre fazer compras via e-commerce. 
FIGURA 3 - Frequência de compra.

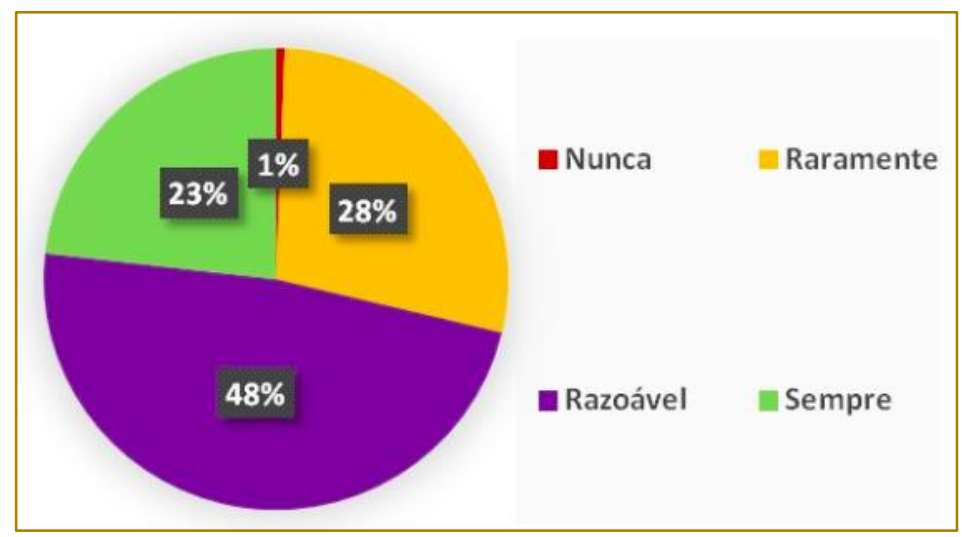

$\mathrm{Na}$ quarta questão foram apuradas as principais categorias onde são feitas a maioria das compras via e-commerce conforme ilustrado na Figura 4. Dentre as principais categorias do e-commerce respondidas pelos clientes pesquisados estão: 11\% Comida,
$26 \%$ roupas e calçados, $26 \%$ eletrônicos, $14 \%$ eletrodomésticos $9 \%$ serviços e $14 \%$ outros. Os resultados apurados demonstram a preferência a dos clientes do e-commerce por compras de vestuários e eletrônicos que somados que representam $52 \%$ das compras.

FIGURA 4 - Categorias do e-commerce.

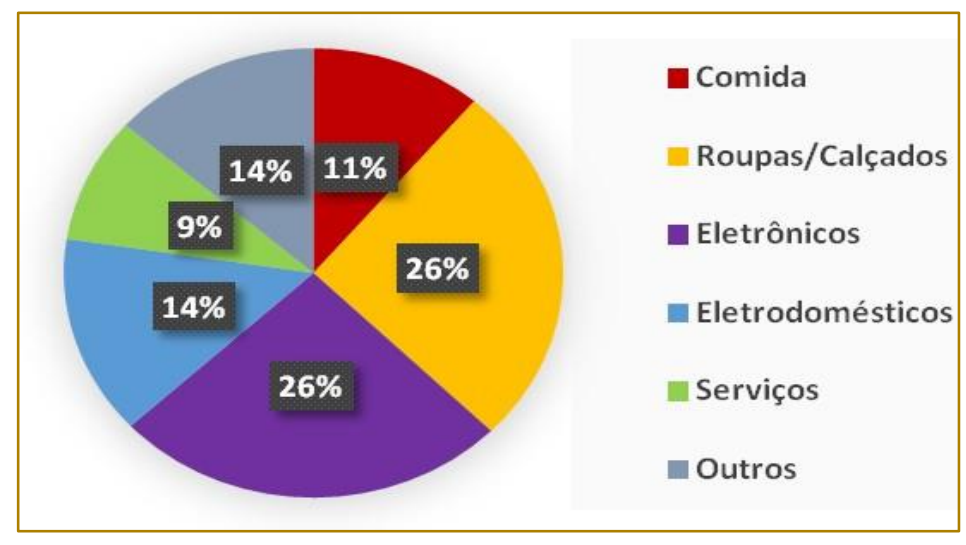

No primeiro cluster foi verificado a entrega no prazo como fator de desempenho logístico. Foi analisado se produtos entregues no prazo e não danificados garantem a fidelização dos clientes para novas compras. Assim sendo, $5 \%$ dos clientes discordam totalmente, 2\% discordam mais do que concordam, 3\% não concordam e nem discordam, 21\% concordam mais do que discordam e 69\% concordam totalmente, demonstrando a importância do atendimento aos prazos para o desempenho logístico na fidelização dos clientes do e-commerce, de acordo com a Figura 5. 
FIGURA 5 - Entregas no prazo.

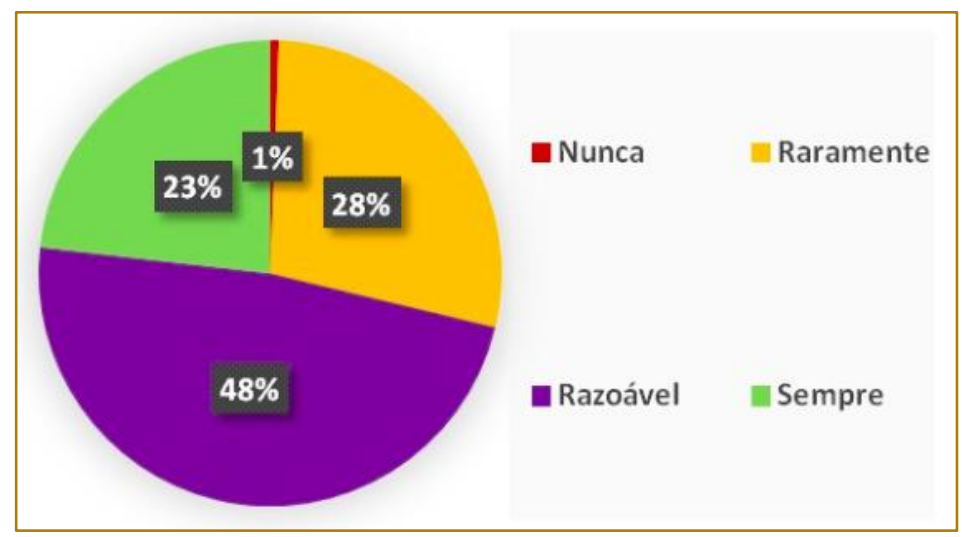

No segundo cluster foi verificado as reclamações não atendidas como fator de desempenho logístico. Foi analisado se o histórico de reclamações não atendidas influenciam os clientes a não realizarem novas compras. Assim sendo, 5\% dos clientes discordam totalmente, $1 \%$ discordam mais do que concordam, 6\% não concordam e nem discordam, 22\% concordam mais do que discordam e 66\% concordam totalmente, demonstrando que o histórico de reclamações não atendidas influenciam os clientes do ecommerce na realização de novas compras, conforme a Figura 6.

FIGURA 6 - Reclamações não atendidas.

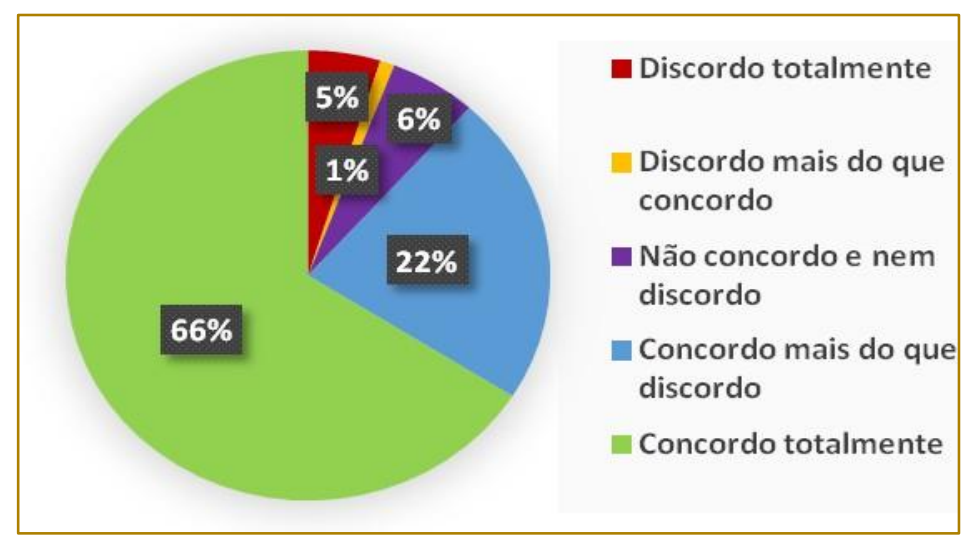

No terceiro cluster foi verificado o suporte ao cliente como fator de desempenho logístico. Foi analisado se um bom serviço de atendimento ao consumidor (SAC) garante a fidelização dos clientes aos sites de compras. Assim sendo, $0 \%$ dos clientes discordam totalmente, $0 \%$ discordam mais do que concordam, 9\% não concordam e nem discordam, 30\% concordam mais do que discordam e 61\% concordam totalmente, demonstrando a importância do suporte ao cliente para os clientes do e-commerce, conforme a Figura 7. 
FIGURA 7 - Serviço de atendimento ao cliente.

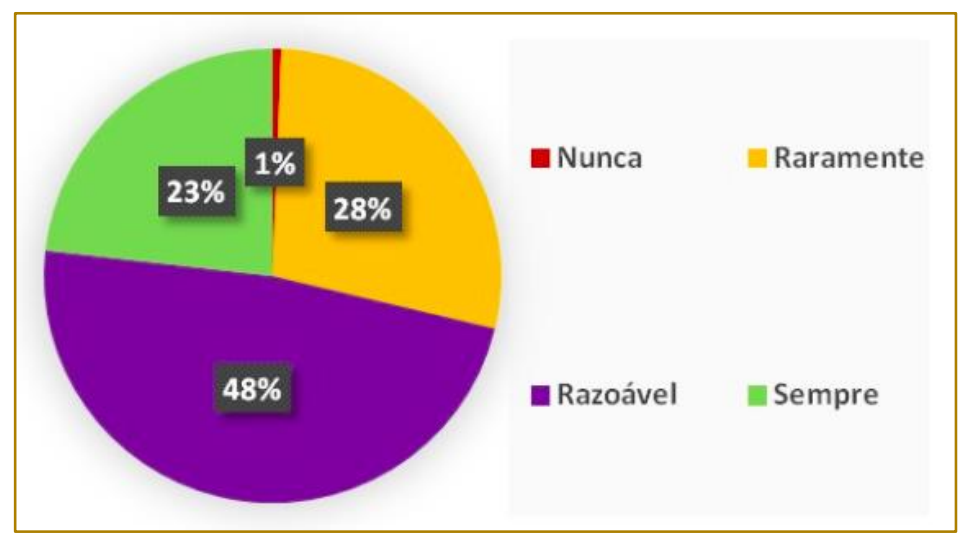

No quarto cluster foi verificado a facilidade de devolução como fator de desempenho logístico. Foi analisado se a facilidade para a devolução/troca de produtos influencia os clientes em compras futuras. Assim sendo, $0 \%$ dos clientes discordam totalmente, $1 \%$ discordam mais do que concordam, $7 \%$ não concordam e nem discordam, 27\% concordam mais do que discordam e $65 \%$ concordam totalmente, demonstrando a importância da facilidade de devolução/troca de produtos para os clientes do e-commerce, conforme a Figura 8.

FIGURA 8 - Facilidade para devolução.

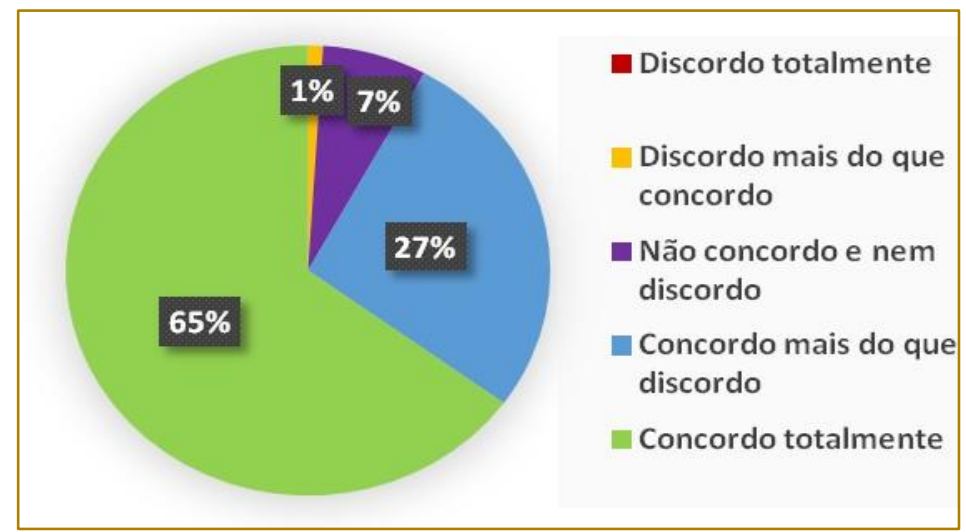

No quinto cluster foi verificado se a disponibilidade dos produtos influencia os clientes em compras futuras. Assim sendo, $0 \%$ dos clientes discordam totalmente, 5\% discordam mais do que concordam, 10\% não concordam e nem discordam, $40 \%$ concordam mais do que discordam e 45\% concordam totalmente, demonstrando a importância disponibilidade dos produtos/serviços para os clientes do ecommerce, conforme a Figura 9. 
FIGURA 9 - Disponibilidade dos produtos.

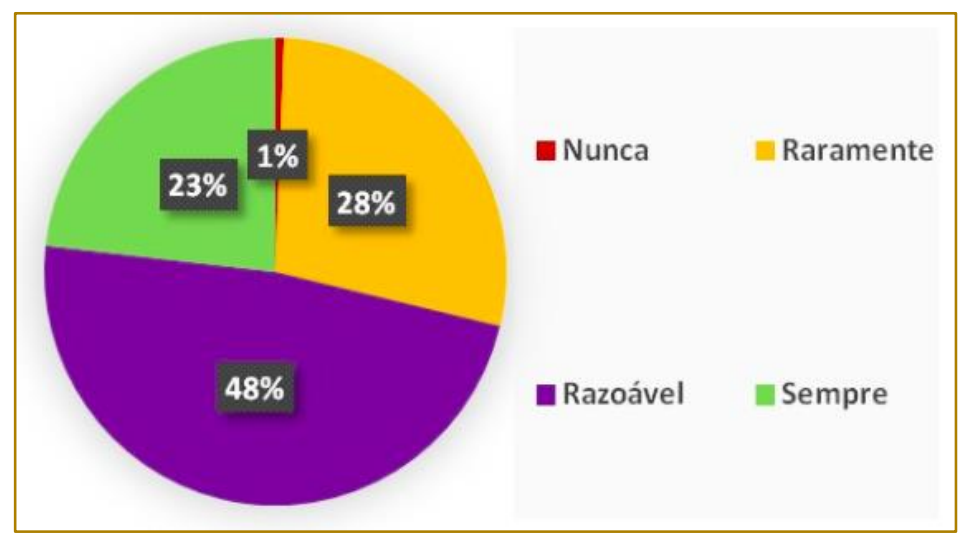

No sexto cluster foi verificado se a

discordam, 33\% concordam mais do que diversidade de opções de pagamento fidelizam os clientes do e-commerce para novas compras. Assim sendo, $2 \%$ dos clientes discordam totalmente, $7 \%$ discordam mais do que concordam, $27 \%$ não concordam e nem discordam e $31 \%$ concordam totalmente, demonstrando este fator como sendo de menor relevância para a fidelização dos clientes do e-commerce, conforme a Figura 10.

FIGURA 10 - Diversidade de opções de pagamento.

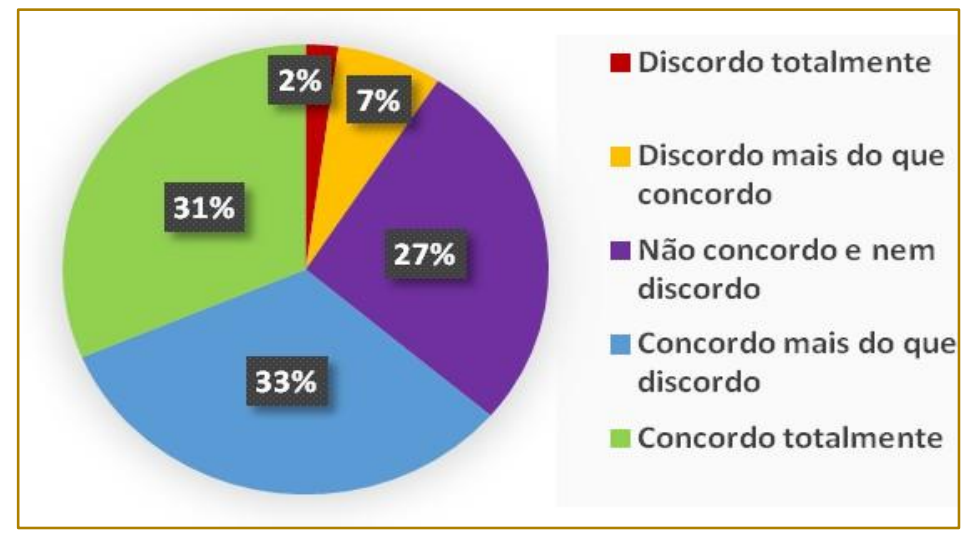

No sétimo cluster foi verificado como fator de desempenho logístico se o preço do frete para a entrega dos produtos/serviços influencia os clientes do e-commerce para novas compras. Assim sendo, $0 \%$ dos clientes discordam totalmente, $2 \%$ discordam mais do que concordam, $11 \%$ não concordam e nem discordam, 38\% concordam mais do que discordam e 49\% concordam totalmente, demonstrando a importância da possibilidade de comparação dos preços dos produtos/serviços para os clientes do ecommerce, conforme a Figura 11. 
FIGURA 11 - Preço do frete.

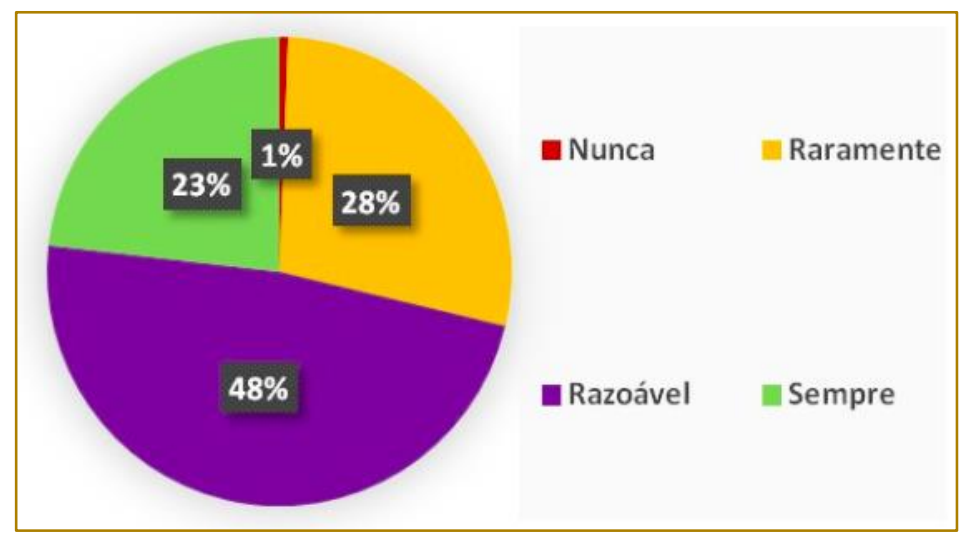

No oitavo e último cluster foi verificado se a segurança ofertada pelos sites para fornecimento dos dados pessoais e dados de cobrança pelos clientes é relevante para a realização de novas compras pelos clientes. Assim sendo, 0\% dos clientes discordam totalmente, $0 \%$ discordam mais do que concordam, 2\% não concordam e nem discordam, $18 \%$ concordam mais do que discordam e $80 \%$ concordam totalmente, demonstrando a maior relevância deste fator para a fidelização dos clientes do ecommerce, conforme a Figura 12.

FIGURA 12 - Segurança oferecida pelos sites.

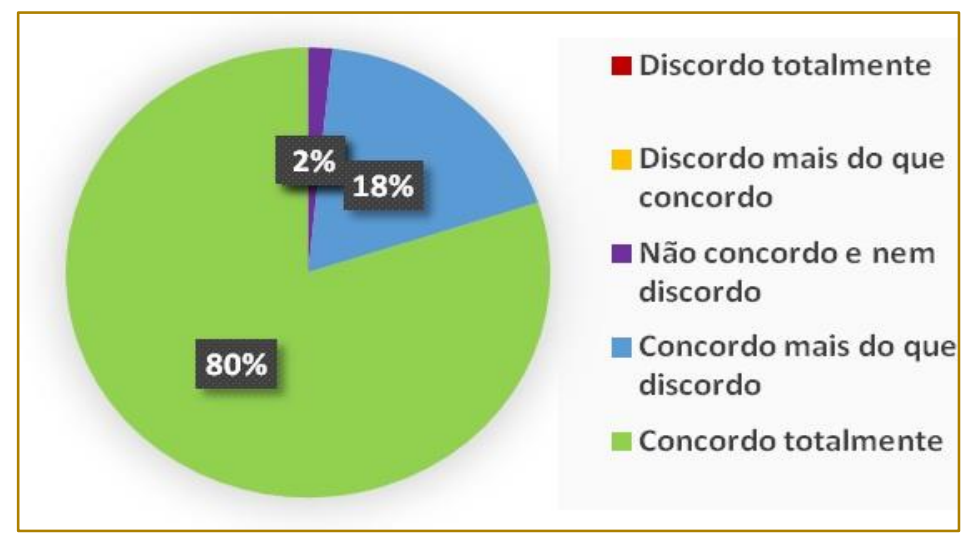

Considerando os oito clusters apresentados anteriormente, destaca-se a segurança oferecida pelos sites de compras como o fator mais relevante para a fidelização de clientes apesar de não fazer parte do desempenho logístico. Os clientes do e-commerce necessitam estar seguros em fornecer seus dados pessoais e seus dados de cobrança durante o processo de compras. Este fator obteve a maior média $(4,78)$ e o menor desvio padrão $(0,45)$ conforme demonstrado na Tabela 1. 
TABELA 1 - Média e desvio padrão dos clusters.

\begin{tabular}{|l|c|c|}
\multicolumn{1}{|c|}{ Fatores de fidelização dos clientes no e-commerce } & Média & Desvio padrão \\
\hline Segurança oferecida pelos sites & 4,78 & 0,45 \\
\hline Atendimento aos prazos & 4,61 & 0,73 \\
\hline Histórico de reclamações não atendidas & 4,58 & 0,70 \\
\hline Facilidade para devolução & 4,56 & 0,67 \\
\hline Preço do frete & 4,33 & 0,82 \\
\hline Serviço de atendimento ao cliente & 4,32 & 0,77 \\
\hline Disponibilidade do produto & 4,24 & 0,83 \\
\hline Diversidade de opções de pagamento & 3,84 & 1,03 \\
\hline
\end{tabular}

O fator diversidade de opções de pagamento obteve a menor média $(3,84)$ e o maior desvio padrão $(1,03)$. Este fator também não é considerado um fator desempenho logístico e dentre os fatores observados, apresenta-se como o de menor de relevância para os clientes pesquisados.

Os fatores considerados sendo de desempenho logístico apresentaram variação da média entre 4,32 e 4,61. Estes fatores são: serviço de atendimento ao cliente, preço do frete, facilidade para devolução, histórico de reclamações não atendidas e atendimento aos prazos.

\section{CONSIDERAÇÕES FINAIS}

O objetivo do presente artigo foi verificar as possíveis estratégias entre 0 desempenho logístico e a fidelização de clientes no segmento e-commerce. Como resultado de análise quantitativa, foi possível confirmar que há relação entre o desempenho de logístico e a fidelização de clientes em razão das médias apuradas para as questões encaminhadas aos clientes e-commerce. As limitações para esta pesquisa apresentam-se principalmente quanto ao tempo para o levantamento e apuração dos dados. Espera-se que os resultados apurados com a realização deste trabalho possam contribuir com futuras pesquisas relacionadas aos fatores que contribuem para a fidelização de clientes no segmento e-commerce e melhores estratégias. Sugere-se aprofundar a pesquisa para os demais fatores de fidelização, como por exemplo, a privacidade que está relacionada às práticas de segurança adotadas pelas empresas deste segmento.

\section{AGRADECIMENTOS}

À todos familiares e amigos, pela dedicação, apoio, incentivo e compreensão nos momentos difíceis.

Aos colegas da turma de Engenharia de Produção, que dividiram suas experiências e amizades durante todos esses anos, tornando o curso muito mais agradável.

Ao nosso Professor Especialista e Mestre Carlos Roberto Franzini Filho, orientador do grupo, pela disposição para tirar dúvidas e transferir seus conhecimentos aos alunos.

\section{REFERÊNCIAS}

[1] ALBERTIN, A. L. Comércio Eletrônico: modelo, aspectos e contribuições de sua aplicação. São Paulo: Atlas, 2000.

[2] ARAÚJO, S.; FAÍSCA, L.; BRAMÃO, I.; PETERSSON, K. M. Lexical and sublexical orthographic processing: An ERP study with skilled and dyslexic adult readers. In: Pub Med Journals, 2014.

Disponível

em:
$<$ https://www.ncbi.nlm.nih.gov/labs/articles/255282 85/>. Acesso em: 10 mar. 2017.

[3] DICK, A.S., BASU, K.. Customer loyalty: toward an integrated conceptual framework. Journal of the Academy of Marketing Science, Mar. 1994.Disponível

em: $<$ https://link.springer.com/article/10.1177/00920703 94222001>. Acesso em: 19 mar. 2017. 
[4] ESPER, T.L., JENSEN, T.D. TURNIPSEED, F.L., BURTOn, S. A última milha: uma análise dos efeitos das estratégias de entrega de varejo on-line sobre osconsumidores. Jornal de negócios logística, 2003.

[5] FERNANDES, F. J. M., SIMÕES, J. S. P., PÁDUA T. P. M., BARROS, E. S. Compras Virtuais: Como a Logística tem se firmado como Componente Essencial para o Ecommerce? In: Congresso Virtual Brasileiro de Administração, 2011. Disponível em: < http://www.convibra.com.br/upload/paper/adm/ad m_2932.pdf>. Acesso em: 05 abr. 2017.

[6] FLEURY, P. F.; MONTEIRO, F. J. R. C. O desafio logístico do e-commerce. São Paulo: Revista Tecnologística, ano VI, n.56, p. 34-40, jul.2000.

[7] FORZA, C.. Survey research in operations management: a process-based perspective. International journal of operations \& Production management, Vol 22, n.2, pp. 152-194, 2002

[8] GIL, A. C. Como elaborar projetos de pesquisa. 4. Ed. São Paulo: Atlas, 2007.

[9] MALAQUIAS, A. Fidelização de clientes. In: Techoje: uma revista de opinião, [2016?]. Disponível em: <http://www.techoje.com.br/site/techoje/categoria/d etalhe_artigo/871 >. Acesso em: 5 maio 2017.
[10] KARPINSKI, 1999. The logistics of ebusiness - web commerce demands new approach to inventory, shipping. InternetWeek. Maio 1999.

[11] KWAK, M. Web sites learn to make smarter suggestions. MIT Sloan Management Review. 2001.

[12] LEITE, K. T. S. FERREIRA, C. L. Ecommerce: a transformação do internauta em consumidor. 2009. Disponível em: <http://www.administradores.com.br/producaoacad emica/e-commerce-a-transformacao-dointernauta-em-consumidor/2404/>. Acesso em: 15 set. 2016

[13] PONTINI, J. Logística Reversa: Um estudo do pós-venda no e-commerce da Empresa X. Porto Alegre: Universidade Federal do Rio Grande do Sul, 2011. Monografia. Departamento de Ciências Administrativas.

[14] RAMANATHAN, Ramakrishnan. The moderating roles of risk and efficiency on the relationship between logistics performance and customer loyalty in e-commerce. Transportation Research Part E: Logistics and Transportation Review, v. 46, n. 6, p. 950-962, 2010.

[15] TURBAN, E., RAINER, R. K. J., POTTER, R.E. Administração de tecnologia da informação: teoria e prática. Elsevier. Rio de Janeiro, 2005. 


\section{Bapítulo 12}

\section{PLANO MESTRE DE PRODUÇÃO COMO SUPORTE À DISTRIBUIÇÃO: $U M$ ESTUDO $D E$ CASO EM $U M A$ PANIFICADORA}

\section{Yasmim Luana Mafra de Lira}

Tarcizio da Silva Barbosa

Clelma Feliz Santos

Avylon Silva Santos

Denilson Ricardo de Lucena Nunes

Resumo: Diante do atual cenário econômico é fundamental se tornar competitivo no mercado, buscando também o uso eficiente dos recursos disponíveis. Existem diversas ferramentas e técnicas que promovem ações de melhoria, que resultam em custos e benefícios, restando ao gestor decidir a prioridade de aplicação e abordagem mais adequada a cada problema. O objetivo desta pesquisa foi de propor um modelo de MPS (plano mestre de produção) e distribuição para uma panificadora industrial situada no município de Ananindeua - PA, que possui particularidades quanto seu modo de produção e distribuição. A metodologia utilizada foi de caráter quantitativo e qualitativo, bem como usando um estudo de caso para a proposição dos modelos de planejamento da produção e da distribuição, consultando dados históricos de venda e rotas diárias. Como resultados foram propostos o método de previsão que se ajustasse as características do histórico de vendas da empresa, bem como uma lógica de previsões de demanda em relação à frequência de pedidos, tanto em quantidade de pães quanto na quantidade de dias. Assim, foi elaborado um MPS que se adaptasse aos dias da semana, mostrando a quantidade total prevista do período. Para a distribuição foi gerada uma proposta viável e eficiente com base no método de Clarke \& Wright. A partir da proposição do MPS e roteirização verificou-se que os elementos da distribuição podem ser diretamente relacionados com a elaboração do MPS.

Palavras-chave: Plano Mestre de Produção; Roteirização; Indústria de Panificação 


\section{INTRODUÇÃO}

Bons planejamentos estratégicos e operacionais são fundamentais para obter uma vantagem competitiva na empresa, isso se tornou imperativo em virtude do crescimento exponencial da competitividade empresarial no mercado atual. Além disso, percebe-se a melhor produtividade e rentabilidade quando tais estratégias são utilizadas, chegando a melhorar os processos relacionados à sua produção, gerando lucros significativos. O MPS (Master Production Schedule) segundo Slack (2009) é uma das fases mais importantes da empresa, pois nele contem a quantidade a ser produzida por tal. Ademais, o MPS tende a viabilizar a redução do lead time, esta é sua maior barreira operacional, tornando os processos mais viáveis e produtivos.

Não obstante, o processo de distribuição de produtos acabados passa pela definição de um roteiro a ser seguido. Esse plano é conhecido como roteirização que, segundo o presente estudo, pode ser considerado juntamente com o planejamento da produção. A distribuição auxilia na forma de como será entregue o produto ao consumidor, de maneira a atender o seu pedido, sendo eficiente e obtendo resultados promissores do seu serviço. Enquanto que, a roteirização visa encontrar a melhor forma de entregar o produto ou serviço ao consumidor, analisando as rotas mais viáveis, reduzindo o tempo e o lead time. A roteirização é uma ferramenta da gestão de logística e seus métodos de planejamento de acordo com Novaes (2007) são: método Clarke \& Wright e o método de Varredura, onde sucintamente tornam as rotas mais eficientes e viáveis.

Consequentemente, o presente artigo visa atingir a finalidade de propor aplicabilidade em uma fábrica industrial de pães, interligando atividades de planejamento (MPS e roteirização), geralmente tratadas separadamente, e aplicando-os ao método de distribuição que a empresa utiliza para entregar seu produto com qualidade e pontualidade. Tal metodologia será demonstrada por meio da interligação dos processos, desde a produção até a entrega do produto. Por conseguinte, o objetivo é permitir que melhore e potencialize a fabricação e a entrega do produto, gerando melhores resultados para a organização.

\section{REFERENCIAL TEÓRICO \\ 2.1 PROGRAMA MESTRE DE PRODUÇÃO}

No ambiente de PCP, o planejamento agregado determina os recursos comuns das famílias de produtos que estarão disponíveis para serem produzidos em determinado período diante do horizonte de tempo que fora planejado. A partir deste raciocínio podem existir propostas formais para um processo de desagregação. Segundo Lustosa et al. (2008), geralmente, dependendo da empresa e dos aspectos envolvidos, fazem esta desagregação de modo informal em reuniões mensais discutindo os dados e as alternativas viáveis e necessárias até chegarem a uma decisão que se torna a base de toda a programação da produção.

Para Fernandes (2010), o MPS é a primeira das atividades de controle da produção propriamente dita, ou seja, seu objetivo é definir qual, quanto e quando determinados produtos serão produzidos ao longo de um horizonte de tempo. A geração do MPS pode ser feita a partir da desagregação do plano agregado, da estimativa da demanda para produtos finais ou então da carteira de pedidos. De forma simples, o MPS é o elo entre o planejamento tático e o planejamento operacional, portanto o plano mestre deve ter flexibilidade suficiente para se adaptar a estas diferenças. Vale ressaltar que o MPS trabalha com um horizonte de curto prazo, porém como a grande maioria dos autores encara o MPS como sendo de vários meses, o resultado é a divisão do horizonte de planejamento em três: plano flexível, plano firme e plano congelado. A grande dificuldade de aplicação do MPS está em se trabalhar com um longo horizonte de tempo, gerando grandes leadtimes tanto na cadeira de suprimentos quanto na produção, esta dificuldade pode ser solucionada nos esforços em reduzir estes leadtimes.

Geralmente a literatura faz uso do registro básico do MPS mostrada na figura 1(ver figura 1) para a obtenção do mesmo. Neste registro constam as unidades de tempo (semanas) representadas pelas colunas $e$ as linhas representam os dados de entrada como: o estoque, o MPS gerando e a quantidade disponível para promessa. 
FIGURA 1 - Registro básico do MPS

\begin{tabular}{|c|c|c|c|c|c|c|c|c|c|}
\hline \multirow[b]{2}{*}{ Item: XXXXXXXXXXXXX } & \multicolumn{9}{|c|}{ Períodos } \\
\hline & 0 & 1 & 2 & 3 & 4 & 5 & 6 & 7 & 8 \\
\hline \multicolumn{10}{|l|}{ Previsão de Demanda Independente } \\
\hline \multicolumn{10}{|l|}{ Pedidos em Carteira } \\
\hline \multicolumn{10}{|l|}{ Demanda } \\
\hline Estoque (Atual Disponível)/Projetado & Io & & & & & & & & \\
\hline \multicolumn{10}{|l|}{ Disponível para Promessa (ATP) } \\
\hline Programa Mestre de Produção (MPS) & & & & & & & & & \\
\hline
\end{tabular}

Fonte: Adaptado Fernandes (2010)

O registro básico do MPS pode ser influenciado por certos parâmetros que afetam diretamente os dados registrados, que são: tamanho do lote de produção, o estoque de segurança e o time fence. Parâmetros como a definição de um tamanho específico de lote de produção pode ser exemplificado com um lote econômico de comprar (LEC) ou então a definição de um lote mínimo. Já parâmetros como estoque de segurança, podem ser exemplificados com a definição de um estoque mínimo para o PCP, de uma forma geral, se precaver das possíveis incertezas na demanda e no fornecimento de suprimentos. (FERNANDES; GODINHO, 2010).

Segundo Arruda (2005), a lógica para a geração do plano mestre parte de apurações sucessivas de diversos fatores que se correlacionam com a produção. O MPS é calculado tomando como ponta pé o estoque inicial que é somado ao que já estava programado para ser produzido naquele período e subtraindo, para o mesmo intervalo, o maior valor entre a previsão de demanda e a carteira de pedidos. A partir deste ponto é calculada então as faltas detectadas na disponibilidade que foi projetada, sempre considerando o tamanho do lote e o estoque de segurança. De forma simples, o MPS pode ser gerado a partir de 3 maneiras distintas: MPS via congelamento do plano desagregado; MPS via previsões semanais e individuais; MPS via carteira de pedidos. Vale ressaltar que a diferença entre as formas de congelamento e previsões semanais são em relação as previsões para itens individuais necessários em cada uma delas. Uma forma prática de entender a geração do MPS e suas formas e assimilar as estratégias de produção (MTS, ATO, MTO, RTO e ETO) com as estratégias citadas acima(ver Figura 2).

FIGURA 2 - Possíveis formas de geração do MPS para cada estratégia de resposta a demanda

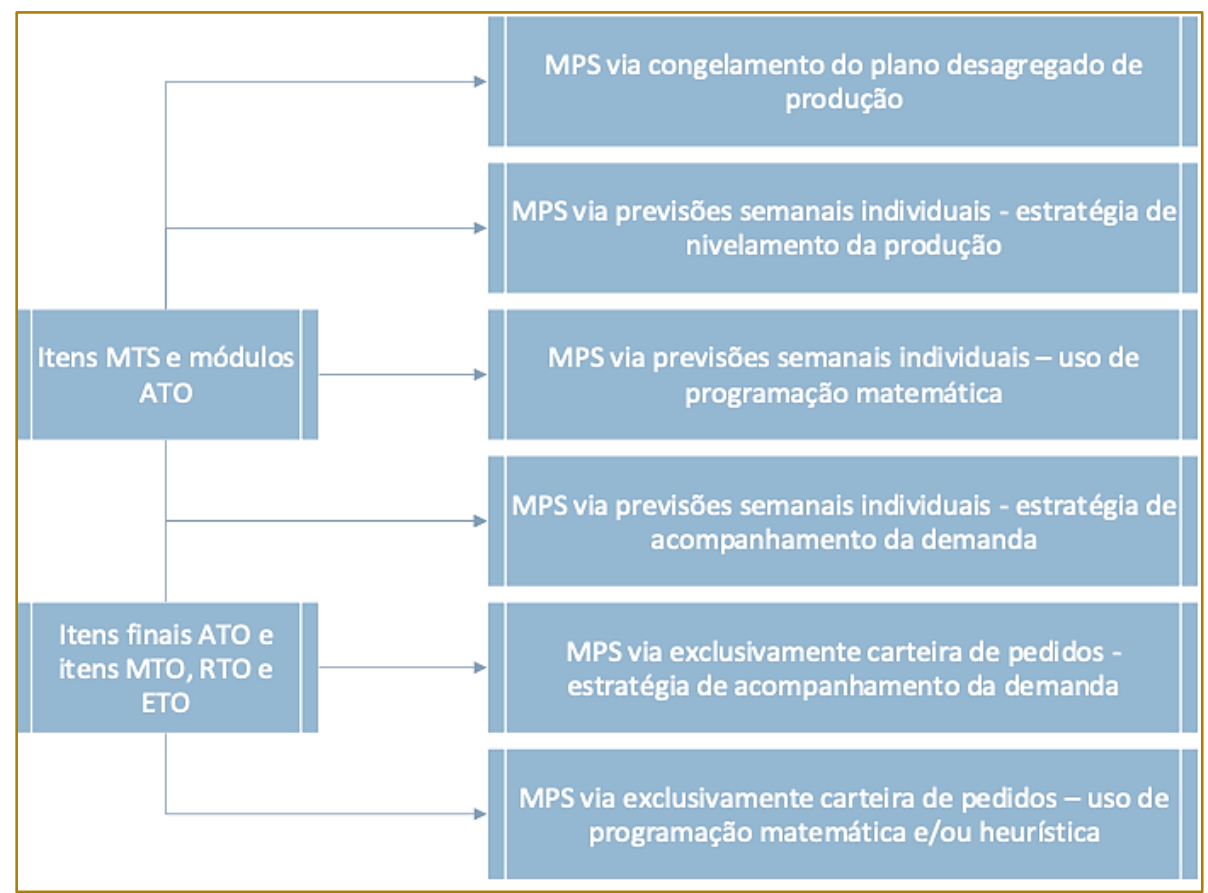

Fonte: Adaptado Fernandes (2010) 
Em suma, os valores iniciais do MPS gerado guiam o programador através de outros ambientes estratégicos que de relacionem melhor com a realidade, e por meio de outros mecanismos interligados ao processo, como a distribuição de produtos, poderiam auxiliar na formulação e refinação de estratégias para a adequação do plano mestre.

\subsection{DISTRIBUIÇÃO}

Segundo Lustosa et al. (2008) a distribuição possui áreas funcionais que são bases da logística, são elas: projeto de rede logística, que envolve o CD (centro de distribuição), fabricas, armazéns, pontos de transbordo, crossdock e vendas; informação, na qual é enfatizado a necessidade da informação em relação aos custos com cada ponto de uma rota por exemplo; o transporte em si, definindo como e o que será transportado em cada rota; estoque, que ele considera como sendo responsável por dois terços dos custos logísticos; armazenagem e manuseio de materiais.

A distribuição é a relação entre um fabricante e seu consumidor onde a distribuição se encaixa como um intermediário nessa relação. O objetivo da distribuição segundo Novaes (2007) é de interceptar o transporte dos produtos para os lugares certos visando o menor custo. A distribuição no geral inclui algumas modalidades de transporte, como rodoviário, aéreo, aquático entre outros. Se deparando com essas modalidades de transporte o responsável pela parte da distribuição deverá analisar qual sistema é o mais adequado para a sua rota, considerando os custos e também o tempo da entrega. A distribuição é a forma como levaremos um produto tendo em consideração os vários caminhos que o produto precisa percorrer até chegar no consumidor final. Com isso o canal de distribuição "é a combinação de instituições pelas quais o vendedor vende produtos ao consumidor final" (CASTIGLIONI, 2011).

De acordo com Novaes (2007) as distribuições são feitas de "um para um", no qual a rota tem apenas um destino que pode ser outro CD, ou apenas um varejista. Nesse tipo de distribuição há diversos fatores que influenciam a sua logística, veja alguns deles: distância entre o CD e o local de destino; a velocidade para chegar ao destino; tempo de carga e descarga; quantidade de produtos; a densidade do carregamento, que pode afetar o tipo de veículo a ser utilizado na hora do transporte; fragilidade; periculosidade, na qual se deve atentar para uma rota com o mínimo de riscos e custos totais. O sistema "um para muitos" também chamado de Distribuição Compartilhada, é o sistema em que há apenas um CD e mais de um destino, e tendo a necessidade de ter um roteiro prédeterminado.

\subsubsection{ROTEIRIZAÇÃO}

Segundo Novaes (2007) roteirização é a forma como uma empresa irá levar um produto ou serviço até o seu consumidor, e essa escolha de rota pode ser feito da maneira mais econômica possível, levando em consideração aspectos como a geografia, quantidade de produtos e tempo. A redução dos custos envolvidos na roteirização afeta a qualidade na entrega, na competitividade da empresa, podendo afetar direta ou indiretamente na tomada de decisão dos gerentes. A roteirização é uma ferramenta da gestão de logística, no qual o transporte representa cerda de dois terços dos custos logísticos totais.

Os métodos de planejar a roteirização mais comum são: método Clarke \& Wright e o método de Varredura segundo Novaes (2007), através do qual se busca obter uma rota mais eficiente possível, vale ressaltar que elaborar a melhor opção de rota não adota uma forma padrão, devido ao fato de que cada problema ter restrições diferenciadas.

Para a roteirização de veículos o método Clarke e Wright é mais confiável, com cerca de $2 \%$ de erro, ele é para casos com restrições, como o tempo. Considerando um CD com dois destinos $i$ e j, no qual ele faz entrega no destino i volta ao CD recarrega e depois se encaminha ao destino j, assim sendo:

$$
L=2 \times d D, i+2 \times d D, j
$$

O método propõe juntar os dois clientes i e j em uma mesma rota, ficando assim:

$$
L^{\prime}=d D, i+d i, j+d D, j
$$

Desse modo esse roteiro há uma economia de percurso que é a diferença entre as distancias (L-L') no qual o autor chama de ganho:

$$
g i, j=L-L^{\wedge \prime}=d D, i+d D, j-d i, j
$$

Resumindo através da roteirização é possível reduzir os custos logísticos, melhorar o nível da qualidade do serviço usando os métodos 
acima citados selecionando a melhor rota considerando a geografia e a demanda do produto, ou seja, dentro das várias estratégias utilizadas pela empresa, definir a rota de distribuição de forma eficiente pode funcionar como uma janela de suporte para estas estratégias a fim de garantir melhores resultados de produção, aumento do nível de serviço e alta competitividade de mercado.

\section{METODOLOGIA}

A pesquisa realizada teve as abordagens quantitativas e qualitativas e usaram-se os seguintes procedimentos: a pesquisa teórica e o estudo de caso. A pesquisa teórica foi realizada com o objetivo de orientar a equipe de trabalho a respeito dos temas de Plano Mestre de Produção, distribuição e roteirização. O estudo de caso foi usado como forma de o entendimento da situação de uma empresa atuante no setor de fabricação de pães que possui particularidades nos seus pedidos e na sua distribuição. Esta empresa foi selecionada por amostragem não probabilística e intencional.

Foram analisados os dados históricos de vendas do pão tipo hambúrguer de oito semanas para 37 clientes. O processo de previsão de demanda e de elaboração do MPS foi da seguinte maneira: a) a soma da quantidade de pães por semana de cada cliente; b) a elaboração da previsão de demanda com base na suavização exponencial simples; c) análise da quantidade de pedidos de cada cliente; d) análise da frequência de pedidos de cada cliente para cada dia da semana; e) a soma da quantidade total para cada dia da semana para o preenchimento do campo de "Previsão de demanda independente". A principal fonte de dados para a realização deste trabalho foi o caderno de registro de vendas.

\section{ESTUDO DE CASO}

Partindo-se da revisão da literatura que apresentou conceitos sobre o programa mestre de produção (MPS), distribuição e roteirização apresenta-se o estudo de caso propriamente dito, onde será apresentado um breve resumo do processo de produção e da logística de distribuição de produtos em uma panificadora situada na região de Ananindeua-PA. A panificadora tem em média 50 clientes distribuídos de maneira não uniforme pela região do município de Ananindeua. A empresa trabalha com cinco tipos de pães (hambúrguer, chá, forma, xtudo e pão francês) e a quantidade a ser produzida é de acordo com os dias da semana e os locais onde serão distribuídos, ou seja, a produção do depende diretamente da rota diária.

A empresa funciona com a produção da quantidade de pães no dia anterior a entrega, por exemplo, o pão de sexta feira é feito na quinta feira, trabalhando assim com antecipação para que os pães cheguem prontos para serem utilizados e facilitando também o transporte. Já a distribuição dos produtos é feita por dois veículos, variando o uso conforme as necessidades de economia com custos de transporte e a quantidade média de pães. A partir das análises feitas sobre a programação da produção e a distribuição de seus produtos será proposto um programa mestre de produção que tem como principal suporte de entrada os dados da distribuição.

\subsection{PROPOSTA DO PLANO MESTRE DE PRODUÇÃO}

A partir da análise de dados históricos de oito semanas de vendas do pão hambúrguer foi possível realizar uma previsão de demanda semanal do tipo séries temporais com a suavização exponencial simples para 37 clientes (ver tabela 1). Somou-se a quantidade pães do tipo hambúrguer da semana e com isso verificou-se como os coeficientes de alfa se comportavam. A escolha do coeficiente de alfa se deu com a observação do erro médio elevado ao quadrado, o alfa que apresentava menor erro era o escolhido para previsão do próximo período. A escolha dos métodos de previsão e da análise dos erros pode ser encontrado em Fernandes (2010). 
TABELA 1 - Previsão de demanda por cliente

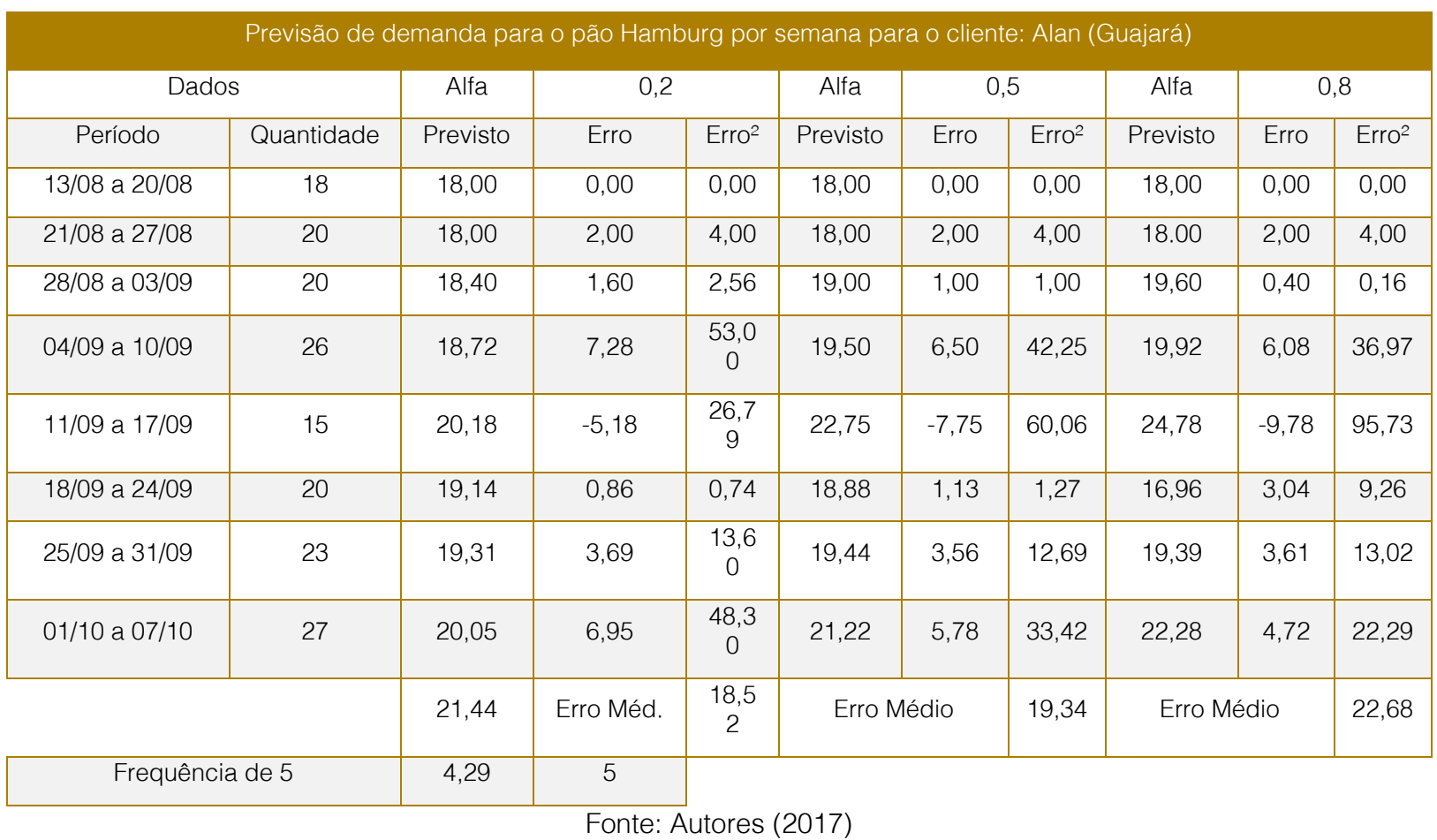

Vale ressaltar que os períodos do MPS são compostos pelos sete dias da semana, ou seja, a previsão para o próximo período levou em consideração a semana toda. Para que a previsão pudesse ser decomposta em dias foram observadas a frequência da quantidade de pedidos do cliente. O resultado da previsão de menor alfa foi divido pela frequência da quantidade de pedidos do pão hambúrguer para se obter uma média da previsão diária dos pedidos do cliente.

Para a elaboração da quantidade total de pães do tipo hambúrguer a serem inseridas na previsão de demanda, independente do Plano Mestre de Produção, observou-se também com que frequência em relação ao dia da semana os clientes efetuavam seus pedidos.

FIGURA 3 - Fluxograma do preenchimento da frequência de pedidos

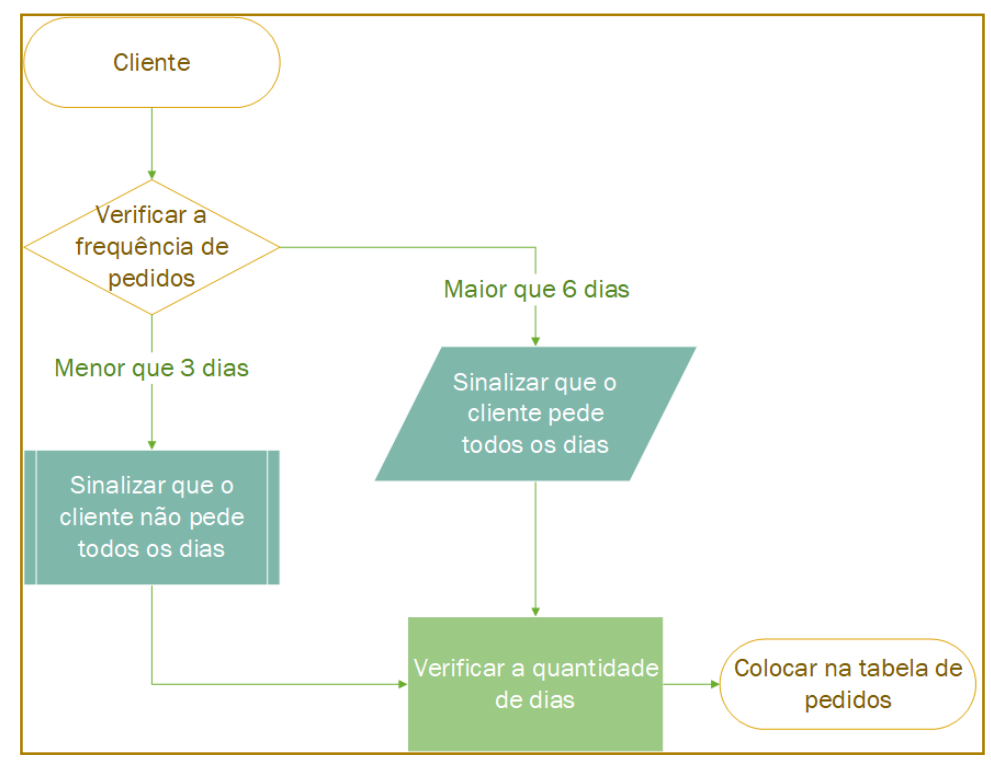

Fonte: Autores (2017) 
TABELA 2 - Tabela de frequência de pedidos diários

\begin{tabular}{|c|c|c|c|c|c|c|c|}
\hline Cliente & SEG & TER & QUA & $\begin{array}{l}\text { a da } \\
\text { QUI }\end{array}$ & SEX & SÁB & DOM \\
\hline Alan (Guajará) & 5 & 5 & 5 & 5 & 5 & 5 & 5 \\
\hline Big Mengão & & 11 & & & 11 & & \\
\hline Diana (Icuí) & & & & & 3 & 3 & \\
\hline $\begin{array}{l}\text { Vânia (Submarino } \\
\text { Lanches) }\end{array}$ & & & & 1 & & & 1 \\
\hline Welder & 3 & 3 & 3 & 3 & 3 & 3 & 3 \\
\hline Paulo Lanches & 4 & 4 & & 4 & 4 & 4 & 4 \\
\hline Blau's & & & & & 2 & 2 & 2 \\
\hline $\begin{array}{l}\text { Alexandre (MC } \\
\text { lanches) }\end{array}$ & 2 & 2 & & 2 & 2 & 2 & 2 \\
\hline Sandro (Brokadus) & & & & & 3 & 3 & 3 \\
\hline Gabriel & & 4 & 4 & & 4 & 4 & 4 \\
\hline Free Lanches & 3 & & & 3 & 3 & 3 & 3 \\
\hline Jofre's & & & & 5 & 5 & 5 & 5 \\
\hline Me Come (Shiley) & & & 3 & 3 & 3 & 3 & 3 \\
\hline Lena Lanches & & 1 & 1 & 1 & 1 & 1 & \\
\hline Mega Lanches & & & & & & 2 & \\
\hline Fabricio & & & & & 2 & 2 & \\
\hline Silvana (Pizzaria) & & & & & 3 & 3 & \\
\hline Acre & & & & 2 & 2 & 2 & \\
\hline Ándreia & & & & 2 & 2 & 2 & \\
\hline Airton & 3 & 3 & 3 & 3 & 3 & 3 & 3 \\
\hline Nadia (Sanduba's) & 4 & 4 & & & 4 & 4 & 4 \\
\hline Bossa Nova & & & & & & 3 & \\
\hline Piriquito's Burg & & & & & & 3 & 3 \\
\hline Ricardo Tapajós & & & 4 & & 4 & & \\
\hline Hélio & 6 & & 6 & & 6 & 6 & \\
\hline $\begin{array}{l}\text { Flavio (Cordeiro de } \\
\text { Farias) }\end{array}$ & 9 & & 9 & & & 9 & \\
\hline $\begin{array}{l}\text { Edgar Lanches } \\
\text { (Sideral) }\end{array}$ & 9 & & 9 & & 9 & 9 & \\
\hline João Paulo & & & 9 & & 9 & 9 & \\
\hline D. Anan & & & 7 & & 7 & 7 & \\
\hline Denilson & 6 & & 6 & & 6 & 6 & \\
\hline Giovani & 3 & & 3 & & & 3 & \\
\hline Alexandre (Sideral) & 4 & & & & & 4 & \\
\hline Renan (Scoobynho) & 7 & & 7 & & 7 & 7 & \\
\hline Sr. Francisco & & 8 & & 8 & & 8 & \\
\hline Maná Lanches & & 8 & & 8 & & 8 & 8 \\
\hline Tango & & 3 & & 3 & & 3 & \\
\hline Cintia & & 8 & & & 8 & & \\
\hline Total & 68 & 64 & 79 & 53 & 121 & 152 & 53 \\
\hline
\end{tabular}

Fonte: Autores (2018)

A frequência dos pedidos em relação aos dias foi preenchida com a quantidade prevista para cada dia da semana por cliente para assim fazer a soma das necessidades de cada dia da semana e preencher o MPS (Tabela 2). Vale ressaltar que o resultado da previsão semanal divido pela frequência da quantidade de pedidos foi arredondada para o maior valor arbitrariamente e sem nenhuma regra de arredondamento, visto que em algumas ocasiões os clientes poder fazer pedidos inesperados (ver figura 4). Com a quantidade total por dia da semana prevista foi possível elaborar o MPS (ver tabela 3). 
TABELA 3 - MPS preenchido com base nas necessidades diárias.

\begin{tabular}{|l|c|c|c|c|c|c|c|c|}
\hline \multicolumn{1}{|l|}{ Item: Pão de Hamburg } & \multicolumn{7}{c|}{ Períodos } \\
\hline $\begin{array}{l}\text { Previsão de Demanda } \\
\text { Independente }\end{array}$ & & 68 & 64 & 79 & 53 & 121 & 152 & 53 \\
\hline Pedidos em Carreira & & 0 & 0 & & 0 & 0 & 0 & 0 \\
\hline Demanda & & 68 & 64 & 79 & 53 & 121 & 152 & 53 \\
\hline $\begin{array}{l}\text { Estoque (Atual } \\
\text { disponível/Projetado) }\end{array}$ & 3 & 0 & 0 & 0 & 0 & 0 & 0 & 0 \\
\hline $\begin{array}{l}\text { Disponível para Promessa } \\
\text { (ATP) }\end{array}$ & & 65 & 64 & 79 & 53 & 121 & 152 & 53 \\
\hline $\begin{array}{l}\text { Programa Mestre de } \\
\text { Produção }\end{array}$ & & & & & & & \\
\hline
\end{tabular}

Fonte: Autores (2017)

Vale ressaltar que a empresa em questão não trabalha com pedidos em carteira, lote econômico, lote mínimo ou estoque de segurança. Como a demanda é o máximo entre a previsão e os pedidos, por consequência a demanda e o MPS será a própria previsão. A partir do método de previsão e do planejamento de produção proposto pelo MPS pode-se articular de forma mais eficiente como a distribuição do pão pode ser feita com base em ferramentas de roteirização que visem à quantidade a ser distribuída, a rota e o tempo.

\subsection{A PROPOSTA DE ROTEIRIZAÇÃO}

O método se inicia com a junção de dois pontos chamados de nós, calcula-se o seu ganho e em seguida os ordenam em forma decrescente, e depois se tem as seguintes etapas:

a) Juntar os pontos (clientes) em dois e calcular os ganhos conforme a equação 3;

b) Ordenar i e j em relação aos ganhos de forma decrescente;

c) Deve-se começar com primeira combinação de dois nós com maiores ganhos;

d) Verificar se os pontos (i, j) escolhidos não fazem parte de um roteiro que já começou;

Para isso têm-se as seguintes regras:

- $\quad$ Se i e j não fazem parte de nenhum roteiro previamente iniciado, pode-se começar com os dois pontos;

- Verificar se i já pertence a um roteiro, e se já, verificar também se ele é o início ou o fim da rota, se em um dos resultados for combinável com a próxima rota, pode-se ligar um ponto no outro (o que estiver livre e não pertencer a outra rota). Fazer a mesma verificação para j, e se nenhum dos dois ocorrer essa condição deve-se passar para o item (c);

- Se os pontos (i e j) já pertencem a um roteiro, só que diferente, verificar se as pontas são do mesmo roteiro, se forem sim se devem unir os dos roteiros em um só, caso não, deve-se passar para o item (d);

- Se os nós i e j pertencerem a uma mesma rota, deve-se passar para a etapa e

e) toda vez que um ponto for aceito ou unido, deve-se analisar se as restrições de tempo e capacidade, se não ultrapassar os limites deve-se aceitá-las;

f) A determinação das rotas termina quando todos os pontos são incluídos no roteiro.

Após as previsões de demanda diárias de acordo com cada cliente do dia serem realizadas, o problema de roteirização será analisado para definir a melhor solução em adequar as rotas com clientes mais próximos e também conseguir nivelar o MPS para que tenha uma produção constante. Ou seja, através da previsão de demanda é gerado o MPS para se realizar a melhor forma da distribuição dos pães. O problema de roteirização será adaptado ao método Clarke e Wright, com restrições de demandas, em uma região de entrega a demanda tem que ser nivelada, não ultrapassando o limite previsto. Ou seja, o método será aplicado em uma determinada área, depois deve-se olhar para a soma do MPS que será designado para essa região, que será uma restrição para a distribuição, essa soma não poderá ultrapassar o valor determinado anteriormente em conjunto com o setor de PCP, para que haja um equilíbrio na produção. 
Após analisar a roteirização da empresa em questão, será proposta uma comparação com rotas que a empresa realiza empiricamente com base na sua própria demanda de produção e a outra rota que ela realizará empiricamente, só que com o MPS proposto neste trabalho. Com o objetivo de analisar diferenças entre elas e verificar se houve melhorias no quesito tempo, e produção em relação ao MPS. A nível de comparação de tempo deve-se atentar para qual rota é mais rápida, comparar por exemplo se a rota realizada pelo método é mais rápida do que a feita pelo funcionário responsável na empresa que tem experiência. E em relação ao MPS, qual rota proposta é mais adequada para que ele se encaixe na produção.

\section{CONSIDERAÇÕES FINAIS}

O objetivo do presente trabalho foi propor um modelo de planejamento desagregado da produção que irá ajudar a determinar a distribuição de seus produtos. Foi proposto o modelo de MPS e de roteirização em uma panificadora industrial que fornece apenas pães para clientes secundários com o intuito de tornar este processo mais eficiente e a empresa mais competitiva. O Planejamento Mestre de Produção possibilitou a identificação e analise da maneira como é feita as previsões de demanda, a distribuição destas previsões para cada cliente, a alocação da quantidade de pães de acordo

\section{REFERÊNCIAS}

[1] ARRUDA, D. M [et al.]. Planejamento mestre de produção: entendendo o problema e propondo solução através de uma abordagem combinada. In: II SIMPÓSIO DE EXCELÊNCIA EM GESTÃO E CASTIGLIONI, José Antônio de Mattos. Logística operacional guia prático. São Paulo: Editora Érica Ltda., 2011.

[2] CUSTOS. Minas Gerais, 2013. Anais eletrônicos... Minas Gerais: CBC, 2013. Disponível em:

<https://anaiscbc.emnuvens.com.br/anais/article/vi ew/186>. Acesso em: 10 nov. 2017.

[3] FERNANDES, Flavio Cesar Faria. GODINHO, Moacir Filho. Planejamento e controle da produção: dos fundamentos ao essencial. São Paulo: Atlas, 2010.

[4] JUNIOR, C. A. M [et al.]. O papel da roteirização na redução de custos logísticos e com a frequência de pedidos alinhando assim com os períodos do MPS. Juntamente com a equipe de trabalho analisou-se também a possível elaboração de um modelo de roteiro de distribuição que leva em consideração a quantidade de pães a serem transportadas, a localização dos clientes e distância entre eles, já que esta roteirização é um importante suporte na elaboração do plano mestre. Vale ressaltar que outras ferramentas de planejamento e controle da produção podem auxiliar a empresa em certos aspectos produtivos como a gestão de estoque, a gestão dos materiais para produção dos pães e os sistemas de coordenação de ordens.

Este trabalho contribui para uma maior compreensão e divulgação, tanto no meio acadêmico quanto no meio empresarial, do Planejamento Mestre de Produção e dos métodos de roteirização em ambientes de produção, característicos da empresa estudada. Ressalta-se também, que este trabalho, faz parte da disciplina do eixo de extensão que visa a união das áreas do curso de engenharia de produção para compreender a dinâmica conceitual e prática destes assuntos. Sugere-se, para pesquisas futuras testar outros métodos de previsão da demanda, o uso de softwares especializados em varredura e roteirização, e o desenvolvimento de um modelo matemático que vise reunir os parâmetros do MPS com a distribuição.

melhoria do nível de serviço em uma empresa do segmento alimentício no Ceará. In: XX CONGRESSO BRASILEIRO DE LUSTOSA, Leonardo [et al.]. Planejamento e controle da produção. 4. ed. Rio de Janeiro: Elsevier, 2008.

[5] NOVAES, Antônio Galvão. Logística e gerenciamento da cadeira de distribuição. São Paulo: Editora CAMPUS, 2007. 303-330 p.

[6] NOVAES, Antônio Galvão. Logística e gerenciamento da cadeira de distribuição. São Paulo: Editora CAMPUS, 2007. 241-274 p.

[7] TOIGO, R. [et al.]. Sistema de roteirização de entregas. Hífen, v. 31, n. 59/60, 2007.

[8] TECNOLOGIA - SEGET. Rio de Janeiro, 2015. Anais eletrônicos... Rio de Janeiro: EADB, 2015. Disponível em: $<$ https://www.aedb.br/seget/artigos2005.php?pag= 6>. Acesso em: 06 nov. 2017. 


\section{Capítulo 13}

\section{PRÁTICAS DA LOGISTICA REVERSA A LUZ DA POLITTICA NACIONAL DE RESÍDUOS SÓLIDOS: UM ESTUDO BIBLIOMETRICO}

\section{Graciela Maria Miranda Borges}

André Geraldo da Costa Coelho

Danilo Henrique Divardin

Christiane Oliveira Valente

Resumo: O consumismo tem provocado aumento da produção de diversos produtos, que geram problemas ambientais à sociedade. Com intuito de diminuir esses transtornos e atender às necessidades do mercado, as organizações buscam trabalhar a logística reversa, ponderando sua rentabilidade com o regresso dos produtos comercializados ao fabricante, tendo em vista o seu reaproveitamento. Este artigo tem como objetivo explorar, por meio de uma pesquisa bibliométrica, as principais publicações acadêmicas que se referem à logística reversa na literatura, no período de 2012 a 2015. Empregou-se a metodologia descritiva exploratória, com abordagem quantitativa, utilizando a revisão bibliográfica, a pesquisa por levantamento longitudinal por estudos em painel e a bibliometria para o levantamento dos dados. O estudo foi desenvolvido a partir da Plataforma Sucupira, onde se analisou periódicos classificados pela Qualis Capes como A1, A2, B1 e B2, que tratam sobre a logística reversa e resíduos sólidos. Os resultados encontrados demostram que o tema tem sido fonte de pesquisa e publicações acadêmicas dentro e fora do país, concentrando um maior número em periódicos internacionais. Portanto, conclui-se que o assunto é de grande relevância à comunidade acadêmica, mas ainda tem sido pouco explorado.

Palavras-chave: Logística Reversa. Política Nacional dos Resíduos Sólidos. Bibliometria. Produções acadêmicas. 


\section{INTRODUÇÃO}

No atual contexto da sociedade em que vivemos, percebe-se que o consumismo tem aumentado, consideravelmente, devido às diversas opções de compra e que a indústria e o comércio buscam alternativas para atender às demandas de mercado, no intuito de obter vantagens competitivas. Para que as empresas consigam majorar seus lucros, é importante introduzir modelos logísticos que priorizem formas de melhor atender os seus clientes.

Segundo Christopher (2011), a logística trabalha no intuito de desenvolver estrategicamente as organizações, acompanhando a compra de matérias primas, a sua movimentação dentro da empresa, a forma de armazenar seus produtos e a viabilização de meios para que a sua comercialização seja rentável no momento em que ela aconteça. A logística proporciona que todo o processo produtivo seja executado adequadamente, com redução dos custos, o tempo de execução, além de trabalhar desde a produção até a venda, procurando mecanismos para retornar esses produtos à empresa fabricante, através da logística reversa.

A Lei no 12.305/2010 conceitua que a logística reversa pode ser um instrumento de desenvolvimento socioeconômico, por meio do qual constitui-se de ações, procedimentos utilizados de coleta e o retorno dos resíduos sólidos para que a empresa possa reaproveitá-los ou thes dar outra finalidade. Desta forma, a logística reversa transforma o processo de distribuição rotineiro em um algo inovador, onde os produtos que seriam descartados passam ser reutilizados como subprodutos ou produtos finais gerando lucratividade e sustentabilidade ambiental. (Lei no 12.305, 2010).

Instituições empresariais brasileiras, na tentativa de melhorar a forma de trabalhar a logística reversa, no descarte de embalagens, firmou o Acordo Setorial de Embalagens em Geral, juntamente com o Ministério do Meio Ambiente, visando à redução de $22 \%$ do volume de resíduos que chegam a aterros sanitários, para que a coleta e destinação final sigam as normas da Política Nacional de Resíduos Sólidos (PNRS). (Ministério do Meio Ambiente [MMA], 2015).

Empresas de grande porte, com a colaboração de catadores e cooperativas, procuram alternativas para aumentar a coleta desses resíduos, como, por exemplo; a Amber e a Danone, que fizeram parcerias com agentes coletores, ampliar a quantidade de embalagens retiradas do ambiente, proporcionando diminuição dos resíduos nos aterros sanitários ou lixões e fortalecendo a empresa e as cooperativas, além de gerar diminuição do impacto ambiental. (Filippe, 2016).

O problema que motivou a escrita do artigo foi o de averiguar o número de publicações acadêmicas referentes à logística reversa, no período de 2012 a 2015. A partir do problema inicial, definiu-se como objetivos do estudo identificar as práticas da logística reversa divulgadas em periódicos nacionais e internacionais; investigar as aplicações da logística reversa no Brasil, a partir da Lei de Crimes Ambientais e apresentar o quantitativo do tema publicado em periódicos classificados pela Capes como Qualis A1, A2, B1 e B2.

\section{REFERENCIAL TEÓRICO}

\subsection{DA LOGÍSTICA EMPRESARIAL A LOGÍSTICA REVERSA}

A busca constante para atender as necessidades da sociedade consumista levou os fabricantes a produzirem novos produtos, cada vez mais diversificados, que atendam as demandas dos consumidores. As empresas aumentaram a produção demandando maior rigor em seus processos logísticos, que atuam desde a fabricação do produto até a entrega final ao consumidor.

Para que as organizações consigam atingir menores custos e maior eficiência, a logística torna-se um fator primordial de integração entre o mercado, o fornecedor e o distribuidor, por ser um método estratégico onde os processos de compra, movimentação e armazenagem de matéria prima são trabalhados pela empresa juntamente aos canais de distribuição para gerar rentabilidade. (Christopher, 2011).

Desta forma, a logística se refere a toda a movimentação e armazenagem de materiais dentro da empresa, facilitando seu fluxo desde a aquisição até a entrega ao consumidor final. Além disso, acompanha e divulga as informações utilizadas no processo produtivo das diferentes mercadorias, visando atender as necessidades dos consumidores. (Ballou, 2011). 
Nas últimas décadas, a população tem almejado alternativas para preservar o meio ambiente e, assim, oportunizam produtos que causem menos danos ambientais. As instituições passaram a lidar com questões relacionadas a sustentabilidade ambiental, buscando em seus processos condições de se adequarem ao novo perfil de cliente e as legislações, surgindo, então, o conceito de logística reversa, como o regresso dos resíduos, após sua geração de renda, possibilitando que produtos, depois de descartados, retornem ao ciclo de produção das empresas gerando retorno econômico. (Guarnieri, 2011).

Essa lucratividade se dá através de duas visões dentro do ciclo produtivo. A primeira visão é a pós-venda e a segunda, conhecida como pós-consumo. Na visão de pós-venda, os produtos com pouco ou nenhum uso retornam a cadeia de suprimentos por validade expirada, defeitos, sazonalidade e deterioração para serem reutilizados na própria empresa fabricante ou na venda para terceiros. A visão pós-consumo lida com os produtos que estão no final de sua vida útil, ou seja, aqueles que serão descartados devido ao excesso de uso e que serão enviados para um novo processo. (Guarnieri, 2011; Leite, 2009).

A logística reversa contribui para que os produtos, após sua vida útil, ou para obter reparos, sejam retornados à organização podendo, assim, obter oportunidades de redução de custos e de impacto ambiental. Nesse sentindo tanto, foram criadas, no Brasil e no mundo, legislações para aplicar a logística reversa, tanto de pós-venda, quanto de pós-consumo. No tópico seguinte, tratarse-á da legislação brasileira que direciona a logística reversa e o controle do descarte de bens, produtos e resíduos sólidos.

\subsection{A APLICABILIDADE DA POLÍTICA NACIONAL DE RESÍDUOS SÓLIDOS NO BRASIL}

Para o alcance do equilíbrio, entre a sociedade e o mercado consumidor, tornouse necessária a elaboração de políticas e legislações específicas que orientem os usuários, ou seja, os fabricantes, consumidores, distribuidores e o poder público tendo em vista a preservação do meio ambiente. A fim de melhorar a atuação da sociedade no cuidado com meio ambiente, foi formulada a Lei dos Crimes Ambientais, $\mathrm{n}^{\circ}$
9.605/1998, que determina sanções penais e administrativas resultantes de crimes ambientais. A lei determina que todos os envolvidos nas contravenções penais serão punidos com penas como: multa, restrição de direitos, prestação de serviços a comunidade e até mesmo reclusão. (Lei no 9.605, 1998).

Em conformidade com a legislação até então vigente, criou-se a PRNS, instituída pela Lei $12.305 / 2010$, dispondo sobre os princípios, os objetivos e as diretrizes ligadas à gestão dos resíduos sólidos aos responsáveis, sejam eles fabricantes ou poder público. Conceituando a logística reversa como o conjunto de procedimentos para a coleta e o retorno dos resíduos sólidos às organizações para sua reutilização em seus próprios ciclos de produção ou venda a terceiros visando sua aplicação apropriada ambientalmente. (Lei no 12.305, 2010).

Perante essas exigências legais, a logística reversa deve ser empregada nas organizações para a reinserção dos resíduos, rejeitos ou produtos ao ciclo produtivo da mesma. Como exemplos ao tema em análise, a literatura discorre sobre as seguintes empresas e setores de atuação: A Tetra Park desenvolve o projeto Rota de Reciclagem que disponibiliza instruções para devolução das embalagens longa vida, no próprio site oportunizando à sociedade informações sobre pontos de coleta e cooperativas que comercializam esses tipos de materiais. Já a fabricante de latas de alumínio Tomara Latasa, desde 1991, trabalha com a reciclagem de suas embalagens no Brasil pela coleta seletiva em parceria com supermercados e fabricantes de bebidas com o projeto Replaneta, proporcionando pontos de coleta para receberem produtos pósconsumo e enviá-los para seu reaproveitamento. (Guarnieri, 2011; Leite, 2009).

Deste modo, várias empresas de capital internacional, instaladas no Brasil, procuram atender a legislação brasileira, trazendo benefícios ambientais à sociedade. As organizações possuem responsabilidades quanto a atuação na preservação ambiental, que estão discriminadas na legislação e serão discutidas a seguir. 
2.3 A RESPONSABILIDADE DAS ORGANIZAÇÕES NA GESTÃO DE RESÍDUOS SÓLIDOS

A responsabilidade das organizações na gestão de resíduos sólidos passou a vigorar a partir da Lei 12.305/2010, cujo artigo 33 elenca os envolvidos no processo: os fabricantes, distribuidores, consumidores e o poder público que compartilham a responsabilidade pelo processo de geração de resíduos e sua gestão garantindo a sociedade um desenvolvimento sustentável.

Os fabricantes responsabilizar-se-ão pelo destino final dos seus produtos após a vida útil, considerando que deverão implantar o sistema de logística reversa, promovendo a compra ou venda para o reuso dos mesmos ao ciclo produtivo, além de arcar com as obrigações financeiras decorrentes do processo reverso. Os distribuidores são obrigados a devolver à empresa fabricante os produtos ou insumos retornados dos consumidores pela logística reversa.

Os consumidores, por sua vez, podem ajudar na gestão dos resíduos sólidos, devolvendo os produtos após o término de sua vida útil aos pontos de coleta oferecidos pelo fabricante, distribuidor, importadores, prefeituras ou empresas terceirizadas. Desta forma, o poder público, especificamente o municipal, é responsável pelo serviço de limpeza urbana e coleta seletiva favorecendo a destinação dos produtos e resíduos ao fabricante, devendo criar e implantar sistemas de compostagem para resíduos orgânicos, estabelecer parcerias com cooperativas e terceirizados para realização de parte ou toda gestão dos resíduos. (Lei no 12.305, 2010).

Por fim, a integração destes atores viabiliza que a PNRS seja desenvolvida, atendendo às exigências legais, possibilitando que os resíduos sejam retornados aos fabricantes, fazendo com que se cumpra a missão do ciclo produtivo, que é retorno do produto a sua origem. Em busca de ampliação acerca do tema, o tópico seguinte define a bibliometria, como fonte de pesquisa para realização deste artigo.

\subsection{PANORAMA HISTÓRICO DA BIBLIOMETRIA}

Segundo Santos e Kobashi (2009), a bibliometria refere-se a um instrumento de pesquisa científica associada à base de dados de bibliotecas, podendo ser virtuais e/ou físicas. A bibliometria ficou conhecida, a partir início do século XIX, como um tipo de pesquisa que apresenta tanto aspectos quantitativos, quanto qualitativos, ou seja, disponibilizando dados estatísticos referentes o assunto pesquisado e apresentando o nível de relevância do tema em análise.

A bibliometria é um método de análise científica, que busca por meio da quantificação de material, trabalhar estatisticamente pesquisas, sejam diretamente em material impresso ou virtualmente, por meio das revistas eletrônicas para obtenção de dados. Apresenta grande relevância ao conhecimento, pois analisa cientificamente as produções, focando na abordagem do tema proposto para estudo. (Araújo \& Alvarenga 2011).

Segundo Machado, Souza, Palmisano, Campanário e Parisotto (2014), as técnicas bibliométricas proporcionam exposição de informações sobre o objeto de interesse do pesquisador, gerando qualidade na pesquisa mediante o número de publicações analisadas. Essa técnica era inicialmente empregada apenas em bibliotecas e hoje é utilizada em diversas áreas, proporcionando a verificação de dados disponíveis em vários tipos de documentos, para que por meio de métodos estatísticos possam gerar informações eficientes.

\section{METODOLOGIA DA PESQUISA}

A metodologia é um conjunto de procedimentos que serão empregadas na coleta e posterior, avaliação dos dados para o desenvolvimento da pesquisa. Esses dados poderão ser analisados, quanto à natureza da pesquisa de duas formas: qualitativa e quantitativamente. A primeira, consiste em interpretar os significados e experiências relacionadas a determinados fenômenos, procurando entender como determinado fato ocorre; a segunda, em mensurar as informações e fazer análises estatísticas visando obter uma conclusão lógica. (Collis \& Hussey, 2005).

A autora Bertucci (2015) classifica a pesquisa quanto aos fins, sendo pesquisa exploratória aquela que trabalha procurando descrever o problema por meio da interligação das variantes para tornar a pesquisa mais conhecida. A pesquisa descritiva por sua vez descreve o tema abordado interligando as variáveis analisadas pelo projeto, 
oportunizando que as hipóteses levantadas sejam explicadas. Sendo assim, o estudo abordou uma visão quantitativa sobre o tema, utilizando a pesquisa descritiva exploratória, com o levantamento de dados bibliográficos.

Segundo Vergara (2016), a pesquisa pode ser feita por análises bibliográficas trabalhando com base em publicações acadêmicas, periódicos, livros, jornais, revistas e materiais que proporcionarão informações sobre o tema pesquisado. Outra técnica de pesquisa aplicada foi a de levantamento, uma vez que esta emprega abordagem direta ao indivíduo para compreender sua conduta. (Gil, 2008).

Bertucci (2015) afirma que o levantamento também pode ser chamado de survey, para descrever, explicar ou explorar um fenômeno. A pesquisa survey pode ser classificada como longitudinal, ou seja, os dados são coletados em períodos diferentes para proporcionar explicações sobre mudanças ocorridas acerca de determinado fenômeno. A pesquisa survey longitudinal pode ser realizada em estudos de painel, que coleta de dados ao longo do tempo da mesma amostra. $\mathrm{O}$ artigo foi elaborado a partir de técnica da revisão bibliográfica juntamente com a pesquisa por levantamento longitudinal por estudos em painel e a bibliometria.

Segundo Santos e Kobashi (2009), a bibliometria analisa livros e periódicos científicos ligados ao gerenciamento de bibliotecas, assim como das bases de dados. Para que essas informações sejam exploradas é necessário o uso de programas estáticos tais como: Excel, VOSviewer, Bibexcel, entre outros.

Vergara (2016) considera que o universo compreende toda a população correspondente a pesquisa, sendo observada de forma geral. A autora define também que a amostra é composta por apenas uma parte do universo, seguindo critérios já definidos na pesquisa, ou seja, trabalhando com um grupo específico, podendo ser não probabilística por acessibilidade, onde o pesquisador pode escolher os elementos da amostra pela acessibilidade. Em função da disponibilidade de periódicos na Plataforma Sucupira, tornouse necessária a utilização de métricas estatísticas para delimitar o universo de periódicos acessados, dentre os quais foram pesquisados 2289 periódicos, sendo classificados como A1 com 400 produtos acadêmicos científicos, 623 classificados como A2, 698 produtos classificados como B1 e 568 classificados como B2.

O artigo verificou, por meio de pesquisa bibliométrica, as práticas de logística reversa e adoção da PNRS, presente na literatura no período de 2012 a 2015, disponibilizados pelo banco de dados da Plataforma Sucupira, os quais são apresentados para consultas públicas por meio da Comissão de Aperfeiçoamento de Pessoal do Nível Superior (Capes).

Neste dispositivo, os periódicos inseridos no sistema pelas instituições de ensino participantes do Sistema Nacional de PósGraduação recebem a classificação Qualis Periódicos A1, A2, B1, B2, B3, B4, B5 e C. O estudo em questão analisou os periódicos classificados como A1, A2, B1 e B2 os quais mencionam a logística reversa $e$ as aplicações acerca da PNRS. Os dados foram coletados na Plataforma Sucupira como mostra a Figura 1:

Figura 1: Passos da coleta de dados na Plataforma Sucupira

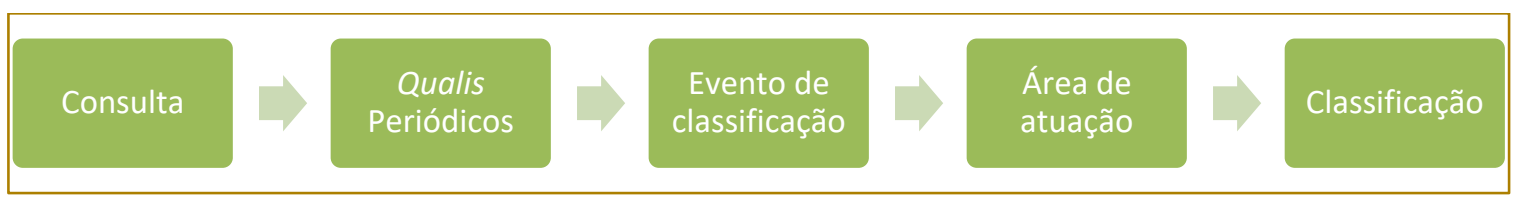

Fonte: Plataforma Sucupira, adaptado. ( 2017) .

Algumas planilhas eletrônicas foram elaboradas no software Microsoft Excel, para inserir os dados coletados, a partir dos títulos, resumos e palavras-chave de artigos publicados nos periódicos que tratam do tema para a avaliação bibliométrica. Os critérios adotados foram: classificação do periódico, período de publicação, periódico nacional ou internacional, área de especificação, nome do artigo, nome do autor e palavras chaves: logística reversa, resíduos sólidos, PNRS. 


\section{ANÁLISE DOS RESULTADOS}

Neste tópico é abordada a discussão dos resultados encontrados a partir da pesquisa bibliométrica nos periódicos classificados pela CAPES, conhecidos como Qualis
Periódicos. Para a pesquisa em questão, utilizou-se a base de dados da Plataforma Sucupira, os períodos de 2012 a 2015, sendo classificados para análise deste estudo os Qualis Periódicos A1, A2, B1 e B2, conforme demonstrado na Tabela 1:

Tabela 1: Distribuição dos periódicos encontrados por ano

\begin{tabular}{c|c|c|c|c|}
\hline \multirow{2}{*}{$\begin{array}{c}\text { Período de publicação } \\
\text { Ano }\end{array}$} & A1 & A2 & B1 pesquisado de periódicos \\
\hline 2012 & 140 & 190 & 223 & 85 \\
\hline 2013 & 51 & 103 & 115 & 147 \\
\hline 2014 & 69 & 140 & 137 & 162 \\
\hline 2015 & 140 & 190 & 223 & 174 \\
\hline Total: & 400 & 623 & 698 & 568 \\
\hline
\end{tabular}

Fonte: Resultado da pesquisa (2017).

Os periódicos classificados como A1, A2, B1 e B2 normalmente estão disponibilizados em inglês, espanhol e português. Após a pesquisa na plataforma, verificou-se que houve variação quanto a quantidade de periódicos publicados no período de 2012 a 2015, tendo em vista que os resultados apresentados foram de 400 periódicos $A 1$, 623 periódicos A2, 698 periódicos B1 e 568 periódicos B2.

\subsection{IDENTIFICAR AS PRÁTICAS DA LOGÍSTICA REVERSA PUBLICADAS EM PERIÓDICOS NACIONAIS E INTERNACIONAIS}

As organizações têm buscado trabalhar, com maior ênfase, a logística reversa objetivando aumentar sua sustentabilidade financeira $e$ ambiental.
Segundo Guarnieri (2011), o crescimento da sensibilização das questões ecológicas pelos consumidores, leva a sociedade a buscar políticas com novas formas de trabalhar a sustentabilidade, a qual gera competitividade nas organizações, possibilitando assim que a logística reversa seja implantada por algumas empresas.

Os resultados encontrados na pesquisa demostraram que a prática da logística reversa está sendo empregada na indústria eletrônica, na indústria do aço, na indústria manufatureira (automóveis, elétricas, plástico e têxtil), no setor de bebidas, de descartáveis, de vidro, de defensivos agrícolas, entre outros. A Tabela 2 apresenta as principais práticas encontradas nos periódicos.

Tabela 2: Práticas encontradas nos periódicos Qualis

\begin{tabular}{|l|c|c|}
\hline \multicolumn{1}{|c|}{ Práticas encontradas nos periódicos A1, A2, B1 e B2 } & Internacional & Nacional \\
\hline Indústria eletrônica & 6 & 0 \\
\hline Roteamento de veículos & 1 & 0 \\
\hline Defensivos agrícolas & 1 & 0 \\
\hline Marketing verde & 1 & 0 \\
\hline Indústria do cimento & 1 & 0 \\
\hline Comércio eletrônico & 6 & 0 \\
\hline Cadeia de suprimento verde & 0 & 1 \\
\hline Reciclagem do aço & 0 & 1 \\
\hline Embalagens descartáveis & 0 & 2 \\
\hline
\end{tabular}


Tabela 2: Práticas encontradas nos periódicos Qualis

(continuação..)

\begin{tabular}{|l|c|c|}
\hline \multicolumn{1}{|c|}{ Práticas encontradas nos periódicos A1, A2, B1 e B2 } & Internacional & Nacional \\
\hline Setor de vidros & 2 & 1 \\
\hline Reciclagem de papel & 0 & 1 \\
\hline Processamento de bebidas & 0 & 1 \\
\hline Recuperação e reciclagem setor de cervejas & 1 & 1 \\
\hline Indústria manufatureira (automóveis, elétricas, plástico e têxtil) & 1 & 0 \\
\hline Bateria e celular & 1 & 1 \\
\hline Autopeças & 0 & 0 \\
\hline Lixo tecnológico & 0 & 1 \\
\hline Sistema de informação sobre LR & 22 & 11 \\
\hline Total: & 1 & 1 \\
\hline
\end{tabular}

Fonte: Resultado da pesquisa, 2017.

Os setores elencados na Tabela 2 aderem às práticas da logística reversa na devolução de descartáveis, reciclagem de papel, vidro, retorno das embalagens de defensivos agrícolas, práticas de marketing verde, cadeia de suprimentos verde, processamento de bebidas e recuperação de produtos elétricos e eletrônicos.

\subsection{AS PRINCIPAIS APLICAÇÕES DA LOGÍSTICA REVERSA NO BRASIL A PARTIR DA LEI DE CRIMES AMBIENTAIS (LEI № 9.605/98)}

A partir da Lei 9.605/98, as questões ecológicas vêm se tornando de grande relevância à sociedade e em detrimento da necessidade de diminuir o uso dos recursos ambientais indevidamente, discussões são trabalhadas para a adequação em relação à melhoria da sustentabilidade econômica e ecológica, além de proporcionar diferencial competitivo no mercado. (Guarnieri, 2011).
Com a pesquisa, constatou-se que no Brasil as organizações estão buscando atender a legislação da PNRS utilizando a logística reversa, a qual possibilita que seus produtos ou resíduos sejam retornados adequadamente às empresas fabricantes para seu correto descarte. Quanto à gestão dos resíduos sólidos brasileiros, destacam-se a coleta seletiva, a reciclagem de vidros e a produção limpa. Identificou-se que as principais aplicações da logística reversa estão presentes no setor industrial e comercial, em que prevalece a sua aplicação em atividades relacionadas à reciclagem e reuso do aço, do vidro, dos descartáveis, das embalagens PET, dos resíduos eletrônicos, produtos têxteis, cervejarias, bem como no retorno das embalagens de defensivos agrícolas.

A Tabela 3 apresenta algumas das principais aplicações da logística reversa, a partir da Lei de Crimes Ambientais: 
Tabela 3: Aplicações da logística reversa

\begin{tabular}{|c|c|c|c|c|c|}
\hline \multicolumn{6}{|c|}{ Aplicações adotadas nas organizações brasileiras } \\
\hline Logística reversa & Quant. & Resíduos sólidos & Quant. & PNRS & Quant. \\
\hline Reciclagem do aço & 1 & Produção limpa & 1 & $\begin{array}{l}\text { Políticas } \\
\text { municipais }\end{array}$ & 3 \\
\hline Embalagens descartáveis & 1 & Coleta seletiva & 2 & & \\
\hline Setor de vidros & 1 & Gestão de resíduos & 3 & & \\
\hline Defensivos agrícolas & 2 & $\begin{array}{l}\text { Sistema de } \\
\text { informação sobre RS }\end{array}$ & 1 & & \\
\hline Reciclagem de papel & 1 & $\begin{array}{l}\text { Equipamentos } \\
\text { eletromédicos }\end{array}$ & 1 & & \\
\hline Processamento de bebidas & 1 & Automóveis & 1 & & \\
\hline $\begin{array}{l}\text { Recuperação e reciclagem setor de } \\
\text { cervejas }\end{array}$ & 1 & Vermicompostagem & 2 & & \\
\hline $\begin{array}{l}\text { Indústria manufatureira (automóveis, } \\
\text { elétricas, plástico e têxtil) }\end{array}$ & 1 & Energia renovável & 1 & & \\
\hline Bateria e celular & 1 & Reciclagem & 1 & & \\
\hline Lixo tecnológico & 1 & & & & \\
\hline Sistema de informação sobre LR & 1 & & & & \\
\hline Total: & 12 & & 13 & & 3 \\
\hline
\end{tabular}

Fonte: Resultado da pesquisa, 2017.

A logística reversa está sendo adotada nas organizações brasileiras em processos como reciclagem do aço, papel, de vidros, embalagens descartáves, processamento de bebidas, indústria manufatureira, lixo tecnológico e defesivos agrícolas.

A autora Guarnieri (2011), salienta que o uso da logística reversa de embalagens de agrotóxicos brasileiras está estruturada seguindo as diretrizes legais e apoiada pelo Instituto Nacional de Processamento de Embalagens Vazias (INPEV). Para que as embalagens sejam retornadas, as empresas fabricantes devem promover campanhas ambientais educativas nos meios de comunicação de maior visibilidade para sensibilizar o produtor.

\subsection{OS PRINCIPAIS PERIÓDICOS QUALISA1, A2, B1 E B2 SOBRE A ÓTICA DA LOGÍSTICA REVERSA}

A pesquisa demonstrou que os periódicos Classificados pela Qualis Capes como A1 são compostas por produtos acadêmicos internacionais e os periódicos classificados como A2, B1 e B2 de produtos acadêmicos nacionais e internacionais.

Constatou-se que as revistas classificadas como A1 abordaram maior quantitativo de artigos referentes à logística reversa, com 41 publicações no período de 2012 a 2015. Logo, os periódicos A2, classificados pela Qualis Capes, encontram-se em menor quantitativo, com 4 artigos, como descrito nas Tabelas 4 e 5. 
Tabela 4: Principais periódicos A1

\begin{tabular}{|c|c|c|}
\hline Ano & Revista & $\begin{array}{c}\text { Artigos } \\
\text { encontrados }\end{array}$ \\
\hline \multirow{7}{*}{2012} & Environment \& Planning. B, Planning \& Design (Print) & 1 \\
\hline & Expert Systems with Applications & 2 \\
\hline & Journal Human and Ecological Risk Assessment: An International Journal & 1 \\
\hline & Industrial Marketing Management & 1 \\
\hline & Journal International Journal of Computer Integrated Manufacturing & 1 \\
\hline & International Journal of Production Economics & 5 \\
\hline & Subtotal: & 11 \\
\hline \multirow{4}{*}{2013} & Industrial Management \& Data Systems & 1 \\
\hline & International Journal of Operations \& Production Management & 2 \\
\hline & Journal of Cleaner Production & 4 \\
\hline & Subtotal: & 7 \\
\hline \multirow{6}{*}{2014} & International Journal of Physical Distribution \& Logistics Management & 4 \\
\hline & International Journal of Production Economics & 1 \\
\hline & Journal of Cleaner Production & 2 \\
\hline & Omega & 3 \\
\hline & Socio-Economic Planning Sciences & 1 \\
\hline & Subtotal: & 11 \\
\hline \multirow{8}{*}{2015} & Benchmarking: An International Journal & 2 \\
\hline & Computers \& Industrial Engineering & 2 \\
\hline & European Journal of Operational Research & 1 \\
\hline & Journal International Journal of Computer Integrated Manufacturing & 1 \\
\hline & International Journal of Physical Distribution \& Logistics Management & 1 \\
\hline & International Journal of Production Economics & 2 \\
\hline & Information Systems Design and Intelligent Applications & 3 \\
\hline & Subtotal: & 12 \\
\hline Total: & & 41 \\
\hline
\end{tabular}

Fonte: Resultado da pesquisa, 2017

A revista Journal of Cleaner Production classificada como A1 se manteve nos anos de
2013 e 2015, com 6 artigos publicados no período. 
Tabela 5: Principais periódicos A2

\begin{tabular}{|l|l|c|}
\multicolumn{2}{|c}{ Ano } & \multicolumn{2}{|c}{ Revista } & Artigos encontrados \\
\hline \multirow{2}{*}{2012} & RAE-Revista de Administração de Empresas & 1 \\
\cline { 2 - 3 } & Subtotal: & 1 \\
\hline \multirow{2}{*}{2013} & Applied Mathematical Modelling & 1 \\
\cline { 2 - 3 } & Subtotal: & 1 \\
\hline \multirow{2}{*}{2014} & $\begin{array}{l}\text { RAE-Revista de Administração de Empresas } \\
\text { Int. J. of Logistics Systems and Management }\end{array}$ & 1 \\
\cline { 2 - 3 } & Subtotal: & 2 \\
\hline \multirow{2}{*}{2015} & & 0 \\
\cline { 2 - 3 } & Subtotal: & 0 \\
\hline Total: & & 4 \\
\hline
\end{tabular}

Fonte: Resultado da pesquisa, 2017.

Na Tabela 5, verifica-se que a RAE-Revista de Administração de Empresas permaneceu como A2, nos anos 2013 e 2014, apresentando 2 publicações no período. Os periódicos B1 dispõem maior número de publicações sobre o tema no período, com 10 artigos, em relação aos classificados como B2, apresentam 6 artigos publicados.

Tabela 6: Principais periódicos B1

\begin{tabular}{|c|c|c|}
\hline Ano & Revista & Artigos encontrados \\
\hline \multirow{4}{*}{2012} & Educação em Revista & 1 \\
\hline & Revista de Economia e Sociologia Rural & 1 \\
\hline & Organizações Rurais \& Agroindustriais & 1 \\
\hline & Subtotal: & 3 \\
\hline \multirow{4}{*}{2013} & Ambiente \& Sociedade & 1 \\
\hline & Gestão \& Produção & 1 \\
\hline & $\begin{array}{l}\text { International Journal of Environmental } \\
\text { Technology and Management }\end{array}$ & 1 \\
\hline & Subtotal: & 3 \\
\hline \multirow{4}{*}{2014} & Ambiente \& Sociedade & 1 \\
\hline & Contaduría y administración & 1 \\
\hline & $\begin{array}{l}\text { Journal International Journal of Logistics } \\
\text { Research and Applications }\end{array}$ & 1 \\
\hline & Subtotal: & 3 \\
\hline \multirow[t]{2}{*}{2015} & $\begin{array}{l}\text { International Journal of Social Ecology and } \\
\text { Sustainable Development (IJSESD) }\end{array}$ & 1 \\
\hline & Subtotal: & 1 \\
\hline Total: & & 10 \\
\hline
\end{tabular}

Nota: Resultado da pesquisa, 2017.

Nos periódicos classificados como B1, a revista Ambiente \& Sociedade permaneceu com a mesma classificação nos anos de 2013 e 2014. O periódico B2, Exacta, continuou 
com a mesma classificação no ano de 2012 e

com as Tabelas 6 e 7 .

2015, com 2 publicações em cada, de acordo

Tabela 7: Principais periódicos B2

\begin{tabular}{|c|c|c|}
\hline Ano & Revista & Artigos encontrados \\
\hline \multirow{4}{*}{2012} & RGSA: Revista de Gestão Social e Ambiental & 2 \\
\hline & S \& G. Sistemas \& Gestão & 1 \\
\hline & Exacta & 1 \\
\hline & Subtotal: & 4 \\
\hline \multirow{2}{*}{2013} & Gestão \& regionalidade & 1 \\
\hline & Subtotal: & 1 \\
\hline \multirow{2}{*}{2014} & & 0 \\
\hline & Subtotal: & 0 \\
\hline \multirow{2}{*}{2015} & Exacta & 1 \\
\hline & Subtotal: & 1 \\
\hline Total: & & 6 \\
\hline
\end{tabular}

Fonte: Resultado da pesquisa, 2017.

Os periódicos encontrados nas Tabelas 4, 5, 6 e 7 estão relacionados às áreas de planejamento, gestão e operações, ecologia, produção, qualidade total, marketing, computação, sistemas, ética, energias, sustentabilidade ciências sociais, ciências florestais, educação, economia e agronegócio.

\section{CONSIDERAÇÕES FINAIS}

As questões ambientais e financeiras têm levado as organizações a trabalhar com a logística reversa no retorno dos resíduos para o seu reuso dentro dos processos produtivos ou a revenda destes as outras empresas.

Os resultados da pesquisa demostraram que as práticas da logística reversa utilizadas pelas organizações estão relacionadas ao reuso de resíduos da construção civil, reciclagem de embalagens pet, papel, vidro, retorno de embalagens de defensivos agrícolas, garrafas de bebidas, comércio eletrônico, com práticas de marketing verde, entre outros.

As questões ambientais brasileiras são tratadas a partir da Lei nº 9.605/98, sendo alterada posteriormente pela Lei $n$ ㅇ 12.305/2010, a qual cria a PNRS, viabilizando diante da logística reversa o retorno dos resíduos às organizações. A PNRS é um marco importante na legislação para adequação das instituições quanto à preservação ambiental, levando-as a adotarem a prática a logística reversa, conforme a legislação. (Lei no 12.305, 2010).

A pesquisa evidenciou que os periódicos internacionais produzem mais publicações sobre a logística reversa do que os brasileiros, uma vez que este conceito está mais difundido internacionalmente. O número de publicações encontradas na base de dados da Plataforma Sucupira demostra que a logística reversa tem sido fonte de pesquisa acadêmica, porém, o tema deve ganhar ênfase em pesquisas futuras, uma vez que é de grande relevância para ações estratégicas de cunho financeiro e ecológico das instituições, tanto internacionais quanto nacionais.

Dentre as limitações da pesquisa, destaca-se o pouco acesso aos periódicos Qualis Capes desde 1998, ano este em que se refere a Lei no 9.605, denominada Lei de Crimes Ambientais. O estudo deste artigo contempla o período de 2012 a 2015 para melhor análise comparativa dos dados e obtenção de resultados, que proporcionem ao pesquisador maior número de informações. Por se tratar de um estudo de levantamento bibliográfico, em uma plataforma de base de dados com muitos periódicos cadastrados, o tempo para o desenvolvimento da pesquisa tornou-se um 
fator limitador, sendo preciso a readequação dos objetivos da pesquisa.

Por fim, sugere-se que outros pesquisadores realizem novos estudos ampliando o tamanho

\section{REFERÊNCIAS}

[1] Araújo, R. F., \& Alvarenga, L.(2011). Bibliometria na pesquisa científica da pósgraduação brasileira de 1987 a 2007. Revista Eletrônica Biblioteconomia e Ciência da Informação, 16 (31). 51-70.

[2] Ballou, R. H. (2011). Logística empresarial: transportes, administração de materiais e distribuição física. São Paulo: Atlas.

[3] Bertucci, J. L.O. (2015). Metodologia básica para elaboração de trabalhos de conclusão de curso: ênfase na elaboração de TCC de pósgraduação lato sensu. São Paulo: Atlas.

[4] Christopher, M. (2011). Logística e gerenciamento da cadeia de suprimentos. São Paulo: Cengage Learning.

[5] Collis, J. \& Hussey, R. (2005). Pesquisa em administração: um guia prático para alunos de graduação e pós-graduação. Porto Alegre: Bookman.

[6] Filippe, M. ( 2016, junho). Eu te ajudo a ajudar. Revista Exame., 50 (11). pp. 56-58.

[7] Gil, A. C. (2008). Métodos e técnicas de pesquisa social. São Paulo: Atlas.

[8] Guarnieri, P. (2011). Logística reversa: em busca do equilíbrio econômico e ambiental. Recife: Clube de Autores.

[9] Lei n. 9.605, de 12 de fevereiro de 1998(1998), que dispõe sobre as sanções penais e administrativas derivadas de condutas e atividades lesivas ao meio ambiente, e dá outras providências. Diário Oficial da União. Brasília, DF. da amostra contemplando periódicos B3, B4, B5 e C, para corroborarem com o estudo ora apresentado.

[10] Lei n. 12.305, de 2 de agosto de 2010 (2010), que institui a Política Nacional de Resíduos Sólidos, e dá outras providências. Diário Oficial da União. Brasília, DF.

[11] Leite, P. R. (2009). Logística reversa: meio ambiente e competitividade. São Paulo: Pearson Prentice Hall.

[12] Machado. C. Jr, Souza, M. T. S. de., Palmisano A., Campanário. M. A. \& Parisotto, I.R.dos S. (2014, setembro). Análise de viabilidade de utilizar as leis da bibliometria em diferentes bases de pesquisa. Anais do Encontro da Associação Nacional de Pesquisa em Administração, Rio de Janeiro, RJ, Brasil, 38.

[13] Ministério da Educação. Coordenação de Aperfeiçoamento de Pessoal de Nível Superior. Plataforma Sucupira. Recuperado em 10 fevereiro, 2017 ,

de:

http://www.capes.gov.br/avaliacao/plataformasucupira.

[14] Ministério do Meio Ambiente. Acordo setorial das embalagens em geral. Recuperado em 10 fevereiro, 2015, de: http://www.sinir.gov.br/web/guest/embalagens-emgeral.

[15] Santos, R. N. M. dos \& Kobashi, N. Y. (2009). Bibliometria, cientometria, infometria: conceitos e aplicações. RevistaTendências da Pesquisa Brasileira em Ciência da Informação, 2 ( 1), 155-172.

[16] Vergara, S. C. (2016). Projetos e relatórios de pesquisa em administração. São Paulo: Atlas. 


\section{Gapítulo 14}

\section{INOVAÇÃO NA CADEIA DE FORNECEDORES DE EMPRESAS BRASILEIRAS COM \\ INTERNACIONAL: UM ESTUDO \\ MARCOPOLO E DA GERDAU}

\section{Maria Laura Romão Degaspari}

\section{Helder Sacks}

\section{Leandro José Morilhas}

Marcos Alberto Castelhano Bruno

Resumo: Este trabalho explora através das teorias da Escola Nórdica de Negócios e Paradigma Eclético da Produção e Internacionalização como se dá a inovação na cadeia de fornecedores a partir da internacionalização de empresas. O estudo com abordagem qualitativa está centrado na Gerdau e na Marcopolo, empresas brasileiras, internacionalizadas, que foram destaque em virtude de suas ações de incentivo a inovação direcionada a sua cadeia de fornecedores em casos publicados pela Confederação Nacional da Indústria [CNI]. Este estudo reforça através de uma análise dos casos versus as teorias apresentadas que através das ações promovidas pelas empresas foi possível observar o desenvolvimento de todo o setor que contribuiu para aquisição de vantagens competitivas para as empresas estudadas. 


\section{INTRODUÇÃO}

A internacionalização das empresas é um fenômeno que surgiu no início do século XX. Esta estratégia foi observada inicialmente em empresas Norte Americanas e Europeias, contudo, trata-se de um fenômeno recente em países em desenvolvimento (Oliveira et al,2010).

O Brasil possui dezenas de empresas que através da internacionalização buscam novos mercados para atuar (Morilhas, 2008). Almeida (2007) complementa que a internacionalização das empresas brasileiras nos últimos anos ocorreu em virtude do baixo crescimento econômico brasileiro, o que propulsionou as empresas a buscarem nos mercados internacionais o dinamismo necessário para crescimento do negócio.

Um fator comum para as empresas globalizadas é o grau de inovação por ser um elemento fundamental nas indústrias e em países que competem com êxito nos mercados mundiais. Para Kline e Rosemberg (1986), as consequências do processo de inovação são observadas em toda a cadeia de valor, pois ao estimular o desempenho tecnológico de todos os participantes, a empresa proporciona o aumento na produção de componentes intermediários e promove crescimento econômico.

Desde o ano de 2006 a Fundação Dom Cabral [FDC] realiza uma pesquisa com empresas multinacionais brasileiras que tem por objetivo avaliar de que forma a internacionalização contribui para a competitividade, quais são os benefícios adquiridos e quais as perspectivas para os negócios realizados no exterior (FDC, 2016).

Nas publicações dos últimos 4 anos, a Marcopolo e a Gerdau figuraram entre as respondentes, sendo possível constatar que no ano de 2013 a Marcopolo apresentou 24 subsidiárias e nos anos subsequentes 25. A Gerdau registrou 19 subsidiárias nos anos de 2013 e 2014, não constou presente no ranking de 2015 e no ano de 2016 registrou 14 subsidiárias (FDC, 2013, 2014, 2015 e 2016).

As mesmas empresas também foram destaque das publicações anuais realizadas pela CNI (Confederação Nacional da Indústria), em virtude de projetos inovadores que buscaram estimular os fornecedores de sua cadeia de valor (CNI, 2013, 2014).

Tendo como base de análise os casos divulgados pela CNI sobre a Gerdau e a
Marcopolo assim como as informações disponíveis nos rankings divulgados pela Fundação Dom Cabral, este trabalho visa responder: Como se dá a inovação na cadeia de fornecedores a partir da internacionalização das empresas?

Como objetivos secundários, este trabalho deverá identificar:

Quais características dos modelos de internacionalização da Gerdau e da Marcopolo são observadas com base nos modelos de Uppsala e Modelo Eclético da Produção;

Quais são as principais vantagens para incentivar a gestão da inovação na cadeia de fornecedores.

\section{REFERENCIAL TEÓRICO}

\subsection{INTERNACIONALIZAÇÃO DAS} EMPRESAS

$\mathrm{Na}$ literatura, a internacionalização das empresas é analisada pelas áreas de administração de empresas e ciências econômicas. Na primeira, destacam-se os modelos que reforçam o comportamento exportador, que observam o processo de internacionalização como algo gradual, reiterando razões e características desse gradualismo. $\mathrm{Na}$ segunda, aplica-se $\mathrm{O}$ conceito de custos de transação às decisões relativas a internacionalização das empresas, procurando explicar as características das empresas e dos mercados que estimulam o processo de internacionalização de uma planta produtiva (Iglesias, Veiga, 2002).

Para Disteffano e Gambillara (2014) a internacionalização dá acesso a pesquisa e desenvolvimento mais avançados, desenvolvimento do marketing organizacional, aumento do conhecimento e no valor da marca além de desenvolvimento do capital humano em competências diferentes. Os autores também identificam que algumas economias emergentes têm aumentado de forma consistente suas pesquisas nos âmbitos de ciências e tecnologia, sendo sociedades potencialmente orientadas a inovação nos próximos anos.

As teorias de internacionalização como o modelo da Escola de Uppsala (ou Escola Nórdica de Negócios) e o Paradigma Eclético da Produção e da Internalização (OLI), descrevem a forma como este processo 
ocorre nas empresas (Moraes, Oliveira, Kovacs, 2006).

\subsubsection{O MODELO DA ESCOLA DE UPPSALA}

O modelo de Uppsala preconiza que a internacionalização de uma firma é um processo que tem inicio em virtude de relativa estagnação de oportunidades dentro do mercado interno do país de origem, sendo uma consequência para a firma que busca manter seu crescimento. O mesmo modelo reforça que a falta de conhecimento sobre o país destino é o maior obstáculo que a firma pode enfrentar, e as barreiras psicológicas relacionadas a distância geográfica também se refletem nas opções de expansão internacional, pois quanto mais distintos em termos de linguagem cultura, sistema político, e outros aspectos, maior tende ser a distância psicológica no processo de internacionalização (Johanson, WiedersheimPaul, 1975).

Ainda segundo os autores, existem quatro fases claramente percebidas no processo de internacionalização de uma empresa, sendo elas:

- Exportação sem regularidade para 0 país destino;

- Exportação para o país destino através de um representante;

- $\quad$ Abertura de uma subsidiária no país destino;

- Abertura de uma planta produtiva no país destino.

Stal (2010) afirma tratar-se de um processo incremental, pois quanto maior o conhecimento que a empresa adquire sobre o país para o qual está internacionalizando suas atividades, maior será a propensão em aumentar os investimentos (Stal, 2010).

Para Prates e Balbinot (2010), através da internacionalização as firmas procuram encontrar uma estratégia que otimize os retornos do processo de expansão internacional e esperam no longo prazo que os retornos financeiros aconteçam de forma crescente e que os riscos sejam diminuídos.

Moraes, Oliveira e Kovacs (2006) reforçam que a evolução do modelo da escola de Uppsala trouxe consigo o conceito de networks, pois a internacionalização também é uma forma de maximizar os relacionamentos entre os países.

\subsubsection{O PARADIGMA ECLÉTICO DA PRODUÇÃO E INTERNALIZAÇÃO (OLI)}

Dunning (1980), afirma que uma empresa que deseja expandir seus negócios possui como alternativas o crescimento horizontal através de novos produtos em seu portfolio; o crescimento vertical, através de novas linhas de negócio, a aquisição de outras empresas ou a exploração de mercados internacionais.

A firma pode optar por atuar em mercados internacionais através da exportação de seus produtos ou através da instalação de uma planta produtiva no país destino (Dunning,1980). Neste último caso, a opção da empresa é escolhida em virtude das vantagens de propriedade por acesso a recursos naturais no país destino, das vantagens específicas (como a aquisição de vantagem competitiva de mercado), ou da localização, quando a firma percebe que a transferência da planta produtiva traz benefícios relacionados aos custos de produção (Dunning, 1988).

Para o autor, as vantagens de propriedade (ownership), localização (Iocalization) e internalização (internalisation), que resultam na sigla OLI, são explicadas à medida que se observa subsidiárias sem a mesma lucratividade que suas matrizes. Contudo, possuem maior desenvolvimento que suas concorrentes locais, em virtude de investimentos que o país da matriz da empresa realiza no país da subsidiária. Os atributos relacionados a internalização estão relacionados aos benefícios de se transferir o ativo dentro da organização (Dunning,2001).

Ainda segundo Dunning, a empresa deve influenciar os aspectos relacionados a inovação, preço e qualidade dos produtos através de alianças com instituições e empresas, influenciando as decisões estratégicas em sua rede de fornecedores, licenciamentos, implementação de franquias locais entre outros aspectos.

\subsubsection{INTERNACIONALIZAÇÃO EMPRESAS BRASILEIRAS}

NAS

A busca por novos mercados internacionais acrescida da internacionalização da produção tornam-se as principais estratégias das empresas brasileiras que buscam atuar em 
mercados estrangeiros. A diversificação de produtos e mercados, aproximação com empresas fornecedoras de tecnologia, visando aumento da competitividade são os principais estímulos deste processo (Coelho, Oliveira, 2011).

Para Chudnovisky e Lopez, apud Stal (2002), investimentos em países desenvolvidos trazem grandes vantagens competitivas para uma firma, que pode optar pela compra de uma empresa existente ou pela instalação de uma filial, especialmente quando isso ocorre em regiões com alta concentração tecnológica ou de fornecedores.

Para Arbix, Salerno e De Nigri (2004), as empresas internacionalizadas que focam em inovações são maiores e mais eficientes em aproveitar os ganhos em escala nos processos de exportação e importação. Já as subsidiarias do exterior contribuem como fonte de informação para inovação tecnológica, sendo este aspecto primordial para manutenção da competitividade das empresas brasileiras.

Para Fleury, Fleury e Borini (2013), as empresas brasileiras que focam na expansão internacional unem suas competências centrais à capacidade de inovação e usualmente realizam sua internacionalização através de setores tradicionais da economia global, contudo não necessariamente naqueles setores onde existe maior dinâmica tecnológica.

\subsection{INOVAÇÃO NA CADEIA DE FORNECEDORES}

O conceito de inovação parte da teoria do desenvolvimento econômico, elaborada pelo economista austríaco e professor da Universidade de Harvard, Joseph Schumpeter, dentro do modelo capitalista no início da revolução industrial, quando ele diferenciou invenção de inovação. Para Schumpeter (1982) uma inovação é relevante economicamente quando a invenção quando envolve uma transação comercial com a capacidade de gerar riqueza.

Costa, Bruno e Vasconcellos (2011), afirmam que durante um longo período, houve uma tendência nas empresas de que as inovações deveriam ser produzidas internamente, contudo recentemente, as empresas aprenderam a combinar suas forças internas e externas para atingir uma maior vantagem competitiva.
Para Kline, Rosenberg (1986) e Morilhas (2008) a partir do processo de inovação, as empresas praticam ações distintas das habituais para organizar recursos, de maneira a gerar produtos, processos e serviços novos, criando diferenciação da empresa em relação aos seus concorrentes e realizando lucro.

Santos, Stamm e Shikida (2014) afirmam que uma firma inovadora precisa entender os papéis de cada um dos membros do sistema de inovação o que inclui seus clientes e fornecedores, que viabilizam materiais e serviços necessários para o novo produto. Ao se analisar a relação de mercado atualmente utilizada pelas empresas, observa-se uma maior especialização e formação de estruturas de cooperação entre as firmas que possibilitam economia de escala e escopo, aumento de marketshare, maior velocidade nos processos de inovação e acesso a novas tecnologias, permitindo que as empresas se concentrem em suas competências centrais (Tigre, 2006).

Sob a ótica de Almeida (2007), para se realizar gestão da cadeia de fornecedores em contextos globais, a empresa que foca em inovação precisa contar com uma cadeia de fornecedores adequada capaz de garantir o abastecimento do suprimento conforme requisitos do mercado local.

Tigre (2006) complementa este conceito definindo as redes de empresas como membros de redes hierarquizadas e não hierarquizadas onde a rede hierarquizada é coordenada por uma empresa principal que define as regras e os padrões que deverão ser seguidos pelos demais membros e a rede não-hierarquizada considera o agrupamento de pequenas e médias empresas que possuem especialidades específicas horizontais ou verticais, não existindo uma hierarquização clara.

Para Correa (2010), uma das principais decisões vinculadas às estratégias da rede de suprimentos refere-se às definições sobre quais atividades serão executadas pela empresa e quais atividades serão terceirizadas.

\section{METODOLOGIA}

Foram selecionadas de forma intencional a Gerdau e a Marcopolo, duas empresas brasileiras internacionalizadas que foram destaque em publicações recentes da CNI pelas ações relacionadas a inovação em sua 
cadeia de fornecedores. A Gerdau e a Marcopolo também estiveram presentes nos 4 últimos rankings das multinacionais brasileiras publicados pela Fundação Dom Cabral entre os anos de 2013 e 2016. Procuramos identificar de que forma a inovação na cadeia de fornecedores ocorreu à partir da internacionalização dessas empresas.

Esta pesquisa é de natureza qualitativa considerando objetivos descritivos. De acordo com Gerhard e Silveira (2009) este tipo de pesquisa está centrada no âmbito das relações sociais e avalia exclusivamente o fenômeno estudado.

Os aspectos descritivos da pesquisa se apoiam na identificação de características específicas das empresas estudadas que corroborem com a relação entre os processos vinculados a internacionalização e inovação. Para Gil (2002), os aspectos descritivos se justificam quando se objetiva a descrição das características de uma determinada população, ou se visa a identificação de relação entre variáveis que neste caso estão centralizadas nos conceitos relativos a internacionalização, inovação na cadeia de fornecedores.

O procedimento técnico utilizado para se atingir os objetivos propostos por este trabalho foi o estudo de caso. Yin (2015) afirma que o estudo de caso permite que os pesquisadores se concentrem em casos com características únicas trazendo uma perspectiva mais abrangente sobre o tema. $\mathrm{O}$ autor ainda complementa que estudos de casos múltiplos trazem consigo conclusões analíticas mais intensas do que aquelas produzidas por um único caso pois são capazes de realizar comparações e reforçar as informações relevantes.

O procedimento de coleta de dados utilizado para este trabalho foi a pesquisa bibliográfica, desenvolvida com dados secundários. Para Marconi e Lakatos (2003), a pesquisa bibliográfica considera todo o material já publicado a respeito do tema estudado e deve proporcionar ao pesquisador uma imersão a respeito de um determinado assunto.

A pesquisa considerou uma avaliação de livros e artigos científicos publicados entre os anos de 1975 e 2017, sendo estes de origem brasileira e estrangeira. Os artigos científicos foram acessados através das ferramentas Google Scholar e EBSCO utilizando-se como terminologia de busca: internacionalização, internacionalização de empresas brasileiras, internacionalização e inovação de empresas, Gerdau, Marcopolo, innovation, internationalization, supply chain innovation entre outras terminologias que pudessem colaborar com um melhor entendimento sobre os pilares teóricos desta pesquisa.

Também buscou se identificar outras publicações que tivessem relação com o objeto de estudo trouxessem informações relevantes sobre as empresas, tais como: informações públicas disponíveis nos sites da Gerdau e da Marcopolo, dados disponibilizados pela $\mathrm{CNI}$, publicações de pesquisas realizadas pela Fundação Dom Cabral entre os anos de 2002 e 2016 e outras noticias veiculadas na mídia nas quais as empresas estavam envolvidas.

Para análise dos casos, pretende-se destacar as vantagens competitivas adquiridas pelas empresas que foram resultantes de seu processo de internacionalização, acrescido dos estímulos de inovação em seus fornecedores. O modelo conceitual utilizado para a análise dos casos pode ser visualizado na Figura 1. 
Figura 1 - Modelo conceitual da pesquisa

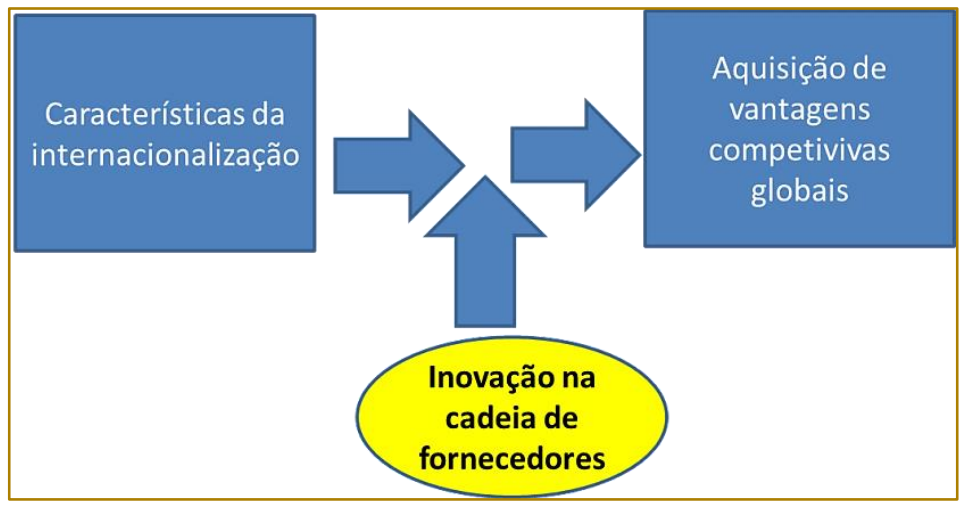

Fonte: Stal (2010), adaptado pelos autores.

\section{APRESENTAÇÃO DOS CASOS E ANÁLISES}

Visto o processo de investigação constante da metodologia, esta sessão deverá apresentar os casos e realizar uma análise comparativa entre as empresas.

\subsection{GERDAU}

Fundada em 1901, inicialmente foi uma fábrica de pregos localizada na cidade de Porto Alegre - RS. Em 1946 iniciou uma importante fase de expansão nos negócios, que culminou com a abertura de capital da empresa e início de negociações de ações na Bolsa de valores de Porto Alegre já no ano de 1947.

Até o início da década de 1960, a expansão da Gerdau se deu dentro do Brasil e o processo de internacionalização se iniciou a partir da década de 1980 através da produção de aço no Uruguai, seguida por outros eventos listados na tabela abaixo:

Tabela 1 - Principais eventos de Internacionalização da Gerdau:

\begin{tabular}{|c|l|}
\hline \multicolumn{2}{|c|}{ Linha do tempo - Internacionalização da Gerdau } \\
\hline 1980 & Início produção de aço no Uruguai \\
\hline 1989 & Adquiriu a empresa Courtice Steel no Canadá \\
\hline 1998 & Adquiriu uma laminadora na Argentina \\
\hline 1999 & Adquiriu uma empresa nos Estados Unidos \\
\hline 2002 & Fusão entre a Gerdau e Co-Steel criando a Gerdau Ameristeel \\
\hline 2004 & $\begin{array}{l}\text { Aquisição da Diaco e da Sidelpa na Colômbia. Nos Estados Unidos ocorre a aquisição } \\
\text { dos ativos da empresa North Star Steel } \\
\text { O grupo inicia suas atividades na Europa por meio da participação na empresa } \\
\text { Sidenor na Espanha }\end{array}$ \\
\hline 2005 & $\begin{array}{l}\text { Início da produção de aço no Peru } \\
\text { Fusão de suas operações na Republica Dominicana }\end{array}$ \\
\hline 2014 &
\end{tabular}

Fonte: Gerdau (2017), elaborado pelos autores.

A Gerdau é hoje uma das principais fornecedoras de aço do mundo e a líder em produção de aço das América. Para manter sua posição competitiva, a Gerdau procura se diferenciar de seus concorrentes, através de ações que busquem fortalecer sua cadeia de negócios (CNI, 2014).
Para o desenvolvimento de sua cadeia, a Gerdau se relaciona com um grande número de clientes e fornecedores dos mais diversos portes. Colaborar para que essa cadeia se mantenha eficiente é tido pela empresa como uma garantia da sustentabilidade do negócio 
do aço e também da sociedade como um todo.

\subsubsection{PROJETO PDF (PROGRAMA DE DESENVOLVIMENTO DE FORNECEDORES)}

No ano de 2006, com o apoio do Serviço Brasileiro de Apoio a Micro e Pequena Empresa [SEBRAE] a Gerdau implementou o Programa de Desenvolvimento de Fornecedores [PDF], com o intuito de fortalecer a cadeia de valor do aço através da capacitação de seus fornecedores.

Para a Gerdau a melhoria de gestão e do desempenho de aspectos que afetavam o negócio tornou-se essencial para competitividade do seu negócio. Para cada um dos

fornecedores envolvidos no projeto, foram definidos KPIs (Key Performance Indicators) com o objetivo de analisar de forma concreta os pontos de atuação e apoio da Gerdau e SEBRAE para cada caso (CNI, 2014).

Por tratar-se de um programa de qualificação de fornecedores, a expectativa foi de buscar a permanência dos mesmos na rede de fornecedores da empresa, atendendo as exigências técnicas e do mercado, além de reduzir os custos de não conformidade e índices de improdutividade.

As experiências adquiridas e o aprendizado motivaram a padronização e a internacionalização das boas práticas desenvolvidas na cadeia de fornecedores.

Inicialmente o projeto PDF foi localizado na região sul do Brasil e em 2010 foi ampliado em nível internacional para ser aplicado em outros fornecedores da Gerdau.

Para a manutenção de sua vantagem competitiva a Gerdau percebeu que ganhos incrementais de produção devem ser cada vez mais aplicados. Para as empresas que participam do projeto PDF, os benefícios são relatados com crescimento médio de faturamento em $29,4 \%$, aumento dos postos de trabalho em $25 \%$, aumento em $17,1 \%$ na produtividade das empresas envolvidas, redução de $70 \%$ na não-conformidade na entrega de produtos.

\subsection{MARCOPOLO}

A Marcopolo foi fundada em 1949, iniciou suas atividades com o objetivo de fabricar carrocerias de ônibus. Hoje é uma das maiores empresas especializadas em encarroçamento de ônibus no mundo, sendo responsável no ano de 2012 por 42\% da produção brasileira deste tipo de veículo e exportando seus produtos para mais de 100 países (CNI, 2013).

Na década de 1960, a empresa já iniciou os primeiros passos rumo à internacionalização através da exportação de seus produtos para mercados importantes para a companhia (CNI, 2013); contudo a percepção que o mercado interno brasileiro não oferecia perspectivas a longo prazo, teve maior peso na década de 1990, momento em que a empresa instalou suas primeiras unidades produtivas fora do Brasil (Abcem, 2008).

Os principais eventos relativos relacionados a instalação de plantas produtivas no mercado externo encontram-se na tabela abaixo:

Tabela 2 - Principais eventos de Internacionalização da Marcopolo

\begin{tabular}{|l|l|}
\hline \multicolumn{1}{|c|}{ Linha do tempo - Internacionalização da Marcopolo } \\
\hline 1991 & Aquisição de uma planta em Coimbra (Portugal) \\
\hline 1998 & Fundação da unidade Marcopolo em Rio Cuarto (Argentina) \\
\hline 1999 & Construção de unidade produtiva no México \\
\hline 2000 & Construção de unidade produtiva na Colômbia e na África do Sul \\
\hline 2006 & Estabelecimento de Joint Ventures na Índia e na Rússia \\
\hline 2007 & Aquisição parcial da Metalpar (Argentina) \\
\hline 2008 & $\begin{array}{l}\text { Estabelecimento de parceria no Egito e instalação de planta } \\
\text { produtiva na China. }\end{array}$ \\
\hline 2011 & Aquisição da Volgren (Austrália) \\
\hline 2013 & Aquisição de 19\% da New Flyer Inc. Encarroçadora (Canadá) \\
\hline
\end{tabular}

Fontes: CNI (2013), Rosa (2012), adaptado pelos autores. 
A empresa possui atualmente 13 unidades produtivas instaladas em territórios internacionais em países como Argentina, Colômbia, México, Egito, África do Sul, China, Índia e Austrália (www.marcopolo.com.br), produzindo internamente cerca de $80 \%$ dos componentes necessários para montagem de um ônibus, e estabelecendo parcerias importantes com fornecedores estratégicos visando o compartilhamento de riscos além de proporcionar sinergias relevantes para sua cadeia de valor (CNI, 2013).

O lançamento do ônibus Geração 7 aconteceu no ano de 2009 e este evento trouxe ganhos importantes para a empresa. No ano de 2012, a Marcopolo registrou a produção de mais de 10 mil unidades além do registro de 35 patentes no INPI (Instituto
Nacional de Propriedade Intelectual) relacionadas ao Geração 7. Para a empresa, o sucesso do projeto foi possível em virtude da formação de alianças estratégicas com seus fornecedores para desenvolvimento de itens específicos do novo modelo do veículo tanto no Brasil, como em suas unidades produtivas do exterior (CNI, 2013).

\subsection{ANÁLISE COMPARATIVA ENTRE AS EMPRESAS}

Com base no exposto, é possível realizar a seguinte comparação entre as empresas utilizando-se do modelo conceitual proposto:

Internacionalização, Inovação na Cadeia de Fornecedores e Vantagens Competitivas Adquiridas

\begin{tabular}{|c|c|c|}
\hline \multirow{2}{*}{ 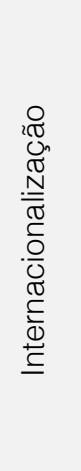 } & Gerdau & $\begin{array}{l}\text { Início na década de } 1980 \text { e estão explicitas características de internacionalização } \\
\text { das teorias de Uppsala e Paradigma Eclético onde a empresa iniciou seu } \\
\text { processo de internacionalização a partir de países onde a distância psíquica era } \\
\text { menor e posteriormente avançou para locais onde em termos econômicos as } \\
\text { estratégias de negócios eram importantes, especialmente Mercosul, Nafta e União } \\
\text { Europeia }\end{array}$ \\
\hline & Marcopolo & $\begin{array}{l}\text { Inicio na década de } 1950 \text { e estão explicitas características de internacionalização } \\
\text { das teorias de Uppsala e Paradigma Eclético. A empresa iniciou sua } \\
\text { internacionalização a partir de exportação de seus produtos para regiões onde a } \\
\text { distância psíquica era menor e posteriormente para locais onde estrategicamente } \\
\text { a presença da companhia seria importante tais como Mercosul, NAFTA, União } \\
\text { Europeia. }\end{array}$ \\
\hline \multirow{2}{*}{ 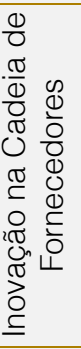 } & Gerdau & $\begin{array}{l}\text { Gerdau Desenvolvimento do programa PDF em 2006, com os objetivos de prover } \\
\text { melhorias continuas nos fornecedores e incentivar um ambiente propício a } \\
\text { geração de inovações incrementais. }\end{array}$ \\
\hline & Marcopolo & $\begin{array}{l}\text { A empresa desenvolve } 80 \% \text { dos componentes necessários para fabricação dos } \\
\text { ônibus terceirizando o restante. No projeto do Geração } 7 \text {, a Marcopolo pode, } \\
\text { através de sua rede de fornecedores, terceirizar o desenvolvimento de } \\
\text { componentes específicos conforme o mercado consumidor garantindo sua } \\
\text { vantagem competitiva }\end{array}$ \\
\hline \multirow{2}{*}{ 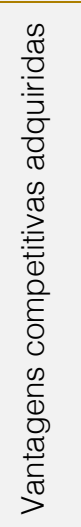 } & Gerdau & $\begin{array}{l}\text { Aprendizado adquirido motivou a internacionalização das boas } \\
\text { práticas desenvolvidas através do projeto PDF, sendo o conceito } \\
\text { aplicado globalmente para toda a cadeia de fornecedores da empresa. Ganhos } \\
\text { incrementais no processo de produção, mostrando que para algumas das } \\
\text { empresas que participaram do houve um aumento no faturamento médio, maior } \\
\text { abertura de postos de trabalho, melhoria na produtividade da empresa e } \\
\text { diminuição no número de não conformidades. }\end{array}$ \\
\hline & Marcopolo & $\begin{array}{l}\text { Estabelecimento de parcerias importantes com fornecedores estratégicos, } \\
\text { diminuindo riscos inerentes ao negócio e proporcionando estímulos na cadeia de } \\
\text { valor como um todo. Através dos investimentos realizados para o lançamento do } \\
\text { Geração 7, que teve componentes "nacionalizados" para cada um dos países } \\
\text { para onde a empresa exporta seus veículos, visando a aceitação do produto. }\end{array}$ \\
\hline
\end{tabular}


de fornecedores a partir da internacionalização das empresas.

Realizou-se uma análise de casos disponibilizados pela CNI das empresas Gerdau e Marcopolo onde se procurou identificar os aspectos mais importantes que relacionam as ações promovidas pelas empresas utilizando como pilares as teorias de internacionalização e inovação na cadeia de fornecedores.

Diferentemente da maior parte das empresas brasileiras, a Gerdau e a Marcopolo começaram seu processo de internacionalização há mais 35 anos, iniciando suas ações em território estrangeiro através de exportações sistemáticas e posteriormente instalando ou adquirindo plantas produtivas. Tornou-se perceptível através de suas estratégias de expansão internacional, que as empresas possuem um foco mais direcionado para um ambiente globalizado onde a inovação na cadeia de valor é peça fundamental para a competitividade, pois internacionalizar a produção é uma das principais estratégias para atuar em mercados estrangeiros e as relações de parceria com fornecedores locais aumentam a competitividade do negócio.

\section{REFERÊNCIAS}

[1] ALMEIDA, A (2007). Internacionalização de empresas brasileiras Perspectivas e riscos. 2.a. edição- editora Elsevier e Campus.

[2] ARBIX, G., SALERNO, M.S, DE NIGRI, J. A. (2004, Junho). Inovação via internacionalização faz bem para as exportações brasileiras. IPEA Brasília.

[3] COELHO, D. B., OLIVEIRA J., M. (2011).

[4] As multinacionais brasileiras e os desafios do Brasil no século XXI. Revista Brasileira de Comercia Exterior, v. 25, n. 110, p. 44-57.

[5] CORREA, H. L (2010). Gestão da Rede de Suprimentos; Editora Atlas; São Paulo - 2010.

[6] COSTA, R., BRUNO, M.; VASCONCELLOS, E. (2011). Strategy of Company Acquisition for Technical Innovation: Management Practices and Critical Success Factors. International Association for Management of Technology; 2011, Miami. Proceedings; Miami :IAMOT.

[7] DISTEFFANO, F; GAMBILLARA, G. (2014, october). Innovation \& Internationalization: Fostering global competitiveness through a local vibrant ecosystem. Greater Europe Desk Office of
Através dos casos analisados, é possível identificar Marcopolo e Gerdau, como empresas internacionalizadas que estimulam seus fornecedores com o objetivo de inovar em seus produtos e desta forma direcionam suas atividades para suas competências centrais (Tigre, 2006, Correa, 2010). Ambas também se caracterizam como empresas internacionalizadas que tem sua capacidade de inovação como estratégia fundamental para manutenção de sua vantagem competitiva perante o mercado global (Fleury, Fleury, Borini, 2013).

Este trabalho possui como limitação o fato de ter sido realizado com dados secundários, não coleta de dados primários das empresas Gerdau e Marcopolo que pudessem trazer a tona aspectos diferentes e relevantes daqueles já publicados ou então reforçar as informações já divulgadas.

Em virtude da internacionalização e inovação serem temas amplamente estudados pela academia, sugere-se para pesquisas futuras que sejam avaliados os setores manufatureiros ou de prestação de serviços.

International Engagement Business and International Development.

[8] DUNNING, J. H. (1980) Toward an eclectic theory of international production: some empirical tests. University of Reading journal of International Business Studies Vol. 11, No. 1 pp. 9-31Spring Summer

[9] DUNNING, J. H.(1988, March) The Eclectic Paradigm of International Production: A Restatement and Some Extentions. Journal of International Business Studies. Volume 19, pp 131.

[10] DUNNING, J. H (2001). The Eclectic (OLI) Paradigm of International Production: Past, Present and Future, Int. J. of the Economics of Business, Vol. 8, No. 2, , pp. $173 \pm 190$.

[11] FLEURY, A; FLEURY, M.T; BORINI, F.M (2013). The Brazilian Multinationals'

[12] Approaches to Innovation. Journal of International Management 19 pp. 260-275.

[13] GIL, A.C.(2002) Como Elaborar Projetos de Pesquisa. 4.a. Edição, editora Atlas. 
[14] GEHARDT, T.E; SILVEIRA D.T (2009) Métodos de Pesquisa. UAB/UFRGS; Porto Alegre:Editora da UFRGS.

[15] JOHANSON, J., WIEDERSHEIM, P.F (1975). The internationalization of the firm -

[16] Fourswedish cases. The Journal of Management Studies, p. 305-322.

[17] KLINE, S. J; ROSENBERG, N. (1986) An overview of innovation. The positive Sum

[18] strategy. Hamessing Technology for Economic Growth. V14, p 640.

[19] MARCONI, M., LAKATOS, E.(2003). Fundamentos da Metodologia Cientifica. 5.a.

[20] Edição, Editora Atlas.

[21] MORAES, W.F.A, OLIVEIRA, B.R.B, KOVACS, E.P (2006, julho/dezembro). Teorias de internacionalização e aplicação em países emergentes: uma análise crítica; Revista

[22] Eletrônica de Negócios Internacionais da ESPM; São Paulo, v. 1, n. 1, p. 203-220.

[23] MORILHAS, J. L.(2008). Estratégias de Internacionalização e adaptação de estruturas para o desenvolvimento de produtos: um estudo de caso na empresa de alimentos Sadia S.A. ; Artigo apresentado para a disciplina de Avaliação e Mudanças na Estrutura Organizacional e Internacionalização da USP.

[24] OLIVEIRA, M. (2010) Multinacionais Brasileiras. Internacionalização, inovação e

[25] Estratégia global. Editora Bookman, Porto Alegre (RS)

\section{INTERNET}

[1] ABCEM, (Associação Brasileira das Empresas da Construção Metálica). A internacionalização da Marcopolo S.A. Recuperado em 06/01/2017. Disponível no site http://www.abcem.org.br/

[2] CNI, Casos de Inovação de Pequenas, Médias e Grandes Empresas. Recuperado em 16/12/2016. Disponível em http://arquivos.portaldaindustria.com.br, 2017.
[26] PRATES, R. C; BALBINOT, Z.(2010, setembro). Integrando as Abordagens de Uppsala e do Paradigma Eclético: um modelo Econométrico; XXXIV encontro da ANPAD. Rio de Janeiro. pág. 1 a 14.

[27] ROSA, P. R. (2012, Octubre) .III Congreso Latinoamericano de História Económica y XXIII

[28] Jornadas de Historia Económica Simposio 2: Inversión Directa Extranjera y Empresas Multinacionales en América Latina (1900-2010) San Carlos de Bariloche, ISSN 1853-2543

[29] SANTOS, M. S; STAMM, C; SHIKIDA, P. F. A.(2014, julho/dezembro). Inovação,

[30] economia dos custos de transação e gestão da cadeia de suprimento: uma discussão

[31] teórica. Revista Política e Planejamento Regional, Rio de Janeiro, v. 1, n. 2, p. 257 a 272. ISSN 2358-4556

[32] SCHUMPETER. J. A (1982). Teoria do Desenvolvimento Econômico. Editor: Victor Civita.

[33] STAL, E. (2010, julho/setembro). Internacionalização de empresas Brasileiras e o papel da Inovação na construção de vantagens competitivas; Revista de Administração e Inovação; São Paulo, v. 7, n. 3, p. 120-149.

[34] TIGRE. P. B. (2006). Gestão da Inovação e a Economia da Tecnologia no Brasil. 5은

[35] edição. Editora Elsevier; Rio de Janeiro $(\mathrm{RJ})$.

[36] YIN, R (2015). Estudo de Caso. Planejamento e Métodos. 5.a. edição. Editora Bookman; Porto Alegre - RS.

[3] MARCOPOLO. Recuperado em 16/12/2016. Disponível no site https://www.marcopolo.com.br.

[4] RANKING FDC, Multinacionais Brasileiras 2013, 2014, 2015 e 2016. Recuperado em 16/12/2016. Disponível no site http://www.fdc.org.br, 2017

[5] IGLESIAS, R. M; VEIGA, P. M. Promoção de Exportações via Internacionalização das Firmas de Capital Brasileiro. Recuperado em 16/12/2016. Disponível no site http://www.bndespar.gov.br/. 


\section{Bapítulo 15}

\section{ESTUDO PARA A DETERMINAÇÃO DO PONTO DE RESSUPRIMENTO DO SETOR DE ALMOXARIFADO DA SEFAZ-MA}

\section{Alisson Castro Barreto}

\section{Bárbara Elis Pereira Silva}

Resumo: Frente ao atual cenário econômico e político brasileiro, a administração correta dos recursos de uma organização ganha ainda mais destaque. Este fato não se restringe apenas ao âmbito das organizações privadas, mas também se adequa à Administração Pública em geral. O presente artigo trata de um estudo para a determinação do ponto de ressuprimento do setor de almoxarifado da Secretaria de Estado da Fazenda do Estado do Maranhão, elaborando-se, para tal, uma ferramenta de apoio à tomada de decisão em um editor de planilhas eletrônicas. Para o alcance dos objetivos foram necessárias visitas ao local, coletas de dados, entrevista com gestores e funcionários, consultas a livros, artigos e legislações e o desenvolvimento de um script, dentro da planilha, em linguagem de programação Google Apps Script, que é baseada na linguagem JavaScript. Observou-se que, por determinação da legislação vigente, ficam caracterizados três cenários possíveis para realizar o reabastecimento dos produtos: (I) o órgão enviar o seu planejamento de consumo à Comissão Central Permanente de Licitação e ser participante de uma Ata de Registro de Preços; (II) o órgão solicitar ser carona em uma Ata de Registro de Preços em andamento ou (III) o órgão abrir processo licitatório próprio. As conclusões apontaram a determinação de apenas um único ponto de pedido que abrangeria os três cenários, sendo, então, proposta uma ferramenta de SAD para auxiliar a gestão do órgão na tomada de decisão quanto ao momento correto de realizar o pedido dos produtos. 


\section{INTRODUÇÃO}

O atual cenário de indefinição política e instabilidade econômica que o Brasil enfrenta, reforça ainda mais a necessidade de utilização correta dos recursos por parte das organizações. Esse fato também se encaixa no âmbito da Administração pública, visto que, quando os recursos públicos são utilizados de forma adequada, contribui para a redução de desperdícios, possibilitando que estes, que sobraram, sejam investidos em outras áreas. Neste contexto, existe a Gestão de Estoques das organizações, que é, frequentemente, atividade de apoio que dá suporte para que estas cumpram seus objetivos principais. Ter controle sobre a quantidade de itens em estoque, conhecer a média de consumo dos clientes e, a partir desses dados, determinar o momento ideal de realização dos pedidos para reabastecimento, proporcionarão condições básicas para que as organizações desempenhem suas atividades.

Este artigo teve como objeto de estudo o setor de almoxarifado da Secretaria de Estado da Fazenda do Maranhão, tratando-se, portanto, de um órgão público que atua no controle das receitas e despesas do Estado. Por se tratar de um órgão público, existem algumas peculiaridades nos objetivos que a gestão de estoques do almoxarifado da Secretaria pretende alcançar, em relação às empresas de âmbito privado: a gestão do estoque não visa o lucro e, sim, apenas ser capaz de atender aos clientes e utilizar de forma correta os recursos públicos.

Para ser capaz de atender aos clientes e utilizar adequadamente os recursos, deve existir controle sobre os itens em estoque, a quantidade que cada cliente costuma solicitar e o momento do ponto de pedido. Por se tratar de um órgão da Administração pública, visando proporcionar igualdade de concorrência entre os fornecedores, quando necessário for o ressuprimento dos itens, o órgão deverá aderir à Ata de Registro de Preços do produto junto à Comissão Central de Licitação ou quando não tiver possibilidade de participar ou não houver ata, iniciar processo licitatório para adquiri-los.

Este fato faz com que se chegue ao seguinte questionamento: como uma ferramenta de apoio à decisão poderia auxiliar na definição do ponto de pedido ideal dos produtos? Este trabalho teve, portanto, como objetivo, elaborar uma ferramenta de apoio à tomada de decisões para o setor de almoxarifado da Secretaria de Estado da Fazenda do Maranhão, que auxiliasse a gestão a determinar o ponto de ressuprimento dos seus produtos.

O artigo está estruturado em Referencial Teórico, Metodologia, Resultados e Discussões e Considerações Finais. No âmbito da seção Referencial Teórico será abordada a Visão Estratégica dos Estoques que tratará sobre estoques e sua gestão, Administração de Suprimentos no Setor Público que apresentará os dispositivos que disciplinando a atividade nesse cenário e Sistemas de Apoio a Decisão que abordarão os sistemas de informação e como estes auxiliam no processo de tomada de decisão.

\section{REFERENCIAL TEÓRICO \\ 2.1 VISÃO ESTRATÉGICA DOS ESTOQUES}

As organizações, para possibilitar o correto desenvolvimento de suas atividades, costumam estocar matérias-primas, produtos em desenvolvimento, produtos acabados e outros mais que serão utilizados para o atendimento da demanda interna ou externa. Tendo em vista esta situação, a atividade de gerenciamento desses itens torna-se de vital importância para a saúde financeira da empresa, podendo influir diretamente no desempenho da instituição como um todo.

Para Gurgel e Francischini (2010, p. 81), a razão de ser de uma organização é maximizar o lucro em cima de todo montante investido, incluindo-se o estoque. A otimização do investimento em estoque torna-se, então, necessária para o aumento do uso eficiente de recursos, diminuindo a necessidade de novos investimentos de capital.

A administração geral das organizações é responsável por determinar ao setor de gerenciamento de materiais as diretrizes ou políticas de estoques, isto é, padrões que servirão de guia à programação e ao controle. Dentre essas diretrizes, podem-se destacar metas quanto ao tempo de entrega, a estrutura física de armazenagem, o que será estocado e em qual lugar; também o nível de flutuação, a especulação e a rotatividade dos estoques (DIAS, 1993, p. 25).

Slack et al. (2006, p. 278) definem estoque como "acumulação armazenada de recursos materiais em um sistema de transformação" e tem, segundo Lélis (2016, p. 63), função 
reguladora de fluxo, já que são responsáveis por conciliar a disponibilidade com a demanda. Este fato ocorre porque a velocidade com que os materiais são reabastecidos não é igual a velocidade com que eles são consumidos.

A gestão de estoques é a atividade que trata do planejamento e gerenciamento da entrada e saída de matérias-primas e produtos necessários para o desenvolvimento das atividades de uma organização, envolvendo, para tal, algumas decisões. Segundo Vitorino (2012, p. 101), é comum questionar-se a respeito do momento certo de se fazer o pedido, da quantidade a ser pedida e do volume de estoque a ser mantido.
Os gráficos de controle de estoque, também conhecidos como Gráfico Dente de Serra, devido ao formato de suas linhas, são utilizados para avaliar o estoque. Segundo Marcousé, Surridge e Gillespie (2013) são gráficos de linha, por meio dos quais os gestores poderão acompanhar como os níveis de estoque se comportam ao longo do tempo, identificando eventos incomuns que deverão ser monitorados. Existem quatro linhas no gráfico que representam os níveis de estoque (em amarelo), os níveis máximo de estoque, o ponto de pedido (reordenação) e o estoque de segurança, conforme imagem abaixo.

Imagem 1 - Gráfico Dente de Serra

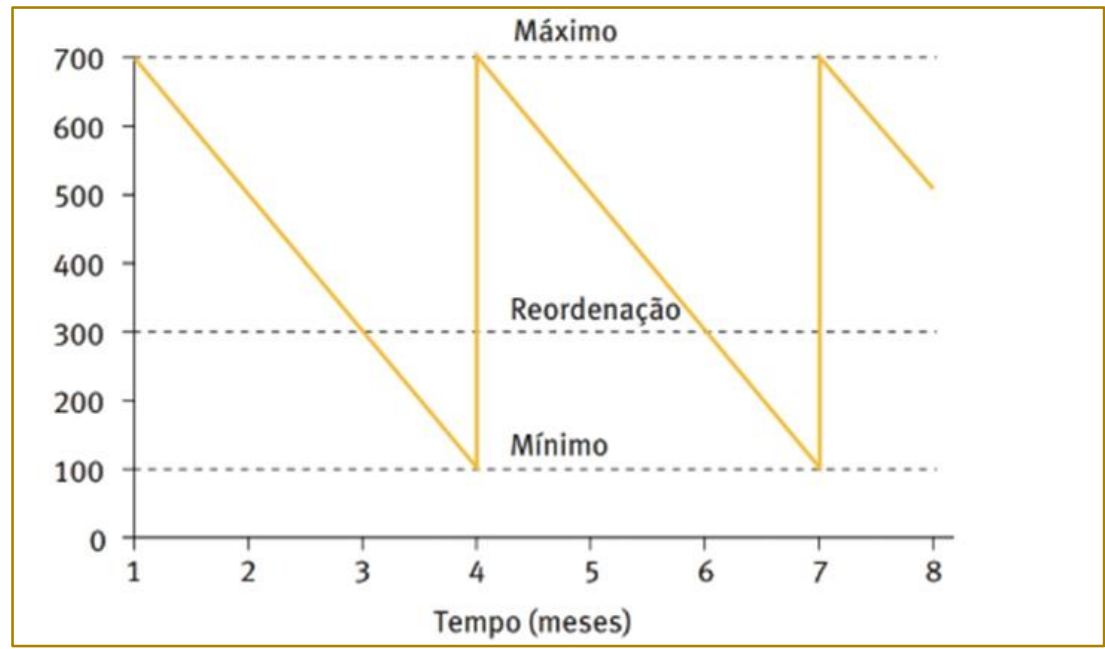

Fonte: Marcousé, Surridge e Gillespie (2013)

O ponto de reposição ou ponto de pedido é o momento em que deve ser acionado o pedido de reabastecimento, devido à quantidade de estoque disponível. Já o tempo entre o pedido realizado e a sua entrega é denominado lead time. (VITORINO, 2012, p. 102). Para Gonçalves e Schwember (1979, p. 54), o ponto de pedido pode ser determinado através da fórmula abaixo:

$P P=T R \times D+E S$

Onde:

$\mathrm{PP}=$ ponto de pedido

TR = tempo de reposição

$\mathrm{D}=$ taxa de demanda por unidade de tempo

$E S$ = estoque de segurança
Quando se trata da quantidade a ser pedida, é preciso levar-se em conta dois tipos de custo: o custo do pedido e da manutenção. Uma maior quantidade na compra diminuirá o custo do pedido e aumentará o custo da manutenção dos estoques. Já com uma menor quantidade, ocorrerá o inverso. Por isso, é necessário encontrar um equilíbrio para que a soma dos dois custos seja a menor possível (VITORINO, 2012, p.104).

Em relação ao volume de estoque a ser mantido, deve-se pensar no nível mínimo de estoque ou o estoque de segurança. Marcousé, Surridge e Gillespie (2013) definem estoque de segurança como sendo o nível mínimo mantido visando satisfazer a demanda caso um pedido não seja entregue a tempo ou, por questões de consumo, acima do 
previsto. Dentre vários métodos para encontrar o valor do estoque de segurança, existe o método da porcentagem de consumo que, segundo Dias (1993, p. 65), deve ser aplicado quando o tempo de reposição (TR) não for favorável. A fórmula é:

$E M=(C M x-$ CMédio $) \times T R(2)$

Onde:

$E M=$ Estoque mínimo ou de segurança

$\mathrm{CMx}$ = consumo máximo

CMédio = consumo médio

TR = tempo de reposição.

Essas decisões em relação ao estoque e o seu controle permitem saber o momento ideal de pedir ou adiar o pedido de reabastecimento. Evitar-se-á que se invista demasiadamente em estoque e se tenha grande volume de capital circulante parado ou não se programe de forma adequada e haja desabastecimento. Lélis (2016, p. 64) reitera esse ponto ao afirmar que o controle dos níveis de estoque é de suma importância para a manutenção das atividades das organizações.

\subsection{ADMINISTRAÇÃO DE SUPRIMENTOS NO SETOR PÚBLICO}

A Administração de Suprimentos não é apenas importante para as instituições de âmbito privado, ela também é necessária para o correto funcionamento da Administração Pública, visto que a falta de materiais ou produtos vai refletir-se no atendimento às necessidades da população. Para Laurindo e Teixeira (2014, p.33), suprimento ou abastecimento pode ser entendido como o fornecimento dos insumos (bens e serviços) necessários à transformação, distribuição e ao transporte do produto organizacional, existindo, para tal, relação fornecedor e comprador, resultando em menor custo para a empresa.

A Gestão dos Estoques nos setores públicos, de forma diferente das organizações privadas, não visa a maximização do lucro, mas, sim, ser capaz de atender às demandas e utilizar de forma eficiente os recursos públicos. Braga (1998, p. 18) confirma esse ponto ao afirmar que a finalidade primária da Administração Pública é a prestação de serviços com eficiência, eficácia e atenção, e o atendimento das demandas da população, para benefício coletivo.

Em 22 de julho de 1999, o Governo do Estado do Maranhão, via decreto, implantou o Sistema Integrado de Administração de Serviços para Estados e Municípios (SIAGEM). O decreto $\mathrm{n}^{\circ}$ 16.905/99 visou suprir quatro necessidades: padronização do Cadastro de Fornecedores do Estado, dos materiais e serviços que estão sob controle do Estado, integração de órgãos que se relacionam com o procedimento licitatório, fornecimento de serviços e obras; e, por fim, identificação de preços e suas variações entre as diversas regiões, para servir de base para um sistema de custo público (MARANHÃO, 1999).

A atividade de compra de novos itens na Administração pública segue uma série de passos. Considerando-se o princípio da razoabilidade em economicidade e eficiência, no setor público, há uma série de etapas e normas para que o processo de compras seja executado (LAURINDO; TEIXEIRA, 2014, p.82). A Administração Pública, quando de sua necessidade, não pode simplesmente escolher um fornecedor e realizar a compra daqueles materiais; para tal, ela deve seguir o que é preceituado na legislação vigente. Três dispositivos regulamentam o processo licitatório no cenário do Estado do Maranhão.

A lei 8.666/93 regulamenta e estabelece regras gerais para processos licitatórios e contratos administrativos para os Poderes da União, dos Estados, do Distrito Federal e dos Municípios. A seção $V$, artigo 15 da lei estabelece que as compras "deverão atender ao princípio da padronização", deverão ser processadas através do sistema de registro de preços que é precedido de ampla pesquisa de mercado; estabelece que qualquer cidadão poderá impugnar preço se houver discrepância em relação ao valor de mercado, dentre outras determinações (BRASIL, 1993).

A lei 10.520/12 trata da adoção da licitação na modalidade pregão para aquisição de bens e serviços comuns, inclusive quando efetuadas pelo sistema de registro de preços, no âmbito da União, Estados, Distrito Federal e Municípios, podendo ser utilizada também a modalidade pregão eletrônico. Bens comuns para fins desta legislação são todo aquele que pode ser objetivamente caracterizado e 
qualificado por especificações usuais de mercado (BRASIL, 2002).

O decreto $n^{\circ}$ 31.553/16 regulamenta 0 Sistema de Registro de Preços do Estado do Maranhão e é aplicável a administração pública estadual direta e indireta. Cabe à Comissão Central Permanente de Licitação (CCL) o gerenciamento do Sistema de Registro de Preços e deverá ser adotado quando, devido às características do bem ou serviço, houver necessidade de contratação frequente, entregas parceladas, ou quando atender a mais de um órgão e em outras hipóteses a critério da Administração (MARANHÃO, 2016).

A Administração não é obrigada a firmar contratos advindos do registro de preços, mas para solicitar dispensa e instaurar licitações específicas; deve solicitar ao Secretário-Chefe da Casa Civil que só autorizará mediante reunião com o Presidente da Comissão Central Permanente de Licitação. Se autorizada, para validação, os preços deverão ser menores que os registrados pela CCL (MARANHÃO, 2016).

\subsection{SISTEMAS DE APOIO A DECISÃO}

Devido à dinamicidade do mercado, ao grande número de dados a serem tratados e informações a serem gerenciadas, não se admite mais que decisões sejam tomadas com base apenas em opiniões ou sem efetivo planejamento. Para tal, existem os sistemas de informações que auxiliam nesse processo de tomada de decisão. Para O'brien (2006, p. 09), sistema de informação é um conjunto de partes interligadas que processam dados $e$ transformam em informações, dependendo para isso de recursos humanos, hardwares, softwares, dados e redes.

Os sistemas de informação influenciam para melhor eficiência, produtividade, qualidade, confiabilidade e inovação dos sistemas produtivos e dos seus serviços e produtos. Uma das aplicações do sistema de informação é o monitoramento do sistema de produção, garantindo-se qualidade e eficiência em processos como $\mathrm{O}$ de estocagem e compras (JÚNIOR; FACANHA, 2011, p. 223).

As organizações lidam diariamente com negócios e problemas decisórios. Os sistemas de informação podem ser de fundamental importância para ajudar nesse processo, podendo auxiliar as empresas com monitoração do nível de estoques e suprimentos, determinação de políticas de aquisição de suprimentos, dentre outros (JÚNIOR; FACANHA, 2011, p. 228).

Gonçalves e Schwember (1979, p. 223) afirmam que a administração de materiais, em áreas como o planejamento e controle de estoque, lida com um volume grande de informações; para tal, é totalmente cabível a adoção de computadores na tratativa desses dados. A junção da tecnologia aplicada aos sistemas de informação originou tipologias de sistemas de informação que são aplicadas a diferentes níveis da organização, dentre elas destaca-se: Sistema de Processamento de Transações (STP), Sistemas de Informação Gerenciais (SIG), Sistemas de Apoio à Decisão (SAD) e Sistemas de Apoio aos Executivos (SAE) (JÚNIOR; FACANHA, 2011, p. 224).

Para Rezende e Abreu (2013, p.189) "os Sistemas de Apoio a Decisões (SAD) são tecnologias fundamentais para a evolução do processo de tomada de decisão nas empresas modernas e usuárias de informações oportunas". O SAD permite que sejam integrados dados e outras partes para fornecer informações que auxiliem no processo de tomada de decisão nas empresas (REZENDE; ABREU, 2013, p.190).

Normalmente o SAD é composto por alguns componentes, dentre eles: o sistema de banco de dados, o sistema de modelos e o software gerenciador de interface. O sistema de banco de dados dispõe de vários dados da organização devendo fornecê-los ao gestor, quando necessário para que este tome uma decisão. O sistema de modelos de gestão é capaz de lidar com os dados por meio de planilhas, simulações, cálculos, fórmulas, algoritmos apoiando os três níveis da gestão organizacional. Já o software SAD é responsável por gerar as informações por meio dos modelos e do banco de dados. (REZENDE; ABREU, 2013, p.191).

As planilhas eletrônicas são exemplos de ferramentas de fácil acesso e bastante popularizadas que fornecem interface amigável ao usuário e que nelas podem ser desenvolvidos Sistemas de Apoio a Tomada de Decisão. Destacam-se duas, o MS Excel produzido pela Microsoft e que atualmente é o principal editor de planilhas disponível no mercado. E o Google Sheets, editor disponível pela empresa Google de forma on-line que permite criar, editar e compartilhar o 
gerenciamento das planilhas com outras pessoas sem a necessidade de baixar e instalar um software no computador, já que as informações ficam salvas no serviço de nuvem Google Drive.

\section{METODOLOGIA}

Para elaboração do presente trabalho, foram necessárias consultas a diversos materiais incluindo livros, artigos e legislações para que fosse possível discorrer sobre o assunto. Houve também seleção de um objeto de estudo, no caso o setor de almoxarifado da SEFAZ-MA e de um objetivo geral, que foi o de elaborar uma ferramenta de apoio à tomada de decisões para o setor de almoxarifado da Secretaria de Estado da Fazenda do Maranhão, o qual auxiliasse a gestão a determinar o ponto de ressuprimento dos seus produtos. Em vista de alcançar-se esse objetivo, foram realizadas visitas para análise do cenário e entrevistas para coleta de dados quantitativos e qualitativos.

Existem diversas classificações quanto ao tipo de pesquisa a ser realizada, Vergara (1998) propõe dois critérios: quanto aos fins e quanto aos meios. Quanto aos fins, o presente artigo é uma pesquisa metodológica já que se utilizou de maneiras para atingir um fim, e é pesquisa aplicada por resolver problemas concretos no nível da proposição. Quanto aos meios, é uma pesquisa de campo, pois a investigação aconteceu no local em que o fenômeno ocorre, é uma pesquisa bibliográfica, pois foram consultados materiais publicados em livros e em meios eletrônicos e é estudo de caso, pois ficou restrito a um órgão público com caráter de profundidade e detalhamento.

\section{RESULTADOS E DISCUSSÕES}

O objeto de estudo do presente artigo foi o setor de almoxarifado da Secretaria de Estado da Fazenda do Maranhão (SEFAZ-MA) localizado no prédio da Administração Tributária na cidade de São Luís - MA. A SEFAZ-MA é um Órgão Público do Poder Executivo Estadual que tem por atividade a Administração Pública em Geral, sendo responsável pelo controle das movimentações financeiras de receitas e despesas do Estado do Maranhão.

Para que sejam atendidos os objetivos pelo qual o órgão foi instituído, não existe apenas a sede da Administração Tributária: em pontos estratégicos, pelo Estado do Maranhão, estão instaladas Agências de Atendimento, Unidades de Fiscalização Regional (UFRES), Unidades Móveis de Fiscalização (UFMI) e Postos Fiscais. O setor de almoxarifado, portanto, da sede em São Luís fica responsável por abastecer não apenas os setores desta, mas também todas as unidades da SEFAZ - MA.

Somando-se setores da Administração Tributária, UFRE's, Agências de Atendimento e Postos Fiscais, o setor de almoxarifado é responsável por atender até 82 unidades. Este fato expõe que é necessário existir planejamento e controle adequado do estoque do setor para ser capaz de suprir toda a demanda. O fato da secretaria ser Órgão público exige ainda mais do planejamento, pois, para a realização da compra, é necessário seguir o disposto na legislação vigente.

O decreto 31.553/16 possibilita a inclusão, no processo licitatório, dos entes submetidos a este decreto, quando se tratar de bens e serviços que são adquiridos frequentemente. Para tal estes deverão fornecer uma estimativa de consumo para o exercício atual com base na demanda do exercício anterior e ficando assim, participantes da Ata de Registro de Preços (ARP) de um produto específico. Quando isto não ocorre, o Órgão deve consultar as ARP's disponíveis e solicitar adesão à CCL para que o fornecedor ganhador do processo licitatório, inicie o fornecimento.

O fornecedor ganhador do processo licitatório, quando um ente da Administração Pública não é participante da ARP desde o início, pode recusar a fornecer para um órgão que queira ser carona em uma ata. Neste caso, o Órgão, justificaria, para a CCL, a não possibilidade de adesão às ARP's disponíveis e abriria processo licitatório apenas para sua demanda. Ficam, então, configurados 3 cenários possíveis para o ressuprimento dos produtos.

Via decreto estadual $n^{\circ} 16.905$ de 22 de julho de 1999, foi implantado o Sistema Integrado para Administração de Serviços (SIAGEM) atingindo os órgãos da Administração Pública Municipal e Estadual Maranhense. Estes órgãos, incluindo-se a SEFAZ-MA, ficaram obrigados a adotar esse sistema, que dentre suas atribuições auxilia no gerenciamento e controle do estoque. Por ser um sistema com 
aproximadamente 19 anos de existência, existem algumas limitações quanto ao seu uso: não é um sistema intuitivo, já que ele funciona por comandos alfanuméricos, nem todas as informações podem ser exibidas em tela, para consultar algumas é necessário a impressão via impressora matricial e o sistema não auxilia quanto ao ponto de ressuprimento dos produtos cadastrados.

Tendo por base o exposto, através de visitas ao local, entrevistas com os funcionários e definição de informações importantes com a gerência, foi proposto um Sistema de Apoio a Decisão que fornecesse ao profissional responsável pela gestão do setor, as informações necessárias para que este tomasse as decisões corretas quanto ao momento mais adequado de realizar as compras para reabastecimento do estoque.
Este sistema foi desenvolvido através do editor de planilhas Google Sheets e os motivos que levaram à escolha deste editor em detrimento do MS Excel foram a possibilidade de compartilhamento do gerenciamento da planilha, salvamento automático de todas as alterações por quaisquer editores e a segurança contra perda das informações, por elas não ficarem armazenadas em memórias físicas de computadores e, sim, no Google Drive. A planilha foi elaborada com base nos dados do ano de 2017 fornecidos pelo setor e possui como itens, de suas colunas, o ano, o mês, o tipo de produto, o saldo anterior, a entrada, a saída, o saldo atual, a média, o estoque de segurança e o ponto do pedido, conforme imagem

abaixo:

Imagem 2 - Tabela para determinação do Ponto de Pedido

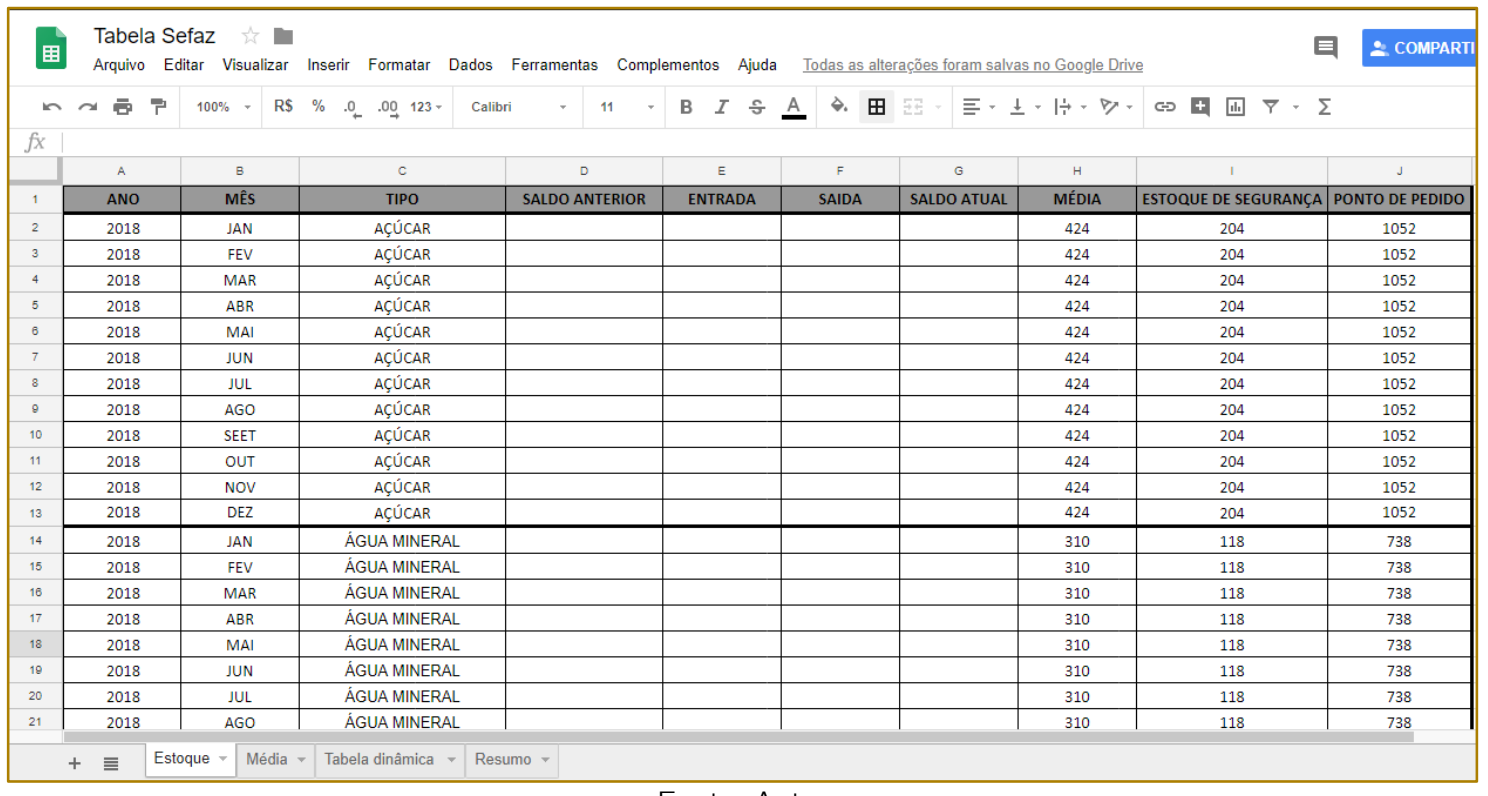

Fonte: Autor

Como é possível consultar o saldo atual de estoque por produto através do sistema SIAGEM e o setor não dispõe de mão-de-obra suficiente para realizar exclusivamente uma atualização diária de entrada e saída por produto, optou-se, durante a elaboração da planilha, por trabalhar com o consolidado mensal por produto, não havendo impedimento dos mesmos serem atualizados constantemente no decorrer do mês, conforme disponibilidade da mão-de-obra.

Para cálculo do estoque de segurança e do ponto de pedido, foi necessário estabelecer o lead time. Esta informação foi obtida por meio de entrevista com a gerência do setor e foi observado que existem três cenários possíveis quando da necessidade de pedir: (I) o órgão enviar o seu planejamento de consumo a CCL e ser participante de uma Ata de Registro de Preços; (II) o órgão solicitar ser carona em uma Ata de Registro de Preços em andamento ou (III) o órgão abrir processo licitatório. Em todos os três cenários, o valor do lead time foi de aproximadamente de 2 meses. 
Com o valor médio do consumo de estoque mensal, a demanda máxima mensal por produto e o lead time, foi possível calcular o estoque de segurança e o ponto de pedido por produto. Estes não são todos os produtos que o setor de almoxarifado contempla, mas são todos os que foram fornecidos dados. Resultou-se, então, nos valores abaixo.

Imagem 3 - Estoque de segurança e Ponto de Pedido

\begin{tabular}{|c|c|c|c|}
\hline TIPO & MÉDIA & ESTOQUE DE SEGURANÇA & PONTO DE PEDIDO \\
\hline AC̣ÚCAR & 424 & 204 & 1052 \\
\hline ÁGUA MINERAL & 310 & 118 & 738 \\
\hline CAFÉ & 413 & 214 & 1040 \\
\hline CAPA P/ PROCESSO & 1529 & 542 & 3600 \\
\hline COPO P/ CAFÉ & 267 & 86 & 620 \\
\hline COPO P/ ÁGUA & 349 & 92 & 790 \\
\hline PAPEL A-4 & 501 & 52 & 1054 \\
\hline PAPEL HIGIÊNICO (Grande) & 135 & 98 & 368 \\
\hline PAPEL HIGIÉNICO (Pequeno) & 20 & 10 & 50 \\
\hline PAPEL TOALHA & 104 & 142 & 550 \\
\hline SABONETE LIQUIDO (Litros) & 14 & 24 & 12 \\
\hline SABONETE LIQUIDO (Galão) & 2 & 8 & 52 \\
\hline
\end{tabular}

Fonte: Autor

O valor do ponto de pedido servirá de base para que o gestor tome a decisão de realizar o ressuprimento. Toda vez que houver alteração no saldo atual da planilha, haverá acompanhamento automático desse valor. Tal acompanhamento se dará da seguinte forma: caso o valor que representa a quantidade em estoque for menor ou igual ao ponto de pedido do produto em questão, a célula ficará destacada em vermelho e uma caixa de diálogo aparecerá avisando que este é o momento de realizar a compra do produto. Porém, caso o valor do saldo atual seja superior ao valor do ponto de pedido, a célula apenas ficará destacada na cor verde, conforme imagem abaixo.

Imagem 4 - Ponto de Pedido

\begin{tabular}{|c|c|c|c|c|c|c|c|c|c|c|c|c|c|c|c|c|c|c|c|}
\hline \multirow{2}{*}{ 田 } & \multicolumn{6}{|c|}{$\begin{array}{l}\text { Tabela Sefaz } \\
\text { Arquivo Editar Visualizar }\end{array}$} & Inserir & Formatar & Dados & Ferramenta: & \multicolumn{2}{|c|}{ Complementos } & \multicolumn{3}{|c|}{ Todas as alteraçổes foram salvas no Google .... } & 目 & \multicolumn{2}{|c|}{2 COMPARTILHAR } & \multirow{2}{*}{$\hat{\imath}$} \\
\hline & 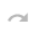 & $\overline{3}$ & F & $100 \%$ & r $R$ & R\$ & $\% \quad .0$ & .00123 & Calibri & $=$ & 11 & $\mathrm{~B} I$ & $\underline{\underline{A}} \diamond . \quad$ 田 & $E 3 . \equiv-\perp$ & $H+\nabla$. & $\leftrightarrow \mp$ & 四 $\nabla=\Sigma$ & & \\
\hline \multicolumn{20}{|l|}{$f x$} \\
\hline & \multicolumn{3}{|c|}{ A } & \multicolumn{3}{|c|}{ B } & \multicolumn{3}{|c|}{ c } & \multicolumn{2}{|c|}{ D } & E & $\mathrm{F}$ & o & $\mathrm{H}$ & & 1 & & $\mathrm{~s}$ \\
\hline 1 & \multicolumn{3}{|c|}{ ANO } & \multicolumn{3}{|c|}{ MÊS } & \multicolumn{3}{|c|}{ TIPO } & & ENTRADA & SAIDA & SALDO ATUAL & MÉDIA & ESTOQUE D & DE SEGURANÇA $\mathrm{P}$ & PONTOD & DE PEDID \\
\hline 2 & \multicolumn{3}{|c|}{2018} & \multicolumn{3}{|c|}{ JAN } & \multicolumn{3}{|c|}{ AÇÚCAR } & SALDO ANTERIOR & & & & 1053 & 424 & & 204 & & 1052 \\
\hline 3 & & 2018 & & & EV & & & AÇÚCAR & & & & 100 & 0 & 1153 & 424 & & 204 & & 1052 \\
\hline 4 & & 2018 & & & MAR & & & AÇÚCAR & & & 53 & 0 & 153 & 1000 & 424 & & 204 & & 1052 \\
\hline 5 & & 2018 & & & $A B R$ & & & AÇÚCAR & & & $m$ & & & & 424 & & 204 & & 1052 \\
\hline 6 & & 2018 & & & MAI & & & AÇÚCAR & & & & & & $x$ & 424 & & 204 & & 1052 \\
\hline 7 & & 2018 & & & UN & & & AÇÚCAR & & & & & & & 424 & & 204 & & 1052 \\
\hline 8 & & 2018 & & & IUL & & & AÇÚCAR & & & $\begin{array}{l}\text { Voce } \\
\text { Saldo }\end{array}$ & $\begin{array}{l}\text { Precisa ázerer pe } \\
\text { (1000) émenor }\end{array}$ & $\begin{array}{l}\text { edido do produto: A } \\
\text { rligual ao ponto de }\end{array}$ & pedido (1052) & 424 & & 204 & & 1052 \\
\hline 9 & & 2018 & & & 160 & & & AÇÚCAR & & & & & & & 424 & & 204 & & 1052 \\
\hline 10 & & 2018 & & & EET & & & AÇÚCAR & & & & ок & & & 424 & & 204 & & 1052 \\
\hline 11 & & 2018 & & & SUT & & & AÇÚCAR & & & & & & & 424 & & 204 & & 1052 \\
\hline 12 & & 2018 & & & IOV & & & AÇúcAR & & & & & & & 424 & & 204 & & 1052 \\
\hline 13 & & 2018 & & & DEZ & & & AÇÚCAR & & & & & & & 424 & & 204 & & 1052 \\
\hline 14 & & 2018 & & & AN & & & GUA MINERAL & & & & & & & 310 & & 118 & & 738 \\
\hline 15 & & 2018 & & & EV & & & GUA MINERAL & & & & & & & 310 & & 118 & & 738 \\
\hline 16 & & 2018 & & & MAR & & & GUA MINERAL & & & & & & & 310 & & 118 & & 738 \\
\hline 17 & & 2018 & & & $A B R$ & & & GUA MINERAL & & & & & & & 310 & & 118 & & 738 \\
\hline 18 & & 2018 & & & MAI & & & GUA MINERAL & & & & & & & 310 & & 118 & & 738 \\
\hline & & & & & & & & & & & & & & & & $\theta$ & & & \\
\hline & + & $\equiv$ & Estoc & que ${ }^{2}$ & Média & & Tabel: & la dinâmica & Resu & umo - & & & & & & & & + $\mathrm{E}$ & Explorar \\
\hline
\end{tabular}

Fonte: Autor 
A interação automática entre a planilha e o usuário foi possível através da inserção de fórmulas e condicionais nas células, além de programação pelo editor de script. A linguagem de programação utilizada pelo editor é a Google Apps Script, que é baseada na linguagem JavaScript. A imagem abaixo expõe um trecho do script que é criado dentro da planilha e, portanto, pode manipular quaisquer de seus dados.

Imagem 5 - Trecho do script

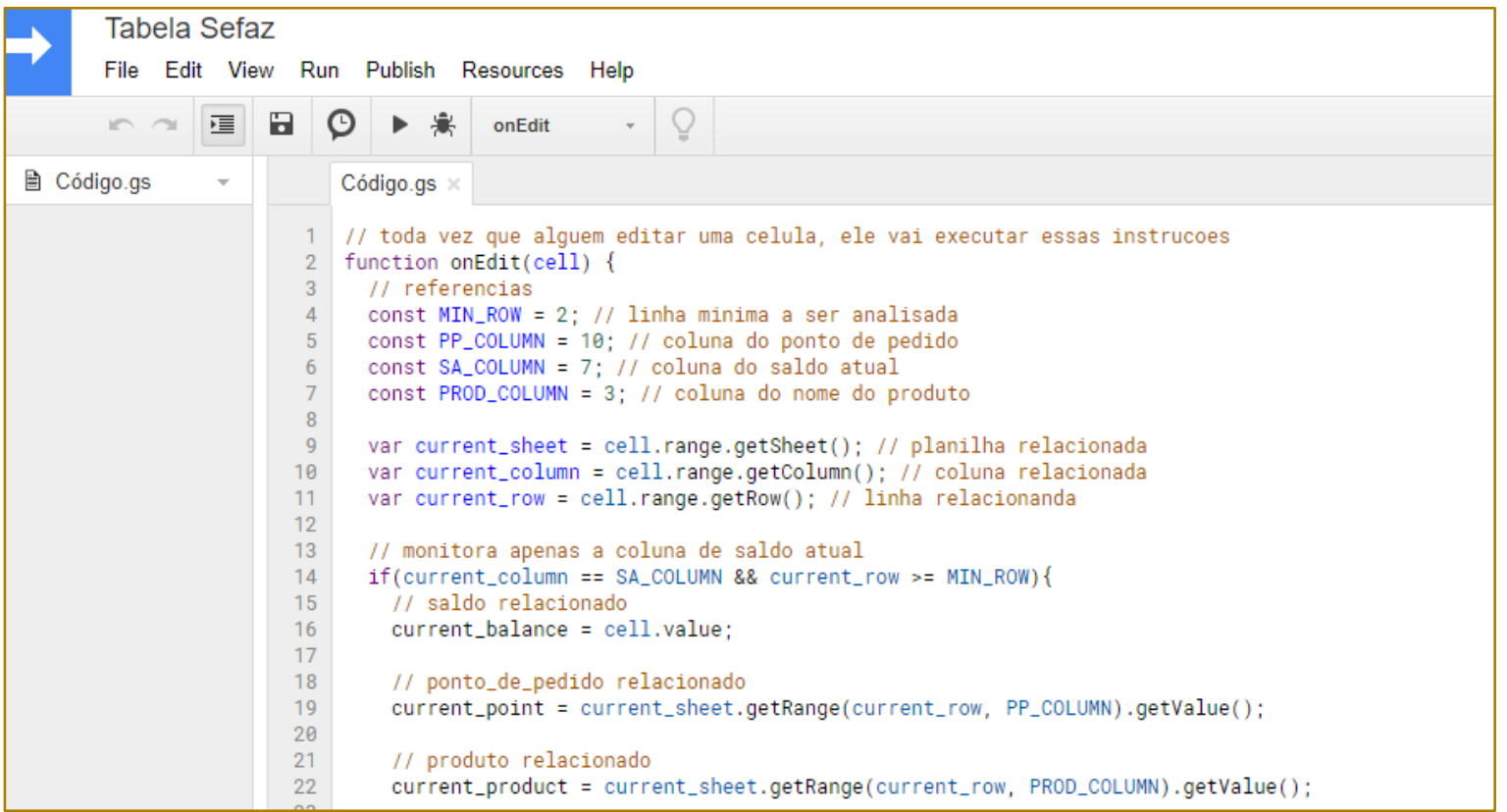

Fonte: Autor

\section{CONSIDERAÇÕES FINAIS}

O SAD é um sistema que fornece informações para auxiliar no processo de tomada de decisão, ou seja: ele não toma a decisão pela gestão ou profissional responsável, apenas o equipa para que este esteja ciente das condições, avalie os cenários e possa tomar decisões com menores riscos. Este trabalho se propôs analisar de que maneira uma ferramenta de apoio à decisão poderia auxiliar na definição do ponto de pedido ideal dos produtos do setor de almoxarifado da SEFAZMA.

Foram definidas quatro hipóteses: 1) determinar o ponto de pedido quando o órgão fosse participante de Ata de Registro de Preço; 2) determinar $o$ ponto de pedido quando o órgão não fosse participante de Ata de Registro de Preço, mas houvesse possibilidade de aderir a ata; 3 ) determinar 0 ponto de pedido quando o órgão não fosse participante de Ata de Registro de preço e 4) nem houvesse possibilidade de aderir a ata ou determinar o ponto de pedido para todos os cenários.
Observou-se que, para o órgão em questão, é comum existirem os três cenários ao longo de um exercício; por isso, a melhor forma de auxiliar na tomada de decisão foi a de determinar o ponto de pedido dos produtos para todos os cenários. Com base nos dados coletados na organização, foi possível, primeiro, definir o lead time para cada cenário, porém os três cenários possuem um lead time aproximado de 2 meses, fato este que resultou em um único ponto de pedido por produto.

Com todas essas informações foi possível desenvolver um SAD em um editor de planilhas online. Este sistema, através de fórmulas, condicionais e linguagem de programação é capaz de alertar o usuário sempre que o saldo mensal de estoque de um produto for menor ou igual ao seu ponto de pedido, orientando que deve ser iniciado um processo para compra daquele produto. O gestor, com base na experiência, conhecendo o produto, o seu consumo e se ele já está sendo fornecido ao órgão por uma ARP, saberá se deve comprar ou adiar a compra. 
Portanto, nota-se que o objetivo geral desta pesquisa foi alcançado e para pesquisas futuras, sugere-se a implantação da ferramenta no setor de almoxarifado da SEFAZ, com vista a observar se as

\section{REFERÊNCIAS}

[1] BRAGA, Douglas Gerson. Conflitos, eficiência e democracia na gestão pública. Rio de Janeiro: Editora FIOCRUZ, 1998.

[2] BRASIL. Lei № 8.666, de 21 de junho de 1993. Regulamenta o art. 37, inciso XXI, da Constituição Federal, institui normas para licitações e contratos da Administração Pública e dá outras providências. Brasília, DF, 21 jun. 1993. Disponível em:

<http://www.planalto.gov.br/ccivil_03/leis//8666con s.htm>. Acesso em: 25 abr. 2018.

[3] BRASIL. Lei $n^{\circ} 10.520$, de 17 de julho de 2002. Institui, no âmbito da União, Estados, Distrito Federal e Municípios, nos termos do art. 37, inciso $X X I$, da Constituição Federal, modalidade de licitação denominada pregão, para aquisição de bens e serviços comuns, e dá outras providências. Brasília, DF, 17 jul. 2002. Disponível em: $<$ http://www.planalto.gov.br/ccivil_03/leis/2002/l105 20.htm>. Acesso em: 25 abr. $201 \overline{8}$.

[4] CAMPOS, Luiz Fernando Rodrigues. Supply Chain: Uma visão gerencial. Curitiba: InterSaberes, 2012.

[5] DIAS, Marco Aurélio P. Administração de Materiais: Uma abordagem logística. 4. ed. São Paulo: Atlas, 1993

[6] GONÇALVES, Paulo Sérgio; SCHWEMBER, Enrique. Administração de estoques: Teoria e prática. Rio de Janeiro: Interciência, 1979.

[7] JÚNIOR, Alceu Salles Camargo; FACANHA, Sandra Lilian de Oliveira. Sistemas de apoio à decisão. In: Abraham Sin Oih Yu. (Org). Tomada de decisão nas organizações: Uma visão multidisciplinar. São Paulo: Saraiva, 2011.

[8] LAURINDO, Alisson M.; TEIXEIRA, Alex V. A logística na administração pública: Conceitos e métodos. Curitiba: InterSaberes, 2014. informações fornecidas auxiliariam de forma efetiva a gestão no processo de compra dos produtos. Para tal, será necessário treinamento dos funcionários e alinhamento com a realidade do setor.

[9] LÉLIS, Eliacy Cavalcanti. Administração de Materiais. São Paulo: Perason Education do Brasil, 2016.

[10] MARANHÃO. Decreto $n^{\circ} 16.905$ de 22 de julho de 1999. Dispõe sobre a implantação do Sistema Integrado de Administração de Serviços para Estados e Municípios - SIAGEM, e dá outras providências. Diário Oficial do Estado do Maranhão, Poder Executivo, São Luís, MA, 16 mar. $2016 . \quad$ Disponível em: $<$ http://www.stc.ma.gov.br/legisladocumento/?id=1708>. Acesso em: 25 abr. 2018 .

[11] MARANHÃO. Decreto $n^{\circ} 31.553$, de 16 de março de 2016. Regulamenta o Sistema de Registro de Preços no Estado do Maranhão. Diário Oficial do Estado do Maranhão, Poder Executivo, São Luís, MA, 22 jul. 1999. Disponível em: <http://www.stc.ma.gov.br/legisladocumento/?id=4269 > . Acesso em: 25 abr. 2018 .

[12] MARCOUSÉ, Ian; SURRIDGE, Malcolm; GILLESPIE, Andrew. Gestão de Operações. São Paulo: Saraiva, 2013.

[13] O'BRIEN, James A. Sistemas de informação: e as decisões gerenciais na era da internet. 2. ed. São Paulo: Saraiva, 2006.

[14] REZENDE, Denis Alcides; ABREU, Aline França. Tecnologia da informação aplicada a sistemas de informação empresariais: o papel estratégico da informação e dos sistemas de informação nas empresas. 9. ed. São Paulo: Atlas, 2013.

[15] SLACK, Nigel et al. Administração da Produção. São Paulo: Atlas, 2006.

[16] VERGARA, Sylvia Constant. Projetos e Relatórios de Pesquisa em Administração. 2. ed. São Paulo: Atlas S.A, 1998.

[17] VITORINO, Carlos Márcio. Logística. São Paulo: Pearson Practice Hall, 2012. 


\section{Gapítulo 16}

\section{MÉTODO DE INTELIGENCIA COMPUTACIONAL APLICADO NA OTIMIZACÃO DA PRODUCÃO POR MEIO DA DETECCÃO DO SISTEMA DE COORDENADAS DO CENTRO DE MASSA DE UMA ESTRUTURA}

\section{Guilherme Damasceno Silva}

Denis Carlos Lima Costa

Heictor Alves de Oliveira Costa

Resumo: A sociedade contemporânea tem vivenciado nas últimas décadas um avanço tecnológico veloz, que vem impulsionando mudanças sensíveis na vida dos indivíduos e, tendo um reflexo decisivo nas relações de âmbito educacional e produtivo. A utilização de novas tecnologias só surte efeito quando são utilizadas para o favorecimento da melhoria da qualidade do ensino, pois tê-la apenas por convenção e modernidade não é garantia de que a educação produzirá um engenheiro de qualidade. O processo de ensino-aprendizagem revela-se nas práxis do professor, e de como este e os alunos utilizam e aplicam os recursos tecnológicos disponíveis. A presença da tecnologia, desenvolvida em ambiente $M A T L A B$, deve impulsionar $\mathrm{o}$ enriquecimento do ambiente educacional e profissional, objetivando a construção do conhecimento por meio de uma atuação ativa e crítica por parte de alunos e professores, refletindo nas indústrias e empresas. O presente trabalho tem como propósito apresentar um método computacional que otimiza o ensino-aprendizagem do curso de Engenharia da Produção por meio cálculo do centro de massa de uma estrutura. Esse mecanismo foi desenvolvido pelo grupo de pesquisa Gradiente de Modelagem Matemática e Simulação Computacional - GM²SC, do Instituto Federal de Educação, Ciência e Tecnologia do Pará, Campus Ananindeua. A ferramenta enfatiza as tecnologias digitais no processo ensino-aprendizagem e produção, sendo classificada como robusta e precisa na construção e aplicabilidade do conhecimento.

Palavras chave: Otimização da Produção, Inteligência Computacional, Tecnologia digital. 


\section{INTRODUÇÃO}

A utilização de métodos tradicionais de ensino-aprendizagem, em que o professor é o sujeito ativo no processo, repassando seu conhecimento aos alunos, normalmente por meio de aula teórica, especialmente nos cursos superiores de engenharia, tem se mostrado desafiador, tanto para os alunos como para os professores. De um lado os professores assumem um papel apoiado na transmissão de conhecimento de fenômenos quase sempre complexos, e os discentes assumem um papel passivo na aprendizagem, e se deparam com dificuldades para compreender e interpretar tais fenômenos.

Para Fiolhais e Trindade (2003), uma característica da engenharia que a torna particularmente difícil para os alunos é o fato de lidar com conceitos abstratos, teorias e modelos resultantes de experimentações práticas e de difícil compreensão. A utilização de recursos diversificados no processo de ensino-aprendizagem é bem aceito pelos alunos e imprimem bons resultados.

As Ferramentas computacionais tem sido alternativas eficazes, uma vez que auxiliam os alunos no entendimento dos conteúdos ministrados, tornando o processo de "aprender" mais dinâmicos, ágil e prazeroso. A prática na utilização das ferramentas computacionais conquista a atenção do aluno de engenharia, além de aproximar a parte teórica da prática, contribuindo para melhoria significativa do aprendizado (Silva, 2003). A utilização desse tipo de prática nos dias de hoje é imprescindível na comunidade acadêmica, principalmente pelo fato da evolução tecnológica e disseminação na sua utilização em indústrias. A Internet, softwares dedicados e animações gráficas podem levar o aluno a compreender com maior facilidade os experimentos mais complexos, que por meio de métodos tradicionais são mais difíceis de serem demonstrados.

Para Veit (2005) o computador se tornou uma importante ferramenta para os estudos científicos atuais. Sua utilização proporciona aos alunos de engenharia métodos para geração de modelos, auxilia na relações e estabelecimento de hipóteses sobre conceitos pouco factíveis, além de ajudar na elucidação de vários problemas concretos voltados para o ensino da engenharia como um todo.

Com a disseminação tecnológica e avanço das técnicas computacionais, diversos métodos que demandavam tempo e esforço de alunos e pesquisadores, estão sendo adotados de forma mais prática e com maior agilidade. O computador digital ampliou a facilidade de utilização destes métodos e permitiu aos alunos o uso dessas ferramentas e técnicas. Dentre as técnicas disponíveis para cálculo e análise de estruturas pode-se citar o cálculo do centro de massa. Vários softwares estão disponíveis no mercado e aplicados em universidades, como por exemplo $\quad 0 \quad$ Tracker (http://www.if.ufrgs.br/cref/uab/lab/tracker.html ), desenvolvido pelo Laboratório de Física da UFGS, que viabiliza os estudos de vários conteúdos da Física, como a mecânica, o eletromagnetismo, a óptica, etc. O cálculo do centro de massa, extremamente importante nas engenharias em especial da Engenharia de Produção, é apresentado na Figura 1, para entusiastas interessados em compreender de maneira mais detalhada a utilização desse tipo de cálculo.

Figura 1- Cálculo do Centro de Massa com o software Tracker

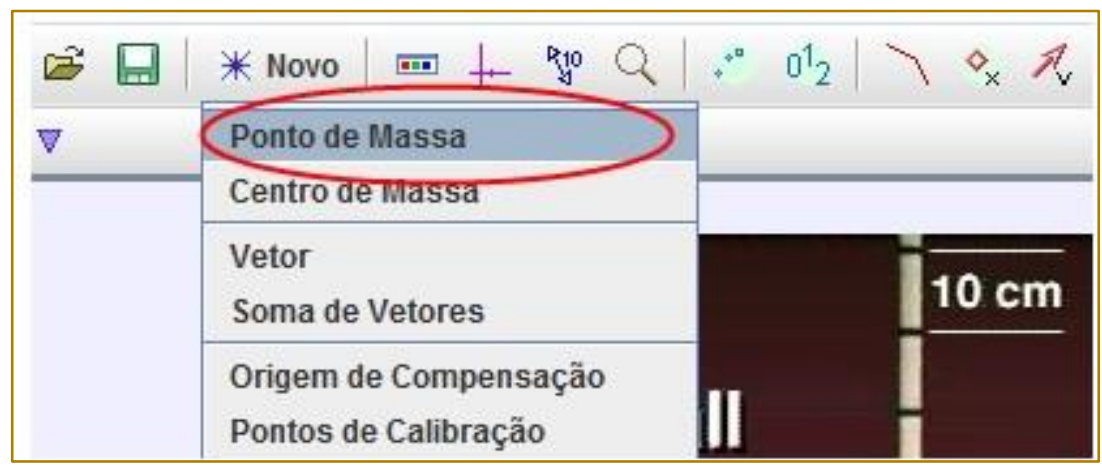

Os professores, diante disso, esforçam-se para utilizar novas estratégias de ensino, que atendam às necessidades de aprendizagens voltadas para realidade atual da grande 
maioria dos alunos, fazendo-se mais presentes na pratica, por meio do envolvimento, orientação e participação mais ativa (GUERRA, 2000). Os cursos de engenharia são constituídos, em grande parte, por complexos cálculos inseridos na sua matriz curricular. Facilitar o processo analítico mediante o uso da inteligência computacional é papel importante das universidades, na formação e capacitação de engenheiros.

Os testes dos materiais são de suma importância para que se possa analisar exaustivamente suas reações em função dos fenômenos que podem ocorrer. Seja uma laje, telhado, vigas, máquinas, equipamentos, empacotamento ou instalações, cada item, dependendo da sua aplicação, vai ter um cálculo para que seja possível observar quanto a estrutura suporta, o que vai ser possível fazer e de que maneira a carga poderá ser substituída, se o método aplicado é adequado, se deverá haver alguma alteração.

Para Hibbeler (2004), o estudo das estruturas nas engenharias reproduz as relações entre cargas que são aplicadas a um corpo deformável externamente, e a intensidade em que as forças internas atuam, abrangendo o cálculo das deformações do corpo e o estudo da sua estabilidade, quando submetido a solicitações externas.

Com isso, pode-se perceber que a resistência dos materiais, por mais complexa que possa ser, é fundamental. Não só em algumas engenharias ou em outras, mas em todas, pois a mesma dá a noção de que os projetos devem ser proporcionais. Assim, é importante que todo engenheiro consiga visualizar onde existe a ocorrência de aplicação de forças, para evitar riscos de deformação e de rompimento.

O objetivo deste trabalho é propor a otimização da produção mediante o cálculo do centro de massa de uma estrutura, por meio do desenvolvimento de um método computacional para auxiliar no ensinoaprendizagem de alunos da área das engenharias, pois este método realiza de forma iterativa e interativa o cálculo do centro de massa, auxiliando na compreensão da teoria utilizada no cálculo processando-o de forma automatizada, fazendo uso de um método prático que reduz a margem de erros, maximizando a produção.

\section{REVISÃO DA LITERATURA}

\subsection{A IMPORTÂNCIA DAS TECNOLOGIAS APLICADAS NO PROCESSO DE PRODUÇÃO.}

Quando se falava em informatizar as universidades, o primeiro pensamento estava diretamente relacionado com educar para o uso da tecnologia, porém hoje é possível afirmar que, precisamos das tecnologias para educar e formar excelentes engenheiros. A utilização desses novos recursos tecnológicos vem para melhorar principalmente a equidade entre os alunos. Ampliando o acesso ao conhecimento melhora-se, também, a qualidade do ensino- aprendizagem e sua aplicabilidade na área profissional (RIBEIRO, 2007).

É importante ressaltar que a utilização da tecnologia não vai resolver todos os entraves encontrados no âmbito do ensino e aprendizagem, faz necessário mesclar a utilização das ferramentas tecnológicas com os saberes, experiências e interações presenciais, que se tornam também fundamentais para o desenvolvimento integral e continuo.

Também é de suma importância que com a utilização da tecnologia, se crie uma versão digital das práticas pedagógicas já tradicionais existentes, pois não se trata de substituir e sim de inovar, utilizando novas abordagens que remetam a educação para o século XXI. As tecnologias educacionais não são utilizadas em substituição ao professor, e sim para empoderar os educadores, fazendo com que abandonem atividades mecanizadas e ultrapassadas, fazendo com que atuem como mediadores e mentores da aprendizagem (CHEVALLARD, 2009).

É necessário atualizar-se constantemente sobre os recursos que estão disponíveis, processos que podem ser aperfeiçoados e novas formas de realizar uma mesma tarefa ou atividade. Todos esses pontos têm potencial para serem desenvolvidos por intermédio das novas tecnologias, mantendo o foco, é claro, no enriquecimento das práticas pedagógicas (LEOPOLDO, 2012).

A tecnologia educacional/profissional já está presente, de diversas formas, em grande parte das universidades e em Institutos de Ciência e Tecnologia do país. Seja por meio dos tradicionais laboratórios de informática ou do uso de lousa digital, tablets, smartphones com recursos digitais, entre outros. Esse avanço tecnológico tem 
acarretado mudanças significativas no espaço escolar e no processo de ensino e aprendizagem (MORAN, 2011).

A sala de aula é um espaço de grande interatividade, sendo terreno fértil para o desenvolvimento de mecanismos capazes de transformar aulas em experiências de conectividade. Nesse contexto, surgem diversas oportunidades para aplicação de diferentes tecnologias, mas é primordial que as mudanças sejam incorporadas ao cotidiano dos alunos, familiares, professores e gestores de forma tranquila e equilibrada, a fim de melhorar a experiência de todos e, principalmente, ajudar no ensino e na aprendizagem (VIEIRA, 2011).

Assim como tem alto poder de contribuir de forma significativa, a tecnologia deve ser utilizada de forma consciente e planejada, pois pode prejudicar todo o processo de ensino e aprendizagem gerando muita dispersão, competição e ampliando a desigualdade entre os que possuem e os que não possuem acesso (ESTEBAN, 2007)

\subsection{TRABALHOS RELACIONADOS}

É impossível negar a importância do uso das tecnologias aplicadas à educação superior, e de que estas exigem mudanças no processo educativo, e principalmente nas formas de como professores e universidades agem em relação a eles. As novas tecnologias aplicadas à educação vêm influenciando às universidades, em consequência dessa influência tecnológica é preciso que seja assumido pela universidade um papel inovador, transformando-se, para melhor trabalhar com os conhecimentos dos indivíduos que passam por ela.

Os educadores, pesquisadores e empresários precisam se adaptar a essas inovações tentando compreendê-las, incorporá-las, socializando experiências e introduzindo essas transformações, no âmbito educacional de modo a contribuir na melhoria da qualidade dos processos de produção.

FREITAS et al., 2012 apresentam em seu artigo a modelagem matemática para 0 desenvolvimento de uma ferramenta computacional para aplicação em problemas na área de engenharia, em especial os relacionados com a estruturação de peças como por exemplo vigas, eixos, lajes e pilares. Para o desenvolvimento da ferramenta utilizou-se as potencialidades contidas no ambientedo MATLAB (Matrix Laboratory). A ferramenta foi desenvolvida no formato de um executável criado na interface gráfica do MATLAB, que disponibiliza para o usuário nove tipos de seções de área pré-definidas, sendo essas seções os tipos mais utilizados em estruturas para problemas de engenharia.

KHALED JAMAL BAKRI, no Congresso Técnico Científico da Engenharia e da Agronomia (2016), expos a proposta de desenvolvimento de uma ferramenta e/ou dispositivo reutilizável que serve ao ensinoaprendizagem, aplicado ao controle de sistemas eletrônicos empregados aos conversores de energia de um sistema de produção.

LIMA et al., 2016 apresentam uma ferramenta computacional para suporte nos processos de ensino-aprendizagem de equações diferenciais parciais, com interface gráfica no GUIDE do MATLAB, como recurso técnico, visando melhorar o processo analítico de resoluções. A ferramenta permite realizar simulações específicas para visualização com uso de gráficos 2D e 3D, como no caso da distribuição de calor em uma barra finita, utilizando os métodos da separação de variáveis e das diferenças finitas.

CRUZ et al., 2017 apresentam uma ferramenta para verificar o aprendizado relacionado à cadeia produtiva na área das construções. A metodologia consistiu na aplicação de um jogo a estudantes e profissionais, divididos em grupos. Como resultados, constatou-se que os grupos mostraram visões com múltiplos cenários quanto à cadeia produtiva nas construções.

\section{OBJETIVOS}

\subsection{GERAL}

Desenvolver um método computacional que otimize o ensino-aprendizagem o processo de identificação do centro de massa de um corpo a fim de viabilizar a produção.

\subsection{ESPECÍFICOS}

- Diagnosticar as equações relacionadas ao cálculo do centro de massa em duas dimensões;

- Modelar matematicamente o algoritmo para o cálculo do centro de massa; 
- Modelar e desenvolver computacionalmente o algoritmo para o cálculo da distribuição de densidade superficial;

- Analisar os resultados obtidos de acordo com a engenharia de produção.

\section{METODOLOGIA}

\subsection{ANÁLISE FÍSICO-MATEMÁTICA PARA A DETERMINAÇÃO DO CENTRO DE MASSA}

A densidade é uma propriedade física que depende do tipo de empacotamento das partículas que constituem a substância. Conforme o tipo de ligação química, o tamanho das partículas e a massa de cada uma, a substância será mais ou menos densa.

$$
m=\frac{M}{L}
$$

sendo, $m$ é a densidade, $M$ é a massa e $L$ é o comprimento.

A densidade, ou mais precisamente, a densidade volumétrica da massa de uma

$$
\rho=\frac{m}{V}
$$

onde $\rho$ é a densidade, $\mathrm{m}$ é a massa e $\mathrm{V}$ é $\mathrm{o}$ volume.

Seja $d \subset \mathbb{R}^{2}$, uma região compacta, representando uma determinada massa. Suponhamos que a função $\mu: d \subset \mathbb{R}^{2} \rightarrow \mathbb{R}$
Existem três tipos importantes de densidade: Linear, Superficial e Volumétrica. Nesse trabalho dar-se-á maior ênfase na densidade Superficial, pois essa apresenta o maior número de aplicações na análise da produção.

O termo densidade linear é mais usado quando se descrevem as características de estruturas unidimensionais, embora a densidade linear também possa ser usada para descrever a densidade de uma quantidade tridimensional ao longo de uma dimensão particular. No entanto, esse é apenas um exemplo de uma densidade linear, pois qualquer quantidade pode ser medida em termos de seu valor em uma dimensão, densidade linear é definida como massa dividida pelo comprimento:

substância é a sua massa por unidade de volume. Matematicamente, densidade é definida como massa dividida por volume:

representa a densidade superficial de massa (massa por unidade de área), ilustrada na Figura 2.

Figura 2 - Representação da Densidade Superficial de uma Estrutura

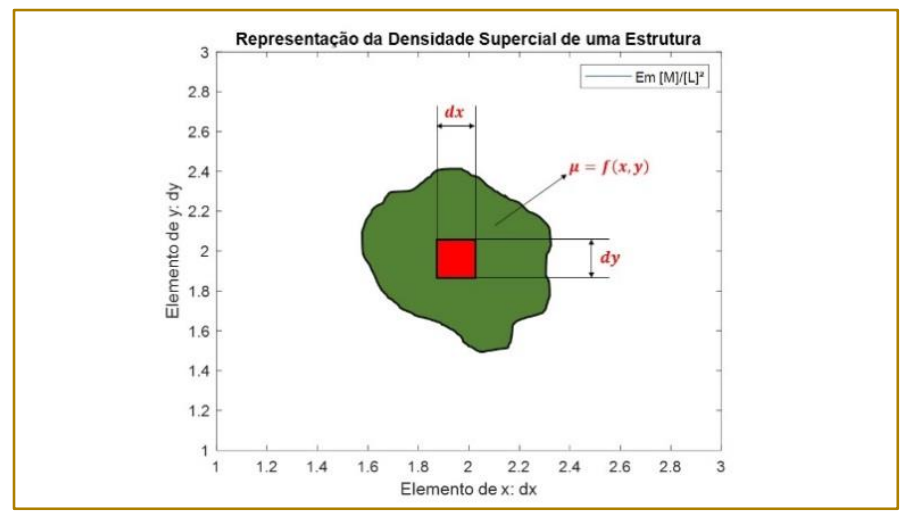

Considerando-se $n^{2}$ subretângulos $R_{i j}$ de algum retângulo $R$ que contém $D$ e uma escolha $\left(x_{i} y_{i}\right) \in R_{i j}$, observamos que a soma 
É uma aproximação da massa $M$ de $D$ onde $\mu\left(x_{i} y_{i}\right)=0$ se $\mu\left(x_{i} y_{i}\right) \notin D$. Logo é razoável definir a densidade de massa $M$ de $D$ com

$$
\begin{gathered}
d m=\mu(x, y) d_{x} d_{y} \\
d m=\iint_{R}(x, y) d_{x} d_{y} \\
R=\left\{\begin{array}{l}
x_{1} \leq x \leq x_{2} \\
y_{1} \leq y \leq y_{2}
\end{array}\right. \\
d m=\iint(x, y) d_{x} d_{y} \\
d m=\int_{y 1}^{y 2} \int_{x 1}^{x 2} \mu(x, y) d x d y
\end{gathered}
$$

O método das diferenças finitas (MDF) é o método de resolução de equações diferenciais baseado na aproximação de derivadas por diferenças finitas. A fórmula de aproximação é obtida da série de Taylor da

$$
\begin{gathered}
\int d m=M(\mathrm{M}=\text { Massa Total do Corpo }) \\
M=\int_{x 1}^{x 2} \int_{y 1}^{y 2} \mu(x, y) d x d y \\
\mu(x, y)=\text { Densidade Superficial } \\
\mu=\frac{m}{A}
\end{gathered}
$$

Figura 3 - Espelhamento de um corpo na terceira dimensão.

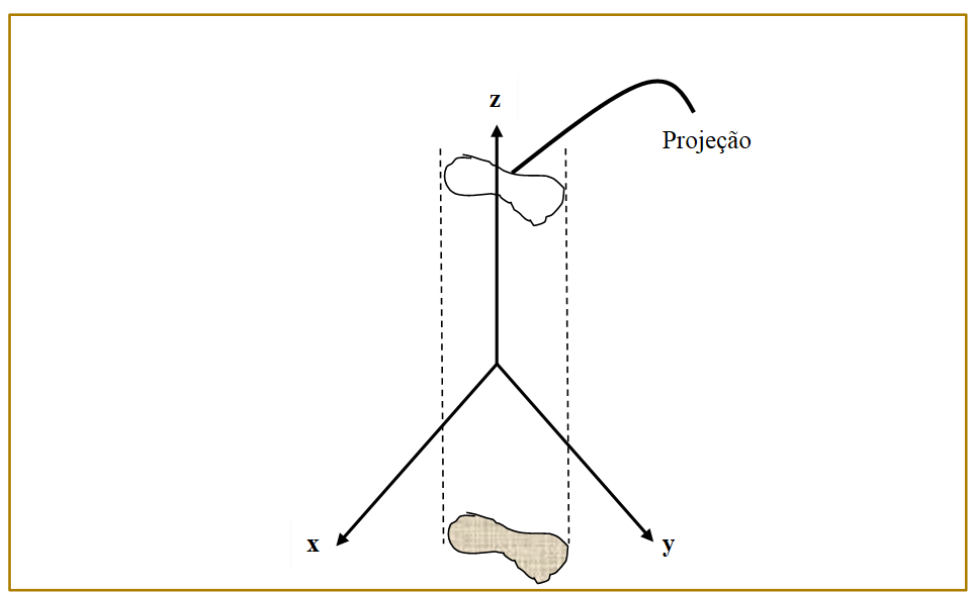

O símbolo nabla é utilizado na matemática para identificar o operador diferencial $\nabla$ no cálculo vetorial. 


$$
\nabla=\frac{\partial}{\partial x} i+\frac{\partial}{\partial y} j+\frac{\partial}{\partial_{z}} k
$$

Existem três tipos de operadores relacionais a serem discutidos Gradiente, Divergente e Rotacional, dando ênfase maior para o rotacional, pois as operações envolvidas utilizam o produto vetorial.

Podendo ser calculado somente em funções escalares, o gradiente de uma função escalar resulta em uma função vetorial que dá a direção de máxima variação da função escalar calculada. Por isso, visualmente, o campo gradiente de uma função escalar apontará para a região de maior variação da função. Sendo $f(x, y, z)$ uma função escalar, seu gradiente será dado por:

$$
\nabla f=\frac{\partial f}{\partial x} \vec{i}+\frac{\partial f}{\partial y} \vec{j}+\frac{\partial f}{\partial z} \vec{k}
$$

Se $F=P_{i}+Q_{j}+R_{k}$ é um campo vetorial em $\mathfrak{R}^{3}$ e existem $\frac{\partial P}{\partial_{x}}, \frac{\partial Q}{\partial_{y}} e \frac{\partial R}{\partial_{z}}$, então a divergência

$$
\operatorname{div} F=\nabla * \mathrm{~F}=\frac{\partial P}{\partial_{x}}+\frac{\partial Q}{\partial y}+\frac{\partial R}{\partial_{z}}
$$

Se $F=P_{i}+Q_{j}+R_{k}$ é um campo vetorial em $\Re^{3}$ e as derivadas parciais em $P, Q$ e $R$ de F é uma função de três variáveis, definida por:

$$
\operatorname{rot} F=\nabla * \mathrm{~F}=\left(\frac{\partial R}{\partial y}-\frac{\partial Q}{\partial_{z}}\right) i+\left(\frac{\partial P}{\partial_{z}}-\frac{\partial R}{\partial_{x}}\right) j+\left(\frac{\partial Q}{\partial_{x}}-\frac{\partial P}{\partial y}\right) k
$$

Chega-se no mesmo resultado fazendo:

$$
\nabla x M=\left(\begin{array}{ccc}
i & j & k \\
\frac{\partial}{\partial x} & \frac{\partial}{\partial_{y}} & \frac{\partial}{\partial_{z}} \\
F & L & P
\end{array}\right)
$$

As integrais pertinentes ao cálculo das coordenadas do centro de massa são denominadas de Momentos de Segunda existem, então o rotacional de $F$ é um campo vetorial no $\Re^{3}$, definido por:

$$
M=F * L(\text { Momento }=\text { Força } \times \text { Distância })
$$


Figura 4 - Relação de força e distância

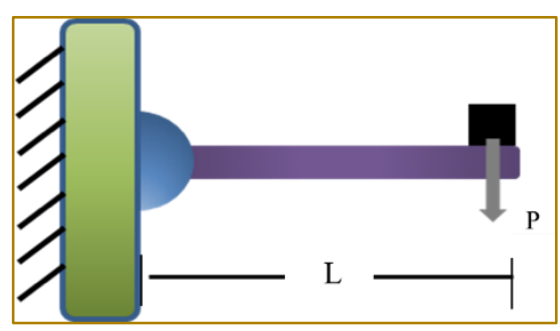

$$
\begin{gathered}
M_{O}=F * L \\
M_{O F}=m \cdot \frac{d^{2} A}{d t^{2}} \cdot L \\
M_{O F}=\mu(x, y) \cdot A \cdot \frac{d^{2} A}{d t^{2}} \cdot L \\
M x=\frac{M_{0} F_{x}}{M} \\
M y=\frac{M_{0} F_{y}}{M} \\
\bar{x}=\frac{M x}{M} \\
\bar{y}=\frac{M y}{M} \quad
\end{gathered}
$$

\section{RESULTADOS E DISCUSSÕES}

Para realizar a execução do algoritmo foi utilizado a linguagem de programação MATLAB. A Figura 5 mostra os dados de entrada para o cálculo do centro de massa, como os valores de delimitação da área utilizada, em seguida é calculada a massa do

corpo. O próximo passo foi inserir a função do momento de massa em relação aos eixos $x$ e y, e como saída foi obtida os momentos Mx e My e por conseguinte os valores das coordenadas do centro de massa.

Figura 5 - Tela dos dados de entrada e saída

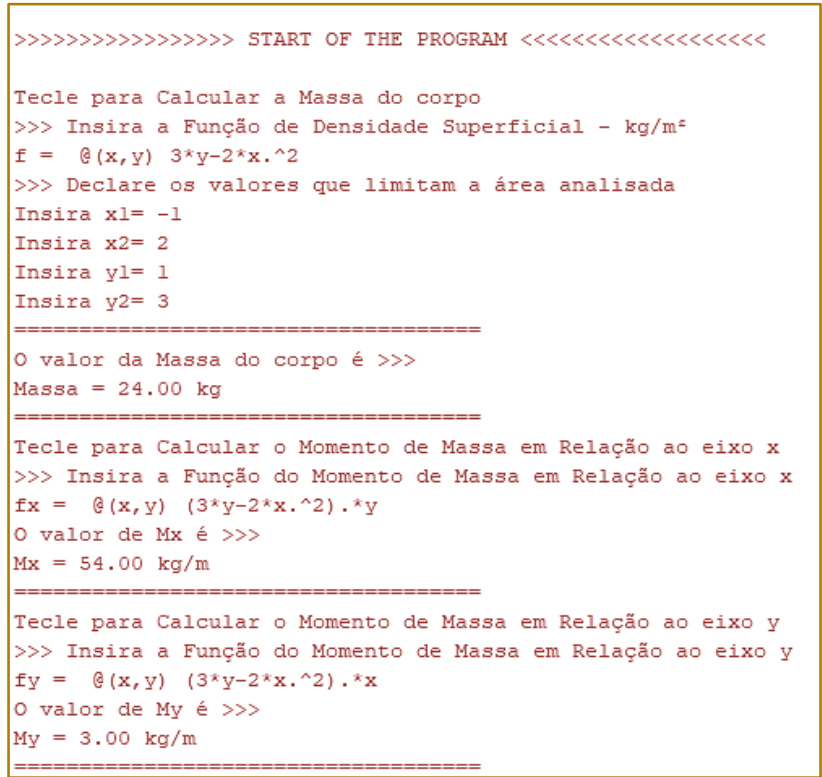




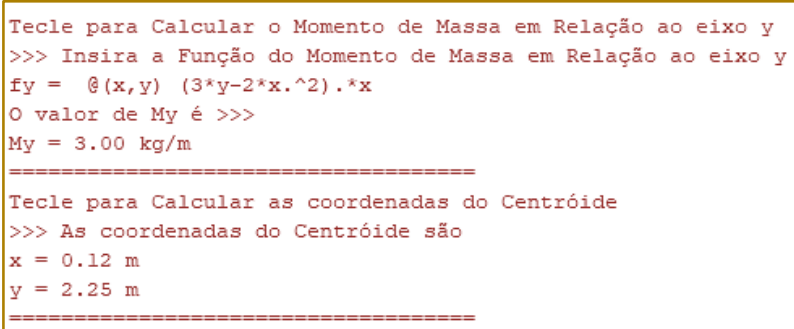

A Figura 6 mostra entrada dos dados para a geração dos gráficos para análise dos dados, como por exemplo, o gráfico que mostra o ponto do centro de massa pode ser visualizado na Figura 7, a distribuição de densidade superficial como mostrado nas Figuras 8, 9 e 10.

Figura 6 - Tela dos dados de entrada e saída dos gráficos

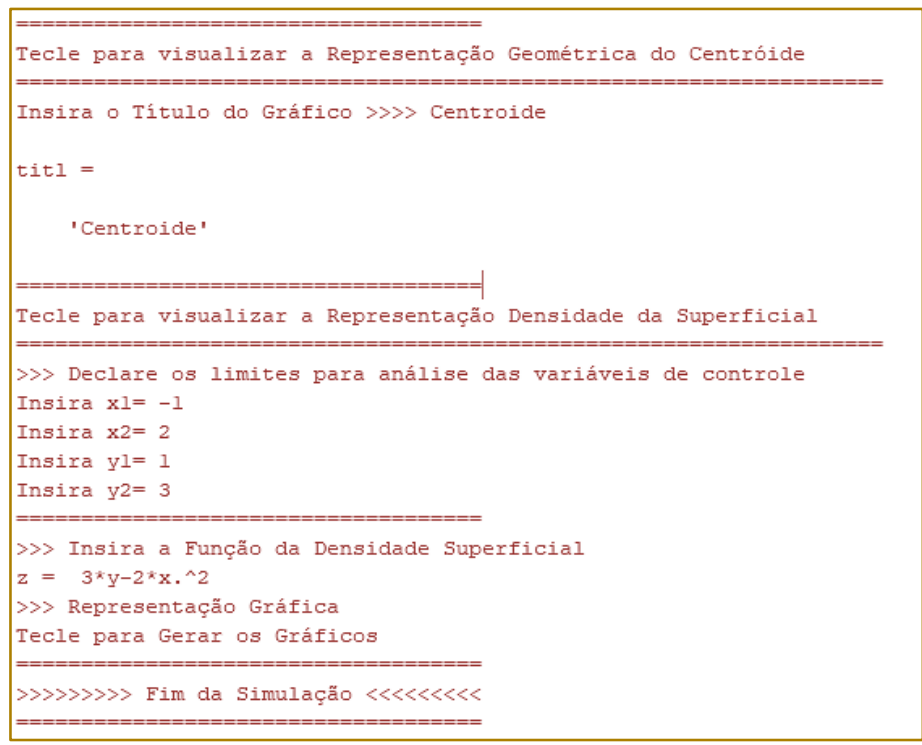

Figura 7 - Coordenadas do Centro de Massa

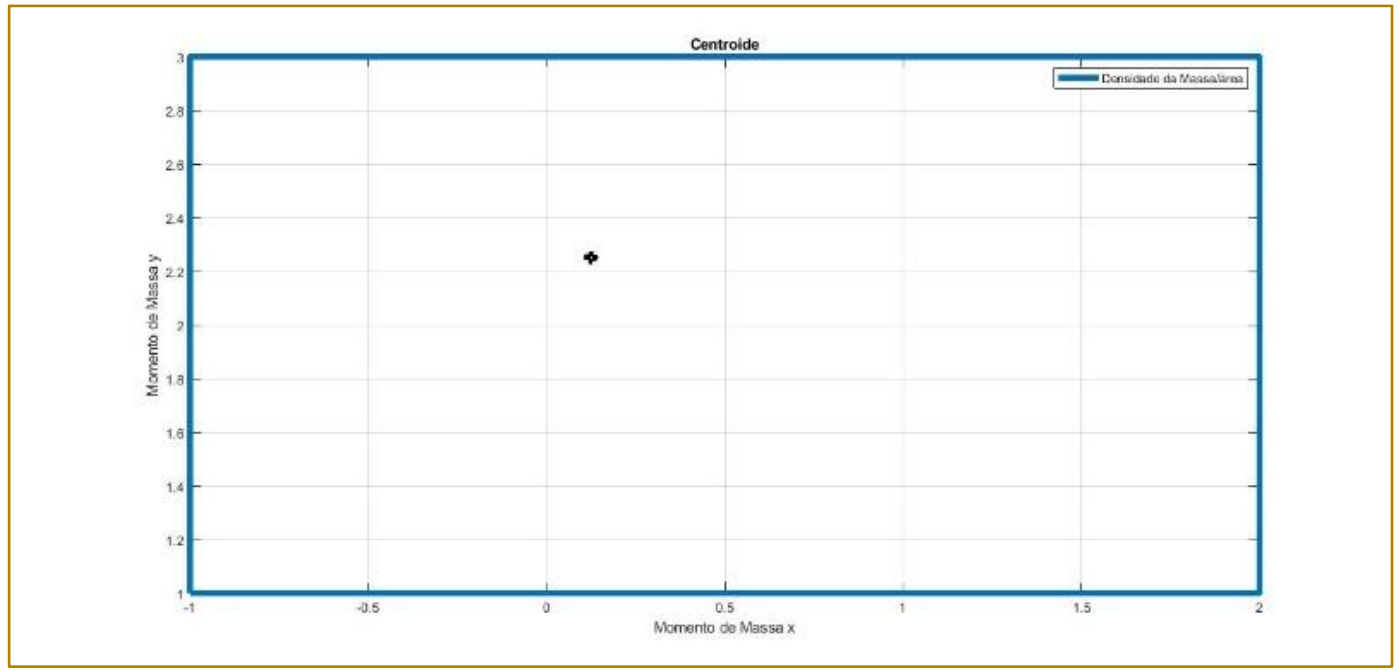


Figura 8 - Densidade superficial em relação ao eixo z

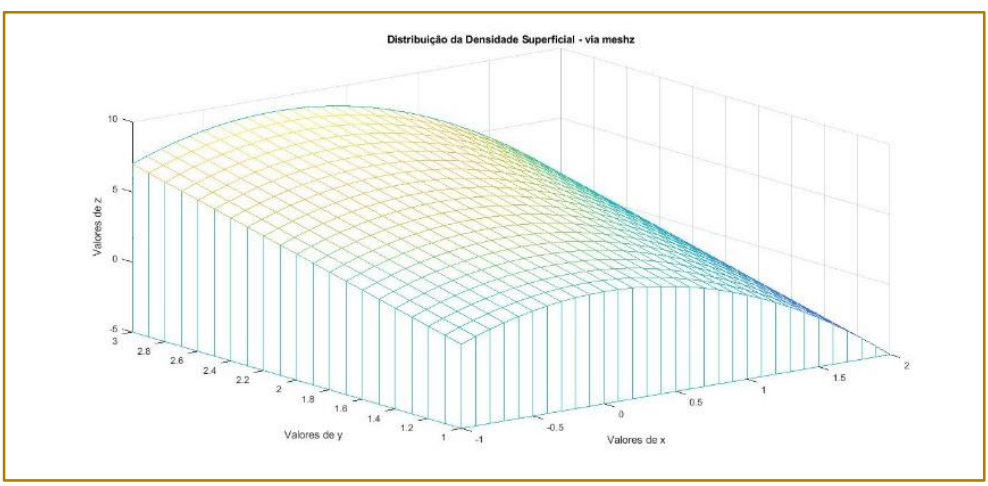

Figura 9 - Densidade superficial em relação ao eixo z

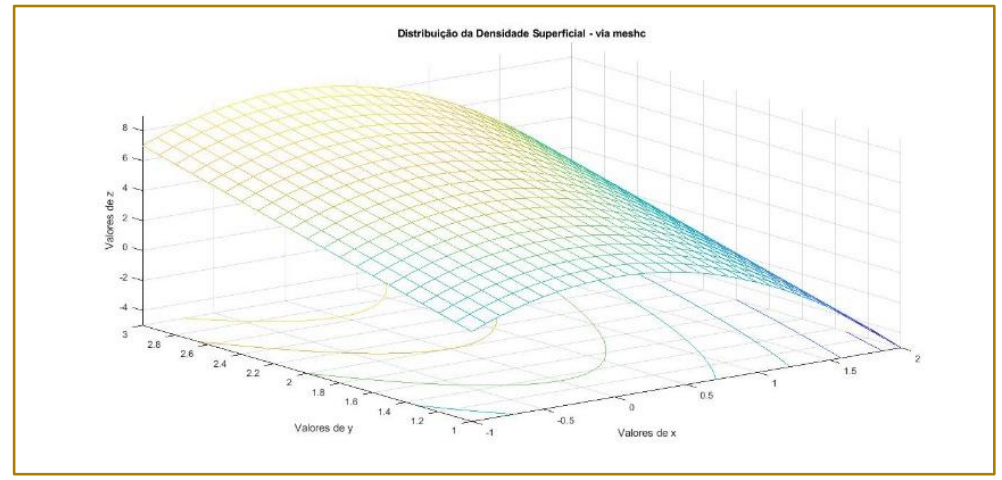

Figura 10 - Densidade superficial em relação ao eixo z.

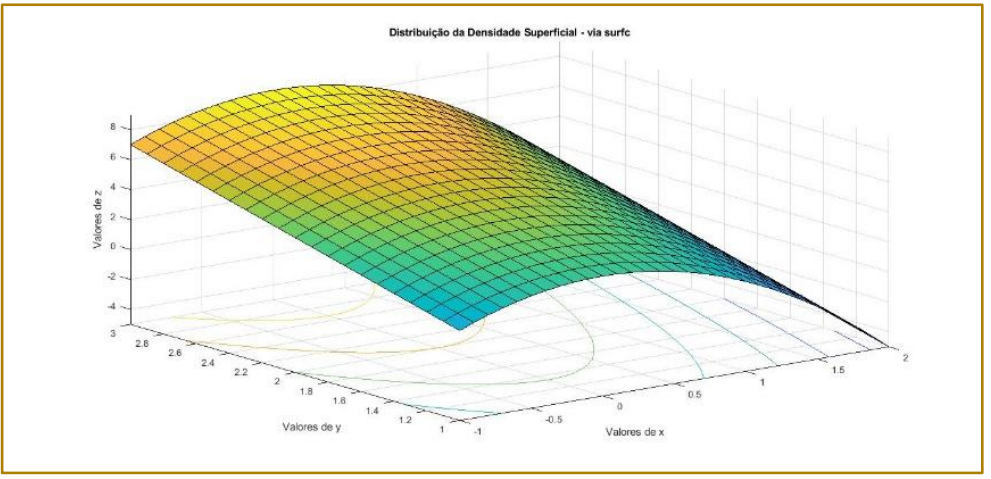

\section{CONCLUSÕES}

A utilização de softwares na formação dos profissioanis de engenharia em sala de aula, sem dúvida alguma, precisa se tornar uma ferramenta rotineira no processo ensinoaprendizagem nas universidades e Institutos de Ciências e Tecnologias, no Brasil. Da mesma forma que os professores precisam ter consciência da importância dessa prática em relação a inclusão desses recursos na aprendizagem dos alunos e sua formação profissional.
Para os cursos de engenharia, em especial, a localização do centro de massa de uma estrutura é de suma importância, pois para produzir uma distribuição uniforme de tensões, as cargas devem ser aplicadas de tal forma que a linha de ação da resultante seja coincidente com as corodenadas centrais da seção reta do componente, além de ser, extremamente, relevante para se determinar a localização da linha ao longo da qual as tensões são consideradas nulas. Por se tratar de um tema complexo, torna-se evidente que implementação de cálculos na 
forma tradicional, poderá ser motivada pelo uso das tecnologias digitais.

O trabalho teve como objetivo, desenvolver um método computacional como ferramenta, a fim de auxiliar no processo de ensinoaprendizagem, maximizando a produção e minimizando os erros de cálculos analíticos complexos. O método proposto foi utilizado no Instituto Federal de Ciência e Tecnologia do Pará - IFPA Ananindeua e produziu uma experiência insólita, por meio de simulações,

\section{REFERÊNCIAS}

[1] CHRISTIAN Grossmann; Hans-G. Roos; Martin Stynes. Numerical Treatment of Partial Differential Equations. [S.I.]: Springer Science \& Business Media. p. 23. ISBN 978-3-540-71584-9, 2007.

[2] CRUZ, HERBERT MELO et al., Jogo Didático "Construbusiness: A Cadeia Produtiva Da Construção Civil": Uma Ferramenta De Aprendizagem Na Engenharia Civil, Rev. Docência Ens. Sup., Belo Horizonte, v. 7, n. 2, p. 113-129, jul./dez, 2017

[3] FIOLHAIS, Carlos e TRINDADE, Jorge. Física no Computador: O Computador como uma Ferramenta no Ensino e na Aprendizagem das Ciências Físicas. Artigo publicado em Revista Brasileira de Ensino de Física, vol. 25, no. 3, Setembro; 2003.

[4] FREITAS, RUAN MAGNO OLIVEIRA, Desenvolvimento de ferramenta computacional para cálculo de propriedades geométricas de seções transversais. / Ruan Magno Oliveira de Freitas. -- Mossoró, 2012.

[5] GUERRA, J.H.L. Utilização do computador no processo de ensino-aprendizagem: uma aplicação em planejamento e controle da produção. São Carlos. 159p. Dissertação (mestrado) - Escola de Engenharia de São Carlos, Universidade de São Paulo, 2000.

[6] IMBERNÓN, Francisco. Formação docente e profissional: formar-se para a mudança e a incerteza. 7. Ed. São Paulo: Cortez, 2010.

[7] KHALED JAMAL BAKRI, et al., Proposta De Ferramenta Didática Para Ensino Em Engenharia Eletrônica: Integração A Conversores De Energia, CONTECC 2016.

[8] LIMA WALBER MEDEIROS et al., Uma Ferramenta Computacional Para Suporte Nos Processos De Ensino E Aprendizagem De Equações Diferenciais Parciais, Revista de Ensino de Engenharia, v. 35, n. 1, p. 65-74 - ISSN 01015001, 2016. nos alunos da área de engenharia. Por intermédio dessa estratégia foi possível analisar conceitos importantes e complexos, como o cálculo do centro de massa, sem a rotina algébrica tradicional. Essa experiência, mais próxima da realidade tecnológica, facilitou o entendimento e a utilização de teoremas e de equações, adequando a formação acadêmica de um estudante, moldando-o para ser mais preciso e consistente na tomada de decisão.

[9] MORAN, Manuel José. As muitas formas de comunicarmo-nos. Trecho do segundo capítulo do meu livro Desafios na comunicação pessoal,3. ed, Paulinas, 2007, p.43-50. Disponível [Online] em 15 de maio de 2011.

[10] MORAN, José Manuel; MASETTO, Marcos; BEHRENS, Marilda. Novas Tecnologias e Mediação Pedagógica. 16. ed. Campinas: Papirus, p.12-17, 2009.

[11] MORAN, José Manuel, MASSETTO, Marcos T., BEHRENS Marilda Aparecida. Novas tecnologias e mediações pedagógicas. Campinas, SP. Papirus, 2012

[12] PERRENOUD, Philippe. Dez novas competências para ensinar. Porto Alegre: Artmed, 2000 .

[13] PRETTO, Nelson. PINTO, Cláudio da Costa. Tecnologias e Novas Educações. Revista Brasileira de Educação, v.11, n. 31, jan/abr.2006

[14] RICHARD L. Burden; J. Douglas Faires. Análise Numérica, Editora CENGAGE Learning, $8^{\circ}$ ediçao. [S.I.: s.n.]

[15] SILVA, M. A. da. "Protótipo de uma ferramenta para auxiliar no ensino de técnicas de programação". 42 f. Trabalho de Conclusão de Curso (Bacharelado em Informática) Departamento de Ciências Exatas e Tecnológicas, Universidade do Planalto Catarinense, Lages, 2003.

[16] VEIT, Eliane Ângela. Modelagem computacional no Ensino de Física. Artigo apresentado no Simpósio Nacional de Ensino de Física; 2005.

[17] VIEIRA, Rosângela Souza. O papel das tecnologias da informação e comunicação na educação: um estudo sobre a percepção do professor/aluno. Formoso - BA: Universidade Federal do Vale do São Francisco (UNIVASF), 2011. v. 10, p.66-72. 


\section{Capítulo 17}

\section{COMPARATIVO DA LUCRATIVIDADE DE LINHAS DE PRODUÇÃO DE PEQUENA INDÚSTRIA DE CONFECÇÕES}

\section{Beatriz Silvestri Ghisi}

Rodney Wernke

Ivanir Rufatto

Ivone Junges

Resumo: O artigo objetivou mensurar o custo de transformação associado a cada produto de duas linhas de produção de uma facção têxtil para conhecer a margem de contribuição fabril desses segmentos. Para essa finalidade foi utilizada metodologia do tipo descritiva, com abordagem qualitativa e no formato de estudo de caso. Com a utilização do método de custeio Unidades de Esforço de Produção (UEP) foi elaborada planilha que apurou os custos de transformação do mix produzido nas linhas "1" e "2", o que facilitou o cálculo da margem de contribuição fabril do período nesses setores produtivos. Concluiu-se que a linha de produção "2" é a mais lucratividade porque foi responsável por $52,69 \%$ do resultado do mês, apesar de ter somente $22,54 \%$ de participação no faturamento mensal. A contribuição do estudo reside principalmente no fato de ter utilizado o método UEP numa fábrica de pequeno porte com a finalidade de conhecer a lucratividade de linhas de produção, uma abordagem que não costuma ser encontrada na literatura que discorre sobre métodos de custeio. Além disso, salientou a importância da apuração dos custos fabris de forma consistente para fundamentar as avaliações gerenciais acerca do desempenho de segmentos de mercado, de vez que o critério "faturamento" pode levar a decisões equivocadas quanto aos itens a serem priorizados.

Palavras-chave: Lucratividade de linhas de produção. Custo fabril. Estudo de caso. 


\section{INTRODUÇÃO}

Para avaliar a lucratividade do mix de produtos fabricados as pequenas indústrias podem utilizar uma planilha de custos que proporcione a identificação dos valores despendidos na produção de cada item comercializado. Para tanto, é necessário selecionar um método de custeio adequado ao contexto visado.

Entre as possibilidades para resolver os problemas de custeamento está a utilização do método UEP (Unidades de Esforço de Produção), cuja concepção básica é a de unificar a medição da produção industrial por meio de uma só unidade de medida abstrata (CAMBRUZZI; BALEN; MOROZINI, 2009). Referido método, portanto, prioriza a determinação do custo de transformar matérias-primas em produtos finais e abrange os gastos consumidos na confecção destes, mas sem considerar o consumo de matériasprimas (WERNKE et al., 2018). Mas, a teoria que fundamenta o UEP é complexa e pode ocasionar dificuldade para entendimento por parte dos gestores e tolher iniciativas a respeito se os benefícios relacionados não forem evidenciados corretamente.

Nesse contexto, então, emerge a questão de pesquisa que se pretende responder: como utilizar o método UEP para avaliar a lucratividade de duas linhas de produção de uma pequena fábrica que atua como facção têxtil (costura industrial terceirizada). Para essa finalidade foi estabelecido o objetivo de mensurar o custo de transformação associado a cada produto das duas linhas de produção para conhecer a margem de contribuição fabril desses segmentos.

\section{REVISÃO DA LITERATURA}

Em virtude da restrição de espaço no texto, nesta seção optou-se por apresentar uma breve revisão da literatura acerca dos principais aspectos do método de custeio escolhido.

Nesse rumo, Gantzel e Allora (1996) asseveram que o método UEP converte a produção da empresa em uma unidade de medida que pode mensurar todo tipo de produção, por mais diversificada que seja. Para tanto, Slavov (2013) registra que o UEP prioriza $O$ custo de transformação de operações homogêneas executadas nos diversos postos operativos pelos quais os produtos passam para serem fabricados.
Para implementar tal metodologia de custeamento é necessário percorrer as seguintes etapas: (1) divisão da fábrica em postos operativos (POs) ou setores; (2) cálculo dos potenciais de produção dos postos operativos; (3) seleção do produtobase; (4) apurar o foto-custo do produto-base; (5) calcular a capacidade de produção (também chamada de potencial produtivo) dos postos operativos; (6) apuração do valor equivalente dos produtos em UEPs e (7) calcular o valor monetário do custo de transformação a partir da multiplicação do equivalente em UEP do produto pelo valor monetário da UEP no período (WERNKE et al., 2018; LACERDA; SCHULTZ; WALTER, 2017; GUIMARÃES FILHO et al., 2016).

Entre as diversas informações que podem ser obtidas da utilização do método UEP podem ser salientadas as seguintes: determinação dos custos de transformação (unitário e total) dos produtos; mensuração da lucratividade dos integrantes do mix comercializado; medição e comparação dos volumes de produção entre períodos para averiguar se houve ganho/ perda de produtividade entre os períodos; definição das capacidades de produção; comparação da produtividade de processos ou linhas de produção; análise da viabilidade da compra de novos equipamentos industriais; definição das necessidades de funcionários ou maquinário e programação da produção fabril (BORNIA, 2009; SOUZA; DIEHL, 2009; ALLORA; OLIVEIRA, 2010).

Contudo, referido método possui limitações que merecem ser comentadas. Talvez a principal restrição a aventar diga respeito ao fato de que o UEP centra atenção exclusivamente no custo relacionado com a transformação das matérias-primas em produtos, de modo que as despesas de estrutura não são abrangidas pelo mesmo. Como os dispêndios com o custo de overhead (como logística de suprimentos e de produção, controle de qualidade etc.) têm aumentado nos últimos anos, é interessante que seja efetuada uma avaliação pormenorizada do montante para verificar as possibilidades de minimizá-las (BORNIA, 2009; MARTINS; ROCHA, 2010).

Além disso, Pereira (2015) apresenta como possíveis limitações do UEP os seguintes aspectos: não identifica a parcela de custos associados às perdas do processo; requer revisão constante dos cálculos e da estrutura de produção; aplicável apenas ao ambiente 
industrial; não permite gerenciar os gastos não fabris; apresenta dificuldades de aplicação em empresas onde os produtos variam regularmente; tem elevada complexidade e custo de implementação; necessita de operações relativamente padronizadas e apresenta subjetividade na escolha do produto-base.

\section{METODOLOGIA}

No que tange à metodologia empregada nesta pesquisa, em relação à tipologia quanto aos objetivos, esta pode ser classificada como descritiva, pois referida modalidade visa, segundo Gil (1999), descrever características de determinada população ou fenômeno ou o estabelecimento de relação entre as variáveis.

Pelo aspecto dos procedimentos adotados, a pesquisa caracteriza-se como estudo de caso, de vez que se concentra especificamente numa pequena indústria $e$ suas conclusões limitam-se ao contexto desse objeto de estudo (YIN, 2005). No âmbito da forma de abordagem do problema, a pesquisa pode ser classificada como "qualitativa", pois é assim que Richardson (1999) denomina os estudos que visam descrever a complexidade de determinado problema, analisar a interação de certas variáveis, compreender e classificar processos dinâmicos vividos por grupos sociais.

Quanto à escolha da empresa, esta ocorreu por dois motivos. A primeira razão está ligada à possibilidade de acesso aos dados necessários por parte dos pesquisadores, facultada pela proprietária do empreendimento. A segunda razão para priorizar essa entidade é que esta possui estrutura produtiva com poucos setores fabris e trabalhava com mix composto por menos de 20 produtos. Essa configuração acarretou maior facilidade na coleta de dados e na elaboração dos cálculos necessários, bem como proporcionou melhores condições de redigir um texto detalhado abrangendo todos os setores das duas linhas de produção visadas e os respectivos produtos.

Os procedimentos de coleta de dados foram realizados em julho de 2018, abrangendo o contexto de junho do mesmo ano. Para essa finalidade, inicialmente, foi empregada a técnica de conversas informais (entrevistas não estruturadas) com a proprietária da empresa, com o responsável pela produção fabril e com o contador. Na sequência foi efetuada uma análise documental (nos controles internos e na contabilidade terceirizada) com a intenção de conhecer a situação vigente no que tange aos dados necessários para efetuar o estudo pretendido. Posteriormente iniciou-se a coleta dos dados requeridos para execução do trabalho nos controles internos existentes, além de outros informes mais específicos que foram obtidos junto à gerente e ao contador da firma.

Quanto às características da empresa pesquisada, a mesma está situada no município de Pedras Grandes (SC) e atua como facção têxtil (presta serviços de costura industrial terceirizada) para indústrias de confecções da região sul de Santa Catarina. Convém esclarecer que a razão social e o nome de fantasia que a entidade utiliza são omitidos neste relato com a finalidade de preservar informações comerciais, por solicitação da gerência da empresa.

Por utilizar parque fabril com duas linhas de produção, a proprietária tinha interesse em identificar o segmento mais lucrativo, visando facilitar a escolha de qual linha deveria ser priorizada em termos de novos investimentos. Como o cálculo do custo de fabricação unitário era feito de forma rudimentar, pois dividia-se o valor total de custos e despesas pelo número de peças produzidas no mês, o valor era pouco confiável pela distorção causada pela disparidade de características dos itens produzidos (tecidos diferentes, modelos diversos, linhas adulto e infantil etc.). Então, a proprietária facilitou o acesso dos pesquisadores para obter os dados necessários para elaborar a planilha de custos que proporcionou os resultados comentados nas próximas seções.

\section{APRESENTAÇÃO E ANÁLISE DOS RESULTADOS}

Para conhecer o custo de transformação dos produtos fabricados foi elaborada uma planilha de custos pelo método UEP, cuja confecção requereu inicialmente identificar os postos operativos (POs) das duas linhas de produção e respectivos custos por hora de trabalho. Porém, por restrição de espaço no texto priorizou-se a apresentação dos dados relacionados com a linha de produção "1". Nesse sentido, a estrutura de custos desta área da empresa consta da Tabela 1. 
Tabela 1 - Custo por hora dos postos operativos - LINHA 1

\begin{tabular}{|c|c|c|c|}
\hline Postos operativos & $\begin{array}{l}\text { 1) Custo } \\
\text { mensal } R \$\end{array}$ & $\begin{array}{l}\text { 2) Expediente do } \\
\text { mês (horas) }\end{array}$ & $\begin{array}{c}3=1 / 2) \\
\text { Custo/hora }(R \$)\end{array}$ \\
\hline L1-CASEADEIRA (1e2) & $3.216,35$ & 187,0 & 17,20 \\
\hline L1-OVERLOQ & $1.332,79$ & 187,0 & 7,13 \\
\hline L1-TRAVETE (1e2) & $3.602,01$ & 187,0 & 19,26 \\
\hline L1-MAQ. RETA $(1,2,3 e 4)$ & $8.341,21$ & 187,0 & 44,61 \\
\hline L1-MAQ.2 AGULHAS $(1,2, e 3)$ & $3.459,46$ & 187,0 & 18,50 \\
\hline L1-PTF & 329,48 & 187,0 & 1,76 \\
\hline L1-GALONEIRA & $2.178,29$ & 187,0 & 11,65 \\
\hline L1-FERRO DE PASSAR & $2.118,21$ & 187,0 & 11,33 \\
\hline L1-CORTAR PASSANTE & 358,16 & 187,0 & 1,92 \\
\hline L1-INTERLOQ $(1,2 \mathrm{e} 3)$ & $3.651,50$ & 187,0 & 19,53 \\
\hline L1-MAQ.CÓS & $1.750,36$ & 187,0 & 9,36 \\
\hline Totais & $36.456,65$ & - & - \\
\hline
\end{tabular}

Fonte: elaborada pelos autores.

Ou seja, com a ajuda do gestor da produção foi apurado o valor total (em $\mathrm{R} \$$ ) dos custos fabris de cada posto no mês utilizado como base para a pesquisa e determinado 0 número de horas do expediente mensal desses POs. A partir disso, fez-se a divisão do (1) custo mensal total (em $R \$$ ) de cada posto operativo pela (2) quantidade mensal de horas produtivas no posto de trabalho. Com isso, encontrou-se o (3) custo/hora (em R\$) de cada posto operativo $(3=1 / 2)$ considerando folha de pagamentos, depreciação do maquinário fabril, energia elétrica da produção, manutenção industrial e depreciação predial. Por exemplo: no Posto Operativo "L1-CASEADEIRA (1 e 2)" foram gastos $R$ \$ 3.216,35 no mês com 187 horas de trabalho, o que implicou no custo/hora de $\mathrm{R} \$ 17,20$.

Quanto à depreciação do maquinário fabril, o custo/hora desse fator foi definido utilizando os itens depreciáveis de cada posto operativo (como máquinas, equipamentos, móveis, utensílios etc.). Entretanto, em virtude da não disponibilidade de controles internos que informassem o valor mensal da depreciação desses equipamentos, preferiu-se calculá-la pela divisão do valor estimado de mercado atual de cada bem pela respectiva vida útil (em anos) projetada para estes. A partir desse resultado foi encontrada a parcela de depreciação anual, que foi novamente dividida por 12 meses para apurar a depreciação mensal. Em seguida, dividiu-se o valor mensal da depreciação pela quantidade de horas que o equipamento trabalha por mês para determinar o valor (em $\mathrm{R} \$$ ) do custo/hora da depreciação das máquinas industriais.

Com relação à folha de pagamentos, o custo/hora foi determinado com base na soma dos salários e encargos sociais dos funcionários que trabalhavam em cada posto operativo (PO) no mês. No caso dos operários, esse valor por posto operativo foi atribuído com base no tempo de expediente dedicado a cada setor, pois havia funcionários que atuavam em mais de um posto durante o mês. Quanto ao supervisor de produção, estimou-se um percentual de tempo que o mesmo dedicava aos POs e utilizou-se esse índice para ratear o valor respectivo aos postos.

No que tange à energia elétrica da produção, o custo/hora respectivo foi determinado de acordo com a estimativa do consumo de energia de cada equipamento industrial utilizado na fabricação dos produtos. Essa informação foi usada para estimar o gasto mensal de cada posto operativo para, posteriormente, apurar o custo/hora (em R $\$$ ) dos mesmos.

Quanto à manutenção industrial, este tipo de custo teve seu valor por hora determinado por meio de uma estimativa mensal realizada pelo responsável pela produção. Nesse sentido, foi estipulada uma média de gastos realizados com a manutenção nos últimos de 12 (doze) meses, de acordo com cada maquinário dos postos operativos abrangidos.

No caso da depreciação predial, este valor foi obtido por meio da multiplicação dos metros quadrados do pavilhão industrial utilizado pela empresa pelo valor (em $\mathrm{R} \$$ ) do CUB (Custo Unitário Básico da construção civil) para obra semelhante. Em seguida, o valor total da depreciação mensal foi alocado a cada posto operativo proporcionalmente à metragem quadrada ocupada pelos mesmos. 


\subsection{LEVANTAMENTO DO TEMPO DE PRODUÇÃO}

$\mathrm{Na}$ segunda etapa buscou-se levantar o tempo de passagem dos produtos em cada um dos postos operativos. Nesse rumo, o procedimento consistiu em apurar o tempo que cada produto permanece nos postos operativos por onde passa durante o processo de fabricação e a realidade apurada na empresa em tela pode ser visualizada na Tabela 2 (para apenas alguns produtos, a título de exemplo).

Tabela 2 - Tempo de produção por unidade produzida - LINHA 1

\begin{tabular}{|l|c|c|c|}
\multicolumn{1}{r|}{ Postos operativos } & Bermuda masc. jeans inf. & Bermuda sarja pt inf. & Calça sarja pt inf. \\
\hline L1-CASEADEIRA (1e2) & 0,01667 & 0,02000 & 0,02222 \\
\hline L1-OVERLOQ & 0,01818 & 0,02000 & 0,02000 \\
\hline L1-TRAVETE (1e2) & 0,01818 & 0,02000 & 0,02000 \\
\hline L1-MAQ. RETA (1,2,3e4) & 0,01667 & 0,02000 & 0,02222 \\
\hline L1-MAQ.2 AGULHAS (1,2,e3) & 0,01818 & 0,02000 & 0,02000 \\
\hline L1-PTF & 0,01818 & 0,02000 & 0,02000 \\
\hline L1-FERRO DE PASSAR & 0,01818 & 0,01818 & 0,01818 \\
\hline L1-CORTAR PASSANTE & 0,01818 & 0,01818 & 0,01818 \\
\hline L1-INTERLOQ (1,2e3) & 0,01818 & 0,01818 & 0,01818 \\
\hline L1-MAQ.CÓS & 0,01818 & 0,01818 & 0,01818 \\
\hline \multicolumn{1}{|c|}{ Totais } & 0,17879 & 0,19273 & 0,19717 \\
\hline
\end{tabular}

Fonte: elaborada pelos autores.

Ou seja, foi necessário levantar os "tempos de passagem" de cada integrante do mix comercializado pela empresa pesquisada, o que foi feito com o auxílio dos encarregados de cada setor fabril. Assim, para obter um melhor diagnóstico da realidade produtiva da fábrica, o cálculo utilizado levou em conta a produção total do mês investigado e englobou as paradas de produção normais (ou eventuais) oriundas de troca matérias-primas, de ajustes nas máquinas, quedas de energia elétrica etc.

Nessa direção, considerou-se que a produção teria alguns fatores que impedem a fabricação ininterrupta, o que refletiria melhor a realidade industrial diagnosticada. Por isso, em vez de "cronometrar" a produção de cada item, foi apurada a quantidade média fabricada (em número de peças) por dia de cada produto. Em seguida, dividiu-se tal quantidade pelo número de horas do expediente diário de cada posto operativo, obtendo-se a produção por hora. Na sequência dividiu-se "1" por essa quantidade fabricada por hora para apurar o tempo de passagem (em fração de horas) dos produtos em cada posto operativo, cujo resultado consta da Tabela 2.

\subsection{DETERMINAÇÃO DO CUSTO DO PRODUTO-BASE E DOS POTENCIAIS PRODUTIVOS DOS POSTOS}

Na etapa três de implementação do custeio UEP foi feita a escolha do produto-base, que serviu para determinar o valor da UEP no mês. Para essa finalidade foi necessário determinar o custo do produto-base (em $\mathrm{R} \$$ ), cujo cálculo consiste no somatório do tempo de passagem desse produto em cada posto operativo multiplicado pelo custo/hora (em R\$) respectivo de cada posto. Acerca disso, a Tabela 3 apresenta o procedimento de cálculo citado para o produto selecionado como produto-base (Bermuda masc. Jeans inf.). 
Tabela 3 - Custo do produto-base (Bermuda masc. jeans inf.) - LINHA 1

\begin{tabular}{|c|c|c|c|}
\hline Postos operativos & $\begin{array}{l}\text { Tempo de passagem } \\
\text { no P. O. em horas (a) }\end{array}$ & $\begin{array}{l}\text { Custo por hora } \\
\text { do P. O. } R \$ \text { (b) }\end{array}$ & $\begin{array}{l}\text { Custo do produto- } \\
\text { base } R \$(c=a X b)\end{array}$ \\
\hline L1-CASEADEIRA (1e2) & 0,01667 & 17,19975 & 0,28666 \\
\hline L1-OVERLOQ & 0,01818 & 7,12722 & 0,12959 \\
\hline L1-TRAVETE (1e2) & 0,01818 & 19,26207 & 0,35022 \\
\hline L1-MAQ. RETA $(1,2,3 e 4)$ & 0,01667 & 44,60539 & 0,74342 \\
\hline L1-MAQ.2 AGULHAS $(1,2, \mathrm{e} 3)$ & 0,01818 & 18,49978 & 0,33636 \\
\hline L1-PTF & 0,01818 & 1,76194 & 0,03204 \\
\hline L1-FERRO DE PASSAR & 0,01818 & 11,32734 & 0,20595 \\
\hline L1-CORTAR PASSANTE & 0,01818 & 1,91531 & 0,03482 \\
\hline L1-INTERLOQ $(1,2 \mathrm{e} 3)$ & 0,01818 & 19,52673 & 0,35503 \\
\hline L1-MAQ.CÓS & 0,01818 & 9,36020 & 0,17019 \\
\hline Totais & 0,17879 & & 2,64428 \\
\hline
\end{tabular}

Fonte: elaborada pelos autores.

O valor total da última coluna $(\mathrm{R} \$ 2,64428)$ foi empregado na próxima etapa do cálculo do método UEP, que refere-se à determinação do potencial produtivo dos postos operativos.

Nesse sentido, o cálculo dos potenciais produtivos dos postos operativos foi realizado com a divisão do custo/hora (em $\mathrm{R} \$$ ) de cada posto pelo custo do produto-base $(R \$ 2,64428)$. Com isso, encontrou-se a capacidade de produção em termos de "UEPs por hora" de cada posto, conforme demonstrado na Tabela 4.

Tabela 4 - Potencial produtivo dos postos operativos - LINHA 1

\begin{tabular}{|c|c|c|c|}
\hline Postos operativos & $\begin{array}{l}\text { a) Custo por hora do } \\
\text { Posto Operativo } R \$\end{array}$ & $\begin{array}{l}\text { b) Custo do } \\
\text { produto-base } R \$\end{array}$ & $\begin{array}{c}\mathrm{c}=\mathrm{a} / \mathrm{b} \text { ) Potencial Produtivo } \\
\text { (em UEP/hora) }\end{array}$ \\
\hline L1-CASEADEIRA (1e2) & 17,19975 & 2,64428 & 6,50452 \\
\hline L1-OVERLOQ & 7,12722 & 2,64428 & 2,69534 \\
\hline L1-TRAVETE (1e2) & 19,26207 & 2,64428 & 7,28443 \\
\hline L1-MAQ. RETA $(1,2,3 e 4)$ & 44,60539 & 2,64428 & 16,86865 \\
\hline L1-MAQ.2 AGULHAS $(1,2, \mathrm{e} 3)$ & 18,49978 & 2,64428 & 6,99616 \\
\hline L1-PTF & 1,76194 & 2,64428 & 0,66632 \\
\hline L1-GALONEIRA & 11,64861 & 2,64428 & 4,40521 \\
\hline L1-FERRO DE PASSAR & 11,32734 & 2,64428 & 4,28372 \\
\hline L1-CORTAR PASSANTE & 1,91531 & 2,64428 & 0,72432 \\
\hline L1-INTERLOQ $(1,2 \mathrm{e} 3)$ & 19,52673 & 2,64428 & 7,38452 \\
\hline L1-MAQ.CÓS & 9,36020 & 2,64428 & 3,53979 \\
\hline
\end{tabular}

Fonte: elaborada pelos autores.

Pelos resultados apurados na Tabela 4 constatou-se que os postos operativos possuíam capacidades de produção em UEPs por hora bastante diferentes. Isso ocasiona um "desbalanceamento" do fluxo produtivo da empresa e reduz a produtividade final da fábrica.

Como os postos operativos representam as fases pelas quais os produtos devem passar para serem fabricados, entende-se que medidas para diminuir tal problema são interessantes, especialmente com o objetivo de maximizar a produção final do empreendimento.

\subsection{CÁLCULO DOS EQUIVALENTES EM UEP DOS PRODUTOS}

No prosseguimento da implementação do método UEP passou-se pela fase de cálculo dos equivalentes em UEPs de cada produto. Para calcular esse valor foi necessário multiplicar o potencial produtivo do posto pelo respectivo tempo de passagem do produto, obtendo o equivalente por produto em cada posto de trabalho.

Em seguida, pela soma desses equivalentes parciais nos postos obteve-se o equivalente em UEP de cada item fabricado, como demonstrado na Tabela 5 para o produto "Bermuda masc. jeans inf." (como exemplo). 
Tabela 5 - Equivalente em UEP dos produtos (Bermuda masc. jeans inf.) - LINHA 1

\begin{tabular}{|c|c|c|c|}
\hline Postos operativos & $\begin{array}{l}\text { (1) Tempo de prod. } \\
\text { em horas por peça }\end{array}$ & $\begin{array}{l}\text { (2) Potencial produt. } \\
\text { (em UEP/hora) }\end{array}$ & $\begin{array}{l}3=1 \times 2) \text { Equivalente } \\
\text { em UEP do produto }\end{array}$ \\
\hline L1-CASEADEIRA (1e2) & 0,01667 & 6,50452 & 0,10841 \\
\hline L1-OVERLOQ & 0,01818 & 2,69534 & 0,04901 \\
\hline L1-TRAVETE (1e2) & 0,01818 & 7,28443 & 0,13244 \\
\hline L1-MAQ. RETA $(1,2,3 e 4)$ & 0,01667 & 16,86865 & 0,28114 \\
\hline L1-MAQ.2 AGULHAS $(1,2, \mathrm{e} 3)$ & 0,01818 & 6,99616 & 0,12720 \\
\hline L1-PTF & 0,01818 & 0,66632 & 0,01211 \\
\hline L1-FERRO DE PASSAR & 0,01818 & 4,28372 & 0,07789 \\
\hline L1-CORTAR PASSANTE & 0,01818 & 0,72432 & 0,01317 \\
\hline L1-INTERLOQ $(1,2 \mathrm{e} 3)$ & 0,01818 & 7,38452 & 0,13426 \\
\hline L1-MAQ.CÓS & 0,01818 & 3,53979 & 0,06436 \\
\hline \multicolumn{3}{|c|}{ (=) Equivalente em UEP do produto } & 1,00000 \\
\hline
\end{tabular}

Fonte: elaborada pelos autores.

O mesmo procedimento foi realizado para todos os produtos fabricados no mês da pesquisa, o que resultou nos seguintes valores para o mix produzido no mês na linha "1": "Bermuda sarja pt inf." 1,10999; "Calça masc. jeans inf." 1,03541; "Calça sarja pt inf." 1,16193; "Bermuda masc. jeans ad." 0,99223; "Bermuda sarja pt ad." 1,22385; "Calça masc. jeans ad." 1,11662 e "Calça sarja pt ad. $1,28878 "$.

Wernke e Junges (2017) afirmam que para avaliar a adequação dos valores calculados como equivalente em UEPs dos produtos fabricados é interessante realizar uma análise de consistência destes. Então, no contexto da empresa pesquisada, com o auxílio do responsável pela produção, foram conferidos os valores em UEPs apurados considerandose a premissa de que a UEP representa o esforço fabril desenvolvido em cada produto. Consequentemente os produtos que exigissem processamento diferente (em máquinas e tempos de passagem) deveriam ter equivalentes em UEPs distintos. Por exemplo: o produto "Bermuda masc. jeans inf." requer menos esforços de produção que uma "Bermuda sarja pt ad.". Com isso, o valor equivalente em UEP de uma peça do produto "Bermuda masc. jeans inf." (1,0000 UEP) deve ser menor que o valor equivalente em UEP de uma unidade do produto "Bermuda sarja pt ad." (cujo equivalente totalizou 1,22385 UEP). Com isso, é correto considerar que o custo de transformação de uma calça de adulto é $22,385 \%$ mais caro que o da outra bermuda, sem computar as matérias-primas consumidas nestas duas peças de roupa. Tal procedimento comparativo foi efetuado para todos os demais itens produzidos, não tendo sido registrada nenhuma inconsistência na opinião do gerente de produção da empresa.

\subsection{PRODUÇÃO MENSAL EM UEPS E CUSTO DE TRANSFORMAÇÃO DOS PRODUTOS}

$\mathrm{Na}$ etapa seguinte foi realizada a mensuração da produção total das linhas de produção da fábrica, em termos de UEPs produzidas, no período analisado. Esse valor foi apurado pela multiplicação das unidades fabricadas de cada produto no mês da pesquisa pela quantidade equivalente em UEPs que 0 mesmo representa.

No caso da empresa em questão, no período pesquisado a produção da fábrica (na linha "1") apresentou-se conforme os dados evidenciados na Tabela 6. 
Tabela 6 - Produção total de UEPs no período - LINHA 1

\section{$\begin{array}{llll}\text { Produto (descrição) } & \text { (a) Produção/mês } & \text { (b) Equiv. UEP produto } & \text { (c=axb) Total UEPs do mês }\end{array}$}

\begin{tabular}{|c|c|c|c|}
\hline Bermuda masc. jeans inf. & 1.000 & 1,00000 & $1.000,00000$ \\
\hline Bermuda sarja pt inf. & 500 & 1,10999 & 554,99368 \\
\hline Calça masc. jeans inf. & 1.000 & 1,03541 & $1.035,41388$ \\
\hline Calça sarja pt inf. & 1.000 & 1,16193 & $1.161,92771$ \\
\hline Bermuda masc. jeans ad. & 1.000 & 0,99223 & 992,22783 \\
\hline Bermuda sarja pt ad. & 500 & 1,22385 & 611,92632 \\
\hline Calça masc. jeans ad. & 1.000 & 1,11662 & $1.116,62281$ \\
\hline Calça sarja pt ad. & 500 & 1,28878 & 644,38904 \\
\hline Totais & 6.500 & - & $7.117,50128$ \\
\hline
\end{tabular}

Fonte: elaborada pelos autores.

Como visto, as 6.500 unidades produzidas no período da pesquisa equivaleram a 7.117,50128 UEPs, que será considerado para calcular o valor da UEP no período.

Para estipular quanto custa cada produto para ser fabricado, mais especificamente no

Tabela 7 - Valor da UEP no mês (R\$) - LINHA 1 que tange à transformação das matériasprimas em produtos prontos, é necessário calcular inicialmente o valor (em R $\$$ ) da UEP no período em estudo, conforme expresso na Tabela 7

\begin{tabular}{|c|c|c|}
\hline Itens & Valores & $\%$ do Custo tota \\
\hline 1) Depreciação das máquinas & $1.874,31$ & $5,141 \%$ \\
\hline 2) Depreciação do prédio & $1.852,62$ & $5,082 \%$ \\
\hline 3) Salários e encargos & $31.672,86$ & $86,878 \%$ \\
\hline 4) Energia elétrica & 114,66 & $0,315 \%$ \\
\hline 5) Manutenção das máquinas & 942,21 & $2,584 \%$ \\
\hline A) Total gasto no mês (soma de 1 até 5 ) & $36.456,65$ & $100,000 \%$ \\
\hline B) Produção do mês em UEP's & $7.117,5013$ & - \\
\hline $\mathrm{C}=\mathrm{A} / \mathrm{B}$ ) Valor da UEP (em $\mathrm{R} \$$ ) do período & 5,12211 & - \\
\hline
\end{tabular}

Fonte: elaborada pelos autores.

Nesse caso, considerou-se que os custos totais de fabricação do período em estudo totalizaram o valor de $\mathrm{R} \$ 36.456,65$, representados pelos fatores enfocados anteriormente (folha de pagamentos, depreciações, manutenção, energia elétrica etc.). No mesmo período foi fabricada uma quantidade de produtos cujo valor equivalente totalizou 7.117,5013 UEPs. Com base nesses dados, o valor unitário (em $\mathrm{R} \$$ ) da UEP foi de $\mathrm{R} \$ 5,12211$ e foi utilizado na próxima etapa.

Na sequência calculou-se o custo unitário de transformação dos produtos (em $\mathrm{R} \$$ ) e, posteriormente, o custo total de transformação (em $\mathrm{R} \$$ ) atribuído ou alocado a cada item fabricado no mês. Assim, no estudo realizado a situação identificada está representada detalhadamente na Tabela 8. 
Tabela 8 - Custo unitário e total por produto no período - LINHA 1

\begin{tabular}{|c|c|c|c|c|c|}
\hline Produto (descrição) & $\begin{array}{l}\text { Equiv. em } \\
\text { UEP }\end{array}$ & $\begin{array}{l}\text { Valor da } \\
\text { UEP }(R \$)\end{array}$ & $\begin{array}{c}\text { Custo de Transf. } \\
\text { Unitário }(R \$)\end{array}$ & $\begin{array}{l}\text { Quantidade } \\
\text { Produzida/mês }\end{array}$ & $\begin{array}{l}\text { Custo total } \\
\text { atribuído } \mathrm{R} \$\end{array}$ \\
\hline Berm. masc. jeans inf. & 1,00000 & 5,12211 & 5,12 & 1.000 & $5.122,11$ \\
\hline Berm. sarja pt inf. & 1,10999 & 5,12211 & 5,69 & 500 & $2.842,74$ \\
\hline Calça masc. jeans inf. & 1,03541 & 5,12211 & 5,30 & 1.000 & $5.303,51$ \\
\hline Calça sarja pt inf. & 1,16193 & 5,12211 & 5,95 & 1.000 & $5.951,53$ \\
\hline Berm. masc. jeans ad. & 0,99223 & 5,12211 & 5,08 & 1.000 & $5.082,30$ \\
\hline Berm. sarja pt ad. & 1,22385 & 5,12211 & 6,27 & 500 & $3.134,36$ \\
\hline Calça masc. jeans ad. & 1,11662 & 5,12211 & 5,72 & 1.000 & $5.719,47$ \\
\hline Calça sarja pt ad. & 1,28878 & 5,12211 & 6,60 & 500 & $3.300,63$ \\
\hline \multicolumn{4}{|c|}{ Totais } & 6.500 & $36.456,65$ \\
\hline
\end{tabular}

Na Tabela 8 procedeu-se da seguinte forma (utilizando-se o produto de código "Calça sarja pt ad." citado na última linha):

1) A partir do equivalente em UEP de 1,28878 (coluna 2), multiplicou-se pelo valor em $\mathrm{R} \$$ da UEP no mês (de $\mathrm{R} \$ 5,12211$ conforme citado na coluna 3) para chegar ao custo unitário de transformação de $\mathrm{R} \$ 6,60 \ldots$ (coluna 4).

2) $\quad$ custo por unidade foi multiplicado pelo número de peças produzidas no mês (500 unidades, conforme mencionado na coluna 5) para apurar o custo total de transformação alocado apenas a esse produto ( $R \$ 3.300,63$ - vide coluna 6).

3) Na última linha da tabela acima foi somada toda a produção física do mês (6.500 unidades) e apurou-se o valor total alocado aos produtos fabricados ( $\mathrm{R} \$ 36.456,63)$. Com isso, todo o custo de transformação foi rateado/distribuído entre os itens produzidos no período.

\subsection{ANÁLISE DA LUCRATIVIDADE DAS LINHAS DE PRODUÇÃO}

O conhecimento do custo de transformação ajuda a analisar a lucratividade do mix comercializado. Nesse sentido, o principal benefício de ter uma planilha que forneça o custo de produção dos itens produzidos é que isso facilita a análise de lucratividade dos segmentos de mercado. No caso desta pesquisa, o levantamento dos dados e a elaboração da planilha pelo método UEP possibilitou fazer a análise do resultado dos produtos conforme exemplificado na Tabela 9.

Tabela 9 - Margem de contribuição unitária e total dos produtos - LINHA 1

\begin{tabular}{|c|c|c|c|c|c|c|}
\hline Descrição & $\begin{array}{c}\text { Preço de } \\
\text { Venda unit R\$ }\end{array}$ & $\begin{array}{l}\text { Tributos sobre } \\
\text { Vendas unit. } \mathrm{R} \$\end{array}$ & $\begin{array}{c}\text { Custo Transf. } \\
\text { Unit. } \mathrm{R} \$\end{array}$ & $\begin{array}{l}\text { MC unit. } \\
\text { em } \mathrm{R} \$\end{array}$ & $\begin{array}{l}\text { Volume } \\
\text { Vendido }\end{array}$ & $\begin{array}{l}\text { MC total } \\
(\mathrm{em} R \$)\end{array}$ \\
\hline Berm. masc. jeans inf. & 5,60 & 0,1910 & 5,1221 & 0,2869 & 1.000 & 286,93 \\
\hline Berm. sarja pt inf. & 5,80 & 0,1978 & 5,6855 & $(0,0833)$ & 500 & $(41,63)$ \\
\hline Calça masc. jeans inf. & 5,70 & 0,1944 & 5,3035 & 0,2021 & 1.000 & 202,12 \\
\hline Calça sarja pt inf. & 6,00 & 0,2046 & 5,9515 & $(0,1561)$ & 1.000 & $(156,13)$ \\
\hline Berm. masc. jeans ad. & 7,00 & 0,2387 & 5,0823 & 1,6790 & 1.000 & $1.679,00$ \\
\hline Berm. sarja pt ad. & 7,20 & 0,2455 & 6,2687 & 0,6858 & 500 & 342,88 \\
\hline Calça masc. jeans ad. & 7,50 & 0,2558 & 5,7195 & 1,5248 & 1.000 & $1.524,78$ \\
\hline Calça sarja pt ad. & 7,65 & 0,2609 & 6,6013 & 0,7879 & 500 & 393,93 \\
\hline \multicolumn{5}{|c|}{ Total } & 6.500 & $4.231,89$ \\
\hline
\end{tabular}

Fonte: elaborada pelos autores.

Inicialmente é interessante ressaltar que o conceito de margem de contribuição utilizado difere do cálculo que geralmente é divulgado na literatura contábil, pois nesta pesquisa foi considerado o custo de transformação para apurar a lucratividade proporcionada pelos produtos abrangidos. Referido procedimento está alinhado ao defendido por Anthony e Govindarajan (2002), visto que os custos de transformação são o principal gasto da empresa na elaboração dos produtos que comercializa e não computá-los distorceria totalmente a análise de lucratividade pretendida. 
Assim, considerando que a "Calça sarja pt ad." é vendida por $\mathrm{R} \$ 7,65$ por peça fabricada, que sobre este valor incide tributação de 3,41\% (SIMPLES-Nacional) e que foi descontado o custo unitário de transformação, a margem de contribuição unitária deste produto foi de $R \$ 0,7879$. Como foram vendidas 500 unidades no mês, a margem de contribuição total deste item chegou a $R \$$ 393,93. Ao fazer o mesmo cálculo para todos os demais produtos da linha "1" se apurou o valor de $\mathrm{R} \$ 4.231,89$ de margem de contribuição total deste segmento no mês da pesquisa.

O mesmo procedimento de avaliação foi realizado com os produtos da linha de produção "2", o que possibilitou a comparação entre as duas linhas, como expresso na Tabela 10.

Tabela 10 - Comparativo entre as linhas de produção

\begin{tabular}{|c|c|c|c|c|c|}
\hline Descrição & Linhas & $\begin{array}{c}\text { Total } \\
\text { Vendas }(\mathrm{R} \$)\end{array}$ & $\begin{array}{l}\% \text { do } \\
\text { Total }\end{array}$ & $\begin{array}{c}\text { Total } \\
\text { MC Total }(\mathrm{R} \$)\end{array}$ & $\begin{array}{l}\% \text { do } \\
\text { Total }\end{array}$ \\
\hline Berm. masc. jeans inf. & L1 & $5.600,00$ & $10,30 \%$ & 286,93 & $3,21 \%$ \\
\hline Berm. sarja pt inf. & L1 & $2.900,00$ & $5,33 \%$ & $(41,63)$ & $-0,47 \%$ \\
\hline Calça masc. jeans inf. & L1 & $5.700,00$ & $10,48 \%$ & 202,12 & $2,26 \%$ \\
\hline Calça sarja pt inf. & L1 & $6.000,00$ & $11,03 \%$ & $(156,13)$ & $-1,75 \%$ \\
\hline Berm. masc. jeans ad. & L1 & $7.000,00$ & $12,87 \%$ & $1.679,00$ & $18,77 \%$ \\
\hline Berm. sarja pt ad. & L1 & $3.600,00$ & $6,62 \%$ & 342,88 & $3,83 \%$ \\
\hline Calça masc. jeans ad. & L1 & $7.500,00$ & $13,79 \%$ & $1.524,78$ & $17,04 \%$ \\
\hline Calça sarja pt ad. & L1 & $3.825,00$ & $7,03 \%$ & 393,93 & $4,40 \%$ \\
\hline TOTAIS DA LINHA 1 & & $42.125,00$ & $77,46 \%$ & $4.231,89$ & $47,31 \%$ \\
\hline Blusa tec. fino inf. & L2 & $2.250,00$ & $4,14 \%$ & 647,52 & $7,24 \%$ \\
\hline Blusa ombro inf. & L2 & $2.300,00$ & $4,23 \%$ & 947,79 & $10,59 \%$ \\
\hline Cam. bás. inf. & L2 & $2.150,00$ & $3,95 \%$ & 975,63 & $10,91 \%$ \\
\hline Cam. peplum div. inf. & L2 & $2.375,00$ & $4,37 \%$ & 849,88 & $9,50 \%$ \\
\hline Vestido tee inf. & L2 & $1.500,00$ & $2,76 \%$ & 673,08 & $7,52 \%$ \\
\hline Vest. Fino c/babado & L2 & $1.680,00$ & $3,09 \%$ & 620,17 & $6,93 \%$ \\
\hline TOTAIS DA LINHA 2 & & $12.255,00$ & $22,54 \%$ & $4.714,06$ & $52,69 \%$ \\
\hline Totais & & $54.380,00$ & $100,00 \%$ & $8.945,94$ & $100,00 \%$ \\
\hline
\end{tabular}

Fonte: elaborada pelos autores.

A linha de produção "1" foi responsável por $\mathrm{R} \$ 42.125,00$ do faturamento mensal, o que representa $77,46 \%$ das vendas do mês pesquisado, que totalizaram $R \$ 54.380,00$. Esse nível de vendas proporcionou margem de contribuição de $R \$ 4.231,89$ (47,31\% do total do mês, que foi de $R \$ 8.945,94)$. Quanto à linha de produção "2", esta teve vendas de $\mathrm{R} \$ 12.255,00$ e acarretou margem de contribuição total de $R \$ 4.714,06$. Assim, participou com $22,54 \%$ do faturamento, mas representou 52,69\% da margem de contribuição obtida pela empresa no período. A partir do exposto, concluiu-se que a linha de produção "2" é a mais interessante porque, mesmo vendendo menos que a linha "1" $(R \$ 12.255,00$ contra $R \$ 42.125,00)$, consegue propiciar margem de contribuição superior ( $R \$ 4.714,06$ contra $R \$ 4.231,89)$.

\section{CONSIDERAÇÕES FINAIS}

O objetivo do estudo foi mensurar o custo de transformação associado a cada produto das duas linhas de produção para conhecer a margem de contribuição fabril desses segmentos. Nesse sentido, os autores consideram que o mesmo foi atingido porque a utilização da planilha de custos pelo método UEP relatada nas seções precedentes permitiu o conhecimento do custo de transformação dos produtos do mix vendido no período. Com isso, ao descontar também a tributação incidente sobre o faturamento da receita proveniente das vendas foi apurada a margem de contribuição (unitária e total) de cada produto, bem como a margem de contribuição total proporcionada pelas duas linhas de produção visadas. Concluiu-se, então, que a Linha "1" foi menos lucrativo que a Linha "2", mesmo que aquela tenha sido responsável por um faturamento quase três vezes superior.

Como possível contribuição do estudo cabe citar a utilização do método UEP em empresa de pequeno porte com a finalidade de conhecer a lucratividade de linhas de produção, uma abordagem que não costuma 
ser encontrada na literatura que discorre sobre métodos de custeio. Além disso, salientou-se a importância da apuração dos custos fabris de forma consistente para fundamentar as avaliações gerenciais acerca do desempenho de segmentos de mercado, de vez que o critério "faturamento" pode levar a decisões equivocadas quanto aos itens a serem priorizados.

No que concerne às limitações associadas ao estudo é pertinente destacar alguns pontos. $\mathrm{O}$ primeiro é que não foi considerado o custo de oportunidade do capital empregado nas duas linhas de produção, que poderia ser relevante e alterar os resultados. O segundo aspecto é que parte dos valores forem determinados com base em estimativa do gestor da empresa, tendo em vista a inexistência de controles internos mais robustos no âmbito da organização em tela. O terceiro ponto a destacar é que foi utilizado o conceito de

\section{REFERENCIAS}

[1] ANTHONY, R. N.; GOVINDARAJAN, V. Sistemas de controle gerencial. São Paulo: Atlas, 2002

[2] ALLORA, V.; OLIVEIRA, S. E. Gestão de custos: metodologia para a melhoria da performance empresarial. Curitiba: Juruá, 2010.

[3] BORNIA, A. C. Análise gerencial de custos: aplicação em empresas modernas. $2^{\underline{a}}$ ed. São Paulo: Atlas, 2009.

[4] CAMBRUZZI, D.; BALEN, F. V.; MOROZINI, J. F. Unidade de esforço de produção (UEP) como método de custeio: implantação de modelo em uma indústria de laticínios. ABCustos Associação Brasileira de Custos, v.4, n.1, p.84-103, 2009 .

[5] GANTZEL, G.; ALLORA, V. Revolução nos custos. Salvador: Casa da Qualidade, 1996.

[6] GIL, A. C. Como elaborar projetos de pesquisa. $4^{\underline{a}}$ ed. São Paulo: Atlas, 2002.

[7] GUIMARÃES FILHO, L. P.; VILSON, B. M.; MARQUES, L. D. R.; FEIL, N. F.; COLOMBO, T. C. Aplicação do método UEP na determinação dos custos de uma empresa de revestimentos cerâmicos. Revista ABCustos. São Leopoldo: Associação Brasileira de Custos, v.11, n.3, p.28-59, 2016

[8] LACERDA, M. S. P. de; SCHULTZ, C. A.; WALTER, F. A aplicabilidade do método das Unidades de Esforço de Produção em uma panificadora: evidências de um estudo de caso. Sistemas \& Gestão, v.12, n.1, p.38-48, 2017.

[9] MARTINS, E.; ROCHA, W. Métodos de custeio comparados: custos e margens analisadas margem de contribuição "fabril", de vez que a empresa não tem gasto com matérias-primas porque estas são fornecidas pelos clientes. Assim, foram considerados somente a tributação incidente sobre o faturamento e os custos de transformação como redutores da receita das vendas no cálculo da lucratividade dos produtos das duas linhas citadas.

Como recomendações para trabalhos futuros é interessante tentar replicar esse tipo de pesquisa comparativa em indústrias de porte maior, com várias linhas de produção e considerar o custo de oportunidade do capital empregado na estrutura física que suporta o processo produtivo. Com isso, além de confrontar os resultados, conhecer-se-iam os resultados das linhas do ponto de vista econômico, ou seja, já descontado o custo do capital investido em prédio, terreno e maquinário.

sob diferentes perspectivas. São Paulo: Atlas, 2010.

[10] PEREIRA, S. I. M. Custeio por atividades $(A B C)$ e unidade de esforço de produção (UEP): similaridades, diferenças e complementaridades. Dissertação (Mestrado). PPGCC. Universidade de São Paulo - USP, 2015.

[11] RICHARDSON, R. J. Pesquisa social: métodos e técnicas. São Paulo: Atlas, 1999.

[12] SLAVOV, T. N. Gestão estratégica de custos: uma contribuição para a construção de sua estrutura conceitual. Tese (doutorado). PPGCC. Faculdade de Economia, Administração e Contabilidade da Universidade de São Paulo FEA/USP, São Paulo, 2013.

[13] SOUZA, M. A. de; DIEHL, C. A. Gestão de custos: uma abordagem integrada entre contabilidade, engenharia e administração. São Paulo: Atlas, 2009.

[14] WERNKE, R., JUNGES, I. Influência da ociosidade fabril no custo unitário do produto: comparativo entre os métodos TDABC e Absorção. Revista de Gestão, Finanças e Contabilidade, v.7, n.3, p. 362-378, 2017

[15] WERNKE, R.; SANTOS, A. P. dos; JUNGES, I.; SCHEREN, G. Comparação do custo fabril apurado pelos métodos Unidades de Esforço de Produção (UEP) e Time-driven Activity-based Costing (TDABC): estudo de caso em linha de produção de frigorífico. Exacta - EP, São Paulo, v. 16, n. 3, 2018.

[16] YIN, R. K. Estudo de caso: planejamento e método. Porto Alegre: Bookman, 2005. 


\section{Gapítulo 18}

\section{MODELOS DE PADRÕES DE QUALIDADE DE FIOS DE ALGODÃO BASEADO EM REDES NEURAIS ARTIFICIAIS QUE RELACIONAM A MATERIA-PRIMA AO PROCESSO DE PRODUCÃO E AO PRODUTO FINAL}

\section{Gilberto Clóvis Antonelli}

\section{Patrícia Lopes da Silva de Araújo}

Rosa Maria de Castro Fernandes Vasconcelos

Resumo: A técnica de Redes Neurais Artificiais (RNAs) é utilizada para a resolução de diversos tipos de problemas característicos da Inteligência Computacional (IC) com a utilização de dados/variáveis relacionadas entre si, cada uma com sua maior ou menor influência na solução de um determinado problema. Neste trabalho utilizam-se dados de uma indústria de produção do fio de algodão que tem como matéria prima a fibra de algodão e seus ajustes no processo. Os dados foram organizados cronologicamente e após a adequação, pode-se determinar as variáveis a serem utilizadas na definição das redes como solução para determinar modelos padrões para a previsão da qualidade do fio. Foram criadas redes neurais do tipo MultiLayer Perceptron e dois tipos de treinamento, o Backpropagation e o Levenberg-Marquardt. Como resultado, obteve-se modelos de padrões de qualidade que a partir dos dados das características das fibras e ajustes das máquinas, resultam na previsão da qualidade do fio a ser produzido.

Palavras chave: Fiação, Redes Neurais Artificiais, Engenharia de Produção. 


\section{INTRODUÇÃO}

Devido à grande quantidade de informações em base de dados, ferramentas computacionais, especialmente os modelos quantitativos de análise de dados, foram requeridas para identificar elementos importantes e necessários para tomada de decisão (PRAHALAD e KRISHNAN, 2008).

A análise das características físicas das fibras constitui um dos pontos fundamentais para o alcance de melhores índices de produção e de qualidade a baixo custo. As características físicas das fibras são ferramentas importantes para o técnico, pois, através delas, ele decide quanto à aprovação ou não da compra da matéria-prima, à sua forma de consumo (misturas programadas), às ajustagens das máquinas e uma série de outras providências correlatas. Para tanto, é necessário medir e avaliar os valores das principais características das fibras, relacionando-os com o sistema de fiar com o produto a elaborar (MARSAL et. al., 1994).

A influência das características da fibra na qualidade final do fio produzido não é simples de ser analisada, porque existem outros fatores externos que determinam essa qualidade, como, por exemplo, a safra, o acondicionamento da matéria-prima (temperatura e umidade), os ajustes das variáveis do processo, a porcentagem de misturas de fibras utilizadas no processo, dentre outros. Portanto, é essencial o desenvolvimento de ferramentas aplicadas ao processo produtivo das indústrias de fio de algodão que auxiliem na decisão da determinação das condições de operação da fábrica, a fim de que esta produza o fio desejado com o algodão disponível. Neste trabalho, é apresentada uma solução com redes neurais artificiais para determinar modelos de padrões de qualidades do fio produzido. Por meio desta solução, o engenheiro da indústria pode simular a produção de um fio, melhorar a qualidade do fio e obter uma constante no processo produtivo com menores índices de quebra e de rupturas.

\section{INDÚSTRIAS DE FIOS}

O Brasil, de acordo com IEMI (2011, apud Souza, 2012), tem 432 empresas de fiação das quais aproximadamente $50 \%$ tem em sua matéria-prima principal o algodão e estão concentradas nas regiões sul, sudeste $e$ nordeste do país. O consumo de matériaprima pelas fiações brasileiras no ano de 2017, segundo ABIT (2017), foi de 1.486.100 toneladas de fibras e filamentos e o consumo de algodão representou aproximadamente $47 \%$ das fibras utilizadas.

Na Figura 1 pode-se observar que o consumo de algodão pelas fiações vem decrescendo ao longo dos últimos cinco anos, entretanto, o algodão é ainda a principal matéria-prima da maioria das fiações brasileiras.

Figura 1 - Consumo de fibras e filamentos em milhares de toneladas

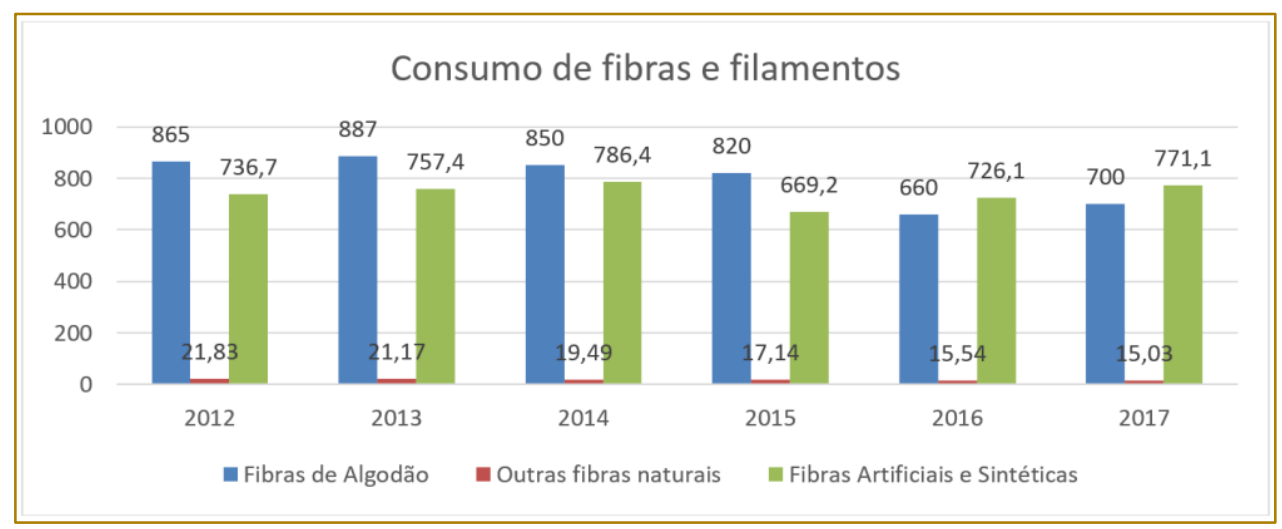

Fonte: ABIT, 2017 


\subsection{PRINCIPAIS CARACTERISTICAS DA FIBRA DO ALGODÃO}

De acordo com Souza et al. (2012), a fibra de algodão é a mais utilizada pelas empresas de fiação brasileira, este predicado se consolida porque o tecido de algodão apresenta característica de conforto e absorção de calor próprio para países de clima tropical.

As características físicas das fibras de algodão são ferramentas importantes e seu conhecimento permite decidir quanto à sua forma de consumo, os ajustes das variáveis do processo e uma série de outras providências correlatas. Para tanto, é necessário medir e avaliar os valores das principais características das fibras, relacionando-os com o sistema de fiar e com o produto a elaborar (ANTONELLI \& NEITZEL, 2015).

Para Rodgers et al. (2012 apud Souza et al., 2012), a fibra de algodão para ser determinada como uma matéria-prima de qualidade deve apresentar características como: Pureza, Maturidade, Comprimento, Umidade, Resistência, Finura e Uniformidade.

As propriedades das fibras de algodão determinam a sua utilização e são da maior importância para os produtores, fiandeiros, acabadores e utilizadores. Esta importância torna-se ainda mais notória quando se leva em conta o processo de produção e o tipo de matéria prima utilizada, que poderão condicionar a produtividade, bem como a qualidade (VASCONCELOS, 1993).

\subsection{PROCESSO DE PRODUÇÃO DO FIO DE ALGODÃO}

O processo de produção do fio de algodão, segundo Vasconcelos (1993), é onde de uma massa desordenada de fibras que se encontram emaranhadas, devido às fortes pressões a que foram sujeitas para que o seu transporte fosse facilitado, consegue-se, através de operações de estiragem e de paralelização, isto é, colocando as fibras paralelas umas em relação às outras com uma determinada secção transversal, obter-se um fio com a secção desejada (título), ao qual é inserida uma certa torção, com o objetivo de Ihe conferir um determinado número de propriedades.

Existem três sistemas diferentes de processos para a produção do fios, fiação penteada, fiação cardada ou convencional e fiação open end. Na Figura 2 estão apresentadas as etapas envolvidas em cada sistema de fiação.

Figura 2 - Etapas dos processos de produção de fios

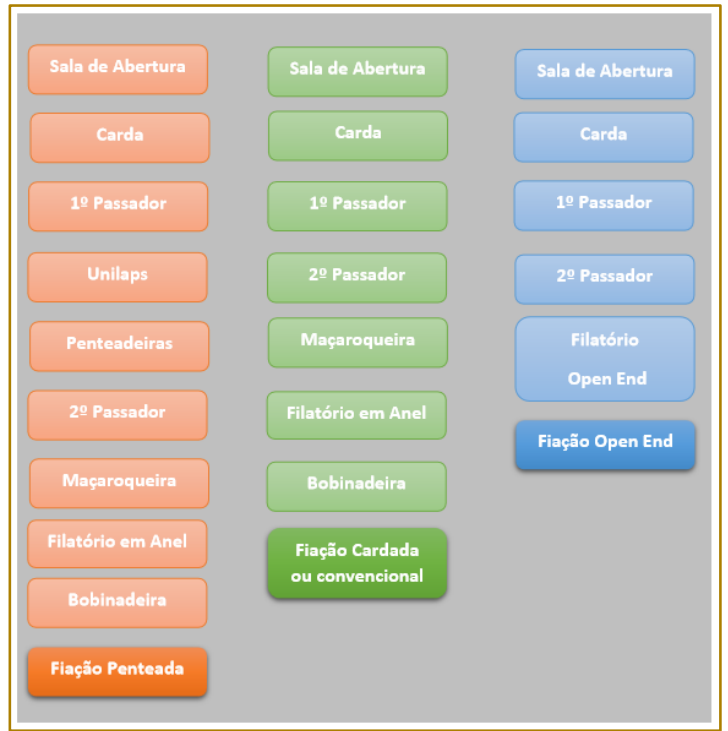

Fonte: Autoria Própria, 2018

De acordo com Araujo \& Castro (1986), os passadores têm como finalidade regularizar o material em massa por unidade de comprimento, corrigindo as irregularidades que as fitas, vindas das cardas ou penteadeira, apresentam, conforme a linha de produção seja cardada ou penteada. Isto é, melhorar a uniformidade deste material 
através dos processos de dublagem e estiragem, minimizando as irregularidades remanescentes do processo anterior.

Na sequencia da linha de produção cardada, tem-se a maçaroqueira onde, segundo Araujo \& Castro (1986), a alimentação se faz pelas fitas armazenadas em potes provenientes dos laminadores e que ao passar pelo sistema de torção, a matéria sai em forma de uma mecha enrolada numa bobina. A última etapa do processo cardado ocorre no filatório, onde após a estiragem e torção o fio é enrolado ao pavil.

É importante observar que as características físicas das fibras são fatores determinantes do tipo de tecnologia a utilizar (ARAUJO \& CASTRO, 1986).

\subsection{QUALIDADE DO FIO DE ALGODÃO}

O termo qualidade é utilizado frequentemente como sinónimo de produto bom, embora a definição clássica seja a capacidade de satisfazer as necessidades de aplicabilidade ou o grau de conformidade com os requisitos do cliente. Também nas indústrias têxteis, a qualidade desempenha um papel vital devido a uma variedade de produtos intermediários e finais com especificações e padrões para aplicações diversificadas. Diante deste fato, o processo empregado e a matéria-prima utilizada têm um papel fundamental, pois sabe-se que a qualidade final do fio é afetada diretamente por eles (CHATTERJEE \& CHAKRABORTY, 2017).

A resistência e alongamento do fio são duas das suas características fundamentais, sendo normalmente utilizadas como índices de qualidade, isto devido ao fato de a suas grandezas serem influenciadas por uma combinação de fatores, tais como as propriedades das fibras, a estrutura dos fios e parâmetros inerentes ao processo. Uma das explicações tradicionais do fenómeno de variações da resistência em relação à torção dada ao fio é baseada na combinação de fatores como o deslizamento das fibras e a própria resistência da fibra. Além destas características, outro dos fatores a levar em consideração é o efeito das próprias fibras ao serem enroladas ao longo do seu eixo, isto é, com a inserção da torção, a qual influencia a resistência e o alongamento do fio (VASCONCELOS, 1993).

\subsection{MODELOS DE PADRÕES DE QUALIDADE DO FIO}

Os modelos de padrões de qualidade do fio, são originados a partir do relacionamento de dados das fibras de algodão e da linha de produção do fio com a técnica das Redes Neurais Artificiais, resultando em algoritmos lógicos computacionais. A representação gráfica deste procedimento pode ser observado na Figura 3.

Figura 3 - Etapas para a determinação dos modelos de padrões de qualidade do fio

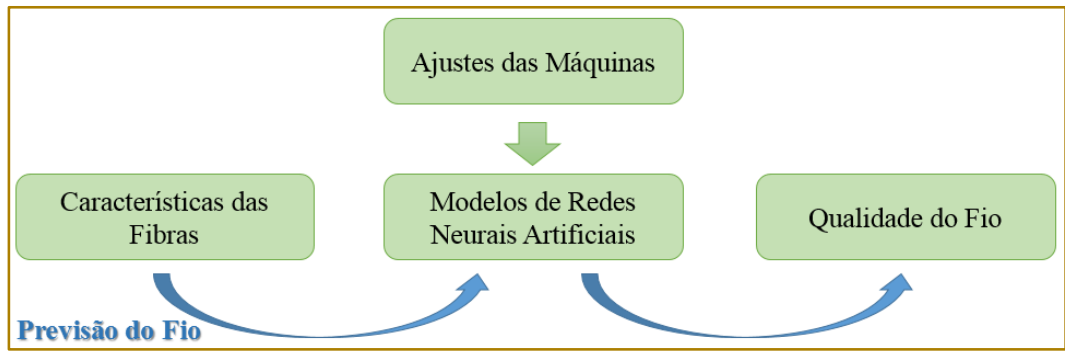

Fonte: Autoria Própria, 2018

Esses algoritmos computacionais podem ser utilizados para a previsão da qualidade do fio utilizando informações das fibras em estoque da empresa e os ajustes das máquinas em operação, auxiliando os engenheiros na Programação e Controle da Produção.

\section{REDES NEURAIS ARTIFICIAIS}

Computação por Redes Neurais Artificiais (RNA) emergiu na última década como um poderoso paradigma que tem encontrado aplicações em quase todos os ramos da engenharia. $O$ desenvolvimento de RNA foi inspirado pelos mecanismos pelos quais neurônios biológicos reais trabalham no cérebro humano. O processo decisório do 
cérebro é emulado por uma rede artificial de elementos de processamento (PE) ou neurônios. Uma rede devidamente treinado pode prever a resposta de saída para um maior grau de precisão do que os modelos matemáticos ou estatísticos convencionais (MAJUMDAR, MAJUMDAR \& SARKAR, 2004).

Antonelli \& Neitzel (2015), afirmam que, basicamente uma rede neural se assemelha ao cérebro em dois pontos: o conhecimento é obtido através de etapas de aprendizagem, e pesos sinápticos são usados para armazenar o conhecimento. Sinapse é o nome dado à conexão existente entre neurônios. Às conexões são atribuídos valores, que são chamados de pesos sinápticos. Isso deixa claro, que as redes neurais artificiais têm em sua constituição uma série de neurônios artificiais (ou virtuais) que serão conectados entre si, formando uma rede de elementos de processamento, conforme mostrado na Figura 4.

Figura 4 - Exemplo de uma Rede Neural Multi Layer Percepton (MLP)

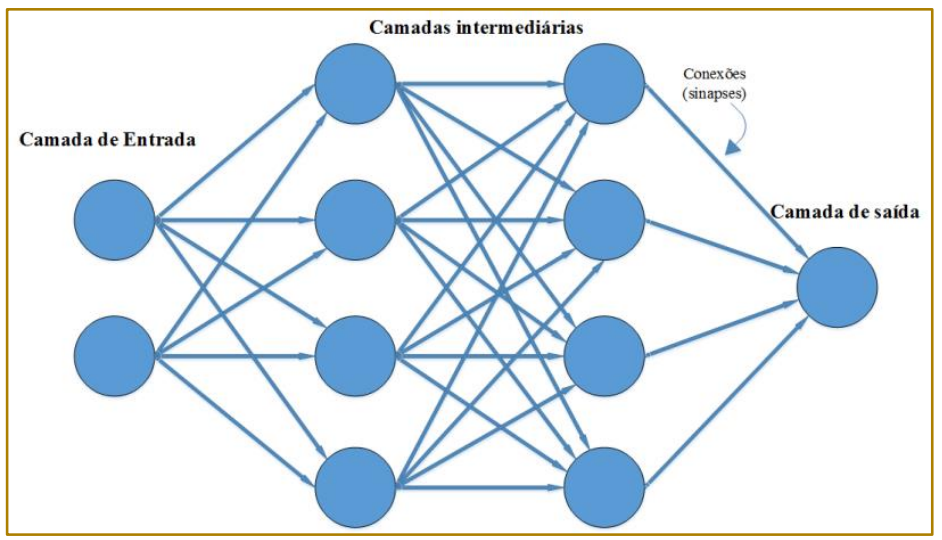

Fonte: ANTONELLI \& NEITZEL, 2015

O potencial e a flexibilidade do cálculo baseado em redes neurais artificiais vêm da criação de conjuntos de neurônios que estão interligados entre si conforme mostra a Figura 2 , que pode ter a notação definida como MLP:2:2-4-4-1:1, uma rede Multi Layer Perceptron, com 2 neurônios na entrada, 1 neurônio de saída e duas camadas intermediárias com 4 neurônios. Esse paralelismo de elementos com processamento local cria a "inteligência" global da rede (ANTONELLI \& NEITZEL, 2015).

$$
E=\frac{1}{2} \sum\left(T_{r}-O_{r}\right)^{2}
$$

onde $E$ é o vetor de erro, $\operatorname{Tr}$ e Or denotam a saída desejada e a saída prevista respectivamente, no nó de saída $r$.

\subsection{TREINAMENTO BACK-PROPAGATION}

Conforme descrito por Majumbar, Majumbar \& Sarkar (2004), o algoritmo back-propagation (também conhecido como regra delta generalizada) é o método de treinamento mais comumente usado para os modelos de RNA. A regra delta generalizada basicamente realiza uma descida de gradiente na superfície de erro. O treinamento ocorre em duas fases, a saber, a forward e a backward. $\mathrm{Na}$ fase forward, um conjunto de dados é apresentado à rede como entrada e seu efeito é propagado, em estágios, através de diferentes camadas da rede. Finalmente, um conjunto de saídas é produzido. O cálculo do vetor de erro é feito a partir da diferença entre a saída real e a prevista de acordo com a Equação 1:

$\mathrm{Na}$ fase backward, este sinal de erro é propagado para trás na rede neural, e os pesos sinápticos são ajustados para que o sinal de erro diminua a cada processo de iteração, e o modelo de rede neural se 
aproxime cada vez mais da saída desejada. As correções necessárias nos pesos

$$
\Delta w_{p q(n)}=-\eta\left[\frac{\partial E}{\partial w_{p q(n)}}\right]
$$

onde $w_{p q(n)}$ é o peso que conecta os neurônios $\mathrm{p}$ e q na enésima iteração; $\Delta w_{p q(n)}$ é a correção aplicada ao $w_{p q(n)}$ na enésima iteração e $\eta$ é uma constante conhecida como taxa de aprendizado. sinápticos são realizadas pela regra delta, que é expressa na Equação 2.

\subsection{TREINAMENTO LEVENBERG-MARQUART}

Em uma RNA de Múltiplas Camadas, o algoritmo de Levenberg-Marquardt (LM) utiliza uma aproximação pelo método de Newton, de forma a minimizar a função erro no decorrer do processo de aprendizagem; esta aproximação é obtida a partir do método de Gauss-Newton modificado. A atualização dos pesos através do método de Gauss-Newton é realizada utilizando a Equação 3 (HAYKIN, 2009):

$$
w_{(n+1)}=w_{(n)}-\left(J_{(n)}^{T} J_{(n)}-\delta I\right)^{-1} J_{(n)}^{T} e_{(n)}
$$

onde $n$ é o número da iteração; $w(n)$ é o peso na enésima iteração; $J(n)$ é a matriz jacobiana do vetor do erro em relação ao vetor peso na enésima iteração; $\delta$ é uma constante positiva pequena escolhida para assegurar que $(J(n) T J(n)+\delta I)$ seja definida positivamente para todo $n$ e e(n) é o erro na enésima iteração.

\section{METODOLOGIA E DESENVOLVIMENTO}

A Metodologia é a aplicação de procedimentos e técnicas que devem ser observados para construção do conhecimento, com o propósito de comprovar sua validade e utilidade nos diversos âmbitos da sociedade (PRODANOV \& FREITAS, 2013).

Segundo Silva e Menezes (2005), pesquisar significa "procurar respostas para indagações propostas", e que para Gil (2002), é um "processo formal e sistemático de desenvolvimento do método científico", ou seja, a pesquisa promove o descobrimento de respostas para problemas com o auxílio de procedimentos científicos.

Este trabalho é classificado como uma pesquisa de natureza aplicada, que tem por objetivo a geração de conhecimento para a aplicação prática e dirigido à solução de problemas específicos, levando em consideração as verdades e os interesses locais. Em relação à forma de abordagem do problema, foi utilizada a metodologia de pesquisa quantitativa pois, trata-se de uma pesquisa que traduz em números as opiniões e informações coletadas, com o intuito de classificá-las e analisá-las. Já em relação aos seus objetivos, a pesquisa pode ser classificada como exploratória, pois têm como objetivo principal o aprimoramento de ideias ou a descoberta de intuições.

O presente trabalho se dividiu em sete etapas distintas: coleta dos dados, adequação dos dados, análise dos dados, definição das redes neurais, treinamento das redes, testes e validação.

\subsection{COLETA, ADEQUAÇÃO E ANÁLISE DOS DADOS}

Para o desenvolvimento desta pesquisa, se utilizou os dados de produção por processo cardado, conforme descrito no item 2.2, de uma fiação brasileira que disponibilizou todo o material desde a matéria-prima, ajustes de máquinas e do fio produzido nas safras de 2014/2015, 2015/2016 e 2016/2017. Após a coleta e importação para o ambiente computacional, se exportou os mesmos para um banco de dados para serem relacionados. Após esse relacionamento cronologicamente, a análise se baseou em determinar as variações dos valores das propriedades, e os resultados obtidos estão representados na Tabela 1 para as características das fibras, na 
Tabela 2 para os ajustes do processo e na Tabela 3 para as qualidades do fio produzido.

Com os valores médios, o desvio padrão e o coeficiente de variação, pode se determinar as variáveis mais influentes na construção dos padrões de qualidade, e com os valores mínimos e máximos se determinou os limites de aplicabilidade destes padrões.

Tabela 1 - Valores apurados dos dados das caracteristicas das fibras

\begin{tabular}{|c|c|c|c|c|c|c|c|c|c|c|c|}
\hline Propriedade & $\begin{array}{l}\text { COM } \\
(\mathrm{mm})\end{array}$ & $\begin{array}{l}\text { UNI } \\
(\%)\end{array}$ & $\begin{array}{c}\text { MIC } \\
(\mu \mathrm{g} / \mathrm{pol} 2)\end{array}$ & $\begin{array}{c}\text { RES } \\
\text { (gf/tex) }\end{array}$ & $\begin{array}{l}\text { ALO } \\
(\%)\end{array}$ & TRC & $\begin{array}{l}\text { TRA } \\
(\%)\end{array}$ & $\begin{array}{l}\text { LFG } \\
(\%)\end{array}$ & $\begin{array}{l}\mathrm{MR} \\
(\%)\end{array}$ & $\begin{array}{l}\text { SFI } \\
(\%)\end{array}$ & $\begin{array}{l}\mathrm{MOI} \\
(\%)\end{array}$ \\
\hline Média & 29,1 & 81,6 & 4,0 & 30,7 & 6,6 & 12,3 & 0,2 & 2,5 & 0,9 & 9,1 & 7,1 \\
\hline Desvio Padrão & 0,31 & 0,49 & 0,13 & 0,88 & 0,06 & 4,66 & 0,06 & 0,47 & $\begin{array}{c}0,0 \\
1\end{array}$ & $\begin{array}{c}0,4 \\
4\end{array}$ & 0,60 \\
\hline CV & 1,07 & 0,60 & 3,25 & 2,87 & 0,91 & 37,89 & 30,00 & 18,80 & $\begin{array}{c}1,1 \\
1\end{array}$ & $\begin{array}{c}4,8 \\
4\end{array}$ & 8,45 \\
\hline Mínimo & 28,8 & 81,1 & 3,9 & 29,8 & 6,5 & 7,6 & 0,2 & 2,0 & 0,9 & 8,6 & 6,5 \\
\hline Máximo & 29,4 & 82,1 & 4,1 & 31,6 & 6,7 & 17,0 & 0,3 & 3,0 & 0,9 & 9,5 & 7,7 \\
\hline
\end{tabular}

Fonte: Autoria Própria, 2018

Conforme apresentado na Tabela 1, utilizouse onze propriedades que caracterizam as fibras utilizadas no processamento do fio produzido.

Tabela 2 - Valores apurados dos dados dos ajustes das máquinas.

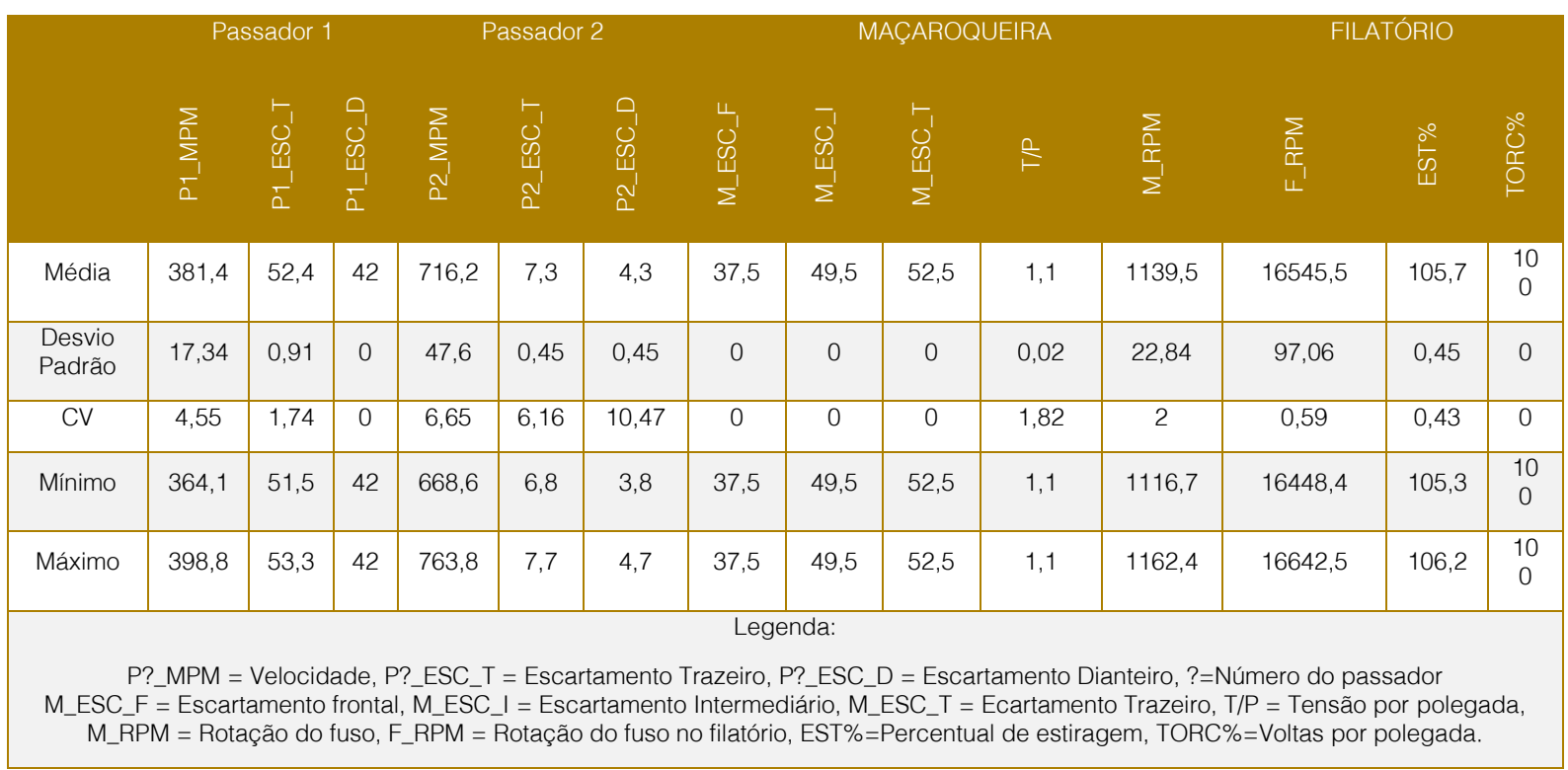

Fonte: Autoria Própria, 2018

Na Tabela 2 se observa os quatorze parâmetros dos ajustes das máquinas existentes no processo que foram utilizados para a produção dos fios em estudo. 
Tabela 3 - Valores apurados dos dados da qualidade do fio.

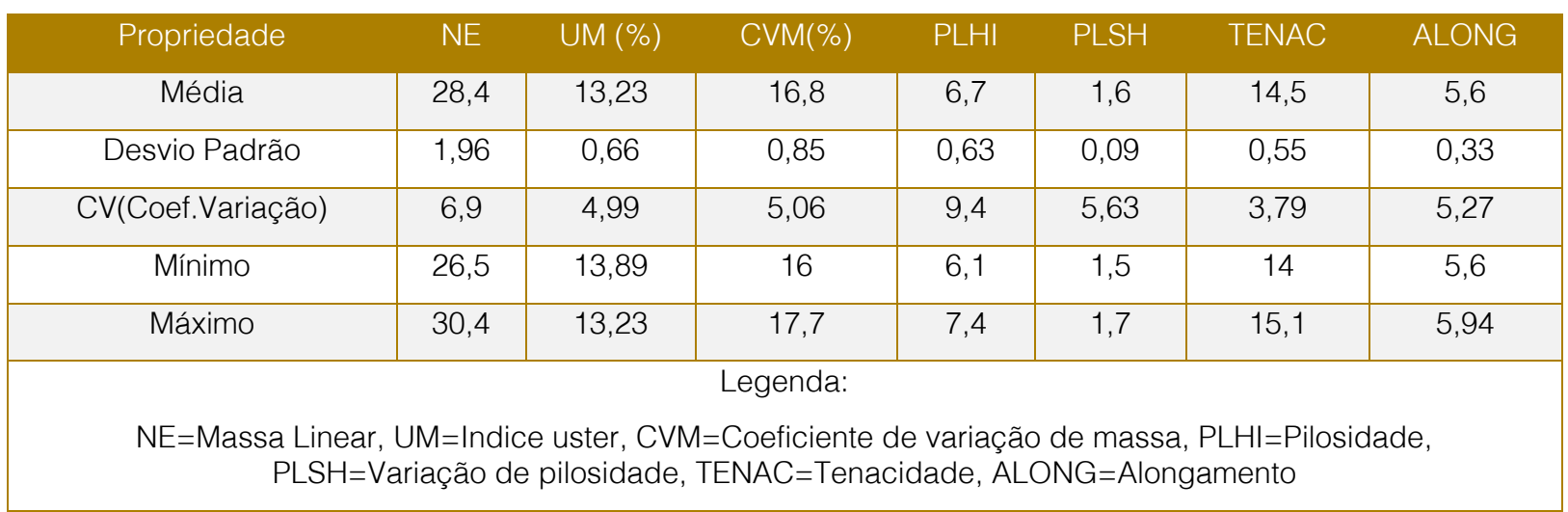

Fonte: Autoria Própria, 2018

Os sete parâmetros apresentados na Tabela 3 correspondem aos padrões de qualidade determinados por meio de modelos computacionais baseados em redes neurais artificiais.

\subsection{DEFINIÇÃO, TREINAMENTO E TESTES DAS REDES NEURAIS ARTIFICIAIS}

Para a definição das redes neurais artificiais utilizou-se o software SNN - STATISTICA: NEURAL NETWORKS®, O qual oferece grande flexibilidade para definição de arquiteturas e treinamento de redes. Com o recurso IPS (Inteligent Problem Solve), existente no SNN, definiram-se as estruturas de redes a serem treinadas. O IPS é uma ferramenta sofisticada que ajuda a criar e testar redes neurais para problemas de análise e predição de dados. Projeta um número de redes para resolver o problema e seleciona aquelas com melhores resultados, baseando-se em análises de desempenho da rede.

O SNN divide o conjunto de dados em três subconjuntos: os casos para treinamento, os casos para seleção e os casos para teste. Essa divisão é feita de forma randômica, na proporção-padrão de 2:1:1, ou seja, para cada dois casos de treinamento temos um caso para a seleção e um caso para o teste. A performance de uma rede, no sistema SNN, é realizada por meio de índices (erros) obtidos com os subconjuntos de treinamento, de seleção e de teste. Esses índices são determinados pela relação entre os desviospadrão do residual (diferença entre o valor desejado e o determinado pela rede) e os desvios-padrão dos dados observados de saída. Na Tabela 4 tem-se os modelos determinados para cada qualidade do fio, bem como os erros calculados durante as etapas de seleção e treinamento, e os tipos de treinamentos utilizados.

Tabela 4 - Modelos de qualidade para o processamento de fios cardados

\begin{tabular}{|c|c|c|c|c|}
\hline Qualidade & Modelo & $\begin{array}{l}\text { Erro durante } \\
\text { seleção }\end{array}$ & $\begin{array}{l}\text { Erro após } \\
\text { Treino }\end{array}$ & Treinamento/Membros \\
\hline NE & MLP 8:8-7-1:1 & 0,59 & 0,23 & BP1000,LM1000 \\
\hline UM & MLP 25:25-26-1:1 & 0,47 & 0,10 & BP200,LM500,BP100 \\
\hline CVM & MLP 25:25-30-1:1 & 1,00 & 0,21 & BP100,BP100,LM500,BP100 \\
\hline PLHI & MLP 25:25-28-1:1 & 0,54 & 0,09 & BP100,LM500 \\
\hline PLSH & MLP 25:25-54-1:1 & 0,46 & 0,08 & BP100,LM500,BP100,LM500,BP100 \\
\hline TENAC & MLP 25:25-131-1:1 & 0,41 & 0,07 & BP100,LM500 \\
\hline ALONG & MLP 25:25-61-1:1 & 0,41 & 0,07 & BP1000,LM500,BP100,LM2500 \\
\hline \multicolumn{5}{|c|}{ Legenda: } \\
\hline \multicolumn{5}{|c|}{$\begin{array}{c}\text { NE=Massa Linear, UM=Indice uster, } C V M=\text { Coeficiente de variação de massa, } P L H I=P i l o s i d a d e, \\
\text { PLSH=Variação de pilosidade, TENAC=Tenacidade, ALONG=Alongamento }\end{array}$} \\
\hline \multicolumn{5}{|c|}{$\mathrm{BP}=$ BackPropagation, LM= Levenberg-Marquart, =Número de iterações } \\
\hline
\end{tabular}


Na Tabela 4 tem-se uma representação de cada modelo na forma MLP E:E-I-S:S, e exemplificando com o modelo MLP 8:8-7-1:1 do NE, trata-se de uma rede MultiLayer Perceptron, com 8 variáveis de entrada, 1 camada intermediária de 7 neurônios e 1 neurônio de saída.
No processo de treinamento das redes neurais utilizou-se como indicador de melhora nas iterações o coeficiente de correlação entre os valores Observados (corretos) e os valores Previstos (determinados pela rede). Assim, na Tabela 5 tem-se um comparativo desses valores antes e depois do treinamento da rede.

Tabela 5 - Coeficiente de Correlação entre os valores Observados e Previstos das qualidades do fio

\begin{tabular}{|c|c|c|c|c|c|c|c|}
\hline & \multicolumn{7}{|c|}{ Qualidade do fio } \\
\hline Etapa & NE & UM & CVM & PLHI & PLSH & TENAC & ALONG \\
\hline ANTES DO TREINAMENTO & 0,7935 & 0,6361 & 0,6935 & 0,6350 & 0,4851 & 0,6516 & 0,4951 \\
\hline APÓS O TREINAMENTO & 0,8056 & 0,8806 & 0,8649 & 0,8448 & 0,8884 & 0,9121 & 0,9142 \\
\hline
\end{tabular}

Fonte: Autoria Própria, 2018

Uma análise gráfica da correlação entre os valores Observados e os valores Previstos pela rede neural do modelo da qualidade
Alongamento (ALONG) está apresentada na Figura 5, as demais representações estão apresentadas no Apêndice deste trabalho.

Figura 5 - Correlação entre valores Observados e Previstos d a qualidade Alongamento Antes do treinamento Após o treinamento
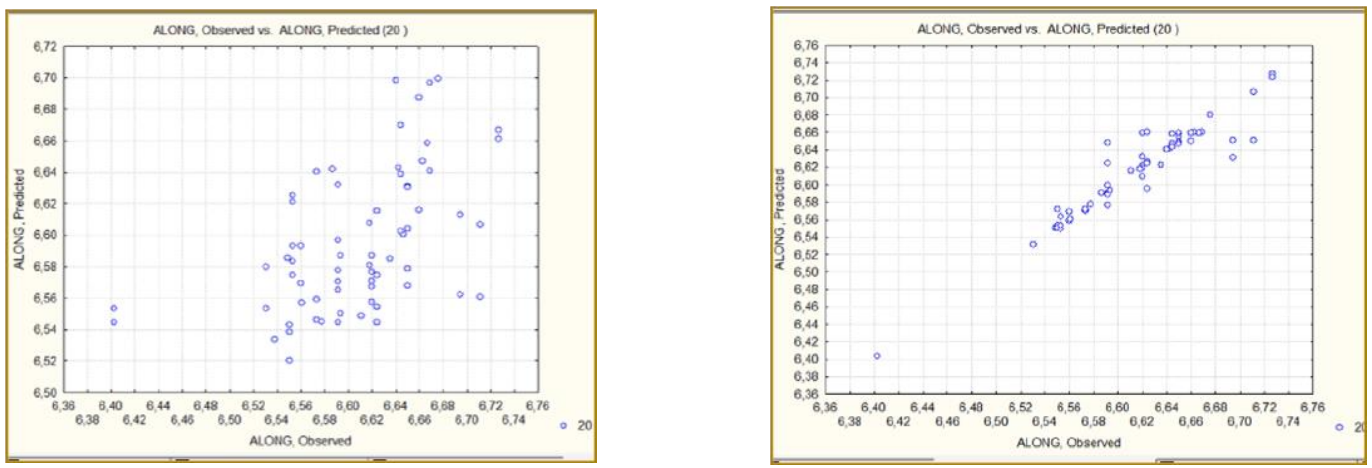

Fonte: Autoria Própria, 2018

\subsection{TESTES E VALIDAÇÃO DOS MODELOS DE PADRÕES DE QUALIDADE}

Após o treinamento da rede, passou-se então para a fase de testes utilizando cases que foram previamente excluídos na fase do treinamento. Esses cases difere-se entre si para cada qualidade do fio determinada. Para avaliação dos resultados dos testes utilizou-se o erro percentual (E) entre os valores

$$
h=t_{n-1,1-\alpha / 2} \frac{s}{\sqrt{n}}
$$


onde temos que $\mathrm{h}$ representa o semi-intervalo de confiança a 1- $\alpha$, S é o desvio padrão da amostra, $n$ é o número de amostragens e tn$1,1-\alpha / 2$ é o valor tabelado de t-student para $n$ 1 graus de liberdade e 1- $\alpha$ o nível de confiança. Assim, tem-se que o intervalo de confiança é dado por [E-h, E+h] para o valor do erro percentual de cada modelo. Determinou-se com um nível de confiança de $\alpha=95 \%$ os intervalos de confiança apresentados na Tabela 6.

Tabela 6 - Erro Médio Percentual do Modelos de Qualidade para o processamento de fios cardados

\begin{tabular}{|c|c|c|c|c|c|c|}
\hline \multirow{2}{*}{ Qualidade } & \multirow{2}{*}{$\begin{array}{l}\text { Número } \\
\text { de cases }\end{array}$} & \multirow{2}{*}{ t-student } & \multirow{2}{*}{$\begin{array}{c}\text { Erro Médio } \\
\text { Percentual } \\
\quad(\%)\end{array}$} & \multirow{2}{*}{$\begin{array}{c}\text { Desvio } \\
\text { Padrão do } \\
\text { Erro Médio } \\
\quad(\%)\end{array}$} & \multicolumn{2}{|c|}{$\begin{array}{l}\text { Intervalo de confiança } \\
\text { do Erro (\%) }\end{array}$} \\
\hline & & & & & $\begin{array}{l}\text { Limite } \\
\text { Inferior }\end{array}$ & $\begin{array}{l}\text { Limite } \\
\text { Superior }\end{array}$ \\
\hline NE & 10 & 1,81246 & 2,28 & 3,92 & 0,03 & 4,52 \\
\hline UM & 10 & 1,81246 & 2,46 & 1,65 & 1,50 & 3,41 \\
\hline CVM & 10 & 1,81246 & 3,48 & 2,77 & 1,87 & 5,08 \\
\hline PLHI & 10 & 1,81246 & 4,62 & 2,98 & 2,89 & 6,34 \\
\hline PLSH & 9 & 1,83311 & 2,40 & 2,31 & 1,06 & 3,74 \\
\hline TENAC & 10 & 1,81246 & 2,12 & 1,67 & 1,15 & 3,08 \\
\hline ALONG & 8 & 1,85955 & 4,21 & 3,30 & 2,27 & 6,15 \\
\hline
\end{tabular}

Fonte: Autoria Própria, 2018

Os intervalos de confiança representam os limites de erros obtidos pelos modelos de padrões de qualidade, por exemplo, tem-se 95\% de confiança que o erro percentual do modelo de padrão de qualidade UM, está entre 1,5 e $3,41 \%$, quando o mesmo é utilizado para prever sua propriedade.

\section{DISCUSSÕES E CONCLUSÕES}

Os resultados apresentados nos testes e validação demonstram que os modelos de padrão de qualidade obtidos podem ser utilizados para prever a qualidade de um fio de algodão por processo de produção cardado com erros percentuais inferiores a 10\%. Entretanto, os modelos padrões de qualidade apresentados estão limitados ao uso pelos valores das variáveis apresentados no item 4.1, valores mínimos e máximos, e à qualidades de fios obtidos por processamento cardado.

A grande dificuldade de obtenção dos padrões de qualidade por meio de redes neurais artificiais reside na definição de sua estrutura e seu treinamento, e seleção dos dados de entrada uma vez que os mesmos devem conter informações suficientes para que o sistema neural consiga detectar a correlação entre a entrada e a saída.

Finalmente, o grande benefício do desenvolvimento deste trabalho foi a inclusão da palavra simulação no cotidiano da indústria em estudo. Os engenheiros responsáveis pela produção possuem muito conhecimento prático, tomam decisões baseadas em conhecimentos anteriores, e este trabalho vem contribuir para um bom desenvolvimento do trabalho desses profissionais.

\section{REFERÊNCIAS}

[1] ABIT - ASSOCIAÇÃO BRASILEIRA DA INDÚSTRIA TÊXTIL. Consumo industrial de Fibras e Filamentos - (1970-2017). Disponível em: $<$ http://www.abit.org.br/cont/dados-comercioexterior>. Acesso em: 24/09/2018.
[2] ANTONELLI, G. C.; NEITZEL, I. Aplicação de redes neurais artificiais na indústria de fios de algodão - determinação do índice de fibras imaturas. Revista Gestão Industrial. ISSN 18080448. v. 011, n. 02: p. 87-105, 2015. D.O.I.:10.3895/gi.v11n2.2662 
[3] ARAUJO, M.; CASTRO, E. M. M. Manual de Engenharia Têxtil. Lisboa: Fundação Calouste Gulbenkian. 694 p, 1986.

[4] CHATTERJEE, P.; CHAKRABORTY, S. Development of a meta-model for the determination of technological value of cotton fiber using design of experiments and the TOPSIS method. Journal of Natural Fibers. Series E. v. 98. 2017.

[5] GIL, A. C. Como elaborar projetos de pesquisa. São Paulo: Atlas, 2002. 176p.

[6] HAYKIN, S. Neural Networks: A Comprehensive Foundation. 3. ed. Mc Master University Hamilton Ontario, Canada: Prentice Hall, 2009. 906p.

[7] MAJUMDAR, A.; MAJUMDAR, P. K.; SARKAR, B. Selecting cotton bales by spinning consistency index and micronaire using artificial neural networks. AUTEX Research Journal, v. 4, n.1, 2004.

[8] MARSAL, F.; OKUDA, K.; TONEU, J. M.; YAMASAKI, S. S. Parametría de hilos. Barcelona: Terrassa, Editions UPC, 1994.
[9] PRODANOV, C. C.; FREITAS, E. C. Metodologia do trabalho científico: métodos e técnicas da pesquisa e do trabalho acadêmico. 2 . ed. Novo Hamburgo: Feevale, 2013.

[10] PRAHALAD, C. K.; KRISHNAN, M. S. A nova era da inovação: a inovação focada no relacionamento com o cliente. Rio de Janeiro: Elsevier, 2008.

[11] SILVA, E. L.; MENEZES, E. M. Metodologia da Pesquisa e Elaboração de Dissertação. 4a Edição. Florianópolis: UFSC, 2005.

[12] SOUZA, F. A. de; KACHBA, Y. R.; HATAKEYAMA, K.; DIAS, M. C. Rastreabilidade e identificação de matéria-prima: estudo de caso em uma indústria de fios. XXXII ENCONTRO NACIONAL DE ENGENHARIA DE PRODUCAO. Bento Gonçalves/RS. Brasil. 2012.

[13] VASCONCELOS, R. M. de C. F. Contribuição à aplicação de técnicas de inteligência artificial na tecnologia da fiação. $231 \mathrm{f}$. Tese (Doutorado) - Programa Doutoral da Escola de Engenharia da Universidade do Minho, Universidade do Minho, Guimarães/Portugal, 1993. 
APÊNDICE

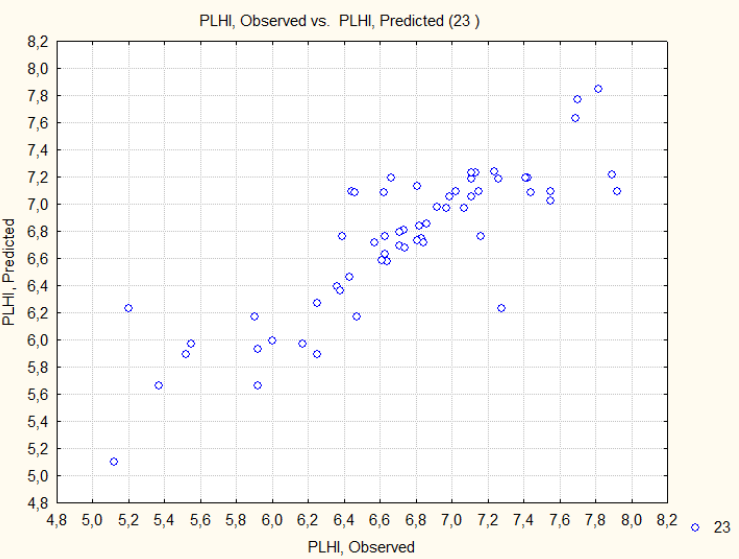

Correlação entre valores Observados e Previstos da qualidade do PLHI

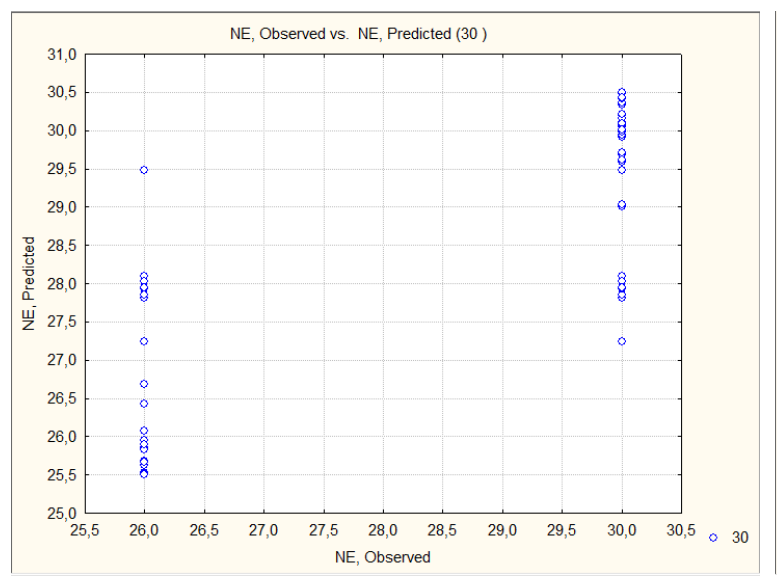

Correlação entre valores Observados e Previstos da qualidade do NE

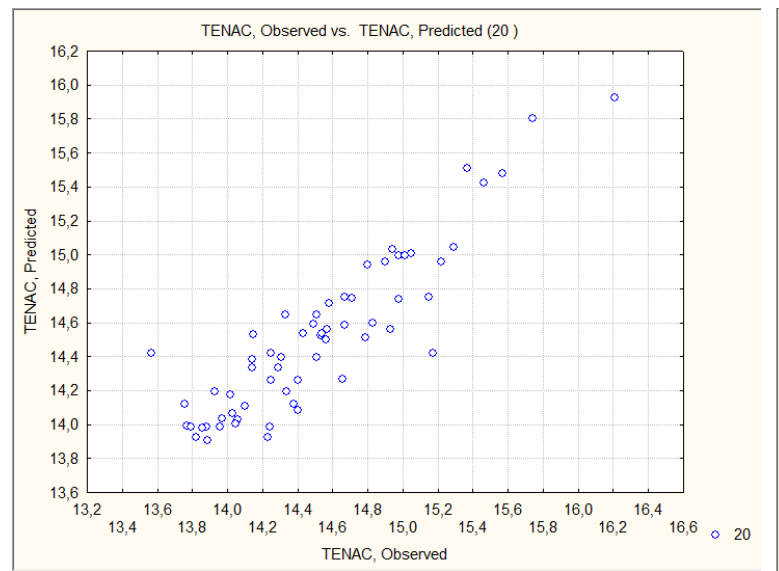

Correlação entre valores Observados e Previstos da qualidade da TENAC

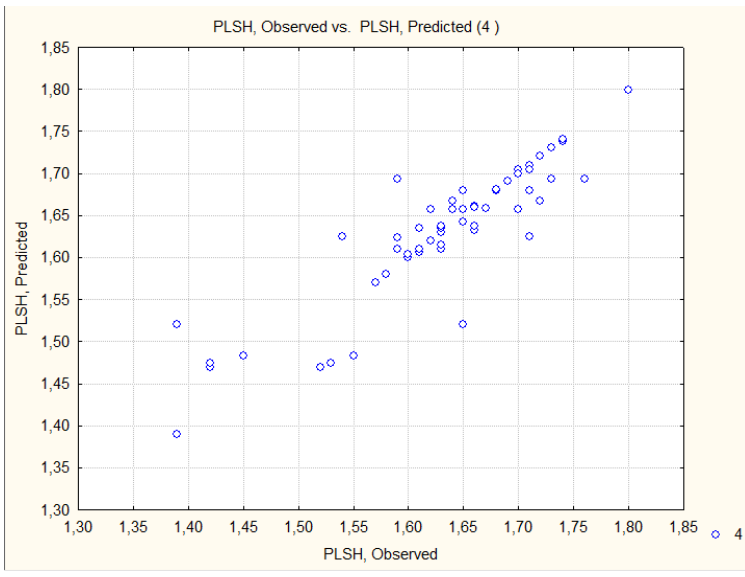

Correlação entre valores Observados e Previstos da qualidade do PLSH

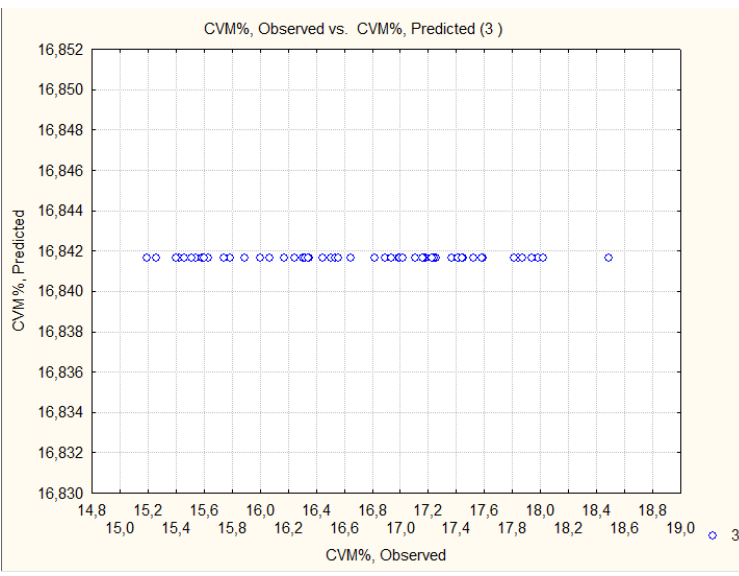

Correlação entre valores Observados e Previstos da qualidade do CVM\%

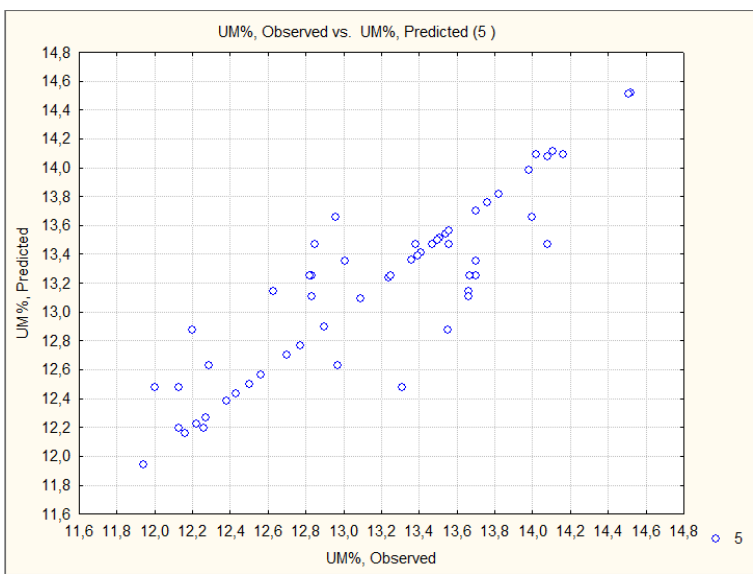

Correlação entre valores Observados e Previstos da qualidade do UM\% 


\section{Gapítulo 19}

\section{ELABORACÃO DE REDE PERT/CPM NO PROCESSO DE CONFECÇÃO DE CAMISAS: UM ESTUDO DE CASO}

Andressa Raquel Weber

Andressa Strey

Ivete Linn Ruppenthal

Resumo: Para que as empresas possam se manter competitivas, torna-se essencial o cumprimento de prazos de entrega dos pedidos e, o adequado gerenciamento das atividades que envolvem seus processos produtivos, auxilia nesta questão. Diante da importância deste tema, foram aplicadas as técnicas PERT/CPM em uma indústria de camisas, localizada no noroeste do Rio Grande do Sul, com o objetivo de elaborar a rede PERT/CPM para estimar o tempo de confecção de camisas, evitando atrasos na entrega dos pedidos. Quanto a metodologia, trata-se de uma pesquisa descritiva, explicativa e aplicada, pois tem como base um estudo teórico, com posterior estudo prático. A pesquisa possui caráter documental caracterizando-se como estudo de caso. Para a coleta de dados foram utilizadas as técnicas de observação e entrevistas informais, para obter informações acerca dos tempos e atividades envolvidas nos processos. A análise de dados se deu por meio da análise de conteúdo, para descrever os resultados de forma objetiva e sistemática. O estudo é embasado através de análise da sequencia de atividades e suas dependências e, posterior definição do caminho crítico, por meio de rede. Como resultados, apresenta-se qual é o caminho de atividades mais longo, onde a demanda de tempo é maior, para que a empresa possa conhecer qual é o gargalo da produção, bem como, realizar um planejamento de otimização do processo referente ao mesmo. Através da análise da rede foi possível identificar o tempo máximo para a confecção de uma camisa, podendo assim estimar o tempo dos lotes e evitar atrasos nas entregas.

Palavras Chave: PERT; CPM; Confecção. 


\section{INTRODUÇÃO}

Diante da acirrada concorrência do mercado, o cumprimento dos prazos de entrega é fundamental para as empresas se manterem competitivas e fidelizar seus clientes. Neste sentido, as redes PERT/CPM auxiliam no gerenciamento das atividades envolvidas em determinado projeto, possibilitando estimar o tempo de conclusão do mesmo, a fim de auxiliar no adequado gerenciamento das atividades envolvidas no processo.

O método PERT/CPM possibilita encontrar 0 caminho crítico, ou seja, o tempo máximo que o produto pode demorar para estar concluído. A fim de conhecer e demonstrar este método, o presente trabalho apresenta um estudo de caso no processo de fabricação de camisas. O objetivo deste estudo é elaborar a rede PERT/CPM para estimar o tempo de confecção de camisas, evitando atrasos na entrega dos pedidos. Avila (2010) recomenda a aplicação desta metodologia, devido a facilidade de integrar e correlacionar as atividades de planejamento, coordenação e controle.

Foram adotados como base, estudos realizados por Panta, Barbosa, Eckardt e Silva (2015) em uma empresa de confecção. O objetivo deste estudo visava sequenciar as atividades do planejamento, com posterior definição das atividades críticas e construção da rede deste caminho. Este trabalho apresentou uma alternativa viável para a empresa, tornando possível o conhecimento do tempo total de fabricação do produto e consequentemente o tempo máximo para a entrega.

O presente trabalho buscou solucionar o problema de definição dos prazos de entrega dos pedidos, de forma que não ocorram atrasos nas entregas. Para isso foram analisados os tempos, previamente disponibilizados pela empresa, e suas atividades, a fim de montar uma rede PERT/CPM para a identificação do caminho crítico. Essa identificação permite que seja estipulado o tempo máximo para a fabricação de uma unidade, sendo calculado posteriormente pela empresa, conforme a quantidade do lote.
A empresa objeto de estudo está localizada na região noroeste do estado do Rio Grande do Sul, atuando na fabricação de indumentária gaúcha. O trabalho segue a ordem: Introdução na primeira seção (atual), na segunda o referencial teórico, seguido de análise e discussão de resultados na terceira seção e, por fim, na quarta seção as considerações finais do estudo.

\section{REFERENCIAL TEÓRICO}

São abordados a seguir estudos fundamentados nos métodos PERT e CPM para a melhoria de processos organizacionais.

\subsection{GERENCIAMENTO DE PROJETOS}

Segundo o PMI (2013), gerenciar um projeto é aplicar o conhecimento, habilidades, ferramentas e técnicas, a fim de atender os objetivos deste. São aplicados e integrados processos em cinco grupos para um gerenciamento eficiente do projeto, sendo eles: Iniciação, planejamento, execução, monitoramento e controle, e encerramento.

O diagrama de rede, na gestão de projetos, define a sequencia de como as atividades serão feitas. É uma ferramenta para organizar a sequencia apropriada das atividades, bem como, definir suas relações de dependência. Cada atividade é representada por um único quadro, sendo que estas atividades consomem tempo, e sua descrição normalmente começa com um verbo (GIDO; CLEMENTS, 2014).

Os autores citam que as atividades têm uma relação dependente, ou seja, estão ligadas em uma sequencia lógica, apontando quais delas devem ser finalizadas antes, para que as outras possam começar. As setas que ligam os quadros de atividade mostram a direção da relação dependente. Uma atividade não pode começar até que todas as atividades anteriores que estão ligadas por setas, estejam finalizadas. A Figura 1 apresenta a interligação entre gestão e redes PERT/CPM. 
Figura 1 - Interligação entre gestão e redes PERT/CPM

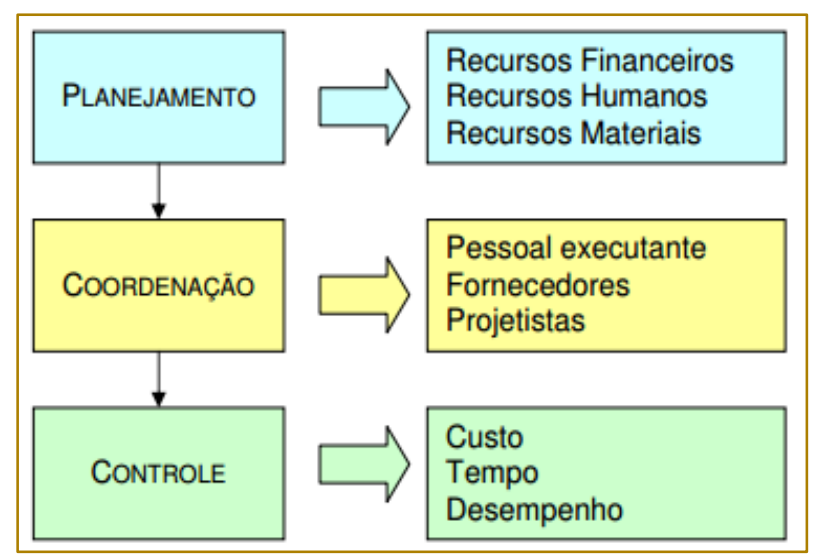

Fonte: Alves, 2010.

O diagrama PERT é uma ferramenta que pode ser utilizada para definir e coordenar o que deve ser feito, de forma a atingir os objetivos em um prazo previamente definido. O diagrama permite ainda, a visualização do conjunto de atividades mais demorado, conhecido como caminho crítico, e possibilita entender, que qualquer atraso em uma dessas atividades irá comprometer o prazo de finalização de todo o projeto (BIAGIO, 2015).

\subsection{REDES PERT/CPM}

O surgimento dos métodos de PERT/CPM se deram devido ao avanço no gerenciamento de projetos. Segundo Loesch e Hein (2009), o Critical Path Method (CPM) surgiu em 1957 com a finalidade de controlar uma das fábricas da DuPont. Em 1958, através de uma empresa de consultoria associada à marinha dos Estados Unidos, surgiu o Program Evaluation and Review Technique (PERT), com a finalidade de prestar auxílio na construção de submarinos Polaris, o qual reuniu um grande número de empresas e contratos.

Este método foi desenvolvido com o objetivo de minimizar problemas em projetos, conhecer o caminho crítico do processo, informar a administração sobre fatores críticos que podem influenciar no desempenho, estabelecer a ordem do processo, controlar e coordenar o processo (AVILA, 2010).

Corrêa, Caon \& Gianesi (2001), as redes PERT/CPM gerenciam as atividades utilizadas para determinado projeto, sendo que 0 cumprimento de prazos é um critério importante diante da competitividade do mercado. As atividades dos projetos se inter- relacionam na rede, em ordem, sendo apresentadas de forma definida o início e fim da atividade.

\subsection{CONSTRUÇÃO DA REDE PERT/CPM}

Para Tubino (2017) o primeiro passo para a utilização da técnica PERT/CPM é a elaboração de uma rede, capaz de representar todas as atividades e eventos envolvidos no projeto.

Fernandes e Godinho Filho (2010) afirmam que representar o projeto em forma de rede é muito importante para o controle da programação, análise de custos e recursos. $\mathrm{O}$ desenho da rede tem como objetivos gerais representar de maneira simplificada o projeto, possibilitar a estimativa do tempo de conclusão, evitar atrasos na entrega de pedidos, auxiliar no gerenciamento de atividades e avaliar propostas de alteração do projeto.

Segundo os mesmos autores, o projeto deve ser separado pelas etapas que o compõe, o que chamam de atividades. Estas precisam apresentar o início e fim bem definidos, de forma bem detalhada ou não, e seus precedentes. Com o alinhamento das atividades exercidas e seus respectivos tempos, é possível construir a rede e definir o tempo previsto para a conclusão do projeto.

Existem dois métodos de representação de redes, representados por setas e nós. O mais usado, e o qual referencia este estudo, adotam os eventos como o início e o final de cada atividade e as setas representam a atividade. O evento não necessita de recursos humanos, materiais, verba e tempo, sendo a situação do projeto naquele tempo. Na rede 
este é sempre representado por nós no grafo, numerados em ordem crescente. As atividades necessitam de recursos humanos, materiais, verba e tempo, pois ela representa o deslocamento do trabalho de um evento para o outro. No grafo, sempre é representado por setas em direção ao evento seguinte, sem escala gráfica (LOESCH; HEIN, 2009). A Figura 2 apresenta como os eventos e atividades são representados em um grafo.

Figura 2: Representação de eventos e atividades em um grafo

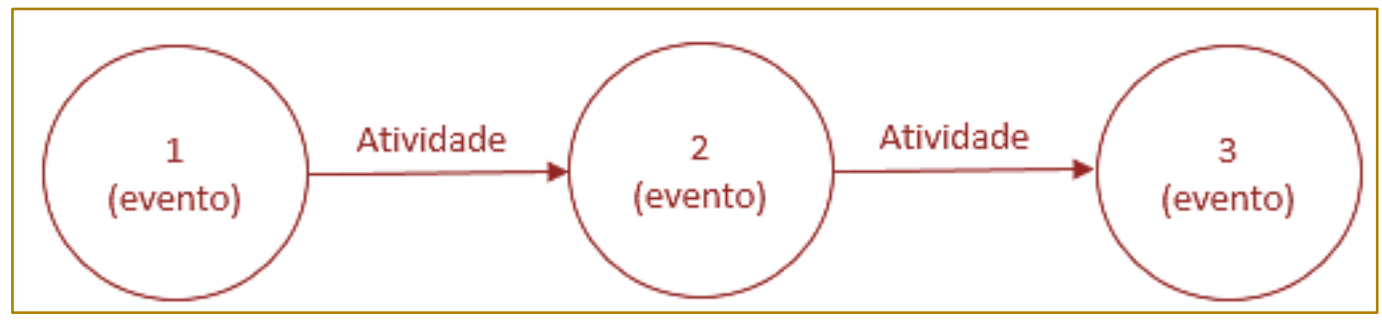

Fonte: Loesch, Hein (2009).

Tubino (2017) afirma que montar a rede de forma correta é fundamental e merece muita atenção. Montar o diagrama de forma errada, sem precedentes corretos, influencia diretamente na validade dos resultados finais.

\subsection{CAMINHO CRÍTICO}

Todas as linhas que ligam o nó inicial ao final, são chamadas de caminho. Para determinar o caminho crítico do projeto são somados os tempos de cada atividade pertencente ao caminho de forma individual (TUBINO, 2017).

A rede de um projeto apresenta as interdependências das atividades. Devido a elas, todas as atividades que não se encaixam no caminho crítico apresentam folgas, ou seja, tempo ocioso. É muito importante que o gestor conheça quais atividades possuem folgas, para então poder gerenciar de forma adequada a alocação das tarefas (ANDRADE, 2015).

Para Martins e Laugeni (2015) e para Tubino (2017), o caminho que apresentar maior tempo é chamado de caminho crítico e determinará o tempo total para a conclusão do projeto. As atividades que pertencem ao caminho crítico, são chamadas de atividades críticas. Aquelas que não pertencem ao caminho crítico, sempre irão apresentar folgas, ou seja, se atrasarem suas tarefas, desde que não ultrapasse o tempo do caminho crítico, não irão impactar no tempo de conclusão do projeto.

Alves (2010) afirma que um evento crítico é aquele que integra a rede e possui folga mínima, quando comparada aos demais eventos, ou for igual a zero. A atividade crítica corresponde a atividade que acontece entre dois eventos críticos. A folga da atividade crítica também precisa ser mínima ou igual a zero.

Segundo Venanzi e Silva (2016), o caminho crítico é o caminho que possui a sequência mais longa de atividades. $O$ atraso na execução de qualquer tarefa que faça parte do caminho crítico, provoca um atraso na execução do projeto como um todo. Desta forma, a ideia básica do PERT e do CPM está na identificação do caminho que consome mais tempo e seus custos.

\section{METODOLOGIA}

O presente estudo foi realizado em uma indústria de confecções, com a finalidade de definir o prazo máximo para confecção, diminuindo as chances de atraso na entrega do pedido.

Vergara (2011) divide a metodologia com base nos fins e nos meios.

Quanto aos fins, a pesquisa possui natureza:

- Descritiva, devido ao embasamento teórico apresentado inicialmente, seguido da análise de resultados apresentados através de redes PERT e CPM.

- $\quad$ Explicativa, por visar deixar evidente o acontecimento e apresentar as justificativas.

- $\quad$ Aplicada, porque tem como base um estudo teórico com posterior estudo prático.

Quanto aos meios, a pesquisa possui caráter: 
- Documental, por utilizar documentos das tomadas de tempo dos processos realizados:

- Bibliográfica por contar com embasamento teórico com base em materiais disponíveis ao público em geral, como livros, revistas, jornais e redes eletrônicas.

- Estudo de caso por contar com profundidade e detalhamento, possuindo dados particulares de uma empresa, não podendo ser aplicada a outras.

Para a coleta de dados do presente estudo, foram utilizadas as técnicas de observação exploratória, onde, segundo Gil (2017), o pesquisador permanece alheio a situação que deseja estudar, observando os fatos que ocorrem. O pesquisador é aproximado do fenômeno que está estudando. Foram ainda realizadas entrevistas informais com cada setor e também com os dirigentes da empresa, para obter informações acerca dos tempos e atividades envolvidas no processo produtivo.

A análise de dados ocorreu por meio da análise de conteúdo, que, segundo Gil (2017), é a técnica mais usada quando se refere a textos escritos ou transcritos. Essa técnica tem como objetivo descrever o conteúdo de forma objetiva, sistemática e qualitativa.

\section{ANÁLISE E DISCUSSÃO DOS RESULTADOS}

\subsection{CARACTERIZAÇÃO DA EMPRESA}

A empresa objeto de estudo, é uma Camisaria, e está localizada na região noroeste do estado do Rio Grande do Sul. Suas atividades foram iniciadas em 15 de maio de 2000, com 3 colaboradores. Inicialmente 0 trabalho era voltado a uniformes empresariais, onde chegou a ter 97 empresas parceiras. Em 2008 mudou o foco para a indumentária gaúcha, fabricando camisas, camisetes, camisetas polo e baby looks, todas com adereços gauchescos, tais como o mapa e brasão do Rio Grande do Sul, cavalo crioulo, entre outros.

Para este estudo, foi considerado o processo produtivo da camisa de manga longa, devido a este ser o produto mais complexo para produção. Na Figura 3 está representado o produto, objeto desta pesquisa.

Figura 3: Camisa de manga longa

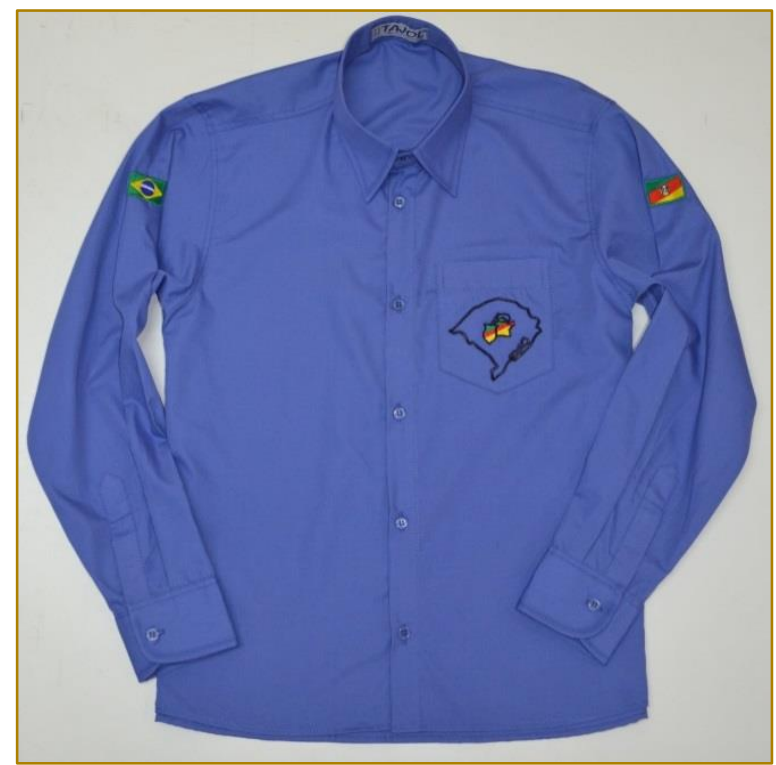

Fonte: Empresa (2018)

Atualmente a empresa conta com 28 colaboradores, possui espaço próprio com amplas instalações, bem como, tem modernos equipamentos para a confecção de seus produtos e chegou a marca de 6 mil unidades produzidas ao mês.

\subsection{ELABORAÇÃO DA REDE PERT/CPM}

A fim de determinar o caminho crítico, é indispensável determinar o tempo de cada atividade. O método PERT indica a 
necessidade do tempo pessimista, mais provável e pessimista. Foram considerados os três tempos e em seguida, realizada a média aritmética das atividades.

Biagio (2015) argumenta que, para entender o funcionamento do diagrama de PERT, é necessário entender os conceitos a seguir:

- Rede é um conjunto de atividades e eventos arranjados de maneira lógica;

- $\quad$ Projeto ou operação, trata-se de um conjunto de atividades envolvendo recursos de entrada (mão de obra, máquinas e equipamentos, materiais, meio ambiente, tecnologias, processos, etc.) e um determinado produto como saída, organizadas com um objetivo definido;

- Atividade ou tarefa: ação que consome tempo e recursos na execução do projeto, evento é o elemento que indica o fim ou o início de uma ou mais tarefas; e

- Atividade fantasma é uma ação que depende de algum fator externo, fora do controle do projeto, e que apresenta alguma condição, como uma atividade que depende de condição meteorológica, por exemplo. A atividade fantasma não consome tempo nem recursos.

A Figura 4 apresenta o diagrama de PERT/CPM e sua respectiva simbologia.

Figura 4 - Modelo de diagrama PERT/CPM com simbologia

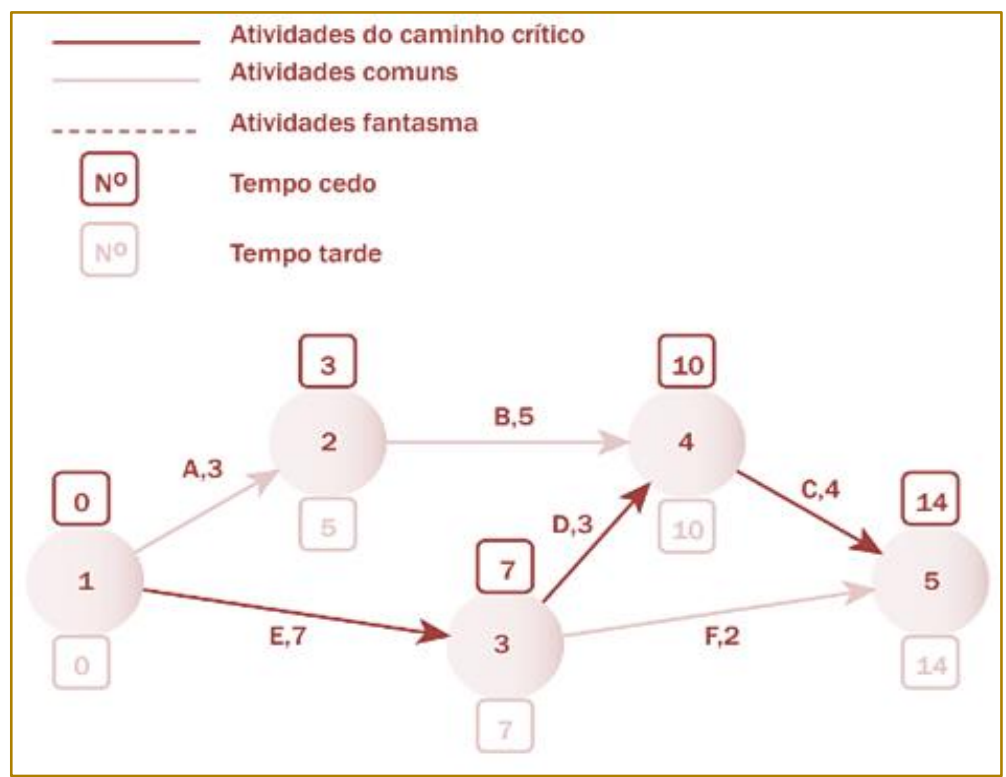

Fonte: Biagio (2015).

A Tabela 1 apresenta as atividades correspondentes ao processo de confecção de uma camisa de manga longa, sua descrição, a dependência entre as atividades e o tempo médio de duração de cada uma, em segundos. O levantamento destes dados foi feito por meio da observação e entrevista informal, realizado na empresa. O projeto envolve 22 atividades, com as seguintes relações de precedências e previsões de duração (em segundos). 
Tabela 1 - Atividades do processo de confecção de uma camisa

\begin{tabular}{|clcc|}
\hline Atividade & \multicolumn{1}{c}{ Descrição } & Dependência & Tempo (s egundos) \\
\hline A & Corte & - & 526 \\
B & Bordado das costas & A & 1740 \\
C & Bordado do bolso & A & 420 \\
D & Bordado da manga & A & 300 \\
E & Frentinha & B, C, D & 27 \\
F & Barra do bolso & E & 7 \\
G & Colocar carcela & F & 90 \\
H & Colocar bolso & G & 32 \\
I & Montagem & H & 138 \\
J & Colar entre telas & $\mathrm{A}$ & 15 \\
K & Costura (punho e pé) & J & 47 \\
L & Recorte (gola e punho) & $\mathrm{K}$ & 52 \\
M & Desviar gola e punho & $\mathrm{L}$ & 12 \\
N & Montagem (gola e pé) & $\mathrm{M}$ & 51 \\
O & Colocar gola e punho & $\mathrm{I}, \mathrm{N}$ & 157 \\
P & Barra do bolso & $\mathrm{O}$ & 56 \\
Q & Casinha & $\mathrm{P}$ & 57 \\
R & Botão & $\mathrm{Q}$ & 85 \\
S & Limpar & $\mathrm{R}$ & 111 \\
T & Passar & $\mathrm{S}$ & 51 \\
U & Dobrar & $\mathrm{T}$ & 35 \\
V & Embalar & $\mathrm{U}$ & 10 \\
\hline & & For & \\
\hline
\end{tabular}

Fonte: Os autores (2018).

Como pode ser observado na Tabela 1, as atividades bordado das costas, bordado do bolso e bordado da manga, possuem o mesmo evento antecedente, que é o corte. Também, evidencia-se que a atividade frentinha depende da conclusão das atividades de bordado das costas, do bolso e da manga, para que esta atividade possa ser iniciada. Já a atividade colocar gola e punho, depende da finalização das atividades da montagem e montagem da gola e pé para inicializar. Evidencia-se também, que a atividade que apresentou maior duração média é o bordado das costas (1740 segundos), sendo necessário dar atenção a esta atividade.

Após elaborar a tabela com as respectivas atividades, suas dependências e os tempos, elaborou-se a rede PERT, a qual é apresentada a seguir, na Figura 5.

Figura 5 - Representação da rede PERT

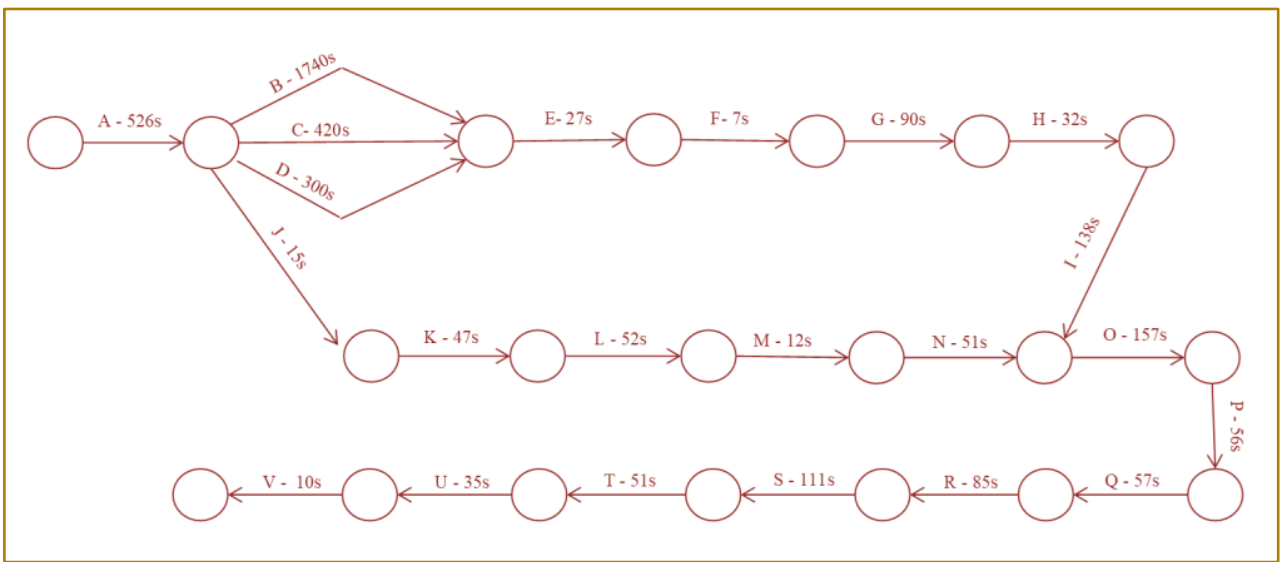

Fonte: Os autores (2018). 
Os caminhos críticos e seus respectivos tempos são listados na Tabela 2, enquanto o caminho crítico é representado através das linhas vermelhas na Figura 6.

Tabela 2 - Caminhos e seus respectivos tempos em segundos

\begin{tabular}{|cc|}
\hline Caminhos & Tempo total (segundos) \\
\hline A - B - E - F - G - H - I - O - P - Q - R - S - T - U - V & 3122 \\
A - C - E - F - G - H - I - O - P - Q - R - S - T - U - V & 1320 \\
A - D - E - F - - - - H - I - O - P - Q - R - S - T - U - V & 1440 \\
A - J - K - L - M - N - O - P - Q - R - S - T - U - V & 1857 \\
\hline
\end{tabular}

Fonte: Os autores (2018).

Pode-se observar que há quatro caminhos a serem avaliados, sendo que o caminho crítico é o de maior duração e, os demais são os que possuem folgas (menor tempo de duração).

Figura 6 - Representação do caminho crítico na rede

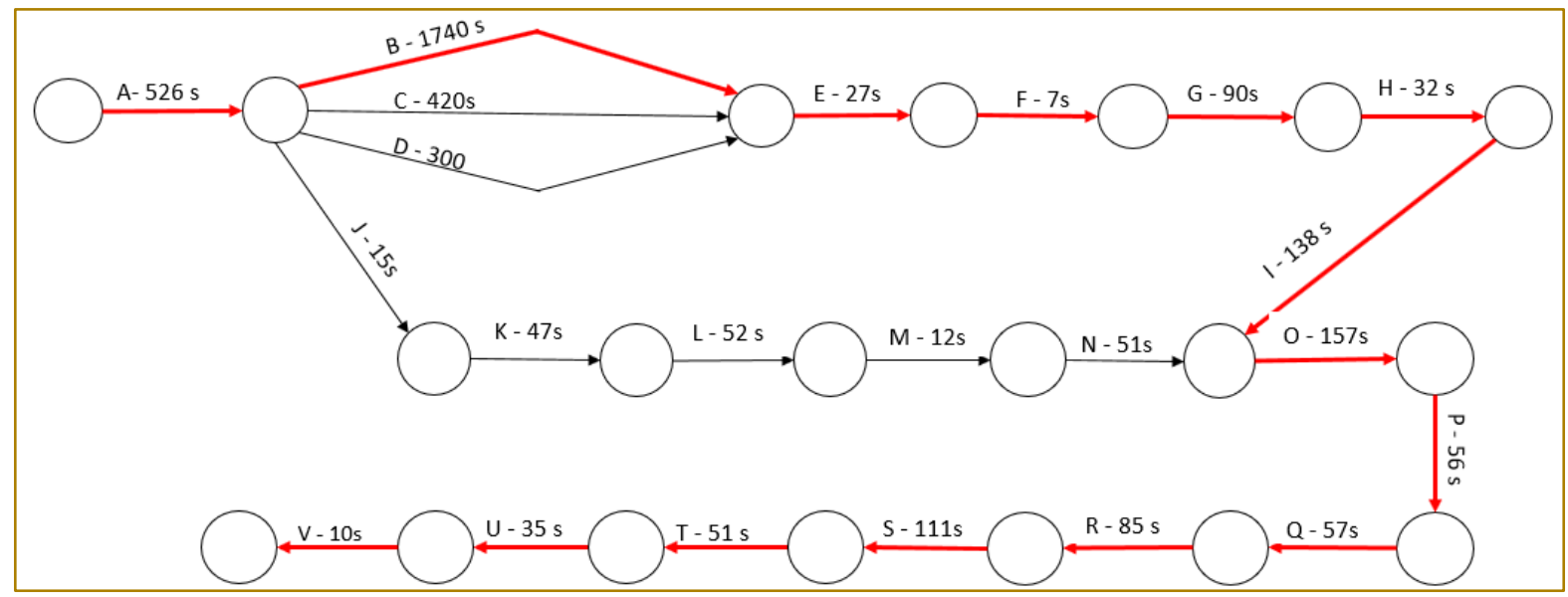

Fonte: Os autores (2018).

Através do cálculo do caminho crítico, verificou-se que, somando as atividades do caminho crítico, tem-se um total de 3122 segundos, não havendo nenhuma folga nestas atividades. $O$ estudo realizado através de montagem da PERT/CPM expôs que o tempo mínimo gasto para confecção de uma unidade de camisa de manga longa é de 52,03 minutos. Através da análise da rede, identificaram-se 15 atividades críticas, de um total de 22 atividades, correspondendo a $68,18 \%$ do total de atividades.

Identificou-se que as atividades que merecem maior atenção, de acordo com o estudo, são as que compõem o caminho crítico, sendo: $A$ - B - E - F - G - H - I - O - P - Q - R - S - T - U $\mathrm{V}$, conforme demonstradas na Figura 6. Atrasos em alguma atividade do caminho crítico podem acarretar em atraso no prazo de entrega do produto ao cliente, caso não seja tomada nenhuma ação corretiva. Neste sentido, o método PERT/CPM é uma forma de gerenciar o projeto, permitindo conhecer as atividades, recursos e tempo. Conhecer o caminho crítico faz com que o prazo estipulado seja fundamentado nas atividades exercidas no processo e em seus respectivos tempos, buscando eliminar atrasos na entrega do produto final.

Através da rede elaborada, a empresa tem maior facilidade com relação a gestão da produção, conhecendo as atividades críticas e a alocação dos recursos disponíveis. Estes dados são significativos quando avaliados de forma correta em lotes de produção, pois facilitam a gestão e o cumprimento de prazos, visando a satisfação do cliente.

Portanto, o método PERT/CPM se apresenta viável para o projeto, pois desta forma a empresa poderá ter um controle maior de suas atividades, identificando aquelas que 
são críticas e consequentemente, determinarão o tempo de conclusão. Pontualidade na entrega dos pedidos também é um fator positivo na garantia de fidelização dos clientes.

\section{CONSIDERAÇÕES FINAIS}

Para Colin (2017) uma informação importante na gestão de qualquer projeto é o caminho crítico. Ele representa o conjunto de atividades que determina o horizonte do projeto. Alterações nos tempos de realização das atividades que pertencem ao caminho crítico podem afetar o tempo de realização do projeto. Em uma empresa não é diferente, o caminho crítico é responsável por informar qual é o conjunto de atividades mais demorado, e que pode ser responsável por afetar os prazos de entregas dos pedidos.

O problema inicial da pesquisa era solucionar os problemas com as entregas de pedidos. Por tratar-se de uma empresa que produz artigos da indumentária gaúcha, o maior pico de atividades está na época em que antecede o dia do Gaúcho, dia 20 de setembro. Desta forma, neste período, é imprescindível que as entregas sejam realizadas dentro do prazo, pois na maioria das vezes, os artigos serão utilizados para algum evento referente a Semana Farroupilha. A rede PERT/CPM possibilitou isso através do cálculo do

\section{REFERÊNCIAS}

[1] AVILA, Antonio Victoriano. O método PERT-CPM. Santa Catarina, 2010. Disponível em: $<$ http://pet.ecv.ufsc.br/arquivos/apoiodidatico/ECV5318\%20-

\%20Planejamento_cap06.pdf>. Acessado em: 29 de junho de 2018.

[2] BIAGIO, Luiz Arnaldo. Como Administrar a Produção. São Paulo: Manole, 2015.

[3] CORRÊA, H. L; CAON, M; GIANESI, I. G. N. Planejamento, Programação e Controle da Produção - MRP II/ERP - Conceitos, Uso e Implantação. 4. rev. ampl. São Paulo: Atlas, 2001

[4] FERNANDES, F. C. F; GODINHO FILHO, M. Planejamento e Controle da Produção - dos Fundamentos ao Essencial. São Paulo: Atlas, 2010.

[5] GIDO, CLEMENTS P. James. Gestão de projetos - Tradução da 5a edição norte-americana. Cengage Learning Editores, 2014. caminho crítico da camisa, ou seja, o tempo máximo para fabricação de cada unidade.

Além de um planejamento adequado do cronograma da empresa, é fundamental definir o caminho crítico das atividades, visando entender quais são as atividades críticas e que podem impactar diretamente nos prazos de entregas dos pedidos.

Para isso foram analisados os tempos, previamente disponibilizados pela empresa, e suas atividades, a fim de elaborar a rede PERT. De acordo com o estudo realizado, identificou se o caminho crítico, que corresponde a 15 atividades críticas, ou seja, aproximadamente $68 \%$ do total das atividades. Qualquer atraso em uma destas atividades pode ocasionar em atrasos das entregas dos pedidos de camisas.

Os resultados evidenciados nesta pesquisa demonstram a importância de um adequado planejamento das atividades de uma camisaria. Diante do contexto geral da empresa, propõem-se como pesquisas futuras: Estudo do layout da empresa visando a diminuição dos tempos; Análise dos custos da empresa visando a diminuição destes; e, Estudo de redes PERT/CPM em todos os mix de produtos da empresa, para que tenham conhecimento das atividades que precisam de atenção para não ocorrer atrasos nos pedidos.

[6] LOESCH, Claudio; HEIN, Nelson. Pesquisa Operacional: Fundamentos e modelos. Saraiva: São Paulo, 2009

[7] MARTINS, Petrônio G.; LAUGENI, Fernando. Administração da Produção. 3. Ed. São Paulo: Saraiva, 2015.

[8] PMI. Um guia do conhecimento em gerenciamento de projetos. Guia PMBOK® 5. Ed. EUA Project Management Institute, 2013.

[9] TUBINO, Dalvio Ferrari. Planejamento e controle da produção: teoria e prática. 3. Ed. São Paulo: Atlas, 2015.

[10] VENANZI, Délvio, SILVA, Orlando da. Introdução à Engenharia de Produção - Conceitos e Casos Práticos. LTC, 2016.

[11] VERGARA, Sylvia Constant. Projetos e relatórios de pesquisa em Administração. 13. Ed. São Paulo: Atlas, 2011. 


\section{Gapítulo 20}

\section{ESTIMATIVA DE PRODUTIVIDADE NO SETOR DE USINAGEM UTILIZANDO O MÉTODO DA TEORIA DAS FILAS}

\section{Carlos Henrique Haefliger}

Geniel de Mello Dias

Ivete Linn Ruppenthal

Resumo: No decorrer do dia-a-dia as pessoas gastam parte de seu tempo na espera pelo atendimento em filas. Porém, a formação de filas pode ocorrer também em processos industriais, o que pode acarretar em perda de produtividade e aumento dos custos. Diante deste contexto, aplicou-se o estudo de Filas em uma indústria metal mecânica, situada na região noroeste do RS. O objetivo foi estimar o índice de produtividade dos itens com maior demanda no setor de usinagem, através do método da Teoria das Filas. Como problemática, buscou-se identificar se o atual sistema de produção viabiliza um aumento na produção de peças. Quanto a metodologia, foi utilizada a abordagem quantitativa e, os métodos de procedimento foram o estudo de caso e pesquisa comparativa. Os dados foram coletados através da observação, entrevista informal com pessoas envolvidas no processo e, por meio da pesquisa documental, sendo os dados coletados do sistema ERP da indústria. Com a aplicação do estudo foi possível comparar a meta de produtividade estabelecida pela empresa que é $85 \%$, com a produtividade atingida na máquina que produz os itens com maior demanda do setor de usinagem. Através dos cálculos realizados verificou-se que há formação de filas das peças produzidas na máquina utilizada. Além disso, foi possível estimar que o processo atual de produção dos itens com maior demanda é eficaz e eficiente, pois no período analisado atingiu um percentual de $89,10 \%$ de aproveitamento do tempo total disponível para produção, contudo, como a produção ultrapassa o percentual da meta, isto pode ocasionar em perda de qualidade.

Palavras chaves: Teoria das Filas. Produtividade. Perda de produção. 


\section{INTRODUÇÃO}

No decorrer das atividades realizadas diariamente as pessoas acabam tendo que aguardar por atendimento em filas, sendo estas, por exemplo, em mercados, farmácias, bancos, etc. Na maioria das vezes as filas são indesejadas, pois acarretam em perda de tempo, podendo gerar a insatisfação do cliente. Já na indústria, pode ocasionar em perda de produtividade, atraso na entrega dos pedidos e ainda, elevação do custo de produção.

Moreira (2007, p. 302) destaca que "[...] uma fila, é o resultado de uma situação em que clientes chegam para $\mathrm{o}$ atendimento $e$, eventualmente, têm de esperar, pois o posto de atendimento pode estar ocupado". A formação de filas não ocorre somente com pessoas, podendo ser filas de espera de peças em processos de fabricação.

A literatura aborda inúmeros estudos com aplicação do método de Teoria das Filas, porém poucos estudos envolvem os processos produtivos em indústrias. Macedo et al (2017) desenvolveram um estudo de caso em uma indústria moveleira, visando avaliar um recurso produtivo que apresentava um gargalo operacional, no qual, puderam observar a necessidade de uma melhoria na eficiência do sistema. Os autores constataram que $\mathrm{o}$ estudo de filas apresenta dados importantes para a tomada de decisão nas indústrias.

No atual mercado competitivo, para que as empresas se mantenham competitivas, estas necessitam ter um controle eficaz das atividades e processos. Para tanto, estas tem a necessidade de avaliar o seu desempenho e ter a capacidade de atuar de forma ágil para fazer correções necessárias, bem como para implementar melhorias em seus processos produtivos, de maneira a reduzir ou ainda, eliminar desperdícios.

Diante da importância da implementação de melhorias nos processos produtivos, este trabalho foi realizado em uma empresa do ramo metal mecânico, localizada na região noroeste do estado do Rio Grande do Sul, tendo por objetivo estimar o índice de produtividade dos itens com maior demanda no setor de usinagem, através do método da Teoria das Filas. Também, diante da necessidade de avaliar a possibilidade de um aumento no lote de produção dos quatro itens com maior demanda do setor de usinagem, o problema da pesquisa buscou identificar se o atual sistema de produção viabiliza um aumento na produção de peças.

Este artigo está estruturado em seções. $\mathrm{Na}$ primeira seção consta a introdução apresentando o tema, o objetivo e o problema da pesquisa. $\mathrm{Na}$ segunda encontra-se $\mathrm{O}$ referencial teórico onde são abordados os principais conceitos relacionados à Teoria das Filas. Em seguida apresenta-se a metodologia, classificando-a quanto aos métodos e técnicas de pesquisa. Na seção quatro expõem-se a análise e discussão dos resultados obtidos com a pesquisa e por fim, apresentam-se as considerações finais do estudo.

\section{REFERENCIAL TEÓRICO \\ 2.1. TEORIA DAS FILAS}

Esperar por um serviço ou atendimento faz parte do dia a dia das pessoas. Estes esperam sob forma de filas nos mais diversos tipos de estabelecimentos como, restaurantes, supermercados, bancos, agências de correios, lojas, etc. Conforme Taha (2008, p. 247), "o fenômeno da espera não é uma experiência limitada somente aos seres humanos: tarefas aguardam para serem processadas em uma máquina, aviões sobrevoam uma área antes de terem permissão de aterrissar em um aeroporto e carros param em semáforos". A espera não pode ser totalmente eliminada sem incorrer em despesas desproporcionais, e a meta é reduzir o impacto adverso a níveis toleráveis.

Segundo Moreira (2007, p. 302) "uma fila, é o resultado de uma situação em que clientes (que não precisam ser apenas pessoas, lembre-se) chegam para o atendimento e, eventualmente, têm de esperar, pois o posto de atendimento pode estar ocupado".

Para Taha (2008, p. 247) "o estudo de filas trata da quantificação do fenômeno da espera em filas usando medidas representativas de desempenho como o comprimento médio de uma fila, o tempo médio de espera em fila e a média de utilização da instalação".

\subsubsection{TIPOS DE FILAS}

Conforme Moreira (2007, p. 311) "uma fila é chamada de fila de canal único quando existe uma única instalação de atendimento". Podendo ser constituída de um só posto, que realiza sozinho todo o atendimento, ou de 
vários postos, cada qual realizando uma parte do atendimento. Pode- se verificar na figura
1, apresentada a seguir, o sistema de fila simples ou única, com um servidor.

Figura 1 - Fila única com um servidor

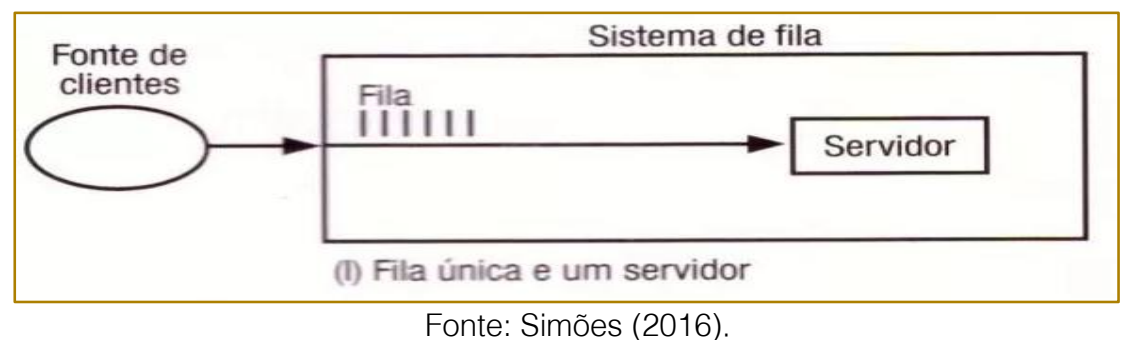

Já nas filas simples com mais de um servidor, conforme Taha (2008, p. 255), "um cliente à espera é selecionado da fila para iniciar o atendimento com o primeiro servidor disponível". Os servidores ficam em paralelo e são idênticos, significando que a taxa de serviço para qualquer servidor é cliente por unidade de tempo. Pode- se verificar na figura 2, o sistema de fila simples com mais de um servidor.

Figura 2 - Fila única com mais de um servidor

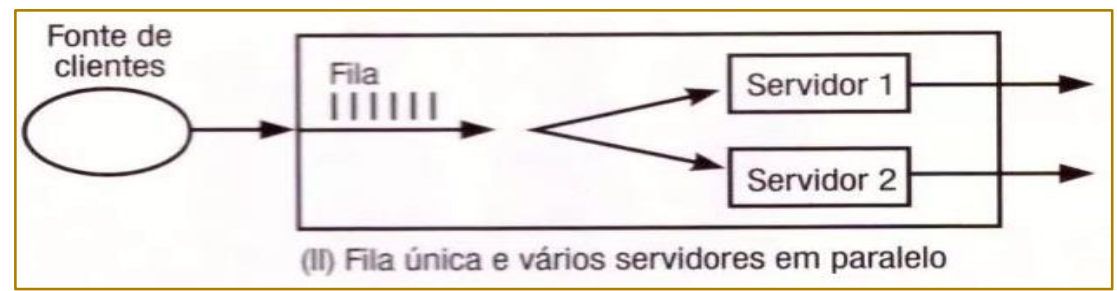

Fonte: Simões (2016).

No sistema de atendimento com mais de um servidor a fila pode ser única, apenas mudando o número de atendentes, ou seja, o primeiro atendente que for liberado chama a próxima pessoa da fila. Dessa forma, consegue-se melhorar a capacidade no atendimento, sendo que não direciona o atendimento em apenas um servidor.

\subsubsection{PADRÃO DE CHEGADA}

O cliente pode chegar sozinho ao posto de atendimento, como acontece, por exemplo, com carros que chegam a um sinal de tráfego ou com uma pessoa que vai fazer uma retirada em um caixa eletrônico; podem chegar em grupos, como se dá quando um ônibus cheio de turistas chega em um restaurante de beira de estrada para o almoço ou, quando um lote de 120 peças chega a um torno (MOREIRA, 2007, p. 305). Podem ser considerados casos intermediários como grupos, de duas, três ou quatro pessoas chegando.
Segundo Moreira (2007, p. 305) referente ao tipo de cliente:

O cliente é considerado paciente se aceitar permanecer na fila até que seja atendido. Caso contrário, ele é dito impaciente, podendo assumir diferentes atitudes: o cliente recusa juntar- se à fila, abandonando o posto de atendimento; o cliente junta-se à fila, mas acaba desistindo ao cabo de algum tempo.

\subsection{PROCESSO PRODUTIVO}

Conforme Campos (2004, p. 19) "processo é um conjunto de causas (que provoca um ou mais efeitos)". São divididos em famílias de causas (matérias primas, máquinas, medidas, meio ambiente, mão-de-obra e método), sendo estes chamados de fator de manufatura e para as áreas de serviços, podem ser chamados de fatores de serviço.

Segundo Damazio (1998, p. 14) "processo pode ser definido como um conjunto de causas e condições que, repetidamente, 
unem-se para transformar entradas em saídas. Alguns estudiosos estabelecem que processo é o conjunto de causas que, articuladas coerentemente, produzem os efeitos desejados".

Qualquer operação entrega serviços e/ou produtos através da transformação de entradas em saídas, usando o processo "input - transformação - output", sendo este processo a sustentação de todas as operações. De um modo geral, as operações são processos constituídos "por um conjunto de recursos de input que são usados para transformar algo ou que se transformam em outputs de serviços e produtos. Embora todas as operações se conformem a esse modelo geral de input - transformação - output, elas diferem na natureza de seus inputs e outputs específicos" (SLACK; JONES; JOHNSTON, 2018, p. 12). Na Figura 3, apresentada a seguir, pode-se observar o processo de transformação.

Figura 3 - Processos de input - transformação - output

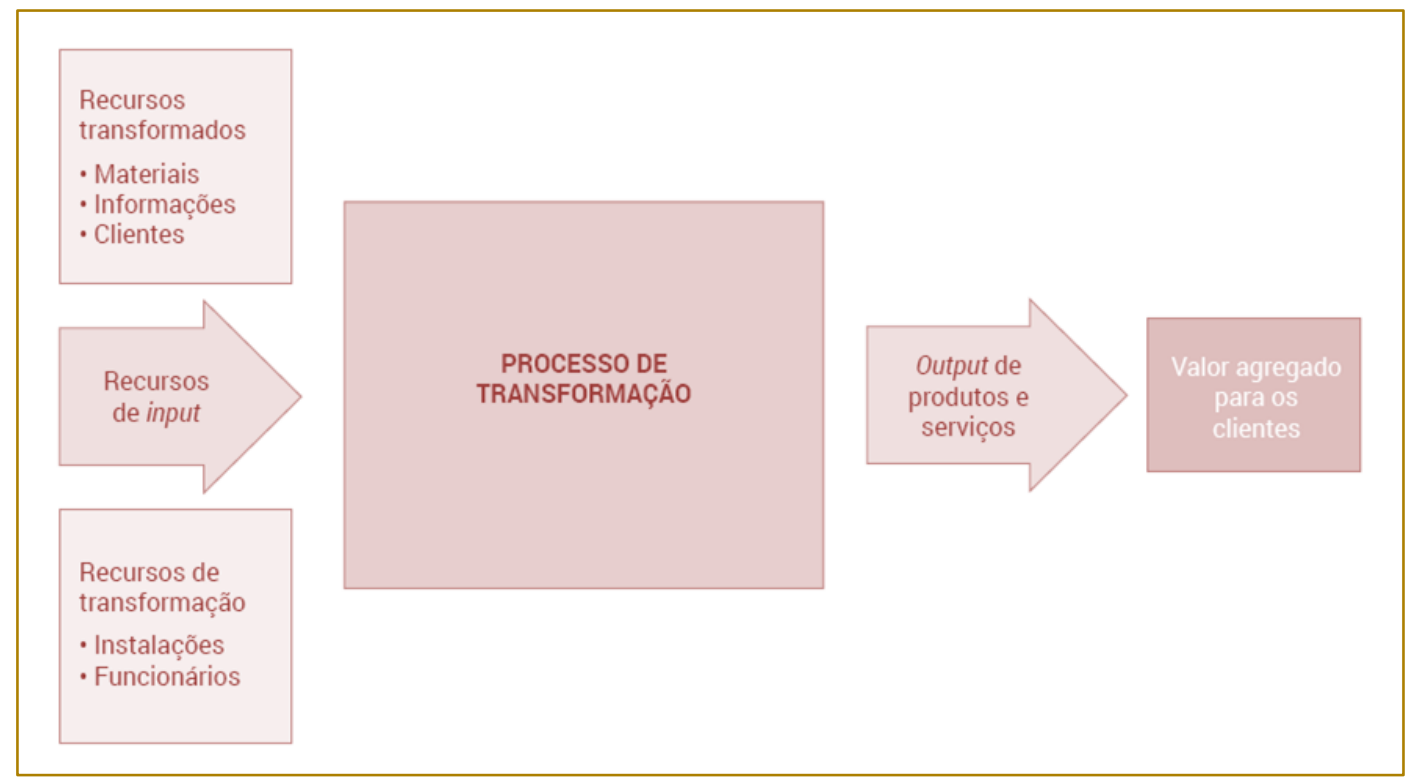

Fonte: Slack; Jones; Johnston (2018).

Pode-se considerar que todas as operações produzem produtos e serviços através da transformação de entradas em saídas, sendo chamado de processo de transformação. Assim, o processo de transformação envolve várias atividades que geralmente envolvem diversos procedimentos e recursos, os quais normalmente constituem uma saída ou um produto acabado (SLACK; JONES; JOHNSTON, 2018).

\subsection{SETUP}

Setup ou preparação é o trabalho realizado para preparar o equipamento e deixa-lo em condição de produzir uma nova peça com qualidade em produção normal. O tempo de setup é considerado aquele gasto na nova preparação do equipamento, até o momento em que a produção é liberada. Neste tempo deve-se considerar "a criação das primeiras peças para verificar se o equipamento pode ser liberado para a produção normal. Setup costuma ser visto como uma atividade acíclica dentro do processo de produção, porque ocorre cada vez que é gerado um lote de peças, e não somente uma peça (MARTINS; LAUGENI, 2015, p. 91).

Para Black (1998, p. 131) "o tempo total de setup é o tempo desde a saída da última peça boa de setup anterior até a primeira peça boa do próximo setup[...]", onde as atividades típicas são, "[...] trocar as ferramentas da máquina ou equipamento, produzir algumas peças, inspecionar estas peças, ajustar a máquina, fabricar outra amostra, medir, ajustar e assim por diante, até que peças de qualidade aceitável sejam produzidas".

Os problemas com o setup estão relacionados com os materiais, sistemas e processos de manufatura e o gerenciamento, sendo a mão-de-obra um fator minoritário. As equipes de operadores devem ser treinadas 
para reduzir o setup das máquinas, onde os mesmos devem ter o conhecimento que a redução de setup gera um menor custo e também é indispensável para o sucesso do projeto, isto é, precisa dar importância ao operador, pois provavelmente este sabe melhor do que qualquer outro como eliminar o tempo de setup no seu trabalho (BLACK, 1998).

\subsection{PERDAS DE PRODUÇÃO}

Pode-se considerar perda de produção, todas as atividades que de alguma forma acrescentam custo ao produto, porém não são necessários para o mesmo, com isso, avaliar as atividades e processos que não agregam valor ao produto é uma tarefa muito importante na produção. Além disso, outra forma para melhorar os processos produtivos e reduzir os custos de produção, é identificar e eliminar os retrabalhos e desperdícios na linha de produção (BARROS; VASCONCELOS, 2016).

A concorrência entre as empresas e conservação de vantagens competitivas no mercado atual, vem obrigando as organizações a ter um controle efetivo das atividades, com o intuito de avaliar seu desempenho e ser capaz de intervir rapidamente para alguma correção e melhoria, além disso, devem dispor de uma melhoria contínua de seu sistema produtivo, de forma a combater toda e qualquer perda (BRUM, 2006).

Para Barros e Vasconcelos (2016), a satisfação do cliente e a maximização do lucro, são decorrentes da otimização dos processos produtivos, da diminuição da onerosidade, do controle de suprimentos e do aumento da eficiência da produção. Portanto, se a empresa deseja alcançar um padrão e uma excelência de seus produtos perante as exigências de seus clientes, essas atividades se tornam indispensáveis em sua organização.

Segundo Brum (2006) investigar e quantificar em valores monetários as perdas e possíveis gargalos nos processos de produção é uma forma eficiente de sensibilizar e motivar as organizações e os colaboradores sobre a necessidade de descobrir as causas dos problemas e desperdícios, desta forma, ao final, propor uma solução, isto é, encontrar uma estratégia de ação imediata para a inconformidade. Em complemento, a organização deve sempre almejar o progresso da melhoria contínua.

As perdas impactam negativamente na lucratividade, pois quando ocorrem, interferem na qualidade do produto final e minimizam o rendimento durante o processo. Dessa forma, reduzindo as perdas, tem-se um aumento na produtividade, onde o processo é otimizado e melhora a eficiência e eficácia da produção, a qualidade do produto atinge padrões mais elevados, o controle do estoque melhora e se contabiliza corretamente os custos reais de produção (BARROS; VASCONCELOS, 2016, p. 2).

Um dos maiores objetivos de uma organização é conseguir que sua gestão melhore continuamente e que sua equipe esteja sempre preparada e adaptada para os desafios do mercado atual. Com isso, evita perdas, buscando analisar e melhorar a eficiência dos processos produtivos, a fim de chegar em um sistema sem desperdícios de tempo, mão de obra e custos, desta forma ampliando seu mercado de venda, e renda final (BRUM, 2006).

\section{MÉTODOS E TÉCNICAS DE PESQUISA}

Este estudo teve por objetivo estimar o índice de produtividade dos itens com maior demanda no setor de usinagem em uma indústria metal mecânica, através do método da Teoria das Filas. Para tal, buscou-se analisar os quatro itens com maior demanda no setor de usinagem, sendo que, identificouse que estes são produzidos na máquina CN29. Após, verificou-se a quantidade média da taxa de chegada das peças ao sistema e o tempo médio de atendimento das mesmas na produção.

Esta pesquisa foi classificada quanto aos métodos de abordagem e procedimentos, baseado em Prodanov e Freitas (2013). Utilizou-se a abordagem quantitativa, uma vez que havia a necessidade de quantificar os dados relacionados a taxa média de chegada e de atendimento das peças, informações estas que foram extraídas do sistema ERP da empresa.

Quanto aos procedimentos, esta pesquisa é classificada como estudo de caso e pesquisa comparativa. É estudo de caso, visto que foram aprofundados conhecimentos sobre formação de filas em uma indústria específica e, os resultados não podem ser estendidos a outros casos devido as suas particularidades. 
É comparativa, uma vez que foram comparados dados quanto ao percentual de produtividade estimado, com o realizado.

Os dados foram coletados por meio da observação dos processos na máquina CN29, entrevista informal com colaboradores envolvidos no processo, a fim de obter informações importantes para a pesquisa. Os dados relacionados aos tempos de produção e taxa de chegada das peças na máquina em estudo, foram extraídos do sistema ERP da indústria, configurando-se em pesquisa documental. A análise dos dados foi por intermédio do Software Excel, através da geração de planilhas e cálculo das equações do modelo de Teoria das Filas.

\section{ANÁLISE DE DISCUSSÃO DOS RESULTADOS}

\subsection{CARACTERIZAÇÃO DA EMPRESA}

A empresa em estudo é uma indústria metalúrgica, localizada no município de Santa Rosa/RS, iniciou suas atividades no ano de 1992. Sua especialidade é usinagem de peças e pequenos conjuntos soldados, produzindo peças para o setor metal mecânico e automotivo.

A metalúrgica é certificada pelo Sistema de Gestão da Qualidade NBR ISO 9001:2015. No que se refere ao gerenciamento de produção, seu sistema ERP monitora tempos de produção, quantidades de peças produzidas, peças não conforme, quantidade de estoque, pedidos e previsões futuras. Cada setor possui terminais para apontamento de operações da ordem de produção, interligando a fábrica com o administrativo.

Diante deste contexto, realizou-se um estudo dos itens com maior demanda produzidos no setor de usinagem e, por meio do sistema ERP de gerenciamento da empresa, constatou-se que estes itens são produzidos na máquina CN29.

$\mathrm{Na}$ referida máquina trabalham dois operadores, um no primeiro turno e o outro no segundo turno, ambos possuindo jornada semanal de 44 horas. A empresa possui setores de apoio que prestam suporte aos operadores, sendo eles, preset e qualidade.
O preset fornece o ferramental e seus insumos, já a qualidade fornece todos os instrumentos necessários para realizar a medição das peças e manter o padrão de qualidade estabelecido no projeto.

Os quatro itens em análise são componentes de máquinas agrícolas fabricadas no setor de usinagem por máquina CNC (Comando Numérico Computadorizado), sendo estas empregadas para itens com maior demanda e complexidade. As peças são produzidas utilizando material em barras no comprimento de um metro.

A máquina possui um sistema de alimentação automático de peças, que usina e corta no comprimento desejado, e assim posicionando o material para a próxima peça. O operador tem a função de alimentar a máquina com novas barras, medir as peças produzidas e armazenar nas caixas padrão, conforme a quantidade do lote de produção e ainda, realizar os apontamentos de abertura e fechamento da ordem de produção no sistema ERP.

A empresa definiu como meta o índice de produtividade de $85 \%$, ou seja, do período disponível para a produção, 15\% do tempo é considerado improdutivo, sendo de extrema importância o monitoramento dessa produtividade, a fim de cumprir o prazo de entrega dos produtos e manter o negócio rentável.

Neste sentido, o presente estudo teve a finalidade de quantificar o percentual de produtividade atingido no período e identificar os possíveis problemas que podem causar perda da produtividade. Considerou-se os dados da produção realizados em três meses.

\subsection{MODELAGEM E RESOLUÇÃO DO PROBLEMA}

Para análise dos dados, buscaram-se as informações no sistema de gerenciamento da empresa. Foi gerado um relatório com os quatro itens produzidos no período de 10/03/2018 a 10/06/2018 no torno CN29, totalizando 66 dias de produção. Como pode ser visto (Tabela 1), foi gerada uma planilha contendo apenas as informações necessárias para a realização dos cálculos. 
Tabela 1 - Dados da produção da máquina CN29

\begin{tabular}{|c|c|c|c|c|c|c|c|c|}
\hline \multicolumn{9}{|c|}{ Apontamentos período 10/03/2018 a 10/06/2018 } \\
\hline Data & Tempo & Produção & Data & Tempo & Produção & Data & Tempo & Produção \\
\hline $10 / 03 / 2018$ & 4:47:00 & 335 & 09/04/2018 & 13:59:00 & 549 & $10 / 05 / 2018$ & $17: 43: 00$ & 640 \\
\hline $11 / 03 / 2018$ & $7: 33: 00$ & 199 & $10 / 04 / 2018$ & $16: 43: 00$ & 601 & $11 / 05 / 2018$ & 18:17:00 & 837 \\
\hline $12 / 03 / 2018$ & $17: 47: 00$ & 886 & $11 / 04 / 2018$ & 13:16:00 & 677 & $14 / 05 / 2018$ & 15:09:00 & 443 \\
\hline $13 / 03 / 2018$ & $15: 56: 00$ & 792 & $12 / 04 / 2018$ & $16: 26: 00$ & 640 & $15 / 05 / 2018$ & 17:45:00 & 639 \\
\hline $14 / 03 / 2018$ & $17: 27: 00$ & 584 & $13 / 04 / 2018$ & 18:10:00 & 857 & $16 / 05 / 2018$ & 17:41:00 & 665 \\
\hline $15 / 03 / 2018$ & $15: 37: 00$ & 925 & $16 / 04 / 2018$ & $12: 47: 00$ & 278 & $17 / 05 / 2018$ & $16: 31: 00$ & 815 \\
\hline $16 / 03 / 2018$ & $17: 12: 00$ & 872 & $17 / 04 / 2018$ & $35: 35: 00$ & 640 & $18 / 05 / 2018$ & $18: 04: 00$ & 699 \\
\hline $19 / 03 / 2018$ & 13:46:00 & 619 & $18 / 04 / 2018$ & 16:54:00 & 742 & $21 / 05 / 2018$ & 14:50:00 & 398 \\
\hline $20 / 03 / 2018$ & $16: 48: 00$ & 579 & $19 / 04 / 2018$ & $12: 48: 00$ & 602 & $22 / 05 / 2018$ & 17:32:00 & 672 \\
\hline $21 / 03 / 2018$ & 12:53:00 & 563 & $20 / 04 / 2018$ & $18: 02: 00$ & 736 & $23 / 05 / 2018$ & 17:46:00 & 960 \\
\hline $22 / 03 / 2018$ & $16: 42: 00$ & 642 & $23 / 04 / 2018$ & 14:08:00 & 548 & $24 / 05 / 2018$ & $18: 35: 00$ & 640 \\
\hline $23 / 03 / 2018$ & $17: 55: 00$ & 734 & $24 / 04 / 2018$ & $16: 10: 00$ & 716 & $25 / 05 / 2018$ & 04:23:00 & 620 \\
\hline $24 / 03 / 2018$ & 5:06:00 & 232 & $25 / 04 / 2018$ & 16:43:00 & 704 & $28 / 05 / 2018$ & 13:42:00 & 505 \\
\hline $26 / 03 / 2018$ & 13:53:00 & 511 & $26 / 04 / 2018$ & $16: 29: 00$ & 704 & $29 / 05 / 2018$ & 17:30:00 & 672 \\
\hline $27 / 03 / 2018$ & $17: 28: 00$ & 654 & $27 / 04 / 2018$ & $17: 04: 00$ & 937 & $30 / 05 / 2018$ & 15:12:00 & 889 \\
\hline $28 / 03 / 2018$ & 16:39:00 & 625 & $02 / 05 / 2018$ & $14: 05: 00$ & 591 & $31 / 05 / 2018$ & 02:34:00 & 237 \\
\hline $29 / 03 / 2018$ & $15: 05: 00$ & 656 & $03 / 05 / 2018$ & $16: 29: 00$ & 730 & $01 / 06 / 2018$ & 08:18:00 & 403 \\
\hline 02/04/2018 & 08:38:00 & 208 & 04/05/2018 & 16:22:00 & 721 & 04/06/2018 & 14:20:00 & 352 \\
\hline $03 / 04 / 2018$ & 13:26:00 & 532 & $05 / 05 / 2018$ & $00: 41: 00$ & 98 & $05 / 06 / 2018$ & 18:59:00 & 263 \\
\hline $04 / 04 / 2018$ & $16: 06: 00$ & 640 & $07 / 05 / 2018$ & $15: 00: 00$ & 541 & $06 / 06 / 2018$ & 22:35:00 & 377 \\
\hline $05 / 04 / 2018$ & $12: 27: 00$ & 504 & $08 / 05 / 2018$ & $16: 54: 00$ & 640 & $07 / 06 / 2018$ & 17:58:00 & 640 \\
\hline \multirow[t]{2}{*}{ 06/04/2018 } & $16: 47: 00$ & 732 & 09/05/2018 & 17:10:00 & 640 & 08/06/2018 & 18:59:00 & 640 \\
\hline & & & & & & 09/06/2018 & 11:01:00 & 677 \\
\hline \multicolumn{8}{|c|}{ Dias trabalhados } & 66 \\
\hline \multicolumn{8}{|c|}{ Horas trabalhadas } & 1017:17:00 \\
\hline \multicolumn{8}{|c|}{ Peças produzidas } & 40599 \\
\hline
\end{tabular}

Conforme pode ser observado, coletou-se a quantidade total de 40.599 peças em um tempo de 1.017:17:00 (horas/minutos/segundos) em 66 dias (ao longo dos três meses) de produção das quatro peças em uma única máquina. Transformando o tempo de produção em minutos e dividindo pela quantidade total de peças, constatou-se que a capacidade média é de 1,503 peças por minuto na máquina. Referente aos operadores, a média diária de horas trabalhadas nos dois turnos é de 17,3 horas $(100 \%)$.

Diante destes dados, foi possível identificar a taxa média de chegada $(\lambda)$ das peças, onde para identificar esse indicador, dividiu-se a quantidade total de peças produzidas, pelos dias de produção nos três meses e após isso, realizou-se a divisão do resultado pela quantidade de horas trabalhadas nos dois turnos, pelos dois operadores $(40.599 / 66 / 17,3)$, resultando na taxa de chegada $(\lambda)=35,557$ por hora. Além disso, foi necessário identificar a taxa média de atendimento $(\mu)$ das peças na máquina. Realizou-se o cálculo de divisão de 60 minutos (1 hora) por 1,503 (capacidade de peças por minuto), resultando em média $\mu=$ 39,909 peças por hora.

Como visto no referencial teórico, a existência ou formação de filas em processos produtivos implicam em gargalos. A espera por peças que necessitam ser processadas ocasiona o aumento do tempo de produção, aumento de custo e perda de produtividade, entre outras consequências para a produção e para a empresa como um todo.

Portanto, em um estudo referente a possíveis formações de filas na máquina, a verificação da porcentagem de produção perante a meta e a capacidade de um eventual aumento de produção diária dos itens com maior demanda da empresa, realizou-se os cálculos das equações da Teoria das Filas do modelo de população ilimitada com servidor único a fim de identificar possíveis melhorias.

Onde:

Taxa média de chegada $(\lambda)=35,557 /$ horas

Taxa média de atendimento $(\mu)=$ 39,909/horas 
Máquinas $=1$

Operadores $=1$ em cada turno (2 turnos)

Unidade de tempo $=$ Horas

A seguir apresentam-se as equações matemática e suas definições, bem como os resultados encontrados.

Probabilidade de haver 0 peças no sistema $\left(P_{0}\right)$

$$
P_{0}=1-\frac{\lambda}{\mu}
$$

$P_{0}=0,109$

Conforme demonstrado na equação 1, a probabilidade de não haver nenhuma peça no sistema é em média 10,90\%.

Número de peças na fila $\left(L_{q}\right)$

$$
L_{q}=\frac{\lambda^{2}}{\mu(\mu-\lambda)}
$$

$L_{q}=7,279$

$\mathrm{Na}$ equação 2 apresenta-se o número médio de peças na fila, onde obteve o valor de 7,279 . Isso significa que, geralmente, há em média 7 peças por hora aguardando na fila para serem processadas na máquina.

Número de peças no sistema $(L)$

$$
L=\frac{\lambda}{\mu-\lambda}
$$

$L=8,1703$

A equação 3 apresenta o número de peças no sistema, isto é, a quantidade de peças que estão na fila de espera, mais as peças que estão sendo processadas pela máquina (em atendimento). Portanto, como resultado encontrou-se que em média 7 peças estão aguardando 0 processo de produção, enquanto 1 peça está sendo processada na máquina, ou seja em média há 8 peças no sistema.

Tempo de espera na fila $\left(W_{q}\right)$

$$
W_{q}=\frac{\lambda}{\mu(\mu-\lambda)}
$$

$W_{q}=0.2047$
$\mathrm{Na}$ equação 4 estimou-se o tempo médio que as peças devem esperar para serem processadas na máquina. Utilizando a taxa de chegada e atendimento em horas, foi encontrado então um tempo de 0,2048 horas por peça, ou seja, cada peça fica em média 12,28 minutos na fila de espera, antes de serem processadas.

Tempo gasto no sistema $(W)$

$$
W=\frac{1}{\mu-\lambda}
$$

$W=0,2298$

O tempo gasto no sistema refere-se ao tempo médio da peça na fila e na máquina, isto é, o tempo total de produção da peça. Também, utilizando as taxas em horas, o resultado encontrado é de 0,2299 horas por peça, ou seja, cada peça fica em média 13,78 minutos no sistema (para ser produzida).

Taxa de ocupação $(p)$

$$
\rho=\frac{\lambda}{\mu}
$$

$\rho=0,891$

De acordo com a equação 6 , a taxa de ocupação da máquina apresentou que a capacidade média diária de produção está em $89,10 \%$, o que significa que a produção está acima da sua média padrão, que é de $85 \%$.

Probabilidade de haver 12 peças no sistema

$$
P_{n}=\left(1-\frac{\lambda}{\mu}\right)\left(\frac{\lambda}{\mu}\right)^{n}
$$

$P_{12}=0,223$

Como já visto, normalmente constam 8,1703 peças no sistema, então foi calculada a probabilidade da empresa possuir mais de 12 peças no sistema. Deste modo, identificou que a probabilidade é de $22,3 \%$, portanto existe pouca chance de acontecer, segundo os cálculos.

No que se refere à produtividade, máquinas e tempo de produção, um fator muito importante que deve ser analisado, é o tempo de setup, onde como visto no referencial teórico, setup é o tempo em que a produção é interrompida para uma manutenção, mudança de equipamentos ou preparação das máquinas. Diante disto, o tempo de setup da máquina 
CN29 também foi analisado, já que interfere diretamente nos resultados do respectivo estudo, além do mais é importante salientar que o tempo de setup não é somado com o tempo total de produção.

Atualmente a empresa tem estipulado o tempo padrão de setup em 25 minutos. No período foram realizados 5 setups tendo 0:09:44 minutos de média (Tabela 2), ou seja, o tempo de setup está dentro do padrão estabelecido e, no momento, pode-se considerar que este tempo não influencia em perdas de produtividade.

Tabela 2 - Tempos de setup da máquina CN29

\begin{tabular}{|c|c|c|c|c|c|c|c|}
\hline PROCESSO & DATA & INÍCIO & FIM & TEMPO & PADRÃO & QTDA.PR. & NOME MÁQUINA \\
\hline USINAGEM CNC & $21 / 03 / 2018$ & $08: 49: 00$ & $09: 05: 04$ & $00: 16: 04$ & $00: 25: 00$ & 1 & CN29 MAZAK QSN 150S \\
\hline USINAGEM CNC & $09 / 04 / 2018$ & $23: 44: 40$ & $23: 48: 42$ & $00: 04: 02$ & $00: 25: 00$ & 1 & CN29 MAZAK QSN 150S \\
\hline USINAGEM CNC & $20 / 04 / 2018$ & $19: 12: 02$ & $19: 12: 43$ & $00: 00: 41$ & $00: 25: 00$ & 1 & CN29 MAZAK QSN 150S \\
\hline USINAGEM CNC & $04 / 05 / 2018$ & $22: 06: 19$ & $22: 14: 17$ & $00: 07: 58$ & $00: 25: 00$ & 1 & CN29 MAZAK QSN 150S \\
\hline USINAGEM CNC & $04 / 06 / 2018$ & $09: 34: 36$ & $09: 54: 30$ & $00: 19: 54$ & $00: 25: 00$ & 1 & CN29 MAZAK QSN 150S \\
\hline \multicolumn{7}{|c|}{ TOTAL: 0:48:39 } \\
\hline \multicolumn{70}{|c|}{ MÉDIA: 0:09:44 }
\end{tabular}

Uma informação importante que também foi coletada nesse intervalor de tempo, é que a produção não gerou nenhuma peça com inconformidade, o que não acarretou em retrabalho, perda de produção e aumento dos custos.

Considerando um período com o tempo de setup dentro do padrão e sem quebra de máquina, utilizando esses mesmos dados de tempo e sistema de produção, realizou-se uma simulação com as mesmas equações da Teoria das Filas, da possibilidade de aumentar o lote diário da produção das mesmas peças. Em primeiro momento foi determinado um aumento de 15 peças por dia, valor esse que resulta em 2,438\% da média de peças por dia. Contudo, a taxa de atendimento continuou a mesma $(\mu)=39,909$, já a taxa de chegada foi alterada para $(\lambda)=36,424$. Realizados os cálculos, obtiveram-se os resultados apresentados a seguir:

Número médio de peças na fila $(L q)=$ 9,5397;

- Número médio de peças no sistema $(L)=10,452$;

- Tempo médio gasto na fila $(\mathrm{Wq})=$ 15,71 minutos;

- Tempo médio gasto no sistema $(\mathrm{W})=$ 17,22 minutos;

- Taxa de ocupação (p) = 91,27\%.

De acordo com os resultados obtidos, por um lado não é indicado que a empresa aumente os lotes de produção das peças, pois além de aumentar o número de peças na fila, o que não é favorável, aumenta também em 3,44 minutos por peça no sistema (até que ela seja produzida), aumentando então o tempo de produtividade por dia. Outro fator a ser considerado é com relação a taxa de ocupação da máquina, que é aumentada para $91,27 \%$, fato esse que aumentando a produtividade e a capacidade de produção pelo tempo de produção, pode acarretar em queda da qualidade e gerar peças inconformes.

Por outro lado, para uma indicação de aumento de produção, seria necessário realizar um estudo mais aprofundado na questão dos custos da produção dessas 15 peças e uma forma para que a qualidade das peças não fosse atingida. Importante também citar que a escolha e o estudo de qual das quatro peças aumentaria a produção não foi realizada, pelo fato de que não interferiria no aumento da ocupação da máquina.

\section{CONSIDERAÇÕES FINAIS}

Com este estudo aplicado a processos industriais, pode-se observar que as filas são encontradas em vários lugares e processos, onde as mesmas tendem a prevalecer. Estudando um processo de fabricação em uma empresa e aliando o mesmo com a Teoria das Filas, ao final pode-se concluir que com as informações que resultam das equações, os gestores podem utilizá-las para um melhor dimensionamento e otimização de 
seus processos, aumentando a produtividade e melhor rendimento de seus operadores, buscando aumentar a margem de lucratividade.

A meta de produção diária da empresa em estudo é de $85 \%$ em relação a jornada de trabalho, onde os outros 15\% do tempo são estimados como improdutivos, pois são momentos de descanso, higiene, lanche e possíveis trocas de ferramental e insumos. Perante esta meta estipulada pela empresa, em relação a produção dos quatro itens com maior demanda de produção, foi verificada a porcentagem diária de produtividade, no intuito de verificar se ela está de acordo com a meta, levando em conta o sistema, a mão de obra e os tempos de produção da máquina. Portanto, através dos resultados das equações da Teoria das Filas, pode-se concluir que a produtividade da máquina CN29, do setor de usinagem, que produz quatro tipos de peças, está em 89,10\%, produzindo acima de sua meta estabelecida como ideal.

No que se refere ao problema da pesquisa, que buscou identificar se o atual sistema de produção viabiliza um aumento na produção de peças, indica-se um novo estudo da porcentagem da meta, no sentido de melhor

\section{REFERÊNCIAS}

[1] BARROS, Jaíne Medeiros; VASCONCELOS, Giancarllo Ribeiro. Análise de perdas durante o processo produtivo: estudo de caso em uma linha de fertilizantes. Universidade de Rio Verde. Rio Verde - GO. 2016. Disponível em: $<$ http://www.unirv.edu.br/conteudos/fckfiles/files/AN \%C3\%81LISE\%20DE\%2OPERDAS\%2ODURANTE\% 200\%2OPROCESSO\%2OPRODUTIVO_\%20ESTUD O\%20DE\%20CASO\%20EM\%2OUMA\%2OLINHA\%2 ODE\%2OFERTILIZANTES.pdf>. Acesso em 28/05/2018

[2] BLACK, J.T. O projeto da fábrica com o futuro. Traduzido por Gustavo Kannenberge. Bookman: Porto Alegre, 1988.

[3] BRUM, Danielli Vacari. Identificação das perdas do processo produtivo da fabricação de massas alimentícias: um estudo baseado em sistemas de custos. Dissertação de Mestrado. Santa Maria - RS. 2006. Disponível em: <http://repositorio.ufsm.br/bitstream/handle/1/8281/ DANIELLI. pdf?sequence $=1>$. Acesso em 28/05/2018. analisar e controlar o tempo de produção que a empresa considera improdutivo, já que a mesma não possui um controle neste sentido. Ainda, como um planejamento de ação estratégico para eliminação de perdas e melhorias, seria importante que este novo processo, ao identificar um gargalo ou perda de produção em relação ao tempo de produção e mão de obra, possa ser quantificado em valores monetários, uma vez que as perdas em valores monetários auxiliam na sensibilização e motivação para os colaboradores da necessidade e importância das melhorias, eliminação de desperdícios e otimização de processos.

Dessa forma, após ser realizado este planejamento, haveria a possibilidade de considerar o aumento do lote de produção das peças. Salienta-se ainda que, para isso, precisa-se ter a certeza de que o processo está adequado para manter o padrão de qualidade e garantir as especificações do cliente.

Como trabalhos futuros sugere-se analisar o percentual de produtividade de todos os setores da empresa, para identificar possíveis gargalos no âmbito geral e, baseado nos resultados seria possível avaliar a média de desempenho geral de produção da indústria.

[4] CAMPOS, Vicente Falconi. TQC Controle Total da Qualidade (no estilo Japonês). Editora INDG tecnologia e serviços. Nova Lima, 2004.

[5] DAMAZIO, Alex. Administrando com a Gestão pela Qualidade Total. Editora Interciência: Rio de Janeiro, 1988.

[6] MACEDO, Elisandro et al. Gestão da produção e o estudo de filas em uma indústria moveleira. 2017.

https://uceff.edu.br/anais/index.php/engprod/article /download/92/95/>. Acesso em: 04/09/2018.

[7] MARTINS, Petrônio Garcia; LAUGENI, Fernando P. Administração da produção. 3. ed. São Paulo: Saraiva, 2015.

[8] MOREIRA, Daniel Augusto. Pesquisa operacional: curso introdutório. Thomson Learing: São Paulo, 2007.

[9] PRODANOV, Cleber Cristiano; FREITAS, Ernani Cesar de. Metodologia do trabalho científico: métodos e técnicas da pesquisa e do trabalho acadêmico. 2. ed. Novo Hamburgo: Feevale, 2013. 
[10] SIMÕES, Márcio. Viu uma fila? Cuidado com os conflitos. 2016. Disponível em: $<$ https://imaginariopuro.wordpress.com/2016/10/11 /viu-uma-fila-cuidado-com-os-conflito>. Acesso em 27/06/2018.

[11] SLACK, Nigel; JONES, Alistair Brandon; JOHNSTON, Robert. Administração da produção.
Tradução Daniel Vieira. 8 ed. São Paulo: Atlas, 2018.

[12] TAHA, Hamdy A. Pesquisa operacional: uma visão geral. Tradução Arlete Simille Marques; revisão Rodrigo Arnaldo Scarpel. 8 ed. Pearson
Prentice
Hall:
São
Paul,
2008. 


\title{
Gapítulo 21
}

\section{GESTÃO DA INOVAÇÃO NA CADEIA DE SUPRIMENTOS DE MICRO E PEQUENAS EMPRESAS}

\author{
Ismael Cristofer Baierle \\ Jones Luis Schaefer \\ João Victor Kothe \\ Elpidio Oscar Benitez Nara \\ Cristiano Roos
}

Resumo: A gestão da cadeia de suprimentos busca integrar as empresas em geral com seus fornecedores e clientes, fazendo com que todos se tornem parceiros, gerando assim uma cadeia. A integração entre fornecedores, empresas e clientes faz com que todos trabalhem em sincronia, acarretando em prazos de entrega menores, programação de estoques mais refinada, entre outros. O que é pouco abordado ainda é como a gestão da cadeia de suprimentos pode e deve ajudar as empresas nos processos de inovação de produtos ou processos produtivos. $\mathrm{Na}$ realidade das micro e pequenas empresas, a limitação de recursos financeiros faz com elas voltem a atenção para o atendimento de necessidades imediatas, dificultando assim um adequado planejamento dos negócios. O presente artigo apresenta um estudo de múltiplos casos em 21 micro e pequenas empresas do Vale do Rio Pardo, região central do Rio Grande do Sul - Brasil. Os resultados apontam que a interação com clientes e fornecedores existe em grande parte das empresas, mas elas não possuem uma estrutura de tratamento adequada. Sem tratamento adequado e sem etapas a serem seguidas, as informações vindas de fornecedores e clientes se perdem dentro da empresa, e com isso a inovação não acontece. Com base nesses resultados, o objetivo é apresentar e propor um framework com um conjunto de elementos importantes para que seja implementada uma gestão adequada das informações vindas da cadeia de suprimentos e que podem dar origem a projetos de inovação de produtos ou processos.

Palavras Chave: Inovação, Gestão da cadeia de suprimentos, Micro e pequenas empresas. 


\section{INTRODUÇÃO}

A atuação das Micro e Pequenas Empresas (MPEs) pode ser considerada um fator que contribui para a economia das nações (PARK e YOO, 2017), sendo que elas têm sido uma parte fundamental da estratégia econômica dos governos para promover o crescimento econômico e competitivo (CADIL, MIROSNÍK e REHÁK, 2017). Garantir a competitividade das MPEs contribui para o crescimento do setor de manufatura e, por consequência, para a economia nacional (MATHUR et al., 2012), uma vez que as MPEs formam a espinha dorsal do setor de manufatura dos países em desenvolvimento e também dos países desenvolvidos.

Em 2013 havia cerca de 6,6 milhões de MPEs no Brasil e o crescimento médio no número de estabelecimentos no período compreendido entre 2003 e 2013 foi de 3,0\% ao ano, sendo que nesse período foram estabelecidas 1,7 milhão de novas micro e pequenas empresas no Brasil; entre 2003 e 2013 as MPEs criaram 7,3 milhões de novos postos de trabalho com carteira assinada, fazendo saltar de 9,8 milhões em 2003 para 17,1 milhões em 2013, o número de pessoas empregadas nessas empresas (SEBRAE, 2014).

Porém, o crescimento da economia brasileira perdurou até 2013 e a partir de 2014, com a mudança dos cenários políticos e econômicos fez com que o país passasse a ingressar num período de recessão econômica em 2015 com variação do $\mathrm{PIB}$ em $-3,8 \%$ e de $-3,6 \%$ em 2016 (G1, 2017). Desta forma, o Brasil continua a não se destacar pela competitividade da sua indústria, ocupando a posição 57 no ranking da IMD World Competitiveness Scoreboard 2016, caindo 17 posições desde 2009, ano em que esteve melhor posicionado em 40임ar (FGV, 2016). A crise pela qual o Brasil está passando tem atingido de maneira significativa as MPEs. De acordo com o Índice de Sobrevivência elaborado pelo SEBRAE, a tendência era de que 600 mil MPEs, entre as 1,8 milhão abertas em 2014, encerrassem suas atividades até o final de 2016, aumentando a mortalidade das empresas ao final dos primeiros dois anos de funcionamento de 23\% em 2014 para 33\% em 2016 (ASN, 2016).

Com a concorrência globalizada, as MPEs precisam crescer e inovar, e desenvolver suas capacidades tecnológicas e de informação pode constituir um fator de sucesso para essas empresas (RAYMOND, et al. 2018), aliando-se à proximidade com o cliente (ARBUSSA, BIKFALVI e MARQUĖS, 2017), à flexibilidade e reatividade frente ao mercado, diminuindo desvantagens como a menor produtividade, custos mais altos e desempenho pior de entregas no prazo em comparado com as grandes empresas (MOEUF, et al. 2018). Vê-se com isso que as MPE devem buscar nos seus fornecedores e clientes informações para seu negócio, seja para avaliar novas matérias-primas, saber se os produtos estão atendendo as exigências do mercado e/ou acompanhando tendências e, principalmente estar sempre em busca do aumento da produtividade e eficiência, refletindo assim em redução de custos e aumento da lucratividade.

Uma das maneiras para enfrentar as dificuldades e a concorrência é através da inovação. Segundo as políticas do estado do Rio Grande do Sul, a inovação corresponde a introdução de novos produtos, processos, serviços, estratégias de marketing e inovações organizacionais. Para que a inovação seja implementada, ela deve ser devidamente tratada, e para isso a empresa precisa ter a consciência de que é preciso inovar e, junto a isso, possuir um procedimento padrão sabendo quais são os elementos básicos que devem ser seguidos para que uma ideia se concretize e dê origem a uma inovação.

A inovação é um processo que deve envolver toda a organização. Para alcançar vantagem competitiva através dela, grandes e efetivos esforços da alta direção e alocação de recursos que reflitam a prioridade estabelecida para a inovação, a elaboração de processos e ferramentas customizados de gerenciamento da inovação, capacidade de se organizar para explorar seus recursos e capacidades, bem como para explorar o gerenciamento efetivo de projetos e capacidade empreendedora e de liderança do nível gerencial e técnico são essenciais para todas as organizações. (BARNEY, HESTERLY e ROSEMBERG, 2008; CARVALHO, SANTOS Y BARROS NETO, 2011; CARVALHO, SANTOS e BARROS NETO, 2013). A inovação busca trazer novas formas de fazer ou pensar algo que é feito há tempo, mas que pode ser feita de uma maneira diferente, mais fácil, menos trabalhosa, com custo mais baixo. Essas são as chamadas inovações incrementais. $\mathrm{Na}$ outra ponta, a inovação pode trazer para o mercado ou para processos produtivos, 
produtos ou processos de fabricação nunca antes vistos no mundo, que são chamadas de inovações radicais, pois mudam totalmente velhos conceitos.

Um empecilho que faz parte do dia-a-dia das micro e pequenas empresas é que não há receitas prontas para gerar inovações ou para gerenciar o seu processo. Além disso, nas MPEs existe pouca setorização, ou seja, uma mesma pessoa é responsável por compras, vendas, financeiro e até produção. Com isso, ideias que surgem de algum parceiro da cadeia de suprimentos muitas vezes são esquecidas ou não são viabilizadas pela falta de conhecimento de passos importantes para a implementação. As demandas ou necessidades de inovação são específicas a cada organização, e cabe a cada uma definir sua estratégia, seu posicionamento, seus recursos e suas capacidades. Dessa forma, as empresas customizam a gestão de seus processos de inovação segundo suas prioridades e recursos, já que determinadas especificidades restringem as opções gerenciais (QUADROS e VILHA, 2006; TIDD, BESSANT E PAVITT, 2008; CARVALHO, SANTOS e BARROS NETO, 2011; VILHA e QUADROS, 2012; CARVALHO, SANTOS e BARROS NETO, 2013).

Sabendo disso, o objetivo deste trabalho é apresentar e propor um framework que faz a integração dos processos de inovação que já são conhecidos na literatura com a realidade das MPE, criando um padrão simples que possa ser seguido por qualquer empresa, não importando a qual ramo pertence e nem qual a estratégia de mercado.

\section{INOVAÇÃO}

Para Collatto et al., (2014), a palavra inovação remete a algo diferente, novo, criativo, nunca visto. Joseph Schumpeter (1982), argumentava que os empresários procurariam fazer uso da tecnologia a fim de obter vantagens competitivas, lançando um novo produto ou um novo processo para produzir. É um processo em que há uma constante busca pela criação de algo novo e que ao mesmo tempo destrói velhas regras e estabelece novas, tudo isto com lucratividade (TIDD, BESSANT e PAVITT, 2008).

A inovação é efeito de um processo sistemático e organizado de mudança administrativa, que transforma novas ideias em realidades de sucesso. É um processo complexo que envolve riscos e precisa de gerenciamento efetivo, envolvendo três passos: novas ideias, seleção das boas ideias e implementação das mesmas (BESSANT e TIDD, 2009).

As MPEs têm vantagens comportamentais relacionadas a sua maior flexibilidade e capacidade de adaptação a mudança no mercado e despontam em atividades diversificadas devido a suas estruturas serem mais flexíveis que a de grandes empresas, o que as favorecem com respostas rápidas a mudanças no mercado. Nesse sentido, Collatto et al. (2014) defende que a inovação depende, em parte, da capacidade de encontrar novas maneiras de fazer as coisas, bem como de obter vantagem competitiva.

No dia-a-dia das empresas milhares de dados e informações circulam entre todos os funcionários, porém pouco ou quase nada é aproveitado da maneira correta. Como já mencionado, para que ocorra inovação, são necessários alguns passos e etapas importantes a serem seguidos. Na figura 1, apresentamos um modelo adaptado de Scherer e Carlomagno (2009) onde são evidenciados os quatro principais critérios para atingir a Inovação, que são: Estratégia, Estrutura, Relacionamento e Processos da empresa.

Figura 1 - Principais critérios para inovação

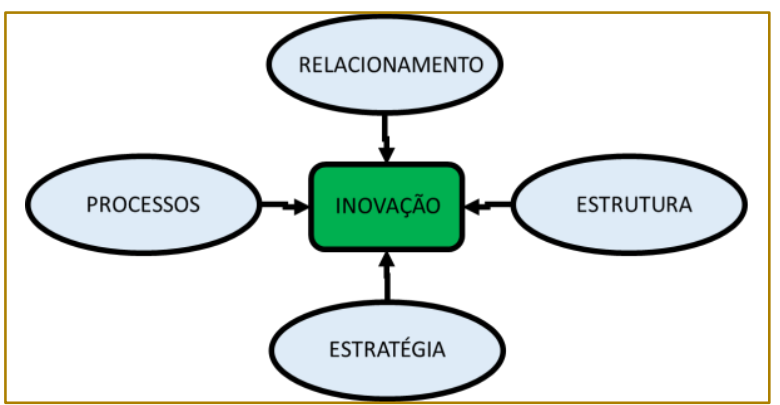

Fonte: Adaptado de Scherer e Carlomagno (2009) 
A estratégia de negócio da empresa deve estar alinhada com a estratégia de inovação e deve adotar objetivos e metas para gerenciar atividades inovadoras. A estrutura deve ser definida conforme o tipo de produto ou projeto da empresa, e definir como os projetos inovadores se inserem nesta. O relacionamento visa identificar a origem e abrangência das fontes de inovação. Ou seja, identificar se as fontes são internas ou se vem da cadeia. Como a empresa gera, avalia, experimenta e seleciona as ideias nas quais investir são os processos.

Esses quatro critérios não são conhecidos na prática pelas MPEs e isso dificulta o desenvolvimento e a implementação de ideias inovadoras no dia-a-dia, o que deixa a empresa obsoleta e apenas reativa a ação do mercado ou da concorrência.

\subsection{GESTÃO DA INOVAÇÃO COM FOCO NA CADEIA DE SUPRIMENTOS}

Como vimos na figura 1 , um dos critérios para inovação são os relacionamentos, que não tem mais importância que os outros três, mas que é um critério chave, pois vai determinar de onde e como virão as informações necessárias para dar origem a um projeto de inovação. O relacionamento com clientes, consumidores e fornecedores deve ser encarado pelas empresas com muita atenção, pois é daí que surge a necessidade de mudança. Para Munksgaard, Stentoft e Paulraj (2014), a inovação é muito importante para melhorar o desempenho de uma cadeia de fornecimento.

Saber se o que está sendo fabricado ou oferecido é o que o mercado procura e saber se o que o fornecedor lhe entrega é realmente o que você precisa. São coisas muito simples, mas que na realidade das MPEs não existe formalmente, ou seja, não são seguidos padrões e etapas. Para corroborar isso, Flint (2007) diz que empresas que inovam seguem processos formalizados para gerar ideias e vão passando para etapas subsequentes até estar pronta para ser implementada, ou seja, fazem a gestão da inovação.

A comunicação com a cadeia de suprimentos deve ir além de apenas troca de informações informais, ela deve ser planejada, programada e processada de uma forma sistemática, seguindo padrões pré-definidos e que estejam alinhados com a estratégia da empresa. Informações que chegam a empresa através da cadeia devem receber um tratamento adequado e preferencialmente envolver todos os funcionários, para que nenhuma ideia seja descartada ou deixe de ser analisada. Ainda segundo Flint (2007), a globalização adiciona uma considerável complexidade ao mercado, e para acompanhar e vencer essa complexidade é preciso o gerenciamento. Hansen e Birkinshaw (2007) comparam o processo de transformar ideias em inovação a um sistema integrado de fluxo, na lógica da cadeia de valor de Michael Porter para transformar matérias-primas em produtos acabados, onde podemos considerar a ideia como a matériaprima e a inovação como o produto acabado. Assim como em qualquer empresa, para transformar uma matéria-prima em um produto final é necessário um processo, para que ideias se tornem uma inovação também é preciso um processo e etapas para serem seguidas.

No capítulo a seguir, apresentamos o método de pesquisa, para saber que tipo de estudo foi feito, qual a amostra que foi entrevistada e o porquê da escolha dessa amostra.

\section{MÉTODOS DE PESQUISA}

Neste trabalho, foi adotada uma abordagem qualitativa utilizada quando se quer descrever o objeto de estudo com mais profundidade, sendo fundamental a influência do pesquisador sobre a pesquisa (MASCARENHAS, 2012). e realizado um estudo de casos múltiplos. Estudo de casos múltiplos tendem a ser mais robustos do que estudos de caso, caracterizados pela análise de evidências obtidas através da observação, análise de documentos e entrevistas (MOURA, GUIMARÃES e MORAES, 2017).

Foi realizada uma pesquisa bibliográfica para investigar sobre a temática da inovação em micro e pequenas empresas. Para Santos (2002), as pesquisas bibliográficas dotam de uma fonte de dados já organizadas e analisadas com informações e ideias prontas. Foram feitas buscas na base de dados Scopus por artigos dos últimos cinco anos, com as palavras-chave "supply chain innovation", "micro and small industries" e "management", e não foram encontrados artigos científicos internacionais que abordam especificamente a gestão das inovação na cadeia de suprimentos em micro e pequenas empresas. 
Desta forma, a pesquisa evoluiu para o estudo de casos múltiplos nas empresas para identificar se elas possuem integração com a cadeia de suprimentos na busca por inovação e como isso é feito. Para obter as informações necessárias de como se dá o processo de inovação em micro e pequenas empresas foram realizadas entrevistas com os gestores das empresas. Uma entrevista caracteriza-se por ser realizada face a face, onde o entrevistador visa conseguir informações de um entrevistado sobre algum assunto ou problema (PRODANOV e FREITAS, 2013). O questionário das entrevistas foi desenvolvido e validado pelo GMAP - Unisinos e é uma das ferramentas de diagnóstico utilizadas no Programa Extensão Produtiva e Inovação da Secretaria do Desenvolvimento Econômico, Ciência e Tecnologia do Rio Grande do Sul. As entrevistas foram feitas com os gestores de 21 empresas de micro e pequeno porte pertencentes ao arranjo produtivo local do Vale do Rio Pardo, região central do Rio Grande do Sul - Brasil. As 21 empresas pesquisadas participam desse Programa e estão trabalhando na conscientização e criação de um ambiente para Inovação e por isso foram selecionadas para esta pesquisa.
As entrevistas foram conduzidas pelo pesquisador e foram aplicadas a um gestor de cada empresa, através de um questionário estruturado com respostas do tipo sim e não. Após as estrevistas as respostas foram analisadas e os resultados gerados são mostrados a seguir.

\section{RESULTADOS E ANÁLISES}

As entrevistas tiveram como base três perguntas realizadas aos gestores:

- A empresa interage com clientes e fornecedores na busca por inovação?

- A empresa possui processo estruturado para condução da inovação?

- As ideias geradas ficam registradas em algum banco de dados?

Além destas 3 perguntas puderam ser coletadas informações complementares, comentários e impressões pessoais dos gestores. Para melhor visualização da proporcionalidade dos resultados obtidos foi elaborado o Figura 2.

Figura 2 - Resultados da pesquisa

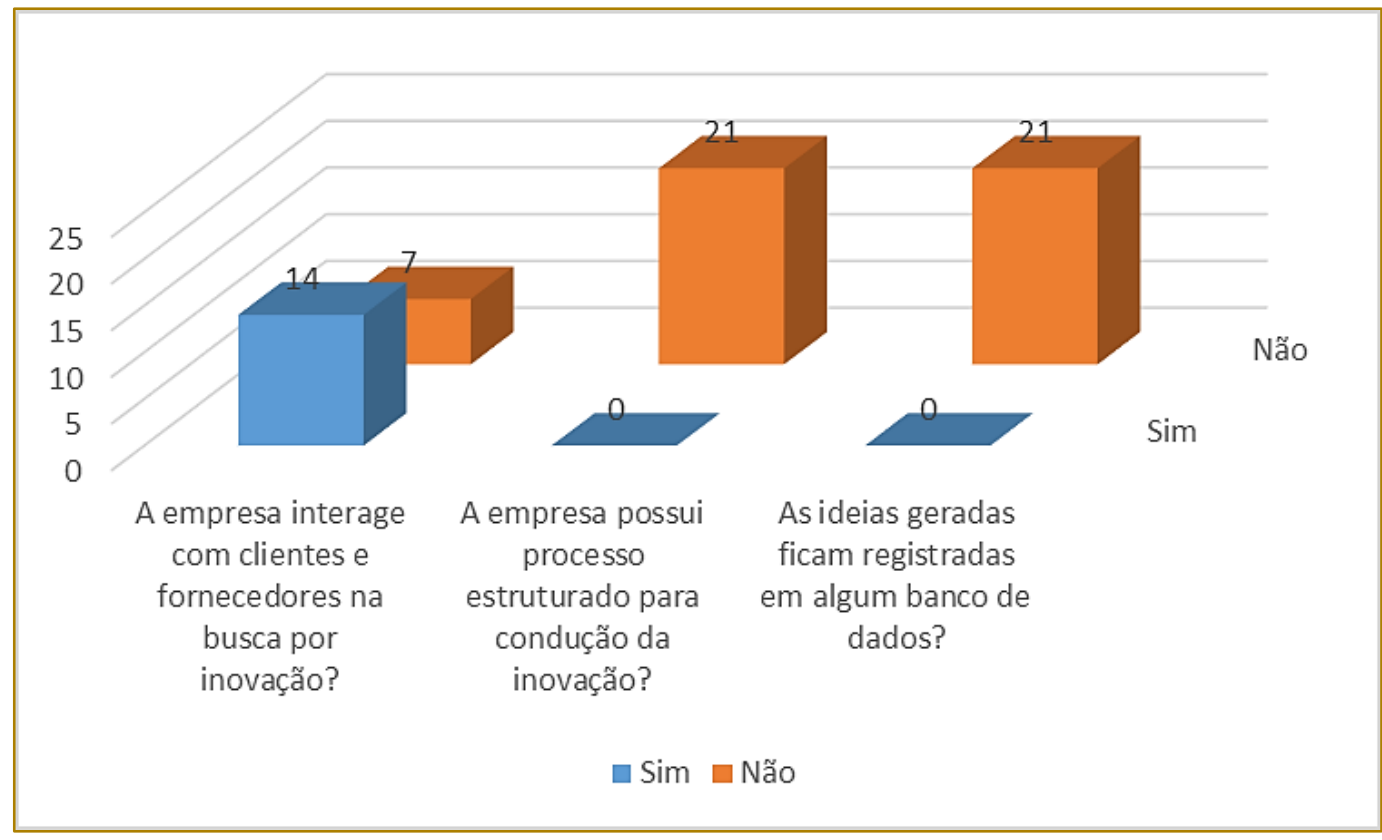

Fonte: Elaborado pelos autores (2018)

Das 21 empresas entrevistadas, 14 fazem a interação com clientes e fornecedores, seja para aperfeiçoar ou desenvolver novos produtos/processos, e garantem que a troca de informações entre os elos da cadeia é a principal fonte para dar origem a projetos de inovação. Isso representa pouco mais da metade da amostra, sendo que 7 empresas 
responderam que não interagem com clientes ou fornecedores, e o principal motivo é o receio de que estas podem Ihes copiar ou passar informações para a concorrência.

A segunda pergunta foi se as empresas possuem algum processo estruturado para condução da inovação, e neste quesito nenhuma delas possui um processo padronizado e fluxo de informações ou elementos importantes a ser seguido para gestão da cadeia com foco na inovação.

Em função disso, a resposta da terceira pergunta foi que elas também não possuem algum tipo de banco de dados onde fiquem registradas as ideias geradas ou projetos de inovação iniciados e já concluídos.

Vê-se com isso que as micro e pequenas empresas na grande maioria reconhecem a importância da inovação, porém nenhuma delas tem conhecimento de como conduzir, utilizar e armazenar de forma mais eficiente toda e qualquer ideia gerada a partir da interação com a cadeia de suprimentos. Pode ser percebido também que não existe nenhum tipo de gestão das informações referentes a ideias de inovação, nem quanto a integração dessas informações junto à cadeia de suprimentos.

Diante disso, propomos, na Figura 3, um framework conceitual onde apresentamos um conjunto de etapas importantes para o tratamento adequado de informações vindas da cadeia de suprimentos e que levam a inovação de produtos ou processos, relacionando os itens da Figura 1 e adaptando para o dia-a-dia das MPEs. Este framework conceitual foi criado com o intuito de ser bem simples e para que as empresas passem a fazer um maior controle das informações que chegam de clientes e fornecedores da cadeia de suprimentos. É um processo que deve envolver todos dentro da empresa, principalmente na coleta de informações.

Figura 3 - Etapas para gestão da cadeia de suprimentos com foco na inovação

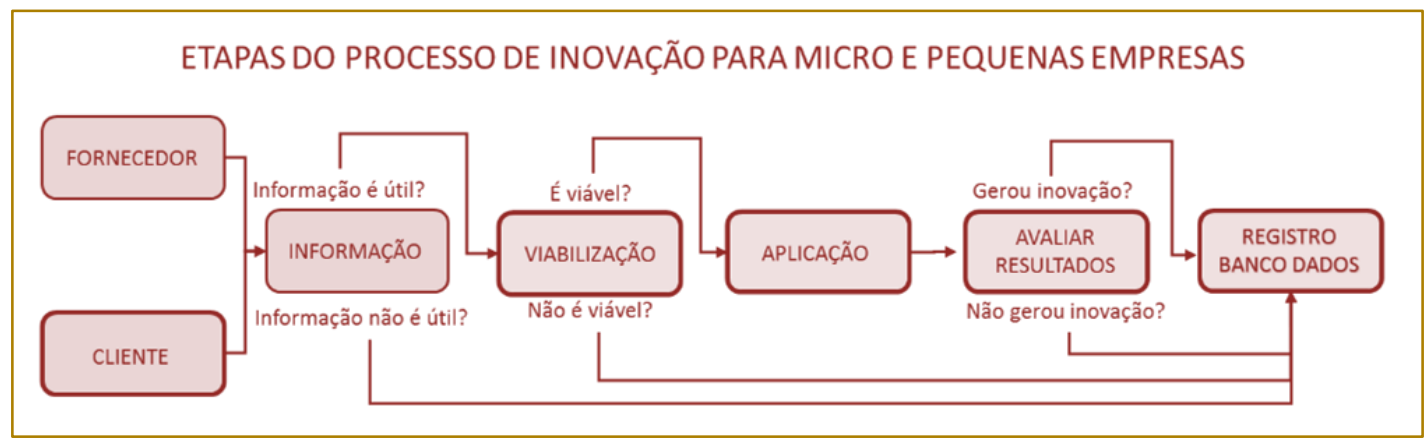

Fonte: Elaborado pelos autores (2018)

Assim que a informação é obtida, a primeira etapa é saber se a informação é útil ou não. Caso seja útil passa-se para a etapa seguinte, que é o estudo de viabilidade. Sendo viável, a etapa seguinte é a aplicação, onde as ideias vão ser testadas e colocadas em prática e após serão avaliados os resultados para validar e ver se eles deram origem a uma inovação. Para as etapas de viabilização, aplicação e avaliação dos resultados recomenda-se que sejam operacionalizadas por uma equipe de especialistas, composta por pelo menos 2 pessoas, de modo a avaliar adequadamente a viabilidade produtiva e econômica da inovação.

O objetivo deste framework com etapas bem definidas é fazer com que as empresas tenham mais controle sobre projetos de inovação, inclusive com a criação de um banco de dados para armazenagem de todos projetos. Pode-se observar no framework que, caso a informação não seja útil ou seja constatado no meio do projeto que ele não é viável, mesmo assim isso deve ser registrado em um banco de dados, para que em projetos futuros se tenha parâmetros para saber se determinadas informações já foram analisadas.

Com esse banco de dados, pretende-se que as empresas tenham um relacionamento maior com clientes e fornecedores e que possam fazer a correta gestão, inclusive para avaliar se a troca de informações está gerando resultados positivos para a empresa ou não. Isso pode ajudar a empresa a procurar por diferentes parceiros, por 
exemplo. É possível também pausar projetos iniciados e ser retomado mais tarde, do mesmo ponto em que foi paralisado, sem que haja perda de informações ou tempo para coletar dados novamente. Além de estimular a inovação nas empresas, através do controle mais pessoas podem se envolver nesse processo de interação com clientes e fornecedores, o que torna o processo mais dinâmico e com maiores chances de êxito nas ações.

\section{CONCLUSÃO}

Ao analisar os resultados obtidos com a pesquisa, observa-se que as micro e pequenas empresas não tratam da maneira correta o tema inovação. Como a estrutura e o número de funcionários é pequeno há um acúmulo de funções, geralmente o próprio dono da empresa é responsável por muitas tarefas administrativas e produtivas. Tudo isso, aliado a uma falta de conhecimento $e$ falta de padrão nos processos, faz com que a empresa tenha dificuldades de gerir novas ideias que podem dar origem a um produto inovador ou algum processo produtivo mais eficiente.

\section{REFERÊNCIAS}

[1] ARBUSSA, Anna, BIKFALVI, Andrea e MARQUĖS, Pilar Marquès. Strategic agility-driven business model renewal: the case of an SME. Management Decision, v. 55, nำ 2, p. 271-293, 2017.

[2] ASN. Disponível em: $<$ www.agenciasebrae.com.br/sites/asn/uf/NA/criseameaca-sobrevivencia-das-microepequenasempresas, f94b1ba91def8510VgnVCM1000004c00210aRCRD >. Acesso em: 09 jun. 2017

[3] BARNEY, Jay B., HESTERLY, William S. e ROSEMBERG, M. Administração estratégica e vantagem competitiva. São Paulo: Pearson Prentice Hall, 2008.

[4] BESSANT, John e TIDD, Joe. Inovação e Empreendedorismo. Porto Alegre: Bookman, 2009.

[5] CADIL, Jan, MIROSNÍK, Karel e REHÁK, Ján. The lack of short-term impact of cohesion policy on the competitiveness of SMEs. International Small Business Journal: Researching Entrepreneurship, v. 35, no 8, p. 991-1009, 2017.

[6] CARVALHO, Ruy de Quadros, SANTOS, Glicia Vieira dos e BARROS NETO, Manoel Clementino. Funil de inovação aplicado à gestão
Através da criação de um procedimento e etapas a serem seguidas para um posterior registro em banco de dados, o controle além de ficar mais fácil, fica disponível para mais de uma pessoa, descentralizando as decisões e fazendo com que a empresa não perca tempo com projetos que já foram iniciados uma vez e não deram certo. Isso vai tornar o processo de inovação mais confiável e vai tomar menos tempo, e com isso podem ser melhor planejadas as coletas de informações junto a cadeia de suprimentos.

As entrevistas com os gestores revelaram que, além da falta de gestão de projetos de inovação, a interação com a cadeia de suprimentos também não é realizada da maneira correta, pois há o medo de que a troca de informações, mesmo gerando alguma inovação e maior lucratividade para a empresa, possa dar margem para a empresa ser copiada por outras. Isso nos deixa em aberta uma lacuna de estudos futuros, a fim de identificar e analisar a cultura das empresas e quais as barreiras que devem ser quebradas para que elas reconheçam que a troca de informações na cadeia de suprimentos não é uma espionagem industrial e sim uma vantagem competitiva.

estratégica de projetos de P\&D focados no desenvolvimento de tecnologias: uma experiência no setor elétrico brasileiro. Anais do Encontro da Associação Nacional de Pós-Graduação e Pesquisa em Administração 35, 2011.

[7] CARVALHO, Ruy de Quadros, SANTOS, Glicia Vieira dos e BARROS NETO, Manoel Clementino. R\&D+ i strategic management in a public company in the Brazilian electric sector. Journal of Technology Management \& Innovation, 2013.

[8] COLLATO, Dalila Cisco, DRESCH, A., LACERDA, D. P., NETO, S. L. H. C. e TOMASZEWSKI, L. A. Modelo de Diagnóstico para Identificação do Nível de Inovação em Pequenas e Médias Empresas do Rio Grande do Sul. XXXVI Encontro Nacional de Engenharia de Produção, 2014

[9] FGV. Competitividade e Práticas de Gestão em Setores da Indústria Brasileira. São Paulo, 2016.

[10] FLINT, D. J. e LARSSON, E. Supply chain innovation. In MENTZER, J. T., MYERS, M. B.; STANK, T. P., Handbook of Global Supply Chain 
Management, SAGE Publications, Inc., United States of America, p. 475-486, 2007.

[11] G1

Disponível

em: $<$ www.g1.globo.com/economia/noticia/pibbrasileiro-recua-36-em-2016-e-tem-pior-recessaoda-historia.ghtml>. Acesso em 09 jun. 2017.

[12] HANSEN, Morten T. e BIRKINSHAW, Julian. The Innovation Value Chain. Harvard Business Review, Boston, p. 1-9, 2007. Disponível em:< http://hbr.org/2007/06/the-innovation-valuechain/ar/1>. Acesso em: 03.11.2017.

[13] LA REOVERE, Renata L. Perspectivas das micro, pequenas e médias empresas no Brasil. Revista de Economia Contemporânea, v. 5, no especial, p.137-154, 2000.

[14] MASCARENHAS, Sidnei A. Metodologia científica. 1 ed. São Paulo: Editora Pearson Education do Brasil, 2012.

[15] MATHUR, Alok, MITTAL, M. L. e DANGAYACH, Govind S. Improving productivity in Indian SMEs. Production Planning \& Control, v. 23, no 10-11, p. 754-768, 2012

[16] MOEUF, Alexandre, PELLERIN, Robert, LAMOURI, Samir, TAMAYO-GIRALDO, Simon e BARBARAY, Rodolphe. The industrial management of SMEs in the era of Industry 4.0. International Journal of Production Research, v. 56, $n^{-} 3, \mathrm{p}$. 1118-1136, 2018

[17] MOURA, Ravena R. A., GUIMARÃES, Eliete A. De A. e MORAES, Juliano T. Análise da implantação dos serviços de atenção à saúde da pessoa estomizada: Estudo de casos múltiplos em Minas Gerais, Brasil. Revista Estima, v. 15, no 4 , 2017.

[18] MUNKSGAARD, Kristin B., STENTOFT, Jan e PAULRAJ, Antony. Value-based supply chain innovation. Operations Management Research, v. 7, p. 50-62, 2014

[19] OSLO, Manual. The measurement of scientific and technological innovation data. In
OECD - Organization for Economic Co-operation and Development, 1997, p. 1-184. Disponivel em: <http://www.oecd.org/dataoecd/35/61/2367580.pdf >. Acesso em: 03.11.2017

[20] PARK, Kyung J. e YOO, Youngtae. Improvement of competitiveness in small and medium-sized enterprises. The Journal of Applied Business Research, v. 33, no 1, p. 173-194, 2017.

[21] PRODANOV, Cleber C. e FREITAS, Ernani C. Metodologia do trabalho científico: métodos e técnicas da pesquisa e do trabalho acadêmico. 20 ed. Novo Hamburgo: Feevale, 2013.

[22] QUADROS, Ruy e VILHA, Anapatrícia M. Tecnologias de informação no gerenciamento do processo de inovação. Revista Fonte, 5, 129-133, 2006.

[23] RAYMOND, Louis, UWIZEYEMUNGU, S., FABI, B. e ST-PIERRE, J. IT capabilities for product innovation in SMEs: a configurational approach. Information Technology and Management, v. 19, no 1, p. 75-87, 2018.

[24] SANTOS, A. Metodologia Científica: a Construção do Conhecimento. 5a ed. Rio de Janeiro: Lamparina, 2002.

[25] SCHUMPETER, J. A. A Teoria do Desenvolvimento Econômico. São Paulo: Abril Cultural, 1982.

[26] SEBRAE. Participação das Micro e Pequenas Empresas na Economia Brasileira. 2014.

[27] TIDD, Joe, BESSANT, John e PAVITT, Keith. Gestão da inovação (3ª ed.). Porto Alegre: Bookman, 2008.

[28] VILHA, Anapatrícia M. e QUADROS, Ruy. Gestão da inovação sob a perspectiva do desenvolvimento sustentável: lições das estratégias e práticas na indústria de higiene pessoal, perfumaria e cosméticos. Revista de Administração e Inovação, v. 9, nํㅜ 3, p. 28-52, 2012. 


\section{Capítulo 22}

\section{MÉTODOS GRÁFICOS PARA ANÁLISE E SOLUÇÃO DE PROBLEMAS NA MANUTENÇÃO DE INSTALAÇÕES UNIVERSITARIAS}

\section{Lenon Pinheiro da Silva}

\section{Cátia Fröhlich}

Resumo: As Instituições de Ensino Superior (IES) necessitam prover serviços de manutenção e conservação (SMC) adequados às demandas de seus públicos e dos requerimentos das suas estruturas e instalações. Inseridas em contextos complexos, onde compreender e comunicar a realidade torna-se fundamental para a gestão, as instituições devem buscar ferramentas que apoiam na visualização integrada dos problemas. Por isso, o objetivo deste artigo é submeter o conteúdo da revisão da literatura sobre SMC em instituições de ensino superior à análise da Teoria das Restrições, Pensamento Sistêmico e Diagrama de Ishikawa, com o objetivo de buscar a melhor análise do cenário encontrado na revisão bibliográfica. Foi possível identificar diferentes vantagens entre as ferramentas.

Palavras Chave: Instituições de Ensino Superior, Manutenção e Conservação, Métodos gráficos. 


\section{INTRODUÇÃO}

Com a expansão do número de instituições de ensino superior (IES) no Brasil, a competitividade vem aumentando entre elas (ODEDIRAN; GBADEGESIN; BABALOLA, 2015; CHIZZOTTI, 2014) e essa situação faz com que ocorra uma disputa para atrair alunos de diferentes maneiras. Uma dessas maneiras é a infraestrutura oferecida e, consequentemente, a conservação da mesma. Conforme a NBR 5674, as instalações são o suporte físico para a realização direta ou indireta das atividades (ABNT, 2012) e devem estar aptas para a realização dessas atividades (OLANREJAWU, 2012).

Os espaços acadêmicos das IES não estão recebendo a devida atenção dos seus administradores (VIDALAKIS; SUN; PAPA, 2013). Além disso, é considerável o número de gestores de IES que desconhecem o planejamento da manutenção e conservação das instalações dos campi (ODEDIRAN; GBADEGESIN; BABALOLA, 2015), faltando a eles uma visão geral da instituição (ARMANDO FILHO, 2012). Os gestores de manutenção e conservação possuem dificuldades em encontrar as causas dos problemas desses serviços (TALYULI, 2013). Agravam-se essas perspectivas quando utilizadas técnicas inadequadas de identificação e solução de problemas.

Entre as diversas ferramentas de análise e solução de problemas conhecidas, destacamse aquelas que possuem como objetivo fornecer a visão do todo, a partir de mapas ou gráficos da realidade, composto pela relação causa-efeito dos problemas. Bivona e Montemaggiore (2010) afirmam que esse tipo de técnica é melhor compreendida pelos gestores.

A partir da perspectiva de que o baixo desempenho de SMC pode prejudicar as IES, o objetivo desse artigo é apresentar diferentes tipos de mapas de causa-efeito de problemas encontrados na revisão da literatura e submeter à análise da Teoria das Restrições (Theory of Constraints - TOC), Pensamento Sistêmico e Diagrama de Ishikawa.

\section{MANUTENÇÃO E CONSERVAÇÃO EM INSTITUIÇÕES DE ENSINO SUPERIOR 2.1 CENÁRIO DOS SERVIÇOS DE MANUTENÇÃO E CONSERVAÇÃO}

Nos últimos anos vem ocorrendo avanços nos métodos de ensino que forçam mudanças nos espaços tradicionais das instituições. Beckers et al. (2015) afirmam que essas mudanças são progressivas em função das necessidades de adaptação aos novos contextos de aprendizagem.

Nesse novo contexto do ensino superior, as metodologias tradicionais de gestão das estruturas e instalações (EI) e dos SMC não acompanham as necessidades atuais, logo, não acompanharão no futuro. Por essa razão, é muito importante que o planejamento das El e SMC faça parte da estratégia das instituições (VIDALAKIS; SUN; PAPA, 2013).

As IES devem buscar a integração desses serviços em seu planejamento estratégico, porém muitas estão sendo forçadas a conseguir um uso mais econômico de suas estruturas (ODEDIRAN; GBADEGESIN; BABALOLA, 2015). Não são raras as instituições que enfrentam problemas inesperados e urgentes, para os quais devem ter uma solução imediata (COX; SCHLEIER, 2013). Situações como essas revelam que os SMC se caracterizam por ser uma das áreas mais negligenciadas em IES (OLANREJAWU; KHAMIDI; IDRUS, 2011). Bisaso (2010) afirma que quando mudanças nos serviços de manutenção representam mudanças para os demais setores da IES, podem-se encontrar resistências, o que dificulta a realização das adequações necessárias.

Geralmente as áreas de manutenção das instituições estão sobrecarregadas de demandas, sendo um agravante a tentativa de atingir consenso entre as partes interessadas (YAU, 2012). A dificuldade de interação entre as partes interessadas pode estar relacionada com 0 envolvimento das pessoas nas atividades, pois as crenças e os valores não são convergentes (REGINATO; GUERREIRO, 2011). Para Armando Filho (2012) essa questão é reflexo da falta de visão como um todo da IES. É importante buscar um consenso sobre as ações de melhoria, de forma a diminuir as vulnerabilidades das instituições (THEKDJI; LAMBERT, 2014).

Essas perspectivas revelam que faltam orientações políticas para o desenvolvimento adequado das EI (ODEDIRAN; GBADEGESIN; BABALOLA, 2015). Para Bisaso (2010) os SMC são adequados quando há integração entre demanda e capacidade dos mesmos. Esses serviços precisam estabelecer constância do propósito dentro da instituição para a sua melhoria contínua (LAWTON; IVANOV, 2014). É necessário melhorar a 
alocação de recursos, de forma que seja equivalente ao crescimento físico e econômico da instituição (DEN-HEIJER, 2012). Lawton e Ivanov (2014) ponderam que, para não ocorrer desperdícios de recursos, é importante priorizar ações de SMC que agreguem valor naqueles elementos que afetam a qualidade do ensino e aprendizagem.

\subsection{CUSTEIO DOS SERVIÇOS DE MANUTENÇÃO E CONSERVAÇÃO}

No atual cenário de mudanças do ensino superior, onde há necessidades de alteração e melhorias das estruturas, alocar recursos para a manutenção das instalações torna-se ainda mais difícil. As mudanças são ainda maiores, visando acompanhar as mudanças do perfil dos alunos que estão cada vez mais exigentes. Para Kamarazaly et al. (2013), tomar decisões de investimento em serviços de manutenção está cada vez mais complexo devido às mudanças em tecnologia educacional, aprendizagem e expectativas dos alunos.

Um agravante desse cenário é o aumento dos valores com a manutenção das estruturas e instalações (OLANREJAWU; KHAMIDI; IDRUS, 2010; LI; GUO, 2012). Tanto os materiais quanto a mão-de-obra estão com custos altos em função do aquecimento do mercado da construção civil. Segundo Lawton e Ivanov (2014), se faz necessário investir na ampliação do conhecimento dos trabalhadores de SMC, bem como na qualidade dos materiais utilizados, pois aumenta a produtividade e poupa recursos.

Os gestores da área de manutenção enfrentam uma "disputa" orçamentária entre departamentos da IES (KAMARAZALY et al., 2013). Isso porque o orçamento para esses serviços concorre com investimentos em outras áreas, como contratação de membros do corpo docente ou novos programas de pesquisa (DEN-HEIJER, 2012). Del-Palacio, Sole e Berbegal (2011) afirmam que, por vezes, o orçamento para a manutenção das instalações é o que sobra da distribuição entre demais gastos da instituição. Como consequência, esses serviços acabam tendo que utilizar o orçamento do período anterior ou usam alguma quota fixada arbitrariamente (REIS; COSTA; TEIXEIRA, 2013).

\subsection{GESTÃO DOS SERVIÇOS DE MANUTENÇÃO E CONSERVAÇÃO}

Mesmo com baixo orçamento e problemas de consenso entre os setores, é esperado dos gestores de SMC formas criativas de alcançar valor agregado e, ao mesmo tempo, buscar que esses serviços sejam de baixo custo para a instituição (KAMARAZALY et al., 2013). Ou seja, independentemente das disponibilidades, a demanda pelos serviços de manutenção não é reavaliada pelas IES. Nessa busca incessante, os gestores se deparam com dificuldades para estabelecer metas e acompanhar as operações de serviços (OLANREJAWU; KHAMIDI; IDRUS, 2010), o que caracteriza as ações corretivas como predominantes nas instituições em comparação com as ações preventivas (BISASO, 2010).

A situação desses serviços fica ainda mais complexa devido à falta de planejamento. Segundo Odediran, Gbadegesin e Babalola (2015), parte considerável dos gestores das IES desconhecem o planejamento dos serviços de manutenção ou têm dificuldades para realizar. Como resultado, nem todas as demandas desses serviços são entregues de forma adequada (SAWYERR; YUSOF, 2013). Para Ni e Jin (2012) o planejamento das atividades deve considerar a produtividade e a qualidade da execução das atividades.

Além da qualidade dos serviços, a velocidade na execução é um dos requisitos importantes dos SMC. Assaf (2011) defende que é necessário aumentar a velocidade de execução dos serviços para melhorar os requisitos de qualidade. Entretanto, a velocidade nas entregas, por vezes, não é acompanhada de qualidade, impactando no aumento do número de falhas por ações inadequadas (TALYULI, 2013).

As instituições de ensino também sofrem deterioração e obsolescência (LI; GUO, 2012), por isso quando ocorre ineficiência ou ausência dos serviços acaba por reduzir a durabilidade, desempenho funcional e satisfação dos alunos (LAI, 2010). Além disso, processos e sistemas ineficientes são frequentemente responsáveis por problemas nas entregas dos SMC, podendo ser agravadas por falta de habilidades técnicas nas operações, gestão inadequada e limitações de recursos (ISA; USMEN, 2015). 


\subsection{RELAÇÃO DOS SMC COM OS ALUNOS}

As relações das IES com os alunos vêm mudando ao longo dos últimos anos. Há uma crescente expectativa dos usuários das El, que estão mais exigentes em um ambiente que está em constante mudança (ISA; USMEN, 2015). Isso explica o motivo do aumento das críticas por parte dos usuários das instalações, que exigem melhorias constantemente.

O perfil atual dos alunos indica que eles buscam mais do que aprendizado em sala de aula, mas também ambientes que oferecem conforto e conveniência. Os alunos consideram importante as estruturas, bem como a sua conservação quando optam pela instituição (ALCARAZ; MORALES, 2012). Por essa razão, os serviços relacionados à manutenção das instalações podem ou não propiciar uma imagem positiva (POLAT, 2011), o que também contribui para a atração e retenção de alunos (KARNA; JULIN, 2015).

Nesse sentido, a falta de ação em função dos altos custos de serviços e materiais, bem como o desempenho abaixo da necessidade, pode prejudicar as atividades acadêmicas e administrativas das IES (ISA; USMEN, 2015). Isso reforça a importância que os serviços de conservação devem ter para as instituições, de forma a estar em equilíbrio com as demandas das estruturas e dos alunos, tornando competitivas as organizações perante o mercado (NI; JIN, 2012).

\section{FERRAMENTAS DA QUALIDADE}

Dentre tantas ferramentas da qualidade como por exemplo, 5W2H, 5WHY e Diagrama de Pareto, esse artigo utiliza a Teoria das Restrições, Pensamento Sistêmico e Diagrama de Ishikawa.

\subsection{TEORIA DAS RESTRIÇÕES}

A Teoria das Restrições (TOC) é um conjunto de ferramentas e técnicas que permitem a resolução de problemas ou desenvolvimento de uma estratégia utilizando a lógica de causa-efeito-causa (COX; SPENCER, 2002). Dentre as ferramentas, esta pesquisa utiliza a Árvore da Realidade Atual (ARA). Essa ferramenta baseia-se na lógica para identificar e descrever as relações, por meio de um mapa de causa-efeito, ajudando a determinar problemas centrais que causam os efeitos indesejáveis. Na obra de Cox e Spencer (2002, p. 253), são apresentadas as etapas para construção da ARA.

O problema principal está localizado na parte inferior da ARA e é lida a partir desse ponto, prosseguindo para cima e utilizando "se... então" (TAYLOR; NAYAK, 2012). A Figura 1 demonstra um exemplo de ARA.

Figura 1 - Árvore da Realidade Atual

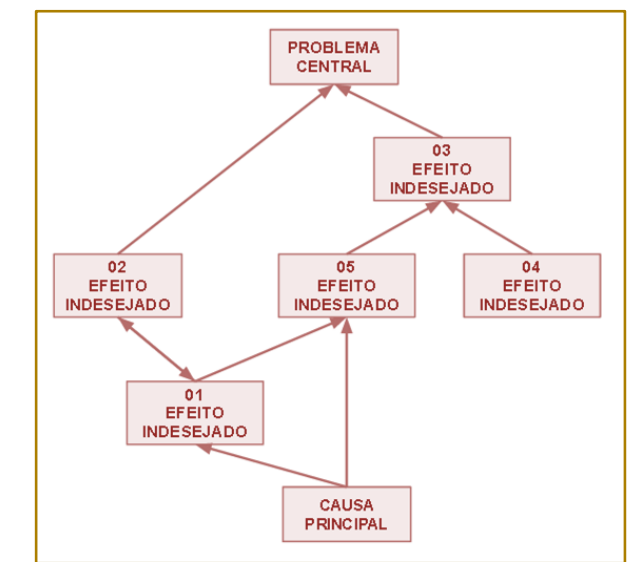

Fonte: Adaptado de Cox e Schleier (2013, p. 774)

\subsection{PENSAMENTO SISTÊMICO}

O Pensamento Sistêmico se inicia com um problema a ser resolvido, uma situação que precisa ser entendida ou um comportamento não desejado que deva ser corrigido ou evitado. Essa ferramenta auxilia a desenvolver descrições explícitas de relação causal dentro de uma estrutura formal de feedback entre os problemas identificados (SAHAY; KUMAR, 2014), conforme apresentado na Figura 2. 
Figura 2 - Mapa Sistêmico

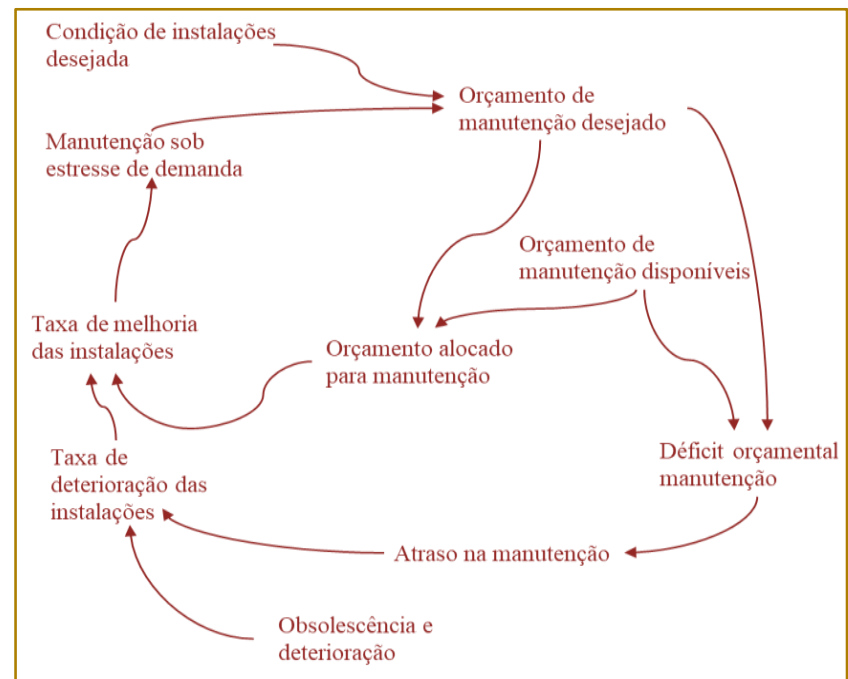

Fonte: Adaptado de Fallah-Fini et al. (2010, p. 05)

\subsection{DIAGRAMA DE ISHIKAWA}

O Diagrama de Ishikawa é amplamente utilizado na análise e solução de problemas, inclusive na gestão da qualidade da manutenção. O diagrama busca apresentar gráfico com as relações de causas e efeitos, bem como ramificações primárias e secundárias (BALLESTERO-ALVAREZ, 2010). A Figura 3 apresenta a estrutura do diagrama.

Figura 3 - Diagrama de Ishikawa

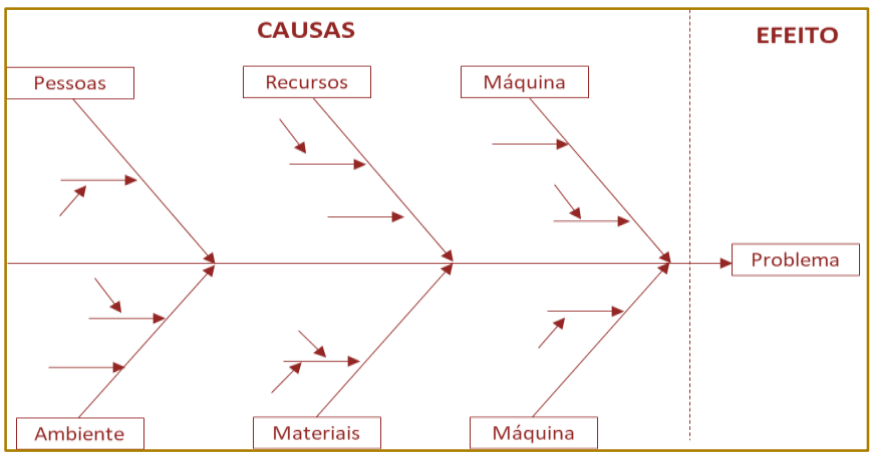

Fonte: Adaptado de Ishikawa (1993)

\section{PROCEDIMENTOS METODOLÓGICOS}

Essa pesquisa qualitativa parte de uma revisão de publicações dos últimos 20 anos, realizada na base de dados Ebscohost, em que se buscou produções científicas por meio do cruzamento de palavras-chaves relacionadas à manutenção e conservação com IES. As publicações foram selecionadas e classificadas conforme o alinhamento com esse estudo.

O conteúdo da revisão da literatura foi submetido às regras de diagnóstico de problemas da TOC, por meio da ferramenta ARA, do Pensamento Sistêmico e do Diagrama de Ishikawa. Foram construídos os mapas com as relações causa-efeito, conforme indicado por cada ferramenta.

Após a análise individual das estruturas foram comparados os resultados de cada ferramenta, de acordo com os seguintes atributos:

- Identificação do problema(s) ou causa(s) central(is);

- Clareza entre as correlações dos problemas;

- Capacidade de análise crítica da situação geral;

- Apresentação e comunicação da estrutura. 


\section{RESULTADOS}

A partir da revisão da literatura sobre o tema abordado foram destacados problemas ou potenciais problemas que podem afetar 0 desempenho dos serviços, bem como suas consequências. O Quadro 1 apresenta as causas/efeitos com os códigos (para orientação nos mapas) e os autores.

Ao analisar todas as causas/efeitos que emergiram da revisão da literatura, buscou-se identificar o maior efeito possível. Considerase o mais grave a "vulnerabilidade da IES", correspondente ao código 43 do Quadro 1.

Quadro 1 - Problemas com SMC

\begin{tabular}{|c|c|c|}
\hline Autores & Código & Causas e/ou Efeitos \\
\hline Alcaraz e Morales (2012) & 41 & El impactam na escolha da IES pelos alunos \\
\hline Armando Filho (2012) & 10 & Falta de visão como um todo da IES \\
\hline \multirow{2}{*}{ Assaf (2011) } & 28 & A velocidade de execução dos SMC é lenta \\
\hline & 29 & A qualidade dos SMC é insuficiente \\
\hline \multirow{2}{*}{ Beckers et al. (2015) } & 1 & Mudanças constantes de necessidades \\
\hline & 3 & Falha de planejamento dos espaços \\
\hline \multirow{3}{*}{ Bisaso (2010) } & 6 & A IES é resistente às melhorias em SMC \\
\hline & 11 & Falta integração entre demanda e capacidade dos SMC \\
\hline & 35 & SMC corretivos são predominantes nas IES \\
\hline Cox e Schleier (2013) & 4 & Ocorrem demandas não planejadas \\
\hline $\begin{array}{c}\text { Del-Palacio, Sole e } \\
\text { Berbegal (2011) }\end{array}$ & 21 & Os SMC acabam ficando com sobras de orçamentos \\
\hline \multirow{2}{*}{ Den-Heijer (2012) } & 14 & Crescimento físico e econômico da IES não é equivalente aos SMC \\
\hline & 19 & Investir em SMC não é prioridade da IES \\
\hline \multirow{5}{*}{ Isa e Usmen (2015) } & 36 & Falta habilidade técnica para execução dos SMC \\
\hline & 37 & Processos ineficientes de SMC \\
\hline & 39 & Há exigência de melhoria dos serviços e estruturas \\
\hline & 44 & A falta de SMC prejudica as atividades acadêmicas \\
\hline & 46 & Baixo desempenho dos SMC prejudica as atividades da IES \\
\hline \multirow{4}{*}{ Kamarazaly et al. (2013) } & 18 & Disputa por orçamento entre setores da IES \\
\hline & 20 & Alocação de recursos não é adequada \\
\hline & 25 & Dificuldade para obter SMC ágeis, de qualidade e baixo custo \\
\hline & 40 & Há um aumento nas expectativas dos usuários \\
\hline Karna e Julin (2015) & 42 & El e SMC ineficientes não retêm alunos \\
\hline \multirow{2}{*}{ Lai (2010) } & 27 & SMC ineficientes reduzem a durabilidade e desempenho das El \\
\hline & 45 & SMC ineficientes reduzem a satisfação dos alunos \\
\hline \multirow{3}{*}{ Lawton e Ivanov (2014) } & 13 & Falta estabelecer os propósitos dos SMC \\
\hline & 15 & Não são priorizados SMC que agregam valor acadêmico \\
\hline & 22 & Os SMC de baixo custo são executados \\
\hline \multirow{2}{*}{ Li e Guo (2012) } & 17 & SMC estão com custos elevados \\
\hline & 31 & As IES também sofrem deterioração e obsolescência \\
\hline Ni e Jin (2012) & 33 & A execução dos SMC é complexa \\
\hline \multirow{4}{*}{$\begin{array}{c}\text { Odediran, Gbadegesin e } \\
\text { Babalola (2015) }\end{array}$} & 2 & Uso elevado dos recursos disponíveis \\
\hline & 12 & Falta de orientações políticas para desenvolvimento das El \\
\hline & 34 & Os gestores de SMC desconhecem as necessidades das EI \\
\hline & 38 & Há dificuldade para realizar o planejamento dos SMC \\
\hline \multirow{3}{*}{$\begin{array}{l}\text { Olanrejawu, Khamidi e } \\
\text { Idrus (2010) }\end{array}$} & 24 & As El são afetadas pelo uso \\
\hline & 26 & Não há tempo hábil para gerir os SMC \\
\hline & 5 & O SMC é uma das atividades mais negligenciadas em IES \\
\hline $\begin{array}{c}\text { Reginato e Guerreiro } \\
(2011)\end{array}$ & 9 & Dificuldade de interação entre os setores da IES \\
\hline $\begin{array}{l}\text { Reis, Costa e Teixeira } \\
(2013)\end{array}$ & 23 & Alocação de recursos é arbitrária ou não planejada \\
\hline Sawyerr e Yusof (2013) & 30 & Os SMC não são entregues de forma adequada \\
\hline Talyuli (2013) & 32 & Apenas velocidade acaba prejudicando a qualidade dos SMC \\
\hline Thekdji e Lambert (2014) & 43 & Aumento da vulnerabilidade da IES no mercado \\
\hline $\begin{array}{c}\text { Vidalakis, Sun e Papa } \\
\text { (2013) }\end{array}$ & 16 & Decisões de investimentos são complexas \\
\hline \multirow{2}{*}{ Yau (2012) } & 7 & O setor de SMC está sobrecarregado \\
\hline & 8 & Não há consenso da IES para priorizar os SMC \\
\hline
\end{tabular}




\section{1 ÁRVORE DA REALIDADE ATUAL DOS SMC EM IES}

A partir da relação "se-então", a estrutura foi construída debaixo para cima, onde constam em extremidades opostas a causa principal (base) e o efeito indesejado principal (topo). A

Figura 4 apresenta a ARA.

Figura 4 - ARA dos SMC em IES

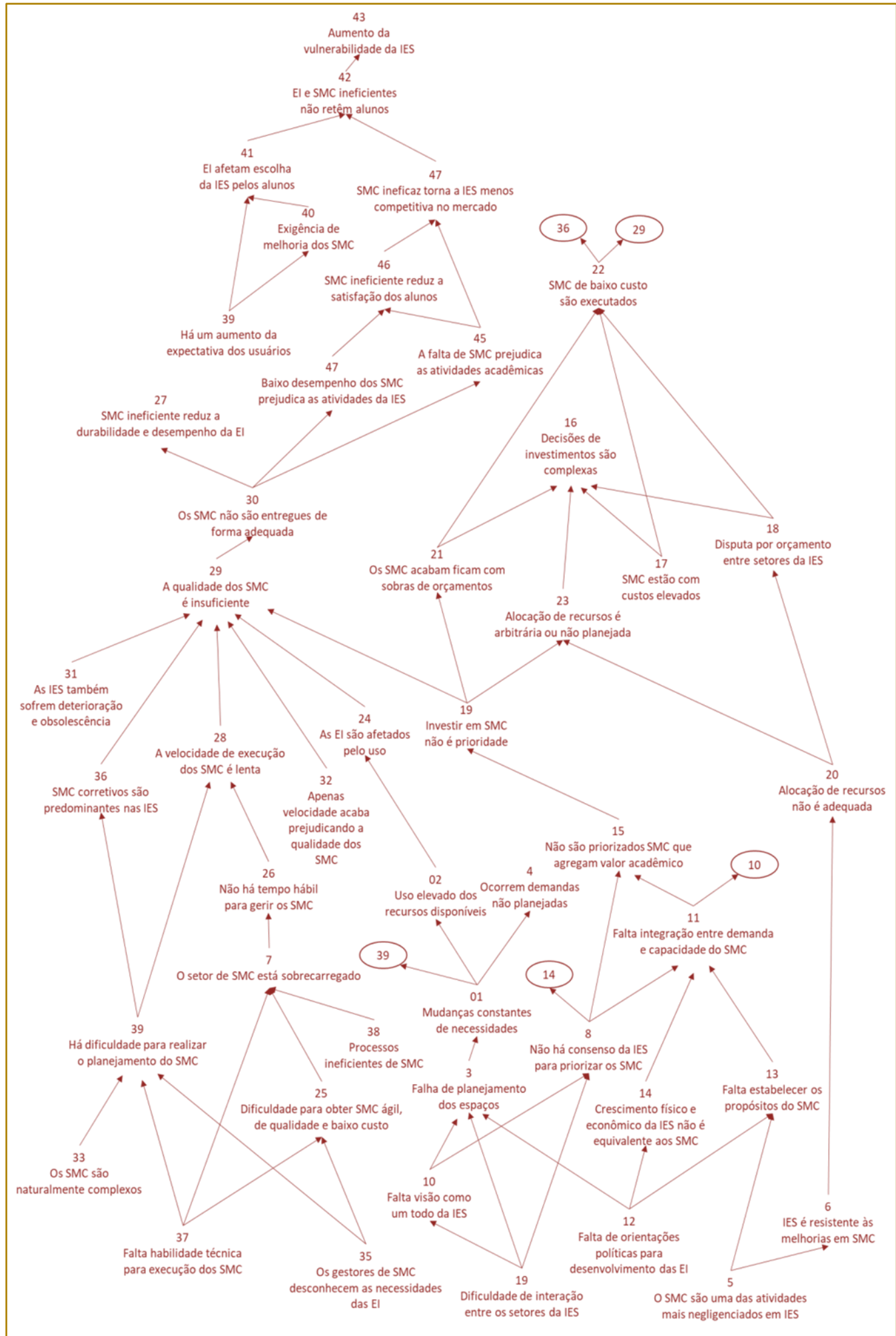

Fonte: Elaborado pelos autores 


\subsection{MAPA SISTÊMICO DOS SMC EM IES}

Para a construção do mapa sistêmico, ao contrário da ARA, a descrição das variáveis foi alterada. Isso se deve ao fato de que nos textos originais, oriundos da revisão da literatura, haviam palavras que denotavam qualidade ou adjetivo, o que não é procedimento no Pensamento Sistêmico. A Figura 5 apresenta essas variáveis e as correlações entre si. As linhas contínuas representam relações diretamente proporcionais e as pontilhadas inversamente proporcionais.

Figura 5 - Mapa sistêmico dos SMC em IES

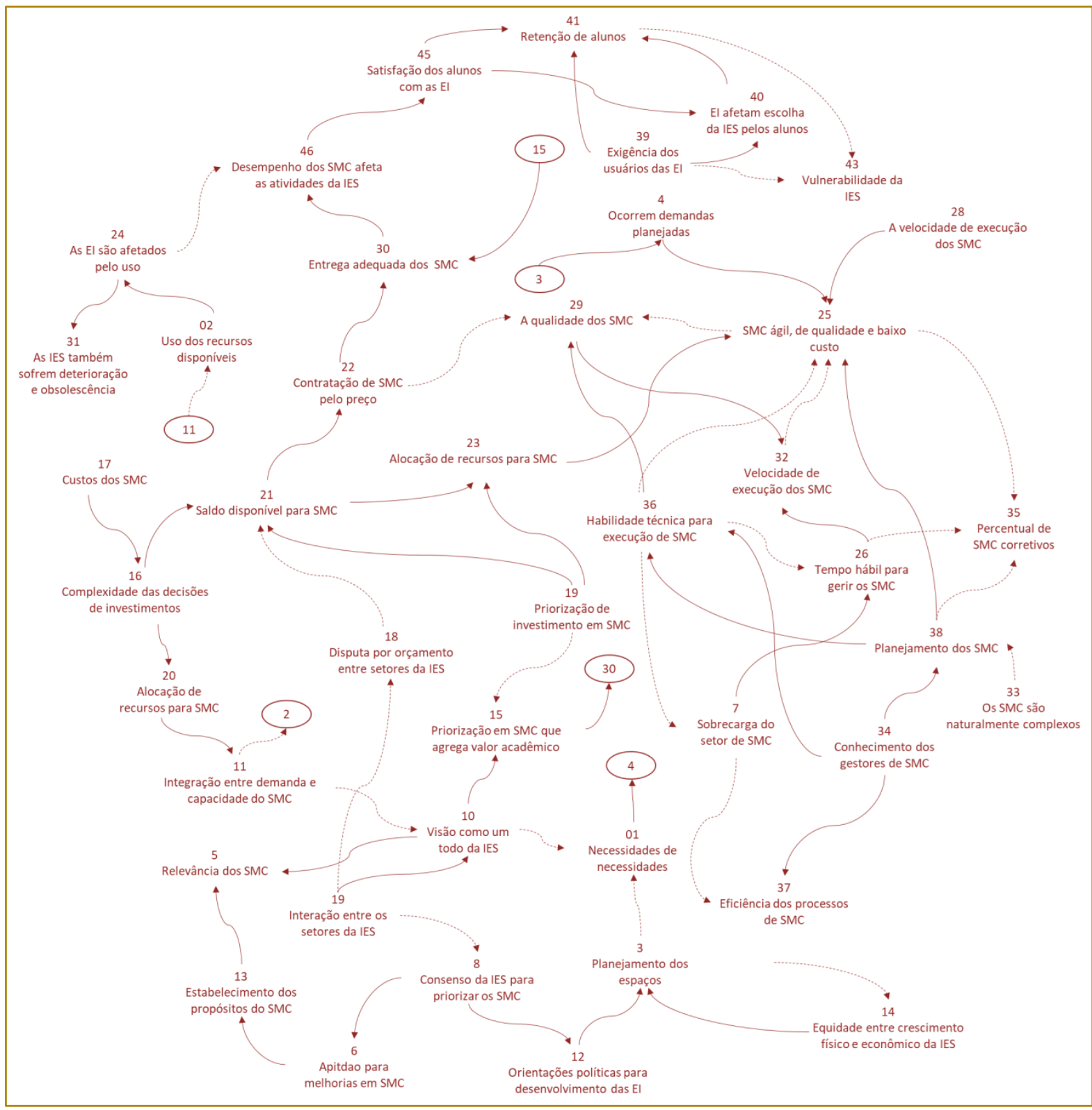

Fonte: Elaborado pelos autores

No mapa podem ser representados e nomeados os enlaces entre as variáveis, podendo ser reforçador ou balanceador. Essa técnica permite particularizar algum ponto do mapa para ser trabalhado individualmente as relações entre as variáveis. Porém, neste artigo não estão representados, por não se tratar do foco. 
A Figura 6 apresenta a estrutura do Diagrama de Ishikawa a partir das mesmas variáveis encontradas na revisão da literatura.

Figura 6 - Diagrama de Ishikawa

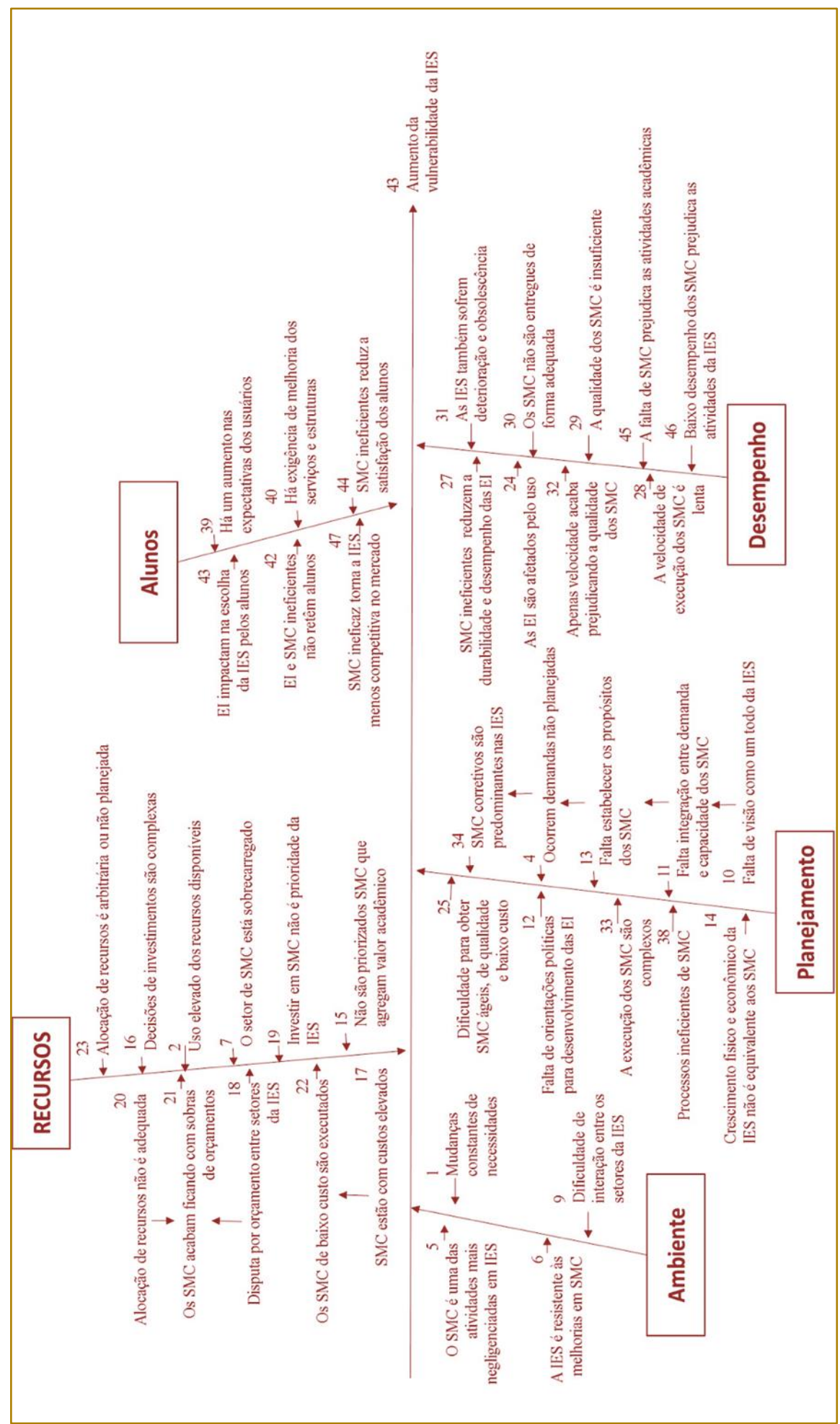

Fonte: Elaborado pelos autores 


\subsection{COMPARAÇÃO DOS RESULTADOS DAS FERRAMENTAS}

O Quadro 2 apresenta a análise dos atributos de cada ferramenta.

Para fins de melhor análise de problemas complexos, principalmente aqueles que envolvem fatores políticos, a utilização combinada dessas ferramentas pode trazer vantagens. Ou ainda, dependendo do nível de amadurecimento sobre o assunto e o domínio de determinada ferramenta, pode-se começar a construção por uma ferramenta menos complexa e complementar com as demais, conforme necessidade. Por exemplo, iniciar com Ishikawa, após avançar para a Teoria das Restrições e finalizar com o Pensamento Sistêmico. O cenário da IES, bem como as pessoas envolvidas no assunto poderão ter mais ou menos aderência à determinada ferramenta.

Quadro 2 - Comparação dos atributos das ferramentas

\begin{tabular}{|c|c|c|c|}
\hline Atributos & Teoria das Restrições (ARA) & Pensamento Sistêmico & Ishikawa \\
\hline 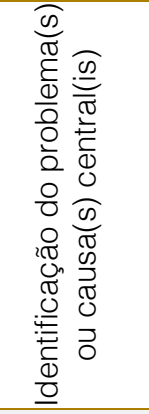 & $\begin{array}{l}\text { Conseguiu definir e destacar } \\
\text { na estrutura as causas } \\
\text { principais dos problemas } \\
\text { (começam pela base da } \\
\text { estrutura). }\end{array}$ & $\begin{array}{l}\text { Colocou os efeitos } \\
\text { principais no centro da } \\
\text { estrutura, mas não deixa } \\
\text { claro o ponto de partida. } \\
\text { Sem auxílio daquele que a } \\
\text { construiu, pode ser difícil o } \\
\text { início da interpretação. }\end{array}$ & $\begin{array}{l}\text { Reúne e destaca as causas } \\
\text { por tema. Não } \\
\text { necessariamente há uma } \\
\text { ordem de apresentação dos } \\
\text { temas, mas considerando a } \\
\text { leitura da esquerda para a } \\
\text { direita, é possível organizar } \\
\text { para que se tenha o princípio } \\
\text { das causas. }\end{array}$ \\
\hline 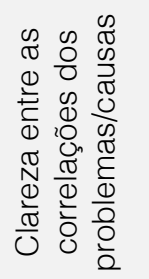 & $\begin{array}{l}\text { É possível observar início e } \\
\text { fim da estrutura. Algumas } \\
\text { correlações não ficam claras } \\
\text { ou se tornam de difícil ligação } \\
\text { em função do método de } \\
\text { construção. }\end{array}$ & $\begin{array}{l}\text { Consegue explorar melhor } \\
\text { as correlações entre as } \\
\text { causas dando oportunidade } \\
\text { para que muitas ocorram. }\end{array}$ & $\begin{array}{l}\text { As correlações ficam dentro } \\
\text { do próprio tema, porém se } \\
\text { torna difícil fazer as } \\
\text { correlações entre os próprios } \\
\text { temas. }\end{array}$ \\
\hline 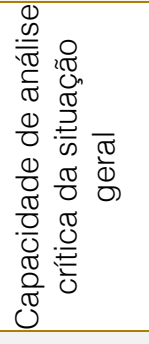 & $\begin{array}{l}\text { É possível visualizar que há } \\
\text { poucas causas dos efeitos, } \\
\text { bem como oportunidades de } \\
\text { melhorias sem, } \\
\text { necessariamente, passar } \\
\text { pelas causas centrais. }\end{array}$ & $\begin{array}{l}\text { Com apoio na leitura, é } \\
\text { possível entender as } \\
\text { causas e efeitos, bem como } \\
\text { identificar "trilhas ou } \\
\text { caminhos" para priorizar as } \\
\text { melhorias. }\end{array}$ & $\begin{array}{l}\text { Deixa clara a situação geral, } \\
\text { porém para uma análise e } \\
\text { proposição de melhorias, } \\
\text { pode ser insuficiente em } \\
\text { função da falta das } \\
\text { correlações dos temas. }\end{array}$ \\
\hline 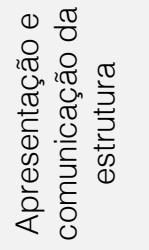 & $\begin{array}{l}\text { Consegue comunicar bem } \\
\text { quais causas geram os } \\
\text { efeitos. Textos na íntegra } \\
\text { permitem compreensão clara } \\
\text { e leitura simples. }\end{array}$ & $\begin{array}{l}\text { Estrutura mais enxuta e com } \\
\text { textos mais simplificados, } \\
\text { porém sem indicação dos } \\
\text { pontos iniciais, a leitura } \\
\text { pode ser complexa. }\end{array}$ & $\begin{array}{l}\text { Estrutura simples. Fácil de } \\
\text { construir, ler e interpretar, } \\
\text { mas não apresenta causas } \\
\text { centrais. }\end{array}$ \\
\hline
\end{tabular}

Fonte: Elaborado pelos autores

\section{CONSIDERAÇÕES FINAIS}

O objetivo deste artigo foi identificar as principais contribuições das ferramentas de análise de problemas por meio de mapas de causa e efeito. Apesar das semelhanças entre os mapas, foi possível identificar diferenças na complexidade na construção, análise, leitura e interpretação dos resultados. Ou seja, para um gestor de serviços de manutenção e conservação uma ferramenta ou outra poderá contribuir mais ou menos 
dependendo do nível de amadurecimento sobre o assunto, bem como a capacidade de domínio sobre a ferramenta.

É importante que as instituições de ensino superior tenham foco na resolução das causas principais dos problemas como a dificuldade de interação entre os setores e a falta de visão global. Além disso, qualificar os serviços de manutenção com gestão habilitada para atuar em um cenário tão complexo como o das IES, torna possível minimizar, ou mesmo, evitar os efeitos.

Para o avanço do tema sugere-se confrontar as variáveis encontradas na revisão da

\section{REFERÊNCIAS}

[1] ALCARAZ, J.; MORALES, C. Factores considerados al seleccionar una universidad. Revista Mexicana de Investigación Educativa, v. 17, n. 52, 2012

[2] ARMANDO FILHO, Tito Armando et al. Application of Theory of Constraints Process Thinking to sustainable development: A theoretical proposal. Revista Espacios, v. 33, n. 8, 2012.

[3] ASSAF, Sadi Mohammad. Factors affecting outsourcing decisions of maintenance services in Saudi Arabian universities. Property Management, v. 29, n. 2, 2011.

[4] ASSOCIAÇÃO BRASILEIRA DE NORMAS TÉCNICAS (ABNT). NBR 5674: Manutenção de edificações - Requisitos para o sistema de gestão de manutenção. Julho/2012.

[5] BALLESTERO-ALVAREZ, M. E. Gestão de qualidade, produção e operações. São Paulo: Atlas, 2010

[6] BECKERS, Roland et al. A conceptual framework to identify spatial implications of new ways of learning in higher education. Facilities, $v$. 33, Iss 1/2 p. 2-19, 2015.

[7] BIVONA, Enzo; MONTEMAGGIORE, G. Understanding short- and long-term implications of "myopic" fl eet maintenance policies: a system dynamics application to a city bus company. System Dynamics Review, v. 26, n. 3, p. 195-215, July-September, 2010.

[8] BISASO, Ronald. Organizational responses to public sector reforms in higher education in Uganda: a case study of Makerere University. Journal of Higher Education Policy and Management, v. 32, n. 4, 2010.

[9] CHIZZOTTI, Antônio. Educação superior e o mercado de serviços educacionais. Revista eCurriculum, São Paulo, v. 12, n. 01, 2014.

[10] COX, James; SCHLEIER, John. Handbook da Teoria das Restrições. Bookman, 2013. literatura com uma pesquisa de campo nas instituições. Durante a construção das estruturas notou-se a necessidade de haver mais variáveis para tornar mais coerentes as correlações, porém esse artigo limitou-se a realizar as correlações que emergiram da revisão da literatura. Além disso, indicar soluções para as causas e ver como as estruturas/mapas se comportam pode trazer resultados importantes na escolha da melhor ferramenta de trabalho. As ferramentas possuem técnicas distintas de elaboração e implantação de soluções dos problemas, que também podem ser explorado em futuros estudos.

[11] COX, James; SPENCER, Michael S. Manual da teoria das restrições. Porto Alegre: Bookman, 2002.

[12] DEL-PALACIO, Itxaso; SOLE, Francesc; BERBEGAL, Jasmina. Which services support research activities at universities? The Service Industries Journal, v. 31, n. 1, p. 39-58. 2011.

[13] DEN-HEIJER, Alessandra. Managing the university campus: Exploring models for the future and supporting today's decisions. Centre for Effective Learning Environment - CELE Exchange. 2012. Disponível em: <http://www.oecdilibrary.org/content/workingpaper> Acesso em: 25 ago. 2015

[14] FALLAH-FINI, S. et al. Optimizing highway maintenance operations: dynamic considerations. System Dynamics Review, v. 26, n. 3, p. 216-238, 2010.

[15] ISA, Mohamed; USMEN, Mumtaz. Improving university facilities services using Lean Six Sigma: a case study. Journal of Facilities Management, v. 13, n. 1, p. 70-84, 2015.

[16] ISHIKAWA, K. Controle da Qualidade Total: à maneira japonesa. Rio de Janeiro: Campus, 1993.

[17] KAMARAZALY, Mysatul et al. Challenges faced by facilities managers in the Australasian universities. Journal of Facilities Management, v. 11, p. 136-151, 2013.

[18] KARNA, Sami; JULIN, Päivi. A framework for measuring student and staff satisfaction with university campus facilities. Quality Assurance in Education, v. 23. p. 47-66, 2015.

[19] LAI, Joseph. Building operation and maintenance: education needs in Hong Kong. Facilities, v. 28, n 9/10, p. 475-493, 2010.

[20] LAWTON, Eddie; IVANOV, Sergey. Satisfying Internal Customer: How to improve facility management quality. The International 
Journal of Organizational Innovation, v. 6, n. 4, 2014.

[21] LI, Chang Sian; GUO, Sy Jye. Life Cycles of Cost Analysis of Maintenance Costs and Budgets for University Buildings in Taiwan. Journal of Asian Architecture and Building Engineering, v. 11, n. 1, p. 87-94, 2012

[22] NI, Jun; JIN, Xiaoning. Decision support systems for effective maintenance operations. CIRP Annals - Manufacturing Technology, v. 61, p. 411414, 2012

[23] ODEDIRAN, Sunday J.; GBADEGESIN, Job Taiwo; BABALOLA, Mujidat Olubola. Facilities management practices in the Nigerian public universities. Journal of Facilities Management, v. 13, p. 5-26, 2015.

[24] OLANREJAWU, Abdul; KHAMIDI, Mohd Faris; IDRUS, Arazi. Quantitative analysis of defects in Malaysian university buildings: Providers' perspective. Journal of Retail \& Leisure Property, v. 9, n. 2, p. 137-149, 2010

[25] OLANREJAWU, Abdul; KHAMIDI, Mohd Faris; IDRUS, Arazi. Investigating building maintenance practices in Malaysia: a case study. Structural Survey, v. 29, p. 397-410, 2011.

[26] OLANREJAWU, Abdul. Quantitative analysis of defects in university buildings: user perspective. Built Environment Project and Asset Management, v. 2, n. 2, 2012.

[27] POLAT, Soner. The Relationship between University Students"e Academic Achievement and Perceived Organizational Image. Educational Sciences: Theory \& Practice, v. 11, p. 257-262, 2011

[28] REGINATO, Luciane; GUERREIRO, Reinaldo. Um estudo sobre a associação entre modelo de gestão e controles gerenciais em indústrias brasileiras. Revista Universo Contábil, v. 7, n. 2, p. 6-27, 2011.
[29] REIS, Ana Carla; COSTA, Ana Paula; TEIXEIRA, Adiel. Diagnóstico da gestão da manutenção em indústrias de médio e grande porte da região metropolitana de Recife. Revista Produção, v. 23, n. 2, p. 226-240, 2013.

[30] SAWYERR, Patricia; YUSOF, Nor'Aini. Student satisfaction with hostel facilities in Nigerian polytechnics. Journal of Facilities Management, v. 11, n. 4, p. 306-322, 2013.

[31] SAHAY, M.; KUMAR, K. Strategy Formation for Higher Education Institutions Using System Dynamics Modeling. International Journal of Intelligent Technologies and Applied Statistics, v.7, n. 3, p. 207-227, 2014.

[32] TALYULI, Helton de Oliveira. Aplicação do processo de raciocínio da Teoria das Restrições na gestão da manutenção de equipamentos submarinos de petróleo: Um estudo de caso. Dissertação de Mestrado de Engenharia de Produção da Universidade Estadual do Norte Fluminense, 2013

[33] TAYLOR, Lloyd J.; NAYAK, Soumya. Goldratt's Theory Applied to the Problems Associated with an Emergency Department at a Hospital. Journal Administrative Science, v. 2, p. 235-249, 2012

[34] THEKDJI, Shital A.; LAMBERT, James $\mathrm{H}$. Quantification of Scenarios and Stakeholders Influencing Priorities for Risk Mitigation in Infrastructure Systems. Journal of Management in Engineering, january/february, p. 32-40, 2014.

[35] VIDALAKIS, Christos; SUN, Ming; PAPA, Aspasia. The quality and value of higher education facilities: a comparative study. Facilities, v. 31, n. 11/12, p. 489-504, 2013.

[36] YAU, Yung. Multicriteria Decision Making for Homeowners' Participation in Building Maintenance. Journal of Urban Planning and Development, p. 110-120, Junho/2012. 
Alutary 


\section{ADRIANA FORMIGONE}

Graduada em: Farmácia Industrial - Faculdade Oswaldo Cruz; Especialização em: Gestão da Qualidade e Produtividade - Instituto Vanzolini; Mestrado na área de Engenharia de produção - Universidade Paulista - UNIP (Finalização Dez. 2019); Linha de pesquisa: Melhoria das Operações logísticas de distribuição de medicamentos, frente aos novos desafios ante a demanda do mercado. EXPERIÊNCIA PROFISSIONAL: Docente na instituição de ensino superior FATEC, na área tecnológica de produção de cosméticos. Atuante na Industrial Farmacêutica a mais de 16 anos, em gestão de produção farmacêutica - Lean Manufacturing (Humana e Veterinária) em empresas de grande porte (nacionais e multinacionais). Vivência na dinâmica dos processos industriais como gestora organizacional nas linhas de: Sólidos, injetáveis, liofilizados, líquidos e cremes. Empresária no segmento comercial na área da saúde, como proprietária de Farmácia de Manipulação. Farmacêutica responsável em Farmácias e Drogarias, responsável pelos serviços técnico-científicos do estabelecimento.

\section{ADRIANO ALFINITO RAIMUNDO}

É graduado em Administração de Empresas pela faculdade Pitágoras (Campus - Poços de Caldas). Possui treinamento em Six Sigma/Green Belt através do curso (R\&L Associados). Têm experiência com análise de dados e simulação de sistemas através do software Arena.

\section{ALEJANDRO MARTINS RODRIGUEZ}

Possui graduação em Ingeniería Industrial Opción-Mecánica - Universidad de la República Oriental del Uruguay (1987) - revalidado no Brasil na Universidade Estadual de Maringá UEM, mestrado em Engenharia de Produção pela Universidade Federal de Santa Catarina (1992) e doutorado em Engenharia de Produção pela Universidade Federal de Santa Catarina (1996). Atualmente é Professor Adjunto IV da Universidade Federal de Pelotas. Tem experiência na área de Engenharia de Produção, com ênfase em Inteligência Aplicada, atuando principalmente nos seguintes temas: educação, tecnologia, educação a distância, internet e gestão de conhecimento. "Agradeço ao CNPq por ter me possibilitado a formação de Mestrado e Doutorado

\section{ALEXANDRE RICARDO MACHADO}

É Doutor em Direito Ambiental Internacional e Mestre em Direito Ambiental pela Universidade Católica de Santos (UNISANTOS/SP), possui Especialização em Direito do Petróleo e Gás (FGV/RJ) e Didática do Ensino Superior (UNIMONTE/SP). É Professor de Terminais Offshore, Transporte Marítimo e Comércio Exterior e Logística na Faculdade Estadual de Tecnologia da Baixada Santista (FATEC Rubens Lara/SP). É Professor Convidado da Pós-Graduação em Direito Marítimo e Portuário e Direito do Trabalho na Universidade Católica de Santos (UNISANTOS/SP), e da Maritime Law Academy (MLAW/SP). Possui Graduação em Administração de Empresas (EAESP/SP), Ciências Sociais e Jurídicas e Pedagogia (UNIMES/SP). É Consultor e Advogado (Brasil/Portugal). Tem experiência na área do Direito Energético e Ambiental, atuando principalmente em planejamento ambiental estratégico, licitações e gestão de contratos em infraestrutura. Interesses de pesquisa: Energia e Meio Ambiente;Terminais Offshore e Gestão Portuária com ênfase em Logística no Transporte Marítimo; Comércio Internacional e Revolução 4.0; Sustentabilidade e Mudanças Climáticas. 


\section{ALISSON CASTRO BARRETO}

Técnico em Portos pelo CEMP-MA, Engenheiro de Produção pela Universidade CEUMA e Mestrando em Engenharia de Produção pela Universidade Federal de Santa Maria - RS.

\section{ANDRÉ DI GIROLAMO}

Graduado em Engenharia de Produção pela Universidade Anhembi Morumbi (2018).

\section{ANDRÉ GERALDO DA COSTA COELHO}

Professor efetivo da área de Administração do Instituto Federal do Norte de Minas GeraisIFNMG. Como docente leciona disciplinas relacionadas à administração geral, Logística \& Produção, metodologia científica, ética e negócios, noções do direito do trabalho e do consumidor, empreendedorismos com ênfase em legislação aplicada à administração, legislação para abertura de novos negócios, legislação tributária para novos negócios, empreendedorismo de base tecnológica e social, redes e incubadoras.Mestre em Administração Profissional pela Fundação Dr. Pedro Leopoldo-FPL(2015). Especialista em Docência para Educação Profissional (2013), pelo Serviço Nacional de Aprendizagem Comercial (SENAC-MG). Possui graduação em Administração (2008) e Especialização em Gestão Empreendedora de Empresas (2011) pela Pontifícia Universidade Católica de Minas Gerais (PUC-MG).

\section{ANDRÉA CRISTINA DOS SANTOS SILVA}

Formada em Ciências da Computação pela Universidade Estadual do Piauí (UESPI) e Pósgraduada em Desenvolvimento para WEB pelo Centro Unificado de Ensino de Teresina (CEUT). Trabalhou na Secretaria Estadual de Administração onde atuou no Programa Nacional de Apoio à Modernização da Gestão e do Planejamento dos Estados Brasileiros e do Distrito Federal - PNAGE na Coordenação de Acompanhamento de Projetos e na Gerência de Monitoramento e Avaliação, sendo responsável pelo componente de Tecnologia da Informação do Projeto. Atualmente trabalha como Analista de Sistemas na Companhia Energética do Piauí (CEPISA), com atuação na Gestão e Governança de TI, tendo participado da elaboração da Política de Segurança da Informação e Comunicações da empresa.

\section{ANDRESSA RAQUEL WEBER}

Granduanda em Bacharelado em Engenharia de Produção. Experiência na área de qualidade, voltada ao desenvolvimento de Sistemas de Gestão da Qualidade. Estagiária na área de melhoria contínua.

\section{ANDRESSA STREY}

Graduanda em Bacharelado em Engenharia de Produção. Consultora de negócios voltados a manufatura.

\section{AVYLON SILVA SANTOS}

Graduando na universidade do estado do Pará no curso de Engenharia de Produção. Possuindo experiência de estágio em uma empresa de beneficiamento de açaí com atuação 
na área do controle da qualidade e atualmente estagia em outra empresa de beneficiamento de açaí no setor de planejamento e controle da produção.

\section{BÁRBARA ELIS PEREIRA SILVA}

Professora nos cursos de Engenharia de Produção e Administração na Universidade CEUMA (MA). Membro do NDE do curso de Engenharia de Produção. É Mestre em Engenharia de Transportes pelo Instituto Militar de Engenharia. Possui especialização em Gerenciamento de Projetos, pela Fundação Getúlio Vargas. Atualmente cursa o MBA em Logística e Negócios Sustentáveis. É graduada em Engenharia de Produção pelo Centro Universitário do Leste de Minas Gerais (2010), fez aperfeiçoamento em Qualidade, Logística e Organização Industrial pela Université de Nantes (2010), e possui curso técnico-profissionalizante pela Escola Técnica de Formação Gerencial-SEBRAE-MG(2005).

\section{BEATRIZ SILVESTRE GHISI}

Graduada em Administração de Empresas/Unisul

\section{CAMILA UGGERI}

Graduada em Engenharia Química pela Universidade Federal de Santa Maria.

\section{CARLOS EDUARDO PINTO}

Professor de Ensino Básico, Técnico e Tecnológico do Instituto Federal de Educação, Ciência e Tecnologia de São Paulo (IFSP), Campus Registro. Mestre em Administração pela Universidade de Extremadura, com reconhecimento pela Universidade Federal de Santa Catarina (UFSC). Especialista em Administração de Marketing pela Fundação de Estudos Sociais do Paraná (FESP). Bacharel em Administração pela Universidade Federal do Paraná (UFPR).

\section{CARLOS HENRIQUE HAEFLIGER}

Acadêmico de Engenharia de Produção na Sociedade Educacional Três de Maio - SETREM. Atualmente é responsável do setor do Tabelionato de Protesto de Títulos da Comarca de Três Passos-RS, Presidente da AUPASSOS - Associação dos Universitários de Três Passos, Colunista no Jornal Atualidades e Diretor de Extensão e Liderança do LEO Clube Tucumã Três Passos.

\section{CÁTIA FRÖHLICH}

Graduada em Administração de Empresas, com MBA em Gestão de Projetos e mestre em Engenharia de Produção e Sistemas pela Universidade do Vale do Rio dos Sinos - UNISINOS. Possui experiência de mais de 21 anos na área de atendimento ao cliente de uma instituição de ensino superior, com sólidos conhecimentos em processos de qualidade de atendimento, análise de indicadores e resultados, e também, em projetos de gerenciamento eletrônico de documentos, gestão do relacionamento com o cliente, dentre outros. Já atuou como ministrante em cursos de Gestão de Projetos. Atualmente atua como coordenadora de serviços acadêmicos em uma instituição de ensino superior.

\section{CÉLIO ADRIANO LOPES}

Possui graduação em Administração (2001) e pós graduação em Gestão Empresarial(2002) pelo Centro Universitário de Patos de Minas UNIPAM e mestrado em Administração pela 
Faculdade Novos Horizontes (2010). Atualmente é coordenador do programa da qualidade do Centro Universitário de Patos de Minas (UNIPAM) e é docente na mesma instituição. Membro do CB-25 - Comité Brasileiro da Qualidade (BH-UBQ), Membro do Comitê Municipal para Educação Empreendedora - Patos de Minas

\section{CHRISTIANE OLIVEIRA VALENTE}

Docente do Instituto Federal do Norte de Minas - IFNMG. Mestre em Administração Profissional pela Fundação Dr. Pedro Leopoldo - FPL . Especialista em Sociologia e licenciada em Sociologia pela Universidade Estadual de Montes Claros - UNIMONTES/MG. Bacharel em Administração pelas Faculdade Santo Agostinho FASA/MG. Bacharel em Ciências sociais pela Universidade Estadual de Montes Claros - UNIMONTES/MG.

\section{CLELMA FELIZ SANTOS}

Graduanda em engenharia de produção, possuindo curso de introdução ao coaching: ferramentas de autodesenvolvimento, marketing pessoal, telemarketing, trabalho em equipe, organização 5S, conhecimento de informática básica pacote office e Excel avançado.

\section{CRISTIANO ROOS}

É Professor do Departamento de Engenharia de Produção e Sistemas no Centro de Tecnologia da Universidade Federal de Santa Maria. É Engenheiro de Produção, Especialista em Engenharia de Produção pela Universidade Federal do Rio Grande do Sul, Mestre em Engenharia de Produção pela Universidade Federal de Santa Maria, e Doutor em Engenharia de Produção pela Universidade Federal de Santa Catarina.

\section{DANILO HENRIQUE DIVARDIN}

Docente do Instituto Federal do Norte de Minas Gerais, IFNMG. Bacharel em Direito; Bacharel e Licenciado em Ciências Sociais; Licenciado em Geografia e Mestre em Ciências Sociais pela Universidade Estadual Paulista, UNESP.

\section{DAVENILCIO LUIZ DE SOUZA}

Doutorando em Engenharia de Produção e sistemas - Área: Gerência da Produção - Linha de Pesquisa: Modelagem de Sistemas Empresariais - Tema: Virtualização da Saúde, Health 4.0. Mestre em Engenharia de Produção e Sistemas - Área: Gerência da Produção - Linha de Pesquisa: Modelagem de Sistemas Empresariais - Dissertação: Avaliação da efetividade de Cartas de Controle multivariadas na detecção de suspeitas de fraude financeira (2017/01). Graduado em Engenharia de Produção (2009/01) e Administração de Empresas (1995/01) (UNISINOS). Engenheiro de Produção Mecânica / Especialista em Manufatura - Com atuação no ramo metal mecânico e automotivo por mais de 30 anos. Experiência em Consultoria e Assessoria em Qualidade - Gestão de Equipes nas funções Qualidade e Processos de Manufatura; Coordenação de Equipes em gestão de processos, qualidade e em manufatura de componentes.

\section{DENILSON RICARDO DE LUCENA NUNES}

Possui graduação em Engenharia Civil pela Universidade da Amazônia (1999) e mestrado em Engenharia Civil pela Pontifícia Universidade Católica do Rio de Janeiro (2002) e doutorado em Engenharia de Produção (2014) pela Pontifícia Universidade Católica do Rio de Janeiro. É 
professor assistente II da Universidade do Estado do Pará no curso de Engenharia de Produção. Tem experiência na área de Engenharia Civil, com ênfase em Estruturas de Concreto e metálica. Na Engenharia de Produção atua principalmente nas seguintes áreas: planejamento e modelagem de estoques, logística e modelagem matemática.

\section{DENIS CARLOS LIMA COSTA}

Professor do Instituto Federal de Educação, Ciência e Tecnologia do Pará - IFPA CAMPUS ANANINDEUA. Líder do grupo de pesquisa GRADIENTE DE MODELAGEM MATEMÁTICA E SIMULAÇÃO COMPUTACIONAL - GM²SC. Doutor em Sistemas de Energia. Mestre em Geofísica na área de Métodos `Potenciais. Pós Graduação em Física na área de Mecânica Quântica. Graduado em Ciências Exatas e Naturais com Habilitação Plena em Matemática.

\section{EDER DE JESUS CARVALHO}

Graduado em Engenharia de Produção, pela Universidade Anhembi Morumbi (2018).

\section{EDWARD LENNON DA FONTOURA DANIEL}

Engenheiro eletricista formado pela Universidade Federal do Ceará, Tecnólogo em Telemática pelo CEFET-CE, especialista em Redes de Computadores (CEFET-CE), MBA em Gestão Empresarial Internacional (FGV) e PMP. Foi engenheiro eletricista na Companhia de Eletricidade do Amapá (CEA). Trabalhou na Companhia Energética do Piauí, onde liderou a implantação do Escritório de Projetos e geriu o Departamento de Tecnologia da Informação e Telecomunicações. Além de coordenar as diligências de interessados no processo de desestatização da companhia. Atualmente, exerce a função de analista de gestão de tecnologia da informação na DATAPREV.

\section{ELPIDIO OSCAR BENITEZ NARA}

Pós Doutorado em Universidade federal de Santa Maria (2014), Doutorado em Gestão da Qualidade e Produtividade pela Universidade Federal de Santa Catarina (2005). MESTRADO em Engenharia de Produção pela Universidade Federal de Santa Maria (1997). Possui GRADUAÇÃO em Engenharia Mecânica pela Universidade Federal de Santa Maria (1986). Atualmente é Professor Titular da Universidade de Santa Cruz do Sul (UNISC) atuando nos cursos de graduação em Engenharia de Produção, Mecânica e como COORDENADOR do Programa de Mestrado em Sistemas e Processos Industriais.Tem experiência na área de gestão e Engenharia com ênfase em Administração da Produção e Engenharia de Produção atuando principalmente nos seguintes temas: Planejamento estratégico, Qualidade total, Analises multicriterios, Planejamento Industrial, Gestão por processos e Gestão Ambiental. Foi CHEFE do Departamento de Engenharia, Arquitetura e Ciências Agrárias da Unisc; Coordenador do programa Universidade -Empresa; Membro do Sebrae- RS; Membro do comitê setorial industrial do CREA-RS; Diretor e gerente industrial de varias industrias, consultor em empresas do pais. Coordenou cursos de pós graduação. Ad hoc de revistas e eventos nacionais e internacionais.

\section{FRANCISCO RAPHAEL CABRAL FURTADO}

Professor de Ensino Básico, Técnico e Tecnológico do Instituto Federal de Educação, Ciência e Tecnologia de São Paulo (IFSP), Campus Registro. Mestre em Engenharia Florestal pela Universidade do Estado de Santa Catarina (UDESC). Especialista em Gestão Ambiental e Meio 
Ambiente pela Universidade do Estado de Santa Catarina (UDESC). Bacharel em Administração pela Universidade do Planalto Catarinense (UNIPLAC).

\section{GENIEL DE MELLO DIAS}

Acadêmico de Engenharia de Produção na Sociedade Educacional Três de Maio - SETREM. Formado Técnico em Mecânica Industrial pela Escola Técnica Estadual Presidente Getúlio Vargas de Santo Ângelo- RS. Atualmente exerce a função de Cronoanalista no setor de desenvolvimento da empresa Metalúrgica JAMA de Santa Rosa- RS.

\section{GILBERTO CLÓVIS ANTONELLI}

Possui graduação, mestrado e doutorado em Engenharia Química pela Universidade Estadual de Maringá. Atualmente é professor associado da Universidade Estadual de Maringá do Departamento de Engenharia de Produção. Tem experiência na área de Simulação Dinâmica, Ciência da Computação, com ênfase em Inteligência Artificial, atuando principalmente nos seguintes temas: modelagem, simulação e otimização, inteligência computacional e engenharia econômica.

\section{GRACIELA MARIA MIRANDA BORGES}

Bacharel em Administração pelo IFNMG (2017), especialista em Gestão da Produção e Logística Empresarial pela Faculdade Única (2018). Atualmente é professora substituta do IFNMG.

\section{GUILHERME DAMASCENO SILVA}

Possui graduação em Sistemas de Informação pelo Instituto de Estudos Superiores da Amazônia (2004), Especialização em Análise de Sistemas pela Universidade Federal de Minas Gerais(2006), mestrado em Engenharia Elétrica pela Universidade Federal de Minas Gerais (2008) e Doutor em Biotecnologia pela Universidade Federal do Pará (2018). Tem experiência na área de Ciência da computação, Análise de Sistemas, Visão Computacional e Bioinformática. Membro do Corpo Docente Efetivo do Instituto Federal de Educação, Ciência e Tecnologia do Pará.

\section{GUSTAVO SCHUSTER}

Graduando do curso de Engenharia de Produção na Universidade Federal de Pelotas - UFPEL. Formou-se no curso de Técnico em Informática (2009-2011). Durante o período de formação acadêmica fez parte do Diretório Acadêmico participando ativamente no desenvolvimento das atividades. Trabalhou na parte administrativa da Universidade, por meio de Bolsa de Iniciação ao Trabalho. Sua última experiência foi na Pró Reitoria de Ensino (PRE) na Coordenação de Registros Acadêmicos (CRA) (2017-2018). Participou de Projeto de Ensino organizando palestras e visitas técnicas. Atuou como membro da Comissão de Apoio do III Congresso de Ensino de Graduação (2017). É um dos membros representantes do Núcleo Gaúcho de Estudantes de Engenharia de Produção (NUGEEP).

\section{HEICTOR ALVES DE OLIVEIRA COSTA}

Graduando em Engenharia da Computação. Desenvolve pesquisa na área de Sistemas Inteligentes nas linguagens de programação: PYTHON, JULIA, LUA C E C++. Membro do grupo 
de pesquisa GRADIENTE DE MODELAGEM MATEMÁTICA E SIMULAÇÃO COMPUTACIONAL $\mathrm{GM}^{2} \mathrm{SC}$. Pesquisador de Iniciação Científica.

\section{HELDER SACKS}

Mestre em Gestão de Negócios, na linha de Inovação pela Faculdade FIA de Administração e Negócios. Atua na indústria financeira a 10 anos e tem interesse por pesquisas em temas como: finanças, estratégia de operações e inovação."

\section{ISMAEL CRISTOFER BAIERLE}

É Professor em cursos de graduação tecnológica; cursos de qualificação profissional básica e aprendizagem industrial básica do SENAI - Departamento Regional do Rio Grande do Sul. É Engenheiro de Produção, Mestre em Sistemas e Processos Industriais pela Universidade de Santa Cruz do Sul, e Doutorando em Engenharia de Produção pela Universidade do Vale do Rio dos Sinos.

\section{IVANIR RUFATTO}

Contador, Mestre em Ciências Contábeis e Administração/Unochapecó, Professor universitário na Unisep.

\section{IVETE LINN RUPPENTHAL}

Mestranda em Gestão Estratégica de Organizações pela Universidade Regional Integrada do Alto Uruguai e das Missões - URI. Pós-Graduada em Gestão Financeira e Controladoria e Graduação em Administração pela Sociedade Educacional Três de Maio - SETREM. É professora na Sociedade Educacional Três de Maio - SETREM e na Faculdade Horizontina FAHOR, atuando nos cursos de Engenharia de Produção, Administração e Ciências Econômicas. Possui experiência na área de Engenharia de Produção e Administração, com ênfase em Pesquisa Operacional e Métodos Quantitativos.

\section{IVONE JUNGES}

Economista, Doutora em Engenharia de Produção/UFSC, Professora universitária na Unisul

\section{JANAÍNA APARECIDA PEREIRA}

Possui graduação em Engenharia Mecânica pela Universidade Federal de Uberlândia (2006). Possui mestrado em Engenharia Mecânica pela Universidade Federal de Uberlândia (2009). Atualmente é aluna regular de doutorado do Programa de Pós Graduação em Engenharia Mecânica da Universidade Federal de Uberlândia, também é docente e coordenadora do curso de Engenharia Mecânica do Centro Universitário de Patos de Minas (UNIPAM).

\section{JEAN MIMAR SANTA CRUZ YABARRENA}

Professor de Ensino Básico, Técnico e Tecnológico do Instituto Federal de Educação, Ciência e Tecnologia de São Paulo (IFSP), Campus Registro. Pós-Doutor em Físico-Química Molecular pelo Instituto de Química de São Carlos, Universidade de São Paulo (IQSC-USP). Doutor em Engenharia Mecatrônica pela Escola de Engenharia de São Carlos, Universidade de São Paulo (EESC-USP). Mestre em Engenharia Mecatrônica pela Escola de Engenharia de São Carlos, 
Universidade de São Paulo (EESC-USP). Bacharel em Engenharia Eletrônica pela Universidad Nacional de San Agustín.

\section{JEAN VEIGA}

Graduado em Engenharia de Produção pela Universidade Luterana do Brasil. 


\section{JOÃO VICTOR KOTHE}

Graduando em Engenharia Mecânica pela Universidade de Santa Cruz do Sul (UNISC), no ano de 2015 atuou na Universidade de Santa Cruz do Sul como bolsista Provex no projeto de extensão Kamikase Aerodesign, com carga horária de 10h semanais. No período de 1/4/2016 à $1 / 2 / 2018$ foi bolsista de Iniciação Científica na UNISC, na qual variou entre as bolsas da modalidade PUIC-IT, PROBIC/FAPERGS e PIBIC/CNPq, com carga horária de $20 \mathrm{~h}$ semanais. No período de $5 / 3 / 2018$ até $24 / 5 / 2018$ realizou estágio na indústria tabagista Souza Cruz. A partir de 01/06/2018 retornou a Iniciação Científica na UNISC através da bolsa PIBITI/CNPq.

\section{JONES LUÍS SCHAEFER}

É mestrando do Programa de Pós-Graduação Sistemas e Processos Industriais da UNISC. Integrante do projeto de pesquisa Tomada de decisão gerencial com enfoque multicritérios: fundamentos teóricos e utilização de prática corporativa. Dissertação em andamento sob o título Mensuração da Competitividade em Micro e Pequenas Empresas. Possui graduação em Engenharia de Produção pela Universidade de Santa Cruz do Sul (2006), tem formação como Técnico em Eletrotécnica.

\section{JOSUÉ FERNANDES ALVES SILVA}

Formado em Ciência da Computação pela Universidade Estadual do Piauí (UESPI) e Pósgraduado em Engenharia de Software pelo Centro Unificado de Ensino de Teresina (CEUT). Exerceu os cargos de Líder de Faturamento e Arrecadação, Gerente do Departamento de Faturamento, Gerente de Sistemas e Análise de Negócios e atualmente trabalha como Executivo de TI e Telecom, ambos na Companhia Energética do Piauí (CEPISA). Tem experiência na área de Ciência da Computação, com ênfase em Metodologia e Técnicas de Computação.

\section{JUAN PABLO SILVA MOREIRA}

Graduando em Engenharia de Produção pelo Centro Universitário de Patos de Minas UNIPAM (2014 - atual). Possui experiência em pesquisas científicas nas áreas de Engenharia da Qualidade, Gestão por Processos, Gestão do Desempenho, Projeto e Organização do Trabalho e Gestão do Conhecimento com ênfase em Sistemas Produtivos.

\section{LEANDRA DA SILVA}

Mestranda em Ciências Contábeis na Universidade do Vale do Rio do Sinos (UNISINOS) com bolsa de estudos pelo programa Capes/Prosup. Componente do grupo de pesquisa Mercados e Competitividade de Instituições de Ensino Superior, da Universidade do Vale do Rio dos Sinos. Possui graduação em Ciências Contábeis pela Universidade Federal de Santa Catarina (2015).

\section{LEANDRO JOSÉ MORILHAS}

Doutor (2012) e Mestre (2007) em Administração pela Faculdade de Administração da Faculdade de Economia, Administração e Contabilidade da Universidade de São Paulo (FEA USP), graduado em Administração pelas Faculdades Integradas de Jales (2002). Foi coordenador de Pós-Graduação, Pesquisa e Extensão da Faculdade FIA de Administração e 
Negócios (FIA), professor no curso de Mestrado Profissional e do MBA Executivo Internacional.

\section{LEILANE RECH}

Acadêmica de Engenharia de Produção na Universidade Federal de Santa Maria-UFSM.

\section{LENON PINHEIRO DA SILVA}

Mestre em Engenharia de Produção e Sistemas e graduado em Administração pela Universidade do Vale do Rio dos Sinos - UNISINOS. Atualmente é Coordenador de Operações na UNISINOS. Tem experiência como Professor/Tutor, gestão de serviços, facility management, gestão de equipes, planejamento orçamentário, comissionamento técnico, teoria das restrições.

\section{LUANA WEIAND FAZOLO}

Graduada em Administração pela CNEC Gravataí. Possuo experiêcnia de 10 anos na área de administração de materiais, especialista em catalogação, classificação e codificação de materiais. Atuo como docente em curso técnico de administração nas diversas áreas do curso e como responsável pela área administrativa de uma Start-up

\section{LUCIANE KEMMERICH LIED}

Pós - graduanda em Gerenciamento Lean - Ulbra Bacharel em Administração - Universidade Franciscana

\section{MARCELO VINICIUS DA SILVA SANTOS}

Graduado em Engenharia de Produção pela Universidade Anhembi Morumbi (2017).

\section{MARCOS ALBERTO CASTELHANO BRUNO}

Graduado em Engenharia Química pela Universidade de São Paulo (1973); Mestrado em Engenharia Química pela Universidade de São Paulo (1979); Doutorado em Administração pela Universidade de São Paulo (1995) e Université Lyon II (1995) e Pós-Doutorado pela Università Luigi Bocconi. Atualmente é Professor na Università Luigi Bocconi / SDA Bocconi School of Management e Professor Visitante Internacional do Departamento de Administração da FEA(USP), desde fevereiro de 2013.

\section{MARIA LAURA ROMÃO DEGASPARI}

Mestre em Gestão de Negócios pela Fundação Instituto de Administração (FIA/USP). Pesquisadora das áreas de gestão da inovação e indicadores de desempenho de inovação em empresas do setor de software. Pós graduação na área de engenharia de marketing pela Fundação Instituto de Administração (FIA/USP). Graduação em Tecnologia em Informática Gestão Financeira pela FATEC/UNESP (2001). Experiência construída em empresas da área de tecnologia da informação, tendo atuado durante 14 anos em empresas do setor. 
Professor Universitário na Universidade Federal de Santa Maria, na Universidade Luterana do Brasil e Antonio Meneghetti Faculdade. Professor de Pós-Graduação na Fundação Getúlio Vargas, na UNIFRA e na URI. Professor nos cursos de Engenharia de Produção, Engenharia Química, Engenharia Civil, Engenharia Mecânica, Administração e Arquitetura. Graduado em Engenharia Op. Mecânica e Ciências Contábeis é Especialista em Gestão Financeira, Mestre em Engenharia de Produção e Doutorando em Engenharia Agrícola. É também consultor associado da Madre Consultoria.

\section{MATHEUS PALMIERI GOBBETTI}

Formado em gestão portuária, atualmente trabalhando em setor administrativo da areá que estuda, possuir vivencia do setor operacional, oque permitiu empregar experiencias pessoais na confecção de diversos artigos.

\section{PABLO FOGAÇA}

Professor do curso de Engenharia de Produção da Universidade Ceuma - Imperatriz (MA). Professor das disciplinas de Introdução à Engenharia de Produção, Gestão de Projetos e Engenharia de Confiabilidade. Consultor com experiência na aplicação das ferramentas Lean Manufacturing: Kanban, Manutenção TPM, Troca Rápida de Ferramentas (TRF), Mapeamento do Fluxo de Valor, Trabalho Padronizado, Produção Puxada, Fluxo Contínuo e 5S. Estágio Docência e desenvolvimento de pesquisas para o curso de Mestrado em Engenharia de Produção e Sistemas - Unisinos. Experiência como Analista de Manutenção responsável pelo Planejamento, Programação e Controle da Manutenção (PCM) da empresa MWM International. Responsável por responder as auditorias ISO 9001, ISO/TS 16949 e ISO 14001 no setor de Manutenção.

\section{PATRÍCIA LOPES DA SILVA DE ARAÚJO}

Graduada em Ciências da Computação e Pós-graduada em MBA Gerenciamento de Projetos e Governança de TI pela Universidade Paranaense. Doutoranda em Engenharia Têxtil pela Universidade do Minho - Portugal. Atualmente Professora Auxiliar e pesquisadora da Universidade Estadual de Maringá. Tem experiência na área de Ciência da Computação, em desenvolvimento a manutenção de softwares e banco de dados em empresas privadas e cooperativas de grãos.

\section{RAFAEL FRANCO MENDES DE OLIVEIRA}

Graduado em Engenharia de Produção, pela Universidade Anhembi Morumbi (2017).

\section{RENATA CORADINI BIANCHI}

Professora do Curso de Administração - Universidade Franciscana

\section{RODNEY WERNKE}

Contador, Doutor em Engenharia de Produção/UFSC.

\section{RODOLFO PINHEIRO}

Estudante, FATEC BS 


\section{ROSA MARIA DE CASTRO FERNANDES VASCONCELOS}

Professora Associada no Departamento de Engenharia Têxtil (DET) da Escola de Engenharia da Universidade do Minho. Licenciada e Doutora em Engenharia Têxtil pela Universidade do Minho. Foi galardoada com o Prémio Rieter em 1993. É responsável por diversas unidades curriculares nos ciclos de estudos integrados em Engenharia Têxtil e Engenharia e Gestão Industrial, no 1으 ciclo de Design e Marketing da Moda e nos 2을 ciclos de Design e Comunicação de Moda, Química Têxtil, Têxteis Avançados e Design e Marketing. Presidente do Conselho Pedagógico da Escola de Engenharia e Vice-Presidente da Escola de Engenharia da Universidade do Minho desde 2013.

\section{ROSSANO NORONHA}

Mestre em Engenharia de Produção e Sistemas - Área: Gerência da Produção - Linha de Pesquisa: Modelagem de Sistemas Empresariais (2017/01). Pós-Graduado em Engenharia de Produção, Unoesc (2010/02). Graduado em Engenharia de Produção, Unisinos (2004/02). Experiência em coordenação de equipes em ambiente industrial, Sistema da qualidade e Sistema Toyota de Produção.

\section{SAULO FONSECA SOARES}

Graduando em Engenharia de Produção pelo Centro Universitário de Patos de Minas UNIPAM (2014 - atual). Possui experiência em pesquisas científicas nas áreas de Engenharia da Qualidade, Planejamento e Controle da Produção (PCP) e Gestão por Processos.

\section{SHERFIS GIBRAN RUWER}

Professor de Ensino Básico, Técnico e Tecnológico do Instituto Federal de Educação, Ciência e Tecnologia de São Paulo (IFSP), Campus Registro. Mestre em Engenharia e Tecnologias Espaciais: Mecânica Espacial e Controle pelo Instituto Nacional de Pesquisas Espaciais (INPE). Especialista em Tecnologias e Educação a Distância pela Universidade Cidade de São Paulo (UNICID). Bacharel em Engenharia Mecânica, com ênfase em Mecatrônica pela Escola de Engenharia de São Carlos, Universidade de São Paulo (EESC-USP) e ênfase em Ciência da Computação pelo Instituto de Ciências Matemáticas e de Computação, Universidade de São Paulo (ICMC-USP).

\section{TARCIZIO DA SILVA BARBOSA}

"Graduando do $9^{\circ}$ semestre no curso de Engenharia de Produção pela Universidade do Estado do Pará. Possuo algumas experiências teóricas/práticas em mapeamento de processos, mensuração de capacidade produtiva, previsões de demanda e PCP. Atuei como bolsista PIBIC pela UEPA durante um ano desenvolvendo estudos sobre práticas Lean Office em ambientes administrativos da rede pública de ensino."

\section{TATIANE PEREIRA LIBRELATO}

Doutoranda, Mestre e Especialista em Engenharia de Produção, Graduada em Administração de Empresas pela Unisinos/RS. Possuo experiência de mais de 20 anos em Supply Chain junto a empresas de grande porte do segmento automotivo. Atuo ainda como coordenadora e 
docente em cursos de graduação nas áreas de Sistemas Logísticos, Sistemas Produtivos, Gestão de Projetos e Qualidade.

\section{THALES BOTELHO DE SOUSA}

Professor de Ensino Básico, Técnico e Tecnológico do Instituto Federal de Educação, Ciência e Tecnologia de São Paulo (IFSP), Campus Registro. Doutorando em Engenharia de Produção pela Escola de Engenharia de São Carlos, Universidade de São Paulo (EESC-USP). Mestre em Engenharia de Produção pela Escola de Engenharia de São Carlos, Universidade de São Paulo (EESC-USP). Bacharel em Engenharia de Produção pelo Centro Universitário Eurípides de Marília (UNIVEM).

\section{UILSON DIEGO GOMES PRESTES}

Graduado em Engenharia de Produção (2018) pela Universidade Federal de Pelotas. Técnico em Eletrotécnica (2006) pelo Instituto Federal Sul-Rio-Grandense. Bolsista da CAPES em graduação sanduíche nos Estados Unidos pelo programa Ciência sem Fronteiras em parceria com a Mercer University, Macon, GA, no período de 08/2013 a 12/2014

\section{VALDENRIQUE SOARES TORRES}

Graduado em Ciências Contábeis pelo Centro de Ensino Superior do Vale do Parnaíba CESVALE, Graduado em Direito pela Universidade Estadual do Piauí - UESPI, Pós-Graduado em Administração Pública pela Universidade Federal do Piauí - UFPI e MBA em Gestão Estratégica de Pessoas pela FIA/USP. Atuou como Assistente da Diretoria de Gestão da Companhia Energética do Piauí - CEPISA de 2003 a 2017 acumulando o Departamento de Gestão de Pessoas da empresa de 2010 a 2013.

\section{VANESSA ALMEIDA DA SILVA}

Mestre em Administração, pelo Programa de Pós Graduação em Administração (PPGA), da Universidade Federal de Santa Maria (UFSM). Doutora em Administração, pelo Programa de Pós Graduação em Administração (PPGA), da Universidade Federal de Santa Maria (UFSM). Professora do Instituto Federal de Educação, Ciência e Tecnologia Farroupilha (IFFar)

\section{VIKTOR DOLL SCHWENCK}

Estudante, FATEC BS

\section{VITOR ABEL MONTEIRO ALVES}

Acadêmico do curso Engenharia de Produção na Universidade Federal de Pelotas. Participou como voluntário no projeto de extensão voltado à Certificação, Qualidade e Rastreabilidade em Empresas Doceiras da Cidade de Pelotas (2014) e bolsista de ensino como Monitor de Álgebra Linear e Geometria Analítica (2015). Trabalhou como consultor financeiro da Eprod JR (2015), e foi Vice-Presidente (2015-2016). Trabalhou no Parque Tecnológico em Florianópolis (2017) e realizou seu programa de estágio na BioPlant Tech e posteriormente em Planfer (2018). Na área acadêmica realiza pesquisas voltadas para o campo do desenvolvimento de produtos e ergonomia, tendo seus estudos divulgados em simpósios e congressos e disponíveis em seu currículo lattes. 
Graduanda do $9^{\circ}$ semestre no curso de Engenharia de Produção pela Universidade do Estado do Pará. Possui algumas experiências teóricas/práticas em mensuração de capacidade produtiva, previsões de demanda e PCP. Atua como bolsista monitora de Engenharia de Produção no Laboratório de Informática na Universidade do Estado do Pará. Ministrou um minicurso de Excel intermediário e uma Oficina e Excel voltado para o curso de Engenharia de Produção. 
Agência Brasileira do ISBN ISBN 978-85-7042-059-6

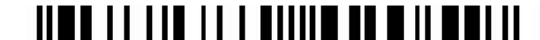

